\author{
Universidade de São Paulo \\ Instituto de Física
}

\title{
O papel de lipídeos oxidados e surfactantes como promotores de agregados proteicos tipo amilóide
}

\section{Gustavo Scanavachi Moreira Campos}

Orientadora: Profa. Dra. Rosangela Itri

Tese de doutorado apresentada ao Instituto de Física da Universidade de São Paulo como requisito parcial para a obtenção do título de Doutor em Ciências.

Banca Examinadora:

Profa. Dra. Rosangela Itri - Orientadora (Instituto de Física - USP)

Profa. Dra. Eneida de Paula (Instituto de Biologia - UNICAMP)

Prof. Dr. Leandro Ramos Souza Barbosa (Instituto de Física - USP)

Prof. Dr. Mario de Oliveira Neto (Instituto de Biociências - UNESP)

Prof. Dr. Mauricio Baptista (Instituto de Química - USP) 
FICHA CATALOGRÁFICA

Preparada pelo Serviço de Biblioteca e Informação

do Instituto de Física da Universidade de São Paulo

Campos, Gustavo Scanavachi Moreira

O papel de lipídeos oxidados e surfactantes como promotores de agregados proteicos tipo amilóide. São Paulo, 2019.

Tese (Doutorado) - Universidade de São Paulo. Instituto de Física. Depto. de Física Aplicada.

Orientador: Profa. Dra. Rosangela Itri

Área de Concentração: Física da Matéria Condensada

Unitermos: 1. Biofísica; 2. Física; 3. Física da matéria condensada; 4. Lipídeos; 5. Amiloidose.

USP/IF/SBI-066/2019 


\section{University of Sao Paulo \\ Institute of Physics}

\section{The role of oxidized lipids and surfactants as promoters of amyloid-like protein aggregates}

\section{Gustavo Scanavachi Moreira Campos}

Supervisor: Profa. Dra. Rosangela Itri

$\mathrm{PhD}$ thesis submitted to the Institute of Physics of the University of Sao Paulo as a partial requirement to obtain a Doctor of Science degree.

Thesis Examination Committee:

Prof. Dr. Rosangela Itri - Supervisor (Instituto de Física - USP)

Prof. Dr. Eneida de Paula (Instituto de Biologia - UNICAMP)

Prof. Dr. Leandro Ramos Souza Barbosa (Instituto de Física - USP)

Prof. Dr. Mario de Oliveira Neto (Instituto de Biociências - UNESP)

Prof. Dr. Mauricio Baptista (Instituto de Química - USP) 

"Enquanto o Eu real não assumir a serventia ao Deus supremo, permanecerá subjugado pela demência de imaginar-se como sendo um personagem fictício de uma realidade temporária de faz de conta, atuando um enredo que continuamente repete as experiências,

variando o cenário,

a máscara

e o figurino,

vida após vida.

Essa vida de faz de conta

voltada ao autodesfrute

sempre encontra um final infeliz,

pois contradiz a própria natureza do $\mathrm{Eu}$

de ser um parceiro imortal de Krishna (Deus).

E esse final infeliz é a permanência no ciclo de morte

- reencarnação -

morte..."

Adaptado do livro "Deus é Gente", de Bhuvana Mohandas, 2004.

"...mas o que eu quero é que todo mundo seja feliz. Não tem problema nenhum você ter cinco refeições ao dia, ou seis. O grande problema é o nosso povo, a maioria, não ter uma refeição no dia... E ainda se sentir culpado."

Criolo em entrevista com Lázaro Ramos no programa Espelho, Canal Brasil em 3 de abril de 2014.

"Aos outros, o direito de ser como são.

A mim,

o dever de ser cada dia melhor.

Francisco Cândido Xavier. 


\section{DEDICATÓRIA}

$\mathrm{D}$

edico esta tese de doutoramento ao vô Luis, que sempre é lembrado por todos nós com muita saudade. Que por onde esteja em seus caminhos evolutivos, possa sempre sentir nosso amor e gratidão, nosso riso e sentimento, nossa música e emoção, que o senhor esteja tão feliz (onde estiver) quanto feliz nos deixava ao contar suas histórias hilárias, ao tocar sua sanfona sertaneja e ao inventar palavras novas.

Que sua humildade de homem da lavoura nos acompanhe sempre.

E o senhor gostaria tanto de conhecer, encarnado, os seu bisneto Luis e sua bisneta Alice, filho e filha de sua netinha Carol. Luis e Alice certamente iriam amar a sua presença.

Que essa homenagem chegue até o senhor, lhe faça muito bem e que sua Santa, Nossa Senhora Aparecida, sempre lhe acompanhe. 


\section{AgradeCimentos Especiais}

Agradeço à minha família por todo imenso, fundamental e maravilhoso apoio em todos os momentos da vida, mais precisamente, pela compreensão e entendimento em minhas ausências em finais de semanas, feriados e datas comemorativas para dedicação e empenho nos meus objetivos pessoais. Saibam que esta conquista também é de vocês.

Agradeço em especial a Carol e Gean pelo Luis (agora você já consegue ler, na dissertação de mestrado você ainda não sabia) e Alice, a mais maravilhosa integrante da família!

Agradeço em especial ao Fe e Rachel por terem arrumado uma casa de férias na Ásia!

Agradeço aos meus familiares em geral, primos, primas, tios, tias, vós, (ariel, yasmim, sofia e meg)... por inúmeros momentos especiais que vivenciamos! Principalmente à Bia (prima-irmãmãe do Lolo) que sempre estivemos juntos desde minha chegada à São Paulo, em 2008! Além disso, carinho especial, às minhas avós e aos meus avôs (e antepassados), por terem originado nossa árvore genealógica.

Agradeço à minha companheira Ju por estar sempre ao meu lado, com seu amor sublime $\mathrm{e}$ emocionante! Seguimos apaixonados desde o dia que nos conhecemos, te amo nenê! Obrigado pela compreensão por minha falta de tempo.

Agradeço ao Tutui e Claudinho por nossa rep seguir sempre divertida!

Agradeço aos amigos e amigas de Resende (inclusive os que não estão mais lá), cidade que deixei em 2008: que nossas amizades sempre sigam fortificadas!

Agradeço em especial à Duda, amiga do coração, pois cada vez mais nos aproximamos em comunhão de ideias, sentimentos e pensamentos!

Agradeço aos amigos e amigas do laboratório pelas inúmeras horas dispensadas em conversas aleatórias, cafezinhos e claro, muita ciência e trabalho. Em especial, à Ju Y. por ter me ensinado os primeiros passos no laboratório.

Agradeço aos amigos e amigas de graduação, por terem participado desta (ainda) curta história científica.

Agradeço aos amigos e amigas do centro espírita, grandes companheiros e companheiras de caminhada nesta encarnação.

Agradeço aos "tios e tias" do bandeco por participarem da minha vida, auxiliando minha alimentação, quase diariamente, por cerca de 10 anos. 
Agradeço aos colegas de Santiago de Compostela, Odense e de Lisboa! Em especial ao Haidar na Espanha, Luis e Koji na Dinamarca e à Joana, Ana Pequena, Ana Grande e Manuel, em Portugal!

Agradeço ao amigo Lê pelas inúmeras horas de conversas do cotidiano e por ensinamentos de SAXS.

Agradeço à amiga Rô, por tudo que tem feito por mim nestes últimos 7 anos de minha vida! Como diria à minha própria mãe: "você não tem uma orientadora, você tem uma mãe". Rô, o meu mais sincero e profundo agradecimento, o mundo precisa de mais pessoas como você.

Agradeço aos espíritos amigos, pelo auxílio, conversas, sugestões e inspirações, inclusive nos momentos que fui incapaz de perceber suas influências.

Agradeço, por fim, a Deus, o que, ainda, não sei o que é. 


\section{Agradecimentos}

O presente trabalho foi realizado com apoio da Coordenação de Aperfeiçoamento de Pessoal de Nível Superior - Brasil (CAPES) - Código de Financiamento 001.

O presente trabalho foi realizado com apoio do programa de Doutorado Sanduíche no Exterior (PDSE), Programa Ciência sem Fronteiras da CAPES.

À FAPESP - Fundação de Amparo à Pesquisa do Estado de São Paulo (Processo no 2014/20107-7) pelo apoio financeiro essencial para realização dessa pesquisa.

Agradeço ao Conselho Nacional de Desenvolvimento Científico e Tecnológico (CNPq) pelo apoio financeiro ao grupo de pesquisa de minha orientadora, Profa. Dra. Rosangela Itri.

Agradeço ao Prof. Juan Ruso por ter me recebido na Universidade de Santiago de Compostela e me orientado nos primeiros passos de surfactantes e interações com proteínas.

Agradeço ao pós doutor Yanis Espinoza por nossas discussões científicas e por suas simulações computacionais.

Agradeço ao Prof. Luis Bagatolli por ter me recebido na Universidade do Sul da Dinamarca (SDU), me apresentado a fluorescência confocal, a fluorescência de dois fótons e pelas profundas discussões científicas.

Agradeço ao Prof. Koji Kinoshita por também ter me recebido na SDU e me ensinado a utilizar a técnica experimental de aspiração de micropipeta.

Agradeço ao Prof. Manuel Prieto por ter me recebido no Instituto Técnico de Lisboa e me apresentado a fluorescência resolvida no tempo. Agradeço também à Profa. Ana Coutinho, pós doutora Ana Melo e doutora Joana Ricardo pelos ensinamentos neste assunto e pelas horas de discussões.

Agradeço ao Prof. Leandro Barbosa por ensinamentos práticos e teóricos de SAXS e outras técnicas experimentais.

Agradeço à minha orientadora Profa. Rosangela Itri por ter me apresentado à ciência, me ensinado com sua vasta experiência e por ter facultado que os ensinamentos mencionados acima tivessem acontecido. 


\section{LiSTA DE ABREVIATURAS}

BSA - albumina de soro bovina

CD - dicroísmo circular

Chol - colesterol

CMC - concentração micelar crítica

DLS - espalhamento de luz dinâmico

FS - fotossensibilizador

GP - polarização generalizada

IAPP - polipeptídeo amilóide das ilhotas humano / amilina

$\mathrm{K}_{\mathrm{C}}-$ módulo de curvatura

Laurdan - 6-lauroil,1-2-dimetilamino naftaleno

Ld - fase líquido ordenada

Lo - fase líquida desordenada

LUV - vesículas unilamelares grandes

MB - azul de metileno

MCT - teoria de Caillé modificada

MD - dinâmica molecular

MLV - vesículas multilamelares grandes

PAZEPC - 1-palmitoil-2-azeloil-sn-glicerol-3-fosfocolina

POPC - 1-palmitoil-2-oleoil-sn-glicerol-3-fosfocolina

POPC-OOH - POPC hidroperoxidado

POPS - 1-palmitoil-2-oleoil-sn-glicerol-3-fosfoserina

POVPC - 1-palmitoil-2-(5-oxovaleroil)-sn-glicerol-3-fosforilcolina

RMSD - raiz quadrada do desvio médio

ROS - espécies reativas de oxigênio

SASA - área acessível ao solvente

SAXS - espalhamento de raio-X a baixos ângulos

SDS - dodecil sulfato de sódio

SEM - microscopia eletrônica de varredura

SPFO - perfluorooctanoato de sódio 
SRCD - dicroísmo circular em fonte de luz síncrotron

TEM - microscopia eletrônica de transmissão

Th $\mathrm{T}$ - tioflavina $\mathrm{T}$

TMA-DPH - 1-(4-trimetilamôniofenil)-6-fenil-1,3,5-hexatrieno p-toluenosulfonato

TRES - Espectro de fluorescência resolvida no tempo 


\section{RESUMO}

Esta tese de doutoramento aborda (i) a formação de agregados proteicos de albumina de soro bovina (BSA) induzida pela ação de sufactantes aniônicos, (ii) o impacto da presença de lipídeos oxidados em membranas, e (iii) a indução de formação de fibra amiloide do polipeptideo das ilhotas humano (IAPP) por membranas miméticas. As principais técnicas utilizadas foram espalhamento de raio-X a baixos ângulos (SAXS) e fluorescência.

Determinamos por SAXS que a adição de SDS ou SPFO em solução de BSA, pH 3.7, induz a formação de agregados que são maiores na presença do SDS. Estes resultados foram confirmados por medidas de turbidez e de microscopia eletrônica. Em paralelo, medidas de dicroísmo circular e fluorescência do Th $\mathrm{T}$ indicaram presença maior de folhas $\beta$ nos agregados induzidos por SPFO. Assim sendo, sugerimos que o SPFO é mais eficiente em induzir agregados do tipo amilóide em BSA devido a sua estrutura ser mais rígida do que a do SDS, restringindo assim o movimento das cadeias polipeptídicas da BSA e favorecendo a formação de estruturas ordenadas.

Em termos do impacto de lipídeos oxidados em membranas miméticas, estudamos membranas compostas por diferentes razões molares POPC:lipídeo oxidado à temperatura de $23^{\circ} \mathrm{C} \mathrm{e}$ $37^{\circ} \mathrm{C}$. Os lipídeos oxidados foram: POPC hidroperoxidado (POPC-OOH) e lipídeos de cadeia alquila oxidadas encurtadas PAZEPC e POVPC, que possuem grupos carboxila e aldeído no terminal das cadeias, respectivamente.

Para membranas contendo POPC-OOH, os resultados de anisotropia resolvida no tempo da sonda TMA-DPH, de TRES da sonda laurdan e dos perfis de densidade eletrônica $(\rho(r))$ obtidos a partir das análises de SAXS, indicam que o grupo $\mathrm{OOH}$ do lipídeo oxidado POPC-OOH está localizado na região da interface membrana/solvente. Com o aumento da concentração do POPC-OOH na membrana lipídica, há diminuição da anisotropia residual $\left(\mathrm{r}_{\infty}\right)$ e do tempo de vida de fluorescência do TMA-DPH sugerindo um aumento progressivo na penetração de água na interface da membrana e/ou a interação da sonda com o grupo $\mathrm{OOH}$ do lipídeo oxidado. De maneira interessante, os perfis de densidade eletrônica das membranas POPC:POPC-OOH apresentam um decréscimo na espessura da bicamada lipídica com aumento da quantidade de POPC-OOH na membrana, acompanhado de um aumento de densidade eletrônica na região dos grupos $\mathrm{CH}_{2}$. As análises das funções de correlação vertical (perpendicular à superfície da membrana) de vesículas multilamelares, obtidas dos experimentos de SAXS, revelaram um aumento da flutuação da membrana e diminuição do módulo de curvatura $\left(K_{C}\right)$ de cerca de $5 \times 10^{-20} \mathrm{~J}$ para membranas compostas por POPC para $1 \times 10^{-20} \mathrm{~J}$ para membranas contendo POPC-OOH.

A presença dos lipídeos oxidados PAZEPC e POVPC induziu aumento no grau de hidratação na interface da membrana, como inferido pelas análises dos espectros de fluorescência. Não foi possível obter uma clara indicação da localizacão dos grupos oxidados de PAZEPC e POVPC na membrana. Além disso, a introdução do PAZEPC e POVPC nas membranas de POPC induziu decréscimo de correlação entre as bicamadas lipídicas observadas por SAXS, extinguindo-se em membranas contendo $25 \%$ de PAZEPC. Sendo assim, estes dois lipídeos devem aumentar expressivamente a flutuação da membrana impedindo seu empilhamento. Além disso, a presença do PAZEPC pode também induzir carga na superfície de membrana dificultando a formação de MLVs.

Por fim, os resultados de cinética de fibrilação de IAPP mostraram que as membranas compostas por lipídeo aniônico POPS aceleram o processo de formação da fibra amiloide na razão molar 10:1 (lipídeo:IAPP), com desaceleração para razões molares superiores. Entretanto, os mesmos experimentos realizados com as membranas oxidadas, caracterizadas neste trabalho, foram inconclusivos, pois não obtivemos reprodutibilidade nos resultados.

Palavras-chaves: lipídeo oxidado; Fluorescência; SAXS; Agregação de Proteína; Amilóide 


\section{ABSTRACT}

Here we studied (i) the formation of bovine serum albumin (BSA) aggregates induced by the action of anionic sufactants, (ii) the impact of the presence of oxidized lipids in biomembranes as well as (iii) the induction of amyloid fiber formation of the human islet polypeptide (IAPP) by mimetic biomembranes. The main techniques employed were small angle X-ray scattering (SAXS) and fluorescence.

Our results from protein aggregates showed that addition of SDS or SPFO to BSA solution, at $\mathrm{pH}$ 3.7, induced the aggregation which are greater in the presence of SDS. On the other hand, measurements of circular dichroism and Th T fluorescence indicated higher degree of $\beta$-sheets in the SPFO induced aggregates. Thus, we suggest that SPFO is more efficient in inducing BSA's amyloid like aggregates due its bulkier structure as compared to SDS, thereby restricting the movement of BSA polypeptide chains and favoring the formation of ordered structures.

In terms of the impact of oxidized lipids on mimetic membranes, we studied membranes composed of different POPC:oxidized lipid molar ratios at two temperatures: $23^{\circ} \mathrm{C}$ and $37^{\circ} \mathrm{C}$. The oxidized lipids were: hydroperoxidized POPC (POPC-OOH) and truncated oxidized alkyl chain lipids PAZEPC and POVPC, which have a carboxyl and aldehyde group at the chain terminus, respectively.

For POPC-OOH containing membranes, time resolved anisotropy results from TMA-DPH probe, TRES from laurdan probe and electron density profiles $(\rho(r))$ obtained from the SAXS analyzes, indicate that the $\mathrm{OOH}$ group of the oxidized lipid POPC-OOH is located in the region of the membrane/solvent interface. As the POPC-OOH concentration increases in the lipid membrane, there is a decrease in the residual anisotropy $\left(r_{\infty}\right)$ and in the fluorescence lifetime of the TMA-DPH suggesting a progressive increase in water penetration at the membrane interface and/or the interaction of the probe with the $\mathrm{OOH}$ group of the oxidized lipid. Interestingly, the electron density profiles of the POPC-OOH membranes show a decrease in lipid bilayer thickness with increasing amount of POPC-OOH in the membrane, accompanied by an increase in electron density in the region of the $\mathrm{CH}_{2}$ groups. An inspection of the vertical correlation functions (perpendicular to membrane surface) of multilamellar vesicles, obtained from the SAXS experiments, revealed an increase in membrane fluctuations and decrease in the bending modulus $\left(K_{C}\right)$ of about $5 \times 10^{-20} \mathrm{~J}$ for membranes composed of POPC to $1 \times 10^{-20} \mathrm{~J}$ for membranes containing POPC-OOH.

The presence of the oxidized lipids with truncated aliphatic chain, PAZEPC and POVPC, induced an increase in the degree of hydration at the membrane interface inferred by the fluorescence spectra. We did not obtain a clear indication of the location of the oxidized groups of PAZEPC and POVPC in the membrane. In addition, the introduction of PAZEPC and POVPC in POPC membranes induced a decrease in correlation between the lipid bilayers as observed by SAXS, extinguishing in membranes containing 25\% PAZEPC. Therefore, these two lipids must expressively increase the membrane fluctuation preventing their stacking. In addition, the presence of PAZEPC may also induce charge on the membrane surface, making it difficult to form MLVs.

Finally, IAPP fibrillation kinetics results showed that membranes composed of anionic lipid POPS accelerates the process of amyloid fiber formation, in 10:1 (lipid: IAPP) molar ratio, with deceleration at higher molar ratios. However, the same experiments performed with the oxidized membranes, characterized in this work, were inconclusive, since no reproducible results were obtained.

Keywords: Oxidized Lipids; Fluorescence; SAXS; Protein Aggregation; Amyloid 


\section{LISTAS}

\section{LiSTA DE FIGURAS}

1.1 Esquema de fibras amilóides adaptado de [4, 5], da esquerda para direita: fibras amilóides visualizada por microscopia eletrônica de transmissão (TEM), fibra amilóide esquematizada por computação, padrão de difração de raio-X de fibras amilóides e estrutura secundária de folhas $\beta$ esquematizada em azul indicando as distâncias de separação obtidas por difração de raio-X. . . . . . . . . . . . . . .

1.2 Esquema do panorama energético do enovelamento e agregação de proteínas mediado por interações intermoleculares, intramoleculares e por chaperonas [11]. Ver texto para detalhes. . . . . . . . . . . . . . . . . . . . . .

1.3 Esquema de cinética de formação de fibras amiloides através do processo de nucleação $[19,20]$. Ver texto para detalhes. Figura adaptada de [19]. . . . . . . . . . . .

1.4 Exemplos do efeito da oxidação lipídica analisado por microscopia de contraste de fase (A e C) e de fluorescência (B): (A) azul de metileno (MB) (comprimento de onda de excitação $\lambda_{e x}=665 \mathrm{~nm}$ e concentração $40 \mu \mathrm{M}$ ) - (a) $1 \mathrm{~s}$, (b) $104 \mathrm{~s}$, (c) $108 \mathrm{~s}$ (d) $138 \mathrm{~s}$, (e) $162 \mathrm{~s}$, (f) $191 \mathrm{~s}$, (g) $193 \mathrm{~s} \mathrm{e} \mathrm{(h)} 246 \mathrm{~s}$. A escala em (a) é de de $20 \mu \mathrm{m}$ (adaptado de [42]). (B) Membrana de POPC:DPPC (1:1) inicialmente homogênea (a), apresentando separação de fases Ld-Lo (rafts lipídicos) induzida por horas de irradiação da porfirina ancorada na superfície da membrana (b) (adaptado de [45]). (C) Imagens de microscopia de contraste de fase de GUVs de DOPC, dispersas em solução contendo azul de metileno $(55 \mu \mathrm{M})$ após a irradiação com $\lambda_{e x}=532 \mathrm{~nm}$. Inicialmente - a - vê-se a GUV intacta, depois há a formação de um grande poro (após 3 minutos de irradiação - b) seguido de total destruição - c - (adaptado de [44]).

3.1 Estrutura química dos surfactantes utilizados SDS e SPFO (F indica átomo de flúor). 13 
3.2 Arranjo experimental de SAXS adaptado de $[81] \ldots \ldots$. . . . . . . . . . . . 16

3.3 Modelo de elipsoide de duas camadas de densidades eletrônicas em relação ao solvente. 21

3.4 Estrutura molecular da Tioflavina $\mathrm{T} \ldots \ldots \ldots \ldots \ldots$

3.5 Modelo Proposto para a ligação da Th T (seta bidirecional) com as fibras amilóides adaptado de [4]: (a) fibra amilóide (esquerda) e estrutura secundária de folhas $\beta$ esquematizada em azul (direita) indicando as distância de separação de fibras amilóides obtidas por difração de raio-X. (b) ligação da Th T entre as cadeias laterais ( R - esquerda) dos aminoácidos se posicionando paralelamente ao eixo da fibra. . .

3.6 Esquema das transições eletrônicas responsáveis pela absorção de luz nos comprimentos de onda de CD. As setas indicam a direção dos dipolos (extraído de

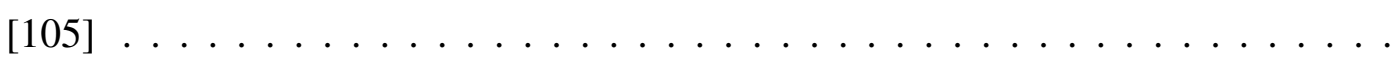

3.7 Espectro de CD característico de protéina predominantemente em conformação de $\alpha$-hélice (vermelho), folhas $\beta$ (azul) e de hélice de poliprolina (amarelo). Importante notar a diferença de posição do pico de $192 \mathrm{~nm}$ (vermelho) para $198 \mathrm{~nm}$ (azul) entre a estrutura secundária de $\alpha$-hélice e folhas $\beta$, além da diminuição da intensidade. MRE é a elipicidade média por resíduo. A região sombreada é acessível apenas em experimentos de SRCD. Adaptado de [108] . . . . . . . . . . . . . . . . .

3.8 Estrutura cristalográfica da BSA extraída do PDB 4F5S a pH 6,5 [54](A), monômero obtido por MD ao baixar o $\mathrm{pH}$ para 3,7 (B) e dímero obtido por modelagem de corpo rígido usando (B) como monômero (C). Representado em azul é o domínio I, verde o domínio II e laranja o domínio III. . . . . . . . . . . . . . . . . . .

3.9 Análise de MD para o aumento médio de SASA por resíduo de BSA em função de RMSD por resíduo após a diminuição do $\mathrm{pH}$ de 6,5 para 3,7 para o domínio I (resíduos 1-185, quadrado), II (resíduos 186-378, círculo), III (resíduos 379-576, triângulo). Os valores de referência SASA e RMSD utilizados na comparação foram obtidos para a BSA (PDB 4F5S) a pH 6,5 . . . . . . . . . . . . . . . .

3.10 Curva de SAXS para a BSA (1 mg/mL) em pH 3.7 (símbolos vazios) juntamente com curvas de SAXS calculadas para as estruturas apresentadas na figura 3.8: PDB 4F5S [54] (linha azul), monômero parcialmente desenovelado obtido por MD em pH 3.7 (linha verde), dímero obtido por modelagem de corpo rígido a pH 3,7 (linha roxa) e o melhor ajuste (linha vermelha) calculado pelo software GENFIT como sendo composto por $75 \%$ de espécies monoméricas parcialmente desenoveladas a pH 3,7 e 25\% do respectivo dímero (fig. 3.8C). Inserido no gráfico estão as mesmas curvas, em escala linear. . . . . . . . . . . . . . . . . . 
3.11 Funções de distribuição de distâncias (p(r)) das curvas de SAXS da BSA apresentadas na figura 3.10 utilizando o mesmo código de cores: PDB 4F5S [54] (linha azul), monômero parcialmente desenovelado obtido por MD em pH 3.7 (linha verde), dímero obtido por modelagem de corpo rígido a $\mathrm{pH}$ 3,7 (linha roxa) e o melhor ajuste (linha vermelha) calculado pelo software GENFIT como sendo composto por $75 \%$ de espécies monoméricas parcialmente desenoveladas a $\mathrm{pH} 3,7$ e $25 \%$ do respectivo dímero (fig. 3.8). Os símbolos pretos vazios representam a função p(r) dos dados experimentais calculados pelo software GIFT - modelo independente e a linha vermelha é a função $\mathrm{p}(\mathrm{r})$ calculada a partir do ajuste mencionado acima. O gráfico inserido mostra o bom ajuste entre as curvas de espalhamento e o ajuste utilizado para calcular a função p(r) usando o software GIFT em todos os casos. . .

3.12 Aumento de área de superfície acessível ao solvente (SASA) ao reduzir o pH de 6,5 para 3,7, conforme obtido por simulações de MD. O SASA está dividido em área de aminoácidos hidrofóbicos e hidrofílicos. . . . . . . . . . . . . .

3.13 (A) Centro: monômero de BSA obtido por MD ao reduzir o $\mathrm{pH}$ de 6,5 para 3.7 (azul é o domínio I, verde o domínio II e laranja o domínio III) e a conformação do monômero obtida pela adição de surfactantes (SDS ou SPFO): 30 ou 60 moléculas. As estruturas atômicas obtidas após a adição do surfactante são coloridas como azul escuro para baixos valores de RMSD e vermelho claro para altos valores de RMSD em relação ao monômero na ausência de surfactante. A sombra da estrutura obtida por MD na ausência do surfacante é apresentada em todas as conformações para fins de comparação. (B) RMSD em comparação com o monômero na ausência de

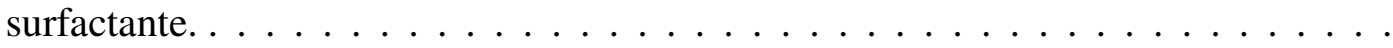

3.14 (A) Curvas teóricas de SAXS para as conformações do monômero de BSA em pH 3,7 na ausência (linha verde) e na presença de 30 (linhas contínuas) ou 60 (linhas pontilhadas) moléculas de SDS (azul) ou SPFO (vinho) obtidas por MD. Figura inserida mostra as mesmas curvas na escala linear. (B) Funções de distribuição de distâncias para cada estrutura apresentada em (A), obtidas utilizando o programa GIFT. 37 
3.15 Curvas experimentais de SAXS de solução de BSA (1 mg/mL) em pH 3,7 (símbolos vazios) juntamente com melhor ajuste calculado pelo software GENFIT (linhas sólidas) para o SDS (A) e SPFO (B): na ausência de surfactante (círculo), razão molar de 15:1 (quadrado), 30:1 (triângulo) e 45:1 (losango - não foi possível realizar um ajuste com os modelos propostos). Neste caso, o melhor ajuste para 0:1 e 15:1 (ambos casos) foi obtido ao se considerar o espalhamento de monômeros parcialmente desenovelados e respectivos dímeros em solução a pH 3,7 em diferentes proporções (ver texto para detalhes). No caso de 30:1 (SDS:BSA) o melhor ajuste foi obtido como a combinação do espalhamento do monômero desenovelado na presença de 30 moléculas de SDS (fig. 3.13), o respectivo dímero (modelado por corpo rígido) e um elipsóide com a massa molecular de um tetrâmero. Para 30:1 (SPFO: BSA), o ajuste foi obtido usando somente o software GIFT para evitar análises superestimadas (ver texto para detalhes). Funções $\mathrm{p}(\mathrm{r})$ na ausência de surfactante (linha preta) e na presença de SDS (C) e SPFO (D) na razão molar surfactante:BSA de 15:1 (linha vermelha) e 30:1 (linha azul). . . . . . . . . . . . .

3.16 Curvas de SAXS para a BSA pH 3,7 na presença de (A) SDS e (C) SPFO para as razões molares de 0:1 (quadrado preto), 90:1 (círculo vermelho) e 120:1 (triângulo azul). A linha verde em (A) e (C) indica a função de Porod $I(q) \sim q^{-4}[114,115]$ para comparação. Imagens de SEM para (B) SDS:BSA na razão molar de 120:1 e (D) SPFO:BSA na razão molar de 105:1. A escala em (B) e (D) é de $1 \mu \mathrm{m}$. . . . .

3.17 Medidas do espectro de absorção de luz UV-VIS para a BSA $(1 \mathrm{mg} / \mathrm{mL})$ em pH 3,7 em função do aumento da concentração de SDS (esquerda) e SPFO (direita). A linha tracejada indica o comprimento de onda $\lambda$ utilizado para as análises de turbidez. . .

3.18 Medidas de fluorescência de tioflavina T dispersa em suspensão de BSA ( $1 \mathrm{mg} / \mathrm{mL})$ em pH 3,7 com razão molar de Th T:BSA 20:1 em função do aumento da concentração de SDS (esquerda - figura inserida com escala expandida) e SPFO (direita). O comprimento de onda de excitação foi de $440 \mathrm{~nm}$. A linha tracejada indica o comprimento de onda $\lambda$ utilizado para as análises de variação da intensidade de fluorescência Th T. . . . . . . . . . . . . . . . . . . . . . . . .

3.19 Medidas do espectro de SRCD para a BSA (1 mg/mL) a pH 3,7 em função do aumento da concentração de SDS (esquerda) e SPFO (direita). A seta cinza tracejada indica a diminuição da intensidade para $\lambda \sim 192 \mathrm{~nm}$ e o deslocamento deste pico para $\lambda \sim 198 \mathrm{~nm}$ 
3.20 Dados de turbidez para $\lambda=350 \mathrm{~nm}(\mathrm{~A})$, intensidade de fluorescência de Th $\mathrm{T}$ para $\lambda$ $=485 \mathrm{~nm}$ (B) e posição do pico de SRCD (C) para amostras de BSA $(1 \mathrm{mg} / \mathrm{mL})$ em pH 3,7 para diferentes razões molares de SDS (quadrados pretos) e SPFO (círculos cinza). Os dados de turbidez e de fluorescência Th $\mathrm{T}$ foram normalizados pelo valor da amostra de BSA na ausência de surfactante. . . . . . . . . . . . . . . . . . .

3.21 (A) Distribuição dos surfactantes SDS e SPFO (ambos em branco) ligados ao monômero de BSA no pH 3.7 como obtido por MD. (B) SASA hidrofílico e hidrofóbico para o monomêro de BSA obtido por MD na presença de SDS ou SPFO na razão molar de 30:1 e 60:1. O SASA apresentado é o aumento relativo ao mesmo parâmetro para a BSA na ausência de surfactante. . . . . . . . . . . . . . . .

4.1 Representação esquemática do lipídeo POPC e dos lipídeos oxidados utilizados nos experimentos destacando o tamanho das cadeias alquilas oxidadas. . . . . . . . . . 55

4.2 Estrutura molecular do TMA-DPH . . . . . . . . . . . . . . . . . . . 57

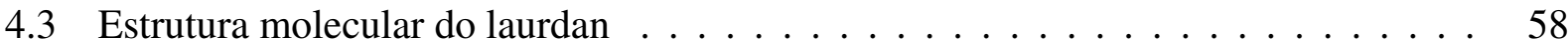

4.4 Diagrama de Jablonski. Adaptado de [131] . . . . . . . . . . . . . . . . . . . . . 60

4.5 (a) Intensidade de fluorescência normalizada para os dados de rendimento quântico do sulfato de quinino diluído em $0.1 \mathrm{~N}$ de $\mathrm{H}_{2} \mathrm{SO}_{4}$ em uma concentração suficientemente baixa para evitar efeito de filtro interno a $23^{\circ} \mathrm{C}$ (pontos vermelhos) obtidos na referência [132]. A linha preta apresenta o ajuste utilizando a soma de 3 curvas gaussianas. (b) Curva experimental de fluorescência do sulfato de quinino, obtida neste trabalho, diluído em $0,1 \mathrm{~N}$ de $\mathrm{H}_{2} \mathrm{SO}_{4}$ em uma concentração suficientemente baixa para evitar efeito de filtro interno à $23^{\circ} \mathrm{C}$ (pontos verdes), após a correção espectral (pontos azuis), o valor do fator de correção para cada comprimento de onda (pontos cinza) e o ajuste utilizando a soma de 3 curvas gaussianas apresentado no gráfico (a) para comparação. As curvas estão normalizadas.

4.6 Esquema de medida de anisotropia . . . . . . . . . . . . . . . . . . . . 67

4.7 Modelo de difusão rotacional para um fluoróforo com simetria cilíndrica. $\Phi$ é o ângulo entre o eixo z e a posição do fluoróforo e $\Phi_{\max }$ é o ângulo máximo para a rotação. [135] . . . . . . . . . . . . . . . . . . .

4.8 Espectro de fluorescência da sonda laurdan em MLVs de POPC a $23^{\circ} \mathrm{C}$ e $37^{\circ} \mathrm{C}$. Os espectros estão normalizados para facilitar a comparação. As linhas pontilhadas indicam os comprimentos de onda de $440 \mathrm{~nm}$ e $490 \mathrm{~nm}$ utilizados na análise de intensidade de fluorescência para calcular o GP. . . . . . . . . . . . . . . . . . 
4.9 Curvas de decaimento de intensidade de fluorescência normalizadas da sonda TMADPH em MLV de POPC a $23{ }^{\circ} \mathrm{C}$ (pontos azuis) e $37^{\circ} \mathrm{C}$ (pontos vermelhos). As linhas pretas mostram o ajuste (equação 4.14) para cada temperatura. As linhas tracejada e pontilhada indicam a $\operatorname{IRF}(t)$ (eq. 4.13 ) para $23^{\circ} \mathrm{C}$ e $37^{\circ} \mathrm{C}$, respectivamente (destacada na figura inserida). . . . . . . . . . . . . . .

4.10 (a) e (b) apresentam as intensidades de fluorescência experimentais $I(t), I_{V V}(t)$ e $I_{V H}(t)$ da sonda TMA-DPH em MLVs de POPC a 23 e $37^{\circ} \mathrm{C}$, respectivamente. (c) apresenta as curvas de anisotropia resolvida no tempo $r(t)$ para os dois casos (4.22). Todas as curvas experimentais estão acompanhadas de seu respectivo ajuste (linhas pretas) . . . . . . . . . . . . . . . . . . . 77

4.11 Esquema de relaxação espectral contínua. Adaptado de [132] . . . . . . . . . . . . 79

4.12 TRES (eq. 4.40) para membranas de POPC a $23{ }^{\circ} \mathrm{C}$ para os tempos de 0,$5 ; 1 ; 4$ e 8 ns. 81

4.13 TRES normalizados para membranas de POPC a $23{ }^{\circ} \mathrm{C}$ para os tempos de $0.5,1,4 \mathrm{e}$ $8 \mathrm{~ns}$.

4.14 TRES (eq. 4.40) normalizados em função do número de onda para membranas de POPC a $23{ }^{\circ} \mathrm{C}$ para os tempos de $0.5,1,4$ e 8 ns. . . . . . . . . . . . . .

4.15 TRES normalizados e em função do número de onda para membranas de POPC a 23 ${ }^{\circ} \mathrm{C}$ para os tempos entre $t_{0}=0.015 \mathrm{~ns}$ até $t_{\max }=20.85 \mathrm{~ns}$ a cada $0.015 \mathrm{~ns}$. A escala de cor indica a perda de energia de emissão de fluorescência em função do tempo: mais energética (azul) e menos enérgetica (verde) . . . . . . . . . . . . . .

4.16 Anisotropia de fluorescência no estado estacionário para MLVs de POPC (100 $\mu \mathrm{M})$ contendo TMA-DPH na razão molar 100:1 (lipídeo:sonda) e concentração crescente de POPC-OOH a $23{ }^{\circ} \mathrm{C}$ (pontos cinzas, média e incerteza em verde) e $37^{\circ} \mathrm{C}$ (pontos pretos, média e incerteza em azul) . . . . . . . . . . . . . . . . .

4.17 Tempo de vida médio de fluorescência para MLVs de POPC $(100 \mu \mathrm{M})$ contendo TMA-DPH na razão molar 100:1 (lipídeo:sonda) e concentração crescente de POPC$\mathrm{OOH}$ a 23 (pontos cinzas, média e incerteza em verde) e $37^{\circ} \mathrm{C}$ (pontos pretos, média e incerteza em azul).

4.18 Tempo de vida médio de fluorescência para MLVs de POPC $(100 \mu \mathrm{M})$ contendo TMA-DPH na razão molar 100:1 (lipídeo:sonda) em função da anisotropia de fluorescência para as mesmas amostras a 23 (pontos cinzas, média e incerteza em verde) e $37^{\circ} \mathrm{C}$ (pontos pretos, média e incerteza em azul). . . . . . . . . . . . .

4.19 Anisotropia residual para MLVs de POPC $(100 \mu \mathrm{M})$ contendo TMA-DPH na razão molar 100:1 (lipídeo:sonda) com o aumento da concentração de POPC-OOH a 23 (pontos cinzas, média e incerteza em verde) e $37^{\circ} \mathrm{C}$ (pontos pretos, média e incerteza em azul). 
4.20 Tempo médio de correlação rotacional do TMA-DPH em MLVs de POPC (100 $\mu \mathrm{M})$ na razão molar 100:1 (lipídeo:sonda) com o aumento da concentração de POPC$\mathrm{OOH}$ a 23 (pontos cinzas, média e incerteza em verde) e $37^{\circ} \mathrm{C}$ (pontos pretos, média e incerteza em azul). . . . . . . . . . . . . . . . . . . .

4.21 Microviscosidade para MLVs de POPC $(100 \mu \mathrm{M})$ contendo TMA-DPH na razão molar 100:1 (lipídeo:sonda) com o aumento da concentração de POPC-OOH a 23 (pontos cinzas, média e incerteza em verde) e $37^{\circ} \mathrm{C}$ (pontos pretos, média e incerteza em azul).

4.22 Valores de GP do laurdan para MLVs de POPC (100 $\mu \mathrm{M}$ - 100:1 lipídeo:sonda) com o aumento da concentração de POPC-OOH a 23 (pontos cinzas, média e incerteza em verde) e $37^{\circ} \mathrm{C}$ (pontos pretos, média e incerteza em azul). . . . . . . . . . .

4.23 TRES obtidos para LUVs de POPC extrusadas com poro de 0,1 $\mu \mathrm{m}$ para obter vesículas unilamelares (LUVs), a concentração lipídica utilizada foi de $500 \mu \mathrm{M}$ e a razão lipídeo:laurdan foi de 100:1. Em cada gráfico estão 1400 espectros resolvidos no tempo em passos de $0,015 \mathrm{~ns}$ entre $\mathrm{t}=0,015 \mathrm{~ns}$ até $\mathrm{t}=20,85 \mathrm{~ns} \ldots \ldots \ldots$

4.24 TRES obtidos para LUVs de POPC-OOH extrusadas com poro de $0,1 \mu \mathrm{m}$ para obter vesículas unilamelares (LUVs), a concentração lipídica utilizada foi de $500 \mu \mathrm{M}$ e a razão lipídeo:laurdan foi de 100:1. Em cada gráfico estão 1400 espectros resolvidos no tempo em passos de $0,015 \mathrm{~ns}$ entre $\mathrm{t}=0,015 \mathrm{~ns}$ até $\mathrm{t}=20,85 \mathrm{~ns} \ldots \ldots \ldots$

4.25 Gráficos de $v(t)$ (a) e $\Gamma(t)$ (b) obtidos para LUVs de POPC (linha preta) e de POPC-OOH (linha vermelha) extrusadas com poro de $0,1 \mu \mathrm{m}$ para obter vesículas unilamelares (LUVs), a concentração lipídica utilizada foi de $500 \mu \mathrm{M}$ e a razão lipídeo:laurdan foi de 100:1 para temperatura de 23 (linha contínua) e $37^{\circ} \mathrm{C}$ (linha tracejada). . . . . . . . . . . . . . . . . .

4.26 Principais resultados para nossas análises, obtidos por SAXS [43] $]^{1}$, MD [36 $]^{2} \mathrm{e}$ micropipeta $[46]^{3}$ para o impacto da presença do lipídeo oxidado POPC-OOH em membranas lipídicas; *levando-se em conta o perfil de densidade eletrônica da água. 102

4.27 Variação percentual para o valor de tempo de vida médio de fluorescência e anisotropia residual para: (i) membranas de $100 \%$ POPC a 23 e $37^{\circ} \mathrm{C}$ (cinza); (ii) membranas de $100 \%$ POPC-OOH a 23 e $37^{\circ} \mathrm{C}$ (verde); membranas com $0 \%$ e $100 \%$ de POPC-OOH (iii) a $23^{\circ} \mathrm{C}$ (azul) e (iv) a $37^{\circ} \mathrm{C}$ (vermelho). Os valores de variação estão em módulo. . . . . . . . . . . . . . . . . . . . . .

4.28 Parâmetro de ordem $S_{C D}$ de membranas de POPC (25 ${ }^{\circ} \mathrm{C}$ - preto) e POPC-OOH $\left(25^{\circ} \mathrm{C}\right.$ - vermelho) [36], POPC entre $20^{\circ} \mathrm{C}$ e $60^{\circ} \mathrm{C}$ (azul) [151] e DPPC na fase gel $\left(36{ }^{\circ} \mathrm{C}\right.$ - verde) e DPPC na fase fluida $\left(49^{\circ} \mathrm{C}\right.$ - rosa) [150]. Resultados obtidos por dinâmica molecular. 
4.29 Variação percentual para o valor de tempo médio de correlação rotacional e microviscosidade para: (i) membranas de $100 \%$ POPC a 23 e $37^{\circ} \mathrm{C}$ (cinza); (ii) membranas de $100 \%$ POPC-OOH a 23 e $37^{\circ} \mathrm{C}$ (verde); (iii) membranas com $0 \%$ e $100 \%$ de POPC-OOH a $23^{\circ} \mathrm{C}$ (azul) e (iv) a $37^{\circ} \mathrm{C}$ (vermelho) . . . . . . . . . . . . . . . 110

4.30 Anisotropia de fluorescência no estado estacionário para MLVs de POPC (100 $\mu \mathrm{M})$ contendo TMA-DPH na razão molar 100:1 (lipídeo:sonda) e concentração crescente de lipídeo oxidado a $23{ }^{\circ} \mathrm{C}$ (pontos cheios e linhas sólidas) e $37^{\circ} \mathrm{C}$ (pontos vazios e linhas tracejadas).

4.31 Tempo de vida médio de fluorescência para MLVs de POPC $(100 \mu \mathrm{M})$ contendo TMA-DPH na razão molar 100:1 (lipídeo:sonda) e concentração crescente de lipídeo oxidado a 23 (pontos cheios e linhas sólidas) e $37^{\circ} \mathrm{C}$ (pontos vazios e linhas tracejadas). 112

4.32 Tempo de vida médio de fluorescência em função da anisotropia do estado estacionário para MLVs de POPC $(100 \mu \mathrm{M})$ contendo TMA-DPH na razão molar 100:1 (lipídeo:sonda) e concentração crescente de lipídeo oxidado a $23{ }^{\circ} \mathrm{C}$ (esquerda) e 37 ${ }^{\circ} \mathrm{C}$ (direita).

4.33 Anisotropia residual para MLVs de POPC $(100 \mu \mathrm{M})$ contendo TMA-DPH na razão molar 100:1 (lipídeo:sonda) e concentração crescente de lipídeo oxidado a 23 (pontos cheios e linhas sólidas) e $37^{\circ} \mathrm{C}$ (pontos vazios e linhas tracejadas). . . . . . . . . . .

4.34 Tempo médio de correlação rotacional para MLVs de POPC $(100 \mu \mathrm{M})$ contendo TMA-DPH na razão molar 100:1 (lipídeo:sonda) e concentração crescente de lipídeo oxidado a 23 (pontos cheios e linhas sólidas) e $37^{\circ} \mathrm{C}$ (pontos vazios e linhas tracejadas). 115

4.35 Microviscosidade para MLVs de POPC $(100 \mu \mathrm{M})$ contendo TMA-DPH na razão molar 100:1 (lipídeo:sonda) e concentração crescente de lipídeo oxidado a 23 (pontos cheios e linhas sólidas) e $37^{\circ} \mathrm{C}$ (pontos vazios e linhas tracejadas). . . . . . . . . . . 116

4.36 Valor de GP do laurdan para MLVs de POPC $(100 \mu \mathrm{M})$ contendo laurdan na razão molar 100:1 (lipídeo:sonda) e concentração crescente de lipídeo oxidado a $23{ }^{\circ} \mathrm{C}$ (pontos cheios e linhas sólidas) e $37^{\circ} \mathrm{C}$ (pontos vazios e linhas tracejadas). . . . . .

4.37 TRES obtidos para LUVs de POPC:PAZEPC (7:3) (a) e POPC:POVPC (75:25) (b) extrusadas com poro de 0,1 $\mu \mathrm{m}$ para obter vesículas unilamelares (LUVs), a concentração lipídica utilizada foi de $500 \mu \mathrm{M}$ e a razão lipídeo:laurdan foi de 100:1. Em cada gráfico estão 1400 espectros resolvidos no tempo em passos de 0,015 ns

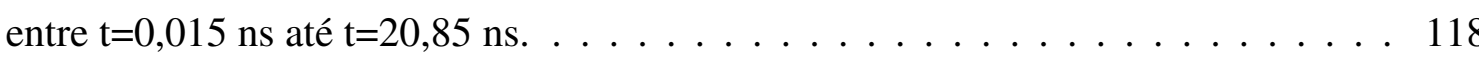

4.38 Gráficos de $v(t)$ (esquerda) e $\Gamma(t)$ (direita) obtidos para LUVs de POPC (linha verde) POPC:PAZEPC (7:3) (linha azul) e POPC:POVPC (75:25) (linha vermelha), extrusadas com poro de $0,1 \mu \mathrm{m}$ e com concentração lipídica de $500 \mu \mathrm{M}$ contendo laurdan na razão molar 100:1 (lipídeo:sonda) a $23^{\circ} \mathrm{C}$. . . . . . . . . . . . . . . . . . 119 
4.39 Principais resultados para nossa discussão obtidos por $\mathrm{MD}\left(37^{\circ} \mathrm{C}-12,5 \%\right.$ e $\left.25 \%\right)$ $[48]^{1}$, SAXS $\left(23{ }^{\circ} \mathrm{C}-10 \%\right.$ e $\left.33 \%\right)[43]^{2}$, TRES $\left(10{ }^{\circ} \mathrm{C}-10 \%\right.$ e $\left.14 \%\right)[47]^{3}$ para o PAZEPC e MD $\left(37^{\circ} \mathrm{C}-10 \%\right)$ e $\operatorname{TRES}\left(5^{\circ} \mathrm{C}\right.$ e ${ }^{\circ} \mathrm{C}-10 \%$, informação sobre a hidratação) $[152]^{4}$ para o POVPC em membranas lipídicas. . . . . . . . . . . . . . .

4.40 Variação percentual para o valor de tempo de vida médio de fluorescência e anisotropia residual para: (i) membranas de $100 \%$ POPC a 23 e $37^{\circ} \mathrm{C}$ (cinza); (ii) membranas de $100 \%$ POPC-OOH a 23 e $37{ }^{\circ} \mathrm{C}$ (ciano escuro sólido); membranas com $0 \%$ e $100 \%$ de POPC-OOH (iii) a $23{ }^{\circ} \mathrm{C}$ (ciano escuro linhas em diagonal) e (iv) a $37^{\circ} \mathrm{C}$ (ciano escuro linhas horizontais); (v) membranas com 25\% POPC-OOH a 23 e $37^{\circ} \mathrm{C}$ (verde sólido); membranas com $0 \%$ e $25 \%$ de $\mathrm{POPC}-\mathrm{OOH}$ (vi) a $23{ }^{\circ} \mathrm{C}$ (verde linhas em diagonal) e (vii) a $37^{\circ} \mathrm{C}$ (verde linhas horizontais); (viii) membranas com $25 \%$ PAZEPC a 23 e $37^{\circ} \mathrm{C}$ (azul sólido); membranas com $0 \%$ e $25 \%$ de PAZEPC (ix) a 23 ${ }^{\circ} \mathrm{C}$ (azul linhas em diagonal) e (x) a $37{ }^{\circ} \mathrm{C}$ (azul linhas horizontais); (xi) membranas de $25 \%$ POVPC a 23 e $37{ }^{\circ} \mathrm{C}$ (vermelho sólido); membranas com $0 \%$ e $25 \%$ de POVPC (xii) a $23{ }^{\circ} \mathrm{C}$ (vermelho linhas em diagonal) e (xiii) a $37{ }^{\circ} \mathrm{C}$ (vermelho linhas horizontais). Os valores estão em módulo e incertezas foram propagadas por derivadas parciais. . . . . . . . . . . . . . . . .

4.41 Variação percentual para o valor de tempo médio de correlação rotacional e microviscosidade para: (i) membranas de $100 \%$ POPC a 23 e $37^{\circ} \mathrm{C}$ (cinza); (ii) membranas de $100 \%$ POPC-OOH a 23 e $37{ }^{\circ} \mathrm{C}$ (ciano escuro sólido); membranas com $0 \%$ e $100 \%$ de POPC-OOH (iii) a $23{ }^{\circ} \mathrm{C}$ (ciano escuro linhas em diagonal) e (iv) a $37^{\circ} \mathrm{C}$ (ciano escuro linhas horizontais); (v) membranas com 25\% POPC-OOH a 23 e $37{ }^{\circ} \mathrm{C}$ (verde sólido); membranas com $0 \%$ e $25 \%$ de $\mathrm{POPC}-\mathrm{OOH}$ (vi) a $23{ }^{\circ} \mathrm{C}$ (verde linhas em diagonal) e (vii) a $37^{\circ} \mathrm{C}$ (verde linhas horizontais); (viii) membranas com $25 \%$ PAZEPC a 23 e $37{ }^{\circ} \mathrm{C}$ (azul sólido); membranas com $0 \%$ e 25\% de PAZEPC (ix) a 23 ${ }^{\circ} \mathrm{C}$ (azul linhas em diagonal) e (x) a $37{ }^{\circ} \mathrm{C}$ (azul linhas horizontais); (xi) membranas de $25 \%$ POVPC a 23 e $37{ }^{\circ} \mathrm{C}$ (vermelho sólido); membranas com $0 \%$ e $25 \%$ de POVPC (xii) a $23{ }^{\circ} \mathrm{C}$ (vermelho linhas em diagonal) e (xiii) a $37{ }^{\circ} \mathrm{C}$ (vermelho linhas horizontais). Os valores estão em módulo e incertezas foram propagadas por derivadas parciais. . . . . . . . . . . . . . . . . .

4.42 Valores de tempo médio de relaxação dipolar em função da temperatura para membranas de POPC [47, 136, 152] com diferentes concentrações de PAZEPC [47] ou POVPC [152] e obtidos neste trabalho.

4.43 Valores de $\Delta v$ em função da temperatura para membranas de POPC [47, 136, 152] com diferentes concentrações de PAZEPC [47] ou POVPC [152] e obtidos neste trabalho 
5.1 Modelo de três níveis para o fator de forma $P_{t}(q)$ da seção transversal de bicamada lipídica (eq. 5.2) . . . . . . . . . . . . . . . . . . . . . . . . . . 133

5.2 Esquema representativo da suspensão de MLVs (círculos concêntricos) que apresenta correlação entre as diferentes bicamadas lipídicas (linhas pretas) separadas por uma distância $D_{r e p}$. O fator de forma que descreve estas bicamadas lipídicas é o mesmo apresentado anteriormente (eq. 5.2). . . . . . . . . . . . . . . . . . . . 134

5.3 Exemplo de "ondulação"(bending) da bicamada lipídica, adaptado de [157]. . . . . 134

5.4 O perfil de densidade eletrônica, $\rho(r)$, acompanhado do esquema da bicamada lipídica para auxiliar no entendimento. . . . . . . . . . . . . . . . . . . . . 135

5.5 Curvas de SAXS para as amostras não extrusadas de POPC (10 mM) com o aumento da concentração de POPC-OOH (de cima para baixo) a $23^{\circ} \mathrm{C}$ (círculos vazios) e $37^{\circ} \mathrm{C}$ (círculos cheios). As curvas estão deslocadas para melhor visualização e as mesmas composições lipídicas possuem o mesmo deslocamento. . . . . . . . . . . . 13

5.6 Curvas de SAXS para amostras extrusadas de POPC (10 mM) com o aumento da concentração de POPC-OOH (de cima para baixo) a $23^{\circ} \mathrm{C}$ (círculos vazios) e $37^{\circ} \mathrm{C}$ (círculos cheios). As curvas estão deslocadas para melhor visualização e as mesmas composições lipídicas possuem o mesmo deslocamento. . . . . . . . . . . . . . . . . 139

5.7 Curvas de SAXS para MLVs de POPC (10 mM) com o aumento da concentração de $\mathrm{POPC}-\mathrm{OOH}$ a $23^{\circ} \mathrm{C}$.

5.8 Curvas de SAXS para amostras de POPC (10 mM) dissolvidas em diferentes soluções: água (verde), hepes (azul), PBS (vermelho) e tampão utilizado nesta tese (preto)

5.9 Curva de SAXS experimental de vesículas de $100 \%$ POPC a $23^{\circ} \mathrm{C}$ não extrusadas (pontos pretos), ajuste total obtido através do modelo de $I_{N e x}(q)$ (eq. 5.8) descrito anteriormente (linha vermelha mais fina) utilizando o programa GENFIT, e cada curva teórica $P(q) S_{i}(q)$ calculada para obter a $I_{N e x}(q)$ (eq. 5.8) . . . . . . . . . 142

5.10 Curvas de SAXS de amostras extrusadas de POPC (10 mM) com o aumento da concentração de POPC-OOH a $23^{\circ} \mathrm{C} \ldots \ldots$. . . . . . . . . . . . . . . . . . . . . 14

5.11 Curvas de SAXS de amostras não extrusadas de POPC (10 mM) com o aumento da concentração de POPC-OOH (de cima para baixo) a $23^{\circ} \mathrm{C}$ (pontos), acompanhadas dos ajustes (linha preta). As curvas estão deslocadas para melhor visualização. . . .

5.12 Curvas de SAXS de amostras extrusadas de POPC (10 mM) com o aumento da concentração de POPC-OOH (de cima para baixo) a $23^{\circ} \mathrm{C}$ (pontos), acompanhadas dos ajustes (linha preta). As curvas estão deslocadas para melhor visualização. . . . 145 
5.13 Perfil de densidade eletrônica $\Delta \rho(r)=\rho(r)-\rho_{\text {sol }}$ calculado (eq. 5.5) utilizando os parâmetros de $P_{t}(q)$ obtidos através do ajuste das curvas de SAXS de POPC:POPCOOH de amostras extrusadas (figs 5.12). O código de cores é o mesmo apresentado nas figuras 5.11 e 5.12: verde claro 100\% POPC, azul escuro 100\% POPC-OOH e o gradiente de cor indica as diferentes razões molares. . . . . . . . . . . . . . . . . . 146

5.14 Espessura de uma monocamada lipídica obtida como $R_{\mathrm{CH}_{3}}+R_{\mathrm{CH}_{2}}+R_{\text {pol }}$ para as vesículas de POPC (10 mM) em função do aumento de concentração do POPC-OOH.147

5.15 Três distâncias de separação entre lamelas obtidas para as MLVS de POPC (10 mM) em função do aumento de concentração de POPC:OOH. As linhas são apenas guias para os olhos. . . . . . . . . . . . . . . . . . . . . 14

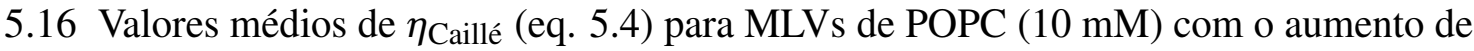
concentração de POPC-OOH.

5.17 Funções de interferência entre lamelas $S(q)$ obtidas através de simulação utilizando os parâmetros descritos na tabela 5.2 mantendo $\eta_{\text {Caillé }}=0,10$ e variando-se o número de lamelas $N$ : (a) escala logarítimica, (b) escala linear.

5.18 Funções de interferência entre lamelas $S(q)$ obtidas através de simulação utilizando os parâmetros descritos na tabela 5.2, $N=20$ e variando-se o valor de $\eta_{\text {Caillé como }}$ indicado na figura.(a) escala logarítimica, (b) escala linear. . . . . . . . . . . . . .

5.19 Ampliação das curvas de SAXS (fig. 5.5) na região da segunda ordem de difração para as amostras de POPC com aumento da concentração de POPC-OOH não extrusadas, nas temperaturas estudadas de $23^{\circ} \mathrm{C}$ e $37^{\circ} \mathrm{C}$

5.20 Perfis de densidade eletrônica calculados a partir dos ajustes das curvas de SAXS de POPC:POPC-OOH de amostras extrusadas medidas neste trabalho $(\Delta \rho(r)=$ $\rho(r)-\rho_{\text {sol }}$, esquerda) e obtidas por Rosa et al. [43] (direita). A imagem obtida de Rosa et al. [43] apresenta também as funções $\rho(r)$ para membranas de POPC na presença de PAZEPC, mas estas não são aqui comparadas.

5.21 Curvas de SAXS de amostras extrusadas de POPC (10 mM) com o aumento da concentração de POPC-OOH (de baixo para cima) a $23^{\circ} \mathrm{C}$ dispersa em tampão salino obtidas neste trabalho (esquerda) e em água obtida por Rosa et al. [43] (direita). As curvas estão deslocadas para melhor visualização.

5.22 Valores calculados para o módulo de curvatura $K_{c}$ (em Joules) estimados a partir dos parâmetros de ajustes das curvas de SAXS para as amostras de POPC com o aumento da concentração de POPC-OOH não extrusadas. A linha é apenas guia para os olhos 
5.23 Curvas de SAXS para amostras de POPC (10 mM) com o aumento da concentração de PAZEPC (esquerda) e POVPC (direita) para suspensões não extrusadas (painel superior) e extrusadas (painel inferior) para $23^{\circ} \mathrm{C}$ (ponto vazios) e $37^{\circ} \mathrm{C}$ (pontos sólidos). As curvas estão deslocadas para melhor visualização, sendo que as mesmas composições lipídicas possuem o mesmo deslocamento. . . . . . . . . . . . . . 164

5.24 Curvas de SAXS para amostras de POPC (10 mM) com o aumento da concentração de PAZEPC (esquerda) e POVPC (direita) para soluções não extrusadas (painel superior) e extrusadas (painel inferior) a $23^{\circ} \mathrm{C}$

5.25 Curvas de SAXS para amostras de POPC (10 mM) na presença de 25\% PAZEPC para suspensões não extrusadas (pontos vazios) e extrusadas (pontos sólidos) para a temperatura de $23^{\circ} \mathrm{C}$ (azul) e $37^{\circ} \mathrm{C}$ (vermelho) . . . . . . . . . . . . .

5.26 Curvas de SAXS para amostras de POPC (10 mM) com o aumento da concentração de lipídeo oxidado: POPC (preto), PAZEPC (azul), POVPC (vermelho) e POPC$\mathrm{OOH}$ (verde) para soluções não extrusadas (painel superior) e extrusadas (painel inferior) para a temperatura de $23^{\circ} \mathrm{C}$

5.27 Curvas de SAXS para amostras de POPC (10 mM) contendo 10\% (tom claro) e $25 \%$ (tom escuro) de PAZEPC (esquerda - azul) ou de POVPC (direita - vermelho) a 23 ${ }^{\circ} \mathrm{C}$ acompanhadas dos ajustes (linha preta). As curvas estão deslocadas para melhor visualização. . . . . . . . . . . . . . . . . . .

5.28 Perfil de densidade eletrônica $(\rho(r))$ calculado (eq. 5.5) utilizando os parâmetros de $P_{t}(q)$ obtidos através dos ajustes das curvas de SAXS de POPC:lipídeos: $10 \%$ (tom claro) e $25 \%$ (tom escuro) de PAZEPC (azul) ou de POVPC (vermelho) e 10\% (tracejada) e $25 \%$ (sólida) POPC-OOH (verde) . . . . . . . . . . . . . . . . . . . 170

5.29 Espessura de uma camada lipídica obtida como $R_{\mathrm{CH}_{3}}+R_{\mathrm{CH}_{2}}+R_{\text {pol }}$ para as vesículas de POPC (10 mM) em função do aumento de concentração dos lipídeos oxidados: PAZEPC (azul), POVPC (vermelho) e POPC-OOH (verde). As linhas são apenas guias para os olhos.

5.30 Três distâncias (círculo, quadrado e triângulo) de repetição obtidas para as vesículas de POPC (10 mM) em função do aumento da concentração dos lipídeos oxidados: PAZEPC (azul), POVPC (vermelho) e POPC-OOH (verde). As linhas são apenas guias para os olhos.

5.31 Valores médios de $\eta_{\text {Caille }}$ (eq. 5.4) para MLVs de POPC (10 mM) com aumento da concentração de POPC-OOH (verde) e de POVPC (vermelho).

5.32 Valores calculados para o módulo de curvatura $K_{c}$ (em Joules) estimados a partir dos parâmetros de ajustes das curvas de SAXS para as amostras de POPC com o aumento da concentração de POPC-OOH e POVPC não extrusadas. As linhas são apenas guias para os olhos. 
6.1 Sequência de aminoácidos do polipeptídeo IAPP [170] . . . . . . . . . . . . 178

6.2 Curvas de intensidade de fluorescência de Th $\mathrm{T}(30 \mu \mathrm{M})$ para amostras de $10 \mu \mathrm{M}$ de IAPP em 20 mM HEPES-KOH, 1 mM EDTA em pH 7,4 a $25^{\circ} \mathrm{C}$ na ausência de lipossomos (painel superior - esquerda) e presença de diferentes concentrações de lipossomos de POPS: dados experimentais para as triplicatas independentes (círculos em tons de azul), controles contendo apenas o lipossomo na presença de Th $\mathrm{T}$ (quadrados pretos, controle contendo apenas Th $\mathrm{T}$ disperso no tampão (quadrados pretos, painel superior - esquerda) e controle contendo apenas IAPP (losango vermelho, painel superior - esquerda) . . . . . . . . . . . . . . . . . 185

6.3 Curvas de intensidade de fluorescência de Th T $(30 \mu \mathrm{M})$ para amostras de $10 \mu \mathrm{M}$ de IAPP em 20 mM HEPES-KOH, 1 mM EDTA em pH 7,4 a $25^{\circ} \mathrm{C}$ na ausência de lipossomos (preto) e presença de diferentes concentrações de lipossomos de POPS: $100 \mu \mathrm{M}$ (vermelho), $500 \mu \mathrm{M}$ (verde) e $1000 \mu \mathrm{M}$ (azul). As curvas representam as médias das triplicatas obtidas na figura $6.2 \ldots \ldots \ldots$. . . . . . . . . . . 186

6.4 Curvas de intensidade de fluorescência de Th $\mathrm{T}(30 \mu \mathrm{M})$ para amostras de $10 \mu \mathrm{M}$ de IAPP em 20 mM HEPES-KOH, 1 mM EDTA em pH 7,4 a $25^{\circ} \mathrm{C}$ na ausência de lipossomo (preto) e presença de $100 \mu \mathrm{M}$ (painel superior) e $500 \mu \mathrm{M}$ (painel inferior) de lipossomos de POPC (vermelho), POPC:POPC-OOH (7:3) (azul) e POPC-OOH (verde) em duas semanas distintas (esquerda e direita). As curvas representam as médias das triplicatas independentes. . . . . . . . . . . . . . . . . . . . . . . . . . 189

6.5 Curvas de intensidade de fluorescência de Th $\mathrm{T}(30 \mu \mathrm{M})$ para amostras de $10 \mu \mathrm{M}$ de IAPP em 20 mM HEPES-KOH, 1 mM EDTA em pH 7,4 a $25^{\circ} \mathrm{C}$ obtidas em dias diferentes como indicado na legenda. . . . . . . . . . . . . . . . . . . . . . . . . . . 190

\section{LISTA DE TABELAS}

1.1 Patologia associada in vivo à fibra amiloide contendo uma proteína/polipeptideo e seu número de aminoácidos $[7] \ldots \ldots \ldots \ldots \ldots \ldots$ 
3.1 Massa Molecular (MM) e o raio de giro $(\mathrm{Rg})$ para a estrutura cristalográfica de BSA a pH 6,5 (PDB 4F5S [54]), conformação parcialmente desenovelada obtida em nossas simulações de MD; dímero obtido por modelagem de corpo rígido utilizando o software GLOBSYMM a pH 3,7; ajuste calculado utilizando o software GENFIT como sendo composto por 75(5)\% do monômero parcialmente desenovelado a pH 3,7 e 25(5)\% respectivo dímero; Guinier fornece os valores de MM e Rg calculados diretamente da curva experimental (eq. Guinier 3.8) . . . . . . . . . . . . . . .

3.2 Percentual de cada população proteica obtido através dos ajustes das curvas experimentais de solução de BSA em pH 3,7 na ausência e na presença de 15:1 e 30:1 SDS e 15:1 SPFO utilizando o program GENFIT. Para 0:1 e 15:1 SDS ou SPFO, utilizou-se a combinção do fator de forma das estruturas atômicas do monômero e respectivo dímero da BSA na ausência de surfactante e para 30:1 SDS obtido por MD utilizou-se o monômero da BSA na presença de 30 moléculas de SDS e o respectivo dímero modelado por corpo rígido. . . . . . . . . . . . .

4.1 Síntese das medidas experimentais apresentadas neste capítulo: os números indicam em quantos dias as medidas foram repetidas. Em todos os experimentos foram utilizados MLVs, exceto para TRES, onde utilizou-se LUVs. Todos os experimentos foram realizados a 23 e $37{ }^{\circ} \mathrm{C}$. *A composição lipídica utilizada foi POPC:PAZEPC 70:30. ${ }^{\$}$ Os experimentos foram realizados apenas a $23{ }^{\circ} \mathrm{C} \ldots \ldots$. . . . . . . . .

4.2 Parâmetros obtidos através do ajuste da equação 4.14 aos dados experimentais de decaimento de intensidade de fluorescência $\left(I_{\text {exp }}\right)$ para MLVs de POPC a $23^{\circ} \mathrm{C}$ e $37^{\circ} \mathrm{C}$ presentes na figura 4.9. O tempo de vida médio $\langle\tau\rangle$ calculado através da equação 4.11 também está indicado para ambas as temperaturas. . . . . . . . . . . .

4.3 Valores de intensidade de fluorescência do estado estacionário da sonda TMADPH para MLVs de POPC a 23 e $37^{\circ} \mathrm{C}$ para diferentes direções de polarização: $I_{V V}$ - excitação vertical e emissão vertical; $I_{V H}$ - excitação vertical e emissão horizontal; $I_{H V}$ - excitação horizontal e emissão vertical; $I_{H H}$ - excitação horizontal e emissão horizontal. O fator $\mathrm{G}$ calculado pela equação 4.19 e a anisotropia do estado estacionário $<r>$ calculada pela equação 4.20 também estão apresentados. .

4.4 Parâmetros de ajuste obtidos utilizando as equações 4.14 para $I(t)$ e 4.22- 4.26 para a anisotropia resolvida no tempo sintetizadas acima. Resultados obtidos para as análises dos experimentos de anisotropia resolvida no tempo da sonda TMA-DPH em membranas de POPC a 23 e $37{ }^{\circ} \mathrm{C} \ldots \ldots \ldots \ldots \ldots \ldots$

4.5 Resumo das sondas fluorescentes, dados experimentais e parâmetros obtidos para cada método experimental de fluorescência realizado neste projeto. ${ }^{*} \mathrm{O}$ espectro de fluorescência do laurdan também é um dado experimental para a técnica de TRES. . 
4.6 Valores obtidos para as MLVs de POPC $(100 \mu \mathrm{M})$ contendo TMA-DPH na razão molar 100:1 (lipídeo:sonda). Entre parênteses estão valores da literatura para 20 ${ }^{\circ} \mathrm{C}[140,141]^{*}$; ${ }^{+}$para $35^{\circ} \mathrm{C}$ [143] e $27{ }^{\circ} \mathrm{C}$ [123] (resultado obtido por dinâmica molecular) separados por vírgula. . . . . . . . . . . . . . .

4.7 Valores obtidos para LUVs de POPC contendo laurdan 100:1 (lipídeo:sonda) a $23^{\circ}$ $\mathrm{C}$ e $37^{\circ} \mathrm{C}$ : GP, $\Delta v$ e $\tau_{R D}$ para os nossos experimentos e entre parênteses os valores publicados por Amaro et al. [128], para comparação. Para calcular o $\Delta v$ foi utilizado o valor de $v(0)=23,800 \mathrm{~cm}^{-1}$ obtido por [144] . . . . . . . . . . . . . . . .

4.8 Valores obtidos para membranas de POPC na ausência e presença de lipídeos oxidados à $23^{\circ} \mathrm{C}$. Para calcular o $\Delta v$ foi utilizado o valor de $v(0)=23,800 \mathrm{~cm}^{-1}$ obtido

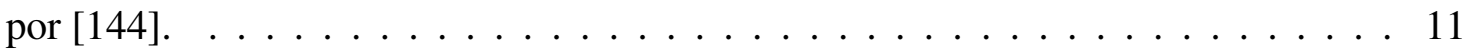

5.1 Variação possível dos parâmetros de ajuste de $S(q)$ e $P_{t}(q)$, para medidas de SAXS. 137

5.2 Parâmetros utilizados para simulações das curvas de $S(q)$ e $P(q)$ para demonstrar o

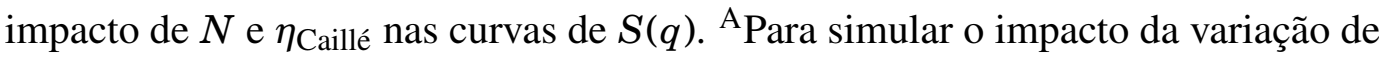
$N$, fixou-se $\eta_{\text {Caillé }}=0,10 .{ }^{\mathrm{B}}$ Para simular o impacto da variação de $\eta_{\text {Caillé }}$, fixou-se

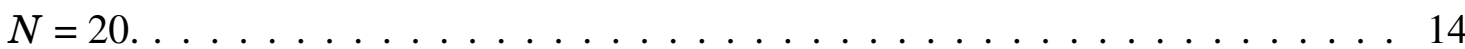

6.1 Parâmetros cinéticos obtidos para a fibrilação do IAPP na ausência e na presença de diferentes concentrações de POPS a partir da análise das curvas de intensidade de Th $\mathrm{T}$ apresentadas na figura 6.3. Utilizou-se o modelo sigmoidal apresentado em 1 (fig. 1.3 e eq. 1.1) 
1 Introdução 1

2 Objetivos

3 Caracterização de agregados da proteína BSA induzidos por surfactantes aniônicos

3.1 Introdução . . . . . . . . . . . . . . . . . . . 11

3.2 Materiais e Métodos . . . . . . . . . . . . . . . . . 15

3.2.1 Simulações de dinâmica molecular All Atom . . . . . . . . . . . . . . . 15

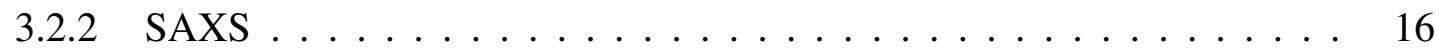

3.2.3 Absorção de luz UV-Vis e Turbidez . . . . . . . . . . . . . . . . . 21

3.2.4 Fluorescência de Tioflavina $\mathrm{T} \ldots \ldots \ldots . \ldots . \ldots 23$

3.2.5 Microscopia Eletrônica de Transmissão (TEM) e de Varredura (SEM) . $\quad 25$

3.2 .6 Dicroísmo Circular . . . . . . . . . . . . . . . . . 25

3.3 Resultados e Discussão . . . . . . . . . . . . . . . . . . . . . . . 28

3.3.1 Estado conformacional e oligomérico da BSA no pH 3.7: SAXS, SRCD

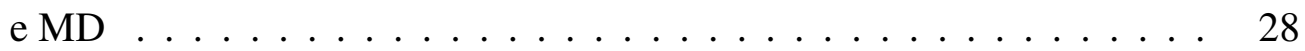

3.3.2 O impacto do SDS e SPFO na conformação e agregação da BSA em pH 3,7 33

3.3.3 Influência dos surfactantes analisada por MD, SAXS e SEM . . . . . . . 34

3.3.4 Influência dos surfactantes na BSA analisada por Turbidez, fluorescência de $\mathrm{Th} \mathrm{T}$ e SRCD . . . . . . . . . . . . . . . . . . . 43

3.3.5 SDS x SPFO - formação de agregados tipo amilóide da proteína BSA . $\quad 50$

4 Impacto de lipídeos oxidados em bicamadas lipídicas investigado por técnicas avançadas de fluorescência

4.1 Materiais e Métodos . . . . . . . . . . . . . . . . . . . 54 
$4.1 .1 \quad$ Preparo de lipossomos $\ldots \ldots \ldots \ldots \ldots \ldots$

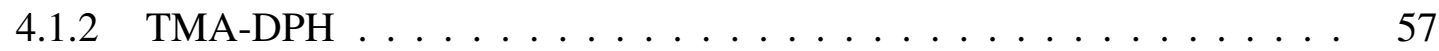

4.1.3 Laurdan e Polarização Generalizada $(G P) \ldots \ldots \ldots$

4.1 .4 Fluorescência I - Teoria . . . . . . . . . . . . . . . . . . . . . 59

4.1.4.1 Fluorescência do estado estacionário . . . . . . . . . . . 61

4.1.4.2 Intensidade de fluorescência resolvida no tempo . . . . . . . 64

4.1.4.3 Anisotropia de fluorescência do estado estacionário . . . . . . 67

4.1.4.4 Anisotropia de fluorescência resolvida no tempo . . . . . . . . 69

4.1.5 Fluorescência II - Experimento e Exemplos: POPC $23^{\circ} \mathrm{C}$ e $37^{\circ} \mathrm{C} \ldots$. . 71

4.1.5.1 Fluorescência do estado estacionário e GP . . . . . . . . 71

4.1.5.2 Fluorescência resolvida no tempo . . . . . . . . . . 72

4.1.5.3 Anisotropia de fluorescência do estado estacionário . . . . . . 74

4.1.5.4 Anisotropia de fluorescência resolvida no tempo . . . . . . . 75

4.1.6 Espectro de fluorescência resolvida no tempo (TRES) . . . . . . . . . . 79

4.1.6.1 Metodologia para obter TRES _ . . . . . . . . . . . 80

4.1.6.2 Interpretação do TRES em membranas lipídicas . . . . . . . 85

4.2 Resultados I - Impacto do lipídeo oxidado POPC-OOH em membranas lipídicas 88

4.3 Discussão I - Impacto do lipídeo oxidado POPC-OOH . . . . . . . . . . . . . . . 102

4.4 Resultados II - Impacto dos lipídeos oxidados PAZEPC e POVPC em membranas

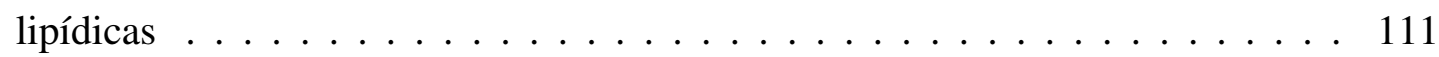

4.5 Discussão II - Impacto dos lipídeos oxidados PAZEPC e POVPC em membranas lipídicas . . . . . . . . . . . . . . . . . . . . . . . . 120

5 Impacto de lipídeos oxidados em bicamadas lipídicas investigado por SAXS 131

5.1 Materiais e Métodos . . . . . . . . . . . . . . . . . . . . . . . 131

5.1.1 Modelo para análise das curvas de SAXS para LUV e MLV . . . . . . 132

5.1.2 Ajuste das curvas de SAXS . . . . . . . . . . . . . . . 136

5.2 Resultados I - Impacto do lipídeo oxidado POPC-OOH em membranas lipídicas 137

5.3 Discussão I: a influência de POPC-OOH nas propriedades físicas de membrana lipídica . . . . . . . . . . . . . . . . . . . . . . . 155

5.4 Resultados II - Impacto dos lipídeos oxidados PAZEPC e POVPC em membranas lipídicas . . . . . . . . . . . . . . . . . . . . . . . 163

5.5 Discussão II: Impacto dos lipídeos oxidados PAZEPC e POVPC em membranas lipídicas . . . . . . . . . . . . . . . . . . . . . . . . . . . . 174

6 Interação do polipeptídeo amilóide das ilhotas humano com membranas modelo contendo lipídeos oxidados $\quad 178$

6.1 Introdução . . . . . . . . . . . . . . . . . . . 178 
6.2 Materiais e Métodos . . . . . . . . . . . . . . . . . . . . . . . 183

6.2 .1 Preparação do IAPP . . . . . . . . . . . . . . . . . . . . . 183

6.2.2 Medidas de cinética de fluorescência de Th $\mathrm{T} \ldots \ldots$. . . . . . . . 183

6.3 Resultados e Discussão . . . . . . . . . . . . . . . . . . . . . . . . . . 184

7 Conclusão 191

$\begin{array}{ll}\text { Bibliografia } & 195\end{array}$

$\begin{array}{ll}\text { Apêndice } & 214\end{array}$ 


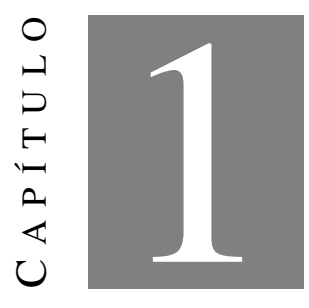

\section{INTRODUÇÃO}

Em 1854, Rudolph Virchow, médico e cientista alemão, percebeu que certos corpos amiláceos retirados de tecido cerebral se tornavam azul quando marcados com iodo e lilás após a adição de ácido sulfúrico, indicando similaridade com os resultados obtidos ao investigar a celulose [1]. Desta maneira, Virchow supôs que o corpo em questão também seria composto por glicose, que são as subunidades da celulose (polissacarídeo), e os denominou amiloide (derivado do latim amylum e do grego amylon, que significa amido - também um polissacarídeo contendo glicose) [1].

Passados 5 anos desta descoberta, foi elucidado que, na realidade, este depósito amiloide era formado principalmente por agregados proteícos que poderiam formar fibras [1]. Mas foi apenas 100 anos depois ( 1960) que se constatou, atráves de experimentos com a sonda Congo Red, que estas fibras amiloides possuiam uma certa organização [2]. Em seguida, experimentos de raios-X demonstraram que esta organização é altamente ordenada, apresentando dois picos de difração indicando duas distâncias de repetições características no interior da fibra: $\sim 5 \AA$ e $10 \sim$ $\AA$ [3].

Atualmente, designa-se fibra amiloide a um tipo de agregado proteico (ou peptídico) com estrutura fibrilar composta por um empilhamento de folhas $\beta$ (estrutura secundária) perpendicular ao eixo da fibra como esquematizado na figura $1.1[4,5]$. Interessante notar que as distâncias de repetição indicadas anteriormente [3] são compatíveis com os resultados atuais para as distâncias entre duas "linhas" $\beta$ (fig. 1.1 - azul) e duas folhas $\beta$ (fig. 1.1 - plano azul e sombreado) $([4,5]$. 


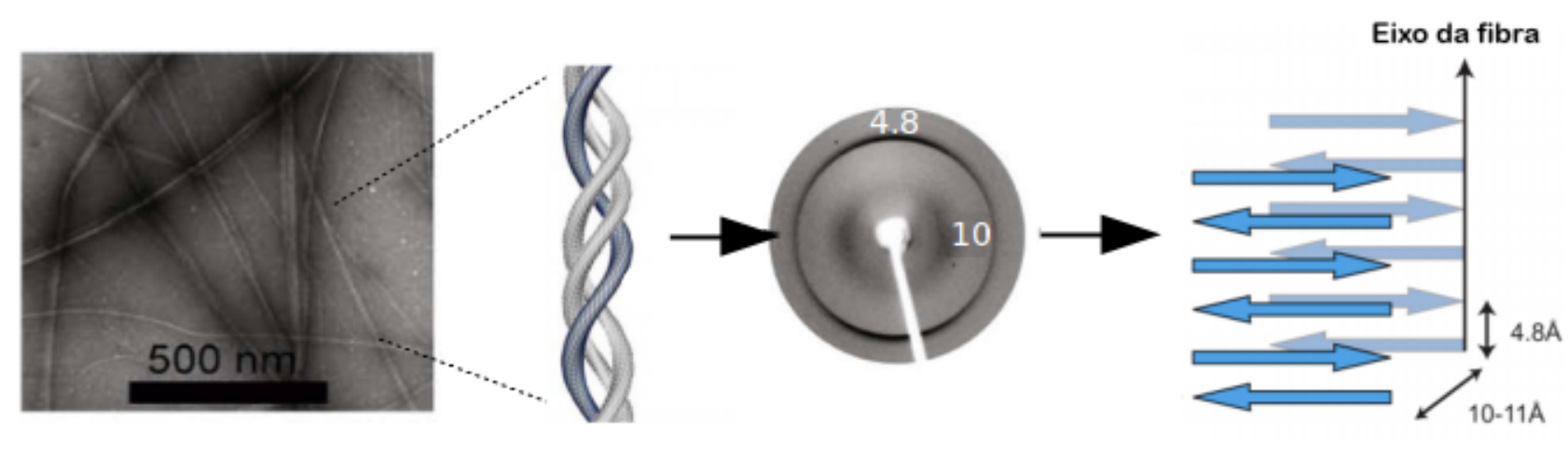

Figura 1.1: Esquema de fibras amilóides adaptado de [4, 5], da esquerda para direita: fibras amilóides visualizada por microscopia eletrônica de transmissão (TEM), fibra amilóide esquematizada por computação, padrão de difração de raio-X de fibras amilóides e estrutura secundária de folhas $\beta$ esquematizada em azul indicando as distâncias de separação obtidas por difração de raio-X.

Cabe acrescentar que o diâmetro da fibra pode ser da ordem de dezenas de nanômetros e seu comprimento está na escala micrométrica, como indicado por TEM na figura $1.1[5,6]$.

Apesar dos mecanismos de formação das fibras ainda serem tema de discussão [7], é conhecido que para ocorrer a fibrilação a proteína normalmente sofre alterações em sua estrutura secundária e/ou modificações na sua estrutura quaternária nos estágios iniciais de agregação $[5,6,8]$. Já para as proteínas que são naturalmente desenoveladas, o primeiro passo é estabilizar uma conformação parcialmente enovelada $[9,10]$.

Estes mecanismos de formação estão intrinsicamente conectados com a barreira energética que define a conformação e estabilidade da proteína [11]. A figura 1.2 apresenta, de maneira resumida, o panorama energético de conformações e formação de agregados proteícos. 


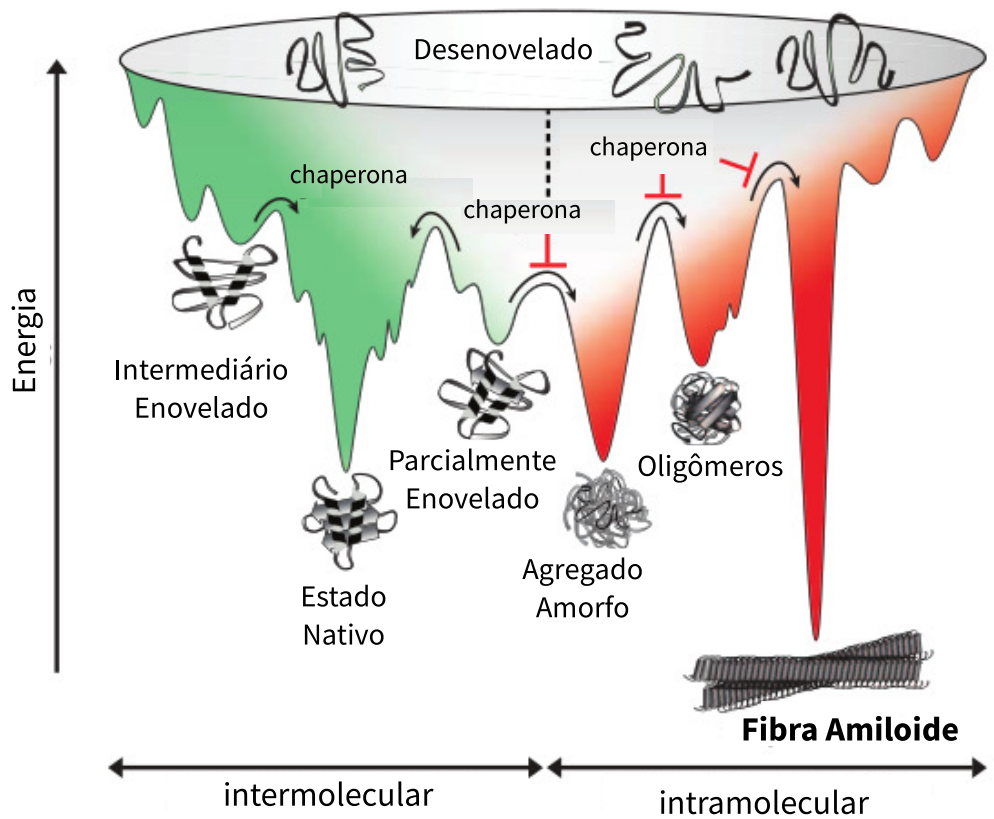

Figura 1.2: Esquema do panorama energético do enovelamento e agregação de proteínas mediado por interações intermoleculares, intramoleculares e por chaperonas [11]. Ver texto para detalhes.

Note que, a não ser pelas proteínas intrinsicamentes desordenadas (IDPs), as proteínas tendem a encontrar uma conformação enovelada que seja termodinamicamente estável podendo passar por estágios intermediários ou parcialmente enovelados até alcançar o estado nativo (região verde fig. 1.2 ) [11]. Interessante notar que este processo é facilitado pela ação de chaperonas (uma classe de proteínas), mas regulado por interações intermoleculares da própria sequência primária da proteína [11]. Por outro lado, podem existir interações intramoleculares (entre diferentes monômeros, por exemplo) que levam à agregação proteica amorfa, oligomérica ou até a formação das fibras amilóides (região vermelha fig. 1.2) [11]. Neste caso, as chaperonas tentam impedir a formação dos agregados. Vale ressaltar que se acredita que a fibra amiloide é o estado proteíco de menor energia, ou seja, o mais estável [11].

Tendo em vista este panorama energético, pode-se sugerir que a capacidade para a formação de fibras amilóides é intrínseca à cadeia polipeptídica e não é exclusiva de algumas sequências de aminoácidos, pois a formação da fibra seria um problema enérgetico [12,13]. De fato, apesar de mais de 30 proteínas e peptideos formarem fibras amilóides in vivo [7], muitas outras podem formas fibras in vitro ao se introduzir energia ao sistema [14]. Essa energia necessária para ultrapassar as barreiras energéticas e realizar a formação destes agregados fibrilares (fig. 1.2) pode ser realizada por variação de $\mathrm{pH}$, temperatura, tempo de agitação e/ou adição de agentes químicos [14-16] (ver capítulo 4). Além disso, a dependência de agregação em relação ao micro ambiente também é evidente in vivo. Por exemplo, a condição fisiológica no cérebro humano, onde o peptídeo $\beta$-amilóide forma a fibra amilóide relacionada à doença de Alzheimer [17], é bastante diferente do ambiente encontrado no pâncreas onde o polipeptídeo amilina (IAPP - 
diabetes tipo II) [18] forma agregados com estrutura semelhante.

O processo de formação das fibras amilóides vem sendo amplamente estudado e, em geral, pode ser brevemente descrito em 3 fases, como apresentado na figura 1.3 [19, 20]: (i) lag phase onde monômeros passam por mudanças de conformação em sua estrutura secundária (formação de folhas $\beta$ ) e terciária através de interações intramoleculares formando núcleos que se agregram por interações intermoleculares, formando os primeiros oligômeros; (ii) crescimento - estes núcleos e oligômeros continuam a se associar criando protofibras ricas em folhas $\beta$ que crescem rapidamente por associação de novos núcleos e oligômeros; (iii) saturação - formação de fibra amilóide madura com a associação das protofibras [19, 20].

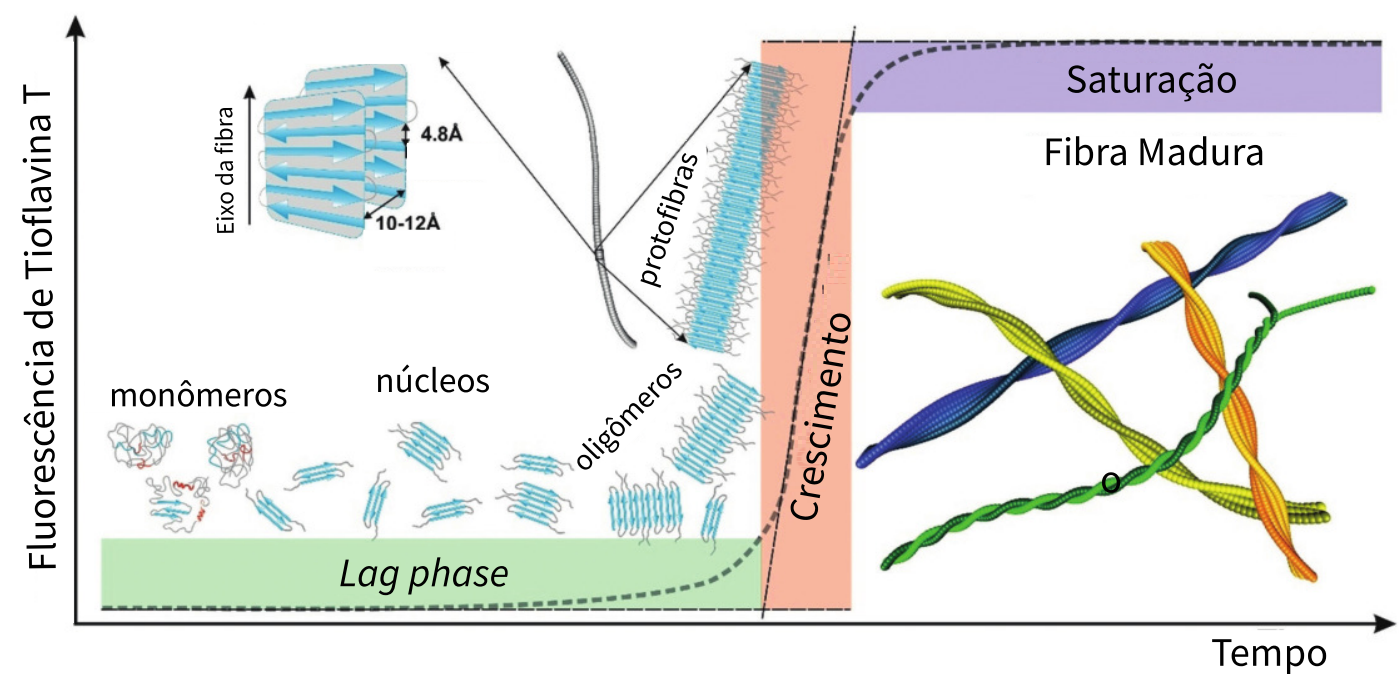

Figura 1.3: Esquema de cinética de formação de fibras amiloides através do processo de nucleação $[19,20]$. Ver texto para detalhes. Figura adaptada de [19].

Esta cinética de fibrilação, em geral, é obtida experimentalmente ao se medir a variação da fluorescência da sonda tioflavina $\mathrm{T}$ (item 3.2.4), que aumenta de intensidade ao se ligar aos oligômeros e protofibras ricos em folhas $\beta$ (fig. 1.3). Esta variação de intensidade em função do tempo pode ser descrita empiricamente pela seguinte equação [20]:

$$
I_{T h T}(t)=I_{0}+\frac{I_{f}}{1+e^{-\frac{t-t_{0}}{\tau}}}
$$

onde $I_{0}$ e $I_{f}$ são as intensidades de fluorescência inicial (lag phase) e final (saturação), respectivamente. $\mathrm{O}$ tempo de duração da lag phase é calculado como $t_{0}-2 \tau$ e a constante de crescimento aparente da fibra $(\kappa)$ é obtida como $1 / \tau$ [20] (ver cap. 6).

Como mencionado anteriormente, é bem conhecido que várias proteínas e polipeptídeos (mais de 30) são encontrados em depósitos amiloides ex-vivo e estão relacionados com diversas 
patologias [7, 12, 21]. Vale ressaltar que existem fibras amiloides que não apresentam citotoxicidade, pelo contrário, possuem uma função biológica bem definida, como é o caso da proteína pre-melanossomal que participa na produção de melanina nos olhos e na pele [22].

De qualquer maneira, maior atenção é dispensada ao estudos das formações amiloides relacionadas à patologias e a tabela abaixo apresenta três exemplos:

\begin{tabular}{cccc} 
Patologia & Proteína/Polipeptídeo & & $\mathrm{N}^{\mathrm{o}}$ de aminoácidos \\
\cline { 1 - 1 } Mal de Alzheimer & $\begin{array}{c}\text { Peptídeo amiloide- } \beta \\
\text { Doença de Parkinson }\end{array}$ & $\alpha$-sinucleína & $40-42$ \\
Diabetes tipo II & IAPP & 140 \\
\hline
\end{tabular}

Tabela 1.1: Patologia associada in vivo à fibra amiloide contendo uma proteína/polipeptideo e seu número de aminoácidos [7]

Estas patologias associadas às fibras amiloides possuem um grande impacto mundial não apenas como um problema de saúde, mas também como uma questão econômica, devido aos custos relacionados aos tratamentos dos pacientes [23, 24]. Estes custos podem ser diretos: despesas com médicos, compra de remédios e internações hospitalares; ou indiretos como horas de trabalho perdidas tanto pelo paciente, quanto pelo familiar que o assiste, bem como a redução da qualidade de vida dos mesmos [24].

Considerando o panorama mundial, estima-se que, em 2017, 50 milhões de pessoas possuíam o Mal de Alzheimer [25], 10 milhões com Doença de Parkinson [24] e 400 milhões com Diabetes tipo II [26]. Apenas considerando a Europa, os custos relacionados a estas doenças deve alcançar mais de 1,6 trilhões de reais em 2050 (para comparação, este valor representa 12\% do PIB brasileiro de 2018) [7, 26].

Mais especificamente, a diabetes tipo II (diabetes mellitus do tipo II - DM2) é um dos focos desta tese de doutoramento (ver cap. 6). Estima-se que o número de óbitos relacionados a esta doença foi de aproximadamente 5 milhões de pessoas ao redor do mundo no ano 2017 [26]. Considerando a população brasileira entre 20-79 anos, em 2013 foram registrados 116 mil óbitos causado por DM2. Em 2014, o número de pessoas com DM2 é de aproximadamente 11 milhões de pessoas (1 a cada 12 habitantes) e a projeção é que este número dobre até 2025 [27].

Como pode-se perceber pelos dados acima, as fibras amiloides possuem uma grande relevância mundial no aspecto da saúde e dos altos custos econômicos. Logo, entender os mecanismos e condições de formação destes agregados é muito importante para a sociedade (ver caps 3 e 6$)$.

Vale a pena ressaltar que estas três doenças relacionadas às fibras amiloides (tab. 1.1) e outras estão associadas ao envelhecimento [7], sendo este um fator de risco para o surgimento destas doenças [24-26]. 
Por outro lado, é conhecido que a presença de membranas lipídicas pode induzir a formação de amilóides (ver cap. 6) [28-30]. No caso de membranas carregadas negativamente, estas atraem prótons da solução que diminui o pH na superfície da membrana [31]. Além disso, deve ocorrer uma grande atração eletrostática entre as cargas negativas da superfície da membrana e os resíduos aminoácidos positivos de proteínas (ou peptídeos positivamente carregados), favorecendo a agregação de proteínas na superfície da membrana. A diminuição de $\mathrm{pH}$, combinado com o ambiente assimétrico do ponto de vista dielétrico da bicamada lipídica, passando de uma interface polar $(\epsilon=80)$ /apolar para um meio de constante elétrica $\epsilon=2$ no interior da bicamada, podem propiciar mudanças na estrutura secundária de uma proteína (ou peptídeo) promovendo a formação de agregados proteicos tipo amiloides (ou não amiloidais) [28, 29, 32].

Mais que isso, alguns estudos também sugerem que membranas biológicas contendo lipídeos oxidados, devido à ação de espécies reativas de oxigênio (ROS), aceleram a formação de fibras amilóides [30, 33, 34]. E é conhecido que o estresse oxidativo altera as propriedades biofísicas de membrana impactando na interação de proteínas com as mesmas [33, 35].

Desta maneira, estas alterações nas membranas contendo lipídeo oxidado podem estar correlacionadas com a gêneses das patologias citadas acima, visto que oxidação por ROS pode acontecer naturalmente in vivo, nos processos de envelhecimento.

Membranas biológicas são suscetíveis à oxidação por ROS devido a presença de grande número de lipídeos insaturados [36, 37]. Neste processo de oxidação, podem-se gerar diferentes produtos lipídicos devido ao ataque de ROS às duplas ligações das cadeias alifáticas insaturadas $[37,38]$. Estes diferentes produtos lipídicos podem causar diferentes graus de danos à membrana, variando entre pouca oxidação lipídica que pode ser compensada por processos naturais antioxidantes celulares até um alto nível de oxidação lipídica que leva à morte celular [39].

Em membranas lipídicas modelo podemos estudar o grau de dano causado pela presença de diferentes produtos lipídicos oxidados [37, 38]. Os impactos destes produtos vêm sendo estudados por microscopia de contraste de fase e de fluorescência de vesículas unilamelares gigantes (GUVs) [40, 41], técnica de aspiração por micropipeta de GUVS [42], espalhamento de raio-X a baixos ângulos (SAXS) [43] e por simulação computacional [36].

A figura 1.4 apresenta três exemplos do impacto da oxidação lipídica em membranas analisadas por microscopia de contraste de fase (A [42] e C [44]) e de fluorescência (B [45]) de GUVs. Nestes casos, os autores promoveram a oxidação lipídica in situ através da foto-oxdidação induzida pela presença de fotossensibilizadores (FS). 

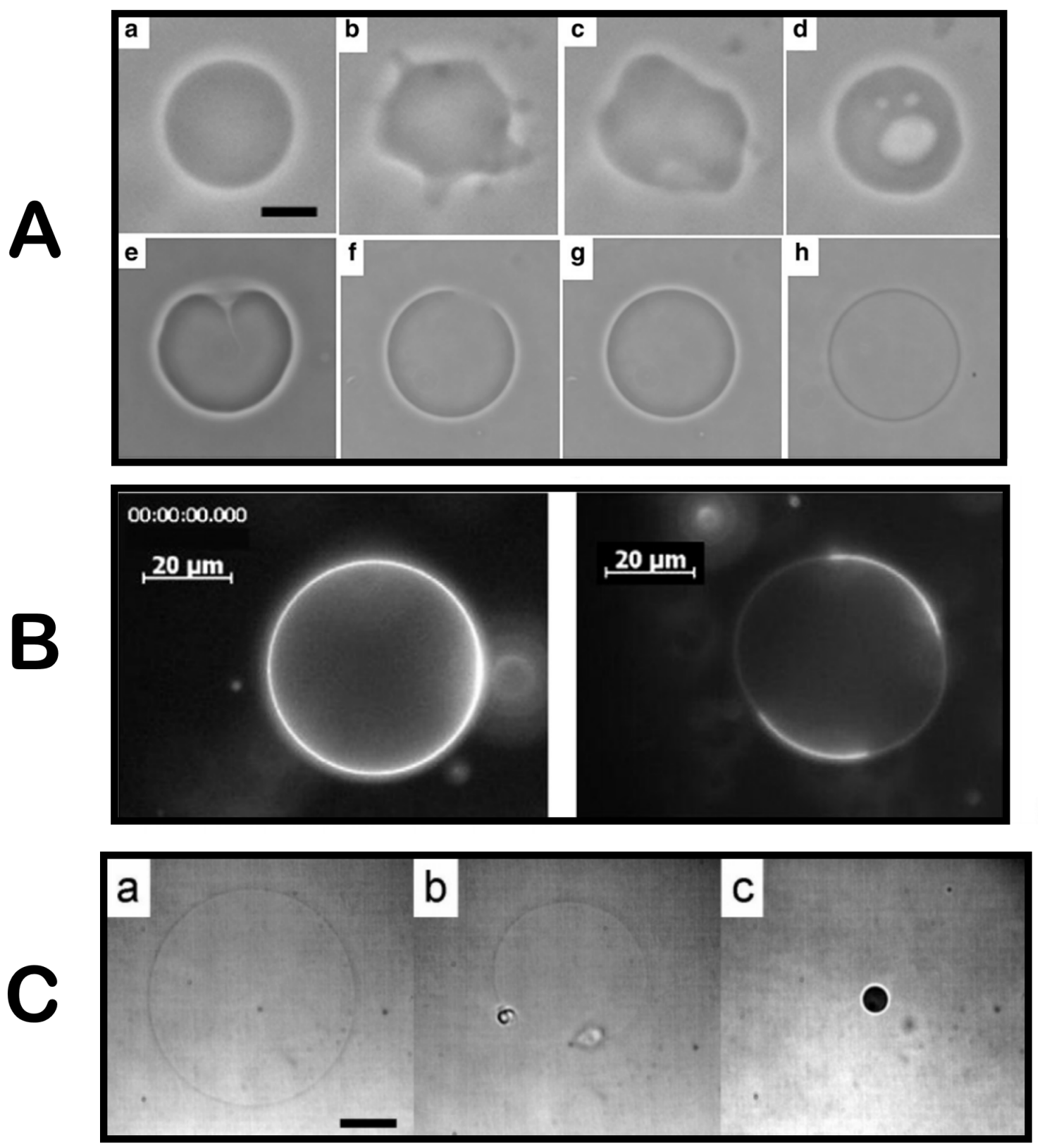

Figura 1.4: Exemplos do efeito da oxidação lipídica analisado por microscopia de contraste de fase (A e C) e de fluorescência (B): (A) azul de metileno (MB) (comprimento de onda de excitação $\lambda_{\text {ex }}=665 \mathrm{~nm}$ e concentração $40 \mu \mathrm{M}$ ) - (a) $1 \mathrm{~s}$, (b) $104 \mathrm{~s}$, (c) $108 \mathrm{~s}$ (d) $138 \mathrm{~s}$, (e) $162 \mathrm{~s}$, (f) $191 \mathrm{~s}$, (g) $193 \mathrm{~s} \mathrm{e} \mathrm{(h)} 246 \mathrm{~s}$. A escala em (a) é de de $20 \mu \mathrm{m}$ (adaptado de [42]). (B) Membrana de POPC:DPPC (1:1) inicialmente homogênea (a), apresentando separação de fases Ld-Lo (rafts lipídicos) induzida por horas de irradiação da porfirina ancorada na superfície da membrana (b) (adaptado de [45]). (C) Imagens de microscopia de contraste de fase de GUVs de DOPC, dispersas em solução contendo azul de metileno $(55 \mu \mathrm{M})$ após a irradiação com $\lambda_{e x}=532 \mathrm{~nm}$. Inicialmente - a - vê-se a GUV intacta, depois há a formação de um grande poro (após 3 minutos de irradiação - b) seguido de total destruição - c - (adaptado de [44]).

Nota-se que a oxidação lipídica pode causar grandes flutuações em membranas de DOPC ou POPC (40 $\mu \mathrm{M}$ de MB) seguida de aumento de área superficial, com emissão de buds - pequenas vesículas ligadas à vesícula original, e finamente aumento da permeabilidade da membrana (fig. 
1.4 A) [42]. Também foi demonstrada a separação de fases lipídicas no estado líquido ordenado (Lo) e líquido desordenado (Ld), chamados rafts lipídicos, podem ser foto-induzidos em sistemas lipídicos compostos por lipídeos insaturados (como POPC) e saturados (DPPC) (fig. 1.4 B POPC:DPPC 1:1 1\% de porfirina) [45]. Além disso, danos severos podem ocorrer devido à foto-oxidação, como a formação de grandes buracos na membrana, até a completa destruição da mesma (fig. 1.4 C - DOPC na presença de $55 \mu \mathrm{M}$ de MB) [44].

Mais ainda, a presença de lipídeos oxidados na bicamada pode evitar a formação ou romper microdomínios lipídicos [41], aumentar a área por lipídeo [36, 43, 46], diminuir a constante elástica da membrana [46, 47] e aumentar a hidratação da membrana [36, 43, 47]. (ver caps 4 e 5 para descrição mais detalhada da influência dos lipídeos POPC-OOH, PAZEPC e POVPC em membranas de POPC).

Estas alterações das membranas lipídicas causadas pela presença de lipídeos oxidados podem ter um impacto significativo na interação com as proteínas e polipeptideos e na formação de fibras amiloides.

De fato, algumas evidências mostram que o lipídeo oxidado PoxnoPC (produto da reação de oxidação do POPC, mediada por ozônio, com a quebra da cadeia na posição da insaturação e formação de um grupo terminal carbonila [48]) interage diretamente com aminoácidos da proteína gelsolina e influencia o alinhamento da mesma. Tal alinhamento é acompanhado por um rearranjo estrutural em folhas $\beta$, levando à formação de fibras amilóides e dando origem à doença neurodegenerativa chamada polineuropatia amiloidótica familiar tipo finlandês (PAFF - síndrome de Meretoja) [29] Outras investigações apontam um papel essencial do colesterol oxidado na formação das fibras amilóides do peptídeo amiloide- $\beta$, relacionado à doença de Alzheimer [34] (tab. 1.1).

Estudos da formação amilóide da protéina $\alpha$-synuclein, responsável pela doença de Parkinson, mostraram que mediadores de oxidação lipídica encontram-se em maior número no cérebro de pacientes com essa patologia, o que também indica que o estresse oxidativo pode estar diretamente relacionado à doença de Parkinson [49]. Além disso, o estresse oxidativo também está associado à degeneração macular, na qual as células do pigmento epitelial da retina sofrem modificações morfológicas e funcionais devido a interação com espécies reativas de oxigênio, levando a perda de visão [50].

Portanto, entender como lipídeos oxidados impactam na formação de estrutura amilóides é de grande relevância, tanto do ponto de vista de pesquisa básica quanto aplicada. Para isso, nesta tese de doutoramento, estudamos agregados proteícos tipo amilóide da proteína BSA induzidos por surfactantes aniônicos com o objetivo de elucidar os princípios físico-químicos que regem este processo (cap 3). Em seguida, realizamos a caracterização de membranas de POPC contendo os lipídeos oxidados POPC-OOH, PAZEPC e POVPC através de técnicas de fluorescência (cap 4) e de SAXS (cap 5). Por fim, utilizamos as membranas caracterizadas neste trabalho para 
induzir a formação de fibra amiloide do IAPP que, in vivo, está relacionada à diabetes tipo II (cap 6). 


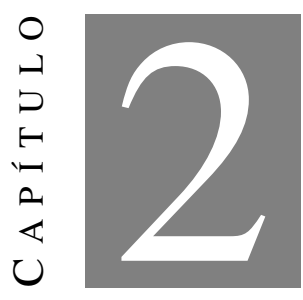

\section{OBJETIVOS}

O objetivo desta tese de doutoramento foi investigar como a oxidação lipídica altera as propriedades biofísicas de membranas e, por consequência, a formação de fibras amiloides. Em particular, objetivamos investigar possíveis mecanismos de formação de fibras de amilina (IAPP), relacionadas com diabetes melitus tipo II. Mais que isso, identificar e caracterizar as espécies formadas durante as primeiras etapas no processo de interação do IAPP com membranas, objetivando compreender o papel de lipídeos oxidados no desenvolvimento de patologias associadas a agregação de proteínas em membranas.

Os objetivos específicos podem ser esquematizados como segue:

- Investigar as principais características físico-químicas envolvidas no processo de agregação proteíca, em especial, agregados tipo amiloide. Para isso, induziremos agregação da proteína albumina de soro bovina (BSA) pela interação com os surfactantes aniônicos dodecil sulfato de sódio (SDS) e perfluorooctanoato de sódio (SPFO).

- Caracterizar as alterações biofísicas de membranas modelo de POPC causadas pela presença do lipídeo hidroperoxidado POPC-OOH e dos lipídeos de cadeia alquila oxidada encurtada, PAZEPC e POVPC, através de técnicas de fluorescência e de SAXS.

- Investigar se e como as membranas oxidadas impactam no processo de formação de fibra amiloide do IAPP. 


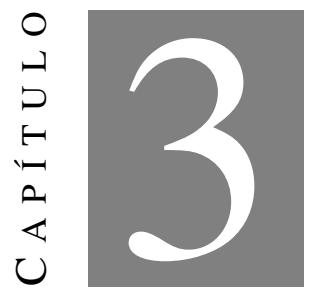

\section{CARACTERIZAÇÃo de Agregados da Proteína BSA INDUZIDOS POR SURFACTANTES ANIÔNICOS}

\subsection{Introdução}

A albumina de soro bovina (bovine serum albumin - BSA é uma proteína globular sintetizada pelo fígado do mamífero [51] e pode atingir uma concentração de até $55 \mathrm{mg} / \mathrm{mL}$ no plasma sanguíneo [52]. A BSA pode se ligar a diferentes compostos, o que lhe confere uma grande importância in vivo no transporte de metabólitos no sangue [52]. Composta por 585 resíduos de aminoácidos, geralmente agrupados em três domínios homólogos (I, II e III - fig. 3.8), a BSA possui massa molecular de $66,4 \mathrm{kDa}[51,52]$. Esta proteína é relativamente estável devido a 17 pontes dissulfeto sendo seu ponto isoelétrico em torno do $\mathrm{pH}$ 5,4 [53]. A sua estrutura secundária é de cerca de $65 \% \alpha$-hélice, menos do que $10 \%$ de folhas $\beta$ [51], sendo que a sua estrutura cristalográfica foi obtida a pH 6,5 [54].

É importante mencionar que a albumina do soro (bovina e humana) sofre transições conformacionais dependendo do $\mathrm{pH}(<3 \mathrm{mg} / \mathrm{mL})[51,52]$. No $\mathrm{pH}$ próximo de 10, a proteína está na conformação A ("aged") com $48 \%$ de $\alpha$-hélice; diminuindo o pH para 8 a estrutura secundária mantém-se inalterada e sua conformação é chamada de B (base) [51, 52]. Entre pH 8 e 4,3 a proteína está no estado N (normal) com cerca de $60 \%$-hélice, sendo que uma transição notável, $\mathrm{F}$ (rápido), acontece para pHs inferiores a 4,3 [51, 55]. No estado F, o domínio III é parcialmente desenovelado com a perda de até $10 \%$ de $\alpha$-hélice e abaixo do $\mathrm{pH}$ 2,7 a proteína sofre uma outra expansão $[52,55]$. Curiosamente, a pH 2,0, e para concentrações superiores a $25 \mathrm{mg} / \mathrm{mL}$ a conformação da BSA pode ser associada a um estado "molten-globule"como demonstrado por espalhamento de raio-X a baixos ângulos [51]. 
É bem conhecido que a BSA não forma fibras amilóides in vivo, mas pode fibrilar em algumas condições in vitro [14-16]. Experimentos realizados à temperatura de $70{ }^{\circ} \mathrm{C}$ de solução de 1; 2,5; 5 e 7,5 mg/mL de BSA a pH 7,4 demonstraram a formação de agregados proteícos (observada por DLS) concomitante com mudança da estrutura secundária de $\alpha$-hélice para folhas $\beta$ (fluorescência de Th T e FTIR) em função do tempo (experimentos realizados na escala de minutos até horas) [16]. Os autores também visualizaram agregados de BSA na escala micrométrica através de medidas de TEM e verificaram a presença de grande polidispersão de agregados (forma e tamanho). Medidas de difração de raio-X indicam que fibras do tipo amilóide coexistem com outros agregados proteicos [16]

Em boa concordância, outros experimentos utilizaram temperatura de $65^{\circ} \mathrm{C}$ para induzir a formação de agregados proteícos da BSA ( $6 \mathrm{mg} / \mathrm{mL})$ e obtiveram resultados similares [15] aos mencionados acima [16]. Em adição, estes experimentos mostraram que a formação dos agregados tipo amilóide da proteína BSA acontecem de maneira mais rápida a $\mathrm{pH}$ 3,0 do que a pH 1,6; 7,0; 9 ou 10,5 [15]. Por exemplo, a constante de crescimento de fibra obtida nos experimentos de fluorescência de Th T ( $k$ - fig. 1.3 modelo cinético introdução) a pH 3,0 é cerca de $40 \%$ maior em relação ao $k$ em pH 10 (segundo maior) e quase 3 vezes maior do que no $\mathrm{pH}$ fisiológico ( $\mathrm{pH} 7,0)$ [15]. Assim, foi sugerida a presença de uma isoforma desenovelada em $\mathrm{pH}$ 3,0 da proteína BSA que possui maior tendência a se associar em agregados mais ordenados [15].

Tendo em vista a importância do $\mathrm{pH}$ na agregação da proteína BSA, outros experimentos também evidenciaram esta depêndencia da formação de agregados tipo amilóide da BSA induzidos pelo surfactante negativamente carregado, dodecil sulfato de sódio (SDS) [14]. Mostrou-se que o SDS, na proporção molar 100:1 com a BSA, não é capaz de induzir a agregação da proteína em pH 5.65 ( ponto isoelétrico da BSA) e 7.65 (proteína carregada negativamente), mas apenas em pH 3.65 [14]. Assim, os autores concluíram que a ligação de SDS à BSA deve impedir a forte repulsão eletrostática entre as isoformas parcialmente desenoveladas no $\mathrm{pH}$ ácido, blindando as cargas positivas da proteína pela presença das cabeças polares com carga negativa do SDS [14].

Com estas informações, neste trabalho induzimos a formação de agregados proteicos da BSA em pH ácido $(3,7)$, a $25^{\circ} \mathrm{C}$ utilizando dois agentes químicos, os surfactantes aniônicos: hidrogenado (ou hidrocarboneto) docecil sulfato de sódio SDS (cmc $\sim 8 \mathrm{mM}$ em água [56]) e o fluorado (ou fluorocarbono) perfluorooctanoato de sódio SPFO (cmc $\sim 28 \mathrm{mM}$ em água [57]) (fig. 3.1). 


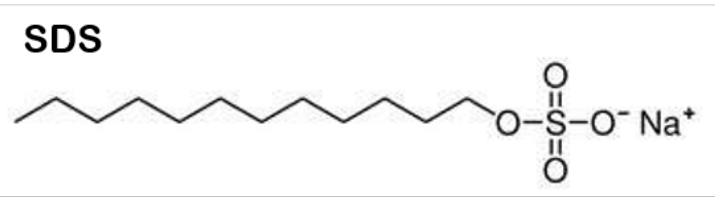

\section{SPFO}

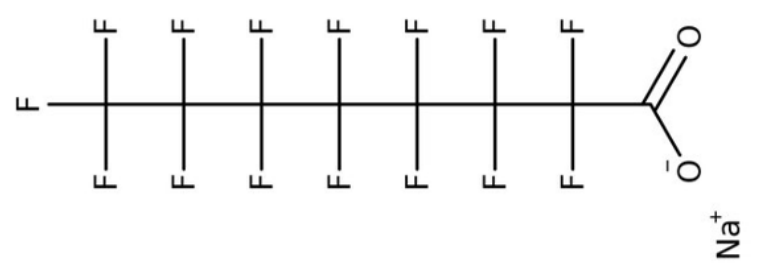

Figura 3.1: Estrutura química dos surfactantes utilizados SDS e SPFO (F indica átomo de flúor).

Os surfactantes são moléculas anfipáticas e podem ser utilizadas em diferentes aplicações, como na área de biociências (interação com proteínas, drug delivery), industrial (tintas, limpadores, materiais), cosméticos e muitos outros [58, 59]. De maneira interessante, existem grandes diferenças entre os surfactantes hidrogenados e os fluorados, sendo que os primeiros foram largamente estudados e os últimos ainda estão em constante desenvolvimento [60]. Cabe acrescentar que a interação de SDS com a proteína BSA encontra-se amplamente estudada na literatura [14, 56, 61-63] enquanto que estudos da interação do SPFO com a mesma proteína ainda são escassos [64]. Existem alguns trabalhos sobre a interação do SPFO com as proteínas HSA [55, 65, 66] e imunoglobulina [60].

Importante ressaltar que uma aplicação dos surfactantes fluorados na área biomédica envolve a formação de emulsões em água para realizar a entrega (delivery) de oxigênio à diferentes tecidos do corpo [67]. Sendo assim, é importante entender melhor a interação destes surfactantes com proteínas do sangue [60].

Desta maneira, variamos o excesso molar de cada um dos surfactantes (fig. 3.1) em relação à proteína BSA para investigar, comparativamente, os efeitos causados pelo SDS e pelo SPFO na BSA utilizando diferentes técnicas biofísicas.

Por fim, experimentos na área de físico-química de colóides tem elucidado diferenças entre os surfactantes fluorados e hidrogenados. Por exemplo, a energia de adsorção de um grupo $C F_{2}$ é duas vezes maior do que um grupo $\mathrm{CH}_{2}[67,68]$ e as propriedades de agregação dos fluorados é similar ao dos hidrogenados com uma cadeia 1,5 vezes maior [69]. Além disso, devido à presença do átomo de flúor, os fluorados são mais eletronegativos, possuem maior seção (área) transversal e maior volume do que os hidrogenados (comparações quantitativas estão presentes na discussão dos resultados).

Tendo em vista estas informações, combinamos simulações de dinâmica molecular (MD), análises de experimentos e cálculos teóricos de espalhamento de raios-X a baixos ângulo (SAXS), microscopia eletrônica de varredura (SEM), turbidez, fluorescência de Tioflavina T (Th T) e 
dicroísmo circular com fonte de radiação síncrotron (SRCD) com o objetivo de investigar a formação de agregados tipo amilóide da proteína BSA promovida pela interação dos surfactantes (SDS ou SPFO) em pH 3,7 para razões molares de 15:1 a 120:1 surfactante:BSA. 


\subsection{Materiais e Métodos}

Glicina, BSA e tioflavina T foram adquiridas na empresa Sigma-Aldrich Co, $\mathrm{SDS}\left(\mathrm{C}_{12} \mathrm{H}_{25} \mathrm{SO}_{4} \mathrm{Na}\right.$ - 288,372 g/mol) foi adquirido na Lancaster e SPFO $\left(\mathrm{C}_{8} \mathrm{~F}_{15} \mathrm{NaO}_{2}-436.052 \mathrm{~g} / \mathrm{mol}\right)$ foi obtido da empresa Lancaster e Alfa Aesar. Soluções estoque de BSA, Th T, SDS e SPFO foram preparadas no tampão de $50 \mathrm{mM}$ de glicina em pH 3,7. Solução de estoque de BSA foi de $15 \mu \mathrm{M}$ e SDS e SPFO era de $0,45,0,90,1,35,1,50,1,80,2,26,2,71,3,16$ e 3,61 mM. Todos os experimentos foram realizados à temperatura ambiente $\left(25^{\circ} \mathrm{C}\right)$ e as amostras foram medidas após 5 minutos de incubação.

\subsubsection{Simulações de dinâmica molecular All Atom}

As simulações de dinâmica molecular (MD) foram realizadas pelo pós doutor Ricardo Y. Espinosa e as análises de dados, discussões e imagens foram feitas em colaboração.

As mudanças conformacionais do monômero de BSA ao diminuir o pH de 6,5 (4F5S código PDB [54]) para pH 3,7 na presença de contra íons de cloro em meio aquoso para equilibrar a carga do sistema, foram estudadas inicialmente utilizando as simulações de Dinâmica Molecular (MD).

As simulações de MD foram realizadas utilizando o pacote GROMACS 4.5.3 [70]. O campo de força Gromos 54A7 [71] foi empregado para simular as interações intermoleculares; o algoritmo PDB2PQR $[72,73]$ foi utilizado para estimar o estado de ionização de resíduos tituláveis da BSA em pH 3,7.

$\mathrm{O}$ estado de protonação da BSA foi solvatado em uma caixa cúbica de simulação com dimensões $\mathrm{X}=\mathrm{Y}=\mathrm{Z}=12,43 \mathrm{~nm}$ com 61240 SPC/E moléculas de água [74], e aplicaram-se as condições de contorno periódicas. Noventa e nove contra íons de cloro foram adicionados para neutralizar o sistema (a pH 3,7, o BSA tem uma carga total de 99) [75].

Os sistemas foram otimizados seguindo o processo de minimização de energia de duas-fases contado com a restrição aplicada à posição atômica dos resíduos da protéina utilizando um potencial harmônico constante de $1000 \mathrm{~kJ} \mathrm{~mol}^{-1} \mathrm{~nm}^{-1}$ em todas as direções cartesianas. O algoritmo de gradiente conjugado foi aplicado para atingir a conversão do gradiente de energia $\leq$ $10 \mathrm{~kJ} \mathrm{~mol}^{-1} \mathrm{~nm}^{-1}$ [76].

Finalmente, removeu-se as restrições de posição e simulou-se o sistema para $100 \mathrm{~ns}$ no "ensemble"NpT à temperatura e pressão constante de $300 \mathrm{~K}$ e 1 bar, respectivamente, utilizando o termostato V-rescale [77] e barômetro Berendsen [78]. As interações eletrostáticas foram calculadas utilizando o modelo "particle-mesh"Ewald (PME) [79]. As interações de LennardJones (LJ) e as eletrostáticas foram calculadas dentro de um limite de exclusão de 1,0 nm. O algoritmo LINCS [80] foi utilizado para restringir todas as ligações covalentes. O tempo de integração de MD foi de 2 fs. 


\subsubsection{SAXS}

O espalhamento de raio-X a baixos ângulos (SAXS) é uma técnica experimental que permite determinar parâmetros estruturais de amostras biológicas em solução, como por exemplo, tamanho, forma e peso molecular no caso de proteínas [81], bem como determinar a espessura e organização de bicamadas lipídicas (ver cap. 5) [82]. Pode-se também investigar a correlação entre os centros espalhadores [51, 82].

Do ponto de vista fenomenológico, o raio-X interage com os elétrons de um objeto provocando a oscilação dos mesmos [83]. Estes elétrons são considerados livres, pois sua energia de ligação ao núcleo atômico é muito menor do que a energia do raio-x [83]. Sendo assim, cada elétron, ao oscilar livremente, passa a ser uma fonte de onda secundária (onda espalhada) emitindo ondas coerentes (considerando baixos ângulos $\sim 10^{\circ}$ [81]) que possuem a mesma intensidade obtida pela equação de Thomson [83]. Como cada elétron está em uma posição, cada onda espalhada possui uma fase e quando estas atingirem, simultaneamente, o mesmo ponto no espaço (detector), haverá interferência de ondas espalhadas [83].

Para realizar o experimento, utiliza-se um arranjo experimental semelhante ao apresentado na figura 3.2: um feixe policromático proveniente de um fonte de raios-X passa por um monocromador (ou filtro) para selecionar um comprimento de onda (ou uma banda estreira de comprimentos de onda) (fig. 3.2) [81]. Este feixe é colimado $\left(\overrightarrow{K_{i}}\right)$ para atingir a amostra, mas pode atravessar o porta amostra sem sofrer nenhuma interação $\left(\overrightarrow{K_{i^{\prime}}}\right)$ sendo absorvido pelo Beam Stopper (em geral um metal) [81]. O Beam Stopper impede que o $\overrightarrow{K_{i}}$, que é muito intenso, danifique o detector [81].

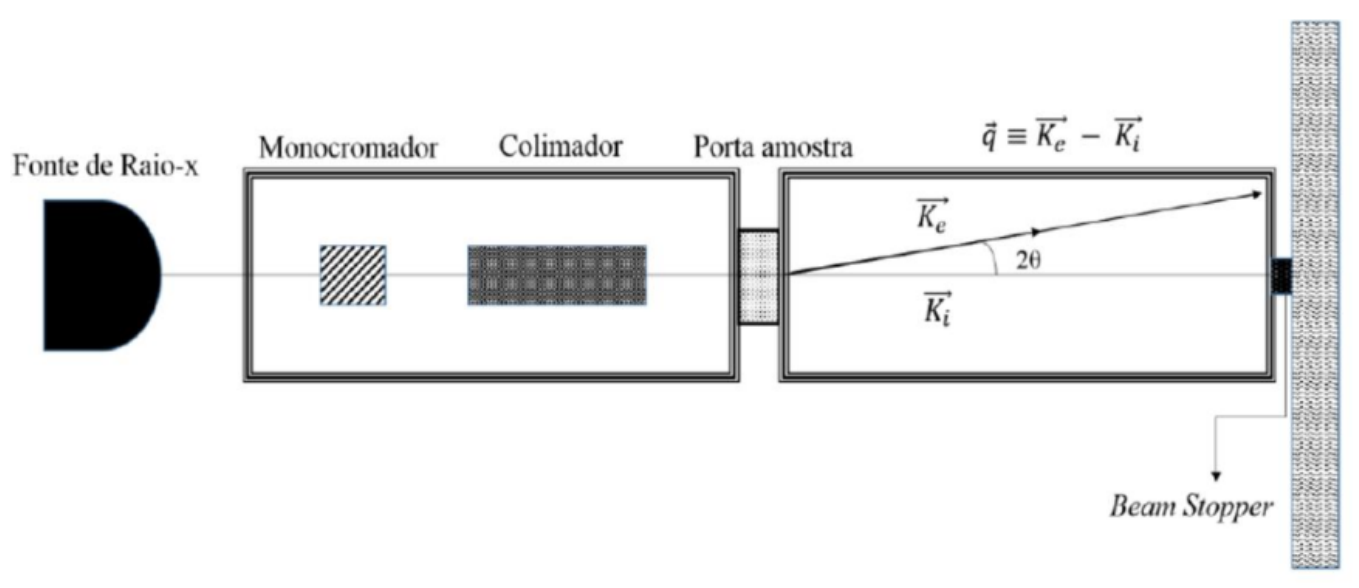

Figura 3.2: Arranjo experimental de SAXS adaptado de [81].

Os elétrons do objeto que interagem com o feixe de raio- $\mathrm{X}$ incidente (representado pelo vetor de onda $\overrightarrow{K_{i}}$ ), emitem ondas espalhadas (representadas pelo vetor de onda $\overrightarrow{K_{e}}$ ) em todas as direções. $O$ ponto de observação no detector ocorre a um certo ângulo de espalhamento indicado $2 \theta$ como na figura 3.2 [81]. Assim, a intensidade de espalhamento de raio-x $(I(q))$ é obtida 
em função do ângulo $\theta$ e expressa em função do módulo do vetor de espalhamento $|\vec{q}|$, onde $\vec{q} \equiv \overrightarrow{K_{e}}-\overrightarrow{K_{i}}$, tal que:

$$
|\vec{q}|=\frac{4 \pi}{\lambda} \operatorname{sen} \theta
$$

A função $I(q)$ é o resultado da interferência de todas as ondas espalhadas num certo ângulo, que por sua vez depende do vetor de posição $\vec{r}$, do volume $V$ da amostra e da flutuação $(\delta)$ de densidade eletrônica $(\rho(\vec{r}))$, em relação ao meio, definida como o número de elétrons por unidade de volume multiplicado pelo raio do elétron $\left(r_{e}=28 \times 10^{-13} \mathrm{~cm}\right)[81,83]$ :

$$
I(q)=\frac{1}{V}<\left|\int_{V} \delta \rho(\vec{r}) d \vec{r} e^{i \vec{q} \vec{r}}\right|^{2}>
$$

As chaves $(<>)$ indicam a média de todas as posições e orientações possíveis dos objetos espalhadores no sistema.

Para amostras com densidade eletrônica homogênea $\left(\rho(\vec{r})=\rho_{\text {amostra }}\right)$ dispersas em um meio que também possui a densidade eletrônica homogênea $\left(\rho_{s o l}\right)$, a flutuação da densidade eletrônica $\delta \rho(\vec{r})$ pode ser substituída por $\delta \rho(\vec{r})=\Delta \rho=\rho_{\text {amostra }}-\rho_{\text {sol }}[81,83]$.

A equação 3.2 pode então ser reescrita em termos do fator de forma $(P(q))$ e do fator de estrututa ("mensurável") $\left(S_{M}(q)\right)$ [51]:

$$
I(q)=\gamma n_{p} P(q) S_{M}(q)
$$

onde $\gamma$ é um fator experimental, $n_{p}$ é a densidade de centros espalhadores, $P(q)$ é a média de todas as orientações da amplitude de espalhamento ao quadrado $\left(<F^{2}(\vec{q})>\right)$ e $S_{M}(q)$ dado por [51]:

$$
S_{M}(q)=1+\frac{<F(\vec{q})>^{2}}{P(q)}(S(q)-1)
$$

onde $S(q)$ é a função de interferência entre centros espalhadores e traz a informação sobre o potencial de interação entres os mesmos. Por outro lado, a função $P(q)$ está correlacionada à estrutura interna do centro espalhador contendo informações sobre tamanho e forma.

Neste capítulo, trabalhamos com soluções de proteína BSA em pH 3,7 com a adição do surfactante SDS e SPFO. Os dados experimentais de SAXS não indicaram a presença de uma função de interferência. Portanto, a partir deste ponto iremos tratar $S_{M}(q)=1$ e centros espalhadores como proteína ou complexo proteína-surfactante.

No caso de soluções de proteínas polidispersas, o fator de forma $P(q)$ é obtido tomando-se em conta a contribuição do fator de forma de cada uma das $k$ populações [84]: 


$$
P(q)=\sum_{i}^{k} \frac{w_{i}}{N_{a g}} P_{k}(q)
$$

onde $w_{i}$ é a contribuição de cada uma das $k$ populações ao $P(q)$ e $N_{a g}$ é o número de agregação de cada população, por exemplo $N_{a g}=2,4$, para dímero e tetrâmero [84].

Assim, pode-se reescrever a equação 3.3 como:

$$
I(q)=\gamma n_{p} \sum_{i}^{k} \frac{w_{i}}{N_{a g}} P_{k}(q)
$$

$\mathrm{Na}$ análise de curvas de SAXS, utilizamos a escala de intensidade absoluta considerando como espalhamento padrão o espalhamento de água pura [81]. Tal procedimento permite estimar a massa molecular de nossas amostras compostas por BSA e surfactante em solução. Isto é possível pois, para o valor de $q=0$ a intensidade de SAXS é dada por [81]:

$$
I(0)=N_{a g}(\Delta \rho)^{2} n V_{p}^{2}
$$

onde $n$ é a densidade de proteína (centros espalhadores) e $V_{p}$ o volume de um monômero de proteína. Assim o valor de $I(0)$ é proporcional ao grau de agregação da proteína em solução [81].

No entanto, como mencionado acima, não é possível medir o valor de $I(0)$ devido à presença do "Beam Stopper"exatamente na posição correspondente ao $q=0\left(\overrightarrow{K_{e}}\right)$. Para ultrapassar esta limitação experimental e estimar o valor de $I(0)$ pode-se utilizar a aproximação de Guinier $[81,85]$, tal que:

$$
I(q \rightarrow 0) \cong I(0) e^{-\frac{R_{g}^{2} q^{2}}{3}} \quad \text { com } \quad R_{g} q_{\max }<1,3
$$

onde $R_{g}$ é o raio de giro definido como a distância quadrática média do contraste de densidade eletrônica em relação ao centro de "gravidade" do contraste de densidade eletrônica total $[81,86]$. O $R_{g}$ pode indicar o grau de compactação da proteína (enovelamento): $R_{g}$ é menor para conformações compactas ao se considerar proteínas com a mesma quantidade de aminoácidos [86].

Podemos ainda obter informações sobre a proteína estudada através da função de distribuição de pares de elétrons $(p(r))$ calculada a partir da transformada de Fourier da função $I(q)[51,83]$ :

$$
p(r)=\frac{1}{2 \pi^{2}} \int_{0}^{\infty} I(q)(q r)^{2} \frac{\operatorname{sen}(q r)}{q r} d q
$$


Para proteínas (considerando a densidade eletrônica homogênea) a função $p(r)$ é o histograma de distâncias entre todos os possíveis pares de átomos (elétrons) contido dentro do volume da mesma [86]. Logo, neste caso, a função $p(r)$ representa a probabilidade de encontrar dois átomos separados por uma distância $r$ dentro do volume da proteína [81].

Por definição, a função $p(r)=0$ para $r=0$ e para o valor de $r$ equivalente à dimensão máxima $\left(D_{\max }\right)$ da proteína [86]. Portanto, é possível determinar o valor de $D_{\max }$ da proteína ao apreciar a função $p(r)$ e obter informações sobre a conformação da mesma [81]. Além disso, pode-se também inferir sobre a forma (esfera, cilindro, elipsoide) da proteína ao se comparar a sua função $p(r)$ com as funções $p(r)$ características destes sólidos [81]. Pode-se também calcular o valor de $R_{g}$ a partir da função $p(r)[81,86]$.

As análises citadas acima $\left(R_{g}\right.$ e $\left.p(r)\right)$ são válidas para as curvas de SAXS de proteínas sem que seja necessário estabelecer um modelo. Por outro lado, pode-se analisar as curvas de SAXS ao descrever o fator de forma $P(q)$ das proteínas definindo-se modelos [81]. Neste trabalho utilizamos dois modelos para descrever a $P(q)$ das amostras de BSA $(1 \mathrm{mg} / \mathrm{mL})$ em tampão a pH 3,7 na presença e na ausência de SDS e SPFO: (i) $P(q)$ calculado através das posições atômicas (PDB - Protein Data Bank) com camada de hidratação e expansão multipolo [87, 88]; (ii) elipsoide com duas camadas de densidades eletrônicas [51, 88, 89], conforme descrevemos a seguir.

(i) $\mathbf{P}(q)$ calculado através das posições atômicas (PDB) com camada de hidratação e expansão multipolo

Brevemente, esta metodologia utiliza a posição de todos os átomos da proteína (PDB) para calcular a curva de SAXS correspondente $[81,87,90]$ :

$$
\left.I(q)=<\mid A_{v}(\vec{q})-\rho_{\text {sol }} A_{e x}(\vec{q})+\left(\rho_{\text {hid }}-\rho_{\text {sol }}\right) A_{h i d}\right)\left.(\vec{q})\right|^{2}>
$$

onde $A_{v}(\vec{q}), A_{e x}(\vec{q})$ e $A_{\text {hid }}$ são as amplitudes de espalhamento da proteína no vácuo, do volume excluído e da camada de hidratação; $\rho_{\text {sol }}$ e $\rho_{\text {hid }}$ são as densidades eletrônicas do solvente e da camada de hidratação, respectivamente. As amplitudes de espalhamento podem ser escritas em termos das funções de Bessel e de harmônicos esféricos [81, 87].

Importante notar que este modelo permite levar em conta o espalhamento de raio-X causado por moléculas de água ligadas na superfície e em regiões internas (cavities) da proteína [87, 88].

Também é possível calcular a função $I(q)\left(=P(q)\right.$ para $\left.S_{M}(q)=1\right)$ através da transformada inversa de Fourier da função $p(r)$ (eq. 3.9) [91]:

$$
I(q)=\int_{0}^{\infty} p(r) \frac{\operatorname{sen}(q r)}{q r} d r
$$


Assim, este modelo calcula a função $p(r)$ da estrutura atômica da proteína e, em seguida, realiza a transformada de Fourier (eq. 3.11) para obter a função $I(q)$. [87, 88].

Neste trabalho, utilizamos este modelo para calcular a função $I(q)$ a partir de estrutura cristalográfica da BSA a pH 6,5 (PDB 4F5S) [54] bem como para as estruturas atômicas obtidas por simulação a pH 3,7, presença e ausência de 30 e 60 moléculas de SDS ou SPFO. Além disso, também calculamos a função $I(q)$ para dímeros simétricos obtidos por modelagem de corpo rígido (GLOBSYMM $[92,93]$ ) a partir da estrutura atômica dos monômeros a pH 3,7 na ausência e na presença de 30 moléculas de SDS e SPFO.

Em nossos ajustes, a densidade eletrônica do solvente, $\rho_{\text {sol }}$, pôde variar entre 0.33 $0.34 e \AA^{-3}$ e $\rho_{\text {hid }}$ pôde variar entre $1-1.15$ vezes o valor de $\rho_{\text {sol }}[51,81]$.

(ii) Elipsoide com duas camadas de densidades eletrônicas em relação à densidade eletrônica do solvente

Este modelo calcula o fator de forma $P(q)$ através da seguinte equação [88, 89]:

$$
\begin{gathered}
P(q)=\frac{2}{\pi} \int_{0}^{\frac{\pi}{2}} \int_{0}^{\frac{\pi}{2}} \operatorname{sen} \beta d \beta d \alpha \times\left[\frac{4 \pi}{3} \sum_{k=0}^{1}(A+k \sigma)(B+k \sigma)(C+k \sigma)\left(\rho_{k+1}-\rho_{k}\right)\right. \\
\left.\left.\times \Theta\left(q\left\{\left[(A+k \sigma)^{2} \operatorname{sen}^{2} \alpha+(B+k \sigma)^{2} \cos ^{2} \alpha\right] \sin ^{2} \beta+(C+k \sigma)^{2} \cos ^{2} \beta\right\}^{\frac{1}{2}}\right)\right]\right]^{2} \\
\operatorname{com} \quad \Theta(x)=3 \frac{\operatorname{sen} x-x \cos x}{x^{3}}
\end{gathered}
$$

onde $A, B, C$ são os três semi-eixos do elipsoide, $\sigma$ é a espessura da camada de hidratação, $\rho_{\text {prot }}(k=2), \rho_{\text {hid }}(k=1)$ e $\rho_{\text {sol }}(k=0)$ são as densidades eletrônicas da proteína, da camada de hidratação e do solvente, respectivamente.

Este modelo está esquematizado na figura 3.3, onde a proteína é descrita por um elipsoide (semi-eixos $A, B$ e $C$ ) de densidade eletrônica homogênea ( $\rho_{\text {prot }}$ - verde) com uma camada de hidratação de espessura $\sigma$ de densidade eletrônica homogênea ( $\rho_{h i d}$ - azul escuro) dispersa em um solvente com densidade eletrônica constante $\left(\rho_{\text {sol }}\right.$ - azul claro). 


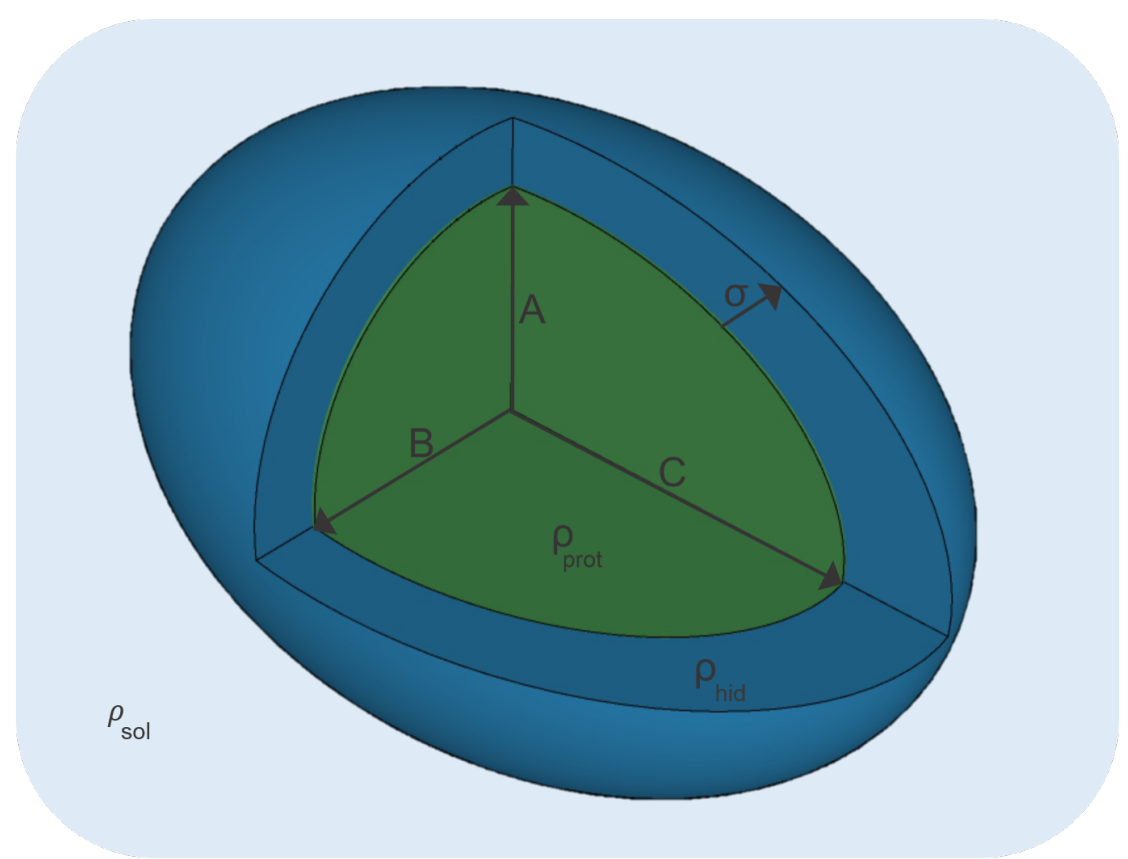

Figura 3.3: Modelo de elipsoide de duas camadas de densidades eletrônicas em relação ao solvente.

Utilizamos este modelo apenas para simular um tetrâmero da proteína BSA onde a densidade eletrônica da proteína pôde variar entre $\rho_{\text {prot }}=0.4200-0.4235 e \AA^{-3}$, sendo o limite superior obtido a partir de sua sequência primária [51]. Os possíveis valores para os semi-eixos $A, B$ e $C$ foram restringidos ao se impor que o elipsoide possua o volume de 4 monômeros de BSA e também 4 x a massa molecular de um monômero (66,4 kDa) somados (massa - 288 Da - e volume) a 120 moléculas de SDS (4 x 30), podendo apresentar pequenas variações destes valores [51]. A espessura $\sigma$ pôde variar entre 2,95 e 3,05 $\AA$ e a $\rho_{\text {hid }}$ e $\rho_{\text {sol }}$ variaram nos intervalos mencionados acima.

Todos os ajustes (modelo (i) e (ii)) foram realizados utilizando o programa GENFIT [88] que também calcula concomitantemente a função $p(r)$. Além disso, utilizamos o programa GIFT [94] para obter a função $p(r)$ diretamente das curvas de SAXS sem a necessidade de assumir um modelo para a proteína.

\subsubsection{Absorção de luz UV-Vis e Turbidez}

A absorção de luz ultravioleta (UV) e vísivel (Vis) acontece quando um fóton com energia igual à diferença de energia de dois estados eletrônicos de uma molécula transfere sua energia para a mesma. Este fenômeno encontra-se explorado no item 4.1.4.

Em soluções de partículas suficientemente diluídas e que possuam dimensões muito menores do que o comprimento de onda de luz ultravioleta-visível $(<<250-700 \mathrm{~nm})$ pode-se medir a absorção de luz, $A$, devido a presença de cromóforos [95]. Para isso, é necessário medir a razão entre a intensidade de luz incidente e a intensidade de luz após atravessar a amostra (Lei de 
Lambert-Beer) [95]:

$$
I=I_{0} \times 10^{-\epsilon c l} \rightarrow A=-\log \left(\frac{I}{I_{0}}\right)=\epsilon c l
$$

onde $\epsilon$ é o coeficiente de extinção molar do cromóforo $\left(\mathrm{M}^{-1} \mathrm{~cm}^{-1}\right), l$ é o caminho ótico $(\mathrm{cm})$ e $c$ é a concentração do cromóforo/partícula (M). Neste trabalho, esta técnica foi utilizada para diferentes aplicações:

- Determinação da concentração de proteína. De maneira geral, no caso de proteínas, os cromóforos são os aminoácidos aromáticos fenilanina $\left(\lambda_{\max }=257 \mathrm{~nm}\right)$, tirosina $\left(\lambda_{\max }=\right.$ $274 \mathrm{~nm}$ ) e triptofano $\left(\lambda_{\max }=280 \mathrm{~nm}\right.$ ) (obs: proteínas que possuem grupos metálicos apresentam outros cromóforos que podem absorver luz em outros comprimentos de onda) [96]. De maneira interessante, a presença de cisteína também contribui para a absorção de luz devido à presença da ponte de disulfeto [97]. Sendo assim, é possível calcular o $\epsilon_{280 \mathrm{~nm}}$ para $\lambda=280 \mathrm{~nm}$ para as proteínas como (adaptado de $\left.[96,97]\right)$ :

$$
\epsilon_{280 n m}=n_{t r p} \epsilon_{t r p}+n_{t y r} \epsilon_{t y r}+n_{p h e} \epsilon_{p h e}+n_{s-s} \epsilon_{s-s}
$$

onde $n_{t r p}, n_{p h e}, n_{t i r}$ e $n_{s-s}$ é o número de triptofanos, tirosinas, fenilaminas, e pontes de dissulfeto presentes na proteína, respectivamente; $\epsilon$ são os respectivos coeficientes de extinção molar para o comprimento de onda de $280 \mathrm{~nm}: \epsilon_{t r p}, \epsilon_{t i r}, \epsilon_{p h e}$, e $\epsilon_{s-s}, 5500,195$, 1490 e $125 \mathrm{M}^{-1} \mathrm{~cm}^{-1}$ respectivamente [97, 98].

- Turbidez: a luz é espalhada na presença de partículas com dimensões de ordem de grandeza do comprimento de onda da luz incidente UV-vis (250-700nm). Este fenômeno pode ser descrito pelo espalhamento de Rayleigh ou de Mie [99, 100]. O primeiro ocorre para a condição [99]:

$$
\left(\frac{2 \pi}{\lambda}\right) \times d<<1
$$

onde $\lambda$ é o comprimento de onda incidente e $d$ é o diametro da partícula (supondo que seja esférica); e o segundo acontece, aproximadamente, para partículas com $d$ da ordem de 1/10 do $\lambda$. É importante ressaltar que o espalhamento de luz depende de outros parâmetros [100], como o indíce de refração do meio e da partícula, que não serão explorados aqui.

Sendo assim, se na solução em estudo existirem partículas com dimensões da ordem de dezenas/centenas de nanômetros haverá o espalhamento de luz incidente. Como o espectrofotômetro mede a intensidade da luz incidente, $I_{0}$, e a intensidade de luz após atravessar a amostra, $I$, o equipamento irá registrar um aumento na medida de absorção, $A$ (eq. 3.13), oriunda da atenuação da intensidade $I$ causada pelo espalhamento de luz. Este fenômeno é conhecido como turbidez. 
Desta maneira, numa análise qualitativa, avaliamos a formação de agregados de proteínas medindo a turbidez das amostras, visto que os agregados podem atingir dimensões de alguns micrômetros.

As medidas de absorção foram realizadas utilizando um espectrofotômetro Cary 100 Bio UV-Visible spectrophotometer, no laboratório do prof. Juan Ruso, à temperatura ambiente. Os espectros foram medidos de 220-800 nm, com intervalo de $1 \mathrm{~nm}$, tempo de medida para cada comprimento de onda foi de $0.1 \mathrm{~s}$ e a velocidade de varredura foi de $600 \mathrm{~nm} / \mathrm{min}$. A cubeta possuia $10 \mathrm{~mm}$ de caminho ótico. Para os experimentos de turbidez, utilizou-se as intensidades no $\lambda=350 \mathrm{~nm}$, pois já não há absorção de luz da proteína BSA neste comprimento de onda, assim, a intensidade medida é relacionada ao espalhamento de luz.

Vale ressaltar que realizamos experimentos de espalhamento de luz dinâmico (DLS) para quantificar o raio hidrodinâmico dos agregados de BSA induzido por SDS ou SPFO. Entretanto, as análises realizadas por outras técnicas experimentais (SAXS, SEM - ver Resultados e Discussão), apontaram uma população de agregados heterogênea, possuindo uma grande polidispersão de tamanhos.

Sendo assim, apesar de termos realizado todos os experimentos e análises de DLS, não vamos apresentá-los aqui visto que a informação qualitativa obtida diretamente da curva de autocorrelação do DLS é a mesma obtida por turbidez: aumento do tamanho do agregado em função da concentração de surfactante.

\subsubsection{Fluorescência de Tioflavina $T$}

A Tioflavina T (Th T) é um sal benzotiazol catiônico com massa molecular de 318,86 g/mol utilizado como marcador fluorescente para detecção de amilóides. Sua fórmula molecular é $\mathrm{C}_{17} \mathrm{H}_{19} \mathrm{ClN}_{2} \mathrm{~S}$, possuindo uma região de maior polaridade contendo o grupo benzotiazol e uma terminação hidrofóbica com o grupo dimetilamino como apresentado na figura 3.4:

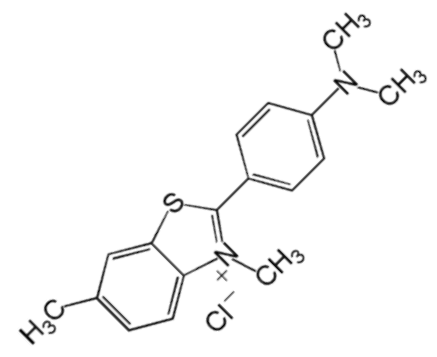

Figura 3.4: Estrutura molecular da Tioflavina T

A Th T tem o máximo de absorção e de emissão de fluorescência nos comprimentos de onda de 340 e $445 \mathrm{~nm}$, respectivamente. Ao se ligar em fibras amilóides, os picos de absorção 
e fluorescência sofrem um redshift, chegando à cerca de $440 \mathrm{~nm}$ e $485 \mathrm{~nm}$, para máximo de absorção e de emissão de fluorescência, respectivamente $[4,101]$. Outra mudança significativa que ocorre na fluorescência da $\mathrm{Th} \mathrm{T}$ ao se ligar com amilóides é o aumento expressivo na intensidade de fluorescência, desde 5 até 200 vezes mais intenso do que a emissão da Th T livre em solução [4, 101].

A figura 3.5 apresenta o modelo de ligação da Th T com as fibras amilóides [4, 102] onde as setas em azul representam as linhas $\beta$ (distâncias entre duas linhas consecutivas $4.8 \AA$ ) formadas pelos aminoácidos da cadeia polipeptídica que formam os planos de folhas $\beta$ (distâncias entre duas folhas $10.5 \AA$ A) [6]. Por outro lado, a molécula de Th T possui cerca de $15,6.1$ e 4.3 $\AA$, de maior eixo, menor eixo e espessura, respectivamente [102]. Por isso, sugere-se que a Th T se liga às formações amiloides com o menor eixo $(6.1 \AA)$ perpendicular à direção da fibra e que as cadeias laterais envolvem a Th $\mathrm{T}[4,102]$.

(a)

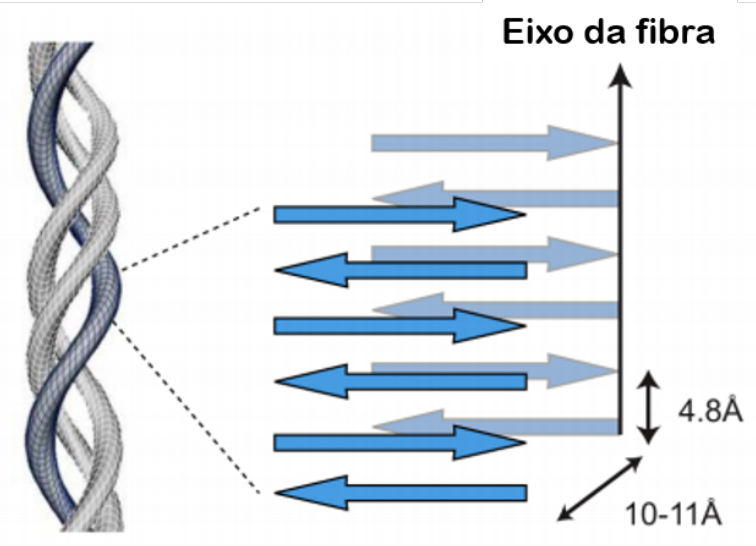

(b)

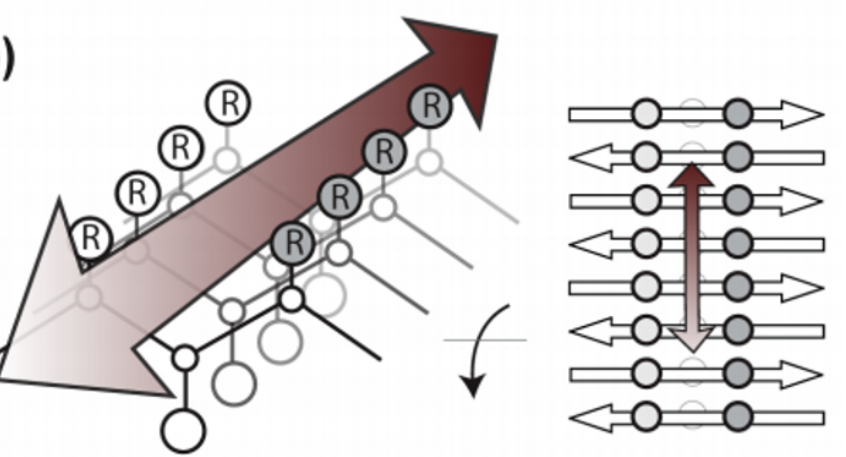

Figura 3.5: Modelo Proposto para a ligação da Th T (seta bidirecional) com as fibras amilóides adaptado de [4]: (a) fibra amilóide (esquerda) e estrutura secundária de folhas $\beta$ esquematizada em azul (direita) indicando as distância de separação de fibras amilóides obtidas por difração de raio-X. (b) ligação da Th $\mathrm{T}$ entre as cadeias laterais ( $\mathrm{R}$ - esquerda) dos aminoácidos se posicionando paralelamente ao eixo da fibra.

Assim sendo, o aumento da fluorescência Th $\mathrm{T}$ seria o resultado do confinamento da molécula impedindo a rotação do grupo benzotiazol em relação ao grupo dimetilamino. Portanto a maior parte da energia absorvida pela molécula através da absorção de luz seria convertida em fluorescência e não mais em agitação térmica ou rotação [4, 101, 102]. 
A tioflavina T foi dissolvida no tampão glicina $50 \mathrm{mM}$ no pH 3,7 à concentração de 0,6 mM. Para isto utilizou-se o agitador magnético a $400 \mathrm{rpm}$ durante 5 minutos. O espectrofluorímetro Varian Cary Eclipse Fluorescence Spectrophotometer, no laboratório do prof. Juan Ruso, foi utilizado para as medidas de fluorescência de Tioflavina $\mathrm{T}$.

O comprimento de onda de excitação foi de $440 \mathrm{~nm}$ e o espectro de fluorescência foi medido de $450 \mathrm{~nm}$ à $550 \mathrm{~nm}$. A fenda de excitação e de emissão foram de $5 \mathrm{~nm}$, a taxa de varredura foi de $120 \mathrm{~nm} / \mathrm{min}$, o tempo de integração para cada comprimento de onda foi de $0,5 \mathrm{~s}$ e o passo foi de $1 \mathrm{~nm}$. A cubeta utilizada possui $10 \mathrm{~mm}$ de caminho ótico, modelo Cary FLR. As análises de formação de folhas $\beta$ foram realizadas levando-se em conta a intensidade de fluorescência para o comprimento de onda $\lambda=485 \mathrm{~nm}$.

A concentração de Th T foi determinada utilizando a absorção de luz com $\epsilon=36000 \mathrm{M}^{-1}$

$\mathrm{cm}^{-1}$ em solução aquosa para o $\lambda=412 \mathrm{~nm}$ [103].

Na solução contendo BSA na ausência e na presença de SDS ou SPFO, descrita anteriormente, adicionou-se uma aliquota da solução de Th T para obter a razão molar 20:1 ThT:BSA. Uma aliquota da solução final foi utilizada para a medida no espectrofluorímetro.

\subsubsection{Microscopia Eletrônica de Transmissão (TEM) e de Varredura (SEM)}

As medidas de TEM e SEM foram realizadas no Centro de Microscopia Eletrônica e Microscopia Confocal na Universidade de Santiago de Compostela (Santiago de Compostela - Espanha). Utilizamos um microscópio Zeiss FESEM Plus Ultra equipado com Inca X-AXT Penta FET Precision (Oxford Instruments) operando a 100 kV, com ampliação de 100000 vezes. As amostras foram diluídas entre 20 e 200 vezes, antes da deposição sobre as grades de cobre. $\mathrm{Na}$ sequência, as grades foram recobertas com carbono e marcadas negativamente com $2 \%(\mathrm{w} / \mathrm{v})$ de ácido fosfotúngstico.

\subsubsection{Dicroísmo Circular}

O dicroísmo circular (CD) é uma técnica experimental que permite realizar a caracterização da estrutura secundária de proteínas e outros biopolímeros através da absorção de luz circularmente polarizada [104].

A luz circularmente polarizada é decomposta em duas componentes circulares que possuem sentido de rotação contrários, uma à esquerda (pe) e outra à direita (pd), e a diferença entre a absorção de cada uma das componentes, $\mathrm{pe}-\mathrm{pd}=\mathrm{e}$ (elipticidade), corresponde ao espectro de dicroísmo circular [104, 105].

A elipicidade ocorre devido a quiralidade das moléculas ou pela quiralidade induzida pela estrutura tridimensional das mesmas [104]. É interessante notar que se o espectro de CD for 
nulo, ou seja a elipicidade for igual a zero para algum comprimento de onda, significa que a absorção de pe $=$ pd, mas não significa que não há absorção de cada uma das componentes.

No caso de proteínas, as transições eletrônicas responsáveis pela absorção de luz nos comprimentos de onda do CD são as $n->\pi^{*}$ e $\pi->\pi^{*}$ do grupo amina (figura 3.6) [105]. Estas transições eletrônicas podem sofrer alterações devido à geometria dos aminoácidos da cadeia polipeptídica. Sendo assim, o espectro de CD possui informações qualitativas e quantitativas da estrutura secundária das proteínas [105].

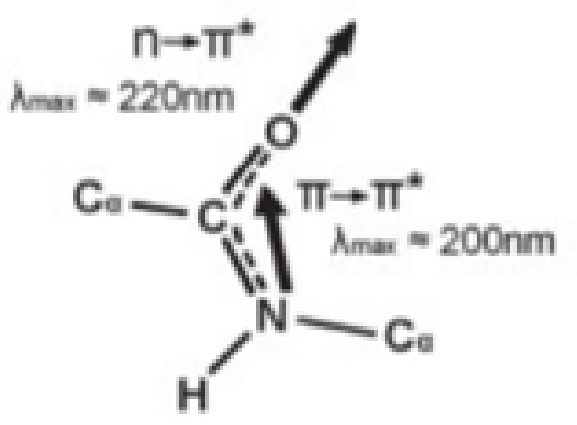

Figura 3.6: Esquema das transições eletrônicas responsáveis pela absorção de luz nos comprimentos de onda de CD. As setas indicam a direção dos dipolos (extraído de [105]

As estruturas secundárias de proteína possuem espectros de CD característicos, como por exemplo, as folhas $\beta$ possuem um pico negativo em $211 \mathrm{~nm}$ e um positivo em $192 \mathrm{~nm}$, já a estrutura secundária $\alpha$ - hélice possui dois picos negativos, um em $208 \mathrm{~nm}$ e outro em $222 \mathrm{~nm}$ no intervalo de comprimentos de onda medidos pro CD convencional (2) (fig. 3.7).

A partir da caracterização empírica de proteínas com esses espectros característicos foi possível desenvolver programas computacionais de análise estrutural [105-107]. Estes programas computacionais utilizam o banco de dados de CD característico para descrever o novo espectro como combinação linear de cada uma das estruturas secundárias conhecida [106, 107].

A priori, as medidas de $\mathrm{CD}$ foram realizadas em um equipamento de bancada convencional e obteve-se os percentuais de cada estrutura secundária para cada amostra estudadas. Entretanto, por inspeção visual dos dados experimentais e através da análises de outras técnicas experimentais (SAXS, SEM, turbidez e DLS) constatamos que essa "decomposição"espectral não estava correta devido a grande contribuição de espalhamento de luz aos dados de CD.

Com o intuito de sobrepor esta limitação, colaboramos com a pós doutora Juliana S. Yoneda que realizou medições de SRCD no Soleil (França) Synchrotron Beamline (DISCO). Os espectros SRCD das amostras foram obtidos entre os comprimentos de onda de 175-280 nm com intervalos de $1 \mathrm{~nm}, 1,2 \mathrm{~s}$ de tempo de acumulação e 3 espectros individuais a $25^{\circ} \mathrm{C}$, utilizando cubetas de quartzo com o caminho ótico de 0,005 ou 0,010 ou 0,020 centímetros (Hellma Scientific). 
As medidas de alta tensão (HT) foram realizadas simultaneamente à aquisição dos espectros, a fim de demonstrar o grau de penetração da luz para as amostras, indicando, portanto, o ponto de corte de comprimento de onda do espectro (190 nm, para este caso). Todos os dados SRCD foram processados utilizando o software CDTool [107], que permitiu calcular a média dos 3 espectros individuais e subtrair a linha de base correspondente que foi obtida pela média de 3 de medidas do tampão de glicina $50 \mathrm{mM}, \mathrm{pH} 3,7$. Os espectros foram normalizados para zero entre os comprimentos de onda de 263 e $270 \mathrm{~nm}$, tendo sido utilizado o método Savitzky-Golay para suavização de curvas.

Contudo, não foi possível decompor os espectros SRCD para obter a percentagem de estrutura secundária para cada uma das amostras de BSA na presença de SDS ou SPFO, principalmente devido à pequena relação sinal-ruído causada pelo espalhamento de luz devido à presença de grandes agregados (tal como avaliado por SAXS, SEM, turbidez - ver Resultados e Discussão). Para obter uma informação qualitativa sobre a estrutura secundária, foi realizada uma análise tendo em conta a posição do pico positivo entre $192 \mathrm{~nm}$ e $198 \mathrm{~nm}$, que são picos característicos de $\alpha$-hélice e folha $\beta$, respectivamente, como mostra a figura 3.7. Importante acrescentar que o CD convencional não permite essa análise visto que a intensidade é muito baixa e que o menor comprimento de onda acessível (com qualidade) é da ordem de $200 \mathrm{~nm}$ [104].

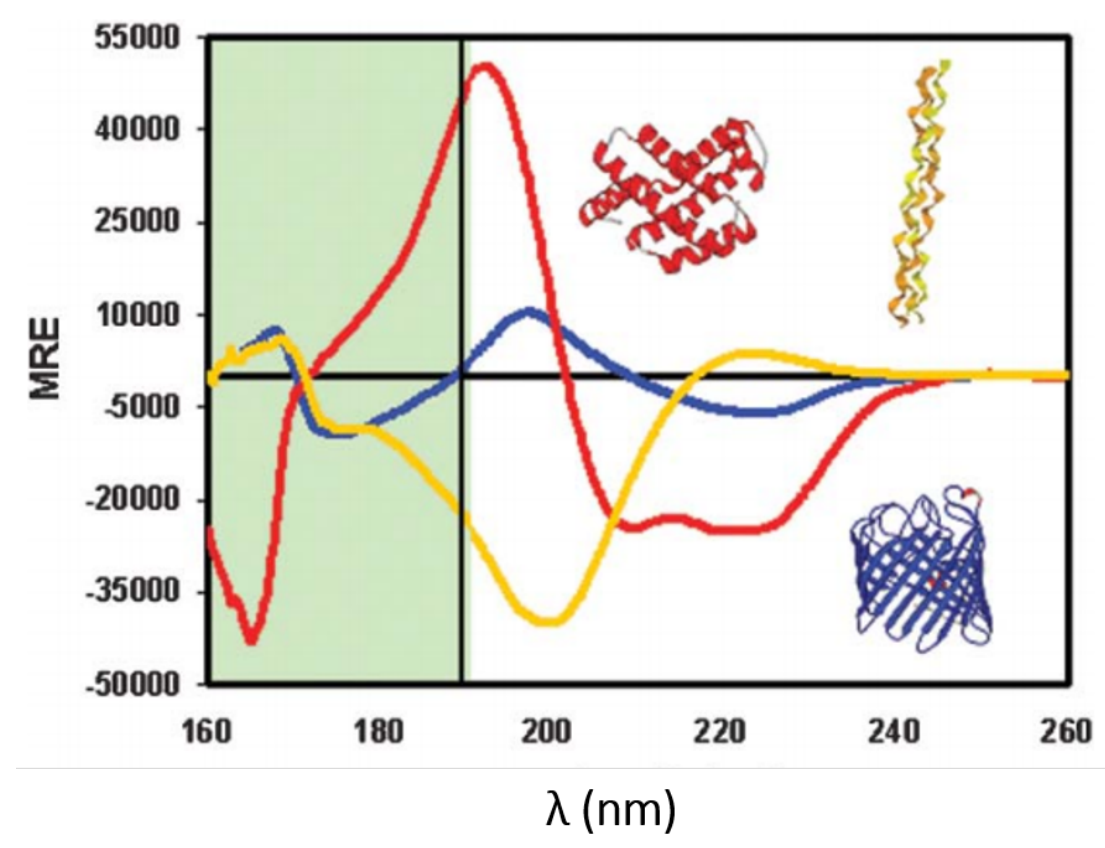

Figura 3.7: Espectro de CD característico de protéina predominantemente em conformação de $\alpha$-hélice (vermelho), folhas $\beta$ (azul) e de hélice de poliprolina (amarelo). Importante notar a diferença de posição do pico de $192 \mathrm{~nm}$ (vermelho) para $198 \mathrm{~nm}$ (azul) entre a estrutura secundária de $\alpha$-hélice e folhas $\beta$, além da diminuição da intensidade. MRE é a elipicidade média por resíduo. A região sombreada é acessível apenas em experimentos de SRCD. Adaptado de [108]. 


\subsection{Resultados e Discussão}

\subsubsection{Estado conformacional e oligomérico da BSA no pH 3.7: SAXS, SRCD e MD}

É bem conhecido que a proteína BSA pode alterar a sua conformação em função de mudanças de pH [52]. Em pH 6,5 (fig. 3.8A) os três domínios principais da proteína estão dispostos em forma de coração contando com 17 pontes dissulfeto que estabilizam esta conformação. Com a diminuição do $\mathrm{pH}$ abaixo do seu ponto isoelétrico a BSA expande-se parcialmente podendo atingir a sua conformação totalmente expandida em pH 2,7 [52]. Realizamos simulações de dinâmica molecular para descrever a conformação da proteína em pH 3,7 (fig. 3.8B) como um recurso para a análise de dados experimentais de SAXS. Além disso, um dímero (fig. 3.8C) foi também obtido através de modelagem de corpo rígido utilizando o software GLOBSYMM $[92,93]$ tendo em vista que as análises das curvas experimentais de SAXS indicaram a presença de um oligômero em solução.

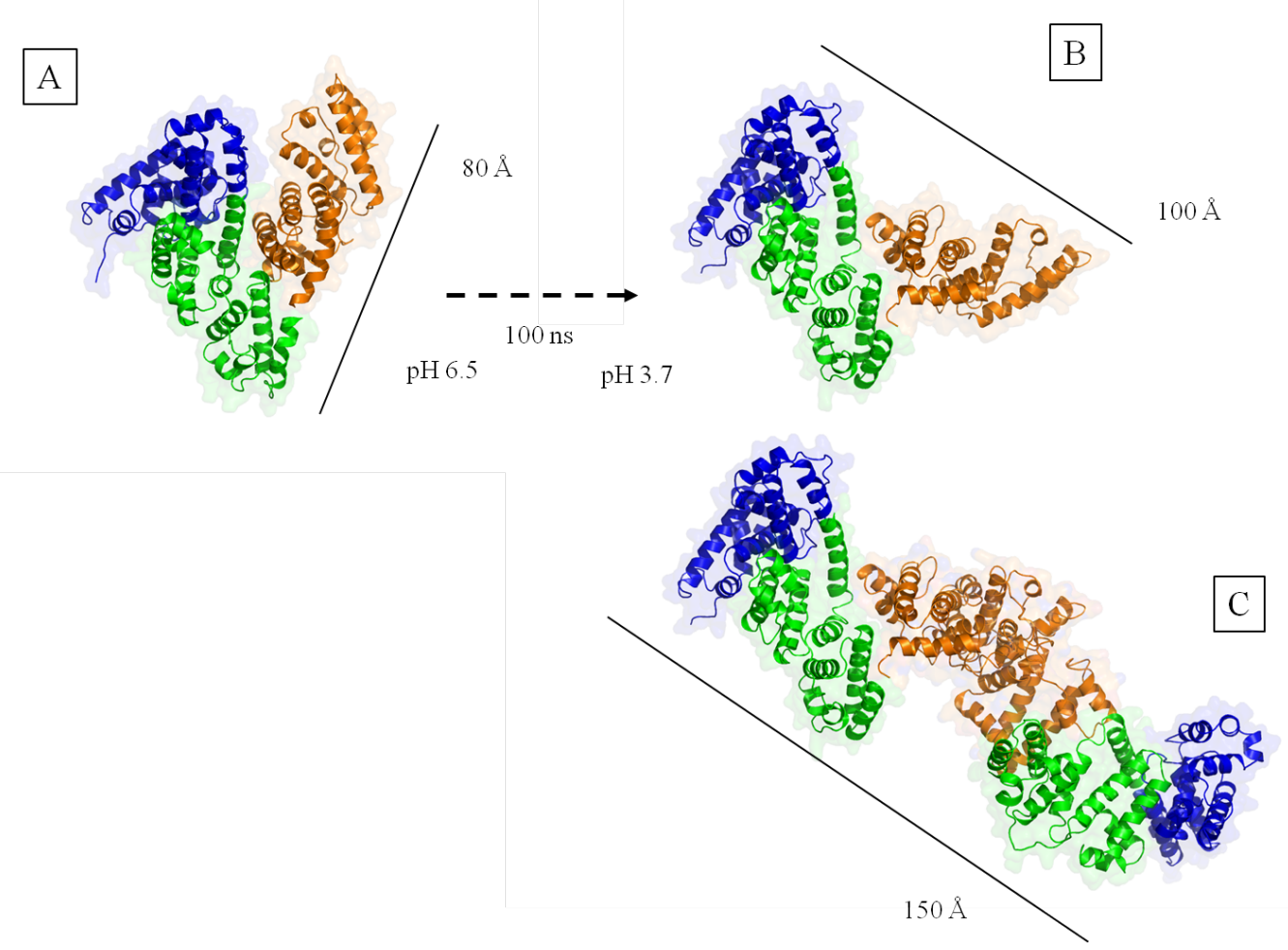

Figura 3.8: Estrutura cristalográfica da BSA extraída do PDB 4F5S a pH 6,5 [54](A), monômero obtido por $\mathrm{MD}$ ao baixar o $\mathrm{pH}$ para 3,7 (B) e dímero obtido por modelagem de corpo rígido usando (B) como monômero (C). Representado em azul é o domínio I, verde o domínio II e laranja o domínio III.

A medida que a proteína se desenovela esperar-se-ia um aumento de área superficial exposta ao solvente. De fato, a análise de MD apresentada na figura 3.9 confirma o aumento 
médio de área acessível ao solvente (SASA) por resíduo e a raiz quadrada do desvio médio (RMSD) de posições atômicas por resíduo do monômero parcialmente desenovelado em relação à conformação enovelada (PDB 4F5S) para cada domínio. Para todos os domínios houve um aumento em SASA e deslocamento na posição média dos resíduos em relação às posições originais (conformação dobrada). A distância média entre os resíduos do domínio I (D1) e domínio III (D3) (azul e laranja na figura 3.8, respectivamente) é semelhante (15 ̊̊/ por resíduo quadrado e triângulo na figura 3.9, respectivamente) e quase duas vezes maior do que o registrado para o domínio D2 (6 Å/ por resíduo - cor verde na figura 3.8 e círculo na figura 3.9). O inverso ocorreu para o aumento de SASA, ou seja, para o D2 o aumento de área acessível ao solvente foi quase duas vezes maior do que o encontrado para os domínios D1 e D3 (figura 3.9). Estes resultados sugerem que, embora os domínios D1 e D3 tenham se movido para longe da posição original, eles mantiveram uma conformação enovelada. Por outro lado, a separação dos domínios D1 e D3 do domínio D2 causou uma exposição dos resíduos que estavam “enterrados" entre os domínios o que resultou no aumento de SASA para o D2. Curiosamente, Baler et al. [75] também demonstraram que o domínio D2 é o mais exposto após a diminuição do pH. Importante acrescentar que uma carga positiva líquida de +99 para a BSA foi obtida na configuração por $\mathrm{MD}$, o que está em boa concordância com o valor de +100 a pH 3,5 reportado por aqueles autores [75].

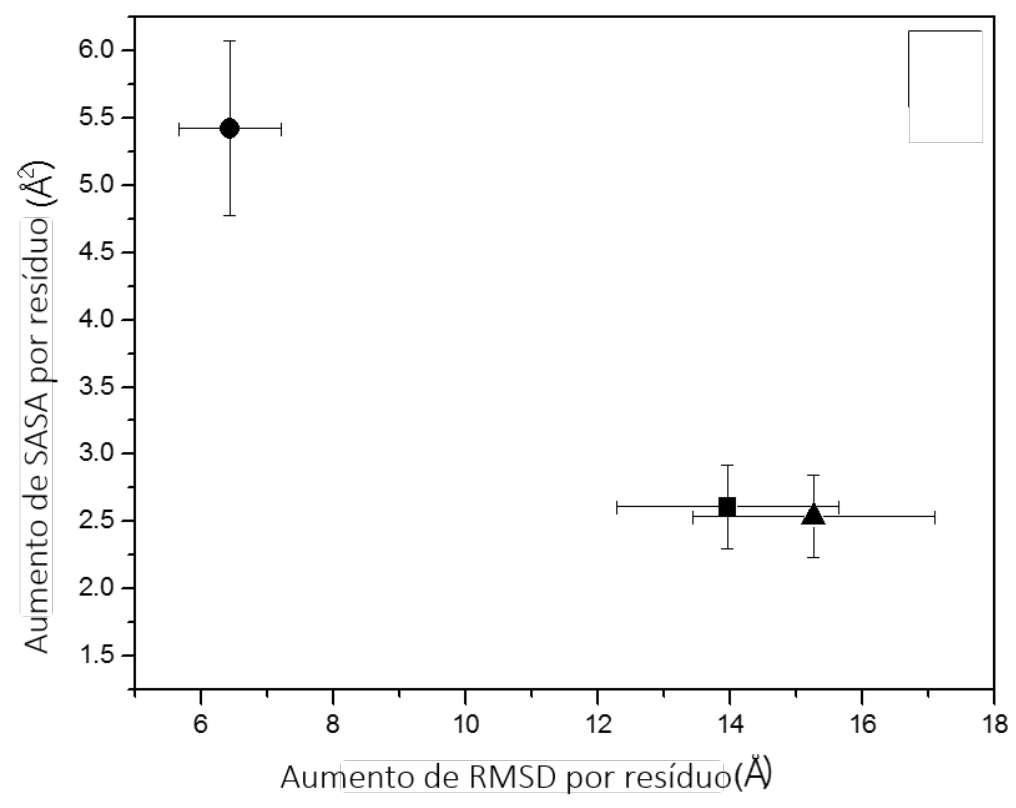

Figura 3.9: Análise de MD para o aumento médio de SASA por resíduo de BSA em função de RMSD por resíduo após a diminuição do $\mathrm{pH}$ de 6,5 para 3,7 para o domínio I (resíduos 1-185, quadrado), II (resíduos 186-378, círculo), III (resíduos 379-576, triângulo). Os valores de referência SASA e RMSD utilizados na comparação foram obtidos para a BSA (PDB 4F5S) a $\mathrm{pH} 6,5$. 
Entretanto, a conformação parcialmente desenovelada reportada por Baler et al [75] é mais expandida do que a encontrada aqui (fig. 3.8B). Este fato provavelmente reflete a pressão constante aplicada durante nossas simulações (ensemble $\mathrm{NpT}$ ), que pode restringir o movimento dos átomos, enquanto Baler et al [75] utilizaram um ensemble NVT, que pode permitir aos átomos alcançarem maiores distâncias a partir das posições originais.

Curiosamente, os resultados de MD não indicaram qualquer alteração no conteúdo de estrutura secundária de $\alpha$-hélices causado pela diminuição do $\mathrm{pH}$ 6,5 para 3,7. Isto está em acordo com os nossos dados de SRCD de BSA a pH 3,7 em 50 mM de solução tampão de glicina, que resultou em $64 \% \alpha$-hélice em meio ácido (ver fig 3.19). Cabe acrescentar que, a glicina, como osmólito, manteve a estrutura secundária inalterada, o que era esperado, pois essa classe de moléculas é conhecida pela sua capacidade de estabilizar a conformação enovelada de proteínas [109-111].

A figura 3.10 apresenta os dados experimentais de SAXS (símbolos vazios) obtidos para a amostra de $1 \mathrm{mg} / \mathrm{mL}$ de BSA $(15 \mu \mathrm{M})$ em solução tampão de glicina $50 \mathrm{mM}$ a pH 3,7 juntamente com a curva teórica (linha verde) calculada a partir da proteína parcialmente desenovelada, prevista por $\mathrm{MD}$ e a partir do dímero (linha roxa) obtido por modelagem de corpo rígido, a $\mathrm{pH}$ 3,7 (representadas na fig. 3.8 B e C, respectivamente). A curva teórica calculada a partir do estado enovelado da BSA nativa (PDB 4F5S) também está incluída na figura 3.10 para efeitos de comparação (linha azul).

Como se pode ver, nenhuma das curvas calculadas a partir das estruturas atômicas se ajusta bem aos dados experimentais. No entanto, a conformação parcialmente desenovelada consegue representar os dados experimentais entre $0,04 \AA^{-1}$ e $0,35 \AA^{-1}$ mas não consegue reproduzir os dados para valores de $q$ menores do que $0,04 \AA^{-1}$.

As funções de distribuição de distâncias $(\mathrm{p}(\mathrm{r})$ ) correspondentes às curvas de SAXS da figura 3.10 são apresentadas na figura 3.11. Todas as funções $\mathrm{p}(\mathrm{r})$ exibem características semelhantes: a frequência máxima de distâncias ocorre em torno de $r=40 \AA ̊$ com a distância máxima $\left(D_{\text {max }}\right)$ $=80 \AA$, $100 \AA$ e $150 \AA$ para configurações nativa, parcialmente desenovelada e para o dímero, respectivamente. É interessante notar que esses valores estão em acordo com as estruturas atômicas apresentadas na figura 3.8. 


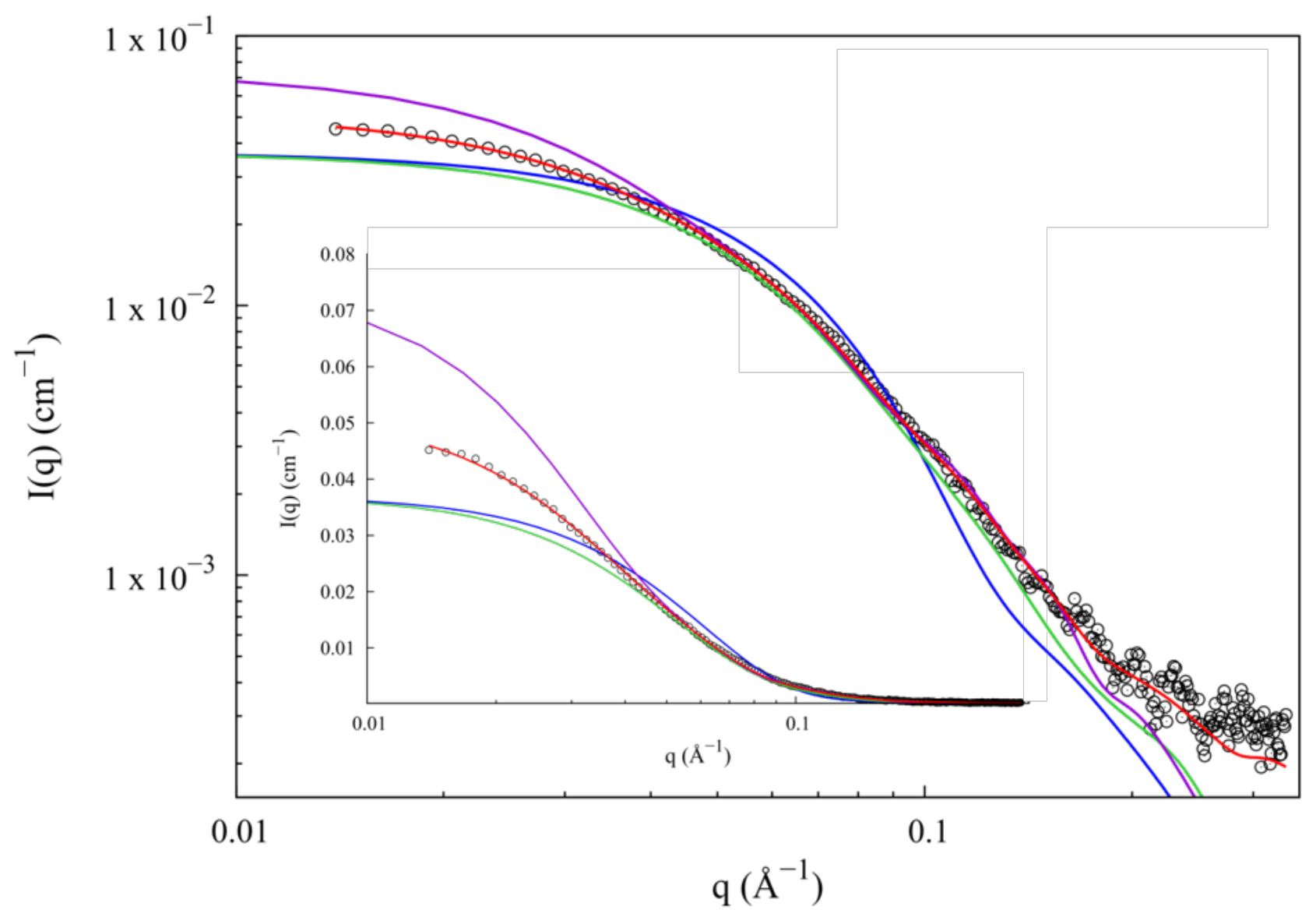

Figura 3.10: Curva de SAXS para a BSA (1 mg/mL) em pH 3.7 (símbolos vazios) juntamente com curvas de SAXS calculadas para as estruturas apresentadas na figura 3.8: PDB 4F5S [54] (linha azul), monômero parcialmente desenovelado obtido por MD em pH 3.7 (linha verde), dímero obtido por modelagem de corpo rígido a $\mathrm{pH}$ 3,7 (linha roxa) e o melhor ajuste (linha vermelha) calculado pelo software GENFIT como sendo composto por $75 \%$ de espécies monoméricas parcialmente desenoveladas a pH 3,7 e 25\% do respectivo dímero (fig. 3.8C). Inserido no gráfico estão as mesmas curvas, em escala linear. 


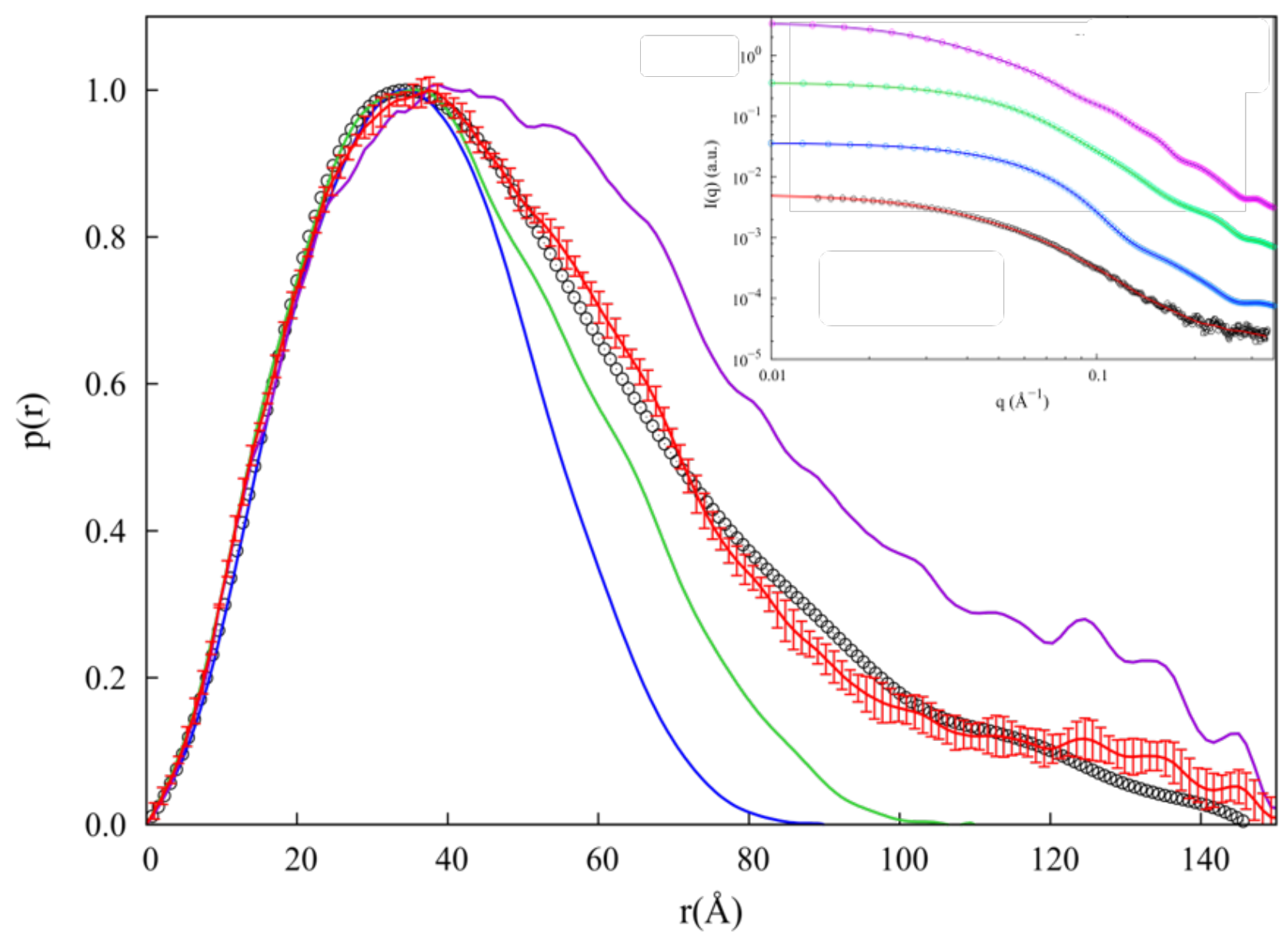

Figura 3.11: Funções de distribuição de distâncias (p(r)) das curvas de SAXS da BSA apresentadas na figura 3.10 utilizando o mesmo código de cores: PDB 4F5S [54] (linha azul), monômero parcialmente desenovelado obtido por MD em pH 3.7 (linha verde), dímero obtido por modelagem de corpo rígido a $\mathrm{pH}$ 3,7 (linha roxa) e o melhor ajuste (linha vermelha) calculado pelo software GENFIT como sendo composto por $75 \%$ de espécies monoméricas parcialmente desenoveladas a $\mathrm{pH} 3,7$ e $25 \%$ do respectivo dímero (fig. 3.8). Os símbolos pretos vazios representam a função $\mathrm{p}(\mathrm{r})$ dos dados experimentais calculados pelo software GIFT - modelo independente - e a linha vermelha é a função p(r) calculada a partir do ajuste mencionado acima. O gráfico inserido mostra o bom ajuste entre as curvas de espalhamento e o ajuste utilizado para calcular a função $\mathrm{p}(\mathrm{r})$ usando o software GIFT em todos os casos.

Além disso, sabe-se bem que o valor de $\mathrm{I}(0)$ está diretamente relacionado com a massa molecular da proteína e, consequentemente, ao seu estado oligomérico em solução [81]. Assim, o aumento da intensidade de espalhamento para valores de $q$ pequenos em relação ao previsto para o estado monomérico da BSA (figura 3.10) indica que monômeros de BSA a pH 3,7 coexistem com agregados de ordem maior em solução. De fato, por extrapolação da curva experimental utilizando a análise de Guinier [81] obteve-se uma massa molecular (MM) de 87 (2) kDa, que é $35 \%$ maior que o esperado para a MM do monômero (ver tabela 3.1), sugerindo que a BSA em solução encontra-se em equilíbrio, com monômeros parcialmente desenovelados (fig. 3.8B) e agregados. 


\begin{tabular}{lccccc} 
& PDB 4F5S & Parc. Desenovelada & Dímero & Ajuste & Guinier \\
\cline { 2 - 6 } $\operatorname{MM}(\mathrm{kDa})$ & 64,4 & 64,4 & 128,8 & $90(2)$ & $87(2)$ \\
\cline { 2 - 6 } $\operatorname{Rg}(\AA)$ & 26,9 & 32,0 & 49,2 & $39(1)$ & $39(1)$ \\
\hline
\end{tabular}

Tabela 3.1: Massa Molecular (MM) e o raio de giro (Rg) para a estrutura cristalográfica de BSA a pH 6,5 (PDB 4F5S [54]), conformação parcialmente desenovelada obtida em nossas simulações de MD; dímero obtido por modelagem de corpo rígido utilizando o software GLOBSYMM a pH 3,7; ajuste calculado utilizando o software GENFIT como sendo composto por 75(5)\% do monômero parcialmente desenovelado a pH 3,7 e 25(5)\% respectivo dímero; Guinier fornece os valores de MM e Rg calculados diretamente da curva experimental (eq. Guinier 3.8).

Deste modo, procedeu-se a análise dos dados de SAXS supondo que os dados experimentais têm uma contribuição do espalhamento do monômero parcialmente desenovelado a pH 3,7 obtido por MD e do dímero modelado por corpo rígido utilizando o programa GLOBSYMM $[92,93]$ composto por dois monômeros a pH 3,7 (fig. 3.8B e C). Portanto, a linha vermelha na figura 3.10 representa o melhor ajuste aos dados experimentais, evidenciando que cerca de $75 \%$ de monômeros de BSA parcialmente desenovelados coexistem com aproximadamente $25 \%$ de dímero (tabela 3.1). Curiosamente, Yeh et al. [112] também sugeriram uma coexistência entre monômeros (82\%), dímeros (16\%) e oligômeros (2\%) de BSA a pH semelhante, avaliada por cromatografia líquida de alta eficiência. Além disso, os autores calcularam um raio de giro médio de $38 \AA$ [112], muito semelhante ao valor obtido nesta tese.

Assim sendo, demonstramos através de análises de SAXS que a isoforma de BSA parcialmente estendida prevista por simulação de MD a pH 3,7 tem a tendência para se agregar como um dímero, apesar do fato de ela adquirir uma grande carga líquida superficial positiva (+99). Isto deve acontecer devido ao aumento na área de superfície hidrofóbica e hidrofílica expostas ao solvente (fig 3.12) ao se reduzir o $\mathrm{pH}$ de 6,5 para 3,7. Estas observações estão de acordo com resultados anteriores de MD de BSA em pH 3,5 [75] onde os autores evidenciaram um aumento de SASA hidrofóbica para os três domínios, expondo assim aminoácidos mais hidrofóbicos ao solvente. A exposição da superfície hidrófobica (apresentada neste trabalho e em [75]) favorece a dimerização de BSA.

\subsubsection{O impacto do SDS e SPFO na conformação e agregação da BSA em pH 3,7}

Como reportado anteriormente [14], o surfactante aniônico SDS pode induzir a formação de grandes agregados de BSA, na razão molar 1: 100 a pH 3,7 (5 $\mu \mathrm{M}$ de proteína e $500 \mu \mathrm{M}$ de SDS, portanto, abaixo da cmc do SDS - $8 \mathrm{mM}$ em água pura [56]). A ligação do SDS com a BSA deve diminuir a forte repulsão eletrostática entre os monômeros parcialmente desenovelados, através da blindagem das cargas positivas de proteína pela cabeça polar negativamente carregada das moléculas de SDS. Além disso, esses agregados induzidos pela interação do SDS com a 


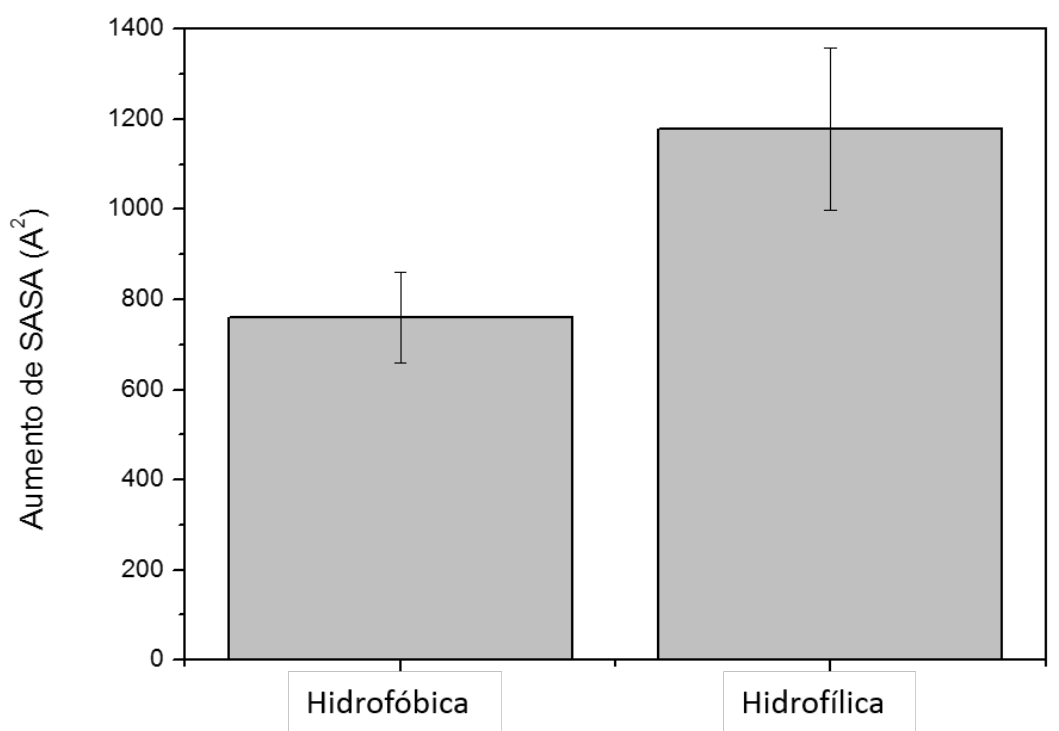

Figura 3.12: Aumento de área de superfície acessível ao solvente (SASA) ao reduzir o pH de 6,5 para 3,7, conforme obtido por simulações de MD. O SASA está dividido em área de aminoácidos hidrofóbicos e hidrofílicos.

BSA foram caracterizados como sendo do tipo amilóide por terem apresentado um significativo aumento na percentagem de folhas $\beta$, observado por CD [14].

Neste trabalho realizamos experimentos de SAXS, DLS, fluorescência de Tioflavina T, SRCD, SEM e simulações de dinâmica molecular para melhor caracterizar a interação de BSA a pH 3,7 com SDS e comparar com as alterações promovidas na BSA pela interação com o SPFO em diferentes razões molares surfactante:proteína (a partir de 15:1 até 120:1). Deste modo, a correlação entre os surfactantes e a formação de agregados de BSA deve acrescentar conhecimento sobre a importância do efeito hidrofóbico, interação eletrostática e efeito estérico no mecanismo de formação de fibras proteicas tipo-amilóide.

\subsubsection{Influência dos surfactantes analisada por MD, SAXS e SEM}

Para analisar os dados experimentais de SAXS realizamos simulações de dinâmica molecular (MD) para obter a conformação do monômero da BSA, a pH 3,7 (fig. 3.8B) após adição de 30 e 60 moléculas de SDS ou de SPFO. Estas estruturas estão expostas na figura 3.13a. 


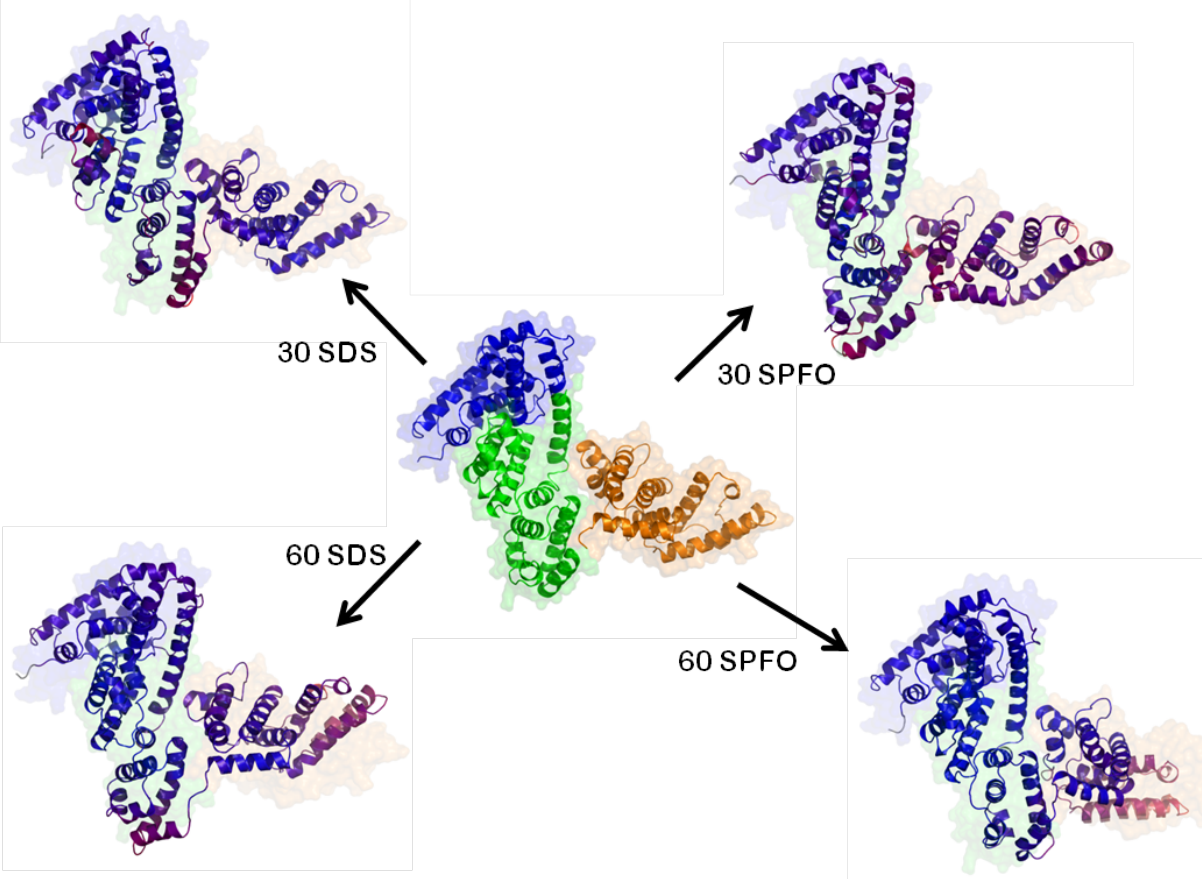

(a)

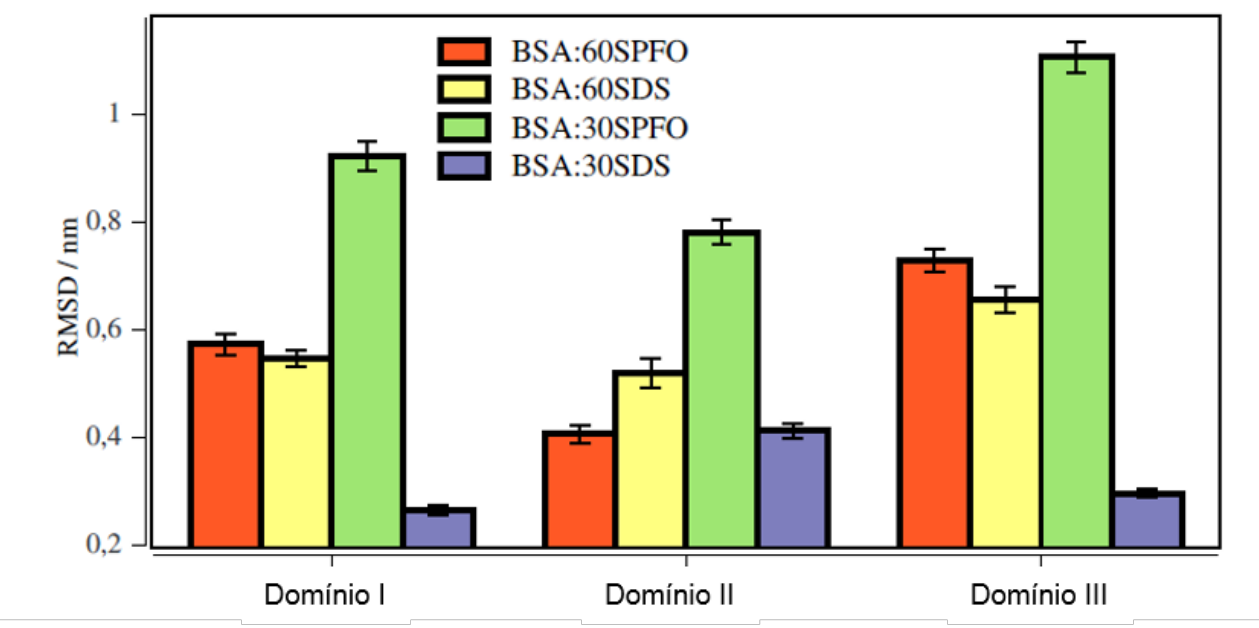

(b)

Figura 3.13: (A) Centro: monômero de BSA obtido por MD ao reduzir o $\mathrm{pH}$ de 6,5 para 3.7 (azul é o domínio I, verde o domínio II e laranja o domínio III) e a conformação do monômero obtida pela adição de surfactantes (SDS ou SPFO): 30 ou 60 moléculas. As estruturas atômicas obtidas após a adição do surfactante são coloridas como azul escuro para baixos valores de RMSD e vermelho claro para altos valores de RMSD em relação ao monômero na ausência de surfactante. A sombra da estrutura obtida por MD na ausência do surfacante é apresentada em todas as conformações para fins de comparação. (B) RMSD em comparação com o monômero na ausência de surfactante.

Pode-se observar que a conformação do monômero de BSA em pH 3,7 não sofreu uma alteração drástica mesmo na presença de 60 moléculas de surfactante (SDS ou SPFO) por MD, atráves de pela inspeção visual da similaridade das estruturas na presença dos surfactantes com a do monômero da BSA na ausência dos mesmos (fig. 3.13). Também é possível perceber que 
não há uma grande variação do valor da raiz quadrada do desvio médio (RMSD) como indicado nas estruturas atômicas na presença do surfactante (fig 3.13a - azul escuro para baixos valores de RMSD e vermelho claro altos valores de RMSD) e quantificado levando-se em conta cada domínio da proteína como apresentado no gráfico da figura 3.13b. Cabe acrescentar que o maior valor de RMSD para cada um dos três domínios foi obtido na presença de 30 moléculas de SPFO (fig. 3.13).

Uma vez que a presença de 30 ou 60 moléculas de SDS ou SPFO não causou um grande impacto na conformação do monômero de BSA em pH 3,7 por MD, como observado na figura 3.13, seria esperado que as curvas teóricas de SAXS e de p(r), calculadas para estas conformações, fossem muito parecidas com a conformação na ausência do surfactante. Esta comparação está presente na figura 3.14 . 


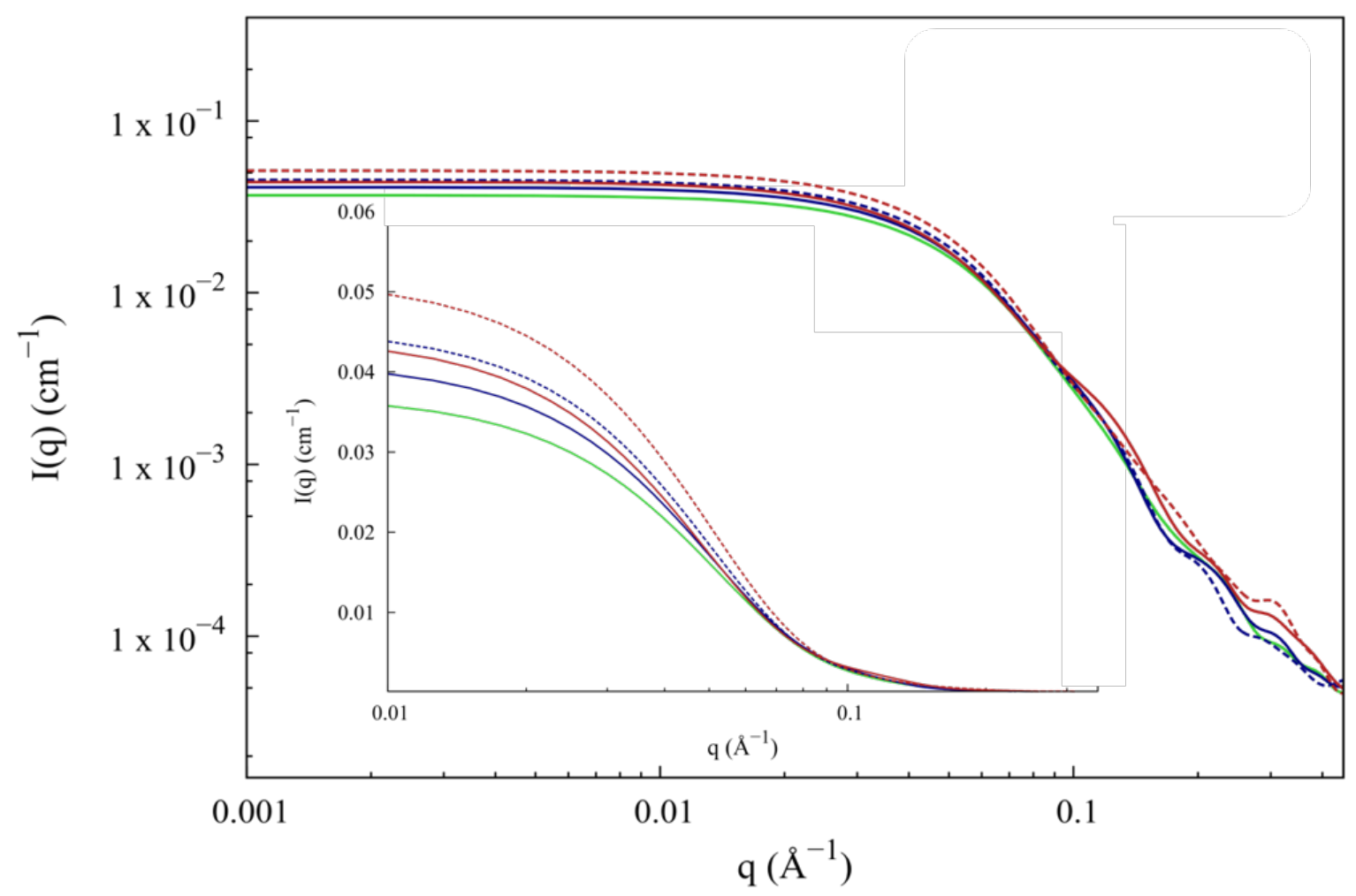

(a)

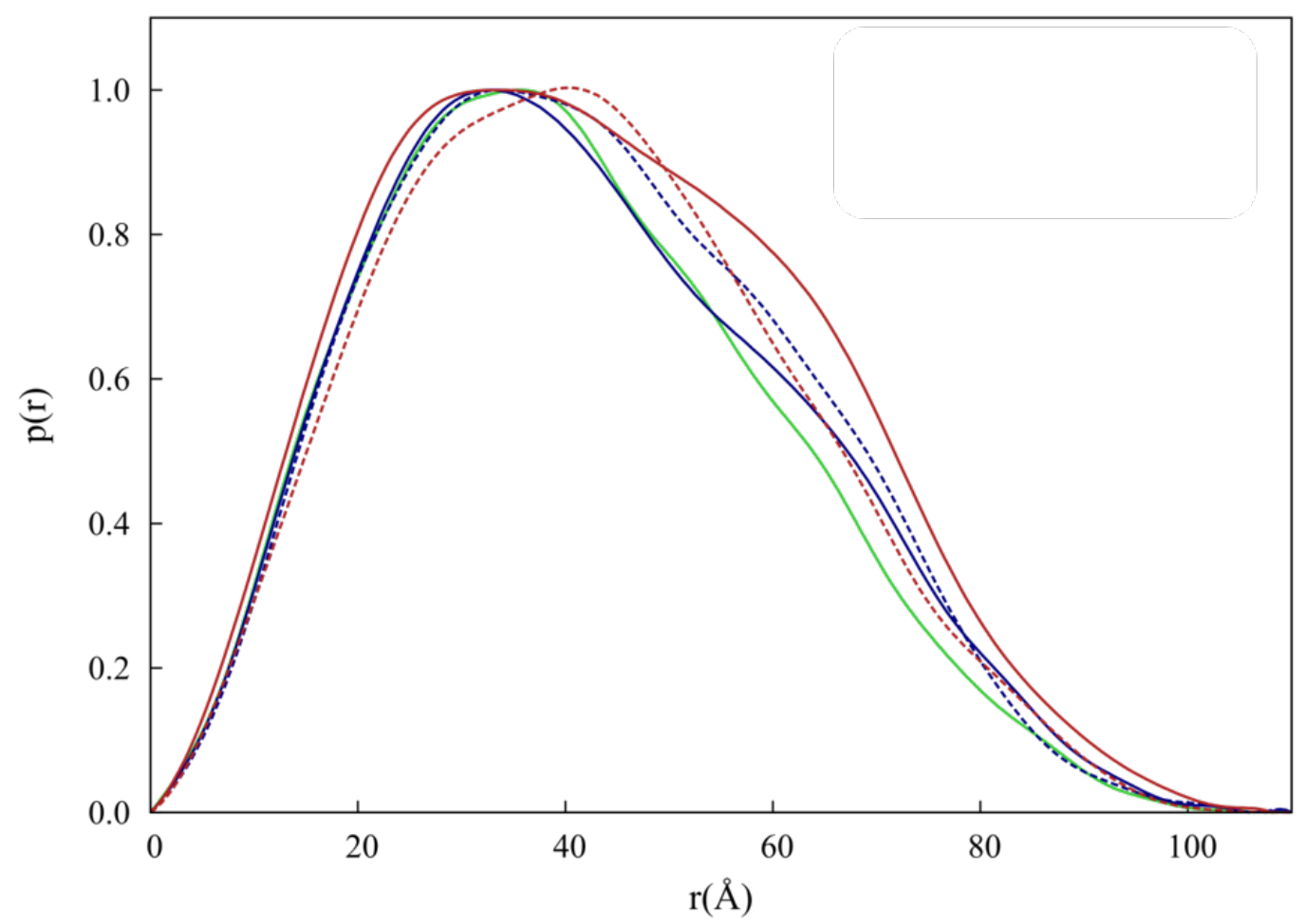

(b)

Figura 3.14: (A) Curvas teóricas de SAXS para as conformações do monômero de BSA em pH 3,7 na ausência (linha verde) e na presença de 30 (linhas contínuas) ou 60 (linhas pontilhadas) moléculas de SDS (azul) ou SPFO (vinho) obtidas por MD. Figura inserida mostra as mesmas curvas na escala linear. (B) Funções de distribuição de distâncias para cada estrutura apresentada em (A), obtidas utilizando o programa GIFT. 
As curvas calculadas de I(q) (fig. 3.14a) para as conformações do monômero da BSA a pH 3,7 na ausência e na presença de 30 ou 60 moléculas de SDS ou SPFO, obtidas por MD, não apresentam diferenças significativas. É interessante notar o aumento no valor de $\mathrm{I}(0) \mathrm{e}$ consequentemente, o aumento da massa molecular do complexo BSA-surfactante, resultante da ligação destas moléculas ao monômero de BSA. Cabe ressaltar que este aumento é mais pronunciado na presença de 60 moléculas de SPFO, que possui maior massa molecular do que o SDS (436.052 g/mol e 288,372 g/mol, respectivamente).

Na mesma direção, as funções p(r) para cada uma das estruturas atômicas (fig. 3.8) na presença de surfactante não apresentaram diferenças significativas em relação ao monômero na ausência do mesmo, sendo possível observar apenas um ligeiro aumento de frequências de distâncias em cerca de $r=60 \AA$, enquanto que o valor de $D_{\max }$ se manteve constante em todos os casos.

Após estas observações do impacto do SDS e do SPFO no monômero de BSA em pH 3,7 visto por MD e SAXS téorico, usamos modelagem de corpo rígido (program GLOBSYMM $[92,93])$ para obter um dímero composto por dois monômeros de BSA (monômeros presentes na figura 3.8) na presença de 30 moléculas de SDS ou SPFO. Estes dímeros foram obtidos com o intuito de, junto com o monômero, ajustar os dados experimentais de SAXS tendo em vista que, como demonstrado, a solução de BSA na ausência dos surfactantes é constituída por monômeros e dímeros. Logo, ao se adicionar o surfactante, esperar-se-ia que a suspensão tivesse, também, um balanço entre essas duas populações.

Desta maneira, realizamos os experimentos de SAXS da suspensão de BSA a pH 3,7 na presença de SDS (A) e SPFO (B) até 45:1 de razão molar e as curvas estão mostradas na figura 3.15. Como mencionado anteriormente, utilizou-se o programa GENFIT [88] para ajustar os dados experimentais, utilizando o fator de forma calculado a partir das coordenadas atômicas do monômero obtido por MD, dímeros simétricos e um modelo geométrico para representar um tetrâmero (ver abaixo). Cabe ressaltar que realizamos os ajustes supondo que todas as moléculas de surfactante se ligam à proteína, pois no intervalo analisado por SAXS, a concentração de surfactante é menor do que a cmc em água pura para ambos os surfactantes $(0.675 \mathrm{mM}$ para 45:1, $8 \mathrm{mM}$ para SDS [56] e cerca de $28 \mathrm{mM}$ para o SPFO [57]). Como controle para os ajustes realizados utilizando o modelo dependente (GENFIT [88]), comparamos as funções p(r) obtidas por esta análise com as funções p(r) obtidas por modelo-independente (GIFT [113]). Foi obtido um bom acordo entre as duas metodologias em todos os casos (resultados não apresentados). 


\section{SDS}
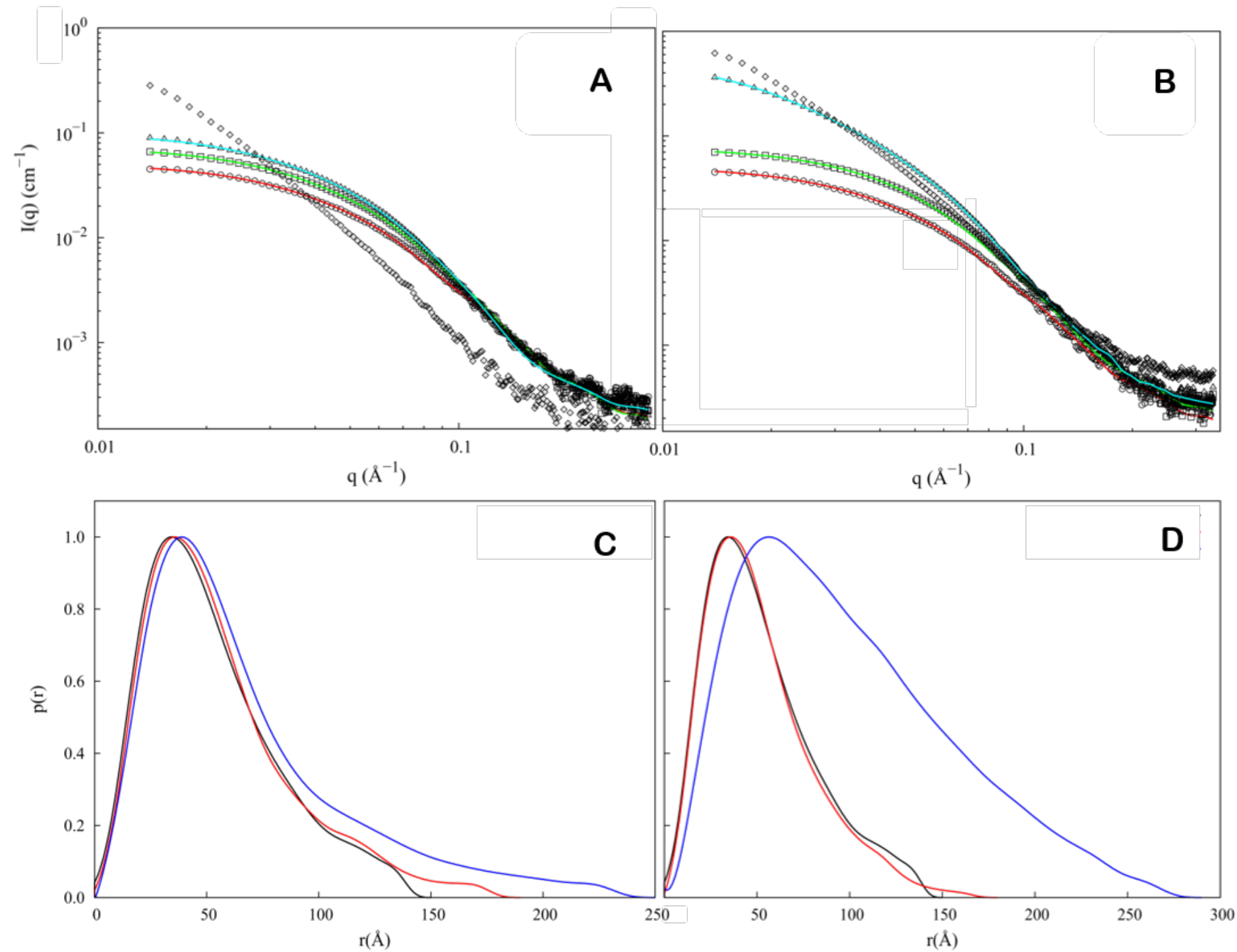

Figura 3.15: Curvas experimentais de SAXS de solução de BSA (1 mg/mL) em pH 3,7 (símbolos vazios) juntamente com melhor ajuste calculado pelo software GENFIT (linhas sólidas) para o SDS (A) e SPFO (B): na ausência de surfactante (círculo), razão molar de 15:1 (quadrado), 30:1 (triângulo) e 45:1 (losango - não foi possível realizar um ajuste com os modelos propostos). Neste caso, o melhor ajuste para 0:1 e 15:1 (ambos casos) foi obtido ao se considerar o espalhamento de monômeros parcialmente desenovelados e respectivos dímeros em solução a pH 3,7 em diferentes proporções (ver texto para detalhes). No caso de 30:1 (SDS:BSA) o melhor ajuste foi obtido como a combinação do espalhamento do monômero desenovelado na presença de 30 moléculas de SDS (fig. 3.13), o respectivo dímero (modelado por corpo rígido) e um elipsóide com a massa molecular de um tetrâmero. Para 30:1 (SPFO: BSA), o ajuste foi obtido usando somente o software GIFT para evitar análises superestimadas (ver texto para detalhes). Funções $\mathrm{p}(\mathrm{r})$ na ausência de surfactante (linha preta) e na presença de SDS (C) e SPFO (D) na razão molar surfactante:BSA de 15:1 (linha vermelha) e 30:1 (linha azul).

Pode-se observar a boa concordância entre os ajustes (linhas) e os dados experimentais em todos os casos (que foram possíveis de ajustar) utilizando os modelos descritos (fig. 3.15). 
Em primeiro lugar, com a maior razão molar surfactante:BSA, para ambos os surfactantes aumentou a tendência do valor de I(q->0) em relação ao valor obtido para a BSA em solução. Como mencionado anteriormente, este valor está relacionado à massa molecular do centro espalhador [81] (BSA-Surfactante) indicando a ligação do surfactante com a proteína e/ou a formação de agregados em função do aumento da concentração de surfactante. Para elucidar esta questão foram realizados ajustes das curvas experimentais utilizando o programa GENFIT [88] (modelo-dependente) e GIFT (modelo-independente)[113]

Após a adição de SDS, apesar do aumento do valor de I(q->0), as curvas de SAXS para as razões molares de 15:1 e 30:1 são semelhantes às curvas da BSA na ausência de surfactante para valores de $q$ maiores do que $0.08 \AA^{-1}$. Isto poderia indicar que as estruturas proteicas com dimensões menores que $80 \AA\left(q \sim 0.08 \AA^{-1}\right)$ tenham sido conservadas com a adição de SDS. Por outro lado, os ajustes obtidos indicaram a coexistência de 72(5)\% do monômero de BSA parcialmente desenovelado (obtido por MD) com 28(4)\% do respectivo dímero para a amostra de 15:1 e coexistência de 89(5)\% do monômero de BSA obtido por MD na presença de 30 moléculas de SDS, 7 (3)\% do respectivo dímero e 5 (2)\% de um elipsóide que representa um tetrâmero (tabela 3.2).

Além disso, as funções de distribuição de distâncias, p(r), para a BSA na ausência e na presença de 15 e 30 moléculas de SDS (fig. 3.15C) são muito similares, o que, em conjunto com as observações acima, indicam a presença das mesmas espécies em suspensão. Para a amostra de 30:1 há um aumento no valor de distância máxima ( $r \sim 250 \AA$ ) que é compatível com a dimensão do elipsóide obtido no ajuste (maior semi-eixo = 117(8) Å). Além disso estimou-se a massa molecular (MM) a partir da média ponderada das populações indicadas pelos ajustes como 96(6) e 107(7) kDa para a de 15:1 e 30:1, respectivamente, indicando o processo de ligação dos surfactantes com a proteína e também a agregação da mesma.

\begin{tabular}{lcccc} 
& $0: 1$ & $15: 1$ SDS & $30: 1$ SDS & $15: 1$ SPFO \\
\cline { 2 - 5 } Monômero (\%) & $75(5)$ & $72(5)$ & $89(5)$ & $76(5)$ \\
\cline { 2 - 5 } $\begin{array}{l}\text { Dímero (\%) } \\
\text { Tetrâmetro (elipsóide) (\%) }\end{array}$ & - & - & $5(2)$ & - \\
\cline { 2 - 5 }
\end{tabular}

Tabela 3.2: Percentual de cada população proteica obtido através dos ajustes das curvas experimentais de solução de BSA em pH 3,7 na ausência e na presença de 15:1 e 30:1 SDS e 15:1 SPFO utilizando o program GENFIT. Para 0:1 e 15:1 SDS ou SPFO, utilizou-se a combinção do fator de forma das estruturas atômicas do monômero e respectivo dímero da BSA na ausência de surfactante e para 30:1 SDS obtido por MD utilizou-se o monômero da BSA na presença de 30 moléculas de SDS e o respectivo dímero modelado por corpo rígido.

Observando, então, a curva de SAXS para a amostra 45:1 (SDS:BSA) é possível perceber que ela é muito diferente das outras curvas de espalhamento, indicando uma transição na conformação (envelope) das espécies presentes. Não foi possível realizar um ajuste da amostra 
45:1, devido ao elevado valor de I(q->0) indicando a formação de grandes agregados (maiores do que monômero, dímero e até mesmo do que o tetrâmero) e a distância máxima obtida na função $\mathrm{p}(\mathrm{r})$ foi maior do que o alcance máximo experimental $\left(D_{\max } \sim \frac{\pi}{q}\right)(54)$ também sugerindo a presença de grandes agregados.

Analisando agora o efeito da adição de SPFO na solução de BSA em pH 3,7, da figura 3.15B pode-se notar que a curva de espalhamento de 15:1 é semelhante à de BSA na ausência de surfactante sugerindo a coexistência de 76(5)\% de BSA a pH 3,7 desenovelado e 24(4)\% do respectivo dímero para a amostra de 15:1 (tabela 3.2). Também, a função p(r) para esta amostra é muito parecida com a da BSA na ausência do surfactante, em concordância com a análise do modelo dependente (fig. 3.15D). Além disso, o valor de I(q->0) aumenta para a amostra de 15:1 indicando aumento de massa molecular que também foi calculada utilizando a média ponderada das populações obtidas no ajuste como sendo cerca de 99(6) kDa.

Ao aumentar a razão molar de SPFO:BSA, as curvas de SAXS apresentam aumento na tendência do valor de $\mathrm{I}(\mathrm{q}->0)$ e os perfis de espalhamento se tornam muito diferentes. Para a 30:1 foi possível ajustar uma curva teórica utilizando o modelo-independente (GIFT [113]) para obter a função p(r) (fig. 3.15D), mas para 45:1 não foi possível ( $D_{\max }$ fora do alcance do experimento). No caso de 30:1, a função p(r) apresenta aumento no valor de distância máxima, de $150 \AA$ para $270 \AA$ A e as frequências de distâncias maiores do que $100 \AA$ Apresentam um significativo aumento em relação à função $\mathrm{p}(\mathrm{r})$ da BSA pura. Tendo em vista estas observações (alteração de $\mathrm{I}(\mathrm{q})$, aumento de $\mathrm{I}(\mathrm{q}->0)$ e variação na $\mathrm{p}(\mathrm{r}))$, pode-se sugerir que a presença de SPFO em razão molar superior a 30:1 induz a formação de grandes agregados.

Seguindo o estudo da interação de SDS e SPFO com a proteína BSA como observado por SAXS, aumentou-se a razão molar para 90:1 e 120:1 para ambos surfactantes (fig 3.16). Para melhor caracterizar estas amostras, também realizou-se experimentos de microscopia eletrônica de varredura (SEM) e microscopia de transmissão eletrônica (TEM) para as mesmas razões molares de surfactante:BSA (15:1 até 120:1). A figura 3.16 apresenta uma imagem para a amostra de BSA na presença de alta concentração de SDS ou SPFO. 


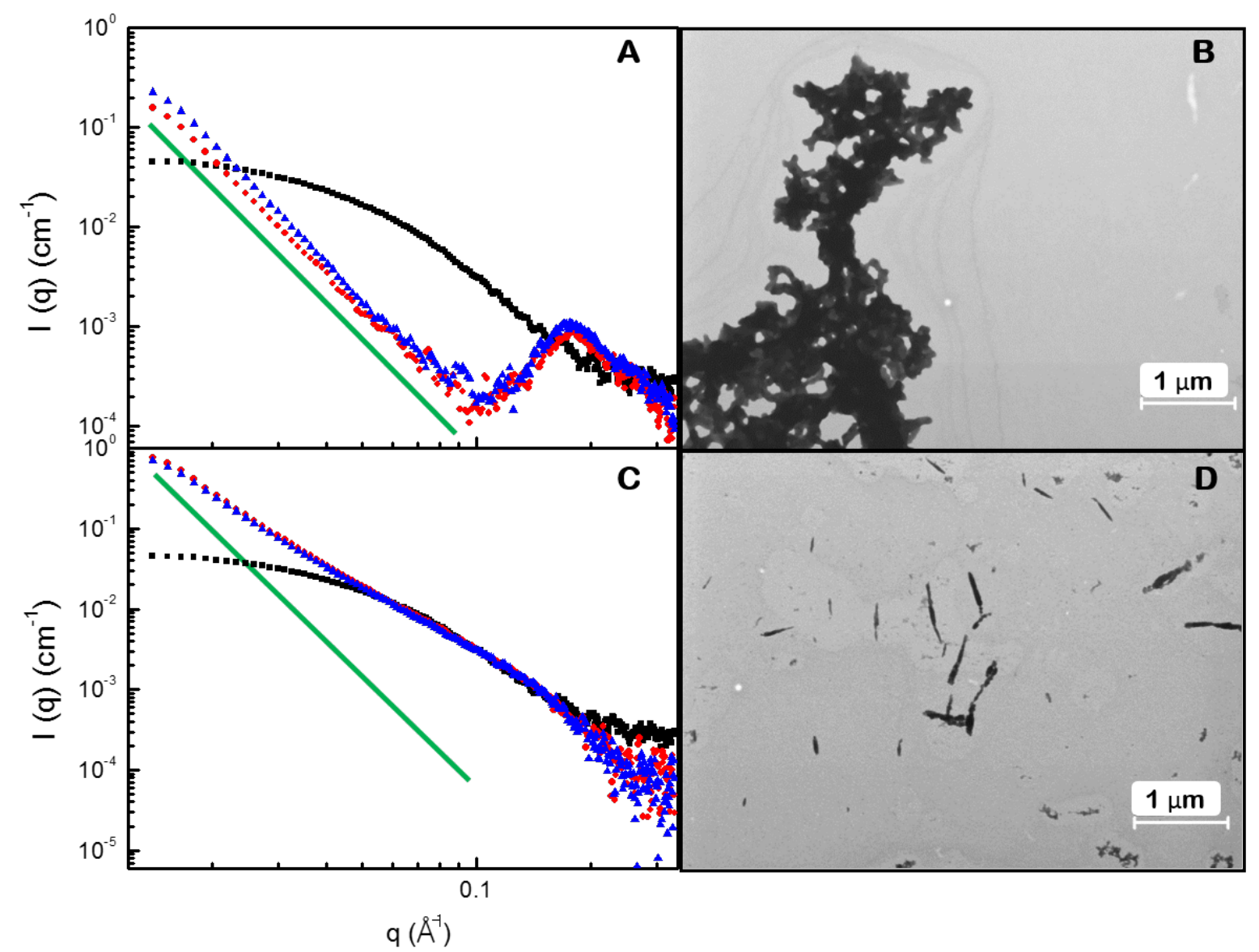

SDS

SPFO

Figura 3.16: Curvas de SAXS para a BSA pH 3,7 na presença de (A) SDS e (C) SPFO para as razões molares de 0:1 (quadrado preto), 90:1 (círculo vermelho) e 120:1 (triângulo azul). A linha verde em $(\mathrm{A})$ e $(\mathrm{C})$ indica a função de Porod $I(q) \sim q^{-4}[114,115]$ para comparação. Imagens de SEM para (B) SDS:BSA na razão molar de 120:1 e (D) SPFO:BSA na razão molar de 105:1. A escala em (B) e (D) é de $1 \mu \mathrm{m}$

As curvas de SAXS para a razão molar de 90:1 e 120:1 para o SDS ou SPFO apresentadas na figura 3.16(A e C) são drasticamente diferentes das curvas de espalhamento da BSA na ausência de surfactante, indicando que as espécies presentes sofreram uma grande alteração com a adição de altas concentrações de surfactante. Por outro lado, a presença de grandes agregados é evidenciado pelo notável aumento no valor de I(q->0) (fig. 3.16 A e C). Como uma comparação, a intensidade de espalhamento de SAXS descrita pela lei de Porod [114, 115] (fig. 3.16 A e C - linha verde), indica o perfil de espalhamento de uma partícula com dimensões maiores do que a escala nanométrica. É possível observar a boa concordância deste espalhamento com o observado para os dados experimentais na presença do SDS enquanto a curva de SAXS na presença de SPFO não apresenta a mesma inclinação. Importante ressaltar que há um pico nas curvas de SAXS $\left(q \sim 0.15 \AA^{-1}\right)$ na presença de altas concentrações de SDS devido à presença de micelas de SDS [116]. A concentração micelar crítica de SDS (CMC) é aproximadamente $8 \mathrm{Mm}$ 
em água [56] mas pode ser reduzida na presença de BSA, como demonstrado por medidas de tensão superficial [56].

De qualquer maneira, as análises de SAXS para amostras de BSA contendo altas concentrações de surfactantes indicaram a presença de grandes agregados que inviabilizaram uma análise mais quantitativa destas curvas. Assim sendo, utilizou-se a técnica de SEM para obter imagens deste grandes agregados.

As figuras 3.16 B e D mostram as imagens de SEM de BSA na presença de 120:1 (SDS:BSA) e 105:1 (SPFO:BSA), respectivamente. Na presença de SDS os agregados possuem maior tamanho do que na presença de SPFO e têm forma mais irregular. No caso do surfactante fluorado, os agregados formados têm uma forma mais fibrilar, podendo indicar a presença de algum tipo de estrutura mais ordenada.

Tendo isto em vista, para elucidar sobre a a estrutura secundária destes agregados realizouse experimentos de fluorescência de tioflavina $\mathrm{T}(\mathrm{Th} \mathrm{T})$ e de dicroísmo circular em síncrotron (SRCD). Em paralelo, foram realizadas experiências de turbidez para obter informação sobre a formação de agregados de BSA induzidos pela presença de SDS ou SPFO na escala mesoscópica.

\subsubsection{Influência dos surfactantes na BSA analisada por Turbidez, flu- orescência de Th T e SRCD}

Com o intuito de investigar a formação dos agregados de BSA induzidos pela presença dos surfactantes, medimos o espectro de absorção de luz UV-VIS das amostras de BSA com o aumento da concentração de SDS e SPFO. A figura 3.17 apresenta um exemplo destas medidas: 

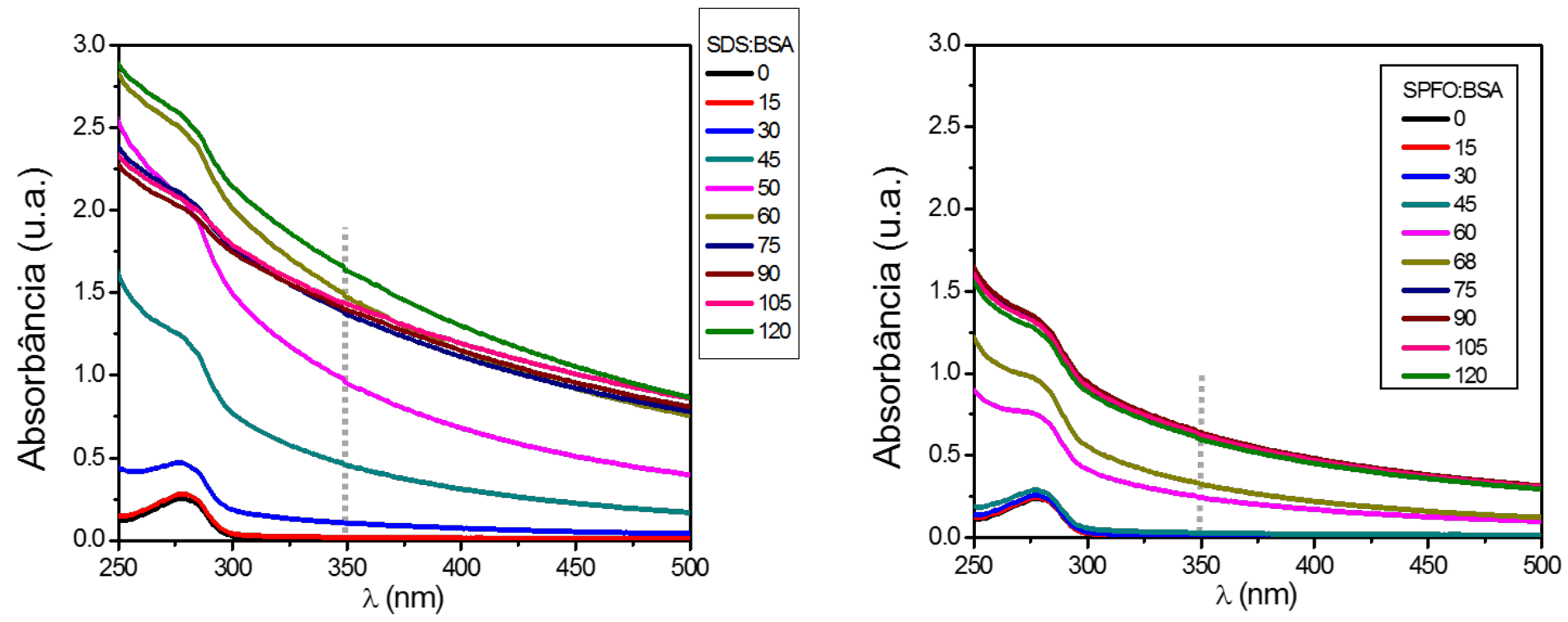

Figura 3.17: Medidas do espectro de absorção de luz UV-VIS para a BSA (1 mg/mL) em pH 3,7 em função do aumento da concentração de SDS (esquerda) e SPFO (direita). A linha tracejada indica o comprimento de onda $\lambda$ utilizado para as análises de turbidez.

Primeiramente, é interessante notar a presença da banda de absorção dos aminoácidos arómaticos da BSA (fenilanina, tirosina e triptofano) com pico de absorção máxima em torno de $\lambda=280 \mathrm{~nm}$ para a proteína na ausência do surfactante (linha preta) e inclusive na presença de 15:1 SDS e até 45:1 SPFO. Com o aumento da concentração destes surfactantes, este pico de absorção passa a ter contribuição do espalhamento de luz (turbidez) causado pela presença dos agregados induzidos pelos surfactantes.

Utilizou-se, então, o comprimento de onda de $\lambda=350 \mathrm{~nm}$ (linha cinza pontilhada fig. 3.17) para obter os valores de turbidez da amostra em função da concentração dos surfactantes e avaliar assim a formação de agregados. A curva de turbidez com análise mais detalhada será apresentada posteriormente (fig. 3.20).

Em paralelo, mediu-se o espectro de emissão de fluorescência de tioflavina $\mathrm{T}$ (Th T) para as mesmas amostras da figura 3.17, como apresentado na figura 3.18. 

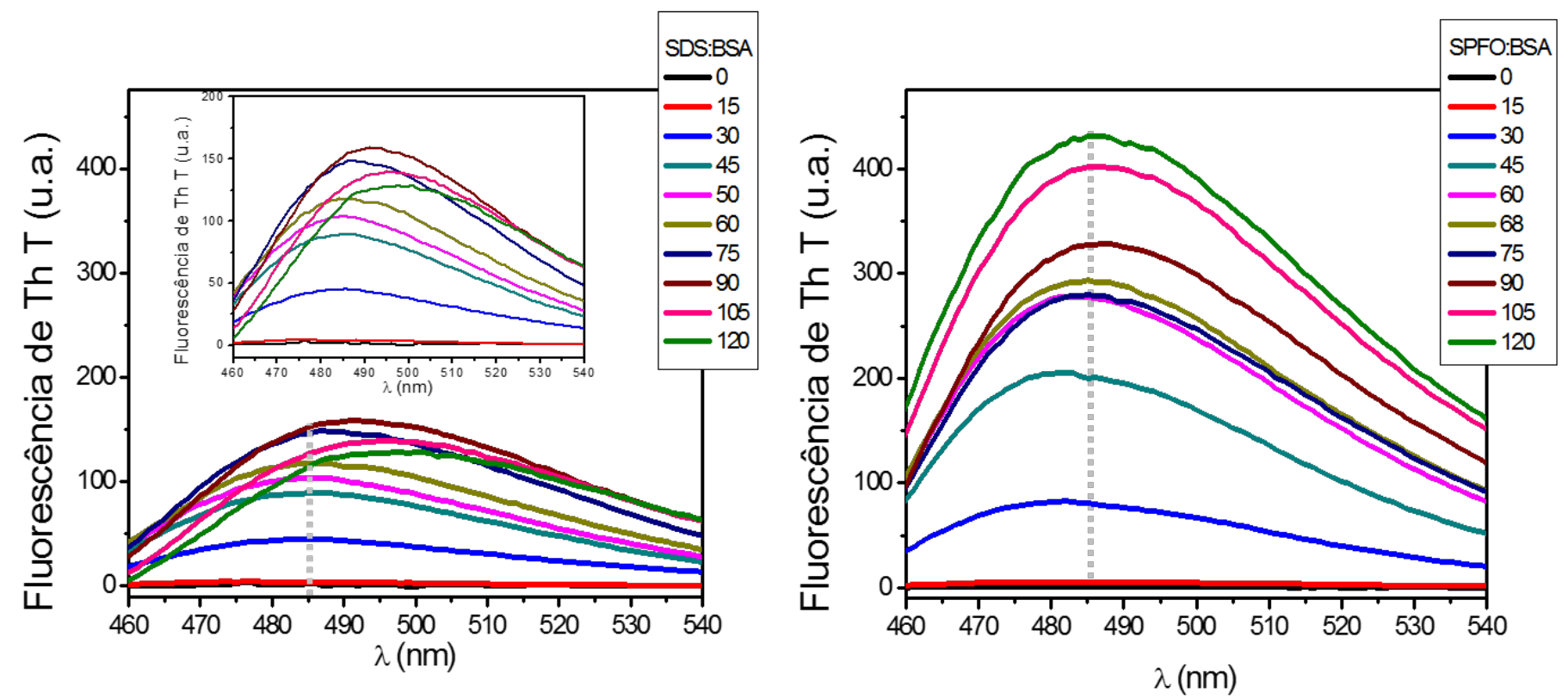

Figura 3.18: Medidas de fluorescência de tioflavina T dispersa em suspensão de BSA $(1 \mathrm{mg} / \mathrm{mL})$ em pH 3,7 com razão molar de Th T:BSA 20:1 em função do aumento da concentração de SDS (esquerda - figura inserida com escala expandida) e SPFO (direita). O comprimento de onda de excitação foi de $440 \mathrm{~nm}$. A linha tracejada indica o comprimento de onda $\lambda$ utilizado para as análises de variação da intensidade de fluorescência Th $\mathrm{T}$.

Na presença de SDS ou SPFO há aumento de intensidade de fluorescência de tioflavina $\mathrm{T}$, sendo mais expressivo no caso do surfactante fluorado. Importante notar que para razões molares de SDS:BSA, acima de 75:1 houve deslocamento da posição do pico de intensidade máxima de fluorescência do Th T (redshift) correspondente as seguintes concentrações de SDS em solução tampão na presença de BSA: 1,125 mM (75:1), 1,350 mM (90:1), 1,575 mM (105:1) e 1,800 mM (120:1). Como mencionado anteriormente, as curvas de SAXS indicaram a presença de micelas de SDS nestas mesmas amostras (75:1 - 120:1, figura 3.16 apresenta os dados para 90:1 e 120:1) e os experimentos de tensão superficial indicaram a diminuição da cmc de 8 $\mathrm{mM}$ em água pura para cerca de $2,2 \mathrm{mM}$ na presença de $10 \mathrm{mg} / \mathrm{mL}$ de BSA dissolvida em tampão $20 \mathrm{mM}$ de ácido succínico a pH 5,4 [56]. Além disso, experimentos de fluorescência de Th T em soluções contendo micelas de SDS demonstraram um deslocamento no espectro de absorção e emissão do Th T [117]. Assim sendo, sugerimos que nas amostras de BSA com razões molares superiores a 75:1 (SDS:BSA) há um equilíbrio entre monomêros e micelas do surfactante hidrogenado. Cabe acrescentar que não tivemos indicações da presença de micelas de SPFO em nossos experimentos.

De qualquer maneira, em todos os casos, utilizou-se a intensidade de fluorescência de Th $\mathrm{T}$ para o mesmo comprimento de onda $\lambda=485 \mathrm{~nm}$ para avaliar a formação de folhas $\beta$ das amostras de BSA em pH 3,7 em função do aumento da concentração de surfactante (fig. 3.20).

Como comparativo aos resultados de fluorescência de Th $\mathrm{T}$ e para obter a composição 
percentual da estrutura secundária dos agregados da proteína BSA em função da concentração dos surfactantes, mediu-se os espectros de SRCD das mesmas amostras. Estes dados foram obtidos em colaboração com a pós doutoranda Juliana S. Yoneda. A figura 3.19 apresenta os resultados.
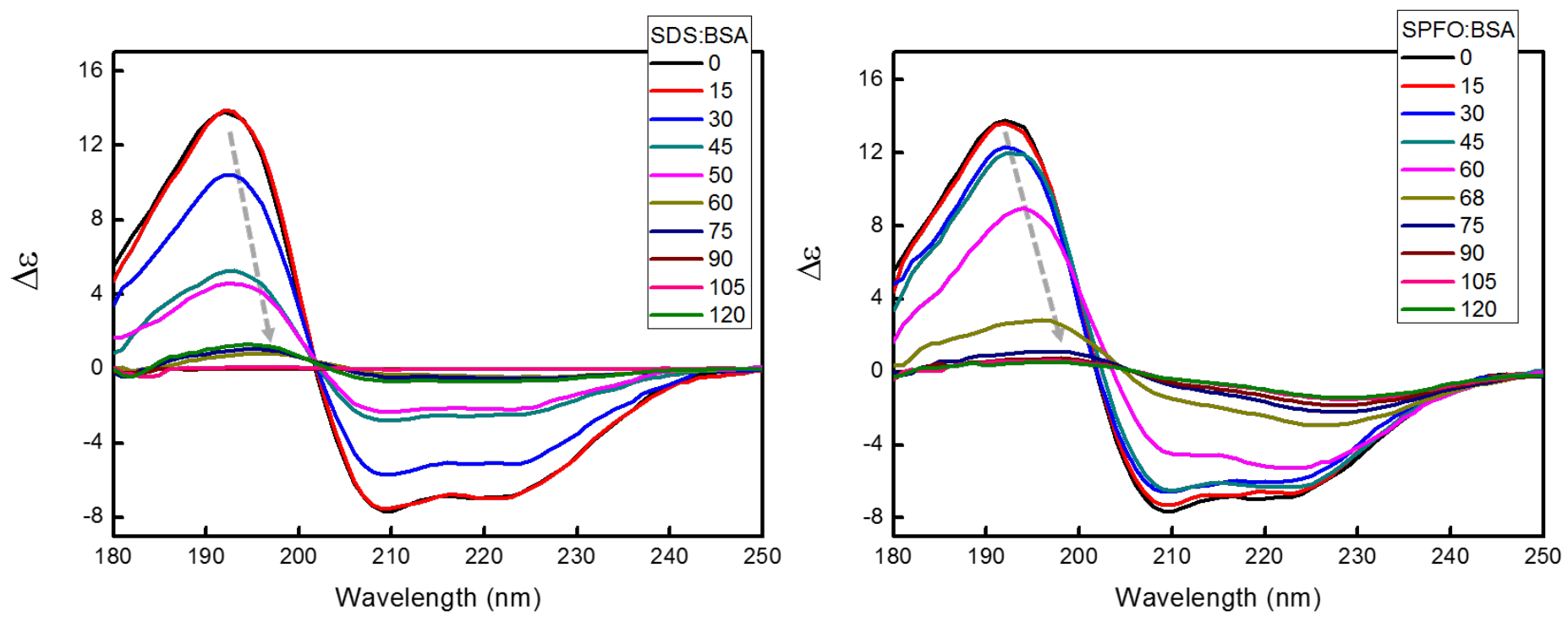

Figura 3.19: Medidas do espectro de SRCD para a BSA $(1 \mathrm{mg} / \mathrm{mL})$ a $\mathrm{pH} 3,7$ em função do aumento da concentração de SDS (esquerda) e SPFO (direita). A seta cinza tracejada indica a diminuição da intensidade para $\lambda \sim 192 \mathrm{~nm}$ e o deslocamento deste pico para $\lambda \sim 198 \mathrm{~nm}$.

Ao observar a figura 3.19 pode-se perceber a diminuição do sinal de SRCD da BSA em função do aumento da concentração de ambos os surfactantes. Esta diminuição na região de $\lambda$ $192 \mathrm{~nm}$ pode ser interpretada como a formação de folhas $\beta$, como exemplificado anteriormente (fig. 3.7). Contudo, esta diminuição do sinal de SRCD também pode resultar do espalhamento de luz causado pela presença de agregados que, de fato, foi constatada em nossas análises (SAXS, SEM e turbidez) e aconteceu em todo o intervalo observado. Sendo assim, não foi possível calcular a composição percentual da estrutura secundária dos agregados induzidos pela presença dos surfactantes. Ao invés disto, estimamos a formação de folhas $\beta$ analisando o deslocamento do pico de $\lambda=192 \mathrm{~nm}$ ( $\alpha$-hélice) para $\lambda=198 \mathrm{~nm}$ (folhas $\beta$ ) (fig. 3.7). Os resultados estão apresentados na figura 3.20.

Tendo em vista os dados experimentais de turbidez (fig. 3.17), espectro de fluorescência do Th T (fig. 3.18) e espectro de SRCD (fig. 3.19) e as análises propostas para cada uma destas técnicas, obtivemos os resultados apresentados na figura 3.20. Os dados de turbidez e de fluorescência Th T foram normalizados pelos valores na ausência de surfactante.

Como se pode observar na figura 3.20, nas razões molares 15:1 e 30:1 para ambos surfactantes, não há aumento sigificativo de turbidez. Por outro lado, com razões molares entre 45:1 e 75:1, há um aumento abrupto de turbidez na presença de SDS e SPFO, e nas razões molares 
superiores a 75:1, há um patamar para ambos surfactantes (figura 3.20A). Assim, tanto SDS quanto SPFO podem induzir o aumento de espalhamento de luz de amostras de BSA em pH 3,7 indicando o aumento de tamanho do centro espalhador que pode ser interpretado como indicativo de agregação da proteína, sendo que estes complexos formados (surfactante:BSA) são maiores na presença de SDS.

Vale acrescentar que realizamos os mesmos experimentos utilizando espalhamento de luz dinâmico (DLS) que, de maneira qualitativa, apresentou resultados semelhantes aos de turbidez. As análises de raio hidrodinâmico não serão apresentadas aqui pois, como explicado anteriormente (Materiais e Métodos), para realizar o cálculo deste parâmetro é necessário aproximar a geometria do objeto espalhador para o de uma esfera. No entanto, as imagens de SEM demonstraram que esta aproximação não é razoável para as amostras de BSA.

Ainda sobre o aumento de turbidez, é interessante notar que o padrão da variação em função do aumento da razão molar de ambos surfactantes é semelhante ao de curvas de ligação de SDS-BSA medidas por titulação isotérmica [61, 62], onde são descritas quatro regiões diferentes de ligação. Além disso, a isoterma de ligação do SPFO à BSA é descrita como análoga à curva de ligação de SDS, como sugerido por estudos da interação de SPFO com a HSA em água (onde mais de $75 \%$ da estrutura secundária da HSA é igual à BSA [51]) através de experimentos de potencial $\zeta$ e de tensão superficial [55], potenciometria e espectroscopia de CD [65] e por experimentos com balança de Langmuir, tensão superficial e CD [66].

A isoterma de ligação de SDS / SPFO com proteínas pode ser dividida em 4 regiões diferentes (a, b, c e d) [61]. Brevemente, pode-se descrever estas 4 regiões e relacionar com os dados de turbidez: (a) ligação específica à proteína através de interação eletrostática (até 30:1, para ambos surfactantes); (b) ligação não cooperativa que mostra um leve acréscimo da interação (30:1 a 45:1 para ambos surfactantes); (c) ligação cooperativa na qual a interação hidrofóbica e o efeito eletrostático atuam em conjunto, aumentando a ligação de surfactante à proteína (45:1 60:1 para SDS; 60:1 - 75:1 para SPFO); (d) um valor máximo de ligação sugerindo que mais surfactantes não irão se ligar à proteína, ao invés disto, poder-se-ia iniciar a formação de micelas de surfactante (> 75:1 para ambos surfactantes, embora não observamos a formação de micelas por SAXS no caso do SPFO) [61].

Além disso, do ponto de vista de SAXS (fig. 3.15) há uma indicação de grande aumento de tamanhos dos centros espalhadores nas razões molares surfactante:BSA superiores a 45:1 para ambos os surfactantes, em boa concordância com os dados de turbidez. Assim, podemos inferir que, na razão molar surfactante:BSA em torno de 45:1 deve ocorrer ligação cooperativa, resultando em agregação pronunciada da proteína.

Note-se que o aumento da turbidez do complexo de BSA-SDS já havia sido relatado na razão molar de 100:1 [14], onde os autores realizaram experiências em pH 3,5; 5,5 e 7,5 sendo que apenas no $\mathrm{pH}$ ácido (abaixo do ponto isoelétrico da BSA 5,65) o surfactante foi capaz 


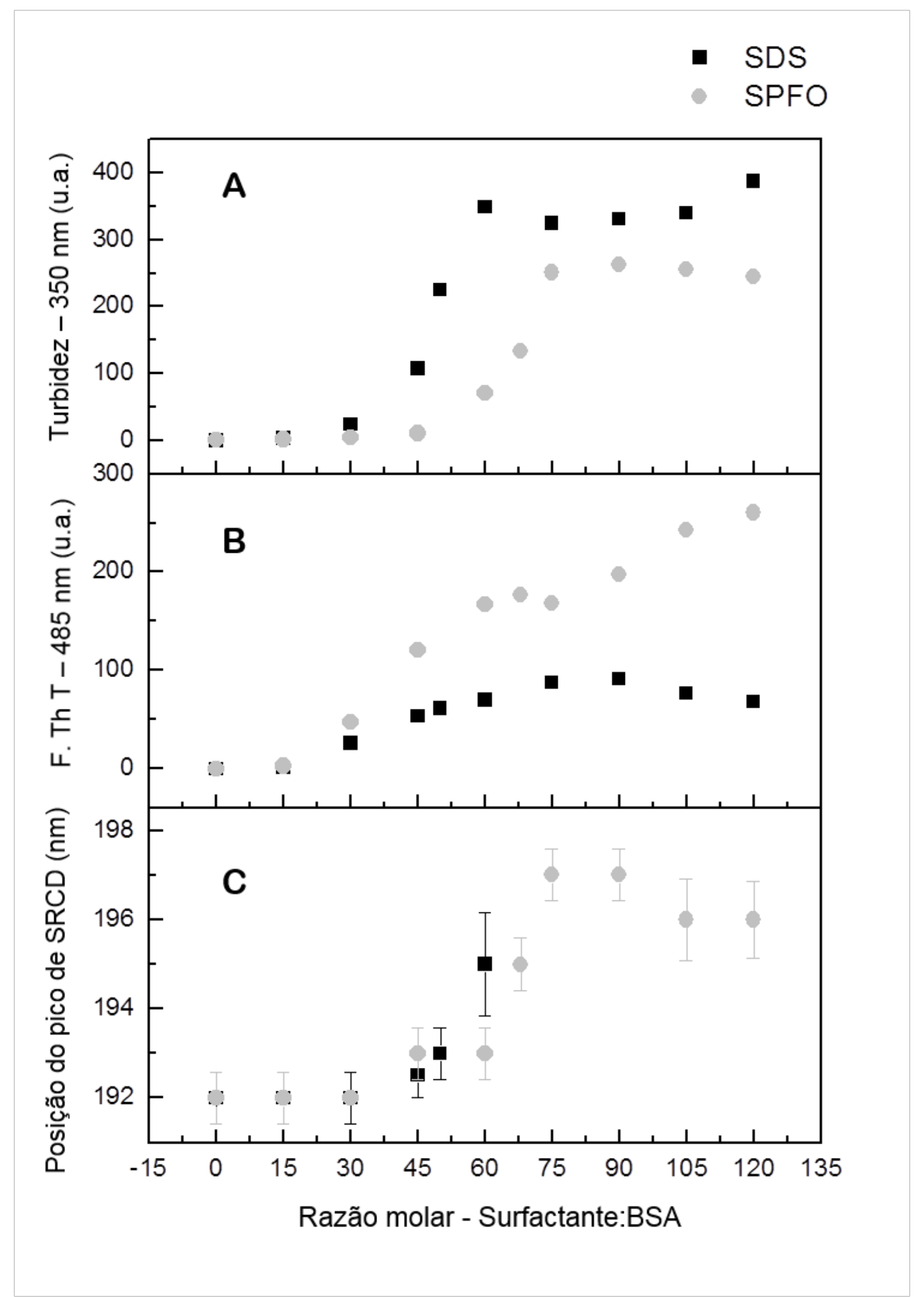

Figura 3.20: Dados de turbidez para $\lambda=350 \mathrm{~nm}$ (A), intensidade de fluorescência de Th T para $\lambda=485 \mathrm{~nm}$ (B) e posição do pico de SRCD (C) para amostras de BSA (1 mg/mL) em pH 3,7 para diferentes razões molares de SDS (quadrados pretos) e SPFO (círculos cinza). Os dados de turbidez e de fluorescência Th T foram normalizados pelo valor da amostra de BSA na ausência de surfactante. 
de induzir a agregação. Por outro lado, demonstrou-se que a BSA em pH 7,0 também não apresenta aumento de turbidez, nem alteração significativa da estrutura secundária na presença de diferentes concentrações de SPFO, indicando que não há a formação de grandes agregados e nem mudanças conformacionais em $\mathrm{pH}$ neutro [64].

Sendo assim, em consonância com os dados relatados na literatura para a interação de BSA com SDS em diferentes pHs [14], e com SPFO em pH 7,0, nossos dados evidenciam que a formação de agregados de BSA induzida pela ligacao de ambos os surfactantes só ocorre quando a proteína está abaixo do seu ponto isoelétrico. Pode-se então sugerir que ligações eletrostáticas desempenham um papel importante no processo de interação do SDS e do SPFO com a BSA, uma vez que a proteína é carregada positivamente em $\mathrm{pH}$ ácido e ambos os surfactantes são carregados negativamente no mesmo pH. Assim, a ligação de ambos surfactantes pode neutralizar as cargas da BSA (+99) para o monômero, neste trabalho e em [75]) permitindo a aproximação das diferentes espécies presentes em solução e/ou promover o desenovelamento da proteína induzindo à exposição de aminoácidos hidrofóbicos. Ambos efeitos podem acarretar no processo de agregação de proteína.

A formação dos agregados devido a ligação com os surfactantes em nossos experimentos pode resultar em oligômeros com estrutura secundária ordenada ou não . Para obter esta informação realizou-se experimentos de fluorescência de Th T e de SRCD da solução de BSA em pH 3,7 em diferentes razões molares de SDS ou SPFO:BSA. Os dados estão apresentados na figura $3.20 \mathrm{~B}$ e C.

Tanto para SDS quanto para SPFO, há um aumento de fluorescência de Th $\mathrm{T}$ em $\lambda=485$ nm com o aumento da razão molar indicando a formação de folhas $\beta$ (fig 3.20 B). A intensidade de fluorescência de Th T aumentou até 250 vezes (SPFO:BSA 120:1) em comparação com a fluorescência da solução de BSA pura. Comparando-se o aumento da fluorescência Th T na presença de SDS e SPFO pode-se observar que SPFO aumentou este parâmetro até 5 vezes mais do que o surfactante hidrogenado (SDS:BSA 120:1), indicando a maior capacidade do SPFO em induzir formação de folhas $\beta$, do que o SDS na BSA.

$\mathrm{O}$ aumento de fluorescência de Th T para a proteína BSA também foi obtido por Holm et al [16] e Bhattacharya et al [15] ao aumentar a temperatura da amostra $\left(65^{\circ} \mathrm{C}-70^{\circ} \mathrm{C}\right) \mathrm{em} \mathrm{pH} \mathrm{7,4} \mathrm{e}$ 3,0 , respectivamente. Nestes casos, não foi observada demora para o aumento de fluorescência de Th T e a intensidade máxima foi observada após 100 minutos de exposição da proteína à alta temperatura. No nosso caso, o aumento de fluorescência aconteceu logo após a adição de surfactante.

Então, tanto nesses trabalhos $[15,16]$ quanto em nossos experimentos, não foi notada a presença do lag phase antes do aumento da intensidade de fluorescência de Th T. Pode-se pensar principalmente em duas hipóteses: o lag phase é muito curto e não foi possível de ser observado ou não há lag phase, o que indicaria que a formação destes agregados ordenados (tipo amilóide) 
da BSA não é explicada pela hipótese de "nucleação" [7, 118] e sim pela hipótese de formação de "protofibras"[7, 119, 120] .

De fato, Holm et al [16] indicaram que o processo de formação destes agregados de BSA não deve ser explicado por "nucleação". Segundo esses autores, se houvesse a formação de um núcleo proteíco para iniciar a agregação de fibras, a diminuição da concentração da proteína diminuiria a velocidade de formação deste núcleo. No entanto, Holm et al. [16] não observaram alteração na velocidade de formação dos agregados tipo amilóide ao variar a concentração da BSA entre 0.5 e $10 \mathrm{mg} / \mathrm{mL}$.

Já o mecanismo de formação de "protofibras" não apresenta o lag phase [16] e tem sido indicado como um caminho possível para a formação da fibra amilóide de alguns polipeptídeos e proteínas [7, 117] como a $\alpha$-sinucleína [7,21]. De qualquer maneira, nossos dados são insuficientes para sugerir um possível caminho (dinâmica) de agregação da BSA induzida por SDS e SPFO e futuros estudos são necessários para investigar tal questão.

Para complementar as análises de fluorescência de Th T, a figura 3.20 C apresenta os resultados obtidos a partir das experiências de SRCD. Como mencionado anteriormente, não foi possível calcular a estrutura secundária para cada uma das amostras, principalmente devido ao espalhamento de luz gerado pela presença de grandes agregados em solução (como avaliado por SAXS, turbidez e DLS). Por isso, realizamos uma análise tendo em conta a posição do pico positivo entre $192 \mathrm{~nm}$ e $198 \mathrm{~nm}$ (fig. 3.7).

A posição do pico de absorção de dicroísmo circular para proteínas varia de $192 \mathrm{~nm}$ (característico de $\alpha$-hélice) para $198 \mathrm{~nm}$ (característico para folha $\beta$ ) em função do aumento da razão molar de ambos os surfactantes, sugerindo a formação de folhas $\beta$ (fig 3.20). Isto está em bom acordo com as análises de fluorescência de Th T. No caso do SDS não foi possível realizar a mesma análise para razões molares superiores a 60:1, devido ao sinal de SRCD ter sofrido uma intensa diminuição causada pelo espalhamento de luz (como avaliado por SAXS, SEM turbidez e DLS).

Vale a pena acrescentar que esta análise da posição do pico só foi possível porque os experimentos foram realizados em uma fonte de radiação sincrotron, onde o fluxo de luz é suficientemente elevado para superar o inconveniente do espalhamento de luz e nos permitiu obter o espectro para comprimentos de onda menores do que $200 \mathrm{~nm}$.

\subsubsection{SDS x SPFO - formação de agregados tipo amilóide da proteína BSA}

Neste trabalho, as simulações computacionais em conjunto com as análises de SAXS indicaram que duas espécies de BSA coexistem em solução a pH 3,7: o monômero parcialmente desenovelado e o dímero. Através de experimentos de SAXS, SEM e turbidez foi possível 
constatar que, com o aumento da concentração de SDS e de SPFO, os monômeros e dímeros presentes em solução sofrem um processo de agregação acarretando na formação de grandes estruturas proteicas. Adicionalmente, caracterizamos que a formação destes agregados está acompanhada de alterações na estrutura secundária da proteína BSA, como observado por fluorescência de Th T e por SRCD, onde foi possível sugerir o aumento da quantidade de folhas $\beta$ formadas em função da concentração do surfactante.

Na presença de SDS, os agregados induzidos são mais desordenados e maiores. Por outro lado, o SPFO induz a formação de estruturas mais ordenadas (tipo fibras amilóides) e menor tamanho. Assim, pode-se analisar as diferenças entre o surfactante hidrogenado e fluorado e sugerir os motivos destas diferenças observadas nos agregados de BSA.

Do ponto de vista eletrostático, ambos os surfactantes são semelhantes devido à presença da mesma carga negativa na cabeça polar [68]. No caso da hidrofobicidade, a energia de adsorção para trazer um grupo $\mathrm{C}_{11} \mathrm{H}_{22}$ (cauda de SDS sem um $\mathrm{CH}_{3}$ ) desde o meio aquoso até a interface ar/água é cerca de $-28,6 \mathrm{kJmol}^{-1}$ (calculado a partir de [67]), enquanto que para um grupo $\mathrm{C}_{6} \mathrm{~F}_{12}$ (cauda do SPFO sem o $\mathrm{CF}_{3}$ ) é de aproximadamente $-30 \mathrm{~kJ} \cdot \mathrm{mol}^{-1}$ (calculado a partir de [67]), indicando que ambos surfactantes possuem uma tendência similar de se ligar à uma superfície polar/apolar (como a proteína) [66]. Assim, a carga elétrica e a hidrofobicidade de ambos os surfactantes são semelhantes e não são suficientes para explicar as diferenças entre os diferentes agregados de BSA complexados com estes surfactantes.

Pode-se então analisar a rigidez do SDS e SPFO. O átomo de flúor é mais eletronegativo do que o hidrogênio [67] e o seu raio de van der Waals é cerca de $25 \%$ maior do que o do hidrogênio [68] acarretando em uma seção transversal de cadeias de $C F$ da ordem de 27-30 $\AA^{2}$ e de 18-21 $\AA^{2}$ no caso de cadeias de $C H[67,68]$. Além disso, o volume de um átomo de flúor é quase $50 \%$ maior do que o átomo de hidrogénio [68] e, consequentemente, as cadeias fluoradas tem maior volume, um grupo $C F_{2}$ e $C F_{3}$ tem o volume de $38 \AA^{3}$ e $92 \AA^{3}$ respectivamente, enquanto que para $\mathrm{CH}_{2}$ e $\mathrm{CH}_{3}$ o volume é de apenas $27 \AA^{3}$ e $54 \AA^{3}$ [67]. Tendo isto em vista, as cadeias de surfactantes fluorados são mais volumosas e mais rigidas do que os hidrogenados [67, 68].

Além disso, a partir dos dados de MD obtidos para a interação do monômero de BSA com 30 e 60 moléculas de SDS ou SPFO pode-se calcular a variação de SASA dos aminoácidos hidrofóbicos e hidrofílicos da proteína BSA. As estruturas atômicas obtidas por MD indicando a distribuição dos surfactantes e os resultados de SASA estão na figura 3.21b. 


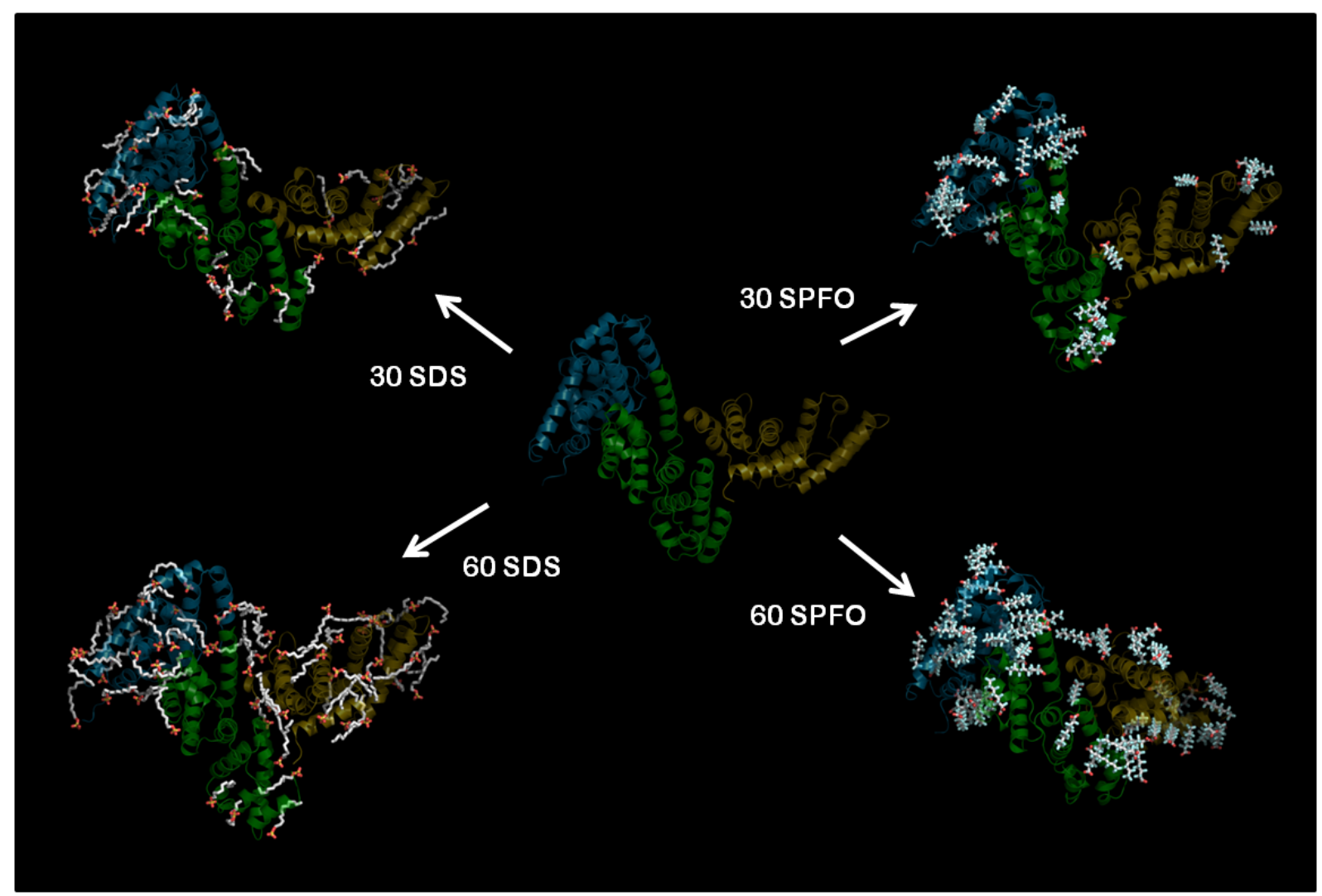

(a)
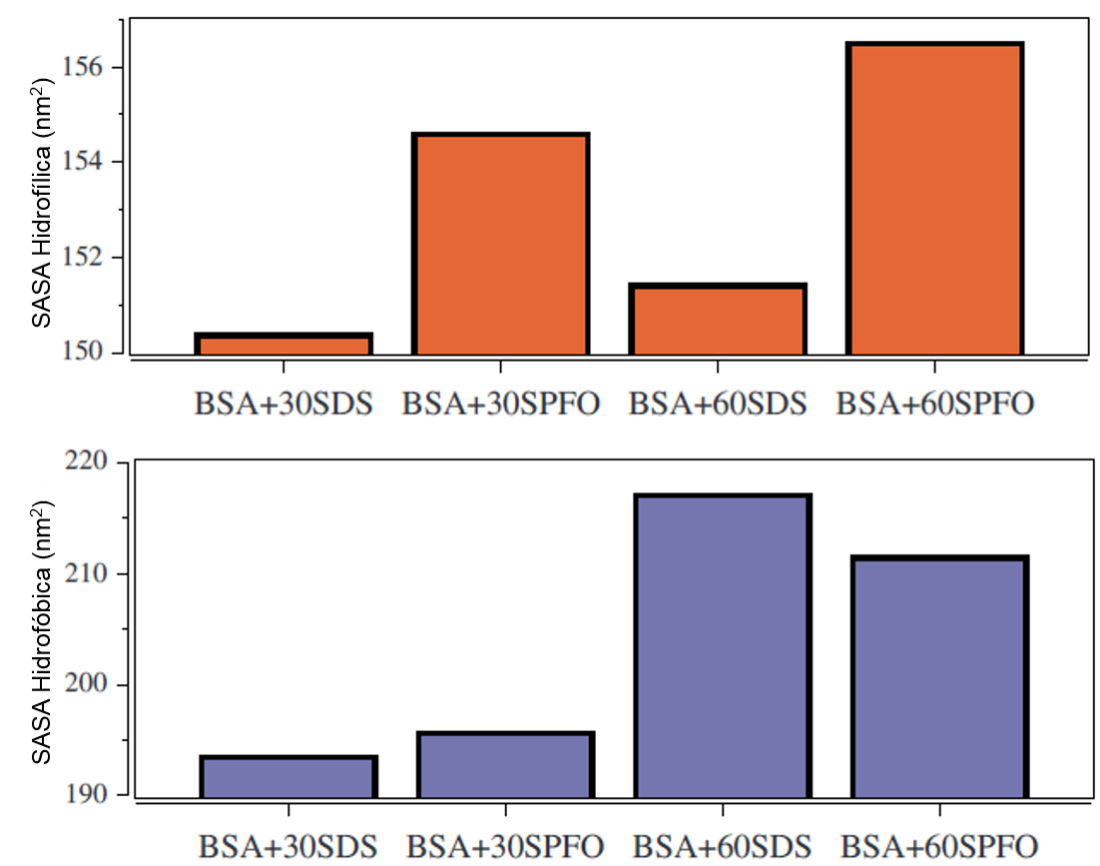

(b)

Figura 3.21: (A) Distribuição dos surfactantes SDS e SPFO (ambos em branco) ligados ao monômero de BSA no pH 3.7 como obtido por MD. (B) SASA hidrofílico e hidrofóbico para o monomêro de BSA obtido por MD na presença de SDS ou SPFO na razão molar de 30:1 e 60:1. O SASA apresentado é o aumento relativo ao mesmo parâmetro para a BSA na ausência de surfactante. 
Pode-se observar que o SPFO (em ambas as razões molares 30:1 e 60:1) se liga de maneira mais organizada à BSA formando regiões bem definidas de ligação, enquanto que o SDS não forma um aglomerado na proteína (fig. 3.21a). Analisando o SASA presente na figura 3.21b, verifica-se que o SPFO induz o maior aumento de SASA hidrofílico para o monômero de BSA do que a adição de SDS, nas mesmas concentrações. Por outro lado, não foram observadas diferenças significativas na SASA hidrofóbico ao se comparar a presença de SPFO e SDS nas mesmas concentrações (fig. 3.21b).

Assim sendo, pode-se sugerir que a exposição dos aminoácidos hidrofílicos ao meio aquoso e (talvez a aglomeração do surfactante) desempenha um papel crucial no processo de formação de agregados menores e mais ordenados (estrutura secundária). Além disso, pode-se sugerir que a interação do SPFO com a proteína BSA em pH 3,7 resulta em uma estrutura mais densa na qual o surfactante mais volumoso e mais rígido restringe os movimentos da proteína induzindo à formação de estruturas mais ordenadas, enquanto que os agregados menos ordenados induzidos pela interação com SDS seriam consequência da maior mobilidade da cadeia alquila do SDS e também de interações mais estocásticas com a proteína (não forma um aglomerado ao se ligar com a BSA). 


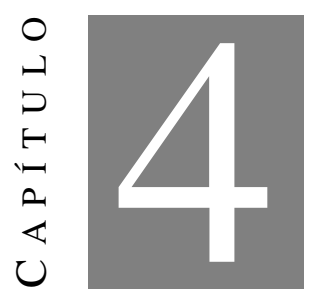

\section{IMPACTO DE LIPÍDEOS OXIDADOS EM BICAMADAS LIPÍDICAS INVESTIGADO POR TÉCNICAS AVANÇADAS DE FLUORESCÊNCIA}

\subsection{Materiais e Métodos}

Para estudar os impactos da presença de lipídeos oxidados em membranas lipídicas, preparou-se vesículas grandes (multilamelares - MLV - e unilamelares - LUV) contendo diferentes proporções dos lipídeos POPC (1-palmitoil-2-oleoil-sn-glicerol-3-fosfocolina) e os oxidados PAZEPC (1-palmitoil-2-azeloil-sn-glicerol-3-fosfocolina) e POVPC (-palmitoil-2-(5oxovaleroil)-sn-glicerol-3-fosforilcolina) adquiridos comercialmente na empresa Avanti Lipids. Também estudamos a influência de POPC hidroperoxidado, $\mathrm{POPC}-\mathrm{OOH}$, produzido em parceria com a doutora Helena C. Junqueira do grupo do Prof. Mauricio S. Baptista, Departamento de Bioquímica, Instituto de Química - USP, São Paulo.

A figura 4.1 apresenta os lipídeos oxidados sendo interessante notar que a cadeia alifática originalmente insaturada do POPC contém os grupos oxidados. Note-se o $\mathrm{OOH}$ no caso do POPC-OOH na posição do carbono 9 ou 10 [37], a carboxila para o PAZEPC e o aldeído para o POVPC. Além disso, as cadeias alquilas oxidadas são encurtadas para PAZEPC e POVPC contendo 9 e 5 carbonos, respectivamente (fig. 4.1). 


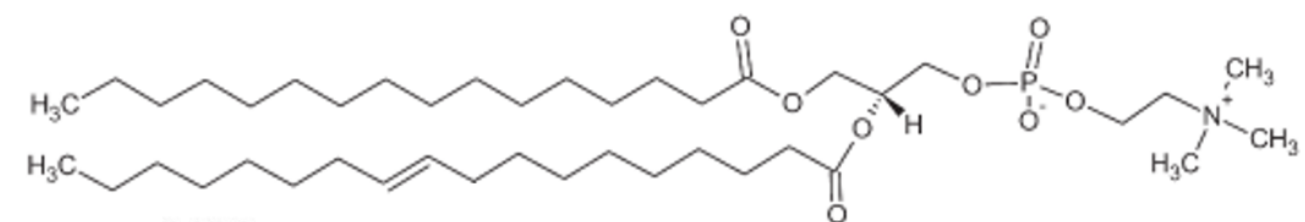

POPC

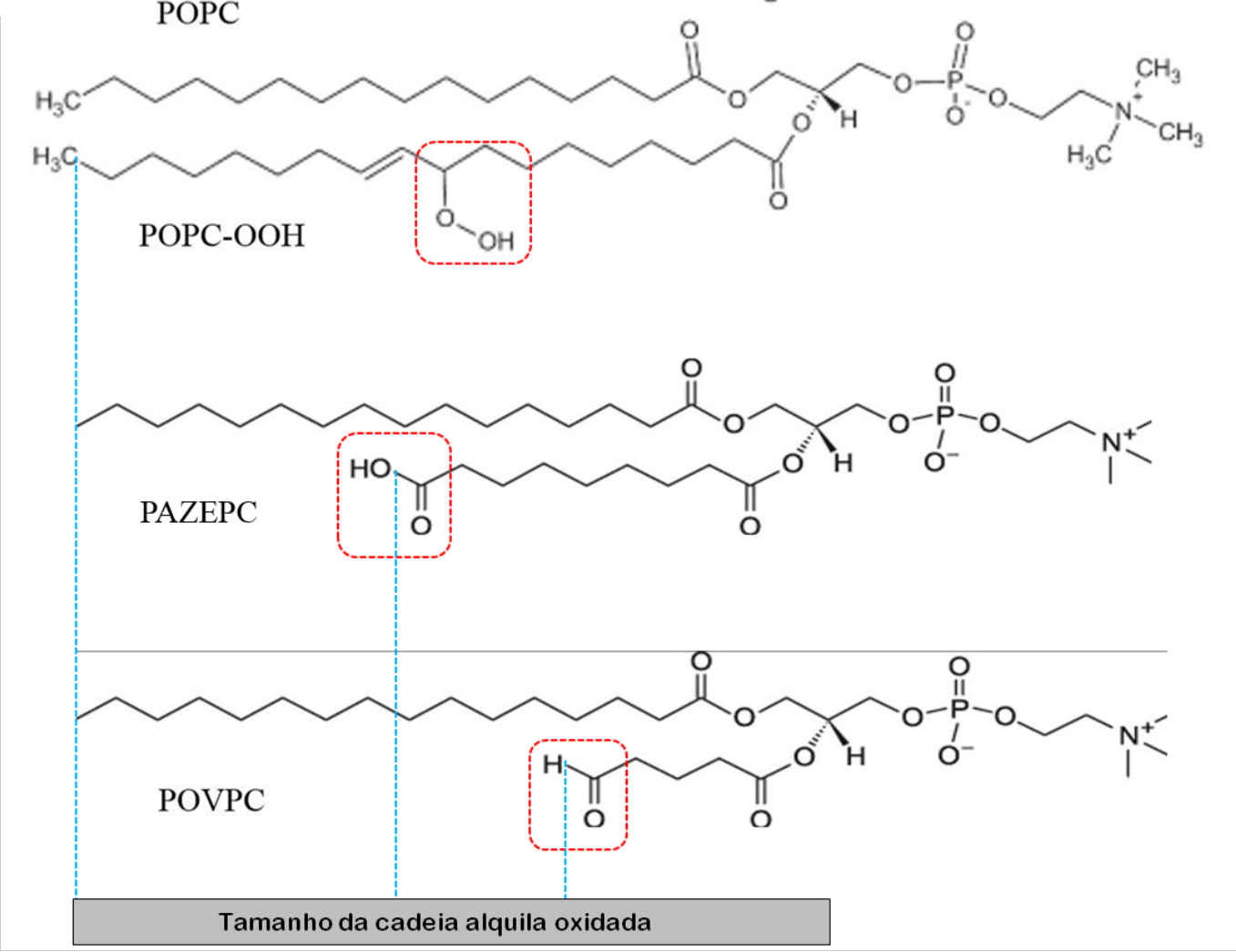

Figura 4.1: Representação esquemática do lipídeo POPC e dos lipídeos oxidados utilizados nos experimentos destacando o tamanho das cadeias alquilas oxidadas.

Para investigar os impactos da presença de lipídeos oxidados em vesículas lipídicas utilizamos as propriedades de fluorescência das sondas TMA-DPH (1-(4-trimetilamôniofenil)-6-fenil1,3,5-hexatrieno p-toluenosulfonato) e laurdan (6-lauroil,1-2-dimetilamino naftaleno). Para isso, realizamos os experimentos de anisotropia no estado estacionário $(<r>-$ TMA-DPH), tempo de vida de fluorescência ( $\tau$ - TMA-DPH), anisotropia resolvida no tempo $(r(t)$ - TMA-DPH), polarização generalizada (Generalized Polarization - GP laurdan) e espectro de fluorescência resolvido no tempo (TRES - laurdan). Estas técnicas serão brevemente descritas nos tópicos seguintes. As duas sondas foram adquiridas na empresa Molecular Probes e diluídas em clorofórmio grau espectroscópico (Merck).

O tampão utilizado em todos os experimentos consistiu numa solução de 10 mM HEPES (Sigma-Aldrich), $150 \mathrm{mM} \mathrm{NaCl}$ (Sigma-Aldrich), 0.2 mM EDTA (Merck) a pH 7.0.

Todas as medidas foram realizadas utilizando cubetas de quartzo de 0,5 $\mathrm{cm} \times 0,5 \mathrm{~cm}$ (Hellma Analytics) com imãs para permitir a agitação da amostra. As medidas foram realizadas 
em triplicatas, repetidas em dias distintos e nas temperaturas de $23^{\circ} \mathrm{C}$ e $37^{\circ} \mathrm{C}$, com controle de temperatura realizado por sistema de circulação de água modelo F25 da empresa Julabo.

A tabela 4.1 apresenta a descrição de todas as medidas experimentais realizadas.

\begin{tabular}{|c|c|c|c|c|c|c|}
\hline \multirow{2}{*}{$\begin{array}{l}\mathrm{T}=23 \text { e } 37^{\circ} \mathrm{C} \\
\text { Composição Lipídica }\end{array}$} & \multirow[b]{2}{*}{ Razão molar } & \multicolumn{3}{|c|}{ TMA-DPH } & \multicolumn{2}{|c|}{ laurdan } \\
\hline & & $<r>$ & $<\tau>$ & $r(t)$ & GP & TRES \\
\hline \multirow[t]{7}{*}{ POPC:POPC-OOH } & 100:0 & 6 & 3 & 3 & 3 & 2 \\
\hline & $90: 10$ & 3 & 2 & 3 & 2 & - \\
\hline & $75: 25$ & 3 & 2 & 3 & 2 & - \\
\hline & $70: 30$ & 6 & 3 & 3 & 3 & - \\
\hline & $50: 50$ & 6 & 4 & 3 & 3 & - \\
\hline & $30: 70$ & 6 & 3 & 3 & 3 & - \\
\hline & $0: 100$ & 6 & 4 & 3 & 3 & 2 \\
\hline \multirow[t]{2}{*}{ POPC:PAZEPC } & $90: 10$ & 3 & 2 & 2 & 3 & - \\
\hline & $75: 25$ & 3 & 2 & 2 & 3 & $1 * \$$ \\
\hline \multirow[t]{2}{*}{ POPC:POVPC } & $90: 10$ & 3 & 2 & 2 & 3 & - \\
\hline & $75: 25$ & 3 & 2 & 2 & 3 & $1^{\$}$ \\
\hline
\end{tabular}

Tabela 4.1: Síntese das medidas experimentais apresentadas neste capítulo: os números indicam em quantos dias as medidas foram repetidas. Em todos os experimentos foram utilizados MLVs, exceto para TRES, onde utilizou-se LUVs. Todos os experimentos foram realizados a 23 e $37^{\circ} \mathrm{C}$. *A composição lipídica utilizada foi POPC:PAZEPC 70:30. ${ }^{\$}$ Os experimentos foram realizados apenas a $23{ }^{\circ} \mathrm{C}$.

\subsubsection{Preparo de lipossomos}

Para a preparação das vesículas grandes (LUVs e MLVs) foram utilizadas alíquotas das soluções estoques de lipídeos em clorofórmio espectroscópico para obter uma solução final com a composição lipídica desejada (diferentes composições, tabela 4.1 - solução 1). Em seguida, gás nitrogênio comprimido foi utilizado para purgar as soluções até a obtenção de um filme lipídico na parede do tubo de ensaio (vidro). Na sequência, o tubo foi colocado no dessecador (4 horas) ligado à bomba de vácuo para garantir a completa evaporação do clorofórmio. Adicionou-se então o volume de tampão necessário para obter a concentração lipídica de $100 \mu \mathrm{M}$ (exceto no caso do TRES) realizando repetidas agitações para a solubilização do filme lipídico, seguida por 30 minutos em repouso. Na sequência, a suspensão de vesículas foi colocada por 30 segundos em nitrogênio líquido e por 2 minutos e 30 segundos em um banho de água à $50^{\circ} \mathrm{C}$. Esse ciclo foi repetido 10 vezes. Por fim a suspensão de vesículas ficou em repouso por mais 30 minutos.

As sondas fluorescentes TMA-DPH e laurdan foram diluídas em clorofórmio espectroscópico e adicionadas à suspensão de lipídeos no mesmo solvente (solução 1). A razão molar lipídeo:sonda foi de 200:1 e de 100:1 para o TMA-DPH e para o laurdan, respectivamente. 
É importante acrescentar que nos experimentos de TRES a mesma amostra é excitada por um longo período para se obter a curva de decaimento de fluorescência da sonda laurdan em diversos comprimentos de onda (item 4.1.6.1). Por isso a concentração lipídica utilizada nesta técnica experimental foi mais alta $(500 \mu \mathrm{M})$ e, consequentemente, o número de moléculas fluorescentes (laurdan) também. Assim, foi possível evitar o fotobranqueamento da sonda. Entretanto, o aumento da concentração de MLVs favorece o espalhamento de luz. Para compensar este efeito, as vesículas foram extrusadas (Avanti Mini Extruder) por um membrana com poro de $0,1 \mu \mathrm{m}$ nos experimentos de TRES.

\subsubsection{TMA-DPH}

A sonda TMA-DPH (fig. 4.2) possui a massa molecular de $461.62 \mathrm{~g} / \mathrm{mol}$ e foi sintetizada como um derivado da molécula DPH (1,6-difenil-1,3,5- hexatrieno) com a adição do grupo catiônico trimetilamônio [121]. Com isso, as características espectroscópicas do TMA-DPH são muito semelhantes à do DPH.

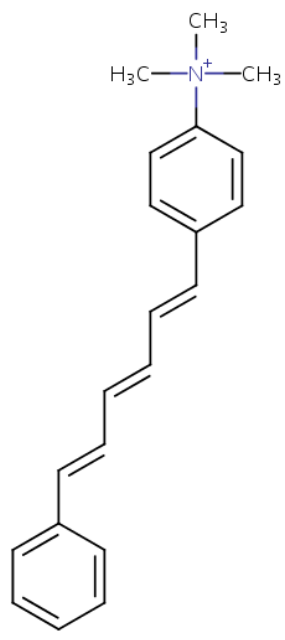

Figura 4.2: Estrutura molecular do TMA-DPH

A introdução do grupo catiônico garante o caratér hidrofílico ao TMA-DPH permitindo que a sonda se localize próxima a região da interface membrana/água [121] (enquanto o DPH se encontra mais inserido na região central da membrana). Simulações de dinâmica molecular mostraram que o centro de massa da molécula do TMA-DPH se encontra a cerca de $11 \AA$ do centro da bicamada lipídica composta por DOPC [122] ou POPC [123].

Assim sendo, o TMA-DPH é amplamente utilizado como um réporter do empacotamento de membrana na região do glicerol e da parte superior das cadeias alifáticas dos lipídeos [122].

Neste trabalho, utilizamos as características da sonda TMA-DPH, as análises de intensidade de fluorescência resolvida no tempo (item 4.1.4.2), anisotropia de fluorescência do estado estaci- 
onário (item 4.1.4.3) e anisotropia de fluorescência resolvida no tempo (item 4.1.4.4) para obter dados sobre a hidratação e empacotamento de membranas contendo diferentes concentrações de lípidos oxidados.

Para excitar e medir a fluorescência da sonda, utilizou-se $\lambda_{e x}=340 \mathrm{~nm}$ e $\lambda_{e m}=430 \mathrm{~nm}$. Para as análises de anisotropia resolvida no tempo utilizou-se o valor de anisotropia intrínseca $r_{0}$ $=0,39$ [124] e volume efetivo $V_{e f}=360 \AA^{3}$ [124] (item 4.1.4.4). A concentração da solução de TMA-DPH foi determinada utilizando a absorção de luz para o $\lambda=364$ com o coeficiente de extinção molar $\epsilon=52000 \mathrm{M}^{-1} \mathrm{~cm}^{-1}$ em clorofórmio [124].

\subsubsection{Laurdan e Polarização Generalizada (GP)}

Com o objetivo de determinar as mudanças de rigidez/empacotamento das membranas lipídica, bem como a hidratação da interface (relaxação dielétrica) se utilizou as propriedades espectrais da molécula fluorescente laurdan - massa molecular $=353,54 \mathrm{~g} / \mathrm{mol}$ [125].

O laurdan é composto por um grupo naftaleno ligado a uma longa cadeia carbônica $\left(\mathrm{C}_{12}\right)$ conferindo hidrofobicidade à molécula (fig. 4.3) [126]. Em consequência a esta característica o laurdan se insere na membrana lipídica alinhando sua cadeia de hidrocarboneto com as dos lipídeos, distribuindo-se homogeneamente em toda a membrana, sem preferência específica por fases [126].

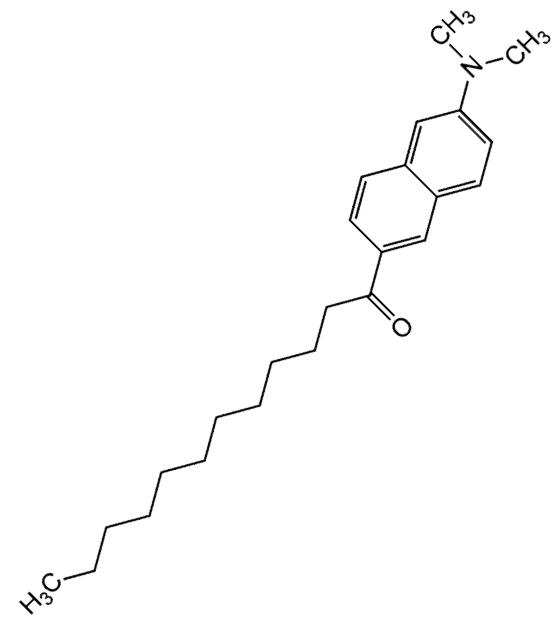

Figura 4.3: Estrutura molecular do laurdan

O naftaleno, que é responsável pela fluorescência do Laurdan, fica próximo aos grupos polares dos lipídeos e pode ficar mais exposto ao solvente ou mais inserido na membrana dependendo do empacotamento lateral dos lipídeos [126].

Ao interagir com o solvente, o naftaleno pode reorientar os dipolos do solvente, conduzindo a um estado estabilizado de menor energia, perdendo energia o que causa um redshift na emissão 
de fluorescência do estado estacionário do Laurdan de $\lambda=440 \mathrm{~nm}$ para $\lambda=490 \mathrm{~nm}$ [125-127]. O espectro de emissão do laurdan é, portanto, sensível ao microambiente (solvatocromia) onde está inserido e pode ser utilizado como um marcador de hidratação e rigidez/empacotamento da membrana. Para quantificar essa mudança na emissão de fluorescência do Laurdan, mede-se o espectro de fluorescência do estado estacionário (item 4.1.4.1) e se utiliza as intensidades em $\lambda=$ $440 \mathrm{~nm}\left(I_{440}\right)$ e em $\lambda=490 \mathrm{~nm}\left(I_{490}\right)$ para calcular a grandeza polarização generalizada $(\mathrm{GP}$ generalized polarization) tal que [127]:

$$
G P=\frac{I_{440}-I_{490}}{I_{440}+I_{490}}
$$

O espectro de emissão da sonda fluorescente laurdan foi medido entre $\lambda_{\mathrm{em}} 390 \mathrm{~nm}$ e 550 $\mathrm{nm}$, utilizando o comprimento de onda de excitação $\lambda_{\mathrm{ex}}=350 \mathrm{~nm}$. A concentração da solução de laurdan foi determinada utilizando a absorção de luz para o $\lambda=360 \mathrm{~nm} \operatorname{com}$ o $\epsilon=19500 \mathrm{M}^{-1}$ $\mathrm{cm}^{-1}$, em clorofórmio [128].

É importante acrescentar que experimentos de fluorescência do laurdan em membranas lipídicas podem ser complexos e diferentes interações podem influenciar na emissão de fluorescência da sonda e, portanto, no valor de GP [129, 130]. Por exemplo, é possível que a membrana lipídica esteja mais fluída (os dipolos do solvente se reorientem mais rápido), mas que o grau de solvatação diminua (por exemplo, menor quantidade de água - dipolos - que interage com a sonda) [129]. O primeiro processo contribui para um redshift (diminuindo a GP) enquanto o segundo contribui para um blueshift (aumentando a GP). Logo, dependendo da contribuição de cada um desses efeitos o valor do GP pode aumentar, diminuir ou permanecer inalterado [129].

Portanto, é importante separar os efeitos de velocidade de reorientação de dipolo do solvente e a "quantidade de dipolos"que interagem com o dipolo do laurdan para melhor intepretar o valor do GP e obter informações qualitativas e quantitativas sobre as membranas lipídicas. Com este intuito, utilizou-se a técnica avançada de fluorescência resolvida no tempo (TRES) - item 4.1.6. Cabe acrescentar que, durante o doutoramento, o aluno realizou um estágio no Centro de Química-Física Molecular do Instituto Superior Técnico da Universidade de Lisboa, sob a orientação do Prof. Dr. Manuel Prieto, onde desenvolveu rotinas computacionais e implementou a técnica de TRES no laboratório, em Portugal.

\subsubsection{Fluorescência I - Teoria}

Em geral, pode-se descrever o fenômeno de absorção e emissão de luz (fluorescência) através do diagrama de Jablonski (fig. 4.4). Os estados singletos estão indicados como $\mathrm{S}_{0}$ (fundamental), $\mathrm{S}_{1}$ (primeiro estado excitado) e $\mathrm{S}_{2}$ (segundo estado excitado), com diferentes estados vibracionais de energia, indicados de 0-5 em cada estado eletrônico. 
Os fenômenos descritos aqui podem acontecer para átomos ou moléculas, sendo que neste trabalho utilizamos moléculas fluorescentes denominadas sondas ou fluoróforos.

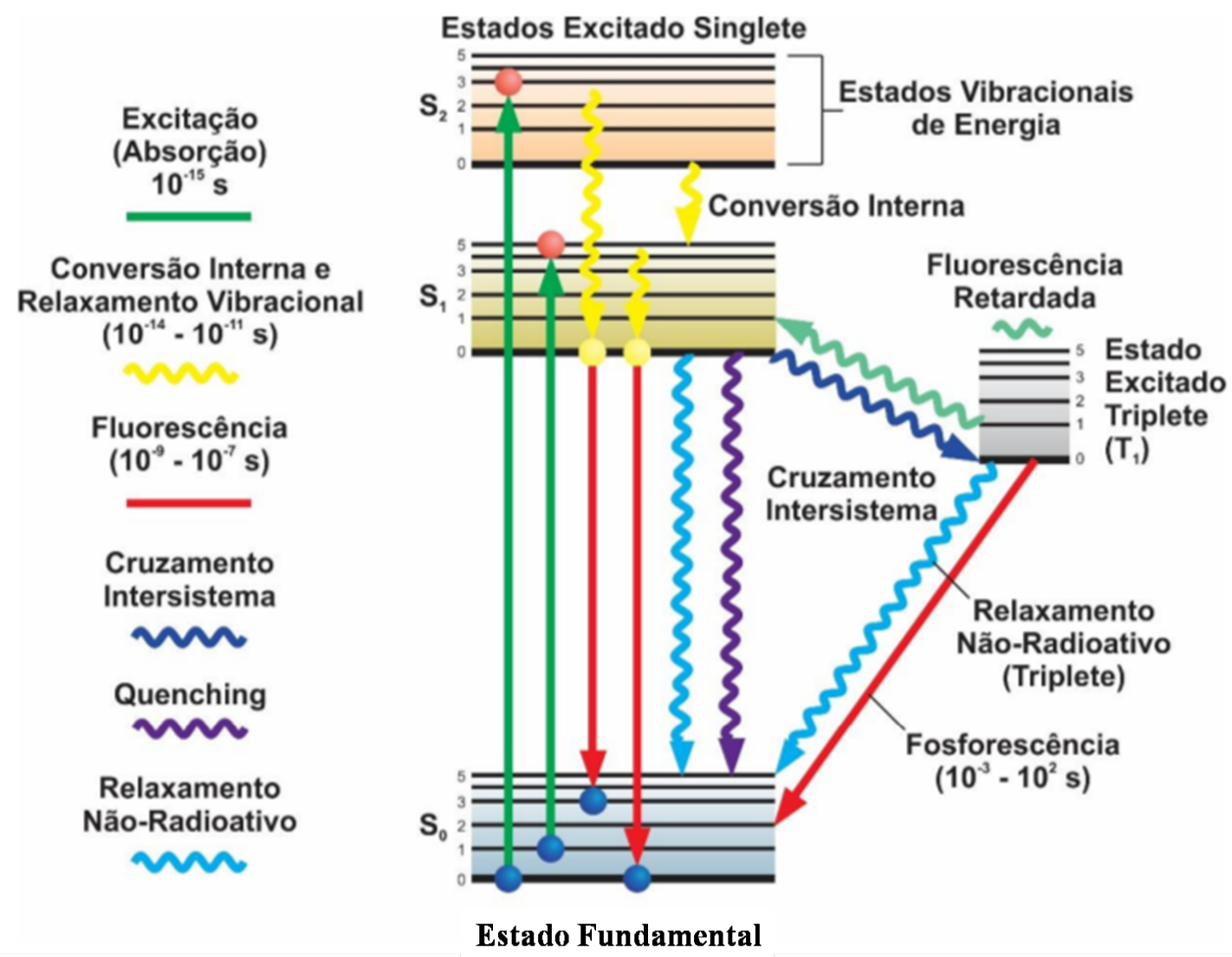

Figura 4.4: Diagrama de Jablonski. Adaptado de [131].

As linhas verdes indicam o processo de transição eletrônica e de estado vibracional devido à absorção de um fóton. Este processo ocorre na ordem de $10^{-15} \mathrm{~s}$ sendo possível assumir que o núcleo atômico permanece estático, pois possui maior inércia do que os elétrons (Princípio de Franck-Condon) [132]. Por isso, os núcleos não se reorganizam durante a absorção do fóton, mas realizam a organização após a nova configuração eletrônica ter sido atingida, dando origem aos efeitos de conversão interna e relaxamento vibracional (linhas amarelas Fig. 4.4). Estes dois processos acontecem na ordem de $10^{-14}-10^{-11} \mathrm{~s}$ nos quais o fluoróforo decai para o estado excitado de menor energia $\left(S_{1}\right)$ e de menor nível vibracional $(0)$. A fluorescência ocorre na escala de tempo de $10^{-9} \mathrm{~s}$, tal que a molécula possui tempo o suficiente para atingir $\mathrm{S}_{1}-0$, estado da qual o sistema irá retornar para o estado fundamental emitindo um fóton (linhas vermelhas Fig. 4.4). Este tempo (médio) em que o fluoróforo permanece no estado excitado antes de retornar para o estado fundamental, é chamado de tempo de vida de fluorescência e será melhor detalhado no item 4.1.4.2.

É importante ressaltar aqui que também é possível que o spin eletrônico total no estado singlete $S_{1}$ seja convertido para um estado triplete, $T_{1}$, e depois de $10^{-3}-10^{2}$ s o elétron retorne para o estado fundamental emitindo um fóton (fosforescência). Essa conversão do estado singlete 
para o triplete é chamada de cruzamento intersistema (linha azul escura Fig. 4.4) e não foi objeto de estudo nesta tese.

Durante a etapa de conversão interna, a molécula perde energia por vibrações (efeitos térmicos) tal que a emissão de um fóton terá menor energia do que a do fóton absorvido (shift de Stokes) [132]. O shift de Stokes pode ser afetado por vários processos, como a interação da molécula com o solvente. É importante ressaltar que o shift de Stokes não acontece quando a excitação é realizada utlizando a técnica de absorção de dois-fótons.

Como mencionado anteriormente, estados excitados de maior energia são convertidos para o $\mathrm{S}_{1}-0$ antes de retornarem para o estado fundamental. Portanto, em geral, a energia do fóton emitido por uma molécula independe da energia do fóton absorvido (Lei de Kasha) [132]. Ou seja, o fóton emitido por fluorescência independe do comprimento de onda de excitação. Por outro lado, o sistema em $\mathrm{S}_{1}-0$ pode retornar para diferentes níveis vibracionais do estado fundamental possuindo, para cada uma dessas transições uma energia característica (comprimento de onda característico) dando origem ao espectro de fluorescência das moléculas.

Note-se que é possível que o elétron retorne para o estado fundamental por processos não radiativos (linha azul claro Fig. 4.4) e também que exista uma molécula que entre em contato com o fluoróforo impedindo a emissão de fluorescência (supressão da fluorescência - quenching).

Existem diversos processos que podem levar à supressão da fluorescência, sendo os dois principais: o quenching dinâmico - quando o fluoróforo, ao colidir com uma molécula (quencher), retorna para o estado fundamental e o lquenching estático - quando o fluoróforo se liga ao quencher formando um novo complexo que não emite fluorescência. Além disso, o quenching dinâmico pode acontecer por diversos mecanismos, dependendo do fluoróforo e do quencher, podendo acontecer por transferência de elétrons do fluoróforo para o quencher, por acoplamento spin-órbita ou por indução de cruzamento intersistema [132].

\subsubsection{Fluorescência do estado estacionário}

A fluorescência observada no estado estacionário é o resultado da contribuição de todas as emissões decorrentes das transições do estado $S_{1}$ para o $S_{0}$. Explicitamente, a intensidade de fluorescência do estado estacionário $\left(I_{S S}\right)$ é dada por [132]:

$$
I_{S S}=\int_{0}^{\infty} I_{0}\left(\sum e^{-t / \tau}\right) d t
$$

onde $I_{0}$ é a intensidade de fluorescência para $\mathrm{t}=0$, e $\tau$ é uma descrição experimental do tempo de vida médio de fluorescência (explicado abaixo). A intensidade de fluorescência do estado estacionário é medida na escala de décimos de microsegundos, o que garante que as transições de $S_{1}$ para o $S_{0}$ já tenham ocorrido ( ns - fig 4.4).

\section{Características de um espectrofluorímetro e correção espectral}


Em medidas de fluorescência do estado estacionário, utiliza-se uma fonte de luz policromática seguida por um monocromador (grade de difração, por exemplo) para selecionar apenas um comprimento de onda de excitação para incidir na amostra. Com um ângulo de $90^{\circ} \mathrm{em}$ relação ao feixe incidente, os fótons emitidos por fluorescência, passam por um monocromador até serem coletados para uma fotomultiplicadora.

Componentes importantes para um espectrofluorímetro são também as fendas de excitação e emissão, que estão posicionadas antes e depois da amostra, respectivamente. Estas fendas impactam na intensidade de fluorescência que será obtida, pois o tamanho da abertura da fenda de excitação é proporcional à quantidade de fluóroforos que serão excitados e a de emissão é proporcional à intensidade de fluorescência que poderá chegar até a fotomultiplicadora.

Além disso, o tamanho da fenda de emissão impacta na resolução espectral: quanto maior a abertura da fenda maior será a contribuição de fluorescência originária de comprimentos de onda adjacentes ao valor de $\lambda$ nominal.

De maneira interessante, a fenda de excitação não possui o mesmo efeito, pois como visto anteriormente, o espectro de emissão não depende do comprimento de onda de excitação, ou seja, mesmo que o fluoróforo seja excitado pelo $\lambda$ nominal e adjacentes, a fluorescência será a mesma (haverá apenas variação na intensidade de fluorescência).

Ainda, tendo em vista o impacto dos componentes de um fluorímetro no espectro de fluorescência é essencial acrescentar que os mesmos não se comportam como componentes ideais: a fonte de luz não possui a mesma intensidade de luz para todos os comprimentos de onda, o monocromador não difrata com a mesma eficiência diferentes $\lambda$ e a fotomultiplicadora não é igualmente sensível para todo o espectro. Sendo assim, os espectros de fluorescência medidos experimentalmente são distorcidos, o que impossibilita as comparações diretas entre intensidades de diferentes comprimentos de onda e entre os espectros medidos em outros equipamentos.

Para solucionar este problema é necessário calcular o fator de correção espectral para cada comprimento de onda no intervalo de interesse. Isto é feito utilizando o rendimento quântico $(Q)$ de um fluoróforo padrão, que é a razão entre o número de fótons emitidos e os fótons absorvidos, sendo também expresso pela relação cinética [132]:

$$
Q=\frac{\Gamma}{\Gamma+\kappa_{\mathrm{nr}}}
$$

onde $\Gamma$ é a taxa de decaimento do estado excitado por emissão de fluorescência e $\kappa_{\mathrm{nr}}$ é a taxa de decaimento do estado excitado por processos não radiativos.

Neste trabalho, utilizamos o sulfato de quinino como padrão para calcular o fator de correção para os comprimentos de onda entre 400 e $600 \mathrm{~nm}$. 


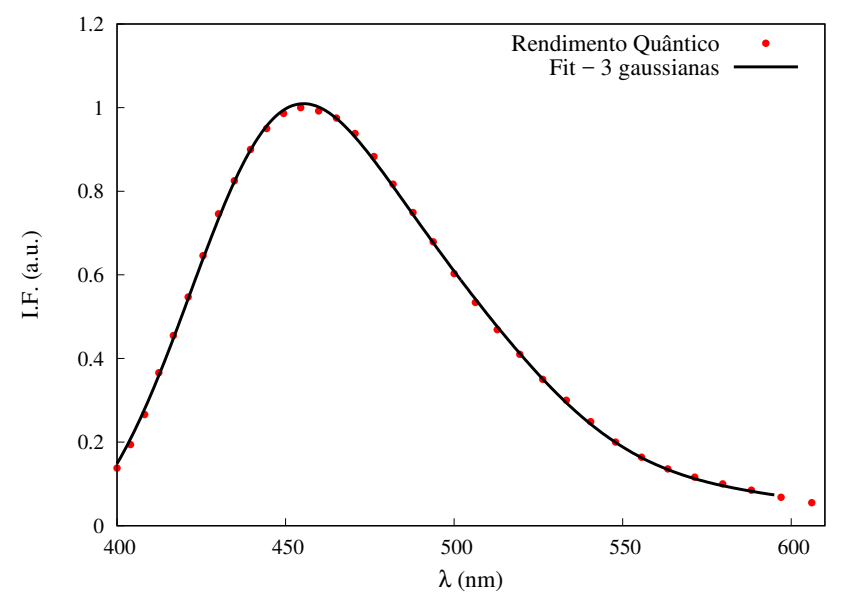

(a)

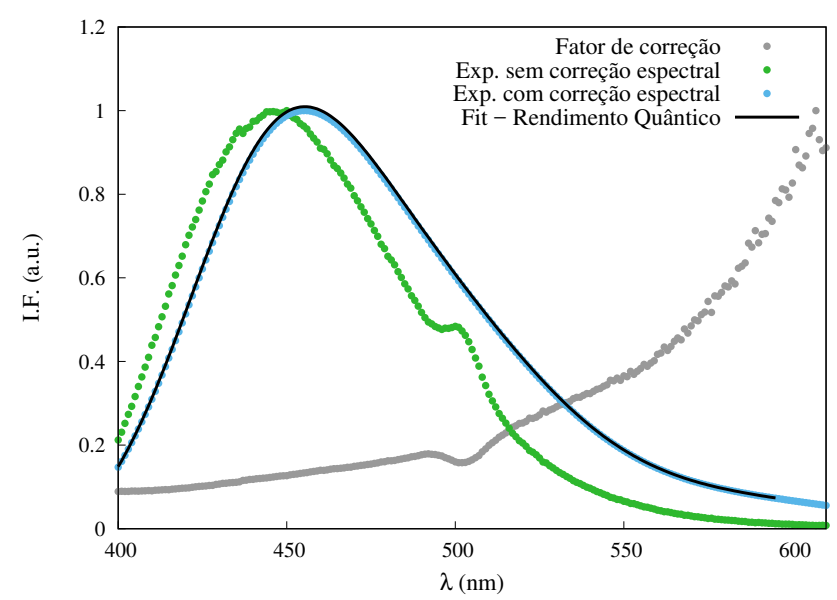

(b)

Figura 4.5: (a) Intensidade de fluorescência normalizada para os dados de rendimento quântico

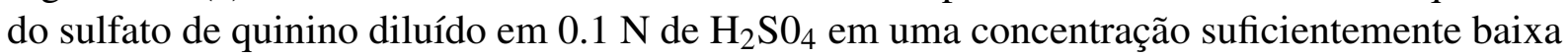
para evitar efeito de filtro interno a $23^{\circ} \mathrm{C}$ (pontos vermelhos) obtidos na referência [132]. A linha preta apresenta o ajuste utilizando a soma de 3 curvas gaussianas. (b) Curva experimental

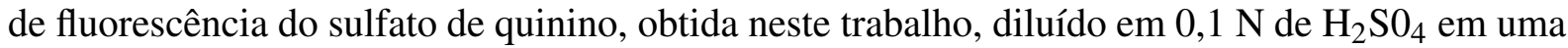
concentração suficientemente baixa para evitar efeito de filtro interno à $23^{\circ} \mathrm{C}$ (pontos verdes), após a correção espectral (pontos azuis), o valor do fator de correção para cada comprimento de onda (pontos cinza) e o ajuste utilizando a soma de 3 curvas gaussianas apresentado no gráfico (a) para comparação. As curvas estão normalizadas.

A figura 4.5a apresenta a intensidade de fluorescência do quinino para os comprimentos de onda disponíveis na literatura [132]. Para obter os valores de rendimento quântico para quaisquer comprimentos de onda é necessário realizar o ajuste de um função contínua aos dados discretos. Este ajuste foi feito através de uma função dada pela soma de 3 funções gaussianas, onde foi possível obter uma boa concordância entre a função e os dados de intensidade de fluorescência na fig 4.5a (linha preta). É importante notar que o ajuste não possui nenhum sentido físico, apenas descritivo.

Então, mediu-se a curva experimental de fluorescência do quinino (fig. 4.5b - roxo) dissolvido em $0,1 \mathrm{~N} \mathrm{H}_{2} \mathrm{SO}_{4}$ à temperatura de $23^{\circ} \mathrm{C}$. A concentração do quinino deve ser baixa o suficiente para evitar efeitos de filtro interno. Essa concentração depende do tamanho do caminho ótico, como descrito pela lei de Beer-Lambert:

$$
A=\epsilon c l
$$

onde A é o valor da absorção, $\varepsilon$ é o coeficiente de extinção molar, c é a concentração e 1 é o tamanho do caminho ótico dentro da amostra. Sendo assim, a condição necessária para evitar o filtro interno depende de c e de le é obtida quando o valor de A é menor do que 0.05 para o comprimento de onda de absorção máximo do sulfato de quinino: $\lambda_{\text {abs }}=347 \mathrm{~nm}$ [132]. 
Como mostrado na figura $4.5 \mathrm{~b}$, a curva experimental do quinino obtida neste trabalho (pontos verdes) é muito diferente da curva esperada para os dados de intensidade corrigida (linha preta). Além disso, é possível observar um pequeno pico para $\lambda \sim 500 \mathrm{~nm}$ devido ao aparato experimental. Então, para obter a correção espectral, utiliza-se a seguinte equação:

$$
F(\lambda)=\frac{I_{r q}(\lambda)}{I_{S S}(\lambda)}
$$

onde $F(\lambda)$ é o fator de correção para cada comprimento de onda (fig. 4.5b - pontos cinza, normalizado), $I_{r q}(\lambda)$ é a função contínua dos dados de intensidade de emissão (fig. 4.5b - linha preta) e $I_{S S}(\lambda)$ é a curva experimental (fig. $4.5 \mathrm{~b}$ - pontos verdes). Portanto, ao multiplicar $I_{S S}(\lambda)$ por $F(\lambda)$ obtém-se o espectro experimental corrigido, que está indicado pelos pontos azuis na fig. 4.5b. Evidentemente, o espectro experimental corrigido é igual ao espectro corrigido publicado (4.5b - pontos azuis e linha preta).

Com o valor de $F(\lambda)$ foi possível corrigir todos os espectros de fluorescência medidos neste trabalho e assim comparar as intensidades de fluorescência entre diferentes comprimentos de onda e entre valores de trabalhos da literatura.

\subsubsection{Intensidade de fluorescência resolvida no tempo}

Como mencionado anteriormente, o tempo médio que um fluoróforo permanece no estado excitado antes de retornar para o estado fundamental e emitir um fóton de fluorescência é chamado de tempo de vida de fluorescência $(\tau)$ e pode ser descrito como [132]:

$$
\tau=\frac{1}{\Gamma+\kappa_{\mathrm{nr}}}
$$

É importante ressaltar que a emissão de fluorescência é um processo aleatório e qualquer molécula no estado excitado possui a mesma probalidade de retornar para o estado fundamental emitindo um fóton em um certo intervalo de tempo. Apenas uma pequena população emite fótons no tempo igual ao $\tau$.

A taxa de desexcitação das populações do estado excitado para o estado fundamental é dada pela seguinte equação [132]:

$$
\frac{d n(t)}{d t}=\left(\Gamma+\kappa_{\mathrm{nr}}\right) n(t)
$$

onde $\mathrm{n}(\mathrm{t})$ é o número de moléculas no estado excitado em um tempo $t$. A solução dessa equação é dada por (e usando eq. 4.7):

$$
n(t)=n_{0} e^{-t / \tau}
$$


onde $n_{0}$ é o número de moléculas no estado excitado no tempo inicial. Entretanto, ao invés de medir o número de moléculas, mede-se a intensidade de fluorescência $I(t)$ que é proporcional ao número de moléculas. De maneira análoga, a equação que descreve o decaimento da intensidade de fluorescência em função do tempo pode ser descrita como:

$$
I(t)=I_{0} e^{-\mathrm{t} / \tau}
$$

onde $\mathrm{I}_{0}$ é a intensidade de fluorescência no tempo $t=0$.

Em geral, as curvas de decaimento de intensidade de fluorescência são complexas e apresentam mais de um $\tau$. Sendo assim, as medidas experimentais são interpretadas como a soma de diferentes tempos de vida:

$$
I(t)=I_{0} \sum_{i=1}^{j} \alpha_{i} e^{-t / \tau_{i}}
$$

onde $\alpha_{i}$ é um parametro de ajuste com $\sum_{i=1}^{j} \alpha_{i}=1$ e pode-se normalizar $I_{0}=1$. Por isso, experimentalmente, o tempo de vida de fluorescência é obtido como a média ponderada de cada um destes $\tau_{i}$ :

$$
<\tau>=\frac{\int_{0}^{\infty} t I(t) d t}{\int_{0}^{\infty} I(t) d t}=\frac{\sum \alpha_{i} \tau_{i}^{2}}{\sum \alpha_{i} \tau_{i}}
$$

Para realizar medidas experimentais do tempo de fluorescência, pode-se utilizar o método de domínio do tempo ou do domínio da frequencia. Neste trabalho, utilizamos o domínio do tempo, mais especificamente o método de correlação temporal para contagem de fótons únicos (TCSPC) [132].

\section{Aparato experimental e modelo para análise}

TCSPC utiliza uma fonte de luz pulsada (laser, por exemplo) na ordem de picosegundos ou femtosegundos para excitar a amostra, sendo necessário que a largura do pulso seja menor do que o tempo de decaimento do fluoróforo. Isto para permitir que o detector (fotomultiplicadora) de alta velocidade consiga medir a fluorescência após a luz de excitação ter sido apagada. Este processo acontece milhares de vezes para a aquisição de uma curva de decaimento.

A detectação de alta velocidade permite a aquisição de um único fóton para cada pulso de excitação do laser, sendo observado o tempo entre a excitação e a detectação de um fóton (lag). Então, o número de fótons detectados para cada lag é contabilizado para a construção de um histograma de quantidade de fótons em função do lag. Este histograma é a curva de decaimento de fluorescência. 
Um aspecto essencial para as medidas de TCSPC é a interferência da largura do pulso do laser na curva de decaimento de fluorescência. Isto acontece pois, infelizmente, o pulso não é uma função $\delta$ de Dirac, mas é similar a uma gaussiana, e excita o fluoróforo ao longo do tempo de duração do pulso. Isso significa que existem fluoróforos que são excitados desde o início do pulso do laser $\mathrm{t}=0$ até $\mathrm{t}=\mathrm{t}_{1}$, onde o pulso termina. Assim, durante o pulso do laser já existem fluoróforos no processo de decaimento de fluorescência e outros que ainda serão excitados, resultando em um curva de decaimento de fluorescência "contaminada" por diferentes tempos de excitação. Além disso, a quantidade de fluoróforos que são excitados em um tempo $t$ é proporcional à intensidade do pulso do laser, que não é constante durante o período do pulso.

Assim, a curva de decaimento de fluorescência sofre o impacto do perfil da luz de excitação $P(t)$. O sistema de detecção também pode apresentar diferença de sensibilidade para diferentes tempos de decaimento, $R(t)$. Por isso, a curva experimental de decaimento $I_{\text {exp }}(t)$ de fluorescência é convoluída, tal que [132]:

$$
I_{\text {exp }}(t)=I(t) * P(t) * R(t)
$$

Para resolver estes problemas, se assume que o pulso do laser é a soma de inúmeras funções do tipo $\delta$ de Dirac com diferentes intensidades e que cada uma dessas funções excita um número de fluoróforos que dão origem a uma curva de decaimento de fluorescência. Além disso, mede-se a resposta do sistema de detecção para o espalhamento de luz do laser, obtendo-se assim, uma função chamada de função de resposta instrumental, a $\operatorname{IRF}(t)$ :

$$
I_{\text {exp }}(t)=I(t) * I R F(t), \quad \operatorname{com} \quad I R F(t)=P(t) * R(t)
$$

A equação 4.13 pode ser escrita na forma integral e $I(t)$ pode ser substituída pela eq. 4.10:

$$
I_{\text {exp }}(t)=\int_{0}^{\infty} I\left(t-t^{\prime}\right) \operatorname{IRF}\left(t^{\prime}\right) d t^{\prime}=\int_{0}^{\infty}\left(\sum_{i=1}^{n} \alpha_{i} e^{-\left(t-t^{\prime}\right) / \tau_{i}}\right) \operatorname{IRF}\left(t^{\prime}\right) d t^{\prime}
$$

onde t' é o tempo da emissão de um pulso de uma das funções do tipo $\delta$ de Dirac. Como a $\operatorname{IRF}(t)$ é obtida experimentalmente (através da medida do espalhamento de luz do laser), é possível obter os valores de $\alpha_{i}$ e $\tau_{i}$ através do ajuste da integral aos dados de $I_{\text {exp }}(t)$.

Este processo de variar $\alpha_{i}$ e $\tau_{i}$ e recalcular a convolução, ou seja, o ajuste das curvas de decaimento, foi realizado utilizando-se o software TRFA [133]. Para as análises, foram utilizados 3 decaimentos ( $j=3$ eq. 4.10) e, quando necessário, uma outra componente foi também utilizada para ajustar o espalhamento do laser. 


\subsubsection{Anisotropia de fluorescência do estado estacionário}

Outro aspecto importante nos processos de absorção e fluorescência é a polarização da luz de excitação e emissão. Todos os fluoróforos possuem um dipolo intrínseco relacionado à absorção de luz, que irá ocorrer quando a luz de excitação tiver alguma componente paralela a este dipolo (fotoseleção). A absorção depende do quadrado do cosseno entre o ângulo da luz polarizada e a direção do dipolo da molécula [132].

A luz de fluorescência será emitida na direção do dipolo de emissão que possui um ângulo $\theta$ em relação ao dipolo de absorção, o que origina a anisotropia intrínseca à molécula $r_{o}$ [132]:

$$
r_{o}=\frac{2}{5}\left(\frac{3 \cos ^{2} \theta-1}{2}\right)
$$

Entretanto, é possível que a molécula tenha tempo de rotacionar antes de emitir a fluorescência mudando, assim, a direção da polarização da luz emitida. Este processo de rotação da molécula é quantificado a partir do designado coeficiente de difusão rotacional $(\phi)$.

A anisotropia, então, é uma medida adimensional sobre a relação entre a intensidade de luz de fluorescência paralela e perpendicular à polarização da luz de excitação, como mostra a seguinte equação [132]:

$$
<r>=\frac{I_{z}-I_{y}}{I_{z}+I_{y}+I_{x}}
$$

onde $I_{z}, I_{y} e I_{x}$ são as intensidades de fluorescência nas direções $\mathrm{z}, \mathrm{y}, \mathrm{x}$, respectivamente e a soma das três resulta no total de luz emitida (fig. 4.6). $\langle r\rangle$ é chamada de anisotropia do estado estacionário.

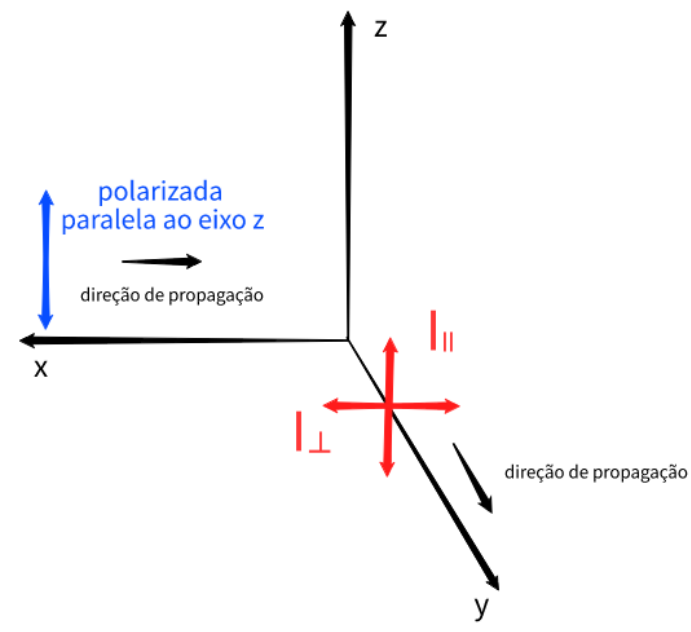

Figura 4.6: Esquema de medida de anisotropia 
Supondo a luz de excitação polarizada na direção $z$, as componentes na direção x e y são perpendiculares e de mesma intensidade (por simetria - fig. 4.6). Logo, $I_{x}=I_{y}=I_{\perp}$ perpendiculares e $I_{z}=I_{\|}$paralela:

$$
<r>=\frac{I_{\|}-I_{\perp}}{I_{\|}+2 I_{\perp}}
$$

A eq. 4.17 pode ser reescrita em termos da direção de polarização da luz de excitação e de emissão:

$$
<r>=\frac{I_{V V}-I_{V H}}{I_{V V}+2 I_{V H}}
$$

onde a primeira letra representa a direção de polarização de excitação e a segunda a direção de polarização da luz de emissão, com V vertical (paralelo ao eixo z) e H horizontal (perpendicular ao eixo z).

É importante acrescentar que as componentes do fluorímetro não possuem a mesma eficiência para ambas polarizações (efeito similar ao descrito no item 4.1.4.1). Por isso, mediu-se as intensidades de fluorescência com a polarização de excitação na direção horizontal (perpendicular ao eixo z) e emissão na direção horizontal e vertical (paralelo ao eixo z), para obter o fator de correção de intensidade $G$ :

$$
G=\frac{I_{H V}}{I_{H H}}
$$

Assim sendo, a equação para a anisotropia do estado estacionário é obtida por:

$$
<r>=\frac{I_{V V}-G \times I_{V H}}{I_{V V}+G \times 2 I_{V H}}
$$

A anisotropia pode ser influenciada pelo tempo de vida de fluorescência $\tau$ e pelo tempo de correlação rotacional $(\phi)$, como descrito na equação de Perrin [132]:

$$
<r>=\frac{r_{0}}{1+\tau / \phi}
$$

onde $r_{0}$ é a anistropia intrínseca à molécula (eq. 4.15 - item 4.1.2 para o TMA-DPH), $\tau$ foi explicado no item 4.1.4.2 e $\phi$ será explorado a seguir. 


\subsubsection{Anisotropia de fluorescência resolvida no tempo}

Outra possibilidade é realizar experimentos de anisotropia resolvida no tempo, $r(t)$, que permite obter a anisotropia já levando em conta o impacto do tempo de vida. Além disso, com estes experimentos é possível calcular $\phi$ e também a anisotropia mínima (residual), $r_{\infty}$. Por isso, realizamos medidas de $r(t)$.

A anisotropia resolvida no tempo pode ser descrita pela eq. 4.18 levando em conta que cada componente $I_{i j}$ deve ser obtida como $I_{i j}(t)$. Para isso, mede-se o tempo de decaimento da intensidade de fluorescência utilizando polarizadores para luz de excitação e emissão obtendo assim, $I_{V V}(t)$ e $I_{V H}(t)$. Além disso, mede-se o tempo de decaimento de intensidade de fluorescência total $I(t)$ como descrito no item 4.1.4.2.

Pode-se então reescrever a eq. 4.18 com resolução temporal:

$$
r(t)=\frac{I_{V V}(t)-I_{V H}(t)}{I_{V V}(t)+2 I_{V H}(t)}
$$

lembrando que o denominador é igual a intensidade total da luz de fluorescência (eq. 4.17):

$$
I(t)=I_{V V}(t)+2 I_{V H}(t)
$$

pode-se escrever cada componente $I_{V V}(t)$ e $I_{V H}(t)$ em função de $I(t)$ e $r(t)$ :

$$
I_{V V}(t)=\frac{I(t)}{3}(1+2 r(t)) \quad e \quad I_{V H}(t)=\frac{I(t)}{3}(1-r(t))
$$

onde $I(t)$ é obtida como no item 4.1.4.2, $r(t)$ é a anisotropia resolvida no tempo e empiricamente pode ser descrita por:

$$
r(t)=\sum_{i=1}^{k} \beta_{i} e^{\left(-t / \phi_{i}\right)}+r_{\infty}
$$

onde $\sum_{i=1}^{k} \beta=1 \leq r_{o}$, $\phi_{i}$ é o tempo de correlação rotacional da $i$ componente e $r_{\infty}$ é o valor da anisotropia residual (mínima) do fluoróforo.

Logo, utilizando as equações eq. 4.10 (resulta de 4.14) e 4.25 pode-se reescrever as componentes $I_{V V}(t)$ e $I_{V H}(t)$ :

$$
I_{V V}(t)=\frac{\sum_{i=1}^{j} \alpha_{i} e^{-t / \tau_{i}}}{3}\left(1+2\left[\sum_{i=1}^{n} \beta_{i} e^{\left(-t / \phi_{i}\right)}+r_{\infty}\right]\right) \quad e \quad I_{V H}(t)=\frac{\sum_{i=1}^{j} \alpha_{i} e^{-t / \tau_{i}}}{3}\left(1-\sum_{i=1}^{n} \beta_{i} e^{\left(-t / \phi_{i}\right)}+r_{\infty}\right)
$$


Para evitar artefatos nas medidas de $r(t)$, obtém-se o fator G como [134]:

$$
G=\left(\frac{1-<r>}{1-2<r>}\right)\left(\frac{\int_{0}^{\infty} I_{V V}(t) d t}{\int_{0}^{\infty} I_{V H}(t) d t}\right)
$$

onde $<r>$ é a anisotropia do estado estacionário. Este parâmetro $G$ foi omitido nas equações de $\mathrm{r}(\mathrm{t})$ (eqs. 4.22 - 4.26) pois é aproximadamente 1 nas condições experimentais utilizadas.

Outro controle importante que conecta $r(t)$ com $<r>$ e restringe os parâmetros de ajuste é dada pela seguinte equação [134]:

$$
<r>=\frac{\int_{0}^{\infty} I(t) r(t) d t}{\int_{0}^{\infty} I(t) d t}
$$

o que indica que a anisotropia do estado estacionário é a soma das contribuições da anisotropia resolvida no tempo ponderada pela intensidade de fluorescência a cada tempo $t$.

Do ponto de vista da interpretação física o esquema da fig. 4.7 ilustra a difusão rotacional de um fluóroforo com simetria cilíndrica e simetria de emissão de fluorescência em relação ao eixo z (como a sonda TMA-DPH utilizada neste trabalho). Brevemente, o fluoróforo pode rotacionar dentro de um cone "rígido"se afastando ou se aproximando do eixo $\mathrm{z}$ atingindo um valor de ângulo máximo $\Phi_{\max }$ em um certo tempo $t_{\max }$ [135]. Este $\Phi_{\max }$ indica a anisotropia mínima que a sonda pode atingir, $r_{\infty}$, devido as restrições laterais do microambiente onde a sonda se encontra. Esse parâmetro é obtido diretamente dos ajustes (eqs.4.25 - 4.26).

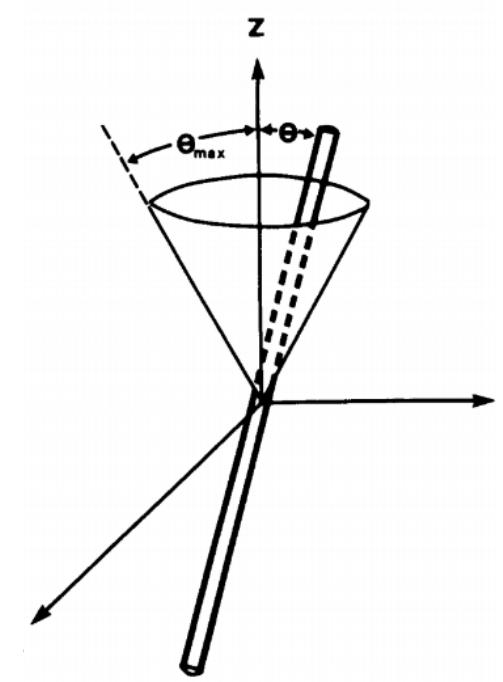

Figura 4.7: Modelo de difusão rotacional para um fluoróforo com simetria cilíndrica. $\Phi$ é o ângulo entre o eixo z e a posição do fluoróforo e $\Phi_{\max }$ é o ângulo máximo para a rotação. [135]

Por outro lado, o tempo que a sonda demora para chegar neste $\Phi_{\max }$ traz informações sobre a resistência apresentada pelo meio para que a sonda alcance o $r_{\infty}$ e pode ser obtido através do tempo médio de correlação rotacional, $\langle\phi>$ dado por $[124,132]$ : 


$$
<\phi>=\int_{0}^{\infty} \frac{r(t)-r_{\infty}}{r_{0}-r_{\infty}} d t=\sum_{i=1}^{n} \beta_{i} \phi_{i}
$$

A partir do valor de $\langle\phi\rangle$ é possível calcular o coeficiente de difusão rotacional perpedincular ao eixo z, $D_{\perp}$, através da equação empírica [124]:

$$
D_{\perp}=\frac{0.1674-0.1066\left(r_{\infty} / r_{0}\right)-0.062\left(r_{\infty} / r_{0}\right)^{2}}{<\phi>}
$$

$D_{\perp}$ pode ser utilizado para calcular a resistência ao movimento de rotação apresentada pelo meio, ou seja, a microviscosidade $\eta$. Esta representa a dinâmica de fricção do meio contrária ao movimento de rotação da sonda. Para calcular $\eta$, supõe-se que o movimento da sonda pode ser aproximado por uma difusão Browniana e se utiliza a equação de Debye-Stokes-Einstein [124]:

$$
\eta=\frac{\kappa_{B} T}{6 D_{\perp} V_{e f}}
$$

onde $\kappa_{B}$ é a constante de Boltzmann e $V_{e f}$ é o volume efetivo da sonda.

\subsubsection{Fluorescência II - Experimento e Exemplos: POPC $23^{\circ} \mathrm{C}$ e $37^{\circ} \mathrm{C}$}

Para exemplificar as análises realizadas a partir de medidas de fluorescência explicadas até agora, utilizamos os dados obtidos para vesículas multilamelares grandes (MLVs) compostas de POPC para as temperaturas de $23^{\circ} \mathrm{C}$ e $37^{\circ} \mathrm{C}$.

\subsubsection{Fluorescência do estado estacionário e GP}

Os espectros de fluorescência do estado estacionário foram obtidos utilizando o fluorímetro SLM Aminco 8100 series 2, com as fendas de emissão e excitação com 4 nm de abertura, tempo de integração em cada comprimento de onda de $0,85 \mathrm{~s}$, a velocidade de varredura de $1,10 \mathrm{~nm} / \mathrm{s}$ e $0,5 \mathrm{~nm}$ de passo.

Os comprimentos de onda de excitação e emissão da sonda laurdan estão descritos no item 4.1.3. Um exemplo de análise de GP para MLVs compostas de POPC para as temperaturas de $23^{\circ} \mathrm{C}$ e $37^{\circ} \mathrm{C}$ está apresentado na figura 4.8 : 


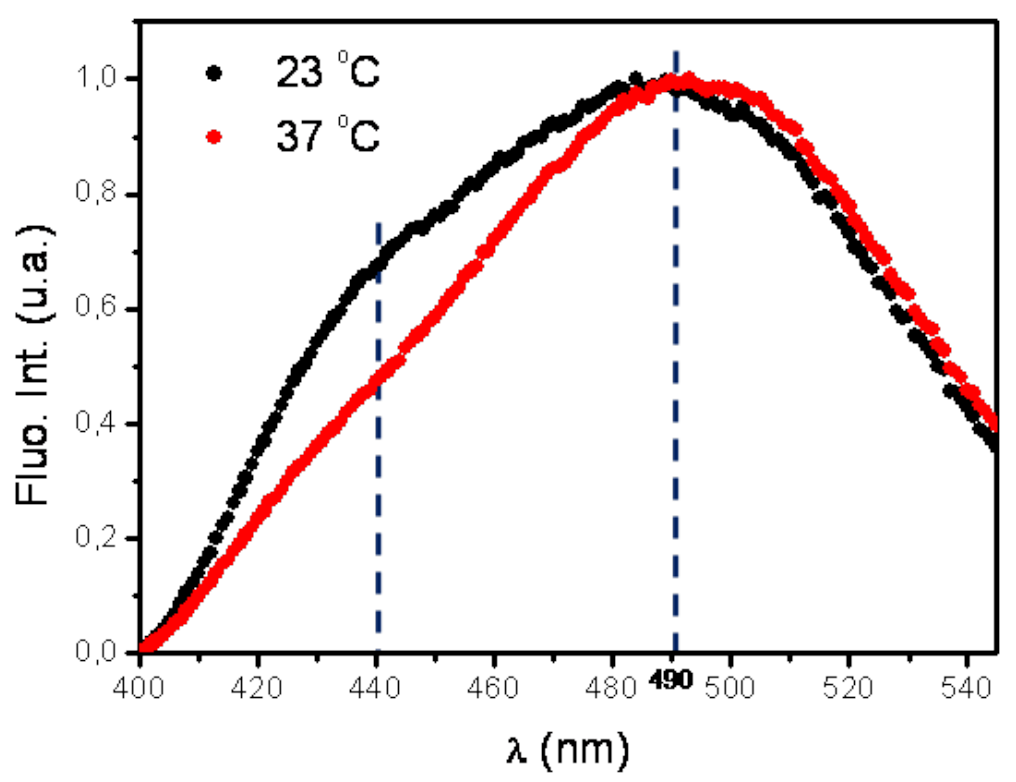

Figura 4.8: Espectro de fluorescência da sonda laurdan em MLVs de POPC a $23^{\circ} \mathrm{C}$ e $37^{\circ} \mathrm{C}$. Os espectros estão normalizados para facilitar a comparação. As linhas pontilhadas indicam os comprimentos de onda de $440 \mathrm{~nm}$ e $490 \mathrm{~nm}$ utilizados na análise de intensidade de fluorescência para calcular o GP.

Utilizando a intensidade de fluorescência em $\lambda=440 \mathrm{~nm}$ e $490 \mathrm{~nm}$ (indicados na figura) calcula-se o valor do GP como indicado na equação 4.1 (item 4.1.3). Neste caso, obteve-se os valores de $-0,189$ e $-0,356$ para o POPC a 23 e $37^{\circ} \mathrm{C}$, respectivamente.

É interessante notar que essa diminuição do valor do GP pode ser observada diretamente do espectro de fluorescência normalizado (fig 4.8) onde há diminuição da intensidade em $\lambda=440$ $\mathrm{nm}$ mas a intensidade em $\lambda=490 \mathrm{~nm}$ permanece a mesma para a temperatura de $37{ }^{\circ} \mathrm{C}$.

Esta diminuição do valor do GP com o aumento da temperatura indica maior hidratação da membrana na região da cabeça polar/carbonila e/ou maior fluidez da membrana [125].

Cabe acrescentar que também foram realizadas medidas de espectro de fluorescência do estado estacionário para o TMA-DPH. Neste caso, o $\lambda_{\mathrm{ex}}$ foi de $350 \mathrm{~nm}$ e o espectro foi medido entre 370 e $500 \mathrm{~nm}$. Entretanto, estas medidas foram realizadas apenas como controle, pois as análises de nosso interesse são oriundas das medidas de anisotropia (itens 4.1.4.3, 4.1.5.3 e 4.1.5.4).

\subsubsection{Fluorescência resolvida no tempo}

As medidas de fluorescência resolvida no tempo foram realizadas em um sistema construído no laboratório do Prof. Manuel Prieto utilizando o laser de excitação Titânio-Safira (SpectraPhysics Tsunami) com duração temporal de pulso inferior a $100 \mathrm{fs}$, um sistema de aquisição de single photon e um monocromador para selecionar o comprimento de onda de emissão. 
Para excitar as sondas TMA-DPH e laurdan utilizou-se o comprimento de onda de $340 \mathrm{~nm}$. Para o TMA-DPH o comprimento de onda de emissão foi de $430 \mathrm{~nm}$ e para o laurdan mediu-se entre $400 \mathrm{~nm}$ até $540 \mathrm{~nm}$ com passos de $10 \mathrm{~nm}$ (item 4.1.6). É interessante acrescentar que as intensidades de decaimento de fluorescência foram obtidas a um ângulo de $54.7^{\circ}$ (ângulo mágico) em relação ao eixo z para a anisotropia ser nula [132].

Como exemplo de resultado de curva de decaimento de intensidade de fluorescência da sonda TMA-DPH em membranas lipídicas, a figura 4.9 apresenta os dados para MLVs de POPC para 23 e $37^{\circ} \mathrm{C}$ (pontos azuis e vermelhos, respectivamente) bem como as curvas da resposta instrumental, $\operatorname{IRF}(t)$, para ambas as temperaturas. A figura inserida apresenta as $\operatorname{IRF}(t) \mathrm{com}$ destaque.

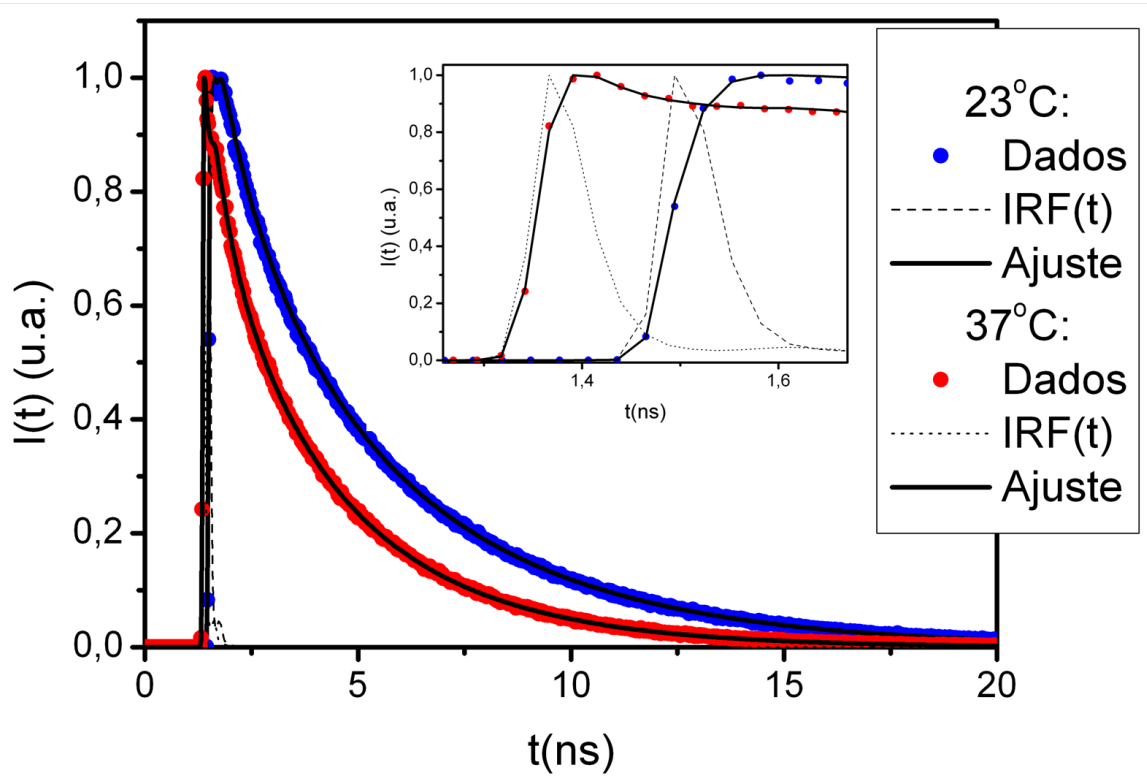

Figura 4.9: Curvas de decaimento de intensidade de fluorescência normalizadas da sonda TMA$\mathrm{DPH}$ em MLV de POPC a $23{ }^{\circ} \mathrm{C}$ (pontos azuis) e $37^{\circ} \mathrm{C}$ (pontos vermelhos). As linhas pretas mostram o ajuste (equação 4.14) para cada temperatura. As linhas tracejada e pontilhada indicam a $\operatorname{IRF}(t)$ (eq. 4.13) para $23^{\circ} \mathrm{C}$ e $37^{\circ} \mathrm{C}$, respectivamente (destacada na figura inserida).

É possível obter os valores de $\alpha_{i}$ e $\tau_{i}$ (eq. 4.14) ajustando-se a função aos dados experimentais $\left(I_{\text {exp }}\right)$ de decaimento de fluorescência. Neste exemplo, utilizou-se $\mathrm{i}=3$ e as linhas pretas mostram o ajuste para cada uma das temperaturas (fig. 4.9). A tabela 4.2 apresenta os parâmetros de ajuste obtidos para cada temperatura, bem como o valor do tempo de vida médio calculado (eq. 4.11): 


\begin{tabular}{cccccc} 
& \multicolumn{2}{c}{$23^{\circ} \mathrm{C}$} & & \multicolumn{2}{c}{$37^{\circ} \mathrm{C}$} \\
\cline { 2 - 3 } \cline { 5 - 6 } 1 & $\alpha_{i}$ & $\tau_{j}(n s)$ & & $\alpha_{j}$ & $\tau_{j}(n s)$ \\
2 & 0,136 & 0,369 & & 0,232 & 0,324 \\
3 & 0,215 & 1,528 & & 0,184 & 1,324 \\
$<\tau>(n s)$ & $\frac{0,649}{4}$ & 4,482 & & 0,584 & 3,320 \\
\hline
\end{tabular}

Tabela 4.2: Parâmetros obtidos através do ajuste da equação 4.14 aos dados experimentais de decaimento de intensidade de fluorescência $\left(I_{\text {exp }}\right)$ para MLVs de POPC a $23^{\circ} \mathrm{C}$ e $37^{\circ} \mathrm{C}$ presentes na figura 4.9. O tempo de vida médio $<\tau>$ calculado através da equação 4.11 também está indicado para ambas as temperaturas.

A tabela 4.2 apresenta dois exemplos dos parâmetros obtidos através do ajuste da equação 4.14 aos dados experimentais de decaimento de intensidade de fluorescência da sonda TMA-DPH em membranas lipídicas, que, neste caso, são compostas de POPC e foram medidas a $23{ }^{\circ} \mathrm{C}$ e 37 ${ }^{\circ} \mathrm{C}$ (fig 4.9).

É interessante notar que a diminuição do valor de $<\tau>$ com o aumento da temperatura como indicado pela análise de dados (tabela 4.2) também é observável diretamente dos dados experimentais da figura 4.9 , onde o decaimento da intensidade de fluorescência a $37^{\circ} \mathrm{C}$ acontece mais rapidamente do que a $23{ }^{\circ} \mathrm{C}$.

Este processo de análise foi realizado para todos os experimentos de intensidade de fluorescência resolvida no tempo da sonda TMA-DPH. Os experimentos foram realizados em dias diferentes para a mesma composição lipídica e a incerteza do $\langle\tau\rangle$ foi associada à diferença entre o maior e menor valor obtidos para cada experimento independente.

Além disso, para os experimentos de TRES (item 4.1.6), mediu-se a intensidade de fluorescência resolvida no tempo da sonda laurdan, que foi analisada utilizando um processo semelhante.

\subsubsection{Anisotropia de fluorescência do estado estacionário}

Para realizar estas medidas, utilizou-se o fluorímetro SLM Aminco 8100 series 2 no laboratório do Prof. Manuel Prieto, com as fendas de emissão e excitação com $4 \mathrm{~nm}$ de abertura e tempo de integração de $0,85 \mathrm{~s}$, comprimento de onda de excitação da sonda TMA-DPH de $\lambda_{\text {ex }}$ $=350 \mathrm{~nm}$ e de emissão $\lambda_{\mathrm{em}}=430 \mathrm{~nm}$.

Para estes experimentos o comprimento de onda de emissão é fixo e um polarizador é adicionado para o $\lambda_{\text {ex }}$ e outro para o $\lambda_{\text {em }}$ variando automaticamente para aquisição de fluorescência: $I_{V V}$ - excitação vertical e emissão vertical; $I_{V H}$ - excitação vertical e emissão horizontal; $I_{H V}$ - excitação horizontal e emissão vertical; $I_{H H}$ - excitação horizontal e emissão horizontal (eq. 4.20) 
Para subtrair possíveis contribuições indesejadas à intensidade de fluorescência, preparou-se MLVs com a mesma composição lipídica da amostra em questão, mas sem adicionar a sonda TMA-DPH.

O resultado da intensidade de fluorescência utilizado para calcular a anisotropia do estado estacionário, $\langle r\rangle$, foi obtido subtraindo os valores de intensidade da amostra de interesse pela intensidade da amostra controle.

Para cada amostra, as medidas de intensidade de fluorescência foram repetidas 10 vezes utilizando o software de aquisição e os dados para um exemplo de MLVs compostas de POPC, nas temperaturas de $23{ }^{\circ} \mathrm{C}$ e $37^{\circ} \mathrm{C}=$, estão apresentados na tabela 4.3:

\begin{tabular}{|c|c|c|c|c|c|c|c|c|}
\hline & \multicolumn{4}{|c|}{$23^{\circ} \mathrm{C}$} & \multicolumn{4}{|c|}{$37^{\circ} \mathrm{C}$} \\
\hline & $I_{V V}$ & $I_{V H}$ & $I_{H V}$ & $I_{H H}$ & $I_{V V}$ & $I_{V H}$ & $I_{H V}$ & $I_{H H}$ \\
\hline 1 & 18566 & 29439 & 19269 & 54192 & 24172 & 42819 & 26289 & 76054 \\
\hline 2 & 18126 & 29228 & 19340 & 53630 & 23291 & 40096 & 27884 & 72846 \\
\hline 3 & 18440 & 28631 & 18801 & 51233 & 24502 & 40119 & 26015 & 73813 \\
\hline 4 & 19440 & 28318 & 18562 & 52528 & 24344 & 38158 & 26220 & 76470 \\
\hline 5 & 18460 & 28202 & 19097 & 53126 & 25169 & 40006 & 27059 & 74499 \\
\hline 6 & 18330 & 28977 & 18928 & 52943 & 24136 & 40702 & 27681 & 73567 \\
\hline 7 & 18458 & 29085 & 19042 & 52188 & 24867 & 40898 & 26890 & 72133 \\
\hline 8 & 18755 & 28753 & 19098 & 51338 & 24188 & 40111 & 26921 & 74483 \\
\hline 9 & 18512 & 27728 & 18889 & 51962 & 24489 & 41149 & 27017 & 72729 \\
\hline 10 & 18106 & 27569 & 19032 & 51918 & 23956 & 38710 & 28097 & 74565 \\
\hline Média & 18519 & 28593 & 19006 & 52506 & 24311 & 40277 & 27007 & 74116 \\
\hline $\mathrm{G}$ & - & - & \multicolumn{2}{|c|}{$0,362(3)$} & - & - & \multicolumn{2}{|c|}{$0,364(3)$} \\
\hline$<\mathrm{r}>$ & \multicolumn{4}{|c|}{$0,208(4)$} & \multicolumn{4}{|c|}{$0,180(4)$} \\
\hline
\end{tabular}

Tabela 4.3: Valores de intensidade de fluorescência do estado estacionário da sonda TMA-DPH para MLVs de POPC a 23 e $37{ }^{\circ} \mathrm{C}$ para diferentes direções de polarização: $I_{V V}$ - excitação vertical e emissão vertical; $I_{V H}$ - excitação vertical e emissão horizontal; $I_{H V}$ - excitação horizontal e emissão vertical; $I_{H H}$ - excitação horizontal e emissão horizontal. O fator $\mathrm{G}$ calculado pela equação 4.19 e a anisotropia do estado estacionário $\langle r\rangle$ calculada pela equação 4.20 também estão apresentados.

A tabela 4.3 apresenta 10 repetições para uma medida de amostra de MLVs de POPC a 23 e $37{ }^{\circ} \mathrm{C}$. Para obter um ponto experimental (mesma composição lipídica a uma dada temperatura), realizou-se o mesmo procedimento para triplicatas, em um mesmo dia e repetiu-se em dias distintos (tabela 4.1).

\subsubsection{Anisotropia de fluorescência resolvida no tempo}

Estas medidas foram realizadas utilizando o mesmo aparato experimental descrito no item 4.1.5.2 para medir a intensidade de fluorescência resolvida no tempo da sonda TMA-DPH, $I(t)$. 
Além disso, adicionou-se polarizadores para luz de emissão $\left(\lambda_{e m}=430 \mathrm{~nm}\right)$ tal que se mediu as intensidades de fluorescência resolvida no tempo $I_{V V}(t)$ (excitação vertical, emissão vertical) e $I_{V H}(t)$ (excitação vertical, emissão horizontal). Cabe acrescentar que a excitação do pulso laser já é polarizada verticalmente. Assim sendo, calculou-se a anisotropia resolvida no tempo, $r(t)$, utilizando a equação 4.22 .

Para ajustar a função $I(t)$ utilizou-se o mesmo procedimento descrito no item 4.1.5.2. Para as análises de $I_{V V}(t), I_{V H}(t)$ e $r(t)$ utilizou-se o ajuste global dado pela equação 4.26.

Portanto, para analisar as curvas de anisotropia resolvida no tempo é necessário ajustar os parâmetros $\alpha_{i}$ e $\tau_{i}$ para a $I(t), \beta_{j}, \phi_{j}$ e $r_{\infty}$ para a $r(t)\left(I_{V V}(t)\right.$ e $\left.I_{V H}(t)\right)$. Para reduzir o número de parâmetros, primeiramente realiza-se o ajuste da $I(t)$ e fixa-se os valores de $\alpha_{j}$ e $\tau_{j}$. Além disso, as curvas de $I_{V V}(t)$ e $I_{V H}(t)$ estão conectadas por $I(t)$ e $r(t)$ possibilitando o ajuste global que adiciona restrições aos parâmetros. Todos estes ajustes foram realizados utilizando o software TRFA [133].

Como exemplo, as figuras $4.10 \mathrm{a}$ e $4.10 \mathrm{~b}$ apresentam as curvas experimentais das intensidades de fluorescência resolvida no tempo $I(t), I_{V V}(t)$ e $I_{V H}(t)$ para a sonda TMA-DPH em membranas de POPC a 23 e $37^{\circ} \mathrm{C}$, respectivamente. A figura 4.10c apresenta as curvas de $r(t)$ calculada utilizando os dados experimentais de $I_{V V}(t)$ e $I_{V H}(t)$ (eq. 4.22).

Como a equação para obter a função $r(t)$ envolve a divisão pelas intensidades de fluorescência $I_{V V}(t)$ e $I_{V H}(t)$ (e por conseguinte, $I(t)$ ), o gráfico de $r(t)$ fica limitado até o tempo máximo para o qual há intensidade de fluorescência (contagem) suficiente para estas componentes. Este efeito é evidente na figura 4.10. 


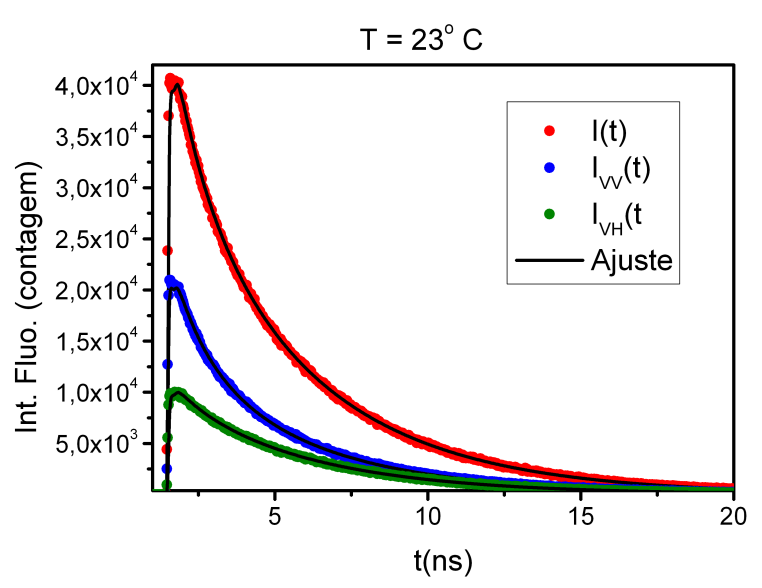

(a)

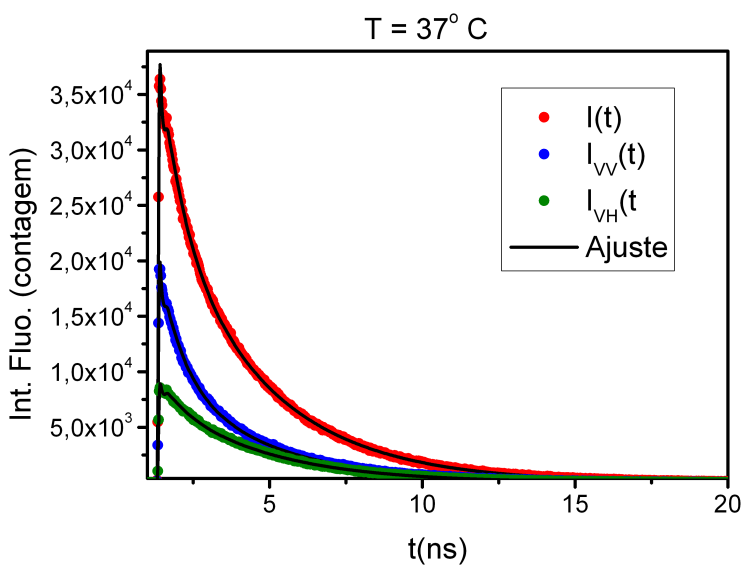

(b)

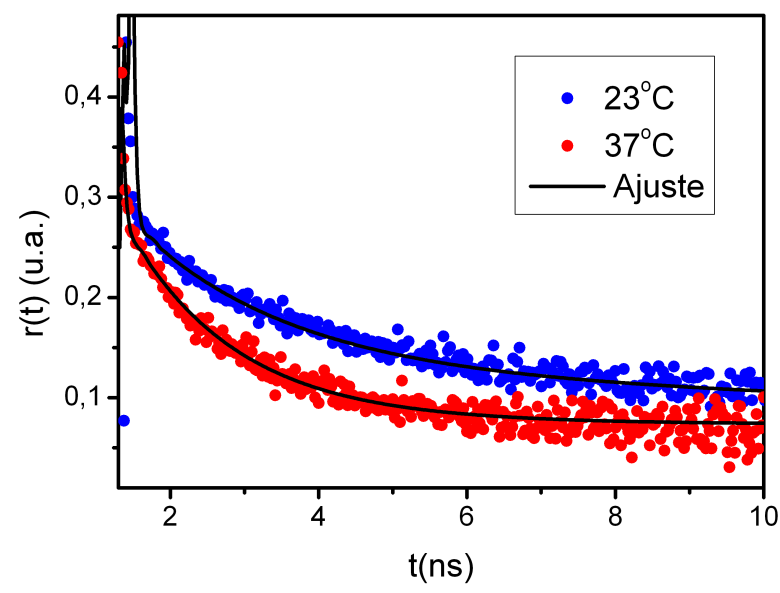

(c)

Figura 4.10: (a) e (b) apresentam as intensidades de fluorescência experimentais $I(t), I_{V V}(t) \mathrm{e}$ $I_{V H}(t)$ da sonda TMA-DPH em MLVs de POPC a 23 e $37^{\circ} \mathrm{C}$, respectivamente. (c) apresenta as curvas de anisotropia resolvida no tempo $r(t)$ para os dois casos (4.22). Todas as curvas experimentais estão acompanhadas de seu respectivo ajuste (linhas pretas).

As curvas experimentais da figura 4.10 estão acompanhadas de seus respectivos ajustes descritos anteriormente (eq. 4.14 e eq. 4.22- 4.26) que podem ser sintetizados como:

$$
\begin{gathered}
I(t)=I_{0} \sum_{i=1}^{j} \alpha_{i} e^{-t / \tau_{i}} \\
r(t)=\frac{I_{V V}(t)-I_{V H}(t)}{I_{V V}(t)+2 I_{V H}(t)} \quad e \quad r(t)=\sum_{i=1}^{k} \beta_{i} e^{\left(-t / \phi_{i}\right)}+r_{\infty} \\
I_{V V}(t)=\frac{\sum_{i=1}^{j} \alpha_{i} e^{-t / \tau_{i}}}{3}\left(1+2\left[\sum_{i=1}^{n} \beta_{i} e^{\left(-t / \phi_{i}\right)}+r_{\infty}\right]\right) \\
I_{V H}(t)=\frac{\sum_{i=1}^{j} \alpha_{i} e^{-t / \tau_{i}}}{3}\left(1-\sum_{i=1}^{n} \beta_{i} e^{\left(-t / \phi_{i}\right)}+r_{\infty}\right)
\end{gathered}
$$


Os parâmetros de ajuste $\alpha_{i}, \tau_{i}, \beta_{j}, \phi_{j}$ e $r_{\infty}$ obtidos neste exemplos estão apresentados na tabela abaixo:

\begin{tabular}{|c|c|c|c|c|c|c|c|c|c|c|}
\hline & & & $23^{\circ} \mathrm{C}$ & & & & & $37^{\circ} \mathrm{C}$ & & \\
\hline & & $I_{V V}$ & t) $I_{V H}($ & $r(t)$ & & & $I_{V V}($ & $I_{V H}(t$ & $r(t)$ & \\
\hline & & $t)$ & & & & & $t)$ & & & \\
\hline & $\alpha_{i}$ & $\tau_{i}(n s)$ & $\beta_{j}$ & $\phi_{j}(n s)$ & $r_{\infty}$ & $\alpha_{i}$ & $\tau_{i}(n s)$ & $\beta_{j}$ & $\phi_{j}$ & $r_{\infty}$ \\
\hline 1 & 0,203 & 1,456 & 0,173 & 2,585 & 0,100 & 0,176 & 0,673 & 0,209 & 1,331 & $0,0 / 4$ \\
\hline 2 & 0,125 & 0,393 & & & & 0,355 & 3,224 & & & \\
\hline 3 & 0,672 & 4,464 & & & & 0,469 & 0,025 & & & \\
\hline
\end{tabular}

Tabela 4.4: Parâmetros de ajuste obtidos utilizando as equações 4.14 para $I(t)$ e 4.22- 4.26 para a anisotropia resolvida no tempo sintetizadas acima. Resultados obtidos para as análises dos experimentos de anisotropia resolvida no tempo da sonda TMA-DPH em membranas de POPC a 23 e $37^{\circ} \mathrm{C}$.

A partir dos parâmetros $\alpha_{i}, \tau_{i}$ (referentes à $I(t)$ - tabela 4.4) foi possível calcular o tempo de vida médio da sonda TMA-DPH, mas como já fora exemplificado anteriormente no item 4.1.5.2, este não será repetido aqui.

Analisando os parâmetros da anisotropia resolvida no tempo $\left(I_{V V}(t), I_{V H}(t)\right.$ e $r(t)$ - tabela 4.4) pode-se diretamente inferir sobre a maior amplitude angular para a qual a sonda TMA-DPH pode rotacionar. Esta informação está contida na anisotropia mínima, $r_{\infty}$.

Por outro lado, a partir dos parâmetros $\beta_{j}, \phi_{j}$ pode-se utilizar a equação 4.29 para obter o tempo médio de correlação rotacional $\langle\phi\rangle$, que indica o tempo necessário até a sonda atingir o valor de maior abertura angular $\left(\Phi_{\max }\right.$ - fig 4.7$)$ para o qual atinge o valor da anisotropia mínima $\left(r_{\infty}\right)$. Nos dois exemplos acima o valor médio $<\phi>$ é o próprio valor de $\phi$ visto que foi utilizada apenas uma componente para ajustar as curvas de anisotropia resolvida no tempo.

Pode-se observar que os valores de $r_{\infty}$ e $\langle\phi\rangle$ diminuem para a sonda TMA-DPH em membranas de POPC com o aumento da temperatura, como apresentado na tabela 4.4. Isto indica que a sonda TMA-DPH experimenta uma maior abertura angular para rotacionar e realiza este movimento mais rapidamente a $37^{\circ} \mathrm{C}$.

De maneira interessante, estas mesmas informações podem ser observadas diretamente das curvas de $r(t)$ para ambas temperaturas (fig. 4.10c), onde os valores de anisotropia a $37{ }^{\circ} \mathrm{C}$ (pontos vermelhos) decaem mais rapidamente (menor $\langle\phi\rangle$ ) e para menores valores para $t>8 \mathrm{~ns}$ (menor $r_{\infty}$ ) do que a $23{ }^{\circ} \mathrm{C}$ (pontos azuis).

Além disso, com os valores de $r_{\infty}, r_{0}$ (0,39 para o TMA-DPH - item 4.1.2) e $<\phi>$ pode-se aplicar a equação 4.30 para obter o coeficiente de difusão rotacional, $D_{\perp}$, do microambiente onde a sonda TMA-DPH está inserida. Por fim, utilizando o valor de $D_{\perp}$ e o volume efetivo do TMA-DPH, $V_{e f}\left(360 \AA^{3}\right.$ - item 4.1.2), calculou-se a resistência ao movimento de rotação apresentada pelo meio, ou seja, a microviscosidade $\eta$ através da equação 4.31 . 
Este processo de análise foi realizado para todos os experimentos de anisotropia de fluorescência resolvida no tempo da sonda TMA-DPH. Os experimentos foram realizados em dias diferentes para a mesma composição lipídica e a incerteza dos parâmetros foi associada à diferença entre o maior e menor valor obtidos para cada experimento independente.

\subsubsection{Espectro de fluorescência resolvida no tempo (TRES)}

Como descrito anteriormente, o fluoróforo, ao ser excitado, apresenta um novo momento de dipolo que induz a reorietanção dos dipolos das moléculas de solvente [132]. Se o tempo para reorientação dos dipolos do solvente $\tau_{S}$ for muito menor do que o tempo de vida de fluorescência $\tau$, o fluoróforo reorienta os dipolos do solvente antes de emitir fluorescência [132]. Nesse caso, há maior estabilização energética e portanto o comprimento de onda de emissão fluorescência será maior (menor energia).

Por outro lado, se $\tau_{S}>>\tau$, o fluoróforo irá emitir o fóton do estado excitado não estabilizado (maior nível vibracional, pois, neste caso, o fluoróforo não interagiu com os dipolos do solvente antes de emitir fluorescência [132]. Logo, o comprimento de onda emitido neste caso é menor (maior energia) do que no caso anterior.

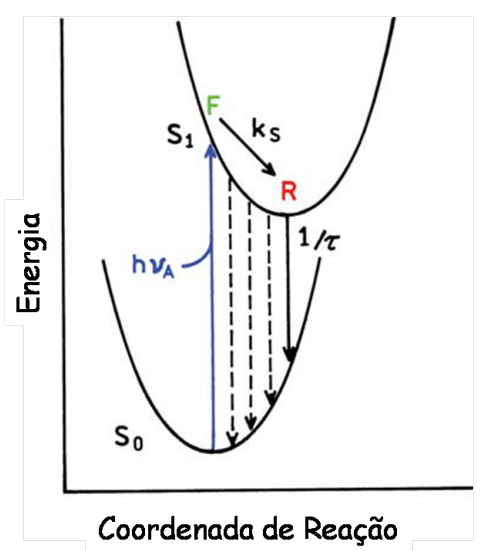

Figura 4.11: Esquema de relaxação espectral contínua. Adaptado de [132]

A figura 4.11 esquematiza este fenômeno. F indica o estado vibracional de maior energia do estado $S_{1}$ após a absorção da energia de um fóton $\mathrm{h} v_{A}$. O solvente pode sofrer a reorientação dipolar com uma taxa $\kappa_{S}=\tau_{S}^{-1}$ e a cada instante de tempo ocorre a diminuição de energia do estado excitado do fluóroforo até atingir o estado de menor energia $\mathrm{R}$ vibracional [132]. Sendo assim, a cada tempo $t$, o fluoróforo emite fótons cada vez menos energéticos (de F até R indicado pelas diminuição do tamanho das setas de $S_{1}$ para $S_{0}$ ).

Entretanto, a fluorescência é um fenômeno aleatório e a cada instante pode ocorrer a emissão de fótons por espécies que interagiram em diferentes tempos com o solvente. Sendo assim, a cada instante há emissão a diversos comprimentos de onda (diversas energias) formando então, o espectro temporal. Este espectro sofre um redshift ao longo do tempo, pois as espécies que 
demoram mais tempo para emitir interagem mais tempo com o solvente e assim emitem em comprimentos de onda maiores $(\mathrm{R})$.

Este fenômeno depende da taxa $\kappa_{S}$ do solvente e de quantas moléculas de solvente estão presentes no microambiente do fluoróforo. Portanto, os espectros de fluorescência resolvidos no tempo (TRES) carregam a informação da hidratação e velocidade de despolarização do solvente no microambiente (ou resistência à despolarização). É importante acrescentar que estas duas informações são obtidas de maneira independente o quer torna essa técnica única [136].

\subsubsection{Metodologia para obter TRES}

O TRES é obtido através de uma extensiva análise de dados e ajustes de modelos que não são possíveis sem o uso de rotinas computacionais. Primeiramente mede-se a intensidade de fluorescência resolvida no tempo $I(t)$ para diferentes comprimentos de onda na região do espectro de fluorescência da sonda.

Como neste trabalho foi utilizado a sonda laurdan, os comprimentos de onda de interesse estão compreendidos entre $400 \mathrm{~nm}$ e $540 \mathrm{~nm}$. Mediu-se, então, a $I(t)$ de 400 até $540 \mathrm{~nm}$ em passos de $10 \mathrm{~nm}$, ou seja, $I_{\lambda}(t) \operatorname{com} 400<\lambda<540 \mathrm{~nm}$.

A metodologia (TCSPC) e o aparato experimental utilizados para medir a intensidade de fluorescência resolvida no tempo são os mesmos descritos anteriormente no item 4.1.4.2.

Para cada $I_{\lambda}(t)$ ajustou-se uma equação como a eq. 4.10 com $\mathrm{n}=4$ :

$$
I_{\lambda}(t)=I_{0, \lambda} \sum_{i=1}^{4} \alpha_{i, \lambda} e^{-t / \tau_{i, \lambda}}
$$

$\operatorname{com} \sum_{i=0}^{4} \alpha_{i, \lambda}=1 \operatorname{com} I_{0, \lambda}=1$. É importante acrescentar que neste caso $\alpha_{i, \lambda}$ e $\tau_{i, \lambda}$ não possuem nenhum significado físico. A eq. 4.36 é apenas uma descrição matemática da curva experimental do decaimento de fluorescência.

Por outro lado mede-se o espectro de fluorescência do estado estacionário $I_{S S}$ e realiza-se a correção espectral como descrito anteriormente. Como explicado anteriormente (eq. 4.2), a intensidade de fluorescência do estado estacionário de um comprimento de onda $\lambda$ é a soma de todos os fótons emitidos no estado transiente para este mesmo $\lambda$ a menos um fator de normalização $H_{\lambda}$ :

$$
I_{S S}(\lambda)=H_{\lambda} \int_{0}^{\infty} I_{\lambda}(t) d t=H_{\lambda} \sum_{i=1}^{4} \alpha_{i, \lambda} \tau_{i, \lambda}
$$

logo, o fator de normalização pode ser calculado para cada comprimento de onda atráves de:

$$
H_{\lambda}=\frac{I_{S S}(\lambda)}{\sum_{i=1}^{4} \alpha_{i, \lambda} \tau_{i, \lambda}}
$$


Com isso é possível calcular a intensidade de fluorescência normalizada para cada $\lambda \mathrm{em}$ qualquer tempo $t$, dentro da escala de tempo do experimento e obter o espectro resolvido no tempo TRES:

$$
\operatorname{TRES}(t)=H_{\lambda} I_{\lambda}(t) \quad \text { com } 400<\lambda<540 \mathrm{~nm}, \text { passos de } 10 \mathrm{~nm}
$$

logo:

(4.40) $\operatorname{TRES}(t)=\frac{I_{S S}(\lambda)}{\sum_{i=1}^{4} \alpha_{i, \lambda} \tau_{i, \lambda}} \sum_{i=1}^{4} \alpha_{i, \lambda} e^{-t / \tau_{i, \lambda}} \quad$ com $400<\lambda<540 \mathrm{~nm}$, passos de $10 \mathrm{~nm}$

Para exemplificar, a figura 4.12 apresenta os gráficos de TRES para membranas de POPC a $23{ }^{\circ} \mathrm{C}$. Os pontos são os valores de $H_{\lambda} I_{\lambda}(t)$ para cada tempo $t(0,5 ; 1 ; 4$ e $8 \mathrm{~ns})$ e as linhas são apenas guias para os olhos para observar o espectro resolvido em cada um destes tempos. Assim, obtém-se os espectros para qualquer tempo $t$.

É interessante notar dois efeitos que ocorrem com o passar do tempo: (i) o espectro sofre o redshift como esperado (explicado acima) e (ii) a intensidade de fluorescência diminui, pois a emissão de fótons é cada vez menor quanto mais tempo passa após o tempo $t=\langle\tau\rangle$, ou seja, a probabilidade do fluoróforo ainda estar no estado excitado é cada vez menor.

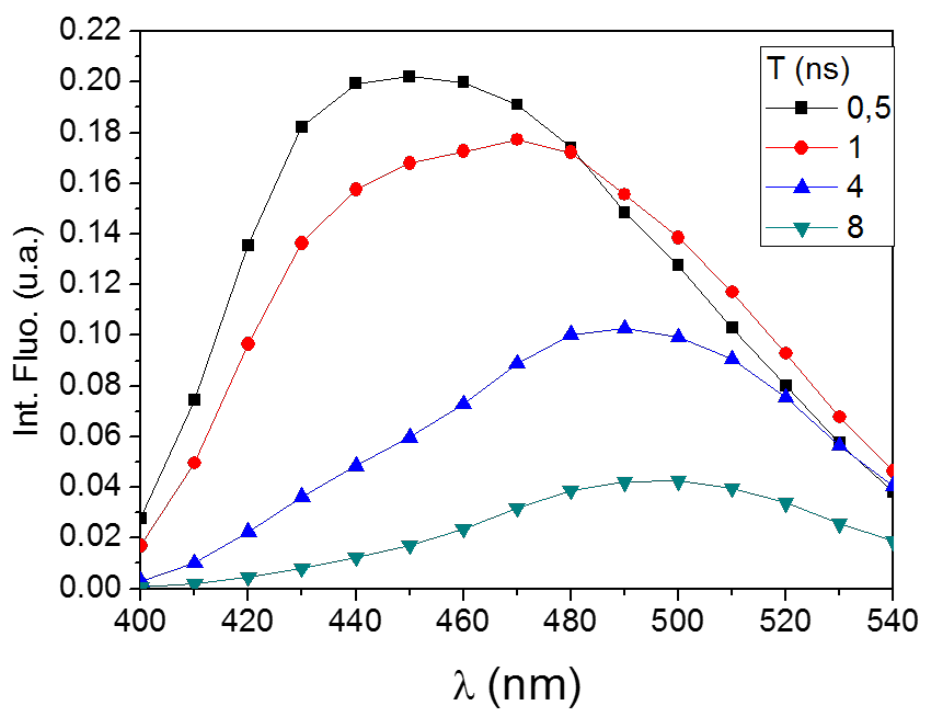

Figura 4.12: TRES (eq. 4.40) para membranas de POPC a $23^{\circ} \mathrm{C}$ para os tempos de 0,$5 ; 1 ; 4$ e 8 ns.

Para evidenciar o efeito (i) é possível normalizar os TRES presentes na figura 4.13: 


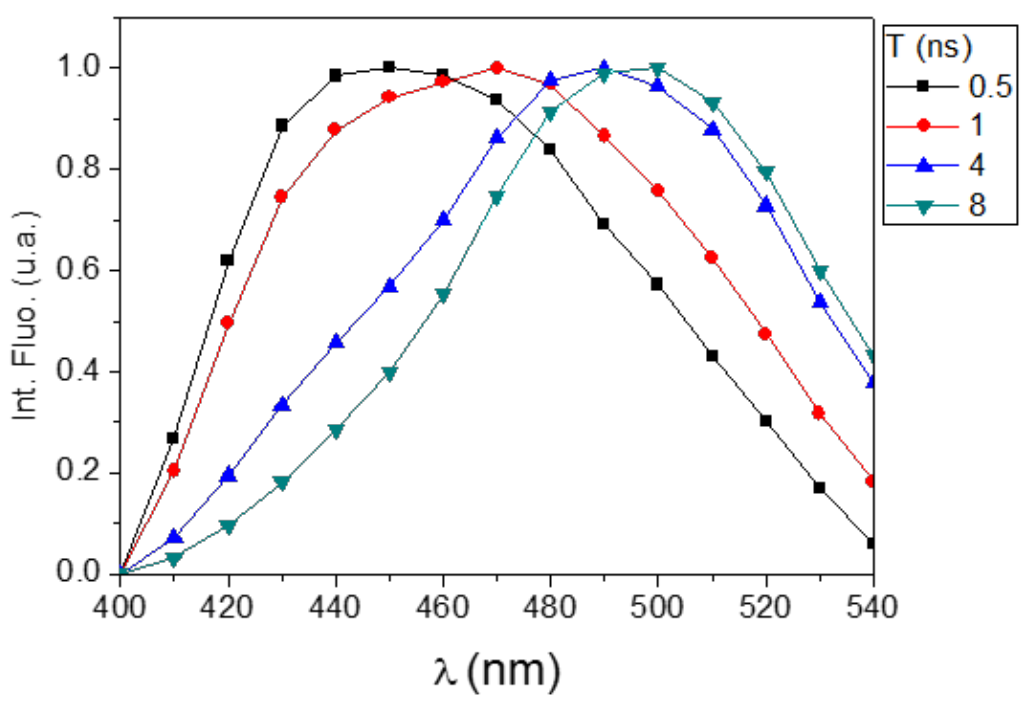

Figura 4.13: TRES normalizados para membranas de POPC a $23{ }^{\circ} \mathrm{C}$ para os tempos de $0.5,1,4$ e $8 \mathrm{~ns}$.

Como o TRES é utilizado para analisar a energia envolvida na interação do fluoróforo com o solvente (relaxação dipolar), converte-se o comprimento de onda $\lambda$ em número de onda $v$, pois $v$ é linearmente proporcional à energia.

É importante acrescentar que ao medir os espectros de fluorescência utiliza-se a resolução do comprimento de onda constante: $\Delta \lambda=\lambda_{2}-\lambda_{1}$. Ao converter $\lambda$ para $v$, a resolução $\Delta v$ não é mantida constante:

$$
\Delta v=v_{2}-v_{1}=\frac{1}{\lambda_{2}}-\frac{1}{\lambda_{1}}=\frac{\lambda_{1}-\lambda_{2}}{\lambda_{1} \lambda_{2}} \simeq \frac{|\Delta \lambda|}{\lambda^{2}}
$$

o que significa que a resolução em $\Delta v$ diminui com o aumento de $\lambda$ (diminuição de $v$ ).

Para entender o impacto deste fenômeno é necessário considerar que ao medir a intensidade de fluorescência $I(\lambda)$ em função de $\lambda$, mede-se a intensidade $I(\Delta \lambda)$, pois há contribuição da intensidade de fluorescênica de $I\left(\lambda-\frac{\Delta \lambda}{2}\right)$ e $I\left(\lambda+\frac{\Delta \lambda}{2}\right)$. Como $\Delta \lambda$ é constante para todos os comprimentos de onda, a intensidade de fluorescência para todo $\lambda$ é afetada igualmente, não gerando distorções no espectro.

Porém, ao converter $\lambda$ para $v$ a intensidade de fluorescência $I(\Delta v)$ recebe contribuições de $I\left(v-\frac{\Delta v}{2}\right)$ e $I\left(v+\frac{\Delta v}{2}\right)$ e $\Delta v$ diminui com a diminuição de $v$ (eq. 4.41). Assim sendo, a intensidade $I(\Delta v)$ para números de onda pequenos é menor, pois há intensidade de "menos $v$ s"contribuindo para a intensidade total.

Para deixar claro, este fenômeno equivale medir o espectro de fluorescência em função de $v$ com uma largura de banda que diminui com a diminuição de $v$.

Para corrigir esta distorção é necessário considerar o fator $\lambda^{2}$ ao converter $I(\lambda)$ em $I(v)$ [132]: 


$$
I(v)=I(\lambda) \lambda^{2}
$$

Por fim, utilizando a equação 4.42 é possível converter os TRES da figura 4.13 em função do número de onda:

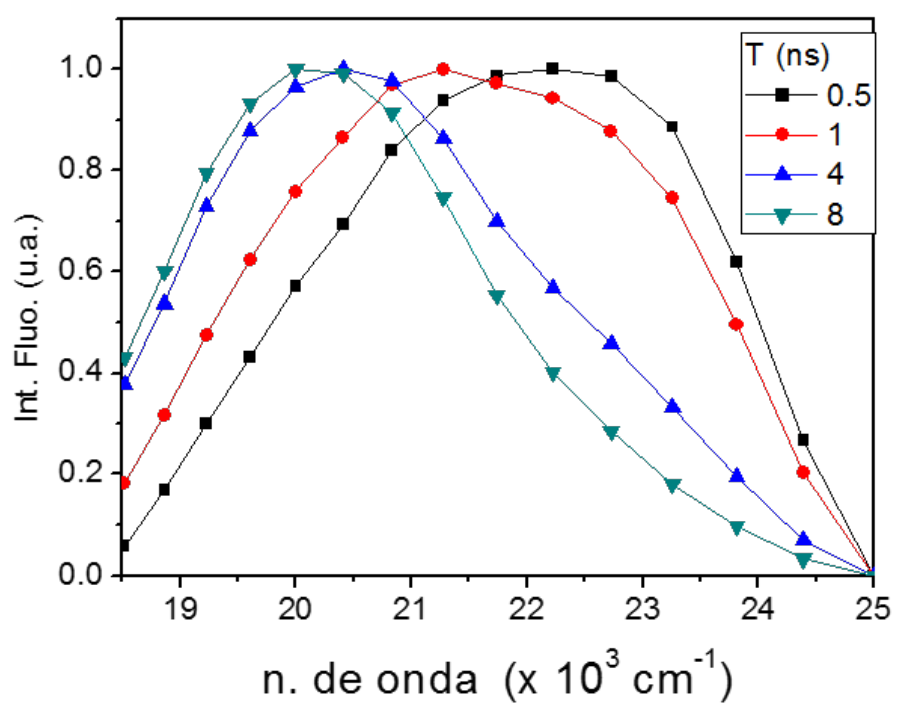

Figura 4.14: TRES (eq. 4.40) normalizados em função do número de onda para membranas de POPC a $23{ }^{\circ} \mathrm{C}$ para os tempos de $0.5,1,4$ e 8 ns.

Como esperado os espectros resolvidos no tempo movem-se para a esquerda, menores valores de $v$, em função do tempo, ou seja, a emissão de fluorescência é cada vez menos energética (fig. 4.14 e 4.15).

Para obter a evolução espectral com uma resolução temporal apropriada, é necessário calcular o TRES com passos temporais muito pequenos dentro da escala de tempo do experimento. Neste projeto, utilizou-se passos temporais de $0,015 \mathrm{~ns}$ entre $t_{0}=0,015 \mathrm{~ns}$ até $t_{\max }=20,85 \mathrm{~ns}$, obtendo assim, 1390 espectros resolvidos no tempo como o exemplo na fig 4.15. 


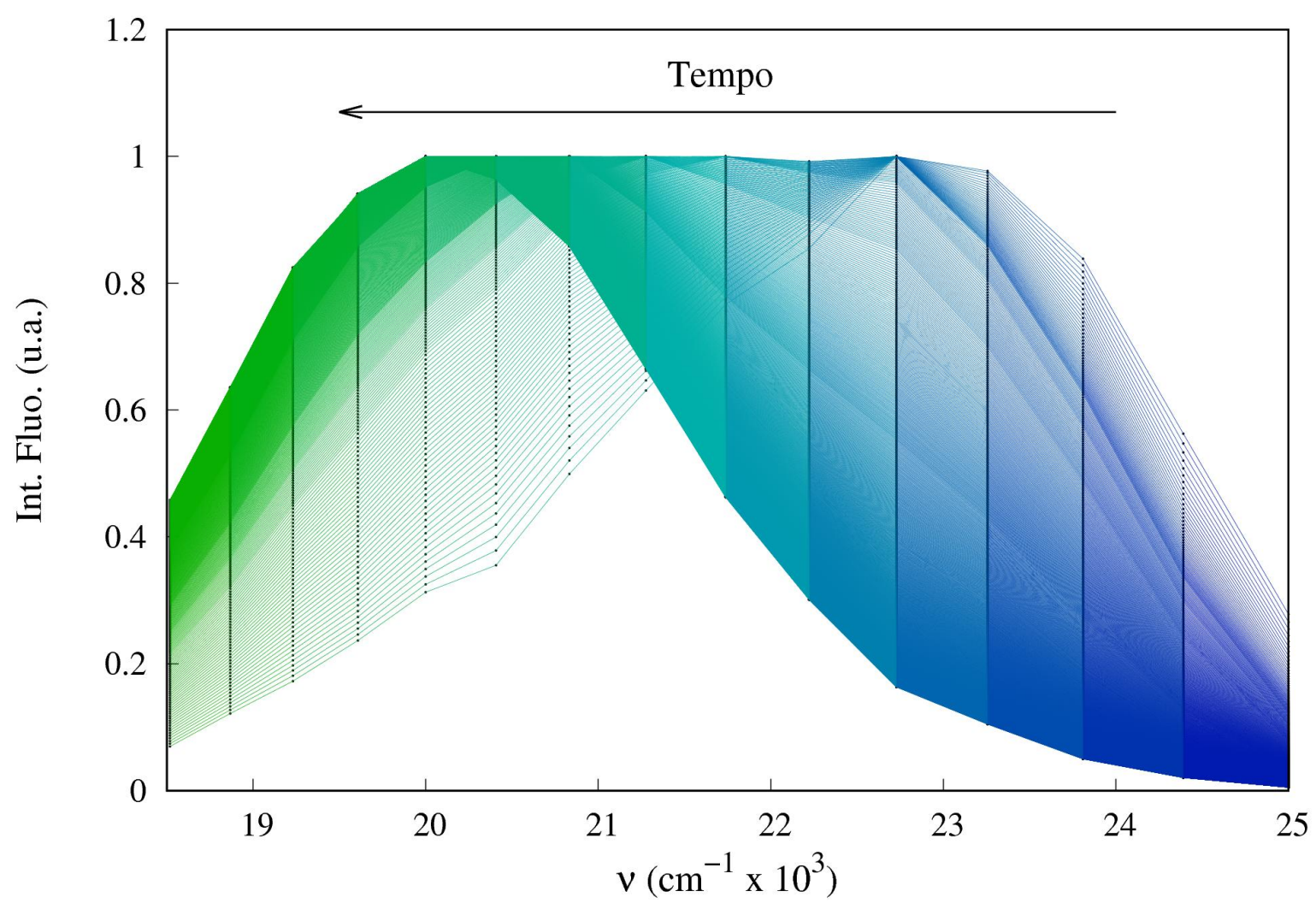

Figura 4.15: TRES normalizados e em função do número de onda para membranas de POPC a $23{ }^{\circ} \mathrm{C}$ para os tempos entre $t_{0}=0.015 \mathrm{~ns}$ até $t_{\max }=20.85 \mathrm{~ns}$ a cada $0.015 \mathrm{~ns}$. A escala de cor indica a perda de energia de emissão de fluorescência em função do tempo: mais energética (azul) e menos enérgetica (verde).

A evolução temporal dos espectros possui a informação da interação do fluoróforo com o solvente (fig. 4.15). Para obter estas informações é necessário ajustar uma função para cada espectro resolvido no tempo. A função ajustada é [137]:

$$
\operatorname{TRES}(t)=h(t) e^{-\ln (2)\left(\frac{\ln (1+\alpha)}{\gamma(t)}\right)^{2}} \quad \alpha \equiv \frac{\alpha\left(v(t)-v_{p}(t)\right)}{\Delta(t)}
$$

com 4 parâmetros de ajuste para cada espectro resolvido no tempo: $h(t)$ é a altura do pico máximo ( $\simeq 1$ pois TRES está normalizado), $v_{p}(t)$ o número de onda do pico máximo, $\gamma(t)$ é a assimetria e $\Delta(t)$ é largura da curva. Os ajustes para todos os 1390 espectros resolvidos no tempo foram realizados usando uma rotina computacional desenvolvida em $\mathrm{C}++$.

Após realizar os ajustes, pode-se fazer o gráfico de $v_{p}$ em função do tempo, $v_{p}(t)$, e ajustar uma curva multiexponencial:

$$
v_{p}(t)=v(\infty)+\Delta v \sum_{i=1}^{3} \alpha_{i} e^{\left(-t / \tau_{i}\right)} \quad \sum_{i=1}^{3} \alpha_{i}=1
$$


onde $v(\infty)$ é o número de onda do pico do espectro de fluorescência para o tempo infinito, $\Delta v$ é a variação do número de onda do pico do espectro de fluorescência entre o tempo $0\left(t_{0}\right)$ e o tempo infinito $\left(t_{\infty}>>t_{0}\right), \Delta v=v(0)-v(\infty), \alpha_{i}$ e $\tau_{i}$ não possuem sentido físico.

É importante destacar a interpretação física para $v(0)$ e $v(\infty)$ : o primeiro indica a posição do pico da emissão de maior energia do fluóroforo, ou seja, sem nenhuma relaxação dipolar do solvente; enquanto o segundo indica a posição do pico da emissão de menor energia do fluóroforo no microambiente onde se encontra, ou seja, após a relaxação dipolar máxima do solvente [137]. Logo, $\Delta v$ indica o quanto de energia o fluoróforo perdeu durante a interação com o solvente.

Outro aspecto importante da curva de $v_{p}(t)$ é a taxa de decaimento em função do tempo que possui a informação da velocidade da relaxação dipolar. É possível quantificar essa velocidade utilizando a evolução temporal da largura a meia altura dos espectros resolvidos no tempo, $\Gamma(t)$. Para isso, calcula-se a seguinte equação:

$$
\Gamma(t)=\Delta(t)\left(\frac{\operatorname{senh}(\gamma(t))}{\gamma(t)}\right)
$$

onde $\Delta(t)$ e $\gamma(t)$ são os parâmetros $\Delta$ e $\gamma$ obtidos para cada espectro resolvido no tempo, respectivamente.

A partir do gráfico de $\Gamma(t)$ em função do tempo é possível observar um valor máximo em um tempo $t_{R D}$ (tempo médio de relaxação dipolar). O maior valor de $\Gamma(t)$ indica o mais largo espectro de emissão resolvida, ou seja, o que possui contribuição significativa de muitos números de onda [137]. Isto significa uma grande heterogeneidade nas espécies dos fluóroforos que estão emitindo fótons naquele instante: alguns fluóroforos ainda não reorientaram o dipolo do solvente, outros já reorientaram totalmente e entre estes dois extremos existem inúmeras possibilidades.

Por isso, esse tempo $t_{R D}$, é interpretado como o tempo médio da relaxação dipolar do solvente e possui a informação da dinâmica da relaxação dipolar do solvente.

\subsubsection{Interpretação do TRES em membranas lipídicas}

Neste trabalho, utilizamos a sonda laurdan (item 4.1.3) para realizar os experimentos de TRES e a maior contribuição para a relaxação dipolar deve ser das moléculas de água que estão ao redor do laurdan [138].

Como mencionado anteriormente (item 4.1.3), o grupo naftaleno da sonda se localiza na região da cabeça polar dos lipídeos podendo ser mais interiorizado em consequência do empacotamento lateral. Com isso, as moléculas de água que interagem com o laurdan estão ligadas aos lipídeos (cabeça polar e carbonila) e, assim, a mobilidade destes lipídeos hidratados é obtida através dos experimentos de TRES [138].

Além disso, o grau de hidratação da membrana, que está relacionado com o número de moléculas de água que interagem com o laurdan, também é obtido por essa técnica experimental. 
Cabe acrescentar que, se houver algum outro grupo químico que mude a polaridade na região do fluoróforo, a interpretação de TRES pode se tornar mais complexa e as alterações dos espectros resolvidos no tempo não poderão ser correlacionadas apenas com as moléculas de água $[130,138]$.

É importante ressaltar que o tempo de relaxação de moléculas de água não ligadas aos lipídeos (livre em solução) é inferior a picossegundo e não contribuem para estes experimentos [138]. Por outro lado, ao se ligar aos lipídeos, o tempo de relaxação dipolar aumenta cerca de $10^{3}$ vezes e, portanto, a relaxação passa a ser na escala de nanossegundo se tornando compatível com o tempo de decaimento de fluorescência do laurdan. Isto possibilita a medida experimental de TRES.

Em resumo, o TRES aplicado ao estudo de membranas lipídicas é interpretado da seguinte maneira: os valores de $\Delta v$ e $\Gamma\left(t_{R D}\right)$ (item 4.1.6.1) podem indicar o grau de hidratação da membrana e a mobilidade dos lipídeos hidratados, respectivamente [138].

\section{Resumo de Experimentos e modelos}

A tabela abaixo visa resumir os experimentos realizados, destacando qual sonda fluorescente foi utilizada em cada caso, quais os dados experimentais obtidos e quais os parâmetros obtidos a partir das análises dos dados experimentais. 


\begin{tabular}{|c|c|c|c|c|}
\hline \multirow[b]{2}{*}{ Fluorescência } & \multicolumn{2}{|c|}{ TMA-DPH } & \multicolumn{2}{|c|}{ Laurdan } \\
\hline & Dados & Parâmetros & Dados & Parâmetros \\
\hline \multicolumn{5}{|l|}{ Estacionária } \\
\hline$<\mathrm{r}>$ & $I_{V V}, I_{V H}, I_{H V}, I_{H H}$ & $\mathrm{G}$ & & \\
\hline GP & & & $\begin{array}{l}\text { Espectro de } \\
\text { emissão } 400 \\
\leq \lambda \leq 540 \mathrm{~nm}\end{array}$ & $I_{440}, I_{490}$ \\
\hline Res. temporal & & & & \\
\hline
\end{tabular}

\begin{tabular}{|c|c|c|c|c|}
\hline$\tau$ & $I(t)$ & $\alpha_{i}, \tau_{i},<\tau>$ & & \\
\hline$r(t)$ & $\begin{array}{l}I(t), \quad I_{V V}(t), \\
I_{V H}(t)\end{array}$ & $\begin{array}{l}\alpha_{i}, \tau_{i},<\tau> \\
\beta_{j}, \quad \phi_{j}, \quad r_{\infty}, \\
D_{\perp}, v\end{array}$ & & \\
\hline TRES & & & $\begin{array}{l}I_{\lambda}(t) \text { para } 400 \\
\leq \lambda \leq 540 \\
\mathrm{~nm}^{*}\end{array}$ & 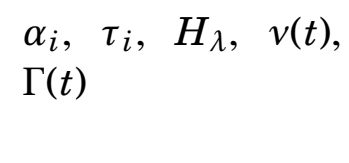 \\
\hline
\end{tabular}

Tabela 4.5: Resumo das sondas fluorescentes, dados experimentais e parâmetros obtidos para cada método experimental de fluorescência realizado neste projeto. ${ }^{*} \mathrm{O}$ espectro de fluorescência do laurdan também é um dado experimental para a técnica de TRES. 


\subsection{Resultados I - Impacto do lipídeo oxidado POPC-OOH em membranas lipídicas}

O primeiro sistema estudado foi composto por vesículas multilamelares (MLVs) de POPC:POPCOOH (fig. 4.1) nas proporções de 100:0, 90:10, 75:25, 70:30, 50:50, 30:70 e 0:100 à temperatura de 23 e $37{ }^{\circ} \mathrm{C}$ (tabela 4.1).

Nos gráficos a seguir, os dados de experimentos independentes estão indicados como pontos cinzas e pontos pretos para 23 e $37^{\circ} \mathrm{C}$, respectivamente. Para facilitar a apreciação dos dados, a média e a incerteza (distância entre o menor e maior valor obtido) dos resultados estão indicados em verde para $23^{\circ} \mathrm{C}$ e azul para $37^{\circ} \mathrm{C}$, respectivamente.

A figura 4.16 apresenta a anisotropia do estado estacionário $(<r>)$ para a sonda TMA-DPH em MLVS (item 4.1.5.3) de POPC:POPC-OOH (100:1 lipídeo:sonda).

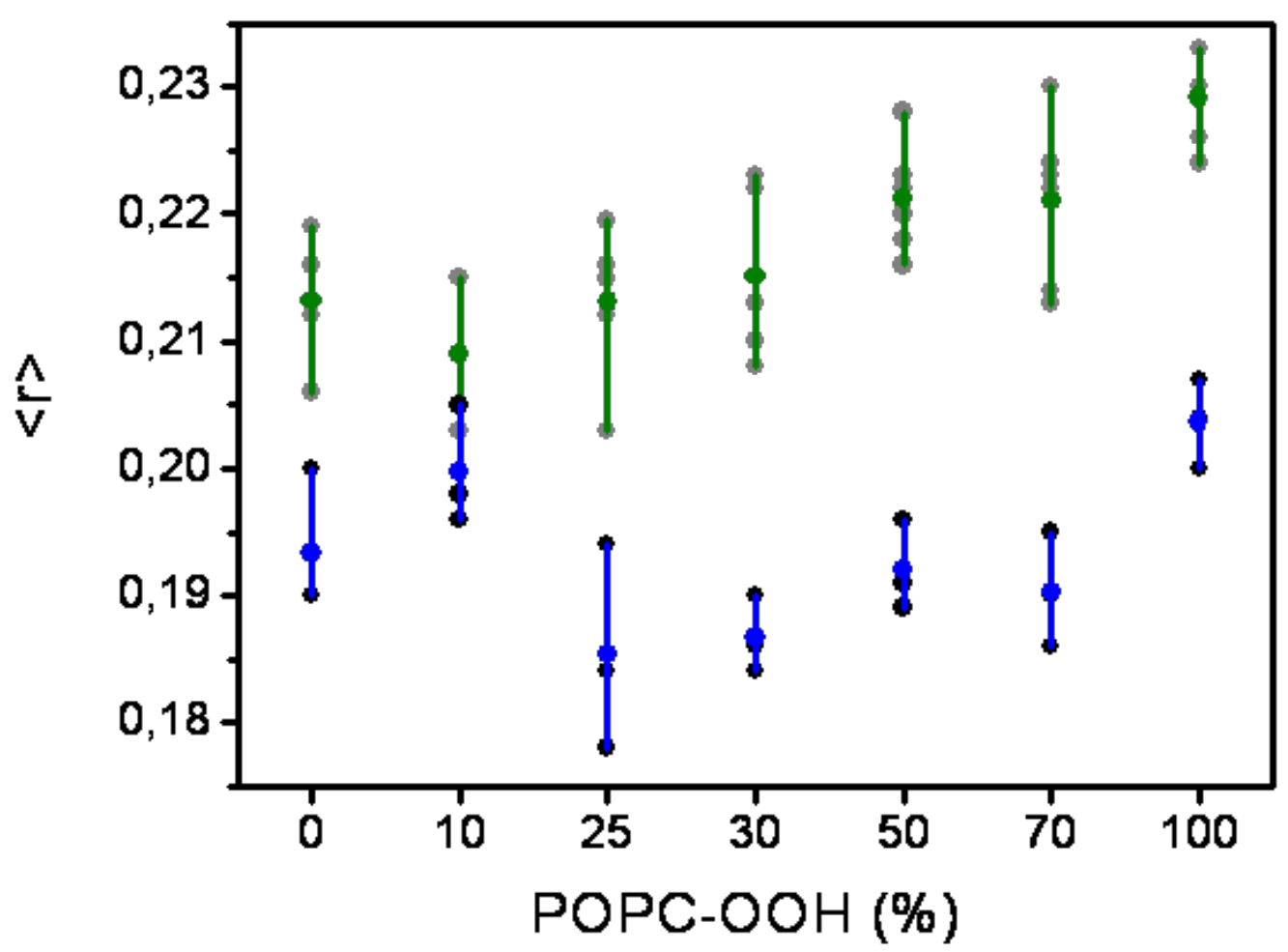

Figura 4.16: Anisotropia de fluorescência no estado estacionário para MLVs de POPC (100 $\mu \mathrm{M})$ contendo TMA-DPH na razão molar 100:1 (lipídeo:sonda) e concentração crescente de POPC-OOH a $23{ }^{\circ} \mathrm{C}$ (pontos cinzas, média e incerteza em verde) e $37^{\circ} \mathrm{C}$ (pontos pretos, média e incerteza em azul).

Primeiramente, pode-se observar que os valores obtidos para a anisotropia do estado estacionário para MLVs de $100 \%$ POPC a 23 e $37^{\circ} \mathrm{C}$ (fig. 4.16) estão em acordo com os dados da literatura: 0,21 [139] a $23^{\circ} \mathrm{C}$ e 0,19 [139] a $37^{\circ} \mathrm{C}$. 
Para avaliar o impacto da presença do lipídeo oxidado POPC-OOH nas membranas, a anisotropia do estado estacionário a $23^{\circ} \mathrm{C}$ (pontos verdes fig. 4.16) mostrou uma leve tendência a aumentar com o aumento da quantidade de POPC-OOH na MLV. Tal fato sugere que a sonda experimenta um microambiente mais rígido ou que diminui seu tempo de vida (eq. de Perrin 4.21). Por outro lado, com o aumento da temperatura para $37^{\circ} \mathrm{C}$ os valores de $<r>$ são praticamente constantes dentro das incertezas avaliadas para todas as composições lipídicas contendo POPC-OOH.

A seguir, utilizando os procedimentos descritos no item 4.1.5.2 foi possível analisar os dados de intensidade de fluorescência resolvida no tempo da sonda TMA-DPH nos mesmos sistemas lipídicos e obter os valores de tempo de vida médio de fluorescência, $\langle\tau\rangle$. Assim sendo, obteve-se a figura 4.17:

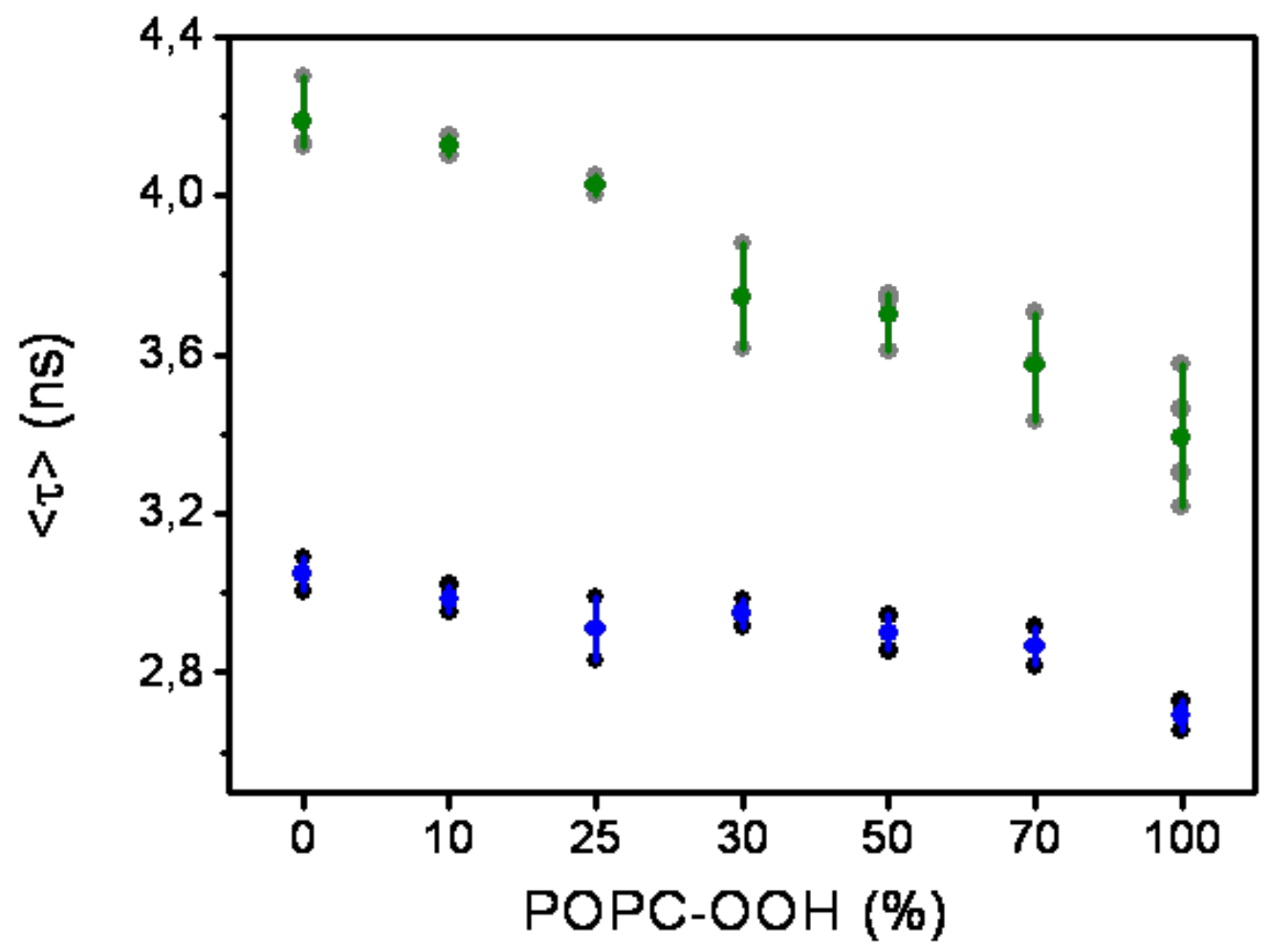

Figura 4.17: Tempo de vida médio de fluorescência para MLVs de POPC $(100 \mu \mathrm{M})$ contendo TMA-DPH na razão molar 100:1 (lipídeo:sonda) e concentração crescente de POPC-OOH a 23 (pontos cinzas, média e incerteza em verde) e $37^{\circ} \mathrm{C}$ (pontos pretos, média e incerteza em azul).

Como controle de nossos experimentos e análises dos tempos de vida de fluorescência da sonda TMA-DPH em MLVs, utilizou-se os resultados para MLVs de 100\% POPC para comparação com os dados da literatura. Como apresentado na figura 4.17 os valores obtidos nesta tese para as MLVs de 100\% POPC estão em acordo com a literatura em ambas as temperaturas, 3,9 - 4,2 ns [139-141] a $23{ }^{\circ} \mathrm{C}$ e $3,0-3,4[142,143]$ a $37{ }^{\circ} \mathrm{C}$. 
Analisando os dados de $\langle\tau\rangle$ (fig. 4.17) é possível perceber a diminuição do tempo de vida médio em função do aumento da concentração de lipídeo oxidado para ambas temperaturas, sendo mais acentuada a $23{ }^{\circ} \mathrm{C}$ do que a $37{ }^{\circ} \mathrm{C}$.

Correlacionando os dados de anisotropia de fluorescência do estado estacionário (fig 4.16) com os dados de tempo de vida médio de fluorescência (fig 4.17) poder-se-ia afirmar que os dois estão em contradição sendo que o leve aumento de $<r>$ com a concentração de POPC-OOH poderia indicar maior rigidez da membrana enquanto a diminuição de $\langle\tau\rangle$ indicaria maior penetração de água (menor rigidez).

Para analisar essa possível contradição dos resultados utilizamos a equação de Perrin (eq. 4.21) para fazer o gráfico de $\langle\tau\rangle$ em função de $\langle r\rangle$ e os resultados estão apresentados na figura 4.18:

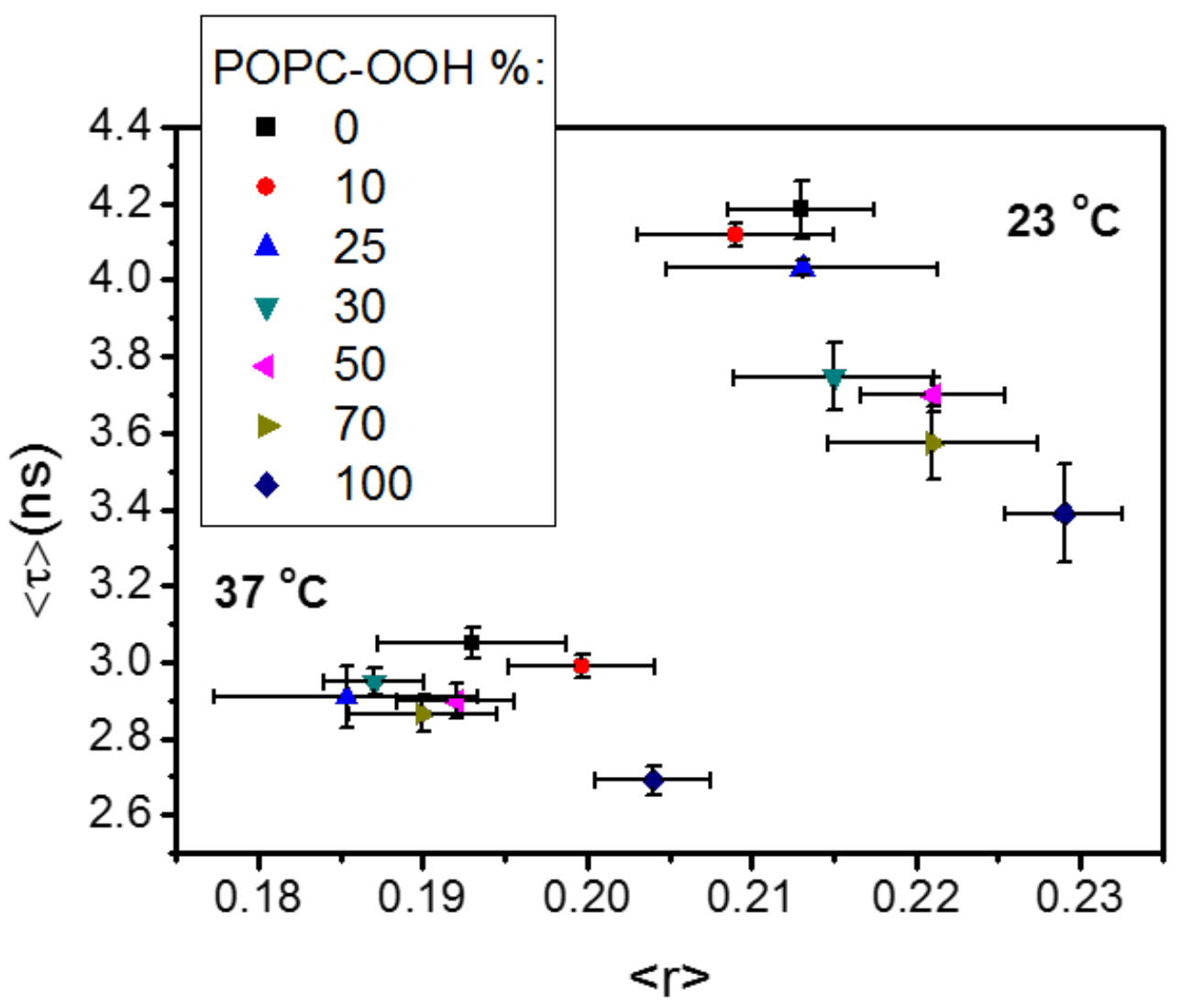

Figura 4.18: Tempo de vida médio de fluorescência para MLVs de POPC (100 $\mu \mathrm{M})$ contendo TMA-DPH na razão molar 100:1 (lipídeo:sonda) em função da anisotropia de fluorescência para as mesmas amostras a 23 (pontos cinzas, média e incerteza em verde) e $37^{\circ} \mathrm{C}$ (pontos pretos, média e incerteza em azul).

Analisando a figura 4.18 para a temperatura de $37^{\circ} \mathrm{C}$ (pontos mais à esquerda) pode-se notar que não existe uma correlação clara entre o tempo de vida médio de fluorescência e a anisotropia de fluorescência do estado estacionário, exceto para MLV de 100\% POPC-OOH (diamante azul escuro) que existe aumento da $\langle r\rangle$ acompanhado a diminuição de $\langle\tau\rangle$. 
Por outro lado, para a temperatura de $23^{\circ} \mathrm{C}$ a diminuição de $\langle\tau\rangle$ acontece com o aumento de $<r>$ para MLVs com concentrações de POPC-OOH maiores do que $25 \%$.

Esta correlação de diminuição de $\langle\tau\rangle$ com o aumento de $\langle r\rangle$ pode ser explicada da seguinte maneira: o aumento da anisotropia ocorre devido ao fato da sonda não emitir fluorescência $(<\tau>)$ até o final do processo de rotação acarretando na diminuição artificial da componente $\mathrm{I}_{\mathrm{VH}}$ (4.20). Dessa maneira, a rotação da sonda pode ser a mesma para todas as composições lipídicas analisadas (mesma $<r>$ ), mas experimentalmente não estamos acessando a rotação completa da sonda.

Para elucidar sobre este possível efeito, foram realizados experimentos de anisotropia de fluorescência resolvida no tempo (4.1.5.4), onde o tempo de vida é considerado concomitante na análise.

Realizando os experimentos e análises explicados no item 4.1.5.4 pôde-se obter os parâmetros da anisotropia de fluorescência resolvida no tempo $(r(t))$ para as MLVs de POPC contendo a sonda TMA-DPH com o aumento da concentração de POPC-OOH para as temperaturas de 23 e $37{ }^{\circ} \mathrm{C}$. Os resultados obtidos para a anisotropia residual $\left(r_{\infty}\right)$ estão presentes na figura 4.19, enquanto que o tempo médio de correlação rotacional $(\langle\phi\rangle)$ está na figura 4.20.

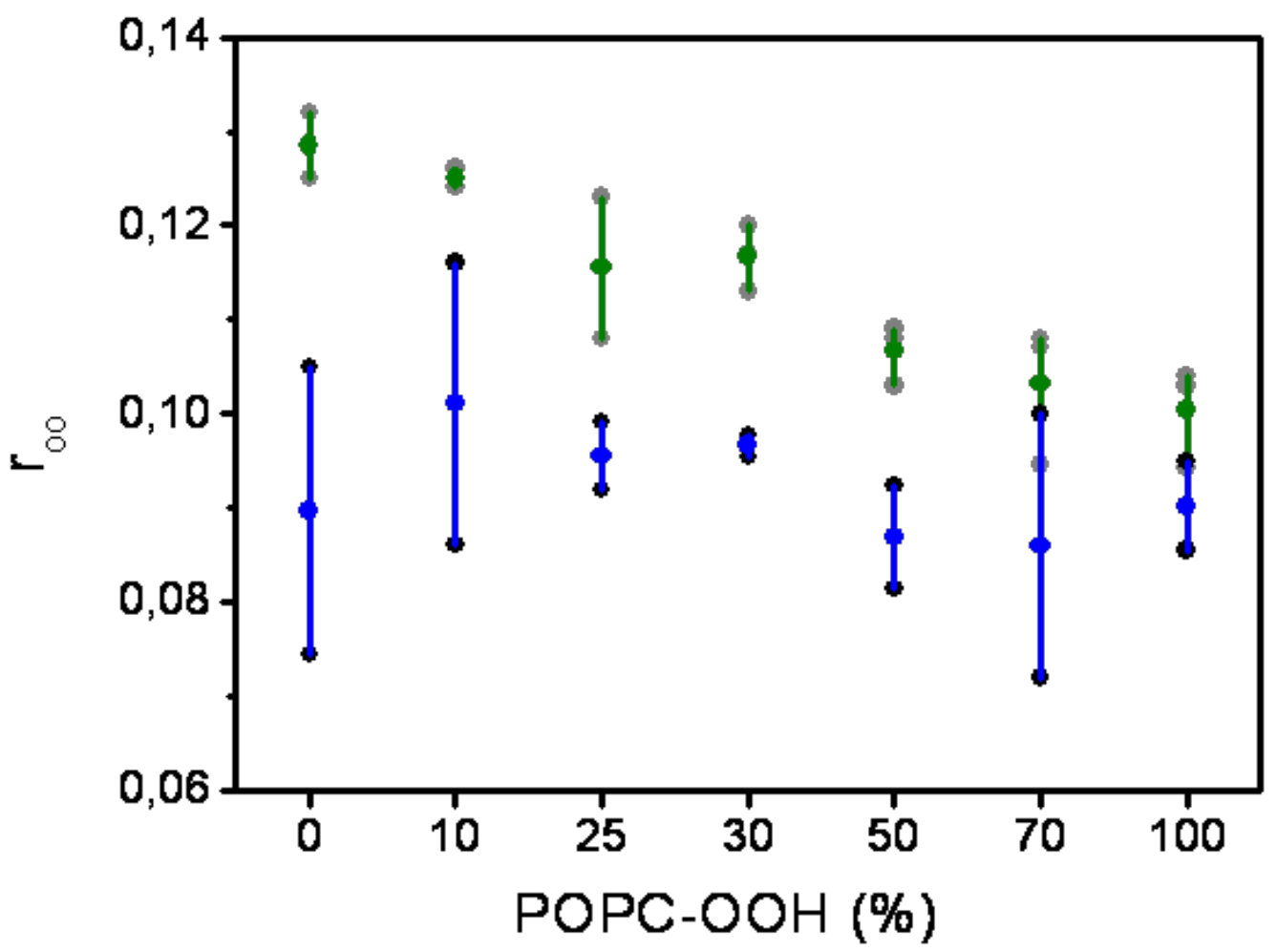

Figura 4.19: Anisotropia residual para MLVs de POPC $(100 \mu \mathrm{M})$ contendo TMA-DPH na razão molar 100:1 (lipídeo:sonda) com o aumento da concentração de POPC-OOH a 23 (pontos cinzas, média e incerteza em verde) e $37^{\circ} \mathrm{C}$ (pontos pretos, média e incerteza em azul). 
Como podemos observar, a anisotropia residual, $r_{\infty}$, apresenta uma diminuição com o aumento da concentração de POPC-OOH a temperatura de $23{ }^{\circ} \mathrm{C}$ (fig. 4.19 - pontos verdes). Já para a temperatura de $37{ }^{\circ} \mathrm{C}$ não foi observada nenhuma alteração no valor da anisotropia residual dentro das incertezas avaliadas em função do aumento da concentração do lipídeo oxidado (fig. 4.19 pontos azuis).

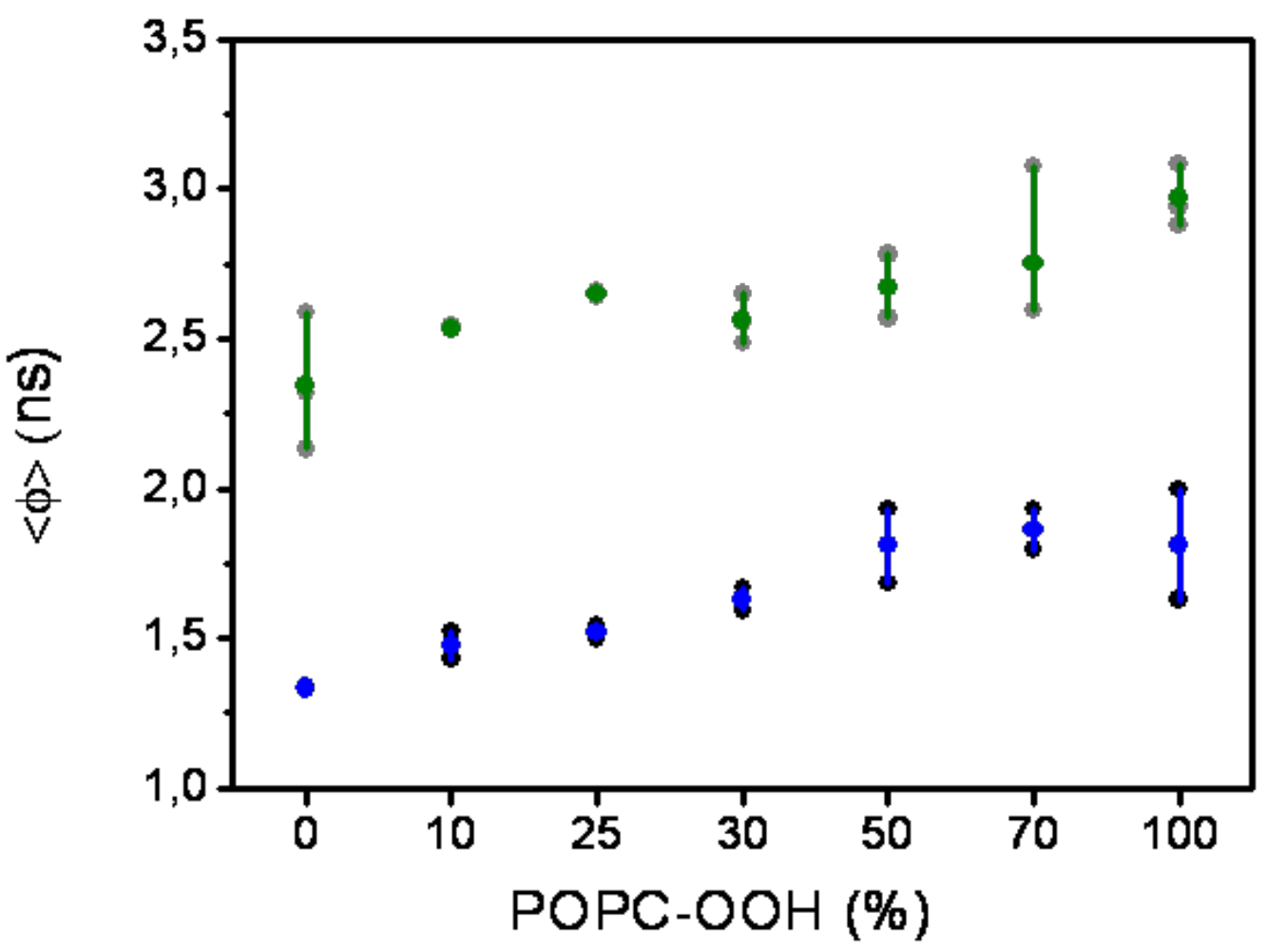

Figura 4.20: Tempo médio de correlação rotacional do TMA-DPH em MLVs de POPC (100 $\mu \mathrm{M})$ na razão molar 100:1 (lipídeo:sonda) com o aumento da concentração de POPC-OOH a 23 (pontos cinzas, média e incerteza em verde) e $37^{\circ} \mathrm{C}$ (pontos pretos, média e incerteza em azul).

Ao mesmo tempo, pode-se observar que os valores de $\langle\phi\rangle$ da sonda apresentam leve aumento com o aumento da concentração do POPC-OOH para ambas temperaturas evidenciando que o tempo para que a sonda atinja $r_{\infty}$ é cada vez maior (fig. 4.20).

Para melhor interpretar os valores obtidos de $r_{\infty}$ (fig. 4.19) e $\langle\Phi\rangle$ (fig. 4.20), a figura 4.21 apresenta os valores obtidos para a microviscosidade $(\eta)$ onde é possível perceber um leve aumento de $\eta$ em função da concentração de POPC-OOH. 


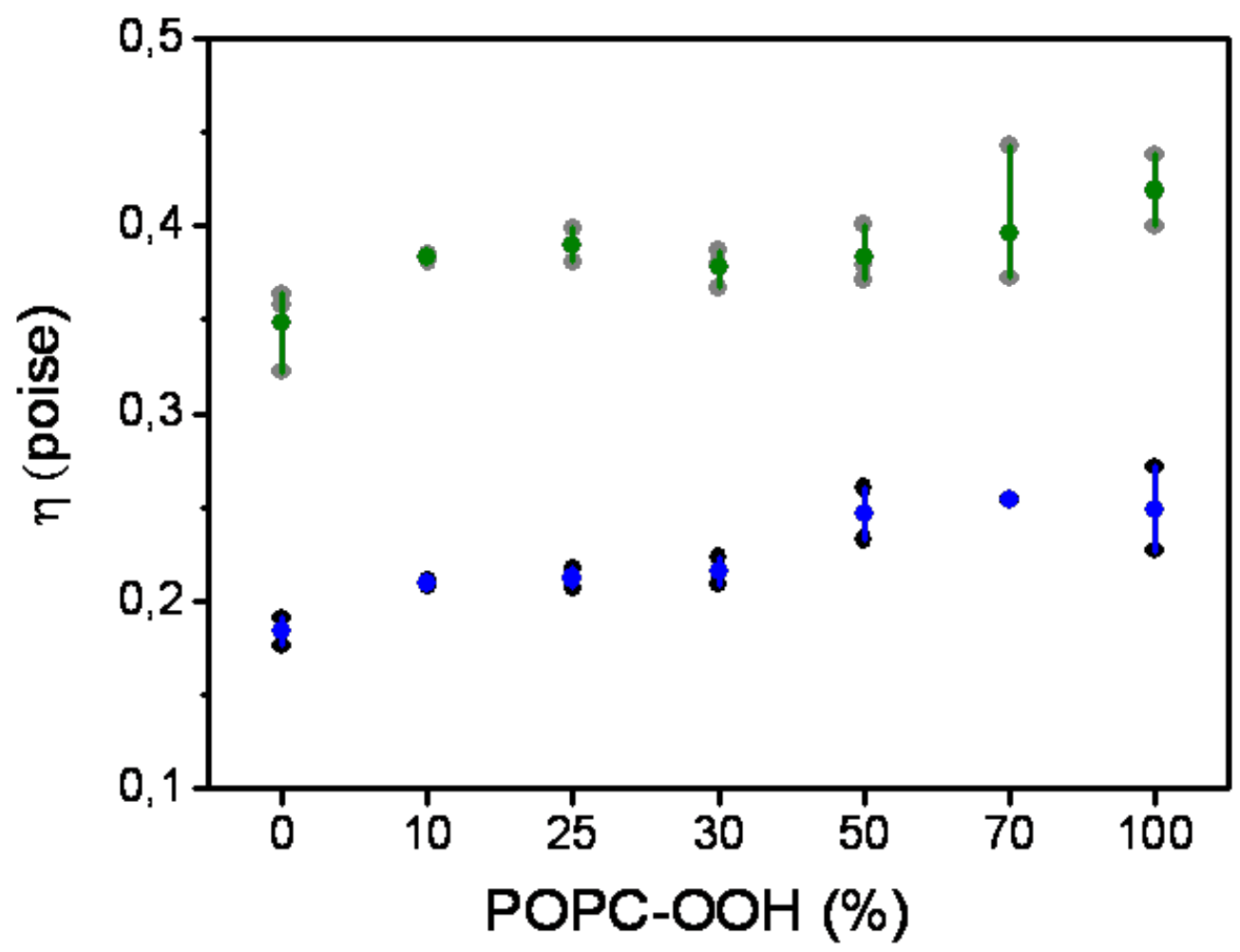

Figura 4.21: Microviscosidade para MLVs de POPC $(100 \mu \mathrm{M})$ contendo TMA-DPH na razão molar 100:1 (lipídeo:sonda) com o aumento da concentração de POPC-OOH a 23 (pontos cinzas, média e incerteza em verde) e $37^{\circ} \mathrm{C}$ (pontos pretos, média e incerteza em azul).

Como controle dos parâmetros obtidos através das análises de anisotropia resolvida no tempo (figs 4.19 - 4.21) a tabela 4.6 apresenta os valores de $r_{\infty},\langle\phi\rangle$ e $\eta$ obtidos neste trabalho para as MLVs de 100\% POPC com os dados presentes na literatura. Nota-se que os parâmetros obtidos estão em acordo com os valores já publicados (tabela 4.6) [123, 140, 141, 143].

\begin{tabular}{cccc} 
& $r_{\infty}$ (u.a) & $<\phi>($ ns $)$ & $\eta$ (poise) \\
\cline { 2 - 4 } $23{ }^{\circ} \mathrm{C}$ & $0,13 \pm 0,01(0,11 ; 0,12)^{*}$ & $2,3 \pm 0,2(2,3 ; 2,9)^{*}$ & $0,35 \pm 0,02(0,338 ; 0,35)^{*}$ \\
\hline $37^{\circ} \mathrm{C}$ & $0,09 \pm 0,02(0,11 ; 0,14)^{+}$ & $1,30 \pm 0,05(0,8 ; 2,1)^{+}$ & $0,18 \pm 0,01(0,11 ; 0,36)^{+}$ \\
\hline
\end{tabular}

Tabela 4.6: Valores obtidos para as MLVs de POPC (100 $\mu \mathrm{M})$ contendo TMA-DPH na razão molar 100:1 (lipídeo:sonda). Entre parênteses estão valores da literatura para $20^{\circ} \mathrm{C}[140,141]^{*}$; + para $35^{\circ} \mathrm{C}$ [143] e $27^{\circ} \mathrm{C}$ [123] (resultado obtido por dinâmica molecular) separados por vírgula.

Cabe acrescentar que ao aumentar a temperatura de MLVs de 100\% POPC há diminuição da anisotropia residual, do tempo de correlação rotacional e da microviscosidade indicando maior abertura angular experimentada pela sonda TMA-DPH, menor tempo para a sonda atingir essa maior abertura angular e menor microviscosidade do ambiente lipídico, respectivamente. 
Sumarizando os resultados obtidos através das análises de fluorescência da sonda TMADPH (figs 4.16 - 4.21) em MLVs de POPC com o aumento da concentração de POPC-OOH: (i) há diminuição do tempo de vida médio de fluorescência da sonda TMA-DPH; (ii) diminuição da anisotropia residual (aumento da abertura angular máxima); (iii) maior tempo para a sonda TMA-DPH rotacionar até a abertura angular máxima; (iv) aumento da microviscosidade no ambiente da sonda. Todas essas observações são derivadas do movimento de rotação (anisotropia estática e resolvida no tempo) e da supressão de fluorescência do TMA-DPH, mas não possuem informações diretas do microambiente do ponto de vista da sua polaridade.

Então, com o intuito de obter as informações do microambiente, na região da interface membrana/água, realizamos experimentos de fluorescência da sonda laurdan para calcular o GP (item 4.1.5) e também experimentos de emissão de espectro de fluorescência resolvido no tempo TRES.

A figura 4.22 apresenta os resultados obtidos para os valores de GP. Conforme pode-se observar, os valores de GP aumentam em função da concentração do POPC-OOH para ambas temperaturas estudadas. Em primeira análise, isto indicaria que a sonda interage com um número menor de moléculas de água caracterizando um microambiente mais apolar (menor hidratação menor quantidade de dipolos) e/ou a velocidade de relaxação dos dipolos é mais lenta (maior rigidez das membranas lipídicas). 


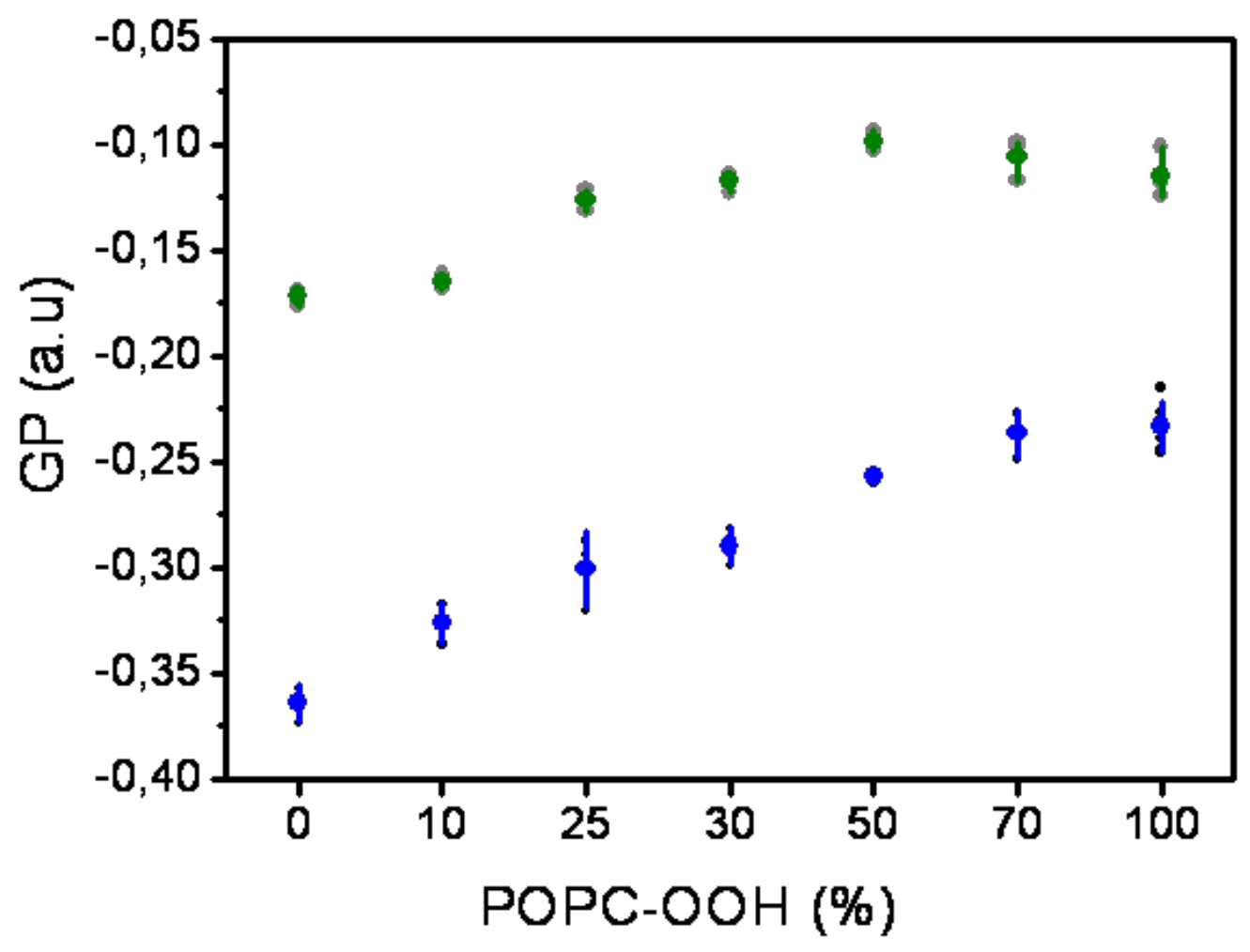

Figura 4.22: Valores de GP do laurdan para MLVs de POPC (100 $\mu \mathrm{M}$ - 100:1 lipídeo:sonda) com o aumento da concentração de POPC-OOH a 23 (pontos cinzas, média e incerteza em verde) e $37^{\circ} \mathrm{C}$ (pontos pretos, média e incerteza em azul).

Para separar estes dois efeitos (hidratação e velocidade de relaxação), utilizamos a metodologia de espectro de fluorescência resolvido no tempo (TRES). Como controle para implementação do TRES foram utilizadas LUVs de POPC a $23^{\circ} \mathrm{C}$ e a $37^{\circ} \mathrm{C}$ que já foram estudadas na literatura [136]. A figura 4.23 apresenta 1400 espectros de emissão de fluorescência do laurdan em LUVs de POPC em passos de 0,015 ns entre $\mathrm{t}=0,015$ ns até $\mathrm{t}=20,85$ ns. Esse conjunto de espectros é denominado TRES: 


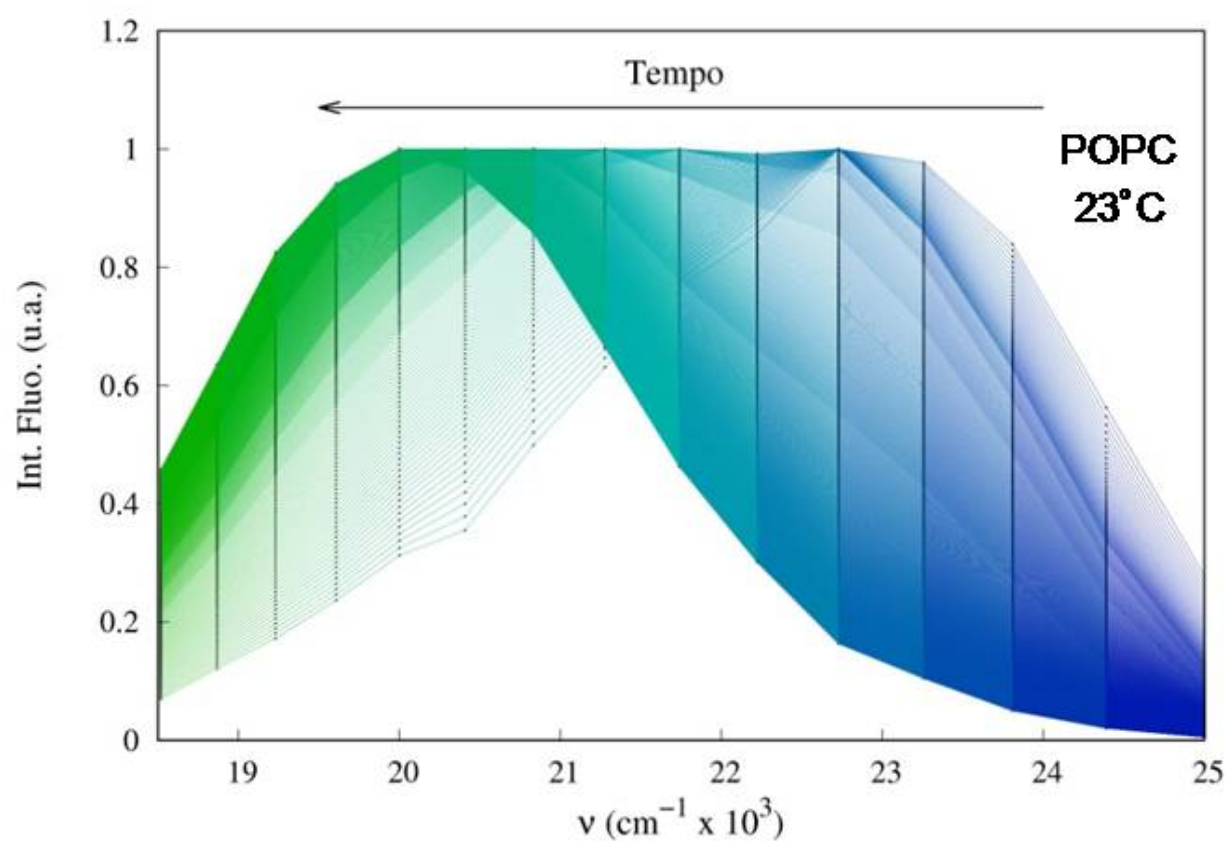

(a)

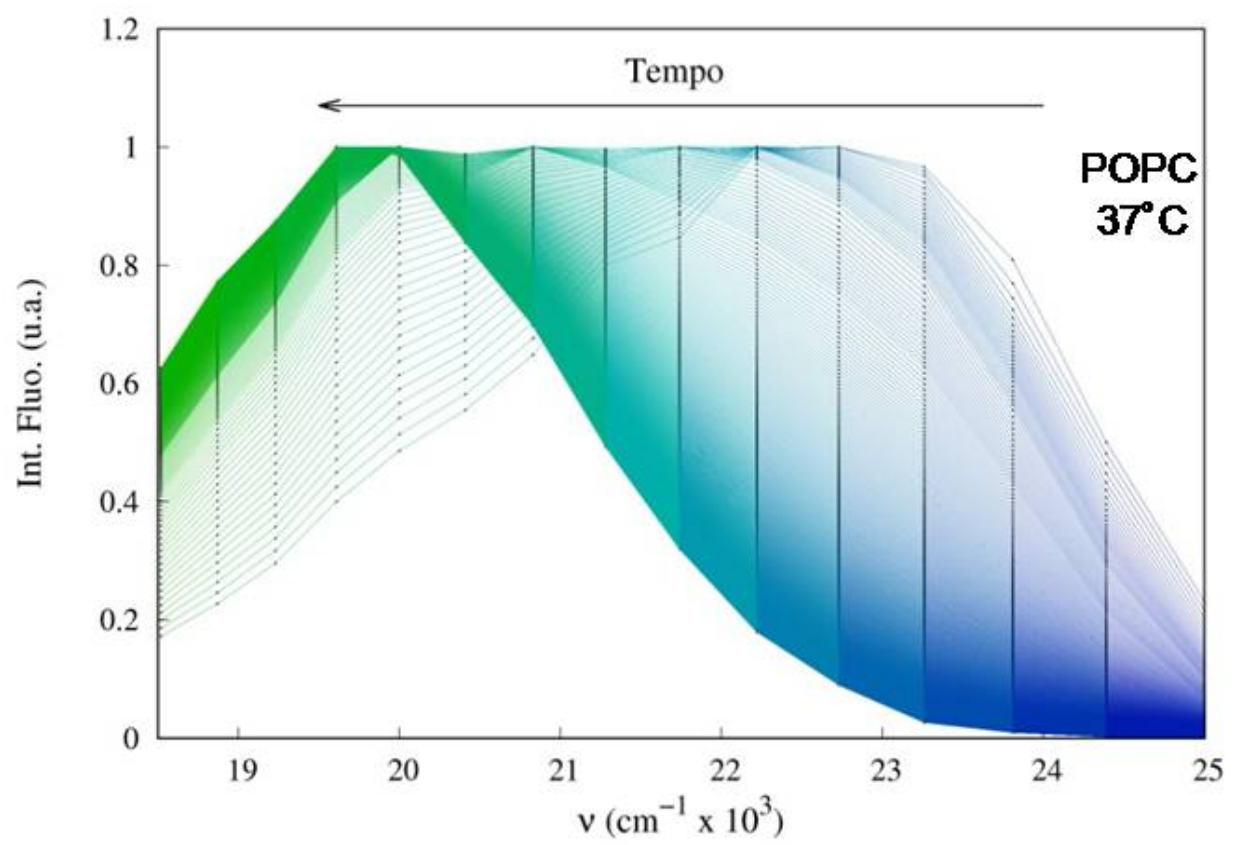

(b)

Figura 4.23: TRES obtidos para LUVs de POPC extrusadas com poro de $0,1 \mu \mathrm{m}$ para obter vesículas unilamelares (LUVs), a concentração lipídica utilizada foi de $500 \mu \mathrm{M}$ e a razão lipídeo:laurdan foi de 100:1. Em cada gráfico estão 1400 espectros resolvidos no tempo em passos de 0,015 ns entre $\mathrm{t}=0,015 \mathrm{~ns}$ até $\mathrm{t}=20,85 \mathrm{~ns}$

Utilizando o procedimento de ajuste para cada um dos espectros resolvidos no tempo descrito no item 4.1.6 obteve-se os valores da posição de pico de emissão de cada um dos 1400 espectros $\left(v_{p}(t)\right)$ para calcular $\Delta v$. Além disso, calculou-se os valores de largura a meia altura para cada espectro em função do tempo $(\Gamma(t))$ para estimar o tempo médio de relaxação dipolar 
$\tau_{R D}$. Os resultados estão apresentados na tabela 4.7 e os gráficos de $v_{p}(t)$ e $\Gamma(t)$ estão presentes na figura 4.25, junto com as curvas obtidas para as LUVS compostas de $100 \%$ POPC-OOH.

Para melhor análise dos parâmetros obtidos para as LUVs de POPC, os valores de GP para estas mesmas amostras (fig. 4.8) também estão presentes na tabela 4.7 assim como os valores disponíveis na literatura para os parâmetros obtidos através das análises de TRES. Os valores de GP, $\Delta v$ e $\tau_{R D}$ obtidos em nossos experimentos estão em ótimo acordo com os publicados na literatura [128].

\begin{tabular}{|c|c|c|}
\hline & $23{ }^{\circ} \mathrm{C}$ & $37^{\circ} \mathrm{C}$ \\
\hline GP (u.a.) & $-0,180 \pm 0,007(-0,177 \pm 0,004)$ & $-0,370 \pm 0,008(-0,360 \pm 0,003)$ \\
\hline$\Delta v\left(\mathrm{~cm}^{-1} \times 10^{3}\right)$ & $4048 \pm 90(4095 \pm 50)$ & $4099 \pm 90(4078 \pm 50)$ \\
\hline$\tau_{R D}(\mathrm{~ns})$ & $1,08 \pm 0,06(1,06 \pm 0,05)$ & $0,39 \pm 0,06(0,32 \pm 0,05)$ \\
\hline
\end{tabular}

Tabela 4.7: Valores obtidos para LUVs de POPC contendo laurdan 100:1 (lipídeo:sonda) a $23^{\circ} \mathrm{C}$ e $37^{\circ} \mathrm{C}$ : GP, $\Delta v$ e $\tau_{R D}$ para os nossos experimentos e entre parênteses os valores publicados por Amaro et al. [128], para comparação. Para calcular o $\Delta v$ foi utilizado o valor de $v(0)=23,800$ $\mathrm{cm}^{-1}$ obtido por [144].

Os valores de $\Delta v$ e $\tau_{R D}$ podem ser qualitativamente apreciados diretamente na figura 4.23: como $v(0)$ é o mesmo, o valor de $\Delta v$ será menor se o valor de $v(\infty)$ for menor; sendo assim, em ambas as temperaturas, a posição do pico máximo dos espectros resolvidos no tempo chega até $v \sim 20 \times 10^{3} \mathrm{~cm}^{-1}$, logo ambas temperaturas possuem $\Delta v$ muito similar.

Por outro lado, $\tau_{R D}$ pode ser estimado como o tempo até alcançar essa posição final. Pode-se perceber que a $37{ }^{\circ} \mathrm{C}$ o número de espectros resolvidos (indicado pela "densidade de espectros"/ transparência) é menor entre 21 e $24 \times 10^{3} \mathrm{~cm}^{-1}$ sugerindo que a perda de energia da sonda laurdan acontece mais rapidamente nessa temperatura.

Vale a pena notar que o valor do GP para membranas de POPC a $37^{\circ} \mathrm{C}$ é menor do que a $23^{\circ}$ $\mathrm{C}$ indicando que a membrana está mais hidratada em temperatura mais alta e/ou apresenta maior mobilidade dos lipídeos (mais fluida). Como o $\Delta v$ não sofre alterações o grau de hidratação é semelhante nos dois casos, embora este parâmetro não seja muito sensível [128]. Por outro lado, o $\tau_{R D}$ é menor a $37^{\circ} \mathrm{C}$ o que indica que a relaxação dipolar acontece mais rapidamente nesta temperatura. Sendo assim, a variação do valor do GP se deve a maior mobilidade dos lipídeos a $37{ }^{\circ} \mathrm{C}$ visto que a hidratação não apresenta diferenças significativas para as duas temperaturas.

Tendo em vista esta validação da técnica experimental implementada, realizamos experimentos com as membranas compostas por $100 \%$ POPC-OOH para as mesmas temperaturas. A figura 4.24 apresenta os 1400 espectros resolvidos no tempo em passos de 0,015 ns entre $\mathrm{t}=0,015$ ns até $\mathrm{t}=20,85 \mathrm{~ns}$ : 


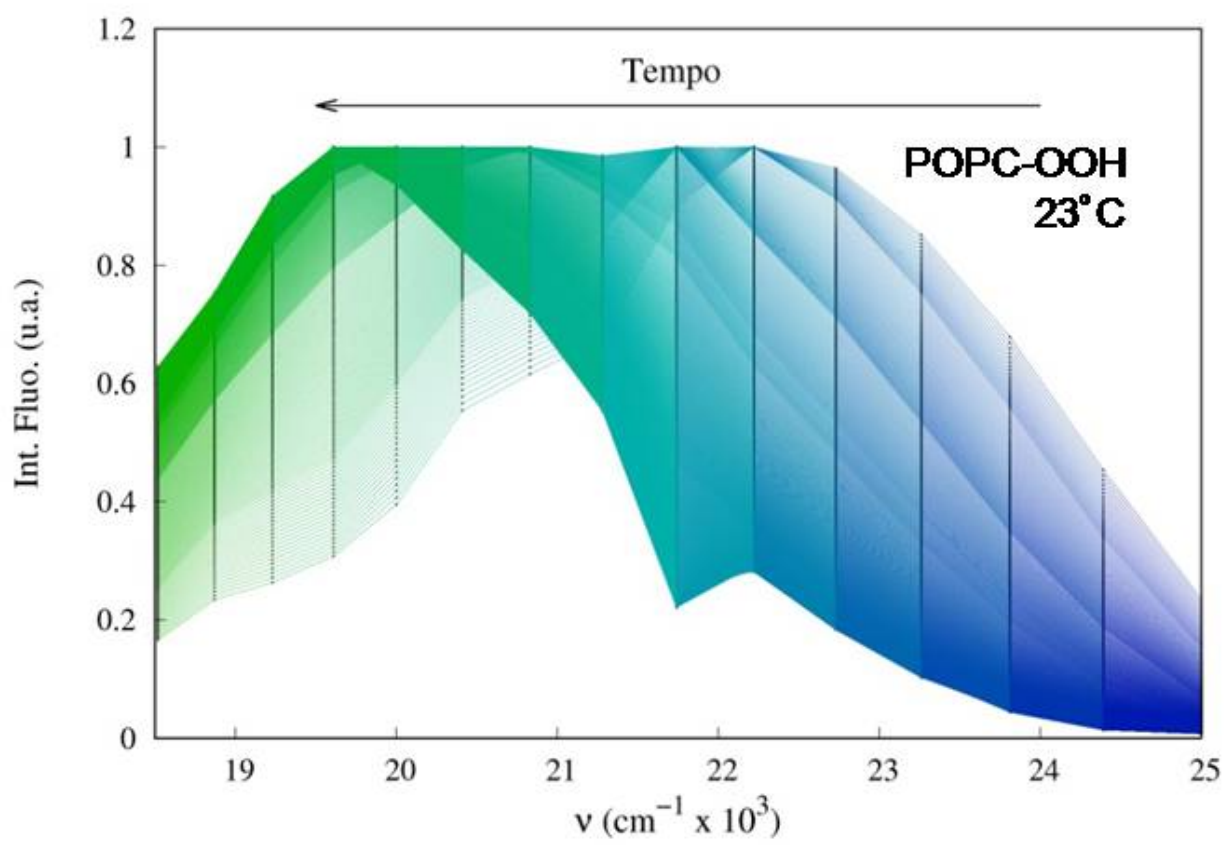

(a)

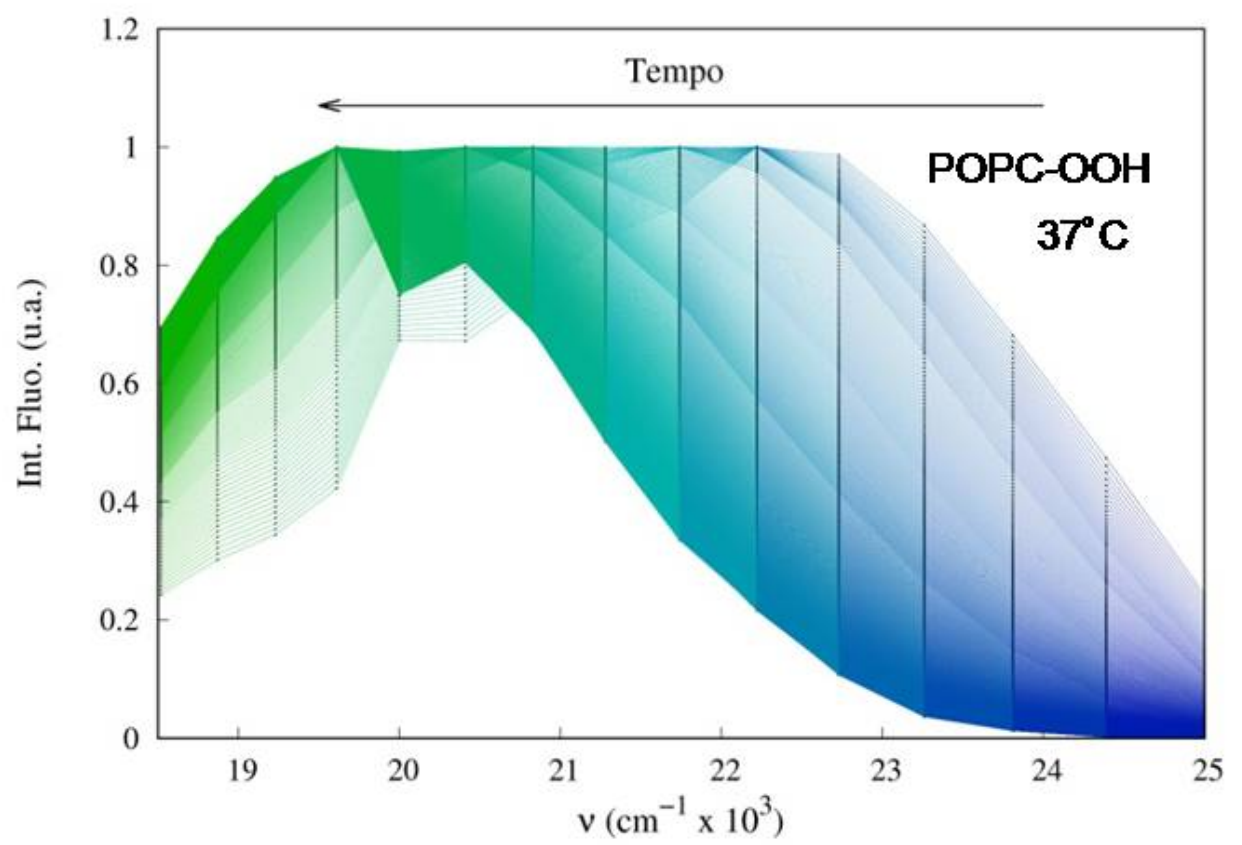

(b)

Figura 4.24: TRES obtidos para LUVs de POPC-OOH extrusadas com poro de $0,1 \mu \mathrm{m}$ para obter vesículas unilamelares (LUVs), a concentração lipídica utilizada foi de $500 \mu \mathrm{M}$ e a razão lipídeo:laurdan foi de 100:1. Em cada gráfico estão 1400 espectros resolvidos no tempo em passos de 0,015 ns entre $\mathrm{t}=0,015 \mathrm{~ns}$ até $\mathrm{t}=20,85 \mathrm{~ns}$

Observando a figura 4.24 pode-se perceber que a reconstrução temporal da intensidade do número de onda $21,74 \times 10^{3} \mathrm{~cm}^{-1}$ para a temperatura de $23{ }^{\circ} \mathrm{C}$ e $20,00 \times 10^{3} \mathrm{~cm}^{-1}$ para 37 ${ }^{\circ} \mathrm{C}$ não aconteceu de forma adequada. Entretanto, isto não atrapalhou a análise dos espectros resolvidos no tempo. 
Assim como no caso anterior, realizou-se as análises de TRES (item 4.1.6) para obter os valores da posição de pico de emissão de cada um dos 1400 espectros $\left(v_{p}(t)\right)$ e os valores de largura a meia altura para cada espectro em função do tempo $(\Gamma(t))$ para estimar o tempo médio de relaxação dipolar $\tau_{R D}$.

A figura 4.25 apresenta as curvas de $v_{p}(t)$ e $\Gamma(t)$ para as LUVs compostas de $100 \%$ POPC (preto) e $100 \% \mathrm{POPC}-\mathrm{OOH}$ à temperatura de $23^{\circ} \mathrm{C}$ (linha contínua) e $37^{\circ} \mathrm{C}$ (linha tracejada). 


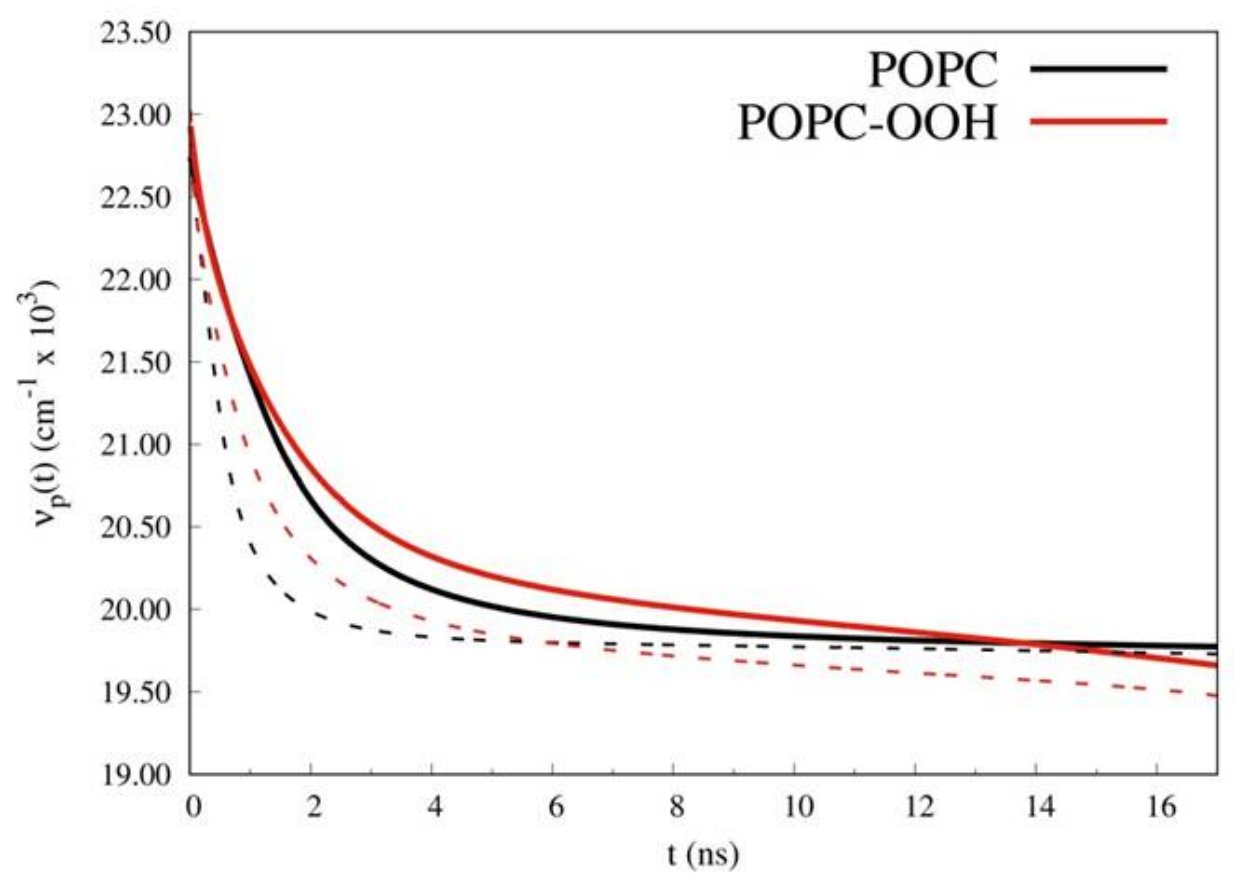

(a)

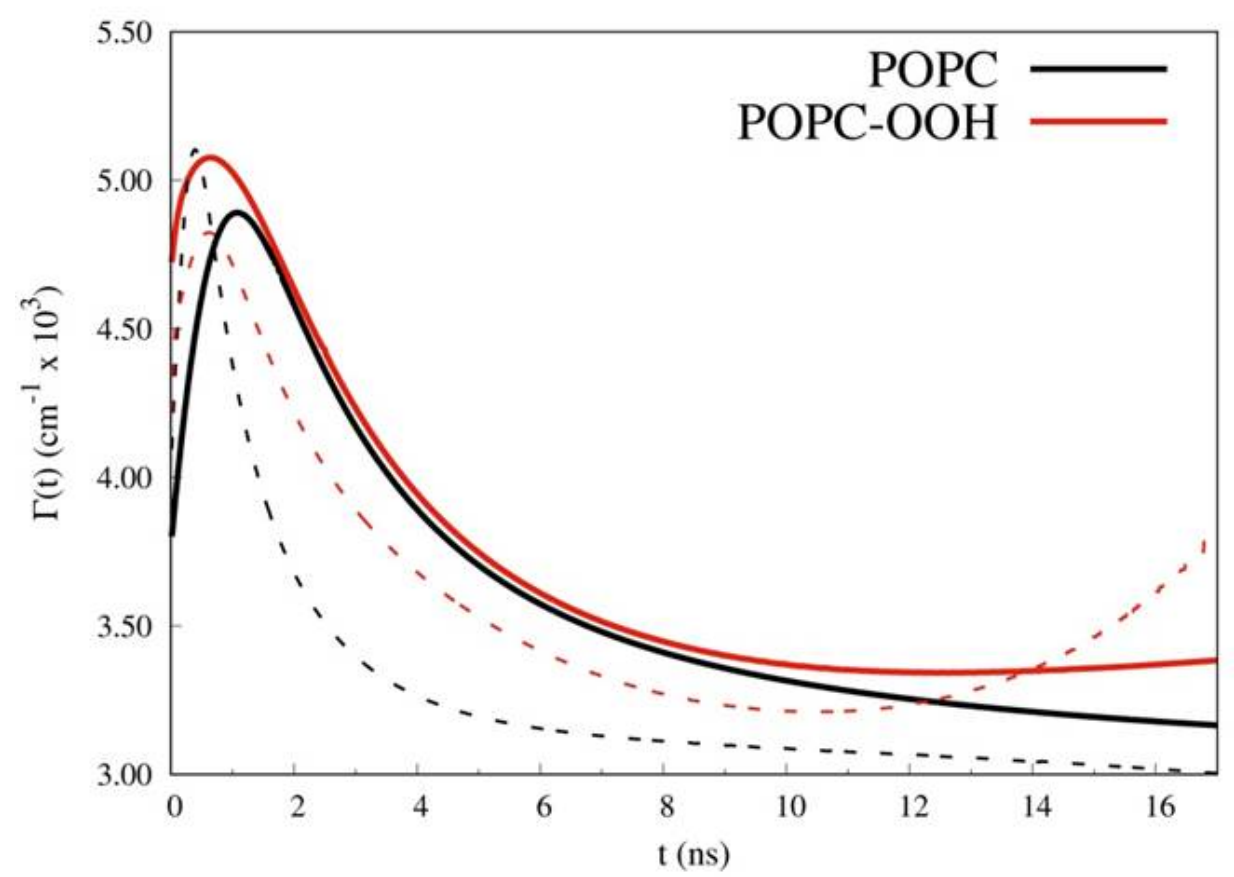

(b)

Figura 4.25: Gráficos de $v(t)$ (a) e $\Gamma(t)$ (b) obtidos para LUVs de POPC (linha preta) e de POPC-OOH (linha vermelha) extrusadas com poro de $0,1 \mu \mathrm{m}$ para obter vesículas unilamelares (LUVs), a concentração lipídica utilizada foi de $500 \mu \mathrm{M}$ e a razão lipídeo:laurdan foi de 100:1 para temperatura de 23 (linha contínua) e $37^{\circ} \mathrm{C}$ (linha tracejada).

Inicialmente, retomando os resultados obtidos para as LUVs compostas por $100 \%$ POPC (fig 4.23 e tabela 4.7) pode-se observar que o valor $v(\infty)(v(t)$ para $t>16 \mathrm{~ns}$ - final da curva) para $23^{\circ} \mathrm{C}$ (linha preta contínua) e $37^{\circ} \mathrm{C}$ (linha preta tracejada) são muito similares como apresentado na figura 4.25a. Portanto, os valores de $\Delta v$ são muito similares para ambas temperaturas, como 
já apresentando na tabela 4.7 .

Por outro lado, pode-se observar na figura $4.25 \mathrm{~b}$ o tempo para o qual a largura a meia altura, $\Gamma(t)$, atinge o valor de máximo. Para as membranas de $100 \%$ POPC a $23{ }^{\circ} \mathrm{C}$ (linha preta contínua) esse tempo é maior do que a $37^{\circ} \mathrm{C}$ (linha preta tracejada) como apresentado na tabela 4.7. Essa informação também pode ser qualitativamente obtida observando os gráficos de $v(t)$ presentes na figura 4.25a: a variação da posição do pico de emissão de fluorescência dos espectros resolvidos no tempo é mais lenta a $23^{\circ} \mathrm{C}$ (linha preta contínua) do que a $37^{\circ} \mathrm{C}$ (linha preta tracejada). Por exemplo, para $t=2 \mathrm{~ns}$ a posição de $v(t)$ é cerca de $20,80 \times 10^{3} \mathrm{~cm}^{-1}$ e $19,90 \times 10^{3} \mathrm{~cm}^{-1}$ a $23^{\circ}$ $\mathrm{C}$ (linha preta contínua) e a $37^{\circ} \mathrm{C}$ (linha preta tracejada), respectivamente.

No caso de POPC-OOH as curvas de $v_{p}(t)$ (fig. 4.25a - linha vermelha) decrescem mais lentamente nas duas temperaturas estudadas do que nos experimentos com POPC, indicando uma velocidade de relaxação dipolar mais lenta na membrana composta pelo lipídeo oxidado.

Além disso, para os tempos $t \sim 14 n s\left(23^{\circ} \mathrm{C}\right) \mathrm{e} \sim 6 n s\left(37^{\circ} \mathrm{C}\right)$ as curvas de $v_{p}(t)$ para as membranas de POPC-OOH cruzam com as curvas de $v_{p}(t)$ para POPC e seguem diminuindo e não atingem um valor constante para $\mathrm{t}>13 \mathrm{~ns}$ indicando que o processo de relaxação dipolar não está completo dentro da escala de tempo do experimento ( $17 \mathrm{~ns})$. Ou seja, a relaxação dipolar é mais demorada e/ou o processo de relaxação dipolar é mais complexo podendo existir mais de um processo.

Esta complexidade da relaxação dipolar pode ser observada no gráfico de $\Gamma(t)$ para as membranas de POPC-OOH em ambas as temperaturas (fig 4.25b - linha vermelha). É possível perceber a posição de um máximo para as curvas de $\Gamma(t)$ para o tempo de cerca de $t=0.6(1)$ ns para as duas temperaturas. Entretanto, para valores de $t>11$ ns pode-se observar que as curvas voltam a crescer ao invés de seguir decrescendo monotonicamente. Este efeito é mais pronunciável a $37^{\circ} \mathrm{C}$ do que a $23^{\circ} \mathrm{C}$. Sendo assim, não se pode descartar a existência de outros pontos de máximo para as curvas de $\Gamma(t)$, ou seja, que a relaxação dipolar é mais demorada e/ou que existem outros processos de relaxação dipolar para um tempo maior do que a escala do experimento e que não foi possível de ser observado.

Como mencionado anteriormente, os valores de $v_{p}(t)$ para $t>13$ ns para as membranas de $100 \%$ POPC-OOH são menores (e continuam a diminuir) em relação às membranas de $100 \%$ POPC nas mesmas temperaturas, indicando que a sonda laurdan interage com maior número de dipolos, sendo maior a estabilização do estado excitado, e consequentemente a sua emissão de fluorescência é cada vez menos energética. Dessa maneira, os valores de $\Delta v$ são maiores para as membranas compostas de lipídeos oxidadas indicando a maior hidratação e/ou que há interação da sonda com o grupo $\mathrm{OOH}$ do lipídeo oxidado. Cabe acrescentar que o $v_{p}(t)$ não atinge um valor constante na escala de tempo do experimento, impossibilitando a quantificação do $\Delta v$. 


\subsection{Discussão I - Impacto do lipídeo oxidado POPC-OOH}

Neste capítulo estudamos o impacto da presença do lipídeo oxidado POPC-OOH em membranas (MLVs e LUVs) de POPC à temperatura de $23{ }^{\circ} \mathrm{C}$ e $37{ }^{\circ} \mathrm{C}$ através de técnicas de fluorescência do estado estacionário e resolvidas no tempo utilizando a sonda TMA-DPH e a sonda laurdan.

Alguns estudos anteriores analisaram como o lipídeo POPC-OOH altera as propriedades de membranas lipídicas de POPC através da técnica de aspiração por micropipeta [46], dinâmica molecular (MD) [36] e espalhamento de raio x a baixos ângulos (SAXS) [43]. Os resultados mais relevantes para nossas análises obtidos nestes trabalhos anteriores estão esquematizados na figura 4.26 abaixo.

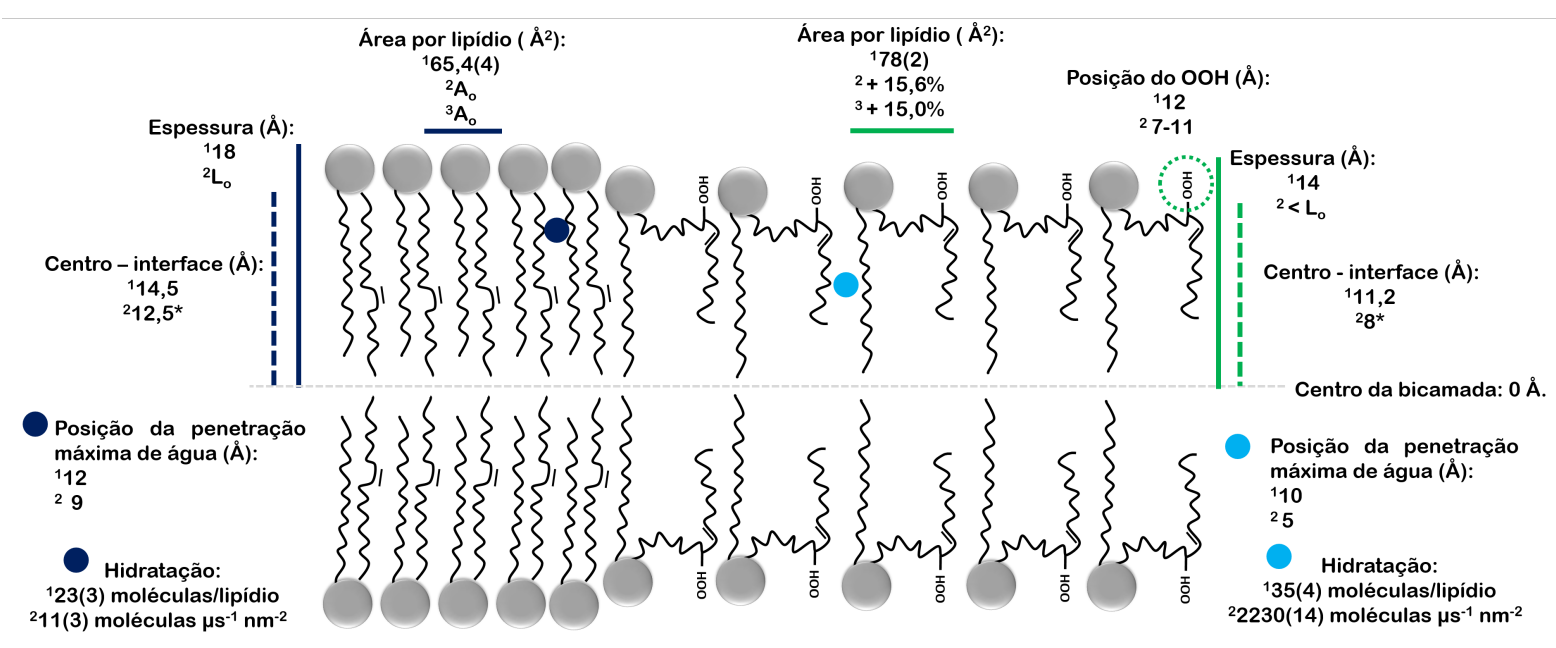

Figura 4.26: Principais resultados para nossas análises, obtidos por SAXS [43 $]^{1}$, MD [36 $]^{2}$ e micropipeta $[46]^{3}$ para o impacto da presença do lipídeo oxidado POPC-OOH em membranas lipídicas; *levando-se em conta o perfil de densidade eletrônica da água.

Primeiramente, simulações computacionais de membranas compostas pelo lipídeo DLPC oxidado contendo um grupo hidroperóxido em sua cadeia alifática indicaram que este grupo está localizado próximo a cabeça polar do lipídeo [145]. Experimentos realizados utilizando a técnica de aspiração por micropipeta para obter as modificações mecânicas de vesículas unilamelares gigantes (GUVs) de POPC com o aumento da concentração de POPC-OOH também sugeriram a migração do hidroperóxido para a região da interface membrana-água [46] (fig. 4.26). Ademais, simulações computacionais de membranas lipídicas de POPC-OOH calcularam que o grupo OOH deve estar localizado entre 7 e $11 \AA$ em relação ao centro da bicamada lipídica [36] e experimentos de SAXS de membranas de POPC com o aumento da concentração do POPC-OOH indicaram que 95\% dos grupos hidroperóxidos deve estar na região da cabeça polar [43] (fig 4.26).

Correlacionado com esta migração do grupo $\mathrm{OOH}$ do lipídeo oxidado para a interface membrana-água, as simulações de MD estimaram a diminuição da espessura da bicamada 
lipídica e o aumento de 15,6\% da área por lipídeo [36]. Os dados de aspiração de GUV por micropipeta indicaram um aumento de área por lipídeo de 15,0\% [46] sendo notável o acordo destes dois resultados (fig. 4.26). Vale também ressaltar que os experimentos de aspiração por micropipeta de GUVS de POPC contendo o lipídeo oxidado POPC-OOH mostraram a diminuição da constante elástica da membrana $\left(\kappa_{A}\right)$ [46]. Este impacto é evidente ao se comparar o valor de $\kappa_{A}$ de GUVs de POPC, $200 m N \times m^{-1}$, com o valor de $\kappa_{A}$ de GUVs de POPC-OOH que é 4 vezes menor, $50 m N \times m^{-1}$ [46].

O aumento de área por lipídeo $[36,46]$ também foi observado por análises de SAXS concomitantemente à diminuição da espessura da membrana lipídica [36, 43]. As análises de SAXS determinaram que a área por lipídeo em membranas de 100\% POPC, 65,4(4) $\AA^{2}$, aumenta em função da concentração de POPC-OOH chegando a 78(2) $\AA^{2}$ para membranas contendo somente o lipídeo oxidado e que a diminuição da espessura da bicamada pode ser cerca de $10 \AA$ [43] (fig. 4.26).

Uma possível consequência do aumento da área por lipídeo é o aumento da penetração de água na membrana e até a permeação da mesma. Experimentos de microscopia de contraste de fase com GUVs de POPC contendo diversas concentrações de POPC-OOH mostraram que não há aumento da permeabilidade da membrana à solução aquosa contendo sacarose e glicose [46]. As análises de SAXS demonstraram um leve aumento do número de moléculas de água no interior da membrana acompanhado de um pequeno aumento da profundidade que elas podem atingir [43] (fig. 4.26). Por outro lado, as simulações computacionais de membranas de POPC 100\%, POPC:POPC-OOH (50:50) e POPC-OOH 100\% apontaram aumento expressivo da quantidade de moléculas de água no interior da membrana, 11(3), 1121(84) e 2230(14)

$\mu \mathrm{s}^{-1} \mathrm{~nm}^{-2}$, respectivamente, com maior interiorização das moléculas de água na membrana (fig. 4.26). Em adição, os dados de MD mostraram que a cadeia sn-2 do lipídeo POPC-OOH para os carbonos que precedem o grupo hidroperóxido (carbono 1 - 9) apresenta menor valor de $S_{C D}$ em comparação com o POPC, indicando maior desordem para esta cadeia alifática do lipídeo oxidado [36].

Tendo em vista estas informações sobre o impacto da presença do lipídeo oxidado POPCOOH em membranas de POPC [36, 43, 46] (fig. 4.26), podemos discutir nossos resultados obtidos através das técnicas de fluorescência utilizando a sonda TMA-DPH e a sonda laurdan.

\section{Presença do grupo $\mathrm{OOH}$ na interface membrana-água}

Através das análises de anisotropia de fluorescência resolvida no tempo da sonda TMA-DPH em membranas de POPC com o aumento da concentração do lipídeo oxidado POPC-OOH a $23^{\circ} \mathrm{C}$ e $37^{\circ} \mathrm{C}$ obtivemos os parâmetros de tempo de correlação rotacional $\left.(<\phi\rangle\right)$ e microviscosidade ( $\eta$ ) (figs. 4.20 e 4.21). O leve aumento de $\langle\phi\rangle$ para ambas as temperaturas na presença do lipídeo oxidado indica que a sonda TMA-DPH demora mais tempo para rotacionar até a 
maior abertura angular $\left(r_{\infty}\right)$, o que é devido a maior restrição em seu movimento. Importante notar que a $37^{\circ} \mathrm{C}$ não há variação do valor de $r_{\infty}$ em função do aumento da concentração do POPC-OOH, ou seja, o aumento de $\langle\phi\rangle$ não é causado pela aumento da variação angular que a sonda TMA-DPH pode rotacionar. Contudo, a $23^{\circ} \mathrm{C}$, há diminuição do $r_{\infty}$ e aumento de $\langle\phi\rangle$ indicando que há uma correlação entre maior abertura angular e maior tempo até atingir este ângulo.

Para verificar esta possível correlação entre $r_{\infty} \mathrm{e}\langle\phi\rangle$, ou se a restrição ao movimento de rotação da sonda era de fato real, calculou-se a microviscosidade experimentada pelo TMA-DPH, que leva em conta o valor de $r_{\infty} \mathrm{e}\langle\phi\rangle$. Os resultados obtidos para ambas as temperaturas estudadas é que há um leve aumento da microviscosidade local em função da concentração de POPC-OOH, ou seja, há maior restrição para o movimento de rotação da sonda TMA-DPH. Sendo assim, podemos sugerir que o sítio preferencial de localização do grupo hidroperóxido $(\mathrm{OOH})$ na interface polar/apolar (fig. 4.26), associado à mudança química conformacional da cauda acila, deve restringir a rotação da sonda TMA-DPH.

Do ponto de vista das análises, utilizando a sonda laurdan (GP e TRES), o valor de GP aumentou para ambas as temperaturas em função do aumento da concentração de POPC-OOH em membranas de POPC podendo indicar menor hidratação e/ou maior rigidez da membrana. Por outro lado, as análises de TRES para as LUVs compostas por 100\% de POPC-OOH indicaram o aumento do tempo de relaxação dipolar e aumento da interação da sonda com dipolos, sugerindo maior hidratação e/ou interação do laurdan com o grupo OOH em comparação com as LUVs de $100 \%$ de POPC para as duas temperaturas.

Assim sendo, pode-se combinar os resultados de GP e TRES da seguinte maneira: o aumento do tempo de relaxação dipolar apresentado nas membranas de POPC-OOH deveria contribuir para o aumento do valor do GP (blueshift). Por outro lado, a interação da sonda laurdan com um maior número de dipolos $(\Delta v)$ deveria contribuir para a diminuição do valor do GP (resdhift). Ou seja, os efeitos da presença do POPC-OOH em membranas lipídicas evidenciados pelas análises de TRES influenciam o valor do GP em direções opostas. Em nossos experimentos, a contribuição do tempo de relaxação dipolar é preponderante no valor do GP o que resultou no aumento deste parâmetro em membranas de POPC com o aumento da concentração de POPC-OOH, em ambas as temperaturas.

Um efeito semelhante a este foi observado em membranas de POPC na presença dos fármacos oxeprenolol e propanolol [129]. Os autores reportaram aumento do GP com a adição de 5 e $10 \mathrm{mM}$ de oxprenolol e de 0,75 e 1,5 mM de propanolol em LUVS de POPC a $10^{\circ} \mathrm{C}$. Por outro lado, observaram aumento do tempo de relaxação dipolar (mais lenta $\tau_{R D}$ ) e maior hidratação $(\Delta v)$ das membranas de POPC na presença destes dois fármacos [129]. Assim sendo, o impacto do $\tau_{R D}$ foi preponderante resultando no aumento do GP [129].

Seguindo a discussão sobre a localização de grupos oxidados em cadeias lipídicas, cabe 
acrescentar que experimentos focados na interação entre a sonda laurdan e colesteróis oxidados [130] mostraram que em membranas de POPC $\left(37^{\circ} \mathrm{C}\right)$ contendo $10 \%$ de colesteróis oxidados com um grupo $\mathrm{OH}$ na cadeia alifática na posição do carbono 24, 25 ou 27, a posição do pico de emissão máxima dos espectros resolvidos no tempo $\left(v_{p}(t)\right)$ não atinge um valor constante na escala temporal do experimento ( $15 \mathrm{~ns})$. Já o gráfico de largura a meia altura dos espectros em função do tempo $(\Gamma(t))$ apresenta o pico esperado para relaxação dipolar $(\sim 1 n s)$, mas o valor de $\Gamma(t)$ volta a aumentar ao invés de diminuir para $\mathrm{t}>13 \mathrm{~ns}$ indicando a presença de outro processo de relaxação dipolar [130]. Neste conjunto de experimentos, os autores utilizaram outros colesteróis oxidados que não possuem o grupo $\mathrm{OH}$ em suas "caudas"alifáticas e os resultados de TRES para estes não apresentaram nenhum destes efeitos. Pode-se então sugerir que a presença do grupo $\mathrm{OH}$ [130] perturba o processo de relaxação dipolar da sonda laurdan.

Assim sendo, tendo em vista que nossos resultados de análises de TRES para membranas de POPC-OOH em ambas temperaturas apresentaram as mesmas caracterítiscas descritas por estes autores [130], pode-se sugerir que a presença do grupo OOH no microambiente lipídico também pertuba o processo de relaxação dipolar da sonda laurdan.

Portanto, tanto os resultados de anisotropia resolvida no tempo para o TMA-DPH quanto os resultados de TRES para o laurdan indicaram a interação das sondas com o grupo $\mathrm{OOH}$ do lipídeo oxidado. De fato, dados de MD indicam a posição do centro de massa dos anéis da sonda TMA-DPH em membranas de POPC a cerca de $10 \AA$ do centro da bicamada lipídica [123] enquanto resultados experimentais apontam que o grupo naftaleno da sonda laurdan está localizado em torno de 11,4 Å a partir do centro da bicamada [146]. Ou seja, ambas as sondas devem estar localizadas numa região próxima à localização do grupo $\mathrm{OOH}$ (7 - 11Å) [36]. Como perspectiva pretende-se estudar por MD a possível interação da sonda laurdan com o grupo hidroperóxido do lipídeo oxidado POPC-OOH.

\section{Aumento de área por lipídeo na presença do POPC-OOH}

Como mencionado anteriormente, a leve diminuição da anisotropia residual $\left(r_{\infty}\right)$ com o aumento da concentração do POPC-OOH para a temperatura de $23{ }^{\circ} \mathrm{C}$ deve estar relacionada com o aumento de área por lipídeo [36, 43, 46]. Assim, haveria um maior espaçamento para a sonda rotacionar na região interfacial polar/apolar. Contudo, com a presença do grupo $\mathrm{OOH}$ na mesma região da sonda TMA-DPH não pode ser descartado que valores de $r_{\infty}$ possam ter sofrido alguma influência da interação da sonda com o grupo hidroperóxido.

\section{Hidratação da membrana na presença do POPC-OOH}

As análises da intensidade de fluorescência resolvida no tempo para a sonda TMA-DPH mostraram a diminuição do tempo de vida médio $(<\tau\rangle)$ com o aumento da concentração de POPC-OOH, para ambas as temperaturas. Como os dados de MD [36] e SAXS [43] determinaram o aumento da hidratação da membrana na presença do lipídeo oxidado, nossos experimentos 
de $<\tau>$ devem indicar a interação da sonda, também com moléculas de água [147] sugerindo uma maior hidratação da membrana na região do grupo carbonila com o aumento da concentração de POPC-OOH. Interessante notar que os dados de MD indicam penetração da água até cerca de $5 \AA$ A partir do centro da bicamada lipídica para membranas contendo POPC-OOH [36], que seria uma profundidade suficiente para interagir com a sonda TMA-DPH e causar a redução do tempo de vida de fluorescência.

Além disso, os resultados das análises de TRES da sonda laurdan também indicaram maior número de dipolos interagindo com a sonda laurdan no microambiente lipídico. Esses dipolos podem ser compreendidos como maior número de moléculas de água, em concordância com os dados de tempo de vida de fluorescência da sonda TMA-DPH e com os dados de MD [36] e SAXS [43]. Além da possível interação da sonda com os grupos $\mathrm{OOH}$.

Portanto, a diminuição do $<\tau>$ do TMA-DPH e o maior número de dipolos interagindo com a sonda laurdan também podem indicar interação das sondas com o grupo OOH do lipídeo oxidado, como discutido acima. Com isso, não foi possível elucidar se o grau de hidratação das membranas com POPC-OOH, tem um leve [43] ou expressivo [36] aumento que permanece uma questão em aberto.

\section{Temperatura x POPC-OOH}

Para comparar as alterações nas propriedades de membranas lipídicas de POPC com o aumento da concentração de POPC-OOH com o impacto da variação da temperatura de $23^{\circ} \mathrm{C}$ para $37^{\circ} \mathrm{C}$, calculamos as variações percentuais do tempo de vida médio de fluorescência, anisotropia residual (fig 4.27), tempo médio de correlação rotacional e microviscosidade (fig 4.29) presentes nas figuras 4.17 - 4.21 para quatro comparações: (i) membranas de $100 \%$ POPC a 23 e $37^{\circ} \mathrm{C}$ (cinza); (ii) membranas de $100 \%$ POPC-OOH a 23 e $37^{\circ} \mathrm{C}$ (verde); membranas com $0 \%$ e $100 \%$ de $\mathrm{POPC}-\mathrm{OOH}$ (iii) a $23^{\circ} \mathrm{C}$ (azul) e (iv) a $37^{\circ} \mathrm{C}$ (vermelho). As incertezas foram propagadas por derivadas parciais. 


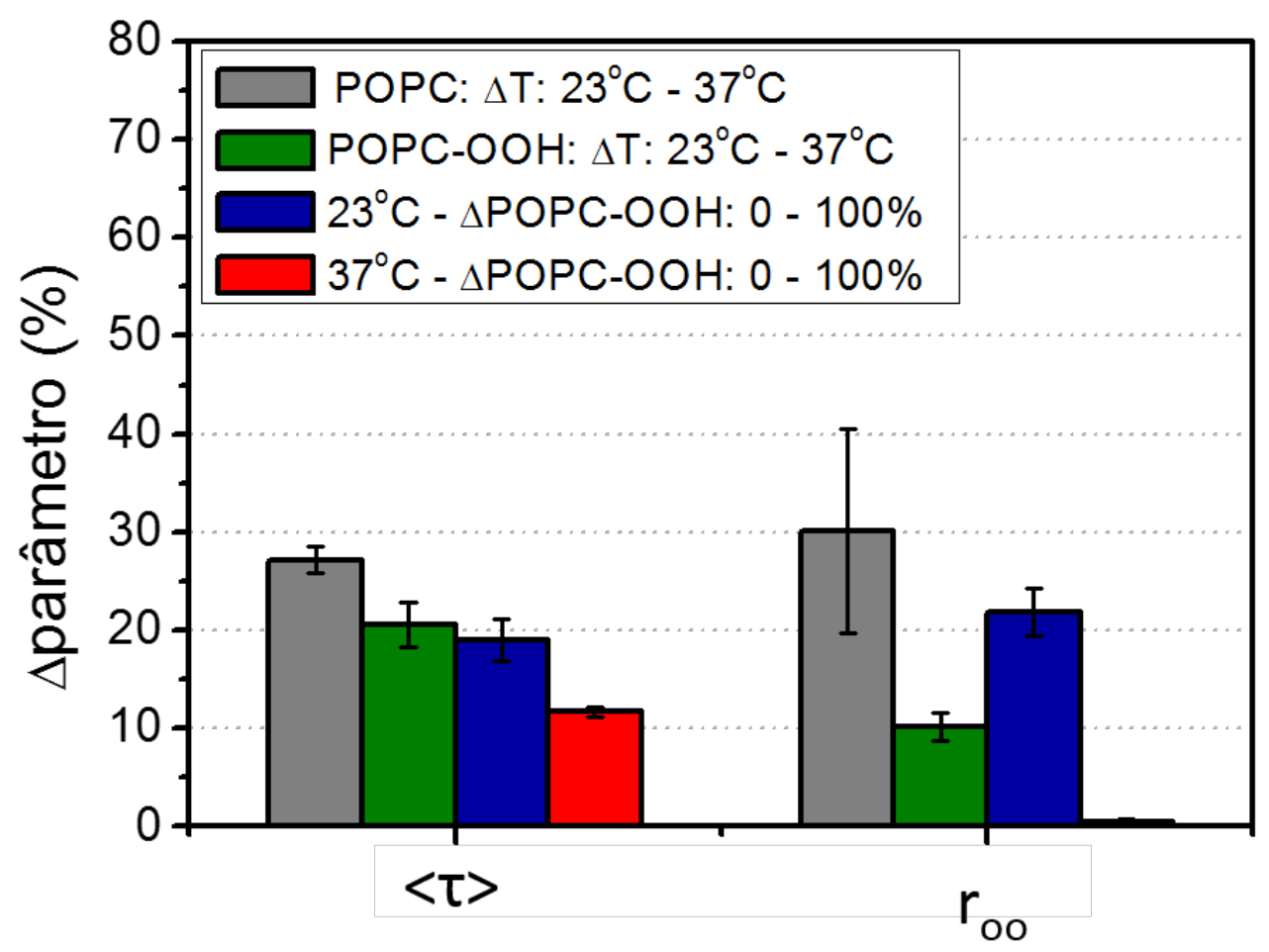

Figura 4.27: Variação percentual para o valor de tempo de vida médio de fluorescência e anisotropia residual para: (i) membranas de $100 \%$ POPC a 23 e $37^{\circ} \mathrm{C}$ (cinza); (ii) membranas de $100 \%$ POPC-OOH a 23 e $37^{\circ} \mathrm{C}$ (verde); membranas com $0 \%$ e $100 \%$ de POPC-OOH (iii) a $23^{\circ} \mathrm{C}$ (azul) e (iv) a $37^{\circ} \mathrm{C}$ (vermelho). Os valores de variação estão em módulo.

A figura 4.27 apresenta a variação do $<\tau>$ onde é possível perceber que a diminuição percentual do tempo de vida médio de fluorescência do TMA-DPH é maior para as membranas de $100 \%$ POPC ao aumentar a temperatura (cinza) do que a substituição de POPC por POPC-OOH em ambas as temperaturas (azul e vermelho) e do que a redução do $<t>$ para membranas de $100 \%$ POPC-OOH com o aumento da temperatura (verde). Para comparação, a redução do tempo de vida médio de fluorescência da mesma sonda em membranas de DPPC na fase fluída $\left(55^{\circ} \mathrm{C}\right)$ é de de $2,8 \mathrm{~ns}$ em relação às membranas na fase gel $\left(35^{\circ} \mathrm{C}\right)$ [148], enquanto o maior impacto obtido em nossos dados foi a $23{ }^{\circ} \mathrm{C}$ com a diminuição de 0,6 ns na presença de $100 \%$ POPC-OOH. Tendo isto em consideração, o aumento da hidratação possivelmente indicado pela sonda TMA-DPH na introdução do lipídeo oxidado POPC-OOH em membranas de POPC é menor do que o acréscimo ocasionado pelo aumento de temperatura em membranas puras de POPC e 4 vezes menor do que o impacto de uma transição de fase lipídica gel-fluido.

Analisando as variações para a $r_{\infty}$ (fig. 4.27), outra vez a maior diferença ocorreu para as membranas de $100 \%$ POPC ao aumentar a temperatura (cinza), seguida pela substituição de POPC por POPC-OOH a $23^{\circ} \mathrm{C}$ (azul), depois pelo aumento de temperatura de membranas de $100 \%$ POPC-OOH (verde) e a substituição de POPC por POPC-OOH a $23^{\circ} \mathrm{C}$ (vermelho) 
praticamente não teve mudança. Com isto, o aumento da abertura angular é mais significativo com o aumento da temperatura em membranas de POPC do que pela introdução do lipídeo oxidado.

De maneira interessante, o aumento de área por lipídeo em membranas de POPC de $20^{\circ} \mathrm{C}$ $\left(62,7(1,3) \AA^{2}\right)$ para $40^{\circ} \mathrm{C}\left(65,3(1,3) \AA^{2}\right)$ é de cerca de $4 \%$ [149] e para membranas de DPPC de $36^{\circ} \mathrm{C}\left(51,7(5) \AA^{2}\right.$ - fase gel) para $40^{\circ} \mathrm{C}\left(63 \AA^{2}\right.$ - fase fluida) é de cerca de $22 \%$ [150]. Como discutido acima, a área por lipídeo ao substituir POPC por POPC-OOH aumenta cerca de $15 \%$ $[36,43,46]$, que é cerca de 4 vezes maior do que o acréscimo observado para o aumento de temperatura para membranas de POPC [149], sendo comparável ao aumento visto na transição de fase do DPPC [150]. Ressalta-se aqui que o lipídeo hidroperoxidado POPC-OOH sofre uma alteração conformacional expressiva em relação a POPC por aumento de temperatura (ou DPPC). Comparando estas informações e as análises da variação do $r_{\infty}$ acima (fig. 4.27), poder-se-ia sugerir que este parâmetro não é sensível ao aumento de área por lipídeo. Entretanto, há aumento de cerca de $30 \%$ de $r_{\infty}$ para membranas de POPC com o aumento da temperatura que pode estar relacionado com o leve acréscimo da área por lipídeo [149]. Outra possibilidade, seria supor que o aumento da abertura angular (aumento de área) provocado pela introdução do lipídeo oxidado POPC-OOH é compensado por uma possível restrição do movimento da sonda imposta pela interação com o grupo $\mathrm{OOH}$.

De fato, a cadeia alifática sn-2 do lipídeo oxidado apresenta maior desordem $\left(S_{C D}\right)$ para os carbonos que precedem o grupo hidroperóxido (carbono 3 - 8) em comparação com o POPC [36] o que poderia impedir a rotação da sonda TMA-DPH, visto que estes carbonos e o grupo OOH estão na mesma região da sonda.

Adicionalmente, o aumento da temperatura de $20^{\circ} \mathrm{C}$ para $60^{\circ} \mathrm{C}$ não diminui significamente o valor de $S_{C D}$ para estes carbonos da sn-2 do POPC (fig. 4.28 - azul). Interessante notar também quem a transição de fase para o DPPC resulta em uma variação do parâmetro de ordem de cerca de 0,1 para cada carbono entre a posição 3 e 8 , que ainda é menor do que a variação vista entre o valor de $S_{C D}$ do lipídeo POPC-OOH em relação ao POPC, que pode chegar a cerca de 0,3 de diferença (fig. 4.28). 


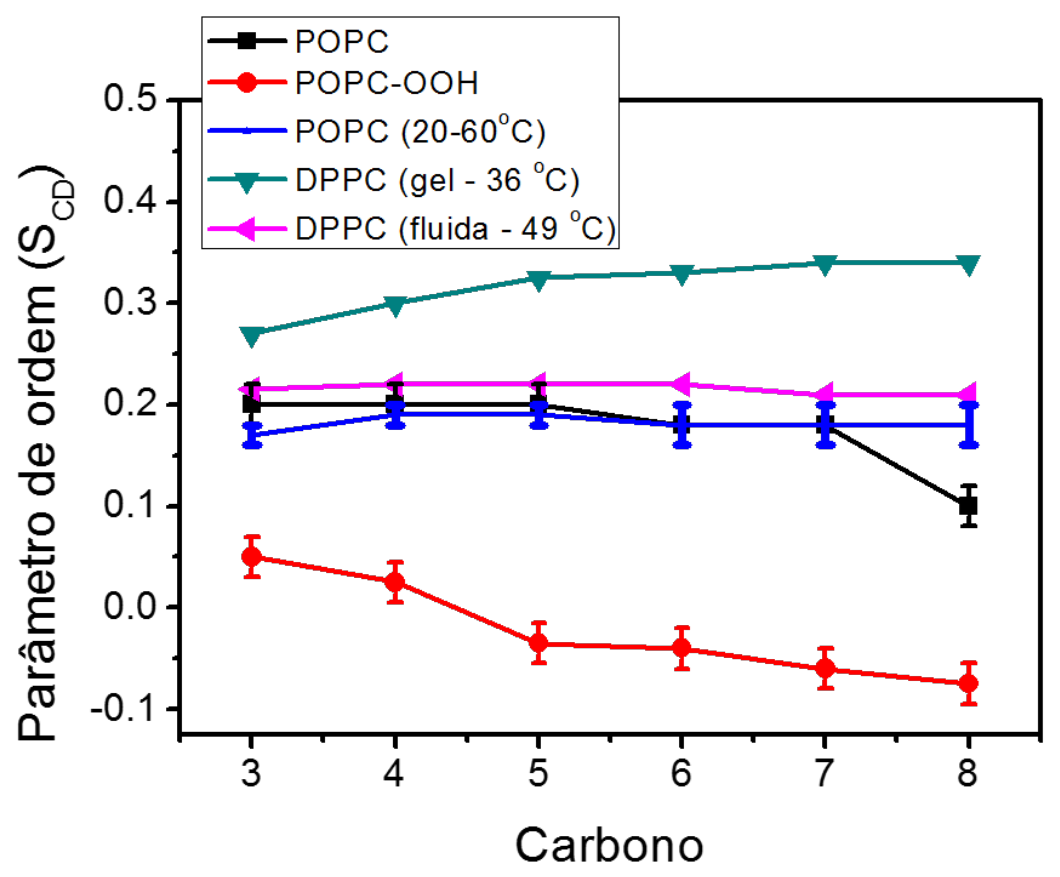

Figura 4.28: Parâmetro de ordem $S_{C D}$ de membranas de POPC $\left(25^{\circ} \mathrm{C}\right.$ - preto $)$ e POPC-OOH $\left(25^{\circ} \mathrm{C}\right.$ - vermelho) [36], POPC entre $20^{\circ} \mathrm{C}$ e $60^{\circ} \mathrm{C}$ (azul) [151] e DPPC na fase gel $\left(36^{\circ} \mathrm{C}\right.$ - verde) e DPPC na fase fluida $\left(49^{\circ} \mathrm{C}\right.$ - rosa) [150]. Resultados obtidos por dinâmica molecular.

Por fim, quanto ao efeito da introdução do lipídeo oxidado POPC-OOH em membranas de POPC com a temperatura, a figura 4.29 apresenta a comparação para as variações de tempo médio de correlação rotacional e microviscosidade. Conforme podemos observar, quando ocorre o aumento da temperatura de $23^{\circ} \mathrm{C}$ para $37^{\circ} \mathrm{C}$ há diminuição percentual similar de $\langle\phi\rangle$ e $\langle\eta\rangle$ para as membranas de $100 \%$ POPC e 100\% POPC-OOH, sugerindo que o aumento da tempertura permite que a sonda TMA-DPH rotacione mais rapidamente (menor tempo até atingir a maior abertura angular) e experimente menor restrição ao movimento. Por outro lado, há o aumento destes dois parâmetros ao substituir POPC por POPC-OOH. 


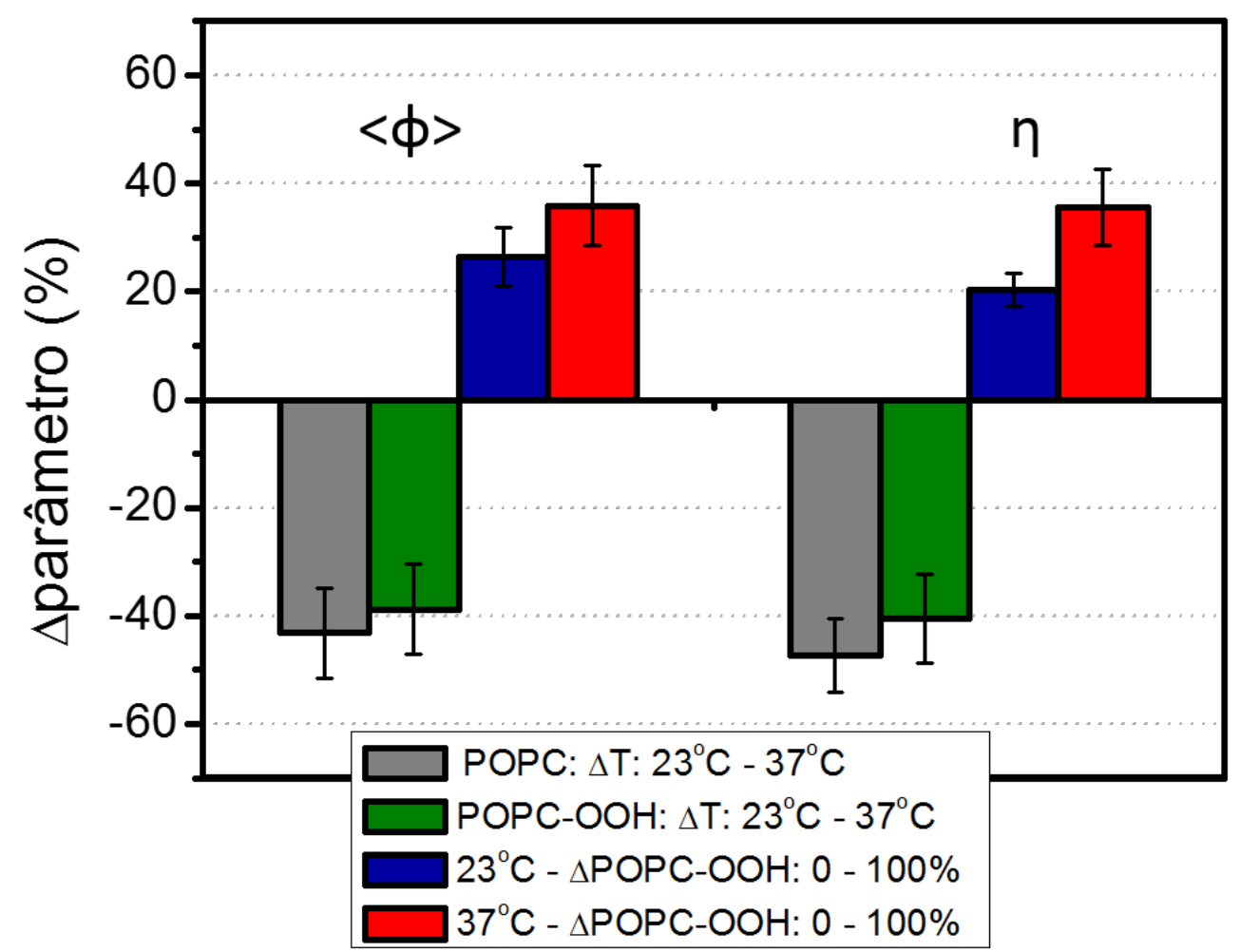

Figura 4.29: Variação percentual para o valor de tempo médio de correlação rotacional e microviscosidade para: (i) membranas de $100 \%$ POPC a 23 e $37^{\circ} \mathrm{C}$ (cinza); (ii) membranas de $100 \%$ POPC-OOH a 23 e $37^{\circ} \mathrm{C}$ (verde); (iii) membranas com $0 \%$ e $100 \%$ de $\mathrm{POPC}-\mathrm{OOH}$ a $23^{\circ} \mathrm{C}$ (azul) e (iv) a $37^{\circ} \mathrm{C}$ (vermelho).

Sendo assim, para estes dois parâmetros a presença do POPC-OOH impacta a membrana no sentido contrário da temperatura indicando maior restrição ou impedimento histérico ao movimento da sonda. Já para o tempo de vida e para a anisotropia residual, a temperatura e a presença do POPC-OOH tem efeitos no mesmo sentido. 


\subsection{Resultados II - Impacto dos lipídeos oxidados PAZEPC e POVPC em membranas lipídicas}

Continuando o estudo do impacto da presença de lipídeos oxidados em membranas miméticas, realizamos os mesmos experimentos anteriores utilizando os lipídeos PAZEPC e POVPC que possuem cadeias carbônicas truncadas (fig. 4.1). Para comparação, incluimos os resultados dos experimentos na presença de POPC-OOH nas mesmas concentrações dos outros dois lipídeos oxidados.

Os valores de anisotropia do estado estacionário ( $<r>$ - item 4.1.5.3) para a sonda TMADPH em MLV de POPC contendo diferentes frações molares de POPC-OOH, PAZEPC ou POVPC (100:1 lipídeo:sonda) são apresentados na figura 4.30. Conforme podemos observar, há um leve aumento da anisotropia do estado estacionário apenas para as membranas de POPC na presença de $25 \%$ de PAZEPC ou POVPC a $23^{\circ} \mathrm{C}$. A $37^{\circ} \mathrm{C}$ não há alteração do valor de $<r>$ dentro das incertezas avaliadas em relação ao controle de membranas contendo $100 \%$ de POPC (fig. 4.30).

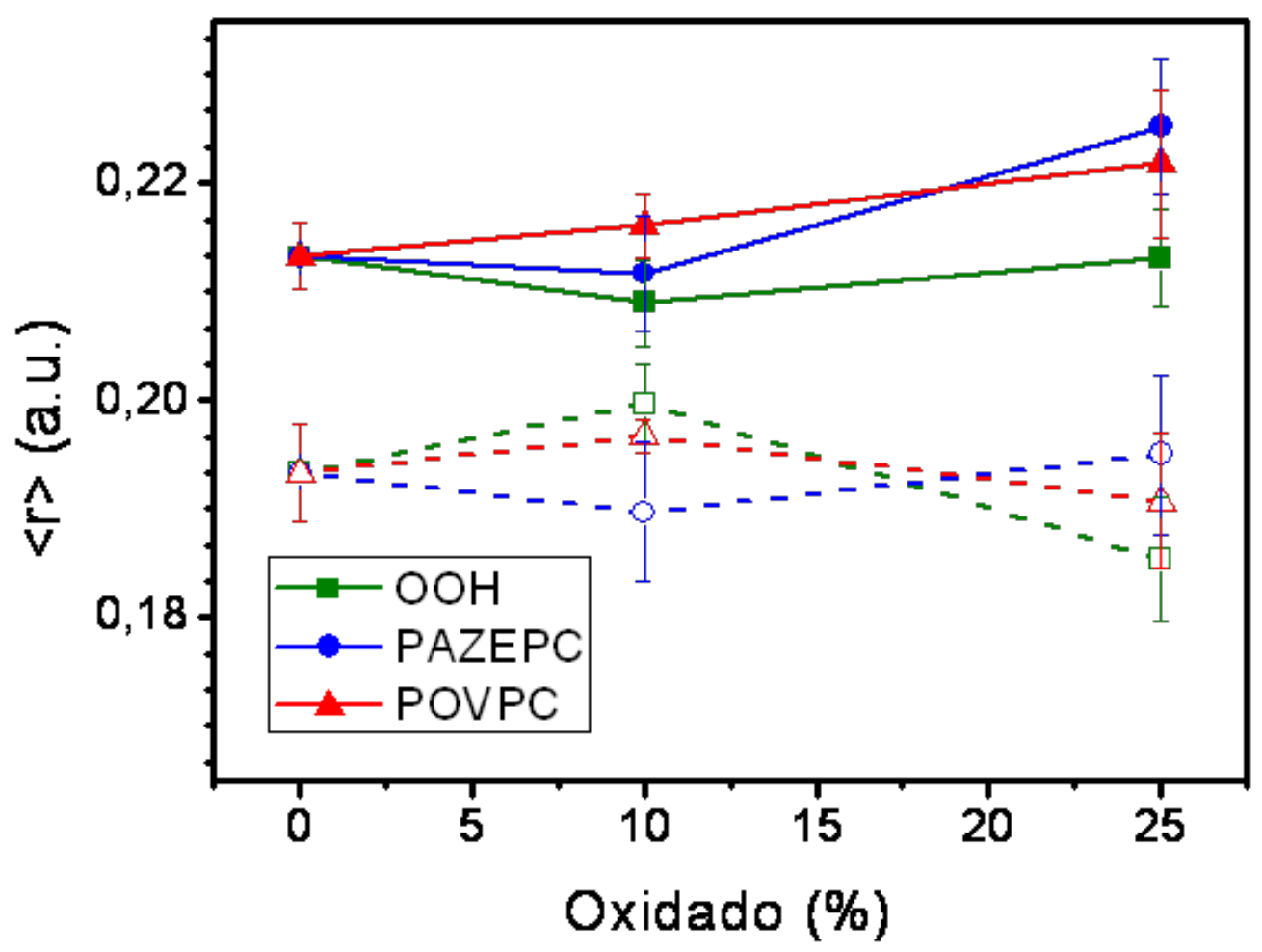

Figura 4.30: Anisotropia de fluorescência no estado estacionário para MLVs de POPC $(100 \mu \mathrm{M})$ contendo TMA-DPH na razão molar 100:1 (lipídeo:sonda) e concentração crescente de lipídeo oxidado a $23{ }^{\circ} \mathrm{C}$ (pontos cheios e linhas sólidas) e $37^{\circ} \mathrm{C}$ (pontos vazios e linhas tracejadas).

Os resultados de tempo de vida médio $(<\tau>)$ são apresentados na figura 4.31: 


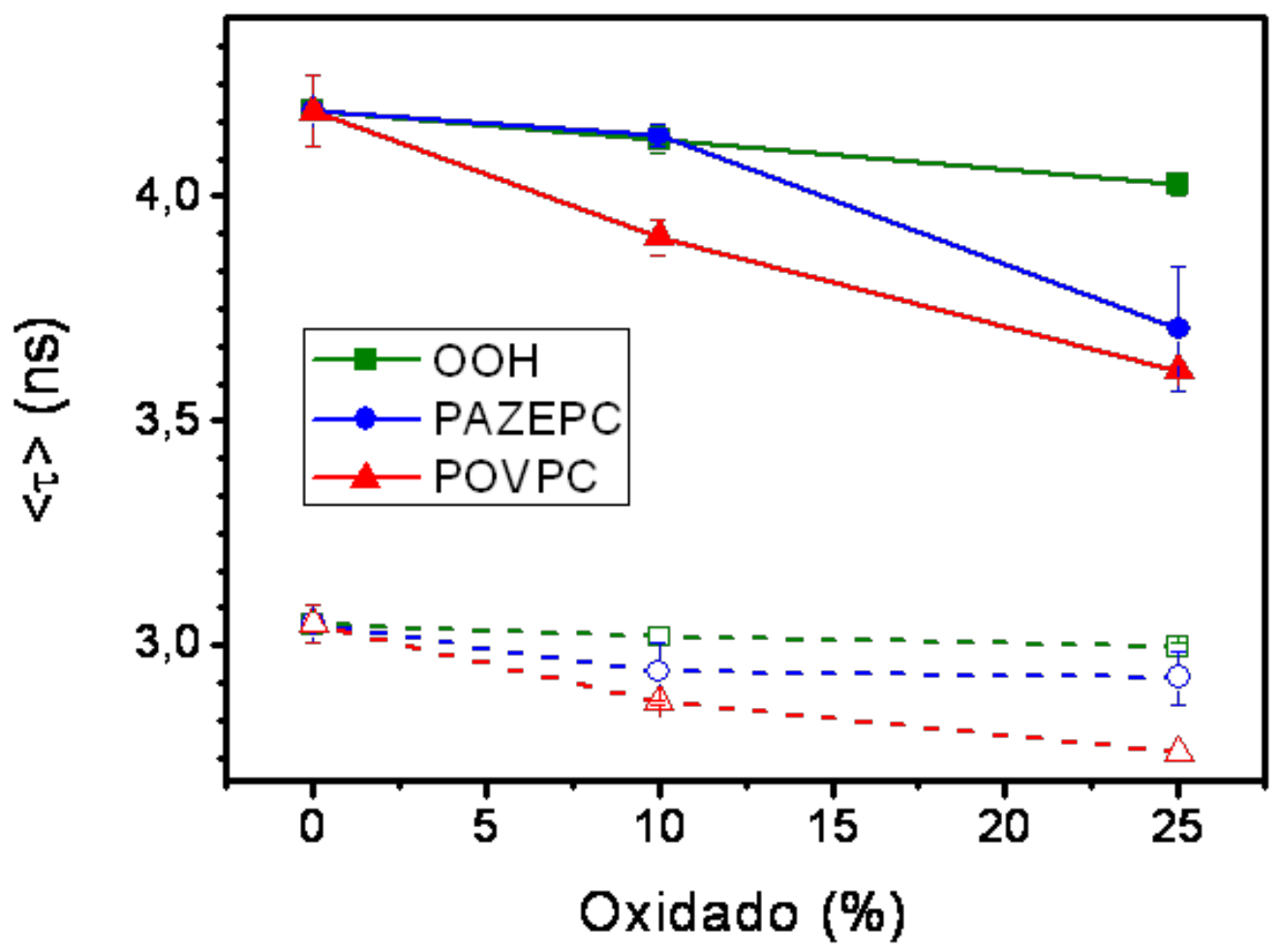

Figura 4.31: Tempo de vida médio de fluorescência para MLVs de POPC (100 $\mu \mathrm{M})$ contendo TMA-DPH na razão molar 100:1 (lipídeo:sonda) e concentração crescente de lipídeo oxidado a 23 (pontos cheios e linhas sólidas) e $37^{\circ} \mathrm{C}$ (pontos vazios e linhas tracejadas).

Pode-se observar que há a diminuição do tempo de vida médio de fluorescência para as MLVS de POPC contendo 10\% e 25\% POVPC e 25\% PAZEPC para ambas as temperaturas (fig. 4.31). As variações de $<\tau>$ são mais acentuadas para a temperatura de $23{ }^{\circ} \mathrm{C}$.

É possível que a diminuiçao de $\langle\tau\rangle$ condicione os valores de anisotropia do estado estacionário (eq. de Perrin) e, por isso, fizemos o gráfico de $\langle\tau\rangle$ em função de $\langle r\rangle$, como mostra a figura 4.32: 

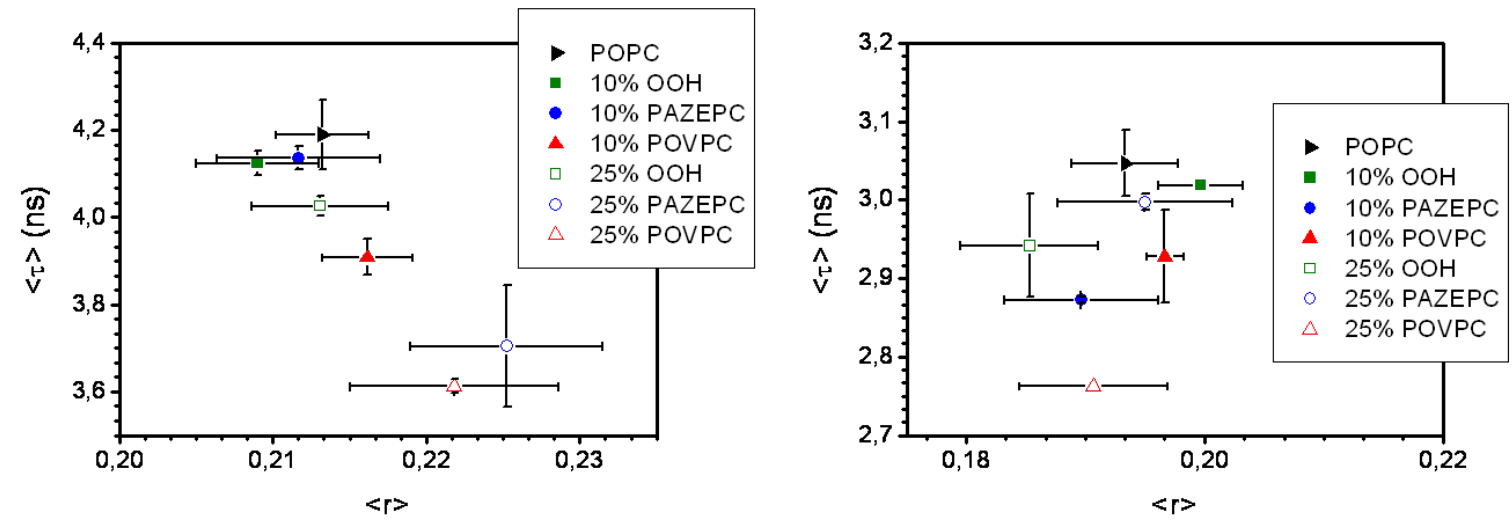

Figura 4.32: Tempo de vida médio de fluorescência em função da anisotropia do estado estacionário para MLVs de POPC $(100 \mu \mathrm{M})$ contendo TMA-DPH na razão molar 100:1 (lipídeo:sonda) e concentração crescente de lipídeo oxidado a $23^{\circ} \mathrm{C}$ (esquerda) e $37^{\circ} \mathrm{C}$ (direita).

Na figura 4.32 é possivel perceber a correlação inversa entre $\langle\tau\rangle \mathrm{e}<r>$ para as MLVs de POPC contendo 25\% PAZEPC ou POVPC a $23{ }^{\circ} \mathrm{C}$ (esquerda). Por outro lado, não existe uma relação entre $<r>$ e a diminuição de $<\tau>$ para as MLVs de POPC na presença de $10 \%$ PAZEPC a $23{ }^{\circ} \mathrm{C}$ e contendo $10 \%$ PAZEPC, $25 \%$ PAZEPC ou POVPC a $37{ }^{\circ} \mathrm{C}$ (direita). Isto pode ter acontecido devido a anisotropia do estado estacionário não ser suficientemente sensível à alteração da membrana ou de fato a anisotropia não ter sofrido alteração. Para elucidar esta questão, mediu-se a anisotropia de fluorescência resolvida no tempo da sonda TMA-DPH das mesmas amostras.

A figura 4.33 apresenta os valores de $r_{\infty}$ obtidos para as MLVs de POPC contendo diferentes concentrações de POPC-OOH, PAZEPC e POVPC. Para todas as concentrações de lipídeos oxidados há a redução da $r_{\infty}$ a $23^{\circ} \mathrm{C}$, sendo mais pronunciável para o POVPC e PAZEPC a $10 \%$ e similar para os três lipídeos oxidados a $25 \%$. Com o aumento da temperatura para $37^{\circ} \mathrm{C}$ nenhuma alteração na anisotropia residual foi registrada a $25 \%$ de lipídeo oxidado. 


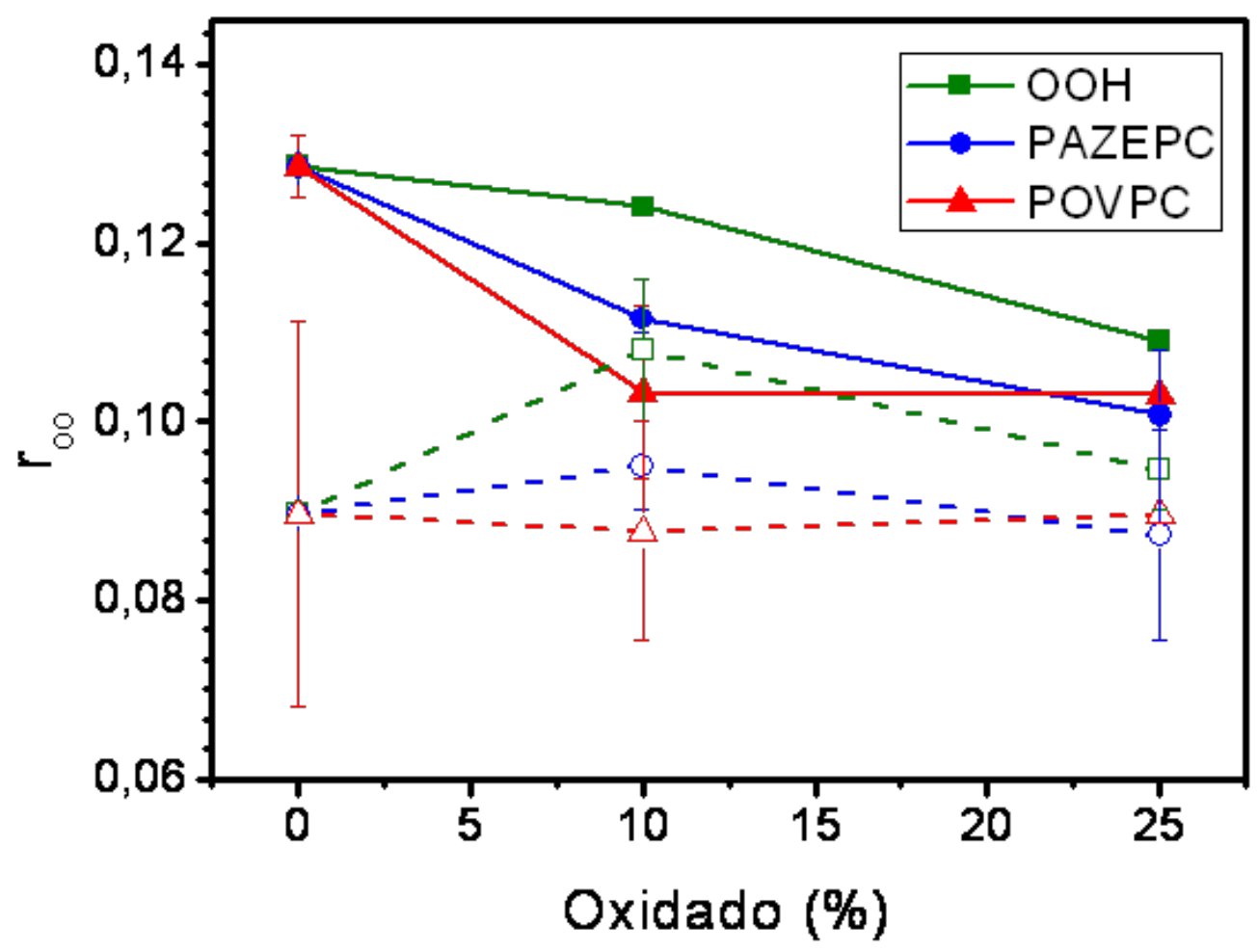

Figura 4.33: Anisotropia residual para MLVs de POPC $(100 \mu \mathrm{M})$ contendo TMA-DPH na razão molar 100:1 (lipídeo:sonda) e concentração crescente de lipídeo oxidado a 23 (pontos cheios e linhas sólidas) e $37^{\circ} \mathrm{C}$ (pontos vazios e linhas tracejadas).

O segundo parâmetro calculado a partir dos ajustes das equações 4.14 e 4.22- 4.26 às curvas de anisotropia resolvida no tempo para as MLVs de POPC contendo diferentes concentrações de lipídeos oxidados foi o tempo médio de correlação rotacional $(<\phi>)$, que é o tempo que a sonda TMA-DPH demora até para rotacionar um radiano. Os resultados estão na figura 4.34.

De maneira interessante, apesar dos valores de $r_{\infty}$ terem diminuído com a presença dos lipídeos oxidados a $23{ }^{\circ} \mathrm{C}$, os valores de $\langle\phi\rangle$ praticamente não sofreram alterações ao se comparar membranas contendo somente POPC com membranas contendo POPC-OOH, POVPC ou PAZEPC. Por outro lado, a $37^{\circ} \mathrm{C}$ o valor de $\langle\phi\rangle$ teve um leve aumento para as membranas contendo os lipídeos oxidados, enquanto o $r_{\infty}$ permaneceu inalterado para as mesmas amostras, com $25 \%$ de lipídeo oxidado. 


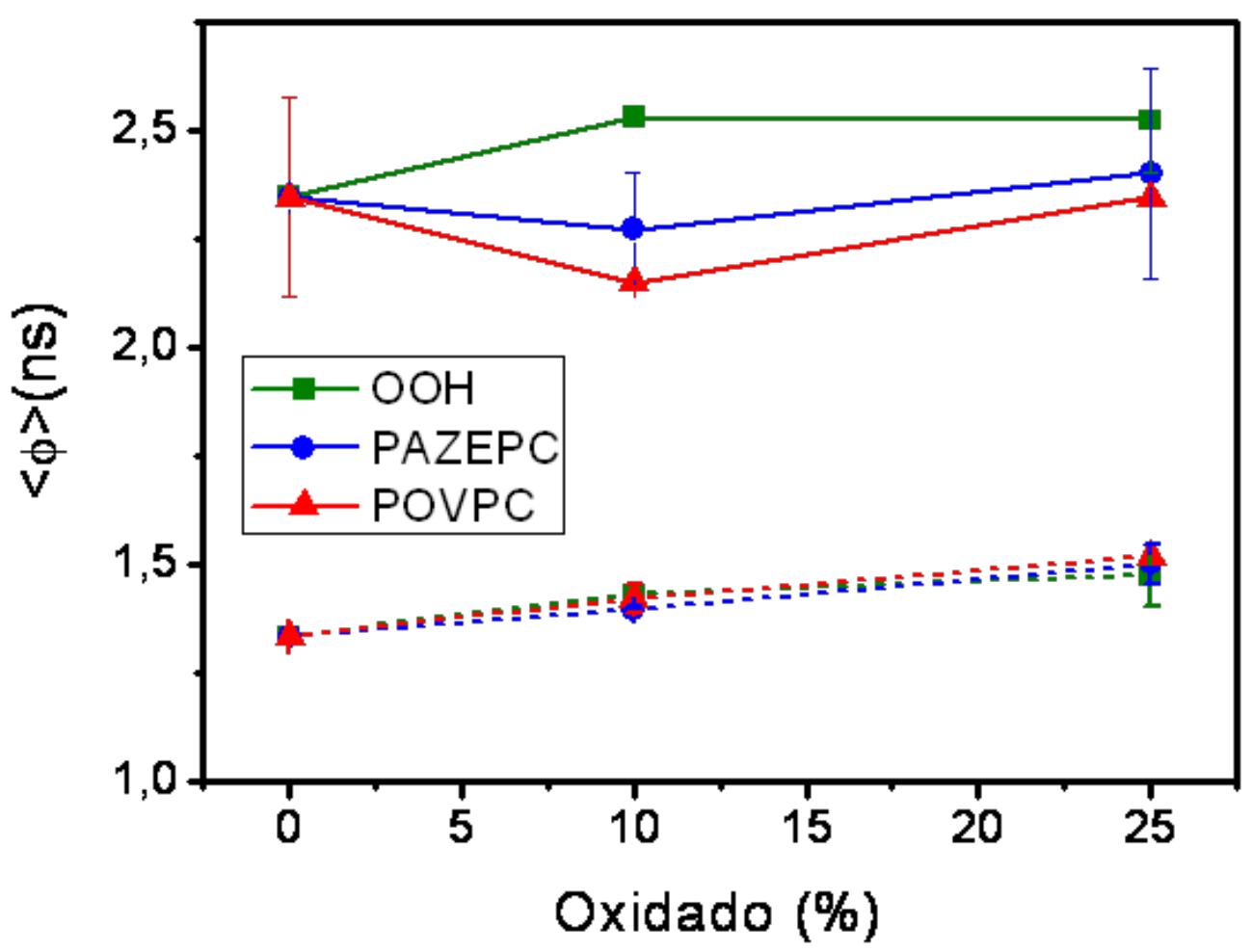

Figura 4.34: Tempo médio de correlação rotacional para MLVs de POPC (100 $\mu \mathrm{M})$ contendo TMA-DPH na razão molar 100:1 (lipídeo:sonda) e concentração crescente de lipídeo oxidado a 23 (pontos cheios e linhas sólidas) e $37^{\circ} \mathrm{C}$ (pontos vazios e linhas tracejadas).

Com os dados de $r_{\infty}$ e $<\phi>$ pode-se calcular o valor da microsviscosidade para as mesmas MLVs. Os resultados estão na figura 4.35. Desta figura podemos observar que $\eta$ não sofre alterações na presença dos lipídeos oxidados PAZEPC e POVPC nas concentrações utilizadas à temperatura de $23^{\circ} \mathrm{C}$, ou seja, ao introduzi-los na membrana de POPC não há aumento da restrição da rotação do TMA-DPH. Já para as mesmas amostras a $37^{\circ} \mathrm{C}$ há uma leve tendência de aumento de $\eta$ na presença de POPC-OOH bem como com 25\% de PAZEPC e POVPC. 


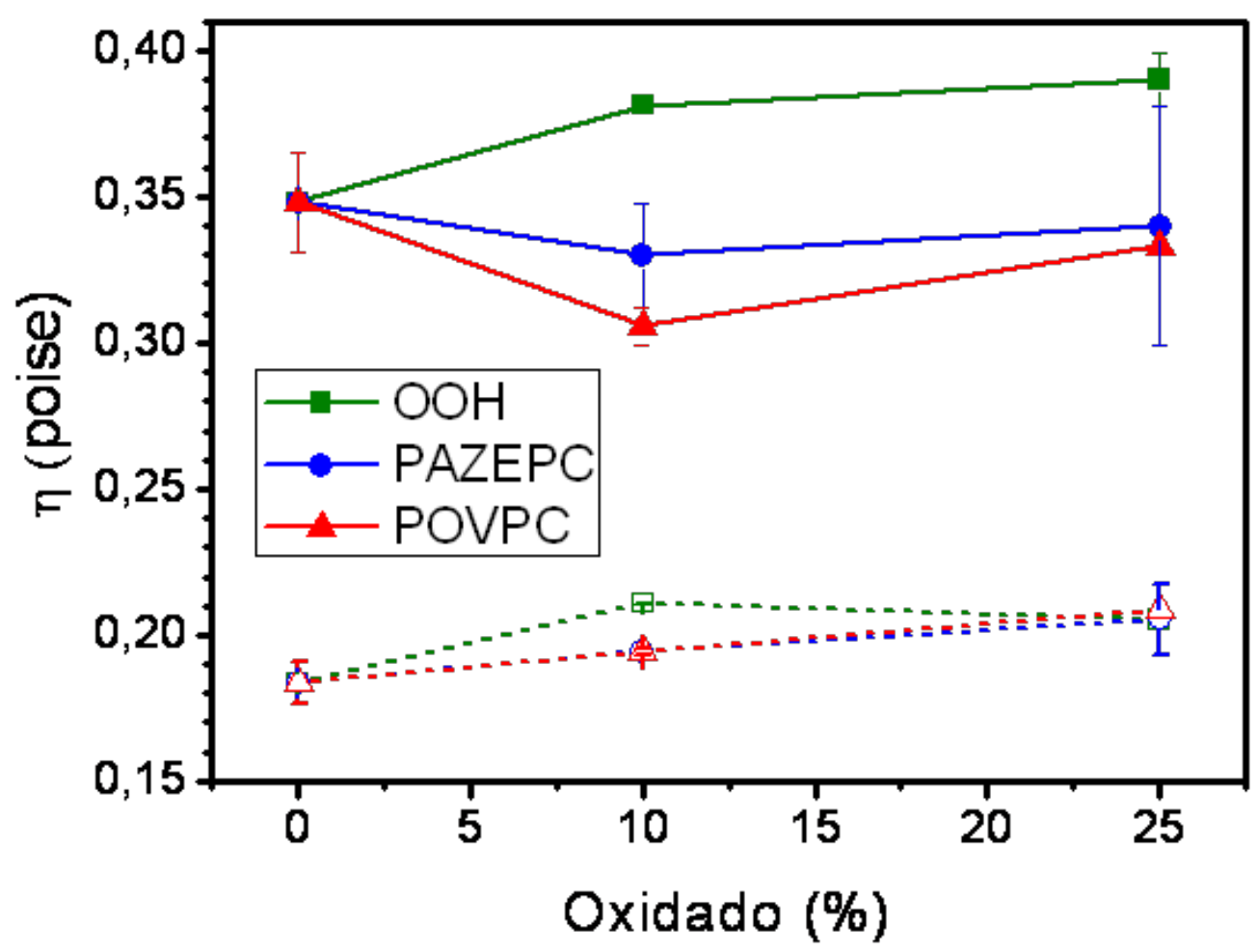

Figura 4.35: Microviscosidade para MLVs de POPC (100 $\mu \mathrm{M})$ contendo TMA-DPH na razão molar 100:1 (lipídeo:sonda) e concentração crescente de lipídeo oxidado a 23 (pontos cheios e linhas sólidas) e $37^{\circ} \mathrm{C}$ (pontos vazios e linhas tracejadas).

Por fim, realizamos experimentos utilizando as mesmas composições lipídicas na presença da sonda laurdan para obter o valor de GP e também os espectros resolvidos no tempo TRES. A figura 4.36 apresenta os valores de GP para as membranas estudadas, nas duas temperaturas. À temperatura de $23^{\circ} \mathrm{C}$ o valor de GP diminui com o aumento da concentração de PAZEPC e POVPC, sendo que o impacto de $25 \%$ de POVPC é mais pronunciável do que o do PAZEPC para a mesma razão molar.

Para as mesmas amostras a $37^{\circ} \mathrm{C}$ o valor do GP é constante na presença de PAZEPC e de $10 \%$ de POVPC, diminuindo para a concentração de $25 \%$ de POVPC. Como observado anteriormente, os valores de GP do laurdan aumentam na presença do lipídeo oxidado POPC$\mathrm{OOH}$ para ambas temperaturas. 


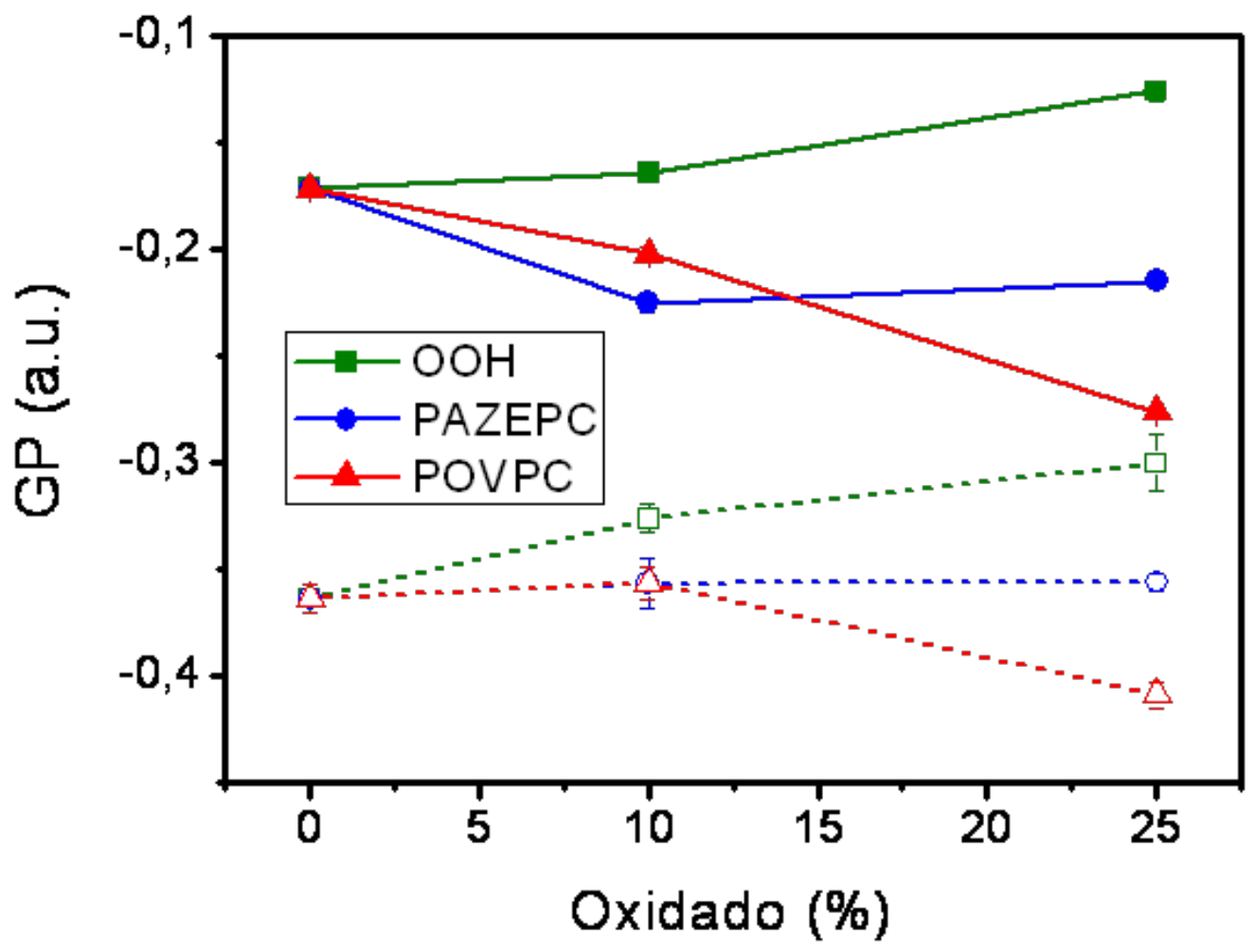

Figura 4.36: Valor de GP do laurdan para MLVs de POPC $(100 \mu \mathrm{M})$ contendo laurdan na razão molar 100:1 (lipídeo:sonda) e concentração crescente de lipídeo oxidado a $23{ }^{\circ} \mathrm{C}$ (pontos cheios e linhas sólidas) e $37^{\circ} \mathrm{C}$ (pontos vazios e linhas tracejadas).

Para obter maiores informações acerca do processo de relaxação dipolar, os experimentos de TRES foram realizados para membranas de 7:3 POPC:PAZEPC e de 75:25 POPC:POVPC a $23^{\circ} \mathrm{C}$. Os 1400 espectros de $\mathrm{t}=0,015$ ns até $\mathrm{t}=20,85$ ns estão apresentados na figura 4.37 . 


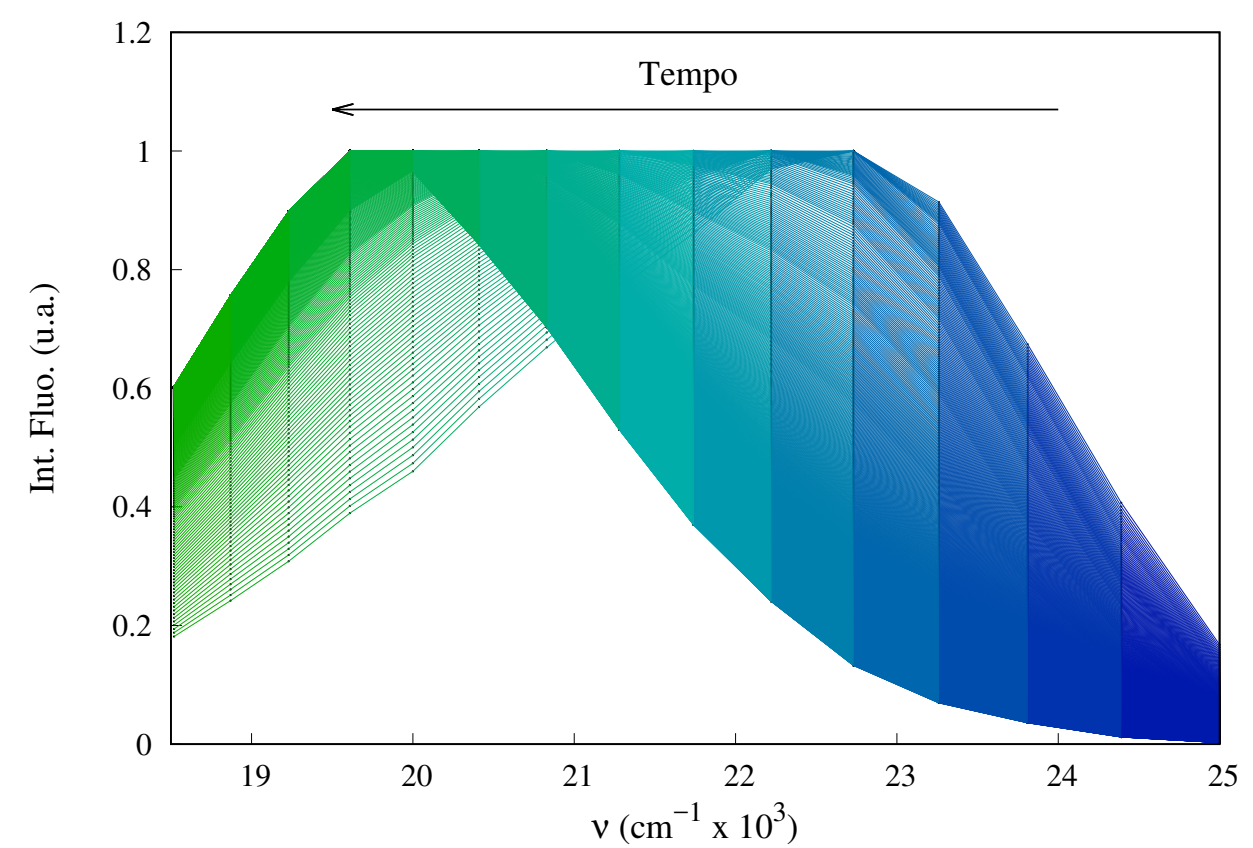

(a)

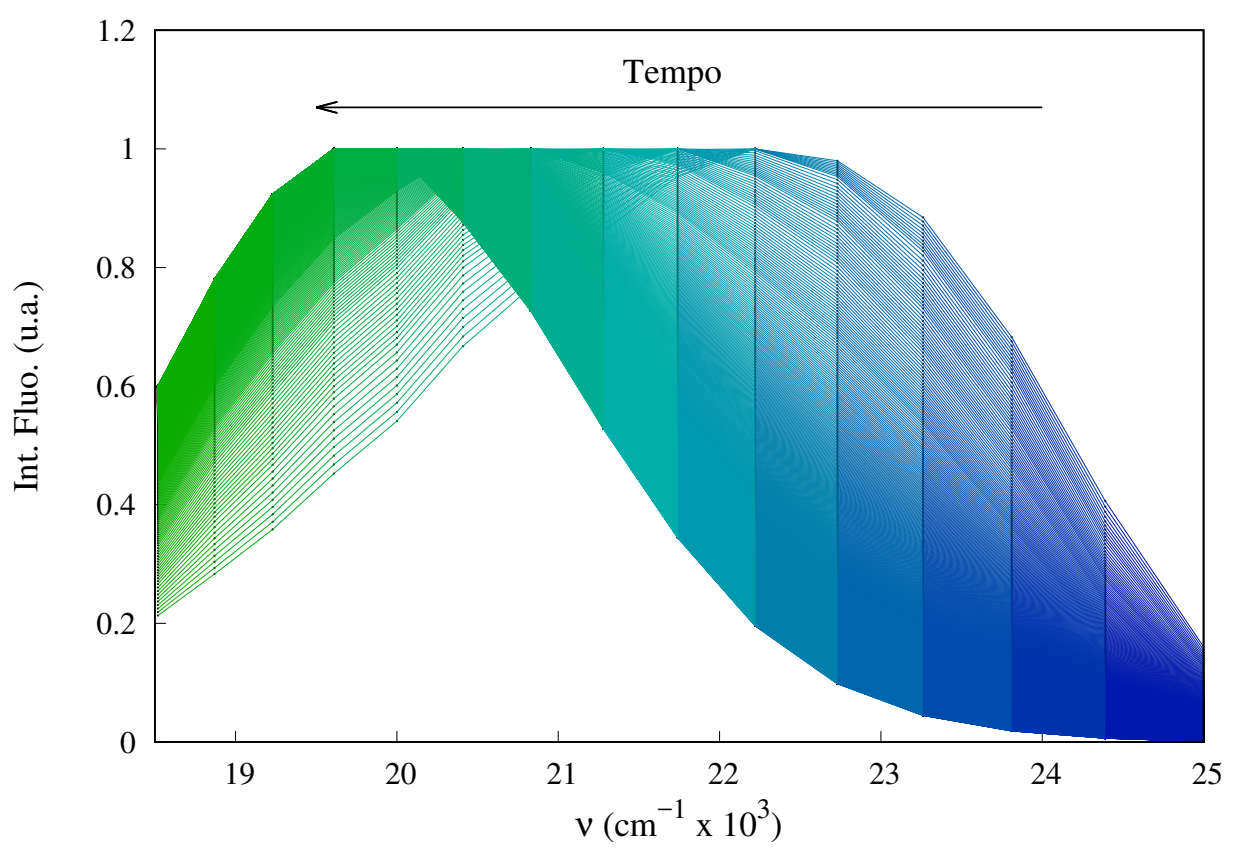

(b)

Figura 4.37: TRES obtidos para LUVs de POPC:PAZEPC (7:3) (a) e POPC:POVPC (75:25) (b) extrusadas com poro de $0,1 \mu \mathrm{m}$ para obter vesículas unilamelares (LUVs), a concentração lipídica utilizada foi de $500 \mu \mathrm{M}$ e a razão lipídeo:laurdan foi de 100:1. Em cada gráfico estão 1400 espectros resolvidos no tempo em passos de $0,015 \mathrm{~ns}$ entre $t=0,015$ ns até $t=20,85 \mathrm{~ns}$.

Os espectros de emissão de fluorescência resolvidos no tempo apresentados na figura 4.37 para os dois casos apresentam uma ótima reconstrução temporal. A partir dos ajustes de cada espectro temporal foi possível obter as curvas de $v(t)$ e $\Gamma(t)$ que estão na figura 4.38 e os parâmetros listados na tabela 4.8 . 

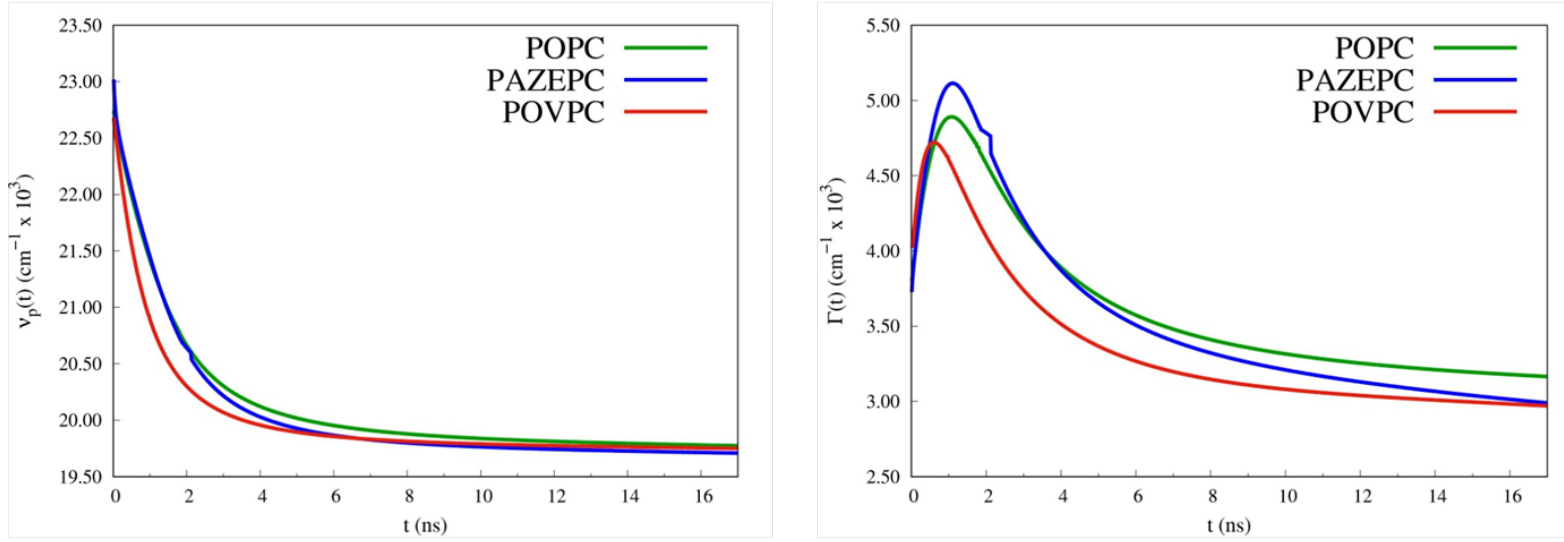

Figura 4.38: Gráficos de $v(t)$ (esquerda) e $\Gamma(t)$ (direita) obtidos para LUVs de POPC (linha verde) POPC:PAZEPC (7:3) (linha azul) e POPC:POVPC (75:25) (linha vermelha), extrusadas com poro de $0,1 \mu \mathrm{m}$ e com concentração lipídica de $500 \mu \mathrm{M}$ contendo laurdan na razão molar 100:1 (lipídeo:sonda) a $23{ }^{\circ} \mathrm{C}$.

\begin{tabular}{lccc}
$23{ }^{\circ} \mathrm{C}$ & POPC & $7: 3$ POPC:PAZEPC & $75: 25$ POPC:POVPC \\
\cline { 2 - 4 } GP (u.a.) & $-0,180 \pm 0,007$ & $-0,201 \pm 0,008$ & $-0,270 \pm-0,008$ \\
\hline$\Delta v\left(\mathrm{~cm}^{-1} \times 10^{3}\right)$ & $4048 \pm 90$ & $4200 \pm 90$ & $4150 \pm 90$ \\
\hline$\tau_{R D}(\mathrm{~ns})$ & $1,08 \pm 0,06$ & $1,02 \pm 0,06$ & $0,64 \pm 0,06$ \\
\hline
\end{tabular}

Tabela 4.8: Valores obtidos para membranas de POPC na ausência e presença de lipídeos oxidados à $23^{\circ} \mathrm{C}$. Para calcular o $\Delta v$ foi utilizado o valor de $v(0)=23,800 \mathrm{~cm}^{-1}$ obtido por [144].

As análises de TRES indicaram a leve aumento do valor de $\Delta v$ e um menor tempo de relaxação dipolar $\left(\tau_{R D}\right)$ para as membranas de POPC contendo $30 \%$ de PAZEPC e $25 \%$ de POVPC) (tabela 4.8). É importante acrescentar que o impacto no $\tau_{R D}$ é maior na presença do POVPC do que na presença de PAZEPC.

Comparando os resultados de valor de GP do laurdan e os parâmetros obtidos por análises de TRES pode-se observar que o decréscimo do GP (fig. 4.36) para as membranas de POPC:PAZEPC (75:25 GP, 7:3 TRES) e POPC:POVPC (75:25) a $23{ }^{\circ} \mathrm{C}$ é gerado pela aumento do $\Delta v$ e diminuição do $\tau_{R D}$ como obtido por TRES. Interessante notar que variação destes dois parâmetros (aumento de $\Delta v$ e diminuição de $\tau_{R D}$ ) é mais expressiva na presença do POVPC (TRES), também indicado pela maior diminuição do valor do GP. 


\subsection{Discussão II - Impacto dos lipídeos oxidados PAZEPC e POVPC em membranas lipídicas}

Com o intuito de elucidar o impacto da presença dos lipídeos oxidados PAZEPC e POVPC em membranas lipídicas, apresentamos neste tópico a discussão sobre os resultados apresentados anteriormente (figs. 4.30 - 4.38). Primeiramente, esquematizamos na figura 4.39 alguns resultados presentes na literatura que são importantes para nossa discussão.

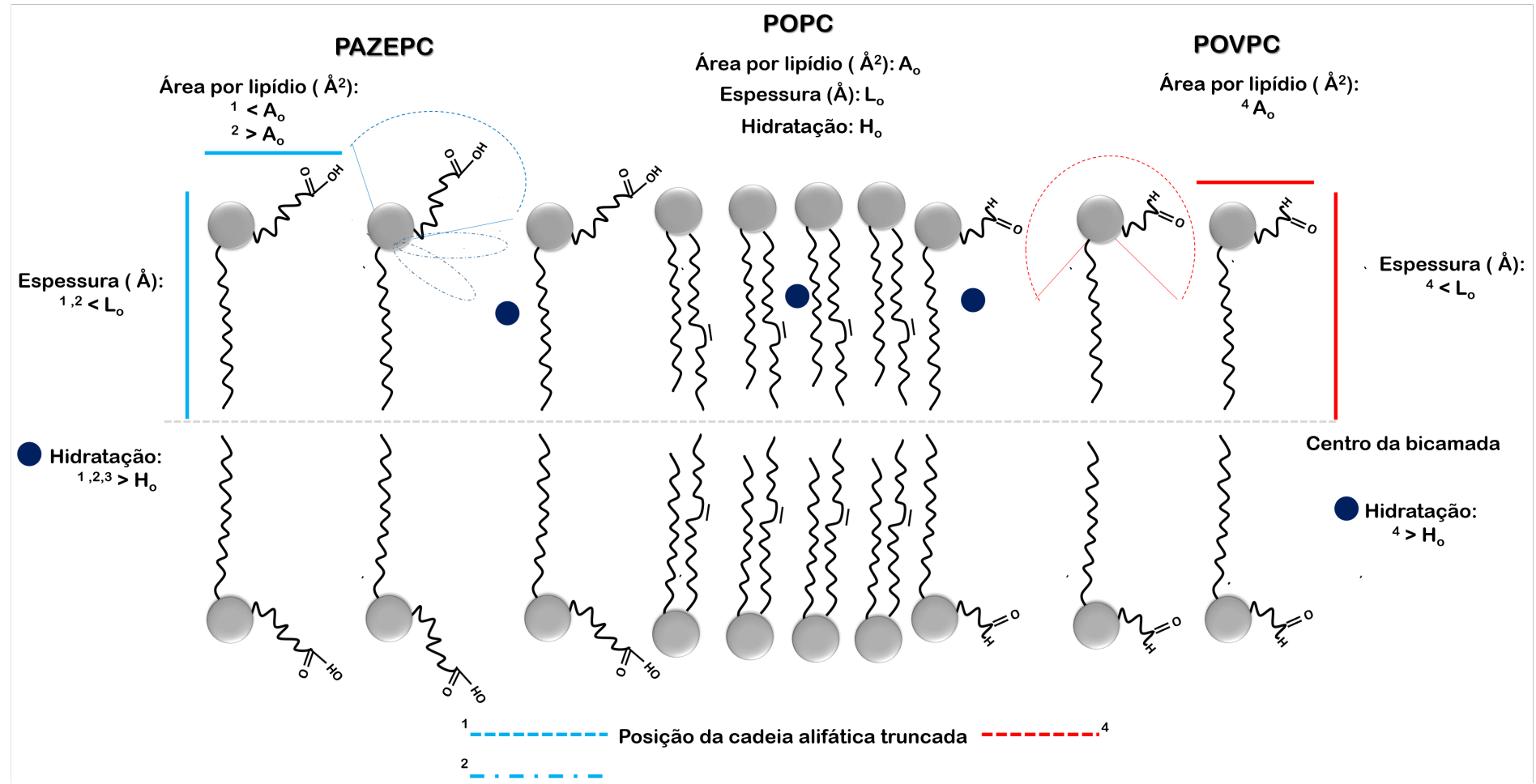

Figura 4.39: Principais resultados para nossa discussão obtidos por MD $\left(37^{\circ} \mathrm{C}-12,5 \%\right.$ e $\left.25 \%\right)$ $[48]^{1}$, SAXS $\left(23{ }^{\circ} \mathrm{C}-10 \%\right.$ e $\left.33 \%\right)[43]^{2}$, TRES $\left(10{ }^{\circ} \mathrm{C}-10 \%\right.$ e $\left.14 \%\right)[47]^{3}$ para o PAZEPC e $\operatorname{MD}\left(37^{\circ} \mathrm{C}-10 \%\right)$ e $\operatorname{TRES}\left(5^{\circ} \mathrm{C}\right.$ e ${ }^{\circ} \mathrm{C}-10 \%$, informação sobre a hidratação) $[152]^{4}$ para o POVPC em membranas lipídicas.

Resultados de dinâmica molecular para membranas de POPC contendo o lipídeo oxidado PAZEPC a $37^{\circ} \mathrm{C}$ mostraram que a cadeia alifática truncada, onde está a carboxila, se movimenta no exterior da membrana podendo até realizar a reversão completa para o meio aquoso para as membranas contendo 12,5\% e 25\% PAZEPC (fig. 4.39 - linha pontilhada azul indica as posições possíveis encontradas por MD para esta cadeia alifática truncada) [48]. No entanto, análises de dados experimentais de SAXS para 10\% e 33\% do lipídeo oxidado em membranas de POPC a 23 ${ }^{\circ} \mathrm{C}$ apontaram duas posições preferenciais para a cadeia truncada, sendo uma na parte hidrofóbica da membrana ( $7 \AA$ a partir do centro da bicamada lipídica) e outra na região da cabeça polar ( $15 \AA$ a partir do centro da bicamada lipídica) (fig. 4.39 - linha e ponto azul indicam as duas regiões com máximos de probabilidade de posição obtida por SAXS) [43]. 
Já para o lipídeo POVPC, resultados de MD de membranas de POPC com 10\% do lipídeo oxidado a $37{ }^{\circ} \mathrm{C}$ reportaram um equilíbrío entre as posições da cadeia truncada contendo o grupo aldeído entre a região hidrofóbica e hidrofílica da membrana (fig. 4.39 - linha pontilhada vermelha indica as posições possíveis encontradas por MD para esta cadeia alifática truncada) [152].

Comparando estas informações com a localização do grupo $\mathrm{OOH}$ na região da interface água/solvente obtidos por dinâmica molecular (e presentes na discussão anterior), foi hipotetizado um fenômeno chamado de "efeito âncora" [36], no qual o grupo hidroperóxido do lipídeo POPC$\mathrm{OOH}$ experimentaria o balanço da interação hidrofílica, que o levaria para o meio aquoso, com a interação hidrofóbica sentida pelos grupos metil posicionados após o $\mathrm{OOH}$, que o levaria para o centro da bicamada lipídica [36]. Desta maneira a posição preferencial do hidroperóxido seria na região da cabeça polar na interface água/membrana [36, 43, 46]. Já os lipídeos oxidados de cadeia truncada, PAZEPC e POVPC, não possuem o balanço hidrofóbico o que permitiria a maior movimentação destas cadeias para o meio exterior [36, 48, 152].

Entretanto, como mencionado acima, ainda não está claro na literatura se a cadeia truncada do lipídeo oxidado PAZEPC está completamente no meio externo [48] ou no interior da membrana [43] (fig. 4.39). Correlacionado a este debate também não está claro se a presença deste lipídeo diminui a área por lipídeo, como observado por MD [48], ou se há o aumento da área por lipídeo, como obtido por SAXS [43]. De qualquer maneira, estes dois estudos apontaram diminuição da espessura e maior hidratação da membrana lipídica na presença de $12,5 \%$ e $25 \%$ PAZEPC em membranas de POPC a $37^{\circ} \mathrm{C}$, como visto por MD [48], e com $10 \%$ e $33 \%$ do lipídeo oxidado em membranas de POPC a $23{ }^{\circ} \mathrm{C}$ como obtido por SAXS [43]. Em bom acordo com estes resultados, experimentos de TRES com membranas de POPC na presença de $10 \%$ e $14 \%$ de PAZEPC a $10^{\circ} \mathrm{C}$ apontaram uma maior hidratação destas membranas na região da interface água/membrana quando comparado ao controle de 100\% POPC [47] (fig. 4.39).

Tendo em vista agora o impacto do POVPC na área por lipídeo e na hidratação da membrana, resultados de dinâmica molecular para membranas de POPC contendo 10\% deste lipídeo oxidado a $37^{\circ} \mathrm{C}$ não apontaram nenhuma alteração na área por lipídeo [152] (fig. 4.39). Segundo os autores, a manutenção do valor de área por lipídeo aconteceu devido ao equilíbrio entre as posições da cadeia truncada mencionado acima: posições mais externas diminuiriam a área por lipídeo enquanto as mais internas aumentariam a área por lipídeo [152]. De maneira interessante, os mesmos autores reportaram o aumento da hidratação da membrana de POPC na presença de $10 \%$ POVPC a $37^{\circ} \mathrm{C}$ obtido por simulações computacionais e também experimentalmente por análises de TRES da mesma membrana a $5^{\circ} \mathrm{C}$ e $10^{\circ} \mathrm{C}$ [152] (fig. 4.39).

Considerando estes resultados da literatura sobre a influência dos lipídeos oxidados PAZEPC e POVPC em membranas lipídicas de POPC [43, 47, 48, 152], discutimos os nossos resultados, obtidos através das técnicas de fluorescência com as sondas TMA-DPH e laurdan. 


\section{Localização dos grupos carboxila do PAZEPC e aldeído do POVPC}

Analisando os dados da anisotropia residual $\left(r_{\infty}\right)$ e do tempo médio de correlação rotacional $(<\phi>)$ das membranas de POPC contendo POPC-OOH, PAZEPC ou POVPC a $23{ }^{\circ} \mathrm{C}$, pode-se perceber que há diminuição do valor de $r_{\infty}$ na presença dos três lipídeos oxidados, indicando maior abertura angular para a sonda TMA-DPH rotacionar. Por outro lado, $\mathrm{o}\langle\phi\rangle$ permanece praticamente constante para os três casos, apresentando apenas uma leve tendência de aumento na presença do POPC-OOH (confirmada para concentracões superiores a $25 \%$ deste lipídeo oxidado), sugerindo que o tempo para atingir a maior abertura angular não sofre alterações.

Para correlacionar o $r_{\infty}$ com o $\langle\phi\rangle$ calculamos a microviscosidade $(\eta)$ para determinar se a sonda TMA-DPH experimenta restrição para rotacionar. De maneira interssante, a $\eta$ apresentou aumento somente na presença do lipídeo POPC-OOH. Mais que isso, na presença de $10 \%$ POVPC há uma leve tendência de diminução do valor de $\eta$.

Tendo em vista que o aumento da microviscosidade obtido na presença do POPC-OOH foi correlacionado com a restrição de rotação da sonda TMA-DPH devido à colocalização do grupo $\mathrm{OOH}$ com a sonda, pode-se sugerir que os grupos carboxila do PAZEPC e aldeído do POVPC, bem como suas cadeias trunctadas, não apresentam tal restrição e, portanto, não estariam colocalizadas com o TMA-DPH.

Do ponto de vista dos dados de fluorescência da sonda laurdan a $23^{\circ} \mathrm{C}$, as análises de $T R E S$ para as membranas de POPC contendo 30\% de PAZEPC e 25\% de POVPC não apresentaram o comportamento descrito na literatura para membranas de POPC na presença de colesteróis oxidados com um grupo $\mathrm{OH}$ na cadeia alifática [130] (como no caso do 100\% POPC-OOH item 4.2). Pelo contrário, na presença de PAZEPC ou POVPC, a posição do pico de emissão $\left(\Delta v_{p}(t)\right.$ - fig. 4.38) atinge um valor constante na escala de tempo de nossos experimentos ( $15 \mathrm{~ns})$ e o gráfico de largura a meia altura dos espectros em função do tempo $(\Gamma(t)$ - fig. 4.38) apresenta o pico esperado e segue diminuindo para t > 13 ns. Sendo assim, as análises de TRES não apresentam indicações da interação do grupo carboxila do PAZEPC e do aldeído do POVPC com a sonda laurdan. Desta maneira, pode-se sugerir que as cadeias truncadas destes lipídeos oxidados não devem estar localizadas na região da interface água/solvente ou se há alguma interação, ela não é suficiente para impactar os espectros resolvidos no tempos.

Portanto, a $23^{\circ} \mathrm{C}$, os resultados de anisotropia resolvida no tempo da sonda TMA-DPH e de TRES da sonda laurdan não apresentam indicações de que as cadeias alifáticas truncadas do PAZEPC e do POVPC estejam na interface água/membrana, podendo estar no meio aquoso como indicado por dinâmica molecular [48, 152].

Seguindo uma análise semelhante para as mesmas amostras à temperatura de $37^{\circ} \mathrm{C}$, não foram observadas alterações significativas para a anisotropia residual e apenas um leve aumento tanto para o tempo médio de correlação rotacional quanto para a microsviscosidade com o aumento da concentração dos três lipídeos oxidados. 
Como discutido anteriormente, este aumento de $\langle\phi\rangle$ e $\langle\eta\rangle$ pode ser relacionado com a restrição do movimento de rotação da sonda TMA-DPH devido à presença do grupo $\mathrm{OOH}$, carboxila e aldeído presente na cadeia alifática oxidada do POPC-OOH, PAZEPC e POVPC, respectivamente. Desta maneira, o aumento da temperatura de $23^{\circ} \mathrm{C}$ para $37^{\circ} \mathrm{C}$ aumentaria a mobilidade destes grupos permitindo que eles adentrassem o interior da membrana e interagissem com a sonda TMA-DPH.

Observando os valores de $\mathrm{GP}$ a $37^{\circ} \mathrm{C}$, pode-se perceber que há o aumento para as membranas de POPC na presença de POPC-OOH como já discutido anteriormente (item 4.2). Na presença do PAZEPC, o valor de GP permanece constante para ambas concentrações do lipídeo oxidado e isso pode ter ocorrido devido a um efeito semelhante ao caso do POPC-OOH: aumento da hidratação [43, 47, 48] (e discussão abaixo) que diminuiria o valor de GP acompanhado de um processo de relaxação dipolar complexo que poderia resultar da interação do grupo carboxila com a sonda laurdan (como indicado pelo leve aumento de $\langle\phi\rangle$ e $\langle\eta\rangle$ ) que aumentaria o valor de GP. Deste balanço, o valor de GP da sonda laurdan poderia permanecer constante. Análise semelhante poderia ser feita para a membrana de POPC contendo $10 \%$ de POVPC a $37^{\circ} \mathrm{C}$, onde não há diminuição do valor do GP. Já para 25\% de POVPC, o possível aumento de hidratação [152] (e discussão abaixo) seria preponderante em relação a um processo de relaxação dipolar complexo resultante da interação do grupo aldeído com a sonda laurdan (como indicado pelo leve aumento de $\langle\phi>$ e $\langle\eta\rangle$ ) acarretando na diminuição do valor do GP.

Sendo assim, a $37^{\circ} \mathrm{C}$, nossos resultados de $\langle\phi\rangle,\langle\eta\rangle$ e GP poderiam indicar a presença das cadeias truncadas do PAZEPC e do POVPC na região da interface água/membrana.

De qualquer maneira, como perspectiva, pretendemos realizar simulações computacionais para avaliar a interação da sonda TMA-DPH e da sonda laurdan com os grupos caborxila e aldeído dos lipídeos oxidados PAZEPC e POVPC, respectivamente.

\section{Aumento da área por lipídeo na presença do PAZEPC ou do POVPC}

Nossos dados de anisotropia residual $\left(r_{\infty}\right)$ apontaram a diminuição dessa em função da concentração dos três lipídeos oxidados a $23{ }^{\circ} \mathrm{C}$ indicando maior abertura angular para a sonda TMA-DPH rotacionar. Esta maior abertura angular deve estar relacionada com o aumento de área por lipídeo para o POPC-OOH [36, 43, 46], PAZEPC [43] e possivelmente para POVPC (não há dados disponíveis nesta temperatura, para este lipídeo).

Ao aumentarmos a temperatura para a $37{ }^{\circ} \mathrm{C}$, o valor de $r_{\infty}$ manteve-se constante, indicando que não há variação da abertura angular na presença destes lipídeos oxidados, nestas concentrações. Com isto, a manutenção do valor de $r_{\infty}$ pode estar relacionada com o valor da área por lipídeo (que permanece inalterada para o POVPC a $37{ }^{\circ} \mathrm{C}$ ) como indicado por MD [152]. Por outro lado, nossas análises não indicaram diminuição da área por lipídeo na presença de PAZEPC como obtido por dinâmica molecular a $37{ }^{\circ} \mathrm{C}$ [48]. 


\section{Hidratação na presença do PAZEPC ou do POVPC}

Como observado anteriormente, a presença dos lipídeos oxidados em membranas de POPC resulta numa diminuição do tempo de vida de fluorescência da sonda TMA-DPH para ambas as temperaturas. Visto que os dados disponíveis na literatura indicam o aumento da hidratação da membrana de POPC na presença destes lipídeos oxidados [36, 43, 46-48, 152], esta diminuição de $\langle\tau\rangle$ obtida em nossos experimentos deve ter ocorrido pela interação de moléculas de água com o TMA-DPH [147] indicando que, na presença dos lipídeos oxidados, há maior penetração de água na região da interface da membrana.

É importante acrescentar também que não pode ser descartado que a diminuição do tempo de vida médio da sonda TMA-DPH possa ter sido causada pela interação da sonda com o grupo carboxila do PAZEPC e com o aldeído do POVPC.

De qualquer maneira, através das análises de TRES a $23{ }^{\circ} \mathrm{C}$, registramos que a sonda laurdan interage como um maior número de dipolos como observado pelo aumento dos valores de $\Delta v$ de membranas de POPC na presença de 30\% de PAZEPC e 25\% de POVPC. Estes dipolos podem ser interpretados como moléculas de água e indicando maior hidratação da membrana na presença deste lipídeos oxidados.

Assim sendo, nossos resultados que apontam maior hidratação de membranas de POPC na presença de diferentes concentrações de PAZEPC e POPVPC a 23 e $37^{\circ} \mathrm{C}$ estão em bom acordo com a literatura $[36,43,46-48,152]$.

\section{Comparações entre temperatura, POPC-OOH, PAZEPC e POVPC}

Para analisar as alterações nas propriedades de membranas lipídicas de POPC na presença de 25\% de POPC-OOH, 25\% PAZEPC ou 25\% POVPC com o impacto da variação da temperatura, de $23{ }^{\circ} \mathrm{C}$ para $37^{\circ} \mathrm{C}$, e também com membranas de $100 \%$ POPC-OOH, calculamos as variações percentuais do tempo de vida médio de fluorescência, anisotropia residual (fig 4.40), tempo médio de correlação rotacional e microviscosidade (fig. 4.41) presentes nas figuras 4.31 - 4.21 para treze comparações. 


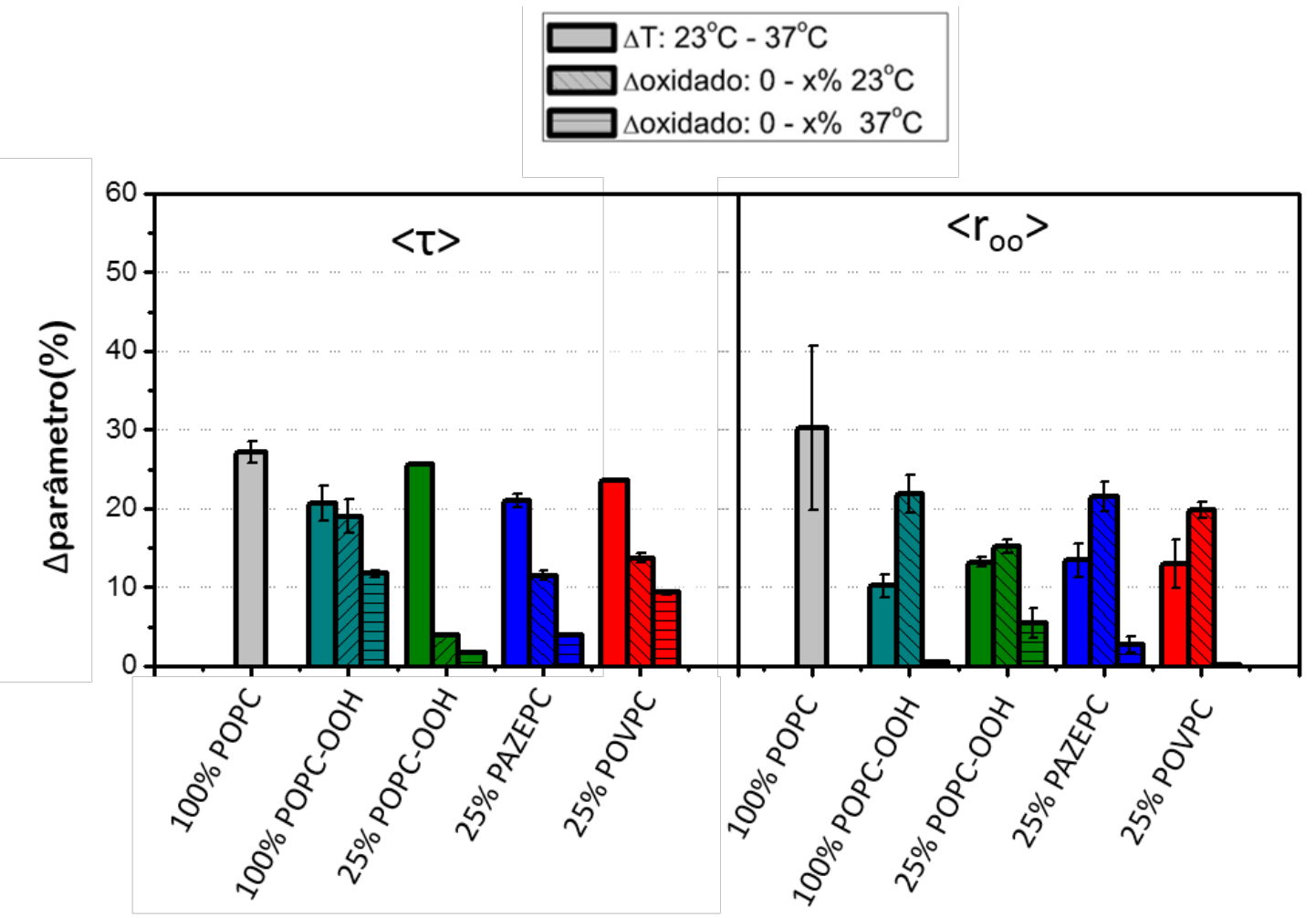

Figura 4.40: Variação percentual para o valor de tempo de vida médio de fluorescência e anisotropia residual para: (i) membranas de $100 \%$ POPC a 23 e $37^{\circ} \mathrm{C}$ (cinza); (ii) membranas de $100 \%$ POPC-OOH a 23 e $37{ }^{\circ} \mathrm{C}$ (ciano escuro sólido); membranas com $0 \%$ e $100 \%$ de $\mathrm{POPC}-\mathrm{OOH}$ (iii) a $23{ }^{\circ} \mathrm{C}$ (ciano escuro linhas em diagonal) e (iv) a $37{ }^{\circ} \mathrm{C}$ (ciano escuro linhas horizontais); (v) membranas com $25 \%$ POPC-OOH a 23 e $37^{\circ} \mathrm{C}$ (verde sólido); membranas com $0 \%$ e $25 \%$ de POPC-OOH (vi) a $23{ }^{\circ} \mathrm{C}$ (verde linhas em diagonal) e (vii) a $37{ }^{\circ} \mathrm{C}$ (verde linhas horizontais); (viii) membranas com $25 \%$ PAZEPC a 23 e $37^{\circ} \mathrm{C}$ (azul sólido); membranas com $0 \%$ e $25 \%$ de PAZEPC (ix) a $23{ }^{\circ} \mathrm{C}$ (azul linhas em diagonal) e (x) a $37{ }^{\circ} \mathrm{C}$ (azul linhas horizontais); (xi) membranas de $25 \%$ POVPC a 23 e $37{ }^{\circ} \mathrm{C}$ (vermelho sólido); membranas com $0 \%$ e $25 \%$ de POVPC (xii) a $23{ }^{\circ} \mathrm{C}$ (vermelho linhas em diagonal) e (xiii) a $37^{\circ} \mathrm{C}$ (vermelho linhas horizontais). Os valores estão em módulo e incertezas foram propagadas por derivadas parciais.

A figura 4.40 apresenta a variação percentual do $<\tau>$ para a sonda TMA-DPH em diferentes composições lipídicas e a $23^{\circ} \mathrm{C}$ e $37^{\circ} \mathrm{C}$ onde é possível perceber que a maiores variações percentuais acontecem para as mesmas amostras ao variar a temperatura (cores sólidas), seguido pela substituição de $100 \%$ de POPC por POPC-OOH a $23{ }^{\circ} \mathrm{C}$ (ciano escuro linhas em diagonal). Também é interessante notar que para ambas as temperaturas a diminuição percentual do tempo médio de vida de fluorescência da sonda TMA-DPH para amostras contendo $25 \%$ de um lipídeo oxidado é mais acentuada para o POVPC, PAZEPC e POPC-OOH, ou seja, é inversamente proporcional ao tamanho da cadeia lipídica oxidada. Este dado poderia indicar que o aumento da penetração de água depende do tamanho da cadeia alifática oxidada, visto que a diminuição do tempo de vida pode estar associada à interação da sonda TMA-DPH com as moléculas de água [147]. Com a diminuição da cadeia alifática oxidada poderia haver o maior 
descasamento (mismatch) da parte hidrofóbica e hifrofílica entre o lipídeo POPC e o lipídeo oxidado, acarretando na maior instabilidade da membrana e, como observado experimentalmente, maior penetração de água. Cabe acrescentar que o impacto da presença de $25 \%$ de POVPC a $37^{\circ} \mathrm{C}$ (vermelho, linhas horizontais) é comparável com uma membrana composta de $100 \%$ do lipídeo oxidado POPC-OOH (ciano escuro, linhas horizontais).

De qualquer maneira, apesar da presença dos lipídeos oxidados em membranas de POPC (ou de 100\% POPC-OOH) causarem diminuição no tempo de vida médio de fluorescência da sonda TMA-DPH, os efeitos ainda são menores do que a variação de temperatura de $23^{\circ} \mathrm{C}$ para $37^{\circ} \mathrm{C}$ de membranas compostas por $100 \%$ POPC (e menos significativas do que alterações no $<\tau>$ para transição de fase lipídica de membranas de DPPC, como discutido anteriormente).

Analisando as variações percentuais para o $r_{\infty}$ (fig. 4.40) pode-se observar que a maior diferença ocorreu ao aumentar a temperatura de membranas de $100 \%$ POPC de $23^{\circ} \mathrm{C}$ para $37^{\circ} \mathrm{C}$ (cinza). Em seguida, a substituição de $100 \%$ POPC por $100 \%$ POPC-OOH ou a presença de $25 \%$ de PAZEPC ou POVPC em membranas de POPC a $23^{\circ} \mathrm{C}$ apresentou variações percentuais de anistropia residual equivalentes. Já a $37^{\circ} \mathrm{C}$, a introdução de um lipídeo oxidado em membranas de POPC ou a total substituição pelo POPC-OOH não apresentam uma alteração significativa no valor de $r_{\infty}$. Portanto, outra vez, o efeito da temperatura em membranas de $100 \%$ POPC é mais impactante na anistropia residual enquanto que a $23^{\circ} \mathrm{C}$ os lipídeos de cadeia alifática truncada PAZEPC e POVPC possuem o maior impacto, tendo em conta a concentração do lipídeo oxidado.

Seguindo a análise da variação percentual dos parâmetros obtidos por anisotropia resolvida no tempo da sonda TMA-DPH, a figura 4.41 apresenta as comparações para o tempo médio de correlação rotacional e para a microviscosidade. 


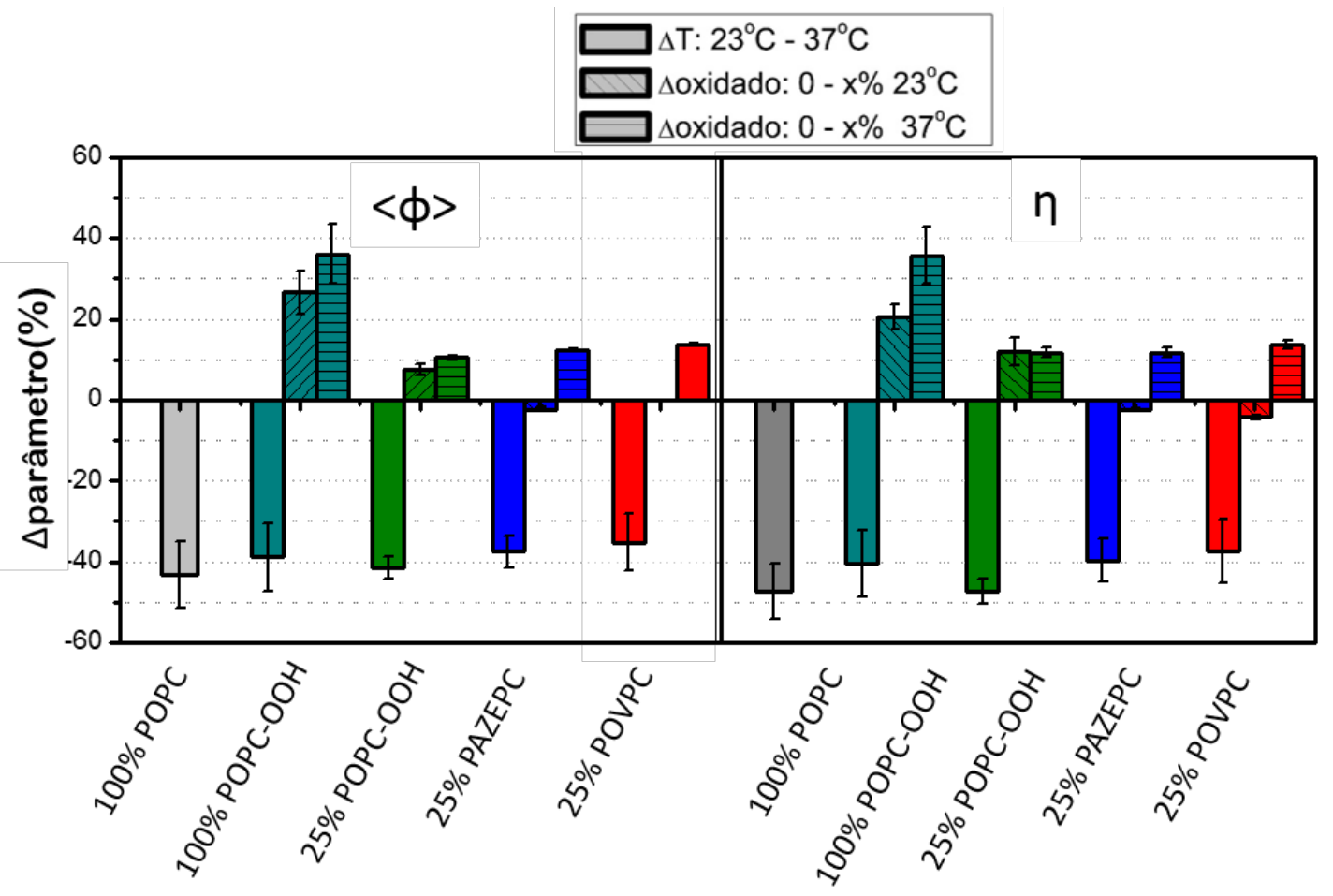

Figura 4.41: Variação percentual para o valor de tempo médio de correlação rotacional e microviscosidade para: (i) membranas de $100 \%$ POPC a 23 e $37^{\circ} \mathrm{C}$ (cinza); (ii) membranas de $100 \%$ POPC-OOH a 23 e $37{ }^{\circ} \mathrm{C}$ (ciano escuro sólido); membranas com $0 \%$ e $100 \%$ de POPC-OOH (iii) a $23{ }^{\circ} \mathrm{C}$ (ciano escuro linhas em diagonal) e (iv) a $37{ }^{\circ} \mathrm{C}$ (ciano escuro linhas horizontais); (v) membranas com $25 \%$ POPC-OOH a 23 e $37^{\circ} \mathrm{C}$ (verde sólido); membranas com $0 \%$ e $25 \%$ de POPC-OOH (vi) a $23{ }^{\circ} \mathrm{C}$ (verde linhas em diagonal) e (vii) a $37^{\circ} \mathrm{C}$ (verde linhas horizontais); (viii) membranas com $25 \%$ PAZEPC a 23 e $37^{\circ} \mathrm{C}$ (azul sólido); membranas com $0 \%$ e $25 \%$ de PAZEPC (ix) a $23{ }^{\circ} \mathrm{C}$ (azul linhas em diagonal) e (x) a $37^{\circ} \mathrm{C}$ (azul linhas horizontais); (xi) membranas de $25 \%$ POVPC a 23 e $37^{\circ} \mathrm{C}$ (vermelho sólido); membranas com $0 \%$ e $25 \%$ de POVPC (xii) a $23{ }^{\circ} \mathrm{C}$ (vermelho linhas em diagonal) e (xiii) a $37^{\circ} \mathrm{C}$ (vermelho linhas horizontais). Os valores estão em módulo e incertezas foram propagadas por derivadas parciais.

Pode-se observar na figura 4.41 que a variação de temperatura (cores sólidas) de $23^{\circ} \mathrm{C}$ para $37^{\circ} \mathrm{C}$ em todas as amostras estudadas levou à diminuição do $\langle\phi\rangle$ e da $\eta$, indicando que o aumento da temperatura permite que a sonda TMA-DPH rotacione até a maior abertura angular em um tempo menor e que ela experimenta menor restrição ao movimento. É interessante notar que a variação percentual é muito similar em todos os casos o que sugere que o efeito da temperatura independe do tamanho da cadeia alifática, seja ela oxidada ou não.

Analisando os valores de variação percentual para $\langle\phi>$ e para $\eta$ decorrentes da presença dos lipídeos oxidados, os maiores impactos são causados na substituição de 100\% POPC por $100 \%$ POPC-OOH, seguido pela introdução de $25 \%$ de $\mathrm{POPC}-\mathrm{OOH}$ a $23^{\circ} \mathrm{C}$ que é equivalente à introdução de qualquer um dos três lipídeos oxidados investigados em membranas de POPC a $37^{\circ} \mathrm{C}$. Vale ressaltar que o POPC-OOH é o único lipídeo oxidado que impactou o valor do tempo médio de correlação rotacional e de microviscosidade para todas as concentrações e em ambas 
as temperaturas.

De maneira interessante, o aumento dos valores de $\langle\phi\rangle$ e $\eta$ para membranas de POPC na presença de $25 \%$ de PAZEPC ou POVPC apenas a $37^{\circ} \mathrm{C}$ pode estar relacionada com o aumento da mobilidade dos lipídeos na região da cabeça polar que poderia acarretar na maior movimentação das cadeias alifáticas truncadas destes lipídeos nesta mesma região. Uma possível explicação para esta relação seria o tempo de relaxação dipolar $\left(\tau_{R D}\right)$ que pode ser obtido através da análise de TRES. Para uma apreciação, fizemos a figura 4.42 com os dados de $\tau_{R D}$ para membranas de POPC com percentuais de PAZEPC ou POVPC em diferentes temperaturas presentes na literatura e obtidos neste trabalho.

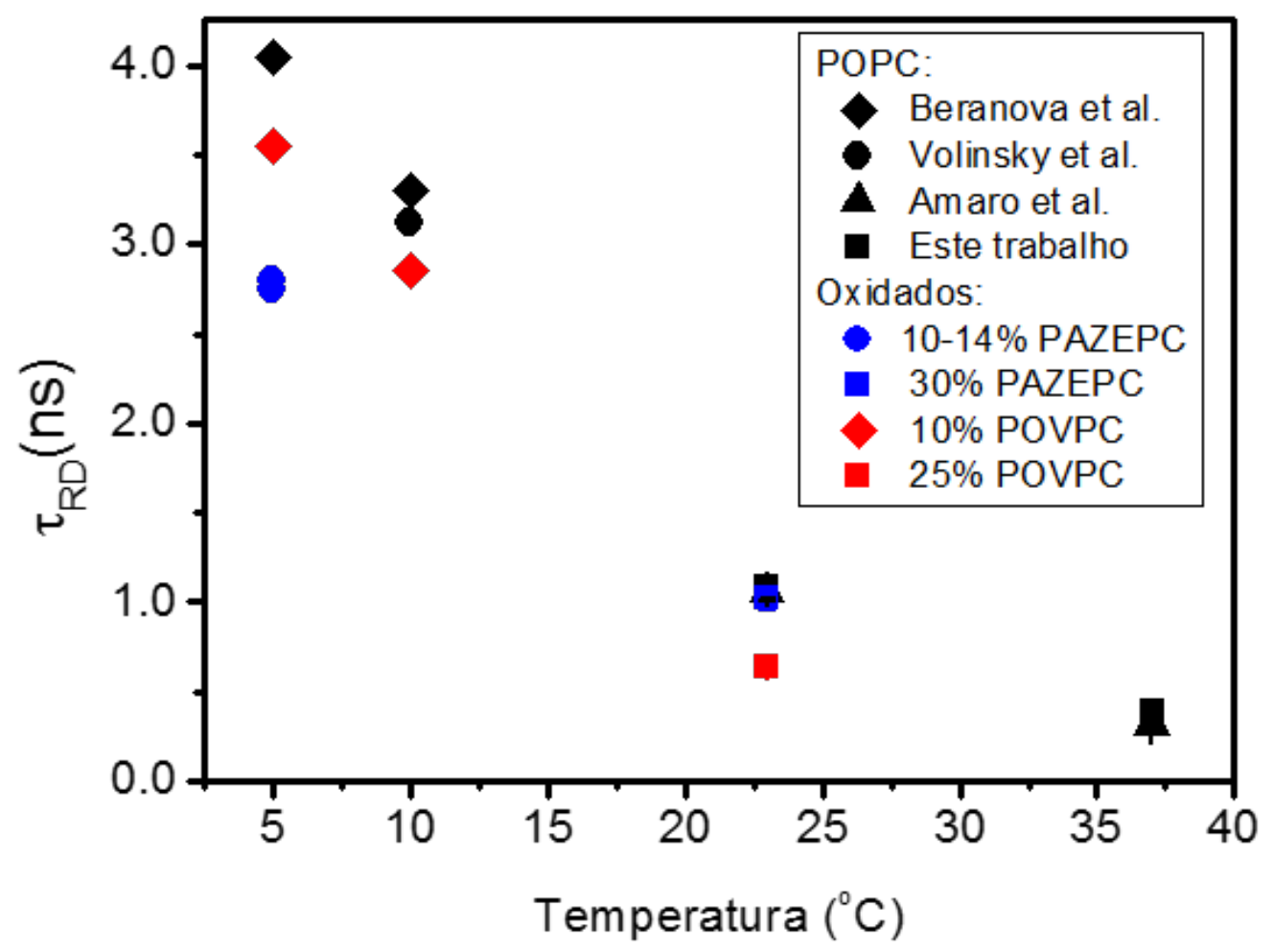

Figura 4.42: Valores de tempo médio de relaxação dipolar em função da temperatura para membranas de POPC [47, 136, 152] com diferentes concentrações de PAZEPC [47] ou POVPC [152] e obtidos neste trabalho.

Primeiramente é interessante notar há a diminuição do $\tau_{R D}$ para as membranas de POPC (símbolos pretos) em função da temperatura $[47,128,152]$ e que nossos resultados se adequam muito bem a este perfil (fig. 4.42). Esta diminuição do $\tau_{R D}$ é entendida como maior mobilidade dos lipídeos na região da interface água/solvente visto que esta é a localização da sonda laurdan em membranas de POPC [146].

Para membranas de POPC contendo percentuais de PAZEPC ou POVPC essa mesma tendência de diminuição de $\tau_{R D}$ com o aumento da temperatura é observada e poderia indicar 
a maior mobilidade dos lipídeos na região da interface da membrana (e possivelmente a maior movimentação das cadeias truncadas nesta região). É importante ressaltar que não existem dados suficientes para os mesmos percentuais de lipídeo oxidado em diferentes temperatura para confirmar este efeito.

Apenas para complementar a discussão, os valores de $\Delta v$ para estes mesmos trabalhos também foram analisados e estão apresentados na figura 4.43 .

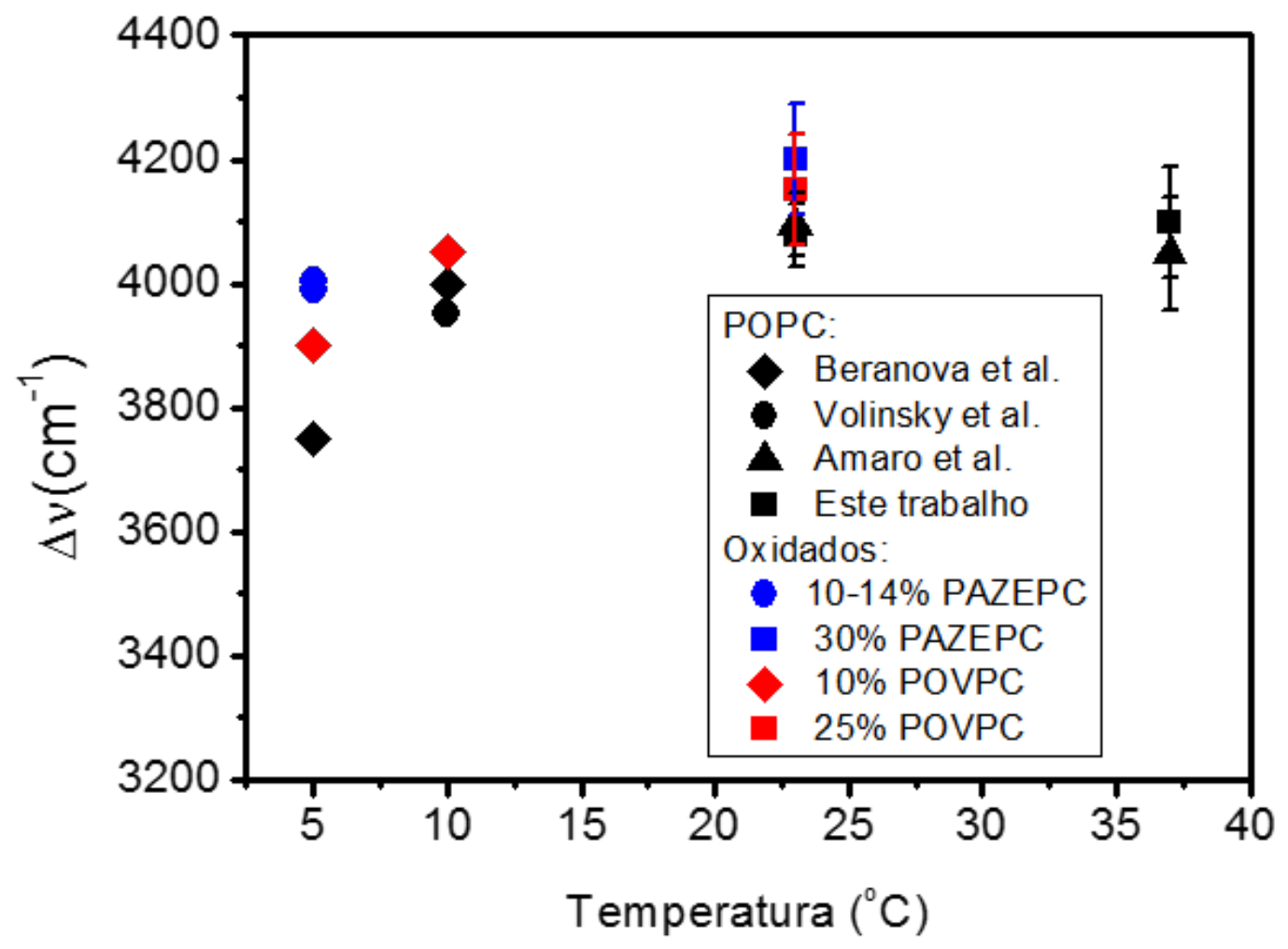

Figura 4.43: Valores de $\Delta v$ em função da temperatura para membranas de POPC [47, 136, 152] com diferentes concentrações de PAZEPC [47] ou POVPC [152] e obtidos neste trabalho.

Pode-se observar na figura 4.43 que para membranas de POPC (símbolos pretos) o acréscimo de temperatura acarreta no aumento de $\Delta v$ indicando maior interação da sonda laurdan com dipolos que neste caso são entendidos como número de moléculas de água, ou seja, a membrana de POPC se torna mais hidratada com o aumento da temperatura. Interessante notar que, a partir de $23^{\circ} \mathrm{C}$, este efeito não é observado e o aumento da hidratação não é perceptível por este parâmetro.

De maneira similar, na presença dos lipídeos oxidados PAZEPC ou POVPC, há tendência de aumento do número de dipolos com que a sonda laurdan interage com o aumento da temperatura, possivelmente pelo aumento de moléculas de água e/ou com a interação com os grupos carboxila e aldeído do PAZEPC e POVPC, respectivamente. Vale ressaltar que com o aumento da 
temperatura a diferença de hidratação $(\Delta v)$ entre as membranas de $100 \%$ POPC e as membranas contendo os lipídeos oxidados diminuiu.

De qualquer maneira, não é claro o motivo do aumento do valor do tempo médio de correlação rotacional e da microviscosidade de membranas de $\mathrm{POPC}$ a $37^{\circ} \mathrm{C}$ na presença de $25 \%$ de PAZEPC ou POVPC e como perspectiva pretende-se estudar por TRES as membranas de POPC a $37^{\circ} \mathrm{C}$ contendo diferentes concentrações de PAZEPC e POVPC.

Finalizando, então, as comparações apresentadas nas figuras 4.40 e 4.41 pode-se constatar que, em membranas de POPC, tanto a temperatura quanto a presença dos lipídeos oxidados impactam os valores de $\left\langle\tau>\right.$ e $r_{\infty}$ no mesmo sentido, enquanto que os valores de $\langle\phi>$ e $\eta$ são impactados em sentido contrário, para os três lipídeos oxidados estudados a $37^{\circ} \mathrm{C}$ e também a $23^{\circ} \mathrm{C}$ para o caso de POPC-OOH. Vale ressaltar que em todos os parâmetros analisados, o aumento da temperatura para membranas de $100 \%$ POPC foi mais significativo do que a introdução dos lipídeos oxidados. 


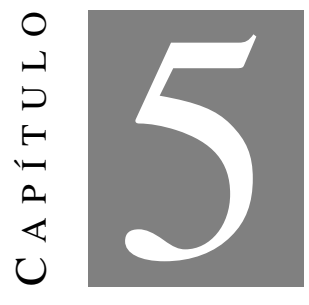

\section{IMPACTO DE LIPÍDEOS OXIDADOS EM}

\section{BICAMADAS LIPÍdICAS INVESTIGADO POR SAXS}

\subsection{Materiais e Métodos}

As mesmas composições lipídicas utilizadas no capítulo 4 (tabela 4.1) foram preparadas para o estudo do impacto de lipídeos oxidados em membranas lipídicas através da técnica experimental de espalhamento de raio-x a baixos ângulos (SAXS). Desta maneira, buscou-se complementar os resultados e discussões obtidos anteriormente.

A preparação das vesículas grandes (LUVs e MLVs) foi realizada de maneira semelhante à descrição do item 4.1.1 com pequenas modificações: por não se tratar de experimentos de absorção/fluorescência na região do espectro UV - visível (como no capítulo anterior) não foi utilizado clorofórmio grau espectroscópico (apenas clorofórmio puro) e nem sonda fluorescente. Não foram realizados ciclos de resfriamento e aquecimento das soluções de LUVs e MLVs . Além disso, a concentração lipídica utilizada foi de $10 \mathrm{mM}$ para se obter uma boa relação de sinal/ruído nas curvas de espalhamento de raio-x. O tampão utilizado foi o mesmo descrito no item 4 e todas as amostras foram medidas a $23^{\circ} \mathrm{C}$ e $37^{\circ} \mathrm{C}$.

Para efeito comparativo, mediu-se as curvas de SAXS para as suspensões de vesículas multilamelares grandes (MLVs) e de vesículas unilamelares grandes (LUVs) que foram obtidas ao realizar a extrusão (51 vezes) da suspensão de MLVs. Para isto, utilizou-se um sistema de extrusão automático construído no laboratório da Profa. Dra. Rosangela Itri em parceria com o laboratório do Prof. Dr. Leandro R. S. Barbosa composto por um extrusor convencional (Avanti Mini Extruder) e utilizando um poro de $0,1 \mu \mathrm{m}$.

Todos os experimentos de SAXS foram realizados na linha de SAXS1 $(\lambda=1,54 \AA)$ do 
Laboratório Nacional de Luz Síncrotron (LNLS) do Centro Nacional de Pesquisa em Energia e Materiais (CNPEM) em Campinas, São Paulo. O tempo de cada medida foi de 100 segundos e as curvas de SAXS obtidas foram subtraídas da curva de espalhamento do tampão. Os dados foram analisados utilizando a escala arbitrária de intensidade de espalhamento de $\operatorname{raios-x}(I(q))$ obtida no aparato experimental. Como esta escala é a mesma em todos os nossos experimentos, pôde-se realizar a comparação direta entre as $I(q)$ das diferentes amostras.

\subsubsection{Modelo para análise das curvas de SAXS para LUV e MLV}

Como o diâmetro das vesículas $\left(D_{V} \sim 1000 \AA\right.$, quando extrusada por poro de $\left.0,1 \mu \mathrm{m}\right)$ é muito maior do que a dimensão máxima $\left(D_{\max }\right)$ obtida por SAXS $\left(D_{V} \gg D_{\max } \sim \frac{\pi}{q_{\min }} \sim 300 \AA\right)$, pode-se considerar que a curvatura das vesículas não é detectada pelo espalhamento de raio-X a baixos ângulos. Sendo assim, analisou-se as curvas de SAXS das suspensões de MLVs e de LUVs utilizando o modelo de membrana (plano) infinita, que supõe que a espessura da vesícula lipídica é muito menor do que o seu raio e que a curva de SAXS $(I(q))$ é resultado do espalhamento de raio-x de diferentes regiões da membrana na direção normal à superfície da mesma (fator de forma - $P_{t}(q)$ ) podendo contar com a contribuição de um fator de estrutura $(S(q))$, no caso da presença de multilamelas correlacionadas. Sendo assim, pode-se escrever o modelo matemático como [153]:

$$
I(q)=P(q) S(q)=\frac{2 \pi A}{q^{2}} P_{t}(q) S(q)
$$

onde o $A$ é a area superficial da membrana, $q$ é o módulo do vetor de espalhamento, $P_{t}(q)$ é o fator de forma da seção transversal da bicamada lipídica (perpendicular ao plano $A$ ) considerado muito menor do que $A$ [153].

Neste trabalho modelamos a função $P_{t}(q)$ supondo que a seção tranversal da membrana é composta por três níveis $(i)$ onde cada um possui uma espessura $R_{i}$ e uma densidade eletrônica média $\rho_{i}$. Estas três faixas são designadas para as seguintes regiões do lipídeo: cabeça polar $(i=p o l)$, cadeia parafínica composta pelos grupos $\mathrm{CH}_{2}\left(i=\mathrm{CH}_{2}\right)$ e grupo metil $\left(i=\mathrm{CH}_{3}\right)$ como esquematizado na figura 5.1 abaixo. 


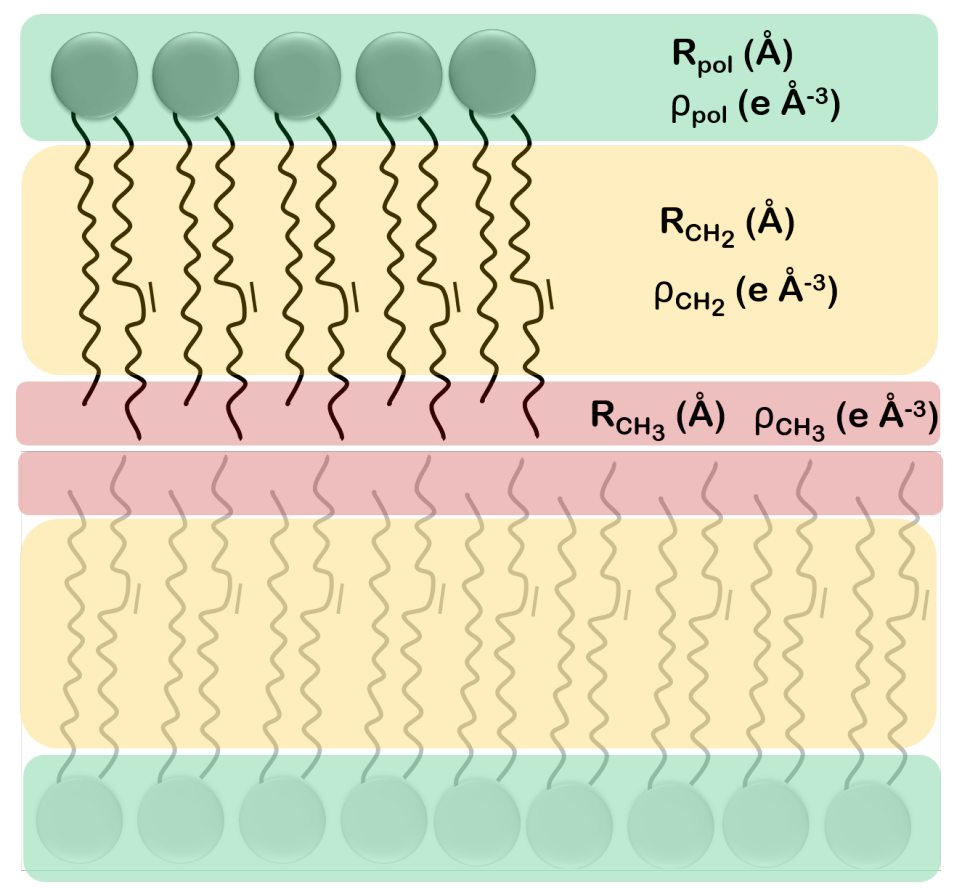

Figura 5.1: Modelo de três níveis para o fator de forma $P_{t}(q)$ da seção transversal de bicamada lipídica (eq. 5.2).

Interessante notar que neste modelo de três níveis, a densidade eletrônica $\rho_{i}$ de um nível é obtida como uma média desta região e por isso não há uma resolução "molecular"dos lipídeos como esquematizado por cada uma das três cores (fig. 5.1).

Tendo em vista cada valor de $\rho_{i}$ médio e o valor de cada $R_{i}$, pode-se escrever o fator de forma $P_{t}(q)$ como [153]:

$$
\begin{array}{r}
P_{t}(q)=\left[\frac { 2 } { q } \left\{\Delta \rho_{C H_{3}} \operatorname{sen}\left(q R_{C H_{3}}\right)+\Delta \rho_{C_{2}}\left\{\operatorname{sen}\left[q\left(R_{C H_{2}}+R_{C H_{3}}\right)\right]-\operatorname{sen}\left(q R_{C H_{3}}\right)\right\}\right.\right. \\
\left.\left.+\Delta \rho_{p o l}\left\{\operatorname{sen}\left[q\left(R_{p o l}+R_{C H_{2}}+R_{C H_{3}}\right)\right]-\operatorname{sen}\left[q\left(R_{p o l}+R_{C H_{2}}\right)\right]\right\}\right\}\right]^{2} \\
\text { com } \Delta \rho_{C H_{3}}=\rho_{C H_{3}}-\rho_{\text {sol }}, \quad \Delta \rho_{C H_{2}}=\rho_{C H_{2}}-\rho_{s o l} \quad \text { e } \Delta \rho_{p o l}=\rho_{p o l}-\rho_{\text {sol }}
\end{array}
$$

onde $\rho_{\text {sol }}$ é a densidade eletrônica do solvente $\left(\rho_{\text {sol }}=0,368-0,372\right.$ e $\left.\AA^{-3}\right)$, e $\rho_{i}$ médio e $R_{i}$ são parâmetros de ajuste, ou seja, $\rho_{C_{3}}, \rho_{C_{2}}, \rho_{p o l}, R_{C_{3}}, R_{C H_{2}}$ e $R_{p o l}$, respectivamente.

Por outro lado, o fator de estrutura (eq. 5.1) utilizado para levar em conta o empilhamento de bicamadas lipídicas correlacionadas, no caso de soluções contendo MLVs, baseou-se na teoria de Caillé modificada (MCT). Este pode ser então descrito pela seguinte equação [153]:

$$
S(q)=N+2 \sum_{n=1}^{N-1}(N-n) \cos \left(q n D_{r e p}\right) e^{-0,0435 n q^{2} D_{r e p}^{2} \eta_{C a i l l e ́}}
$$

onde $N$ é o número de bicamadas lipídicas correlacionadas, $D_{\text {rep }}$ é a distância de repetição

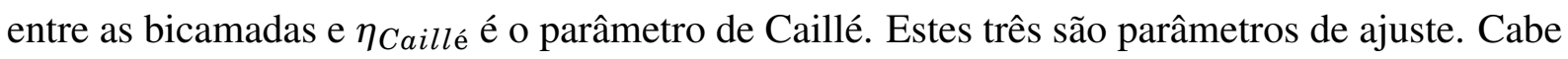


acrescentar que, em geral, esta $D_{\text {rep }}$ apresenta um pico de interferência definido pela lei de Bragg na curva de SAXS para o valor do módulo do vetor de espalhamento $q=\frac{2 \pi}{D_{r e p}}$. O modelo que este fator de interferência pode representar está esquematizado na figura 5.2.

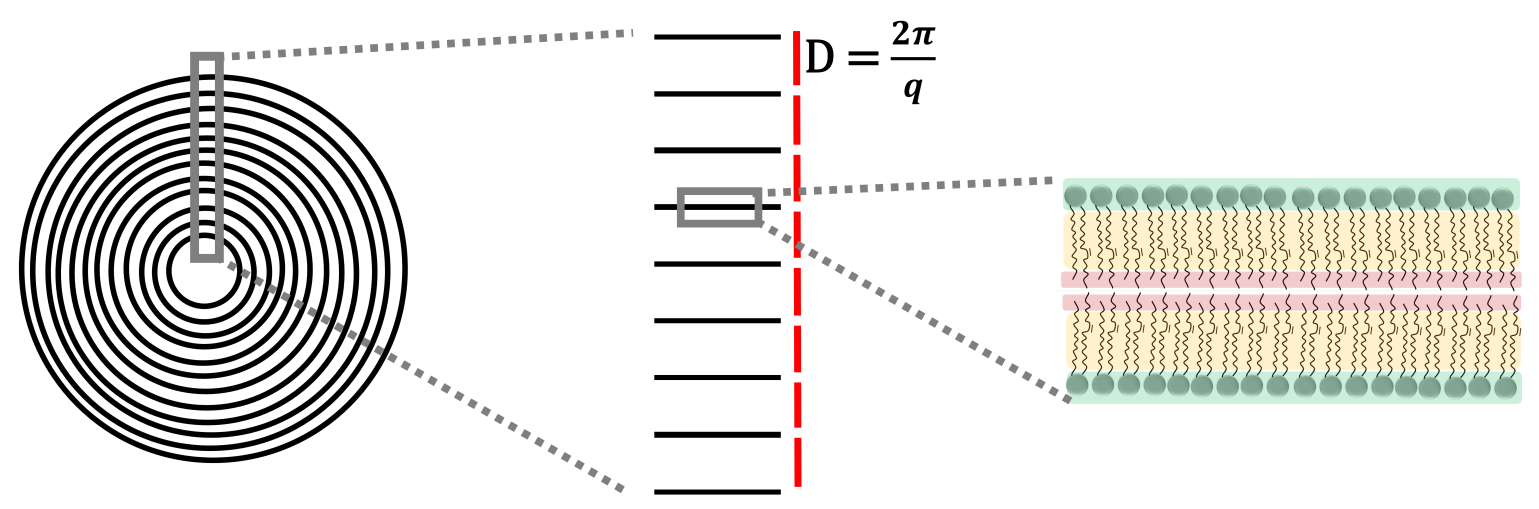

Figura 5.2: Esquema representativo da suspensão de MLVs (círculos concêntricos) que apresenta correlação entre as diferentes bicamadas lipídicas (linhas pretas) separadas por uma distância $D_{\text {rep }}$. O fator de forma que descreve estas bicamadas lipídicas é o mesmo apresentado anteriormente (eq. 5.2).

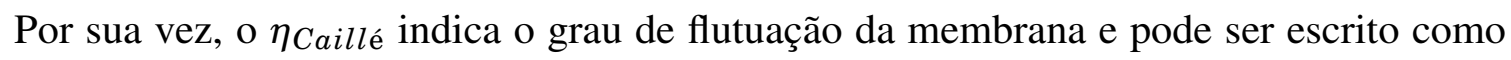
[154]:

$$
\eta_{\text {Caillé }}=\frac{\pi \kappa_{B} T}{2 D_{r e p}^{2} \sqrt{K_{C} B}}
$$

onde $\kappa_{B}$ é a constante de Boltzmann $\left(\kappa_{B}=1.38 \times 10^{-16} \operatorname{erg}^{-1}\right), T$ a temperatura em kelvin, $B$ é o módulo de compressibilidade do solvente entre as lamelas $\left(B=15 \times 10^{13} \mathrm{erg} \mathrm{cm}^{-4}\right.$ para $D_{\text {rep }}$ típicos de $61 \AA$ a $65 \AA$ [155]) e $K_{C}$ é o módulo de curvatura da bicamada (bending modulus, $K_{C}$ típicos para membranas de POPC $\sim 1-16 \times 10^{-13}$ erg [156]). Este está diretamente relacionado à flutuação da membrana $[154,157]$. A figura 5.3 apresenta um exemplo de flutuação de membrana.

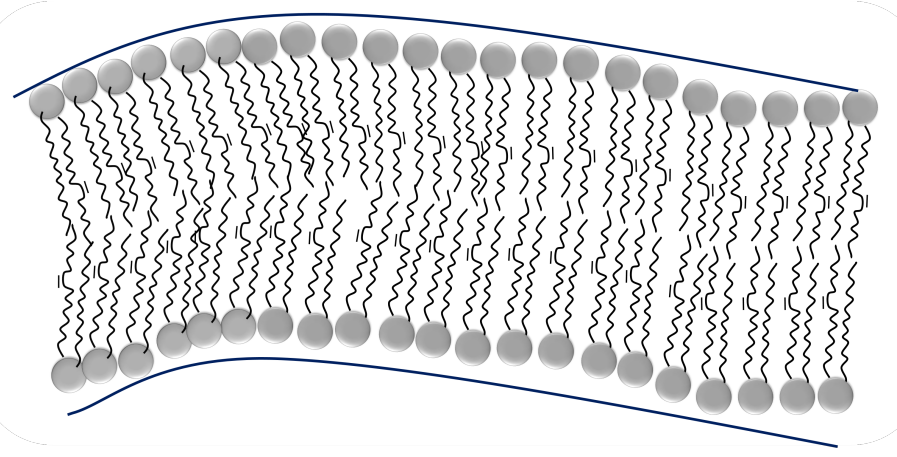

Figura 5.3: Exemplo de "ondulação"(bending) da bicamada lipídica, adaptado de [157]. 
Além de obter o fator de forma $P_{t}(q)$ e o fator de estrutura $S(q)$, bem como os parâmetros relacionados à estas funções, também calculamos o perfil de densidade eletrônica da seção transversal da membrana $(\rho(r))$, levando em conta a suavização das densidades eletrônicas entres os três diferentes níves e o solvente, através da função erro $\operatorname{erf}(r)$. Para isso, utilizou-se a seguinte equação [158]:

$$
\begin{aligned}
\rho(r)=\rho_{s o l}+ & \frac{1}{2}\left\{\left[\rho_{\text {sol }}-\rho_{\text {pol }}\right]\left[\operatorname{erf}\left(\frac{r-R_{1}}{\sqrt{2} \sigma_{1}}\right)-\operatorname{erf}\left(\frac{r+R_{1}}{\sqrt{2} \sigma_{1}}\right)\right]\right. \\
& +\left[\rho_{p o l}-\rho_{C H_{2}}\right]\left[\operatorname{erf}\left(\frac{r-R_{2}}{\sqrt{2} \sigma_{2}}\right)-\operatorname{erf}\left(\frac{r+R_{2}}{\sqrt{2} \sigma_{2}}\right)\right] \\
+ & {\left.\left[\rho_{C H_{2}}-\rho_{C H_{3}}\right]\left[\operatorname{erf}\left(\frac{r-R_{3}}{\sqrt{2} \sigma_{3}}\right)-\operatorname{erf}\left(\frac{r+R_{3}}{\sqrt{2} \sigma_{3}}\right)\right]\right\} }
\end{aligned}
$$

onde $R_{1}, R_{2}$ e $R_{3}$ são $R_{p o l}+R_{C_{2}}+R_{C_{3}}, R_{C_{2}}+R_{C_{3}}$ e $R_{C_{3}}$, respectivamente, $\sigma_{i}$ representa o desvio padrão da função erro $\operatorname{er} f(r)$ [158]. A figura 5.4 apresenta um exemplo da função $\rho(r)$ obtida para membranas de POPC nesta tese, acompanhada do esquema de bicamada lipídica, para melhor entendimento.

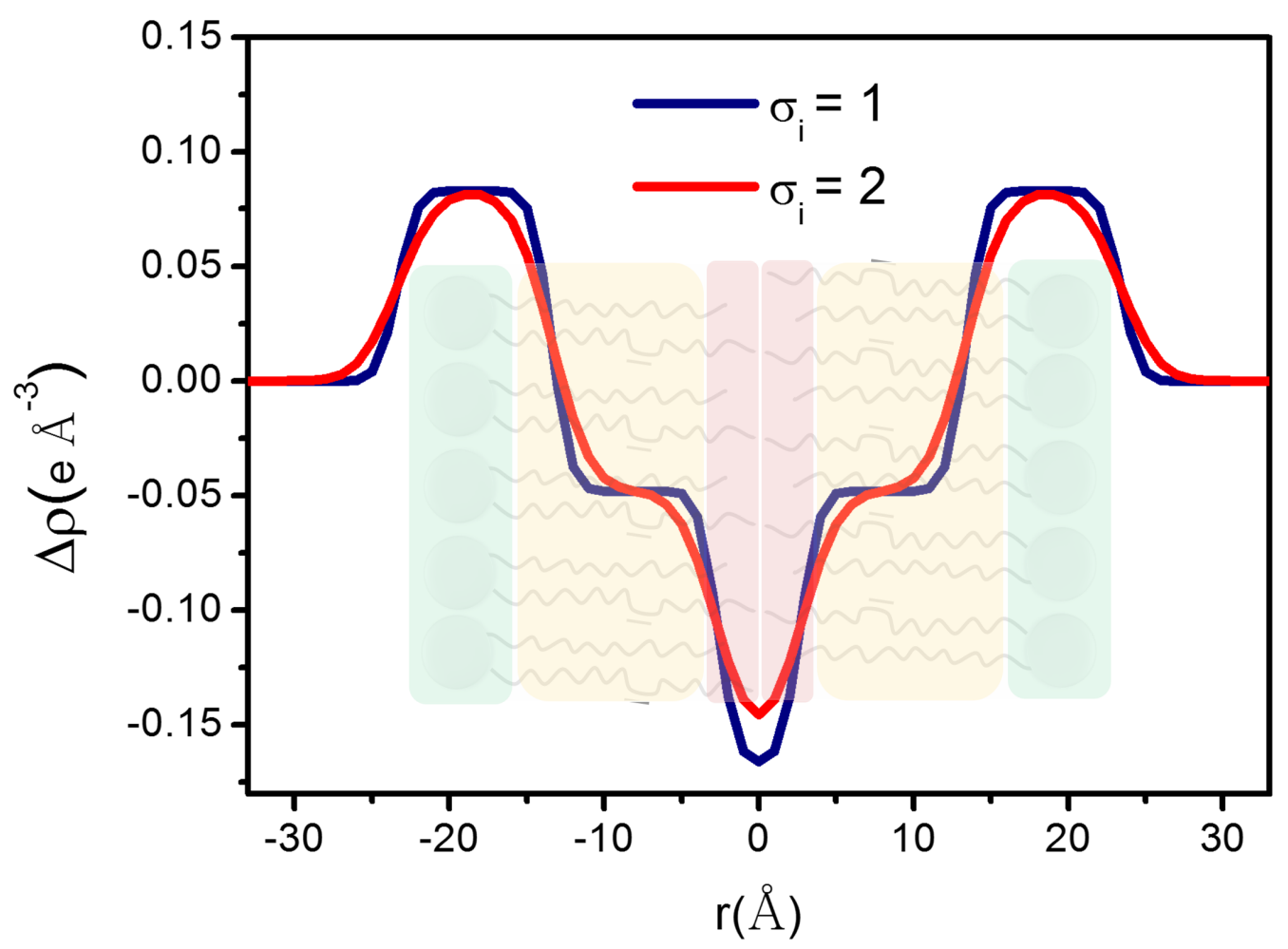

Figura 5.4: O perfil de densidade eletrônica, $\rho(r)$, acompanhado do esquema da bicamada lipídica para auxiliar no entendimento.

Vale a pena destacar aqui que a maneira de representar a função $\rho(r)$ (eq 5.5) depende da funcao erf(x) e esta, por sua vez, depende de seu desvio padrao $\sigma_{i}$. A figura 5.4 exemplifica esta 
dependência onde a linha azul e vermelha apresentam as funções $\rho(r)$ obtidas utilizando $\sigma_{i}=$ $1 \AA$ e $\sigma_{i}=2 \AA$, respectivamente. Pode-se observar a maior suavização entre os três diferentes níveis para $\sigma_{i}=2 \AA$ e a divisão acentuada entre os mesmos para $\sigma_{i}=1 \AA$ (5.4). Neste trabalho utilizamos $\sigma_{i}=2 \AA$.

\subsubsection{Ajuste das curvas de SAXS}

Todas as curvas experimentais de SAXS foram analisadas através do software GENFIT [88] utilizando os modelos de $P_{t}(q)$ e $S(q)$ explicados anteriormente. Para as amostras extrusadas utilizamos o método de ajuste global, onde os parâmetros do fator de forma $P_{t}(q)\left(\rho_{i}\right.$ e $\left.R_{i}\right)$ foram obtidos ao se ajustar todas as curvas experimentais simultaneamente. Os valores de $\rho_{i}$ e $R_{i}$ de uma amostra contendo $\gamma \%$ de POPC e 100- $\gamma \%$ de POPC-OOH foram obtidos como $\rho_{i}=\gamma \rho_{i}^{P O P C}+(1-\gamma) \rho_{i}^{P O P C-O O H}$ e $R_{i}=\gamma R_{i}^{P O P C}+(1-\gamma) R_{i}^{P O P C-O O H}$.

Após realizar os ajustes das amostras extrusadas, os fatores de forma $P_{t}(q)$ obtidos para cada composição lipídica foram fixados para ajustar os correspondentes fatores de forma $P_{t}(q)$ das amostras não extrusadas. Desta maneira, a estrutura da bicamada lipídica independe do número de multilamelas. Cabe acrescentar que os ajustes das curvas de SAXS para as amostras não extrusadas também foram realizados utilizando o método de ajuste global para as funções de estrutura $S(q)$. Ou seja, as funções $P_{t}(q)$ para cada composição lipídica foram fixadas e os parâmetros $\eta_{\text {Caillé, }} D_{\text {rep }}$ e $N$ foram obtidas como combinação linear destes parâmetros para as amostras 100\% POPC e 100\% POPC-OOH. Assim, o número de parâmetros foi reduzido.

As curvas de SAXS para as amostras não extrusadas apresentam 3 picos de correlação (3 valores de $D_{r e p}$ ) que poderiam indicar a separação de 3 fases lipídicas ([159] - observaram a separação de 2 fases). No entanto, este comportamento também pôde ser observado para amostras de MLVs compostas apenas por POPC, que está na fase fluída a $23^{\circ} \mathrm{C}$ e $37^{\circ} \mathrm{C}(\mathrm{T}$ de transição de fase $\sim-2^{\circ} \mathrm{C}$ ). Assim, associamos que todas estas $3 D_{\text {rep }}$ presentes em nossos dados vem do espalhamento de partes da mesma membrana lipídica.

Algumas amostras extrusadas ainda apresentram picos de interferência típicos de MLVs. Por isso, os ajustes das curvas de SAXS destas amostras foram obtidos considerando a contribuição de LUVs e MLVs.

Pode-se então resumir os modelos utilizados para analisar as curvas experimentais de SAXS de uma mesma composição lipídica para amostras não extrusadas $(N e x)$ e extrusadas $(E x)$ :

$$
\begin{array}{r}
I_{N e x}(q)=\alpha_{1} P(q) S_{1}(q)+\alpha_{2} P(q) S_{2}(q)+\alpha_{3} P(q) S_{3}(q)+\alpha_{4} P(q) S_{4}(q)+F \\
I_{E x}(q)=\alpha_{5} P(q) S_{5}(q)+\alpha_{6} P(q) S_{6}(q)+F
\end{array}
$$

onde $F$ é um valor constante de espalhamento de fundo. Como supomos que as $3 D_{\text {rep }}$ estão na mesma vesícula, o número de multilamelas deve ser o mesmo, tal que $N_{1}=N_{2}=N_{3}$, e supomos 
que $S_{4}(q)=S_{6}(q)=1$ ou seja, representam uma unilamela. Desta maneira, podemos reescrever as equações acima como:

$$
\begin{array}{r}
I_{N e x}(q)=P(q)\left[\alpha_{1} S_{1}(q)+\alpha_{2} S_{2}(q)+\alpha_{3} S_{3}(q)+\alpha_{4}\right]+F \\
I_{E x}(q)=P(q)\left[\alpha_{5} S_{5}(q)+\alpha_{6}\right]+F
\end{array}
$$

onde $P(q)$ é o mesmo para ambas as amostras $(N e x$ e $E x), \sum \alpha_{i=1}^{4}=1$ e $\sum \alpha_{i=5}^{6}=1$. Cabe acrescentar que em todos os casos $\alpha_{4}=0$, exceto para as membranas de contendo PAZEPC e POVPC e 100\% POPC-OOH, onde a presença de unilamelas foi detectada.

Em todos os experimentos, os intervalos nos quais os parâmetros de ajuste poderiam variar

\begin{tabular}{|c|c|c|c|c|}
\hline \multicolumn{2}{|c|}{$S_{i}(q)$} & \multicolumn{3}{|c|}{$P(q)$} \\
\hline & & & $\mathrm{R}(\AA)$ & $\rho\left(e \AA^{-3}\right)$ \\
\hline$D_{i}(\AA)$ & $55-85$ & $\mathrm{CH}_{3}$ & $2,2-3,6$ & $0,195-0,210$ \\
\hline$N$ & $1-30$ & $\mathrm{CH}_{2}$ & $4,0-12,0$ & $0,265-0,350$ \\
\hline$\eta_{\text {Caillé }_{\mathrm{i}}}$ & $0,0-0,20$ & $P O L$ & $6,0-10,0$ & $0,390-0,465$ \\
\hline
\end{tabular}
estão descritos na tabela abaixo:

Tabela 5.1: Variação possível dos parâmetros de ajuste de $S(q)$ e $P_{t}(q)$, para medidas de SAXS.

Em todos os casos, o ajuste dos modelos aos dados experimentais for repetido por 10 vezes para avaliar a incerteza associada a cada parâmetro.

\subsection{Resultados I - Impacto do lipídeo oxidado POPC-OOH em membranas lipídicas}

Primeiramente, estudou-se o impacto da presença do lipídeo oxidado POPC-OOH em membranas de POPC à temperatura de $23^{\circ} \mathrm{C}$ e $37^{\circ} \mathrm{C}$ utilizando amostras de LUVs e MLVs nas razões molares POPC:POPC-OOH nas proporções de 100:0, 90:10, 75:25, 70:30, 50:50, 30:70 e $0: 100$.

As figuras 5.5 e 5.6 apresentam as curvas de SAXS para as amostras não extrusadas e extrusadas, respectivamente, para ambas as temperaturas. Para melhor apreciação dos dados, as curvas foram deslocadas, e para facilitar a comparação do efeito da temperatura amostras de mesmas composições lipídicas foram igualmente deslocadas. 


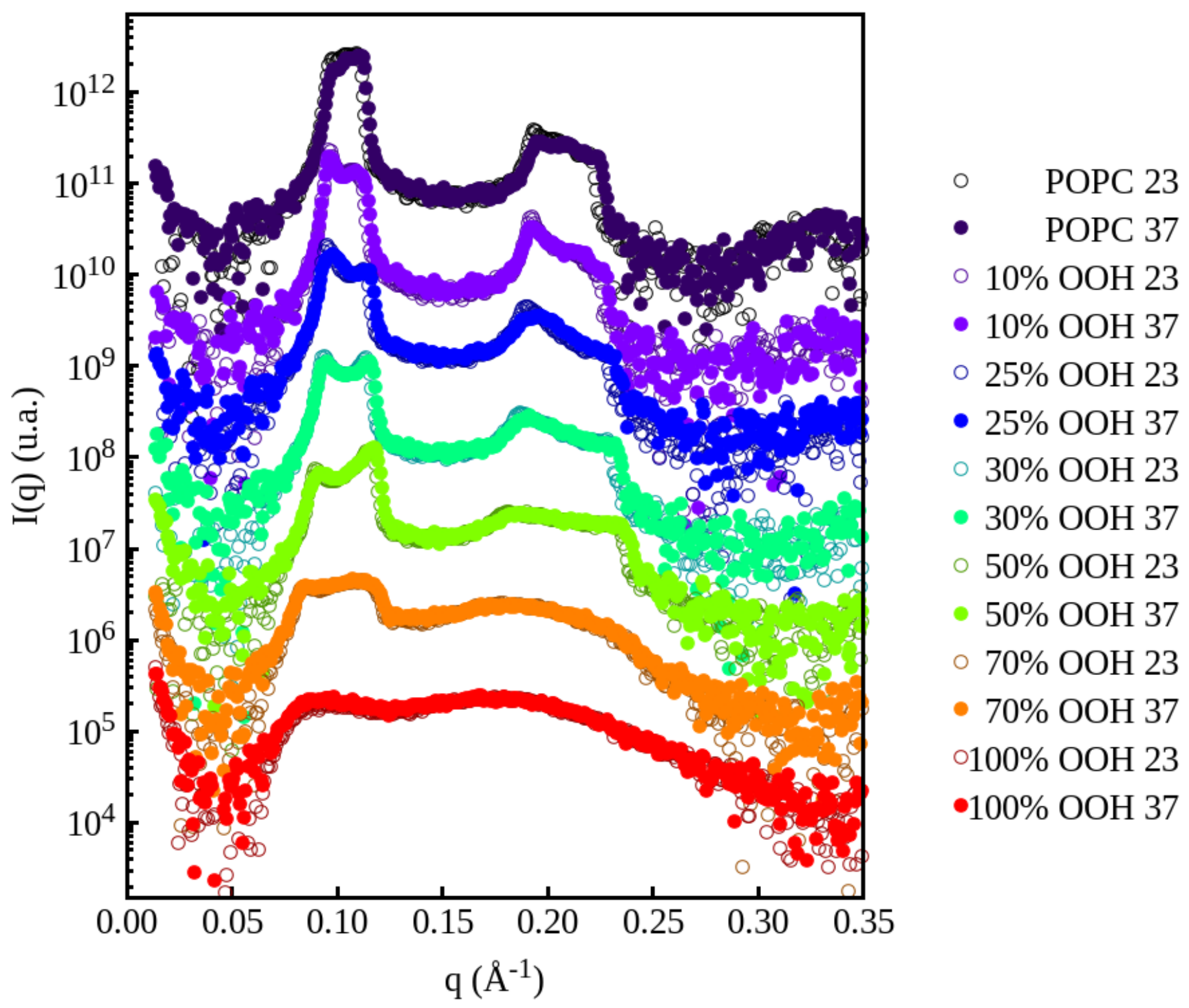

Figura 5.5: Curvas de SAXS para as amostras não extrusadas de POPC (10 mM) com o aumento da concentração de POPC-OOH (de cima para baixo) a $23^{\circ} \mathrm{C}$ (círculos vazios) e $37^{\circ} \mathrm{C}$ (círculos cheios). As curvas estão deslocadas para melhor visualização e as mesmas composições lipídicas possuem o mesmo deslocamento. 


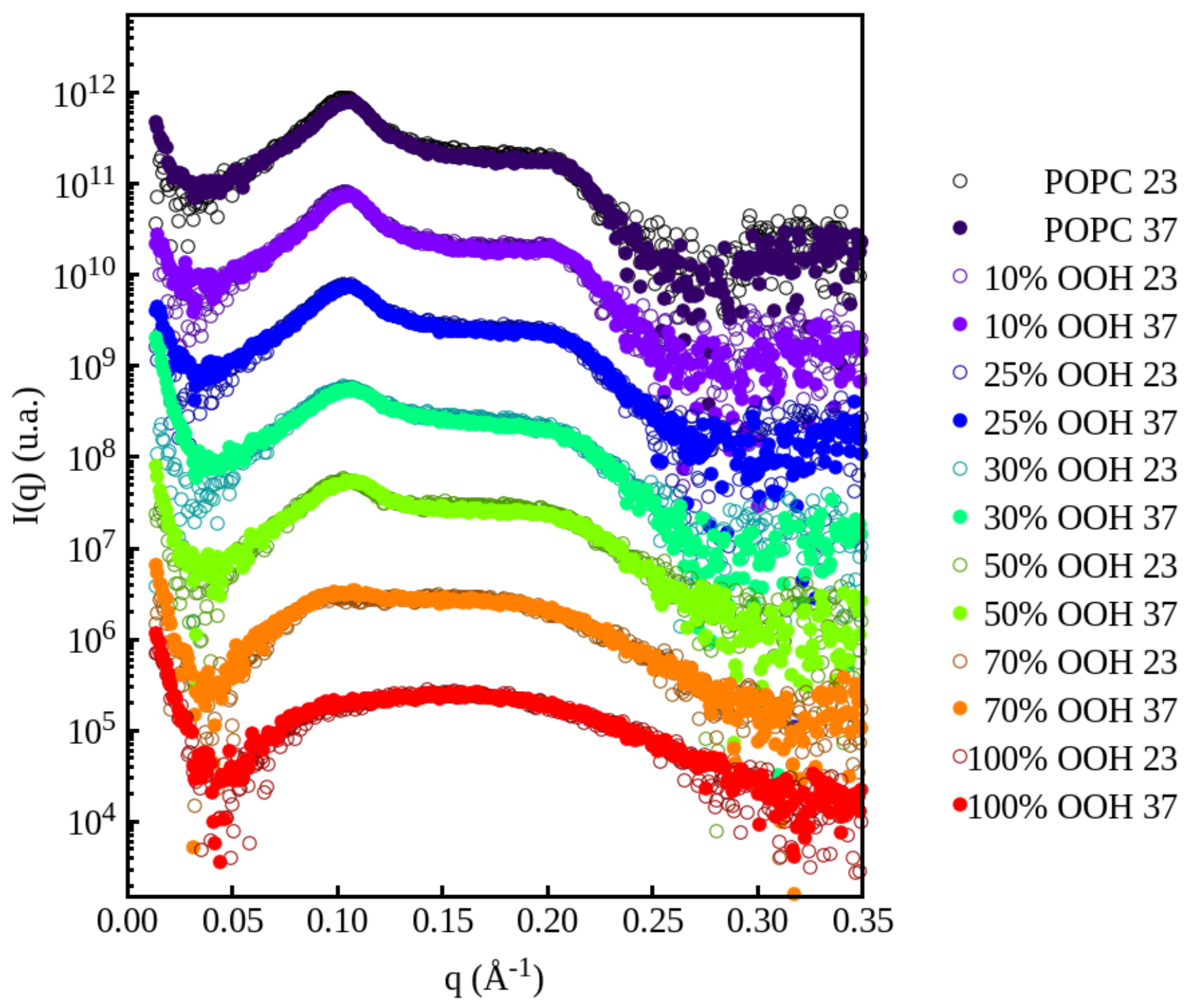

Figura 5.6: Curvas de SAXS para amostras extrusadas de POPC (10 mM) com o aumento da concentração de POPC-OOH (de cima para baixo) a $23^{\circ} \mathrm{C}$ (círculos vazios) e $37^{\circ} \mathrm{C}$ (círculos cheios). As curvas estão deslocadas para melhor visualização e as mesmas composições lipídicas possuem o mesmo deslocamento.

Primeiramente, pode-se observar nas figuras 5.5 e 5.6 que o aumento da concentração do lipídeo oxidado POPC-OOH (de cima para baixo) promove claras alterações nas curvas de SAXS de POPC, conforme exploraremos a seguir.

Outra observação importante é que o aumento de temperatura de $23^{\circ} \mathrm{C}$ para $37^{\circ} \mathrm{C}$ não provoca alterações pronunciávies nas curvas de SAXS, tendo em vista a comparação para a mesma composição lipídica. Note que, no caso das amostras não extrusadas (fig. 5.5), há uma leve diminuição de $I(q)$ com a variação da temperatura para $q \sim 0,1 \AA^{-1}$ e $0,2 \AA^{-1}$ que será explorado no final deste tópico (fig. 5.19). 
Para detalhar as diferenças nas curvas de SAXS de vesículas de POPC com o aumento da concentração de POPC-OOH, as figuras 5.7 e 5.10 apresentam os resultados obtidos para as amostras não extrusadas e extrusadas, respectivamente, utilizando a mesma escala em todas as curvas.

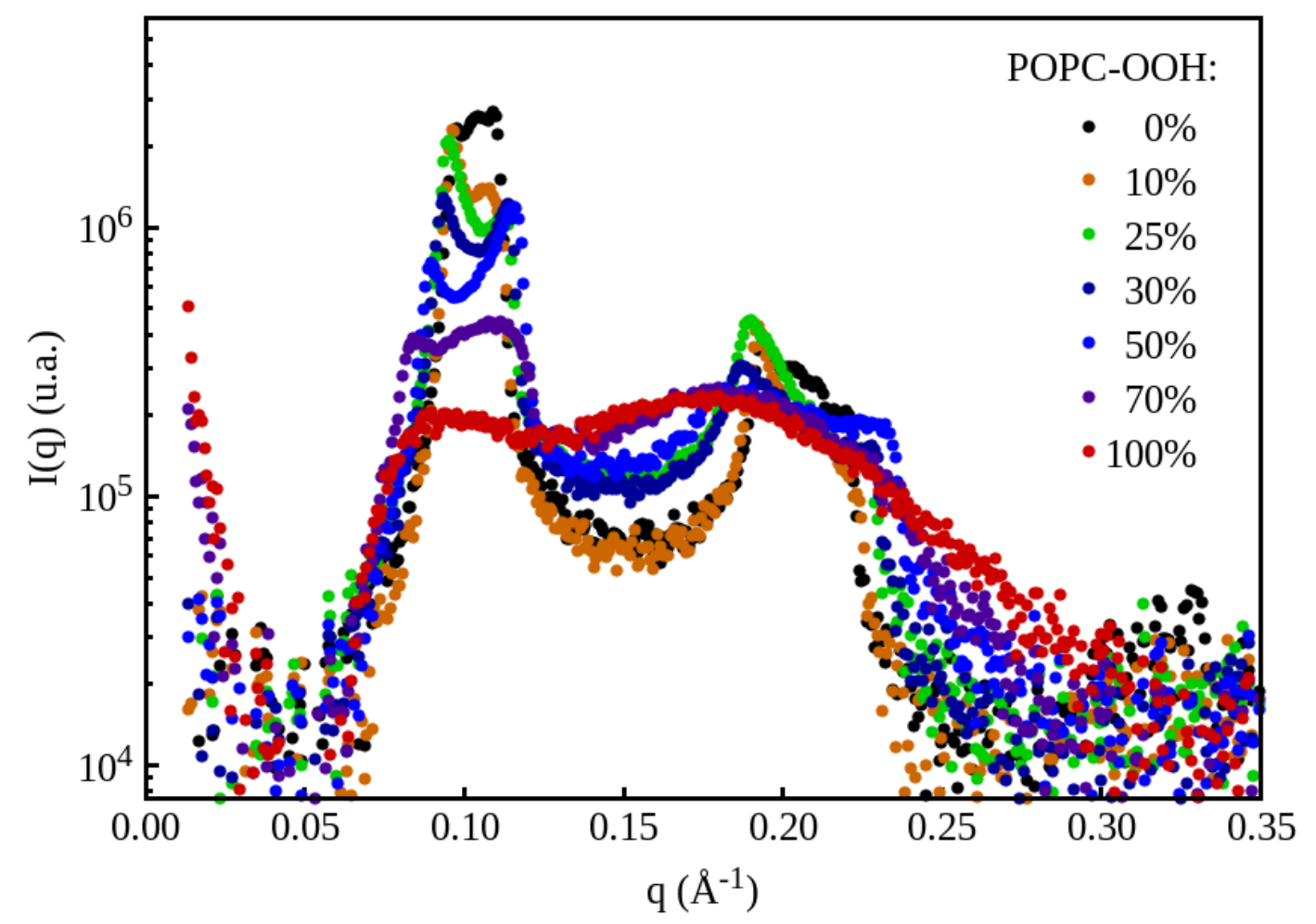

Figura 5.7: Curvas de SAXS para MLVs de POPC (10 mM) com o aumento da concentração de $\mathrm{POPC}-\mathrm{OOH}$ a $23^{\circ} \mathrm{C}$.

A curva de SAXS de amostras não extrusadas compostas apenas por POPC apresenta "picos" não usuais (semelhante à um "platô", ver figura 5.8 para maior detalhe) com a primeira ordem de difração em torno de $q=0,1 \AA^{-1}$ e segunda ordem em $q=0,2 \AA^{-1}$, indicando a presença de correlação entre as membranas, ou seja, a presença de vesículas multilamelares como esperado (fig. 5.7). Com o aumento da concentração de POPC-OOH estes "picos" diminuem de intensidade, parecem se separar em diferentes picos, se deslocam para valores de $q$ menores e a segunda ordem de difração vai se tornando cada vez menos perceptível.

Tendo em vista a presença destes "picos" não usuais para as amostras não extrusadas de POPC levantamos a hipótese que estes poderiam corresponder à contribuição de diferentes picos de correlação devido a presença de diferentes distâncias de repetição $\left(D_{r e p}\right)$ entre as MLVs. É conhecido que a presença de moléculas (sal, por exemplo) na solução de vesículas pode influenciar na $D_{\text {rep }}$ [154] e nossos experimentos foram realizados em tampão composto por 10 $\mathrm{mM}$ de HEPES, $150 \mathrm{mM}$ de $\mathrm{NaCl}$ e $0.2 \mathrm{mM}$ EDTA (pH 7.0). Então para avaliar se a composição do tampão utilizado nesta tese poderia estar relacionada a presença destes "picos", realizou-se 
uma comparação das curvas de SAXS para o mesmo lipídeo preparado neste tampão, apenas em água, tampão HEPES ou tampão PBS (com $137 \mathrm{mM} \mathrm{NaCl).} \mathrm{A} \mathrm{figura} 5.8$ apresenta a comparação de amostras de POPC a $23^{\circ} \mathrm{C}$ não extrusadas (fig. 5.8).

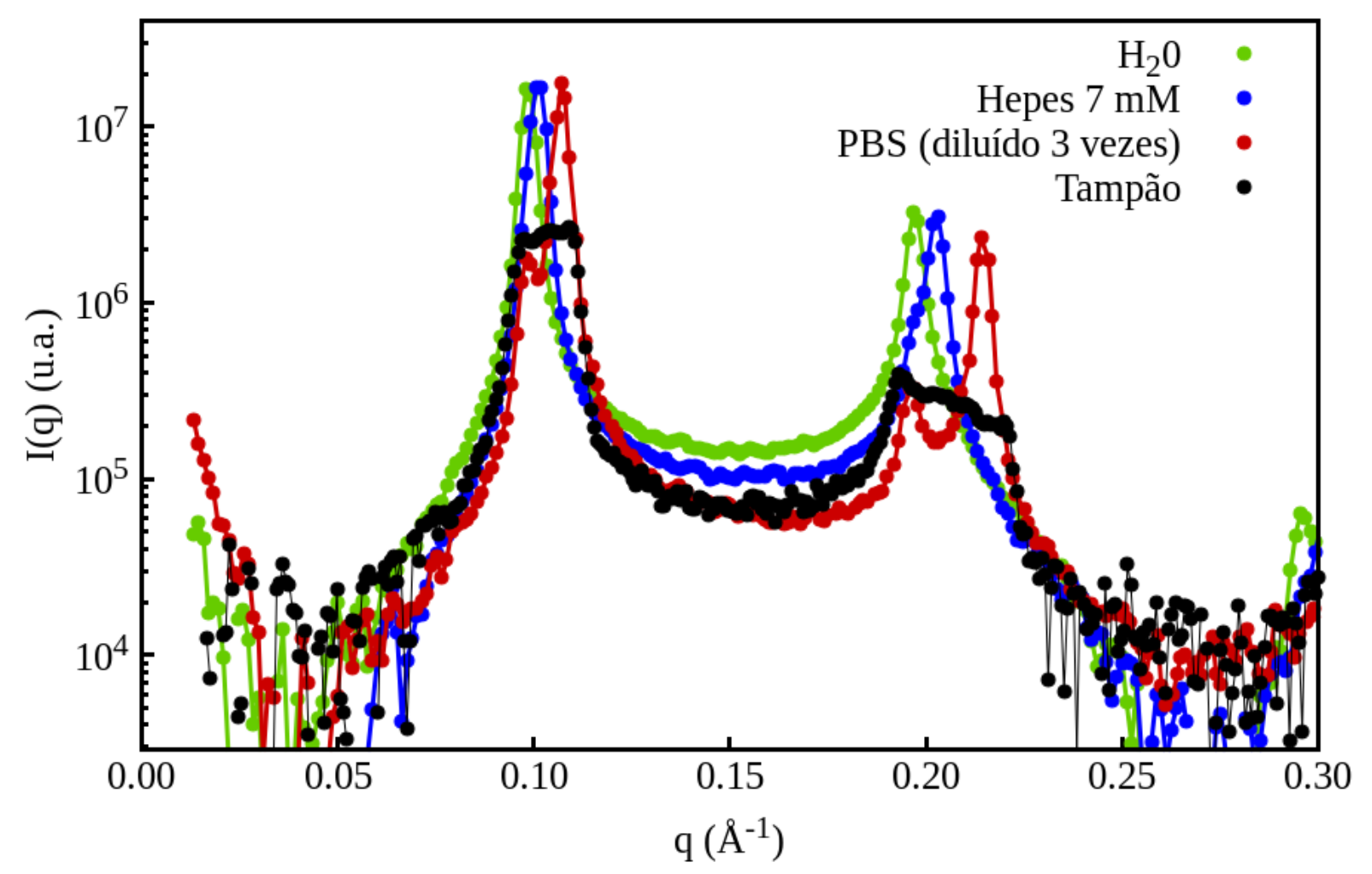

Figura 5.8: Curvas de SAXS para amostras de POPC (10 mM) dissolvidas em diferentes soluções: água (verde), hepes (azul), PBS (vermelho) e tampão utilizado nesta tese (preto).

Como podemos observar, a posição do pico de correlação varia em função do solvente onde foram preparadas as vesículas de POPC. Na figura 5.8 notamos a presença de duas ordens de difração para as 4 condições experimentais, sendo que os picos estão em $q=0,098 \AA^{-1}-D_{\text {rep }}$ $64,1 \AA(\mathrm{A}), q=0,101 \AA^{-1}-D_{r e p} \sim 62,2 \AA$ (B) e $q=0,098 \AA^{-1}$ e $0,0107 \AA^{-1}-D_{r e p} \sim 58,7 \AA$ (C) (dois picos) para $\mathrm{H}_{2} \mathrm{O}$, Hepes e PBS, respectivamente. Vale lembrar que cada pico está relacionado a um distância de repetição. Como o tampão utilizado neste trabalho pode ser visto como uma mistura dos três "tampões" mencionados acima, é possível que o pico não usual observado para as vesículas de POPC dissolvidas neste tampão apresente os picos para os três valores de $q=$ (A), (B) e (C). Importante notar que a largura do pico "inusual"está em bom acordo com a largura obtida pela sobreposição dos três picos (A) - verde, (B) - azul e (C) vermelho. Sendo assim, as análises de SAXS para o fator de estrutura $(S(q))$ das vesículas não extrusadas foi obtido como a soma de três $S(q)$, cada uma relacionada à uma $D_{r e p}$ como explicado em Materiais e Métodos e apresentado na figura 5.9, para o caso da amostra composta por 100\% POPC: 


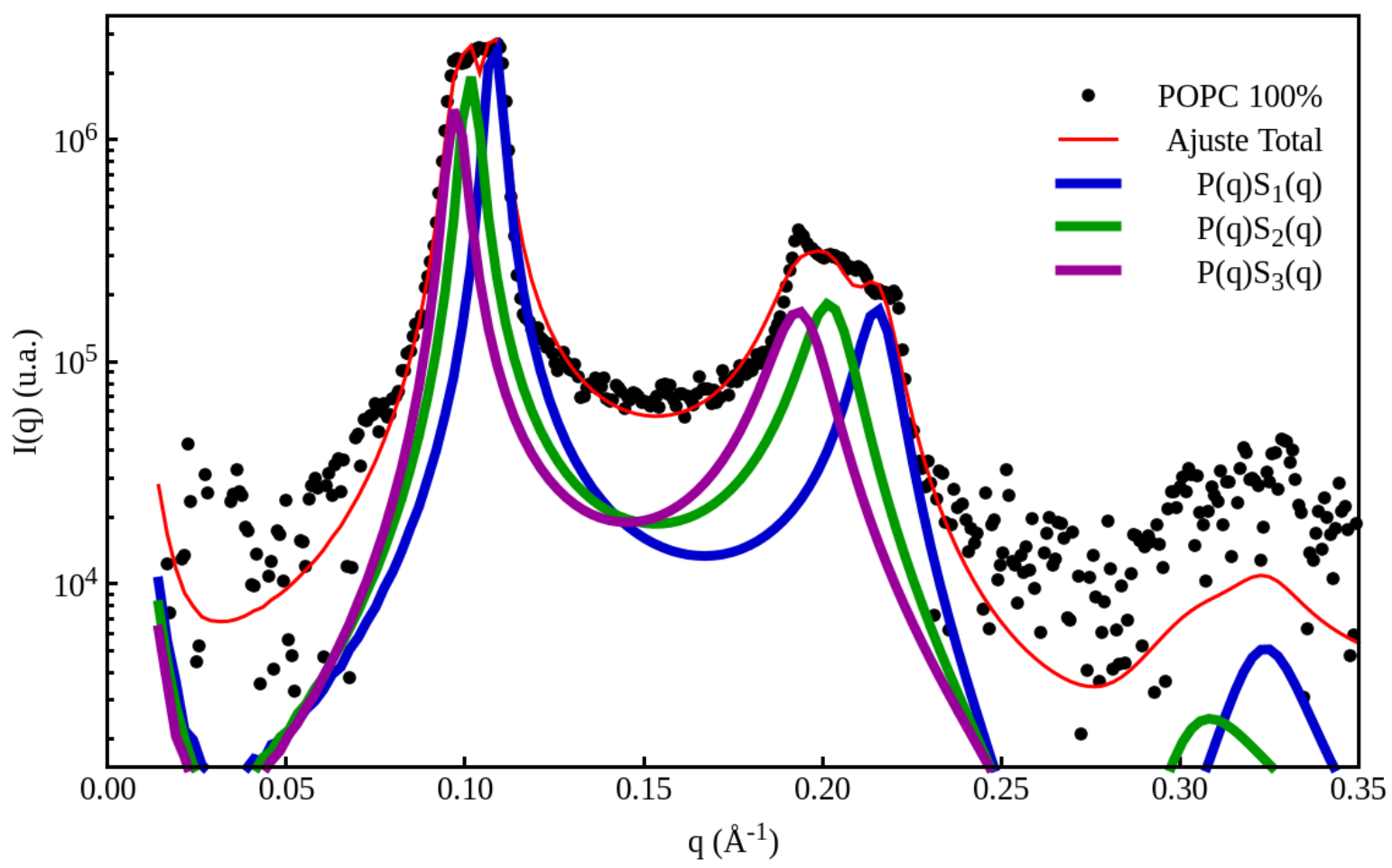

Figura 5.9: Curva de SAXS experimental de vesículas de $100 \%$ POPC a $23^{\circ} \mathrm{C}$ não extrusadas (pontos pretos), ajuste total obtido através do modelo de $I_{N e x}(q)$ (eq. 5.8) descrito anteriormente (linha vermelha mais fina) utilizando o programa GENFIT, e cada curva teórica $P(q) S_{i}(q)$ calculada para obter a $I_{N e x}(q)$ (eq. 5.8).

Pode-se observar o bom acordo entre a curva experimental (pontos pretos) e o ajuste obtido (linha vermelha) além de apreciar que a soma de três fatores de estrutura, como hipotizado, é suficiente para justificar a presença dos "picos"alargados. Desta maneira, realizou-se os ajustes para as demais curvas de SAXS de amostras não extrusadas.

Por outro lado, as curvas de SAXS de vesículas extrusadas de POPC com o aumento da concentração de POPC-OOH a $23^{\circ} \mathrm{C}$, utilizando a mesma escala de intensidade, são apresentadas na figura 5.10 . 


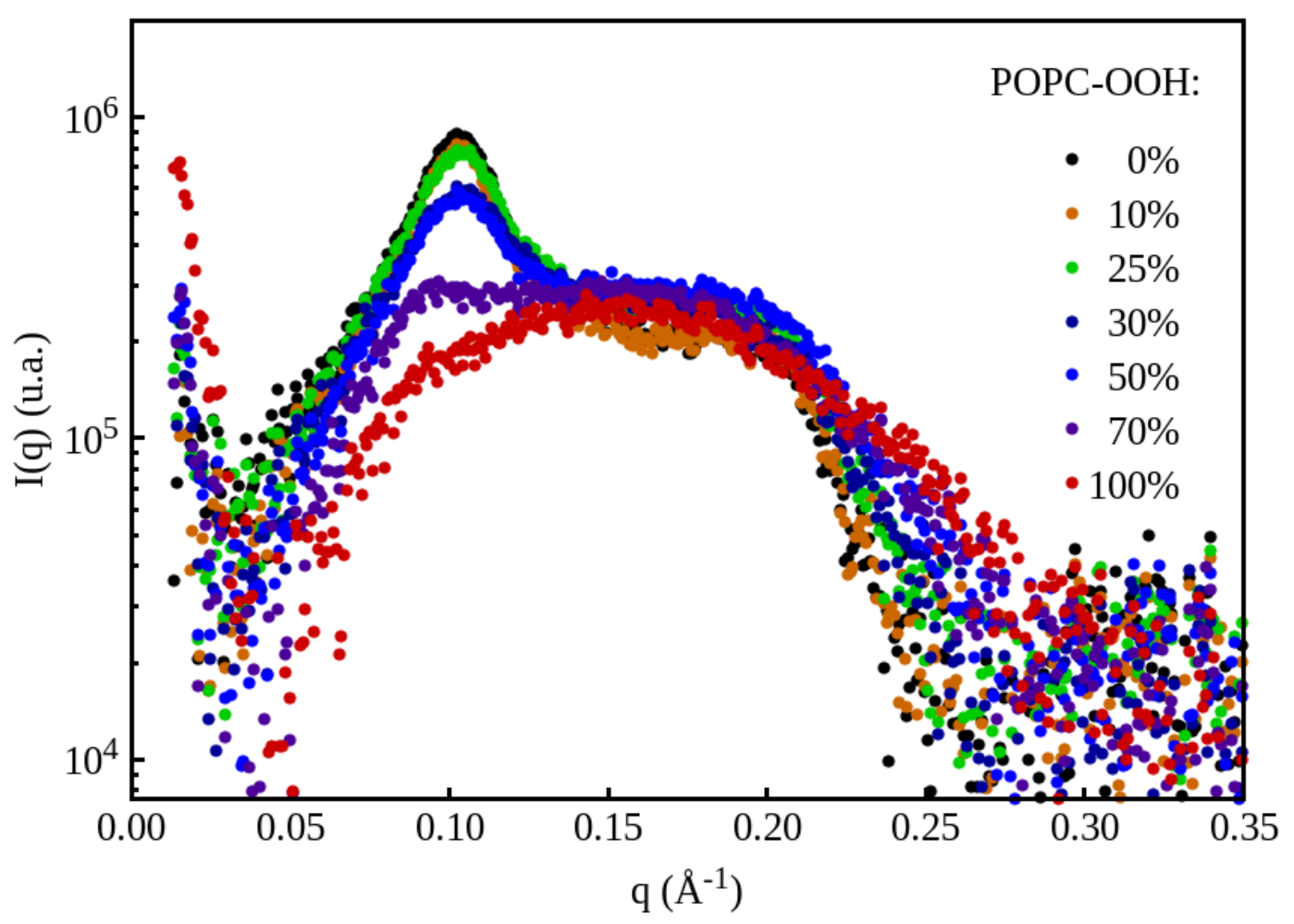

Figura 5.10: Curvas de SAXS de amostras extrusadas de POPC (10 mM) com o aumento da concentração de POPC-OOH a $23^{\circ} \mathrm{C}$.

Para a amostra de 100\% POPC extrusada também é possível perceber a presença de um pico de correlação em torno de $q=0,1 \AA^{-1}$ que outra vez diminui com o aumento da concentração de POPC-OOH (fig. 5.10). Da mesma forma, este pico se desloca para valores de $q$ menores e para a amostra extrusada de 100\% POPC-OOH não é possível observá-lo. Estas observações podem indicar a presença de MLVs em todas as amostras extrusadas, exceto para o caso de amostras compostas somente pelo lipídeo oxidado. Por este motivo, utilizamos a combinação de $P(q)$ para LUVs e MLVs para ajustar as curvas experimentais (eq. 5.8).

Após as análises qualitativas apresentadas e a justificativa da necessidade de três fatores de estrutura para o ajuste das curvas das vesículas não extrusadas e de um fator de forma para as curvas extrusadas, apresentamos os ajustes obtidos utilizando o programa GENFIT para todas amostras de POPC:POPC-OOH nas figuras 5.12 e 5.11. 


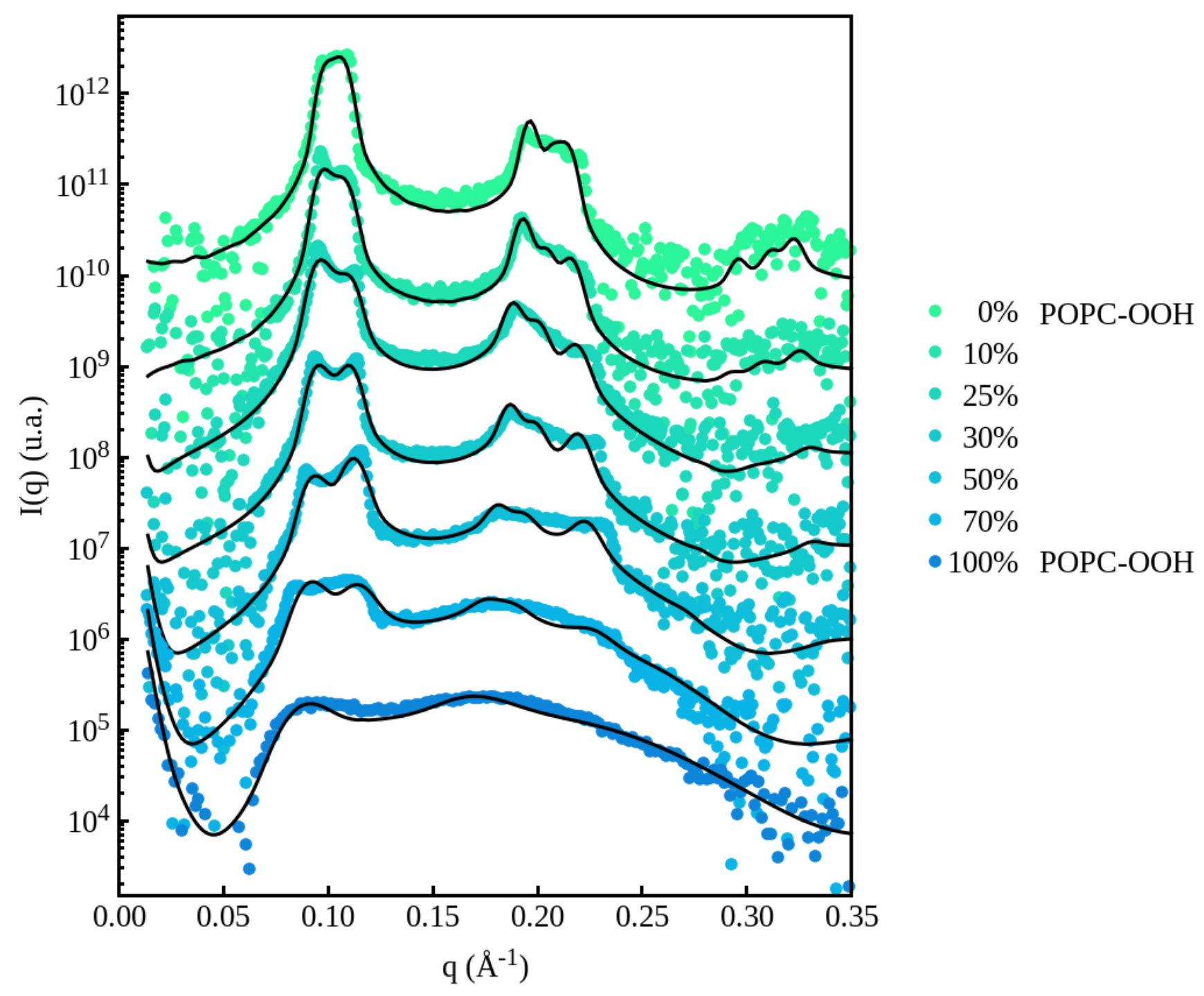

Figura 5.11: Curvas de SAXS de amostras não extrusadas de POPC (10 mM) com o aumento da concentração de POPC-OOH (de cima para baixo) a $23^{\circ} \mathrm{C}$ (pontos), acompanhadas dos ajustes (linha preta). As curvas estão deslocadas para melhor visualização. 


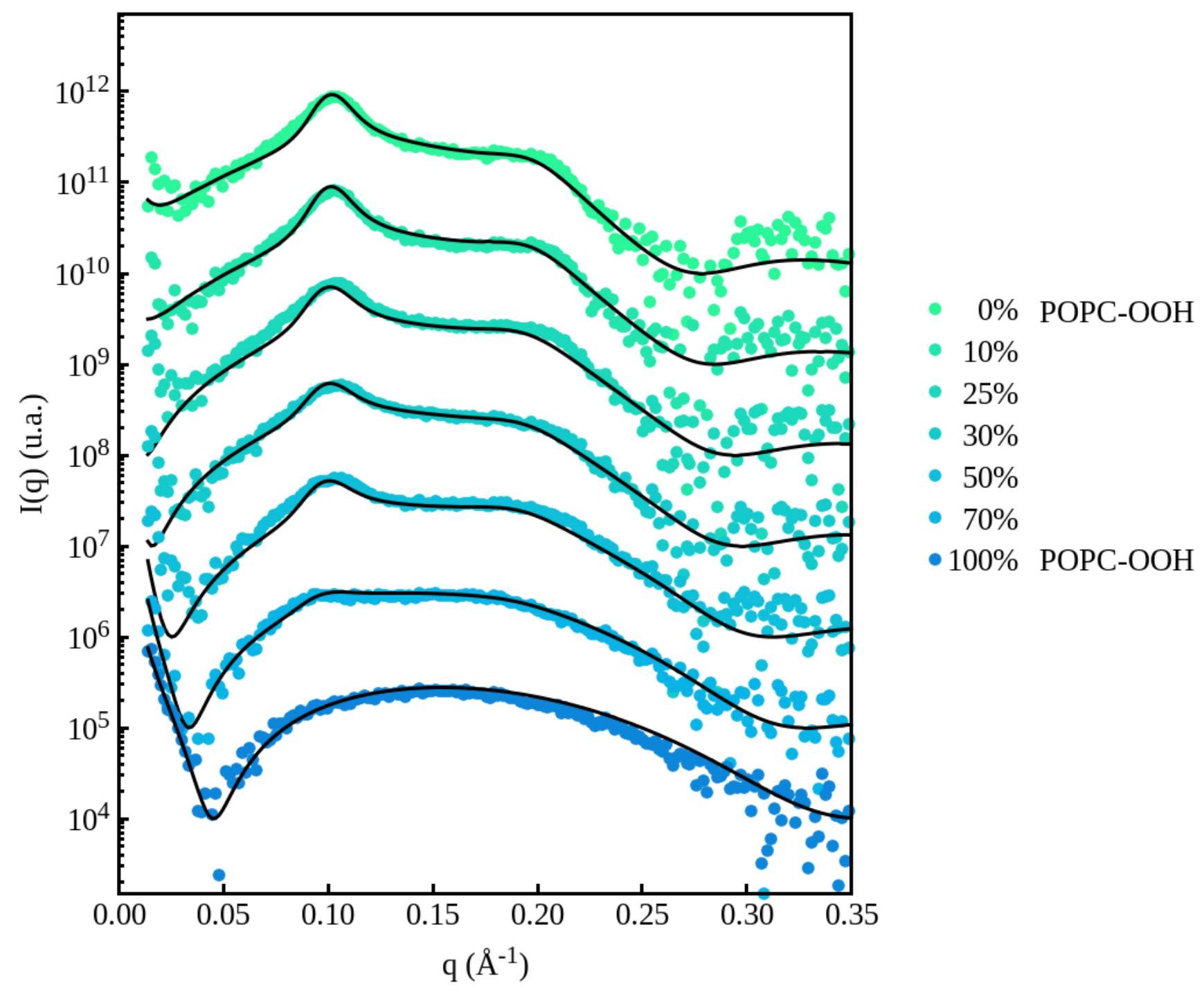

Figura 5.12: Curvas de SAXS de amostras extrusadas de POPC (10 mM) com o aumento da concentração de POPC-OOH (de cima para baixo) a $23^{\circ} \mathrm{C}$ (pontos), acompanhadas dos ajustes (linha preta). As curvas estão deslocadas para melhor visualização.

Observando as figuras 5.11 e 5.12 pode-se apreciar o bom acordo entre os modelos utilizados para os ajustes e as curvas experimentais, para todas as amostras. Importante lembrar que o fator de forma, $P_{t}(q)$, é o mesmo para amostras não extrusadas e extrusadas compostas pela mesma razão molar POPC:POPC-OOH. Sendo assim, os parâmetros de ajustes envolvidos no cálculo do fator de forma $\left(R_{i}\right.$ e $\left.\rho_{i}\right)$ são comuns para os dois conjuntos de curvas (figs 5.11 e 5.12) e foram utilizados para o cálculo do perfil de densidade eletrônica $(\rho(r))$ (eq. 5.5).

A figura 5.13 apresenta as funções $\rho(r)$ para as bicamadas lipídicas compostas por diferentes razões molares de POPC:POPC-OOH. Com o aumento da concentração do lipídeo oxidado pode-se destacar dois efeitos importantes: (i) a região de máximo de densidade eletrônica, 
associada à cabeça polar do lipídeo, sofre um deslocamento em direção a $r$ menores, em direção ao interior da membrana (fig. 5.13); (ii) acompanhado de uma diminuição de espessura de região hidrofóbica (em particular a região dos grupos $\mathrm{CH}_{2}$ ).

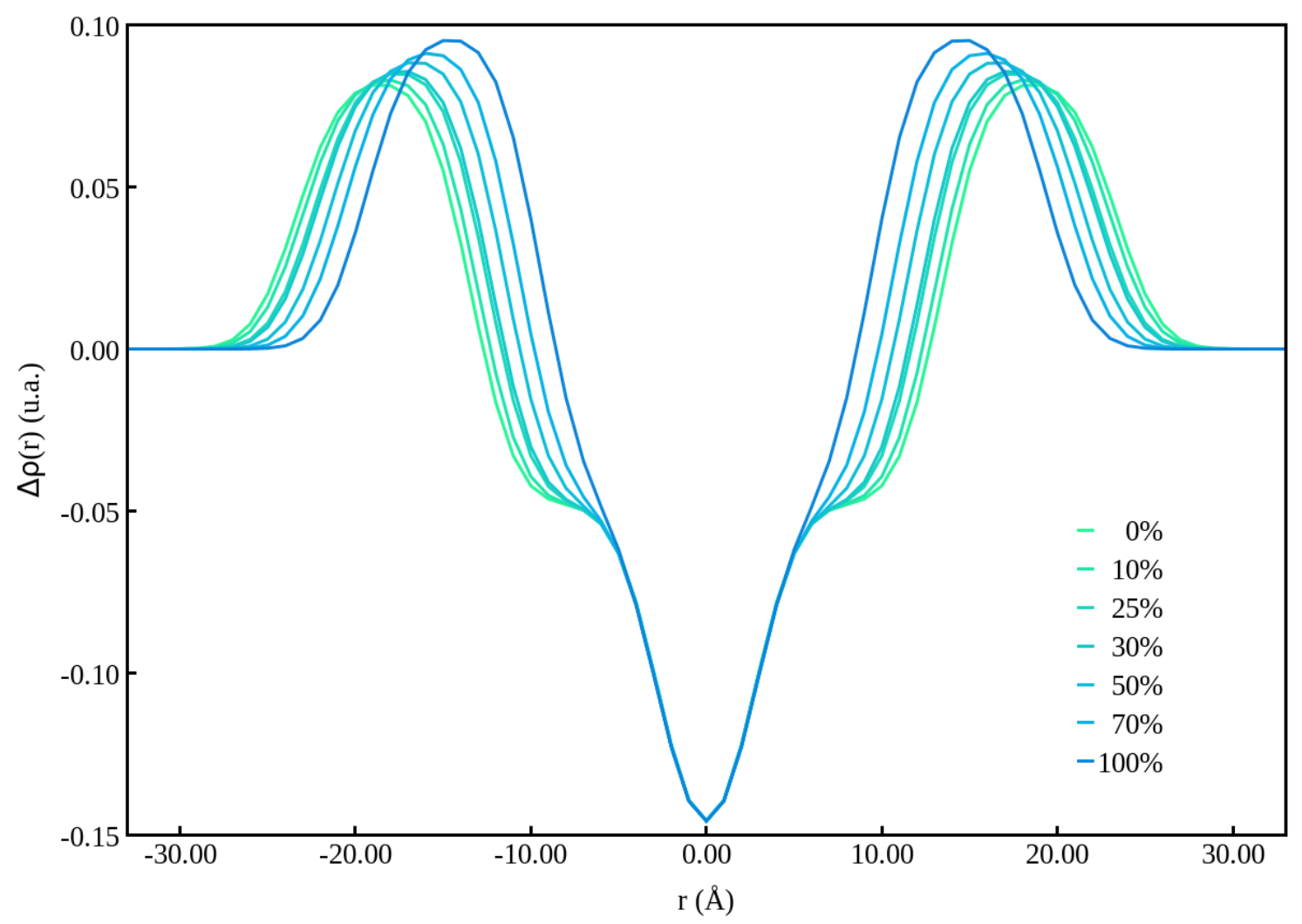

Figura 5.13: Perfil de densidade eletrônica $\Delta \rho(r)=\rho(r)-\rho_{\text {sol }}$ calculado (eq. 5.5) utilizando os parâmetros de $P_{t}(q)$ obtidos através do ajuste das curvas de SAXS de POPC:POPC-OOH de amostras extrusadas (figs 5.12). O código de cores é o mesmo apresentado nas figuras $5.11 \mathrm{e}$ 5.12: verde claro $100 \%$ POPC, azul escuro $100 \%$ POPC-OOH e o gradiente de cor indica as diferentes razões molares.

Portanto, nota-se do perfil $\rho(r)$ (fig. 5.13) uma diminuição da espessura total da bicamada lipídica. Para deixar claro este efeito, calculou-se o valor de espessura de uma monocamada lipídica $\left(R_{\mathrm{CH}_{3}}+R_{\mathrm{CH}_{2}}+R_{p o l}\right)$ para cada amostra de POPC:POPC-OOH, utilizando os valores de $R_{i}$ obtidos nos ajustes. A figura 5.14 apresenta os resultados. A diminuição da espessura pode ser de cerca de $8 \AA$ ao se comparar a espessura da bicamada lipídica de membrana contendo $100 \%$ de POPC com a de $100 \%$ POPC-OOH. 


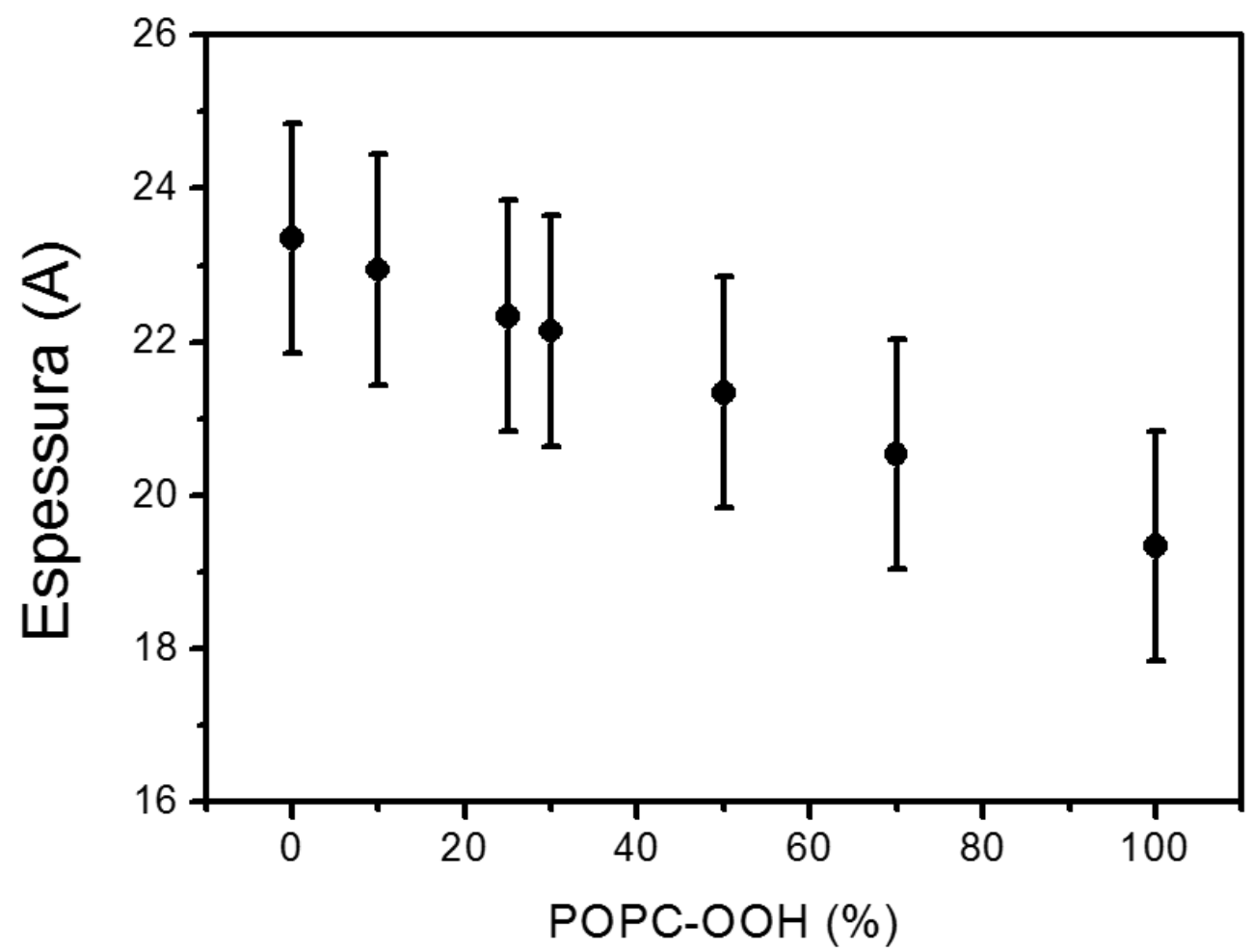

Figura 5.14: Espessura de uma monocamada lipídica obtida como $R_{C_{3}}+R_{C_{2}}+R_{p o l}$ para as vesículas de POPC $(10 \mathrm{mM})$ em função do aumento de concentração do POPC-OOH.

Vale a pena ressaltar aqui que os resultados apresentados para as funções $\rho(r)$ e espessuras da bicamada lipídica são válidos para as vesículas não extrusadas e extrusadas, visto que estes dados são obtidos a partir da função $P_{t}(q)$ comum às amostras não extrusadas e extrusadas compostas pela mesma razão molar de POPC:POPC-OOH. Em termos do fator de estrutura, $S(q)$, há a separação entre os dados obtidos para as diferentes membranas como discutido qualitativamente (figs. 5.7 e 5.10).

No caso das amostras extrusadas, apenas um pico foi identificado $\left(q \sim 0,1 \AA^{-1}\right)$ e eles são relativamente menos intensos do que os picos para as amostras não extrusadas. Por isso, escolhemos analisar detalhadamente apenas os fatores de estrutura, $S(q)$, para as vesículas não extrusadas. Com os ajustes das curvas experimentais de SAXS (fig. 5.11) obteve-se os valores das três distâncias de repetição, $D_{1}, D_{2}$ e $D_{3}$, para cada composição lipídica como apresentado na figura 5.15. 


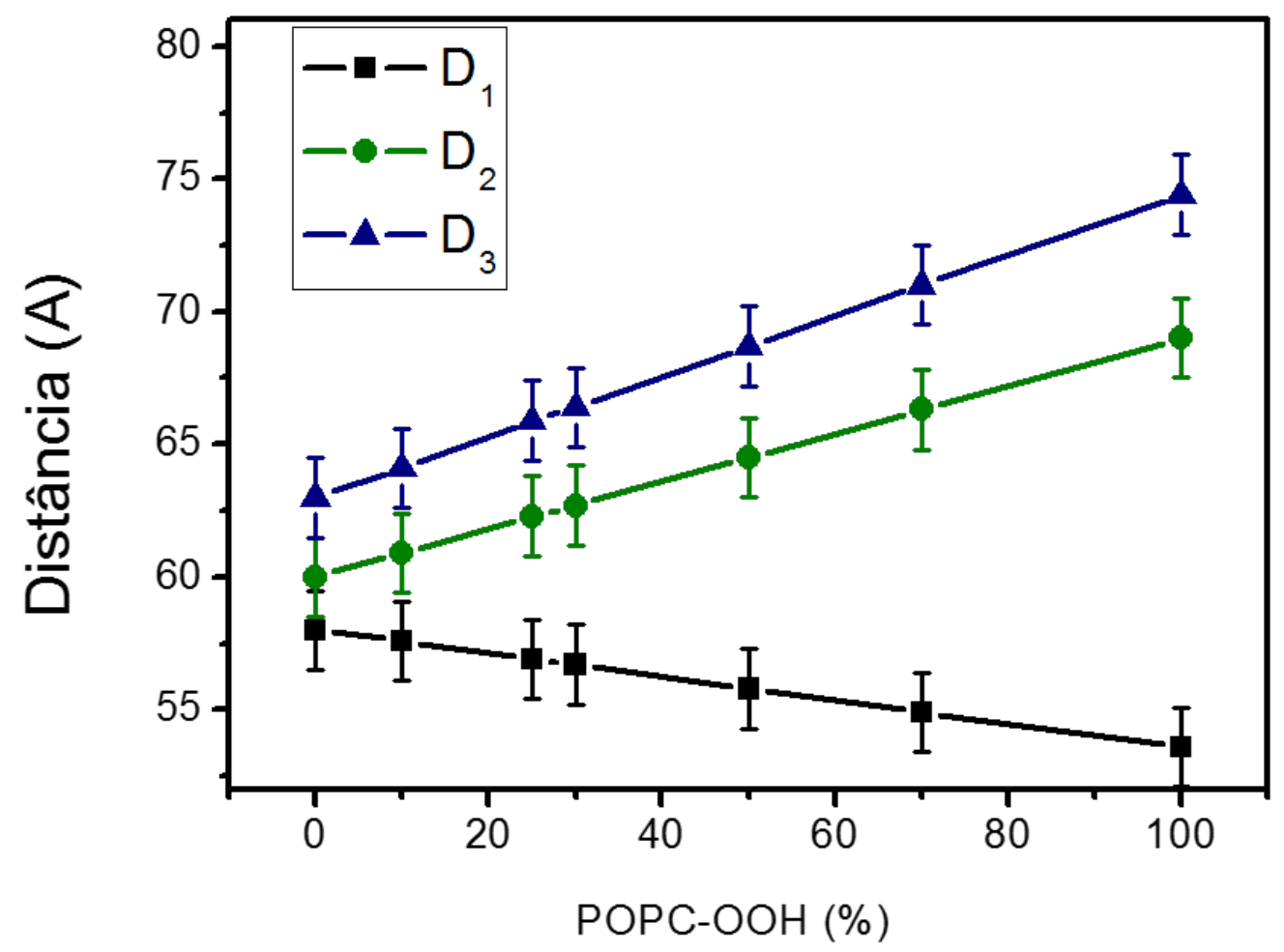

Figura 5.15: Três distâncias de separação entre lamelas obtidas para as MLVS de POPC (10 $\mathrm{mM}$ ) em função do aumento de concentração de POPC:OOH. As linhas são apenas guias para os olhos.

Pode-se observar que as três distâncias de repetição variam com a introdução de maiores percentuais de POPC-OOH em vesículas multilamelares de POPC, ou seja, as bicamadas lipídicas se afastam e se aproximam em função do aumento da concentração do lipídeo oxidado. Tal fato deve estar correlacionado com flutuações das membranas.

Seguindo a análise dos parâmetros obtidos pelos ajustes de $S(q)$, obtivemos os valores de

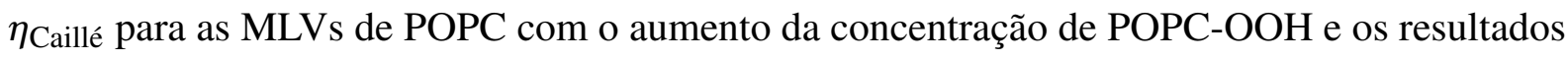
estão apresentados na figura 5.16.

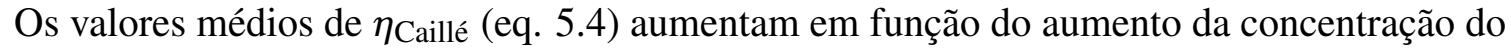
lipídeo oxidado, podendo ser cerca de 4 vezes maior ao se comparar vesículas de 100\%POPCOOH com as de $100 \%$ POPC. Estes resultados serão melhor discutidos adiante. 


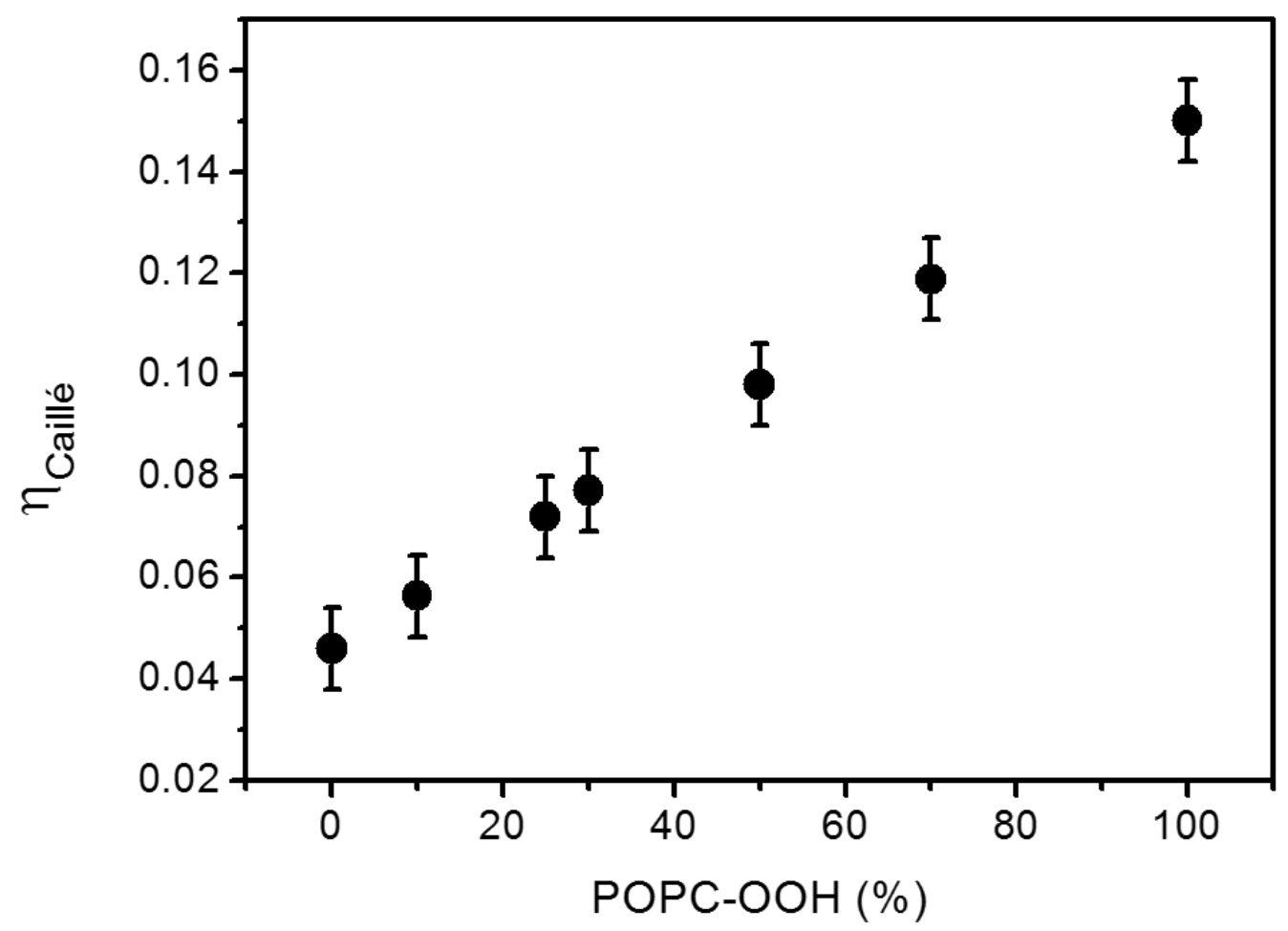

Figura 5.16: Valores médios de $\eta_{\text {Caillé }}$ (eq. 5.4) para MLVs de POPC (10 mM) com o aumento de concentração de POPC-OOH.

Por fim, voltamos para a comparação do aumento da temperatura de $23^{\circ} \mathrm{C}$ para $37^{\circ} \mathrm{C}$ nas curvas de SAXS das amostras não extrusadas. Como mencionado anteriormente, na presença de MLVs a curva de SAXS apresenta o fator de estrutura, $S(q)$ que depende da distância de repetição $D_{r e p}$, do número $N$ de multilamelas e do paramêtro de Caillé ( $\left.\eta_{\text {Caillé}}\right)$. A $D_{r e p}$ define a posição do pico de correlação como descrito pela lei de Bragg e o impacto de $N$ e de $\eta_{\text {Caillé }}$ está exemplificado nas figuras 5.17 e 5.18. Os parâmetros utilizados nas simulações estão apresentados na tabela 5.2.

\begin{tabular}{|c|c|c|c|c|}
\hline \multicolumn{2}{|r|}{$S(q)$} & \multicolumn{3}{|c|}{$P(q)$} \\
\hline & & & $\mathrm{R}(\AA)$ & $\rho\left(e \AA^{-3}\right)$ \\
\hline$D(\AA)$ & 75 & $\mathrm{CH}_{3}$ & 3 & 0,180 \\
\hline$N$ & $20-100^{A}$ & $\mathrm{CH}_{2}$ & 9 & 0,300 \\
\hline$\eta_{\text {Caillé }}$ & $0,02-0,20^{\mathrm{B}}$ & POL & 10 & 0,410 \\
\hline
\end{tabular}

Tabela 5.2: Parâmetros utilizados para simulações das curvas de $S(q)$ e $P(q)$ para demonstrar o

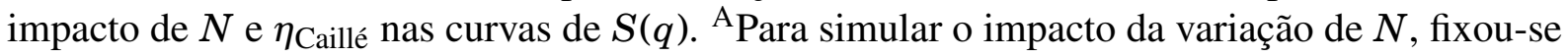

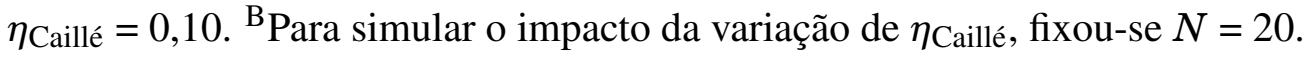

Nota-se da figura 5.17 que o aumento no número de multilamelas de 20 até 100 não impacta 
significativamente nas curvas de fator de estrutura: o pico se torna mais fino e um pouco mais intenso com o aumento de $N$. Pode-se observar a presença do pico de interferência para todas as 4 ordens de difração ( $n=1,2,3$ e 4 - lei de Bragg), em todos os casos.

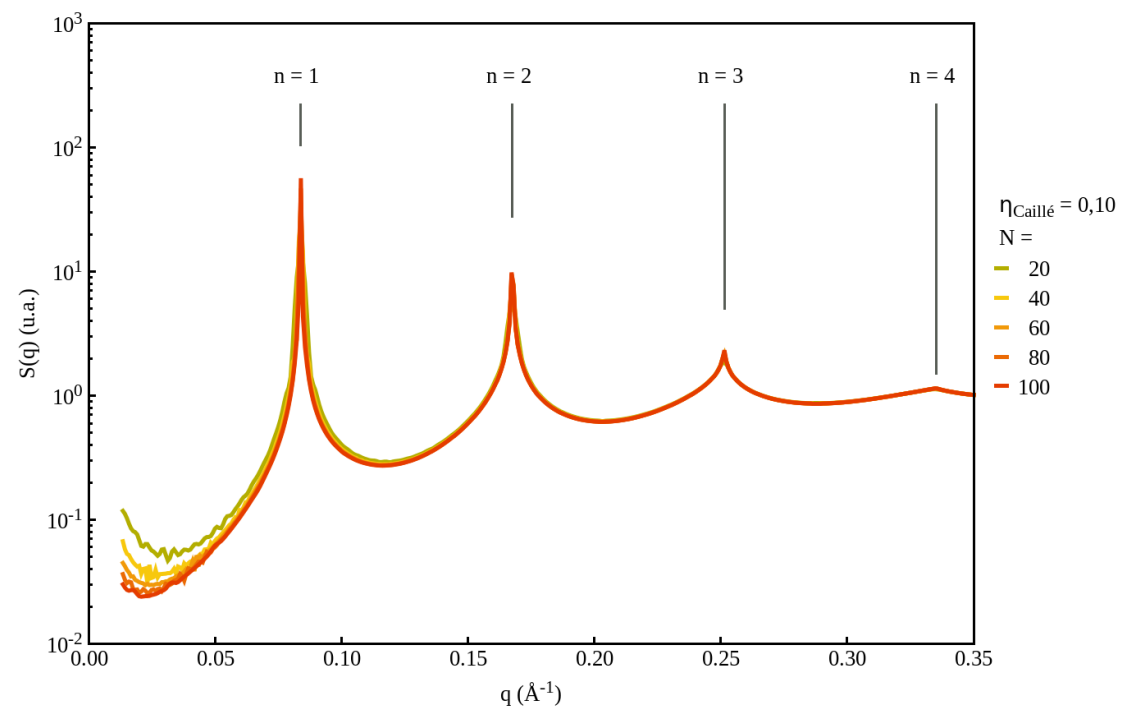

(a)

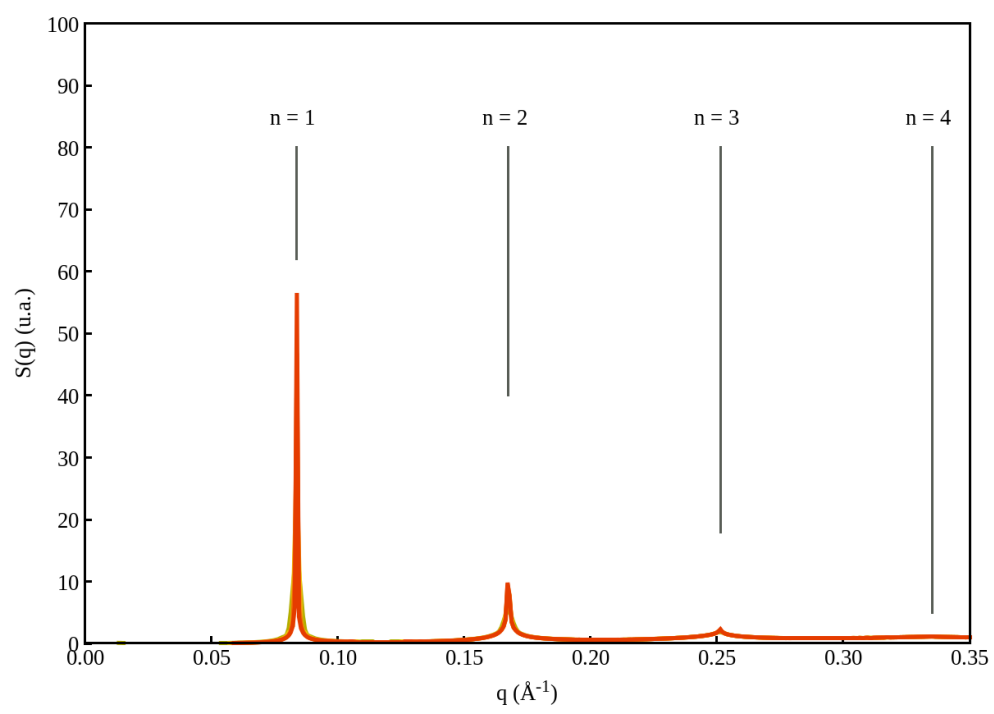

(b)

Figura 5.17: Funções de interferência entre lamelas $S(q)$ obtidas através de simulação utilizando os parâmetros descritos na tabela 5.2 mantendo $\eta_{\text {Caillé }}=0,10$ e variando-se o número de lamelas $N$ : (a) escala logarítimica, (b) escala linear.

Por outro lado, ao se manter constante o número de multilamelas e variar o parâmetro de Caillé, pode-se perceber que as curvas de $S(q)$ sofrem alterações significativas (fig. 5.18). Para $\eta_{\text {Caillé }}=0,02 ; 0,06$ e 0,10 é possível apreciar a presença de picos de interferência até a quarta ordem de difração $(n=4)$ (linhas cinza pontilhadas, fig. 5.18). Já para $\eta_{\text {Caillé }}=0,15 ; 0,20$ e 0,25 a 
função $S(q)$-> 1 para n $>1$. Além disso, para a mesma ordem de difração (n) a intensidade do pico de interferência é inversamente proporcional ao valor de $\eta_{\text {Caillé }}$

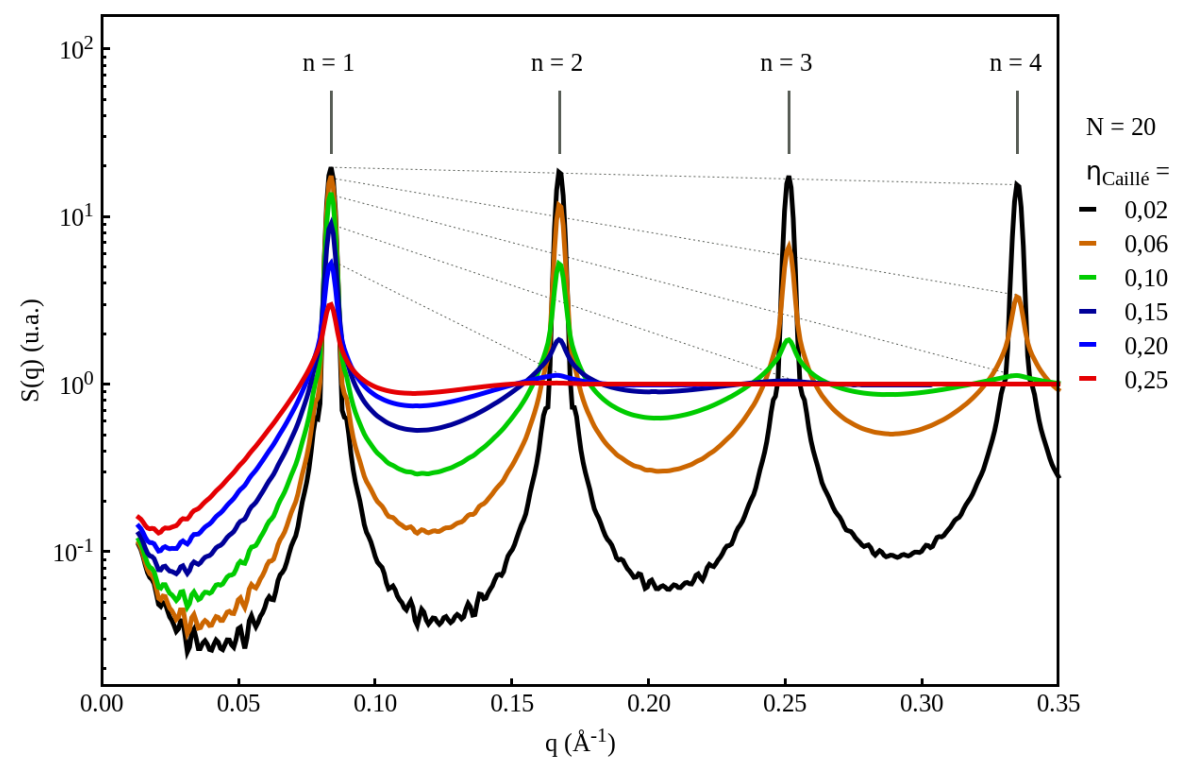

(a)

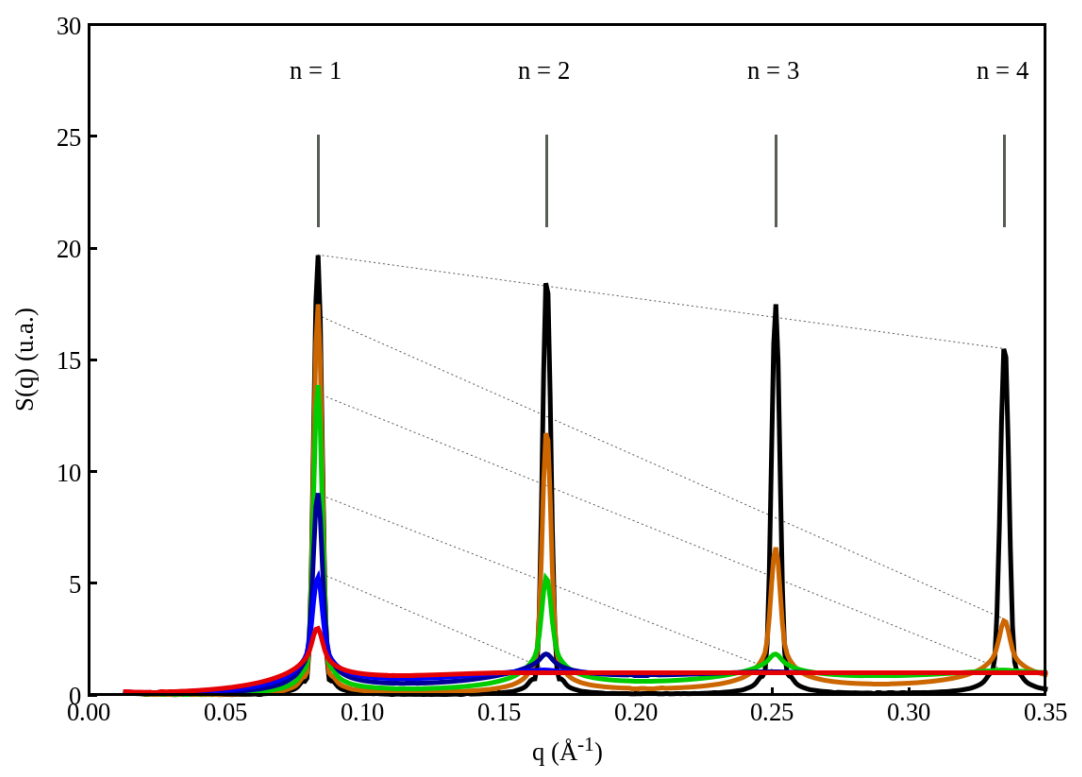

(b)

Figura 5.18: Funções de interferência entre lamelas $S(q)$ obtidas através de simulação utilizando os parâmetros descritos na tabela $5.2, N=20$ e variando-se o valor de $\eta_{\text {Caillé como indicado na }}$ figura.(a) escala logarítimica, (b) escala linear.

Tendo em vista estas observações acerca do impacto de $N$ e $\eta_{\text {Caillé nas curvas de } S(q) \text { e }}$ consequentemente em $I(q)$, pode-se relacionar as leves alterações provocadas nas curvas experimentais de SAXS para as amostras não extrusadas de POPC com o aumento da concentração 
de POPC-OOH em ambas as temperaturas com os parâmetros $N$ e $\eta_{\text {Caillé. Para isso, a figura }}$ 5.19 apresenta uma ampliação da região de $q$ entre 0,15 - 0,22 Å referentes à segunda ordem de difração para cada composição lipídica a $23^{\circ} \mathrm{C}$ e $37^{\circ} \mathrm{C}$ (ampliação das curvas apresentadas na fig. $5.5)$. 


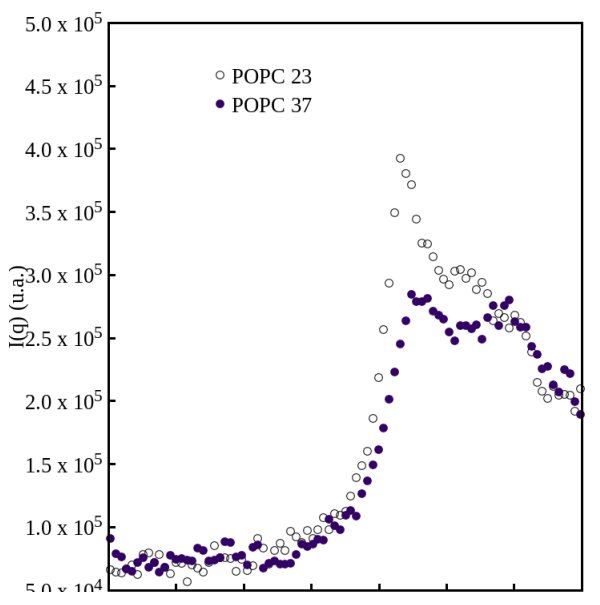

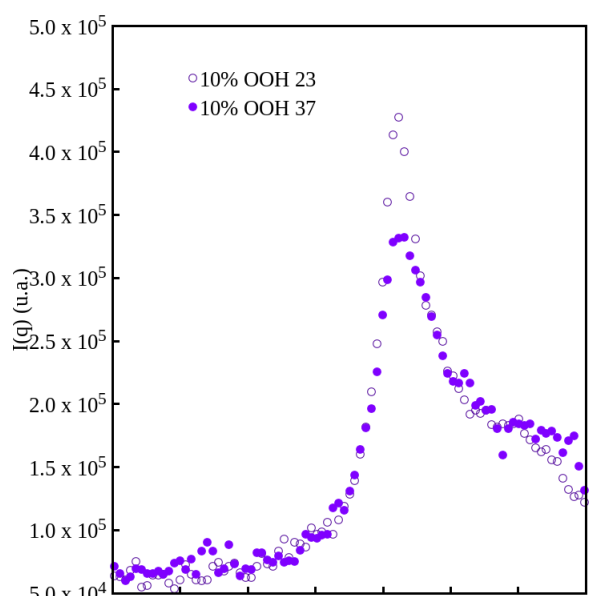

(a)

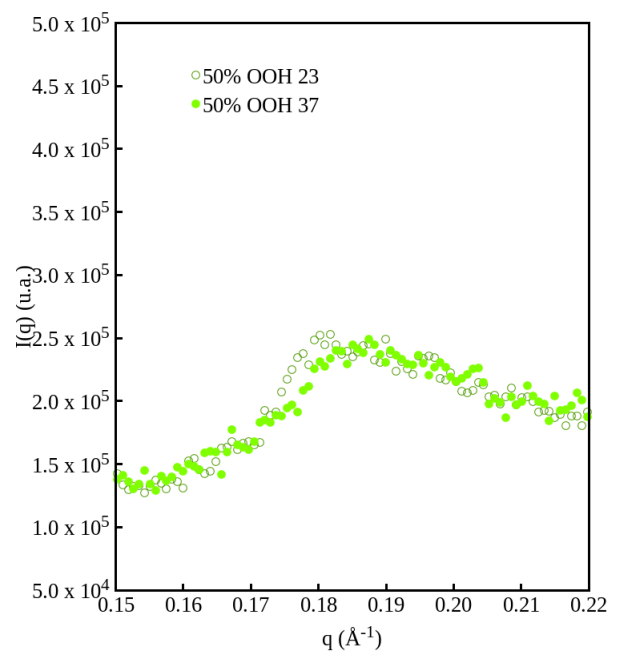

(d)

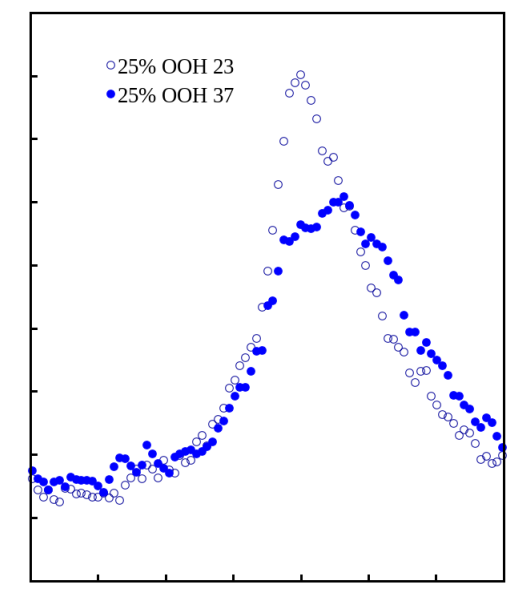

(b)

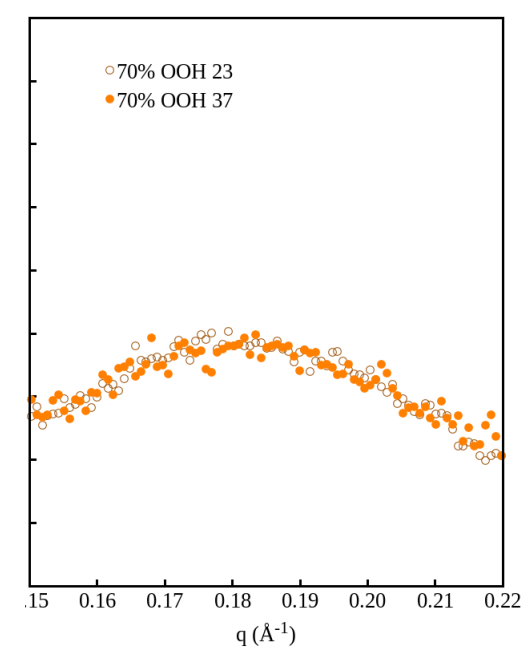

(e)

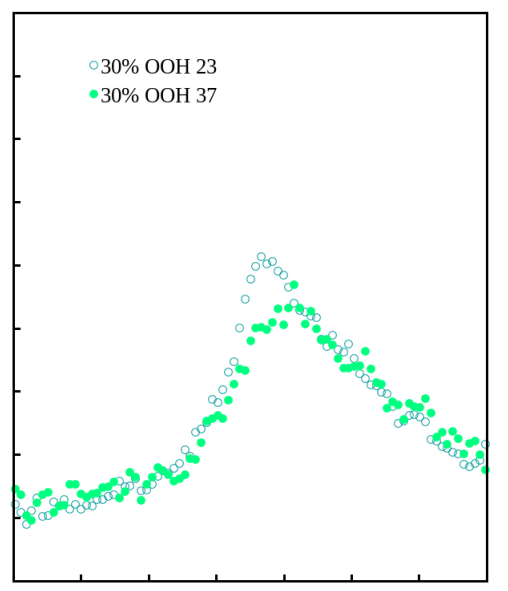

(c)

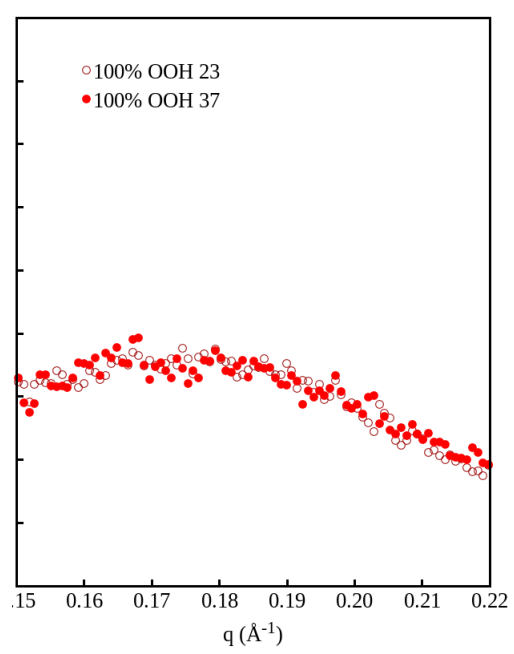

(f)

Figura 5.19: Ampliação das curvas de SAXS (fig. 5.5) na região da segunda ordem de difração para as amostras de POPC com aumento da concentração de POPC-OOH não extrusadas, nas temperaturas estudadas de $23^{\circ} \mathrm{C}$ e $37^{\circ} \mathrm{C}$.

Então, a partir da figura 5.19 percebe-se que as intensidades dos picos de correlação, referentes a $S(q)$, são menos intensas ao se aumentar a temperatura de $23^{\circ} \mathrm{C}$ para $37^{\circ} \mathrm{C}$ para o caso das amostras contendo $0 \%, 10 \%, 25 \%$ e $30 \%$ de POPC-OOH e não apresentam diferença para 
$50 \%, 70 \%$ e $100 \%$ de POPC-OOH. Associando estes dados com as observações mencionadas acima acerca das simulações de $S(q)$, pode-se afirmar que esta diminuição de intensidade está relacionada com o aumento do parâmetro de Caillé para as amostras contendo 0-30\% do lipídeo oxidado com o aumento de temperatura. Por outro lado, o $\eta_{\text {Caillé se mantém inalterado nas }}$ amostras contendo $50-100 \%$ de POPC-OOH com a variação da temperatura de $23^{\circ} \mathrm{C}$ para $37^{\circ} \mathrm{C}$. 


\subsection{Discussão I: a influência de POPC-OOH nas proprieda- des físicas de membrana lipídica}

Nesta primeira parte do capítulo estudamos o impacto da presença do lipídeo oxidado POPC-OOH em membranas de POPC a $23^{\circ} \mathrm{C}$ e $37^{\circ} \mathrm{C}$ através das análises de curvas de SAXS para amostras de vesículas não extrusadas e extrusadas.

Para discutir os dados de maneira sistemática, apresentamos primeiramente as análises dos parâmetros obtidos para o fator de forma $\left(P_{t}(q)\right.$ - estrutura da bicamada lipídica) seguida da discussão dos resultados para o fator de estrutura $(S(q))$, lembrando que o fator de forma $P_{t}(q)$ é comum às amostras não extrusadas e extrusadas, enquanto que as funções $S(q)$ foram obtidas das amostras não extrusadas.

Além disso, para evitar repetição, os resultados da literatura apresentados no tópico 4.3 (cap. 4) sobre o impacto da presença do lipídeo POPC-OOH em membranas lipídicas de POPC não foram reapresentados aqui, mas são utilizados para a discussão dos resultados.

\section{Estrutura da bicamada lipídica de membranas compostas por POPC-OOH}

Dados prévios de SAXS de vesículas extrusadas dispersas em água contendo POPC e $0 \%, 33 \%, 67 \%$ e $100 \%$ de POPC-OOH a $23^{\circ} \mathrm{C}$ [43] foram analisados levando-se em conta a contribuição do espalhamento de cada grupo químico no modelo de perfil de densidade de espalhamento (SDP). Tal modelo necessita de um grande número de parâmetros de ajuste. Neste trabalho, optamos por utilizar o modelo de três regiões de densidade eletrônicas diferentes em relação ao solvente. Os resultados permitem a comparação dos modelos.

Uma comparação direta entre os parâmetros extraídos do fator de forma $P(q)$ neste trabalho $\left(R_{C_{3}}, R_{C H_{2}}, R_{p o l}, \rho_{C H_{3}}, \rho_{C H_{2}}\right.$ e $\left.\rho_{p o l}\right)$ e os obtidos por SDP [43] pode ser feita através da comparação dos perfis de densidade eletrônica ( $\rho(r)$ - fig. 5.20) calculadas em ambos os trabalhos. Nossos resultados estão em excelente acordo com os obtidos por Rosa et al [43] como pode ser observado na figura 5.20. 

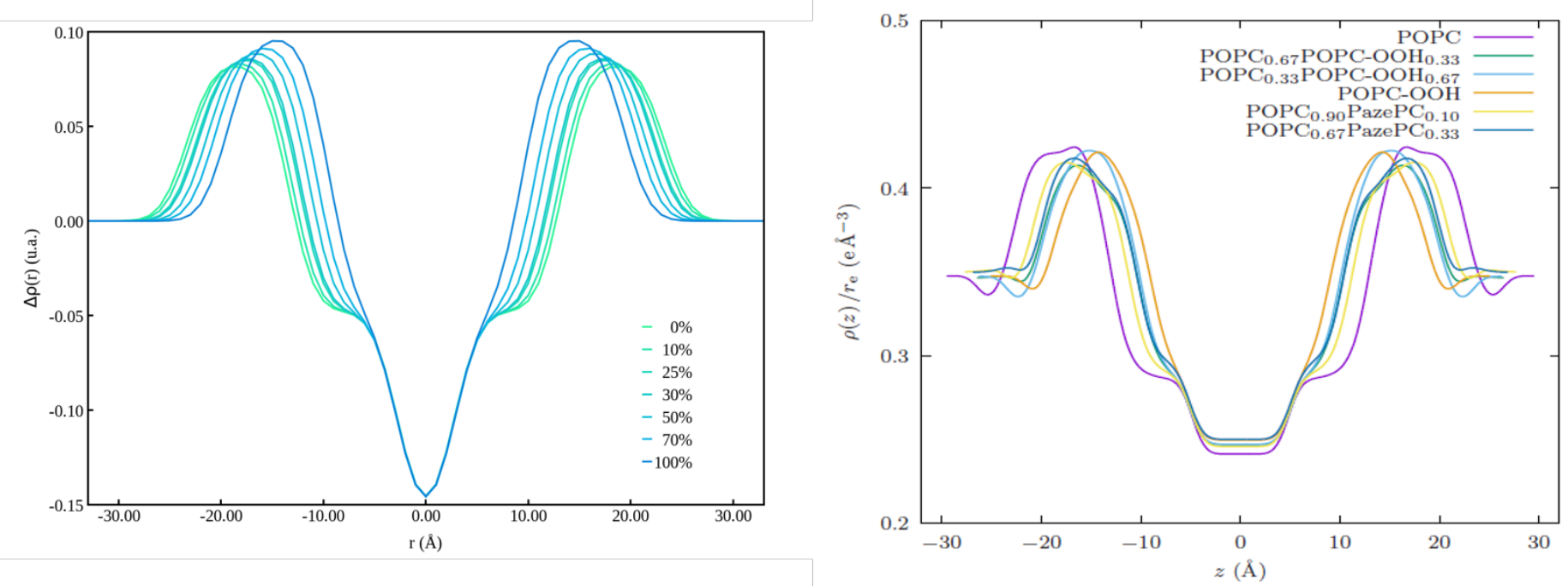

Figura 5.20: Perfis de densidade eletrônica calculados a partir dos ajustes das curvas de SAXS de POPC:POPC-OOH de amostras extrusadas medidas neste trabalho $\left(\Delta \rho(r)=\rho(r)-\rho_{\text {sol }}\right.$, esquerda) e obtidas por Rosa et al. [43] (direita). A imagem obtida de Rosa et al. [43] apresenta também as funções $\rho(r)$ para membranas de POPC na presença de PAZEPC, mas estas não são aqui comparadas.

De acordo com o modelo de SDP, podemos sugerir que o aumento de densidade eletrônica na parte polar e na região dos grupos $\mathrm{CH}_{2}$ próxima a interface polar/apolar acontece devido a localização preferencial do grupo $\mathrm{OOH}$ do lipídeo oxidado POPC-OOH nesta região. Tal localização também foi prevista por simulações de dinâmica molecular [36].

Como a espessura da região contendo os grupos $\mathrm{CH}_{2}$ se desloca para o interior da membrana lipídica é de se esperar que a espessura da bicamada sofra uma diminuição, como já observado anteriormente [36, 43, 46]. Nossas análises também apontaram essa diminuição, podendo ser cerca de 4 A para uma camada lipídica ao se comparar a espessura de membranas compostas por 100\% POPC com amostras contendo 100\% do lipídeo oxidado (fig. 5.14). Novamente, nossos dados estão em ótimo acordo com os dados da literatura e vale ressaltar que as análises de SAXS para estas composições lipídicas utilizando o modelo de SDP apontaram a mesma diminuição de espessura [43].

Os resultados anteriores com o modelo SDP [43], mostraram que a diminuição da espessura da bicamada é acompanhada por um aumento da área por lipídeo. Isto pode ser entendido do ponto de vista de conservação do volume dos grupos químicos dos lipídeos: se há a diminuição da espessura da bicamada lipídica é necessário que haja o aumento da área por lipídeo. Como discutido anteriormente, tal aumento de área foi medido experimentalmente também por técnica de micromanipulação de GUVs [46] e simulações de MD [36].

Além disso, utilizando o modelo de SDP, foi possível perceber um leve aumento de penetração de água na membrana [43], embora nossas análises não possuam nenhuma informação sobre o grau de hidratação da membrana. Isto porque o modelo que utilizamos calcula apenas 
uma densidade eletrônica média em cada uma das regiões, em relação a densidade eletrônica do solvente.

Por fim, nossos dados experimentais para as amostras extrusadas não apresentaram diferenças significativas ao se comparar as curvas de SAXS a $23^{\circ} \mathrm{C}$ e $37^{\circ} \mathrm{C}$ para a mesma composição lipídica (POPC:POPC-OOH). Ao se extrusar, a maioria das multilamelas são quebradas resultando em LUVs, o que acarreta uma diminuição significativa da correlação vertical $(S(q))$ entres as bicamadas.

De maneira interessante, análises de dados de SAXS para LUVs de POPC preparadas em água, medidas desde $20^{\circ} \mathrm{C}$ até $60^{\circ} \mathrm{C}$, apontaram que as funções $P(q)$ s obtidas paras estas amostras não apresentam grandes diferenças neste intervalo de temperatura devido ao POPC já se encontrar na fase fluída entre $20^{\circ} \mathrm{C}$ e $60^{\circ} \mathrm{C}$ [149]. Assim, o aumento da temperatura não deve ter um grande impacto na estrutura da bicamada como visto por SAXS. Semelhante análise deve ser válida para membranas de POPC-OOH. A adição deste lipídeo já causa perturbações na membrana e o aumento da temperatura é ainda menos pronunciável (ver discussão abaixo). Cabe acrescentar que para o intervalo de temperatura de nossos experimentos $\left(20-40^{\circ} \mathrm{C}\right)$ as membranas de POPC apresentam apenas uma leve diminuição da espessura da bicamada de cerca de $1 \AA$ e de diminuição de área por lipídeo de cerca de 1,5 $\AA^{2}$ [149].

\section{O impacto da presença do POPC-OOH em membranas de POPC, analisado através do fator de estrutura $S(q)$}

A presença de vesículas multilamelares (MLVs) dá origem a um fator de estrutura nas curvas de SAXS que depende do número de lamelas, temperatura, distância de repetição, módulo de curvatura da membrana e módulo de compressão do solvente [160]. A formação (ou a destruição) desta correlação pode sofrer influências de alguns parâmetros [160].

Curvas experimentais de SAXS obtidas a $27^{\circ} \mathrm{C}$ utilizando vesículas não extrusadas de POPC, preparadas em água, apresentaram um pico de interferência característico da correlação entre bicamadas lipídicas em $q \sim 0,098 \AA^{-1}$ indicando uma $D_{\text {rep }}$ de aproximadamente $64,1 \AA$ observada até a terceira ordem de difração (n=3) [154]. Estes resultados são compatíveis com os nossos apresentados na figura 5.8. Na presença de tampão (10 mM Hepes, $150 \mathrm{mM} \mathrm{NaCl}$ ) a $D_{\text {rep }}$ diminui até $10 \%$ do valor em água.

Ressalta-se aqui que em amostras não extrusadas compostas por vesículas de DOPG [161] ou DPPG [162], ao se adicionar concentrações de até $60 \mathrm{mM}$ de $\mathrm{CaCl}_{2}$ [161] ou até $700 \mathrm{mM}$ de $\mathrm{NaCl}$ [162], respectivamente, há o deslocamento do pico de difração para valores de $q$ maiores, indicando a diminuição da distância de repetição. No primeiro caso, $\mathrm{DOPG}+\mathrm{CaCl}_{2}$, a maior diminuição de $D_{\text {rep }}$ foi cerca de $3 \AA$ [161], enquanto que para o segundo caos, DPPG + NaCl, a diminuição atingiu um pouco mais de $30 \AA$ [162]. Portanto, a blingadem de carga superficial favoreceu a aproximação das lamelas [161, 162]. 
Nota-se também que nossos dados de SAXS de membranas extrusadas de POPC:POPCOOH dispersos em tampão salino (fig. 5.10 repetidas abaixo na figura 5.21, esquerda) diferem de dados anteriores de membranas dispersas em água [43] (fig. 5.21, direita). A figura 5.21 destaca tais diferenças.
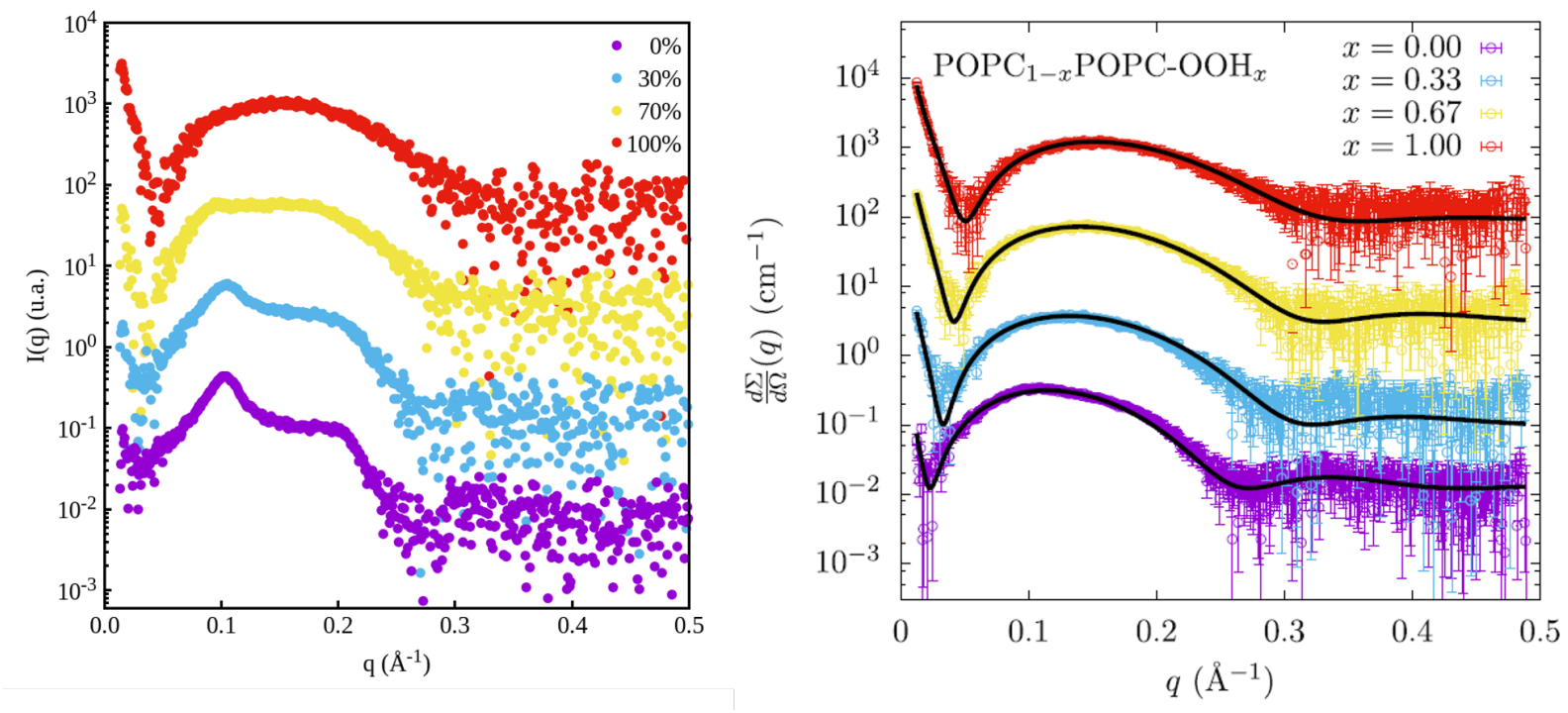

Figura 5.21: Curvas de SAXS de amostras extrusadas de POPC (10 mM) com o aumento da concentração de POPC-OOH (de baixo para cima) a $23^{\circ} \mathrm{C}$ dispersa em tampão salino obtidas neste trabalho (esquerda) e em água obtida por Rosa et al. [43] (direita). As curvas estão deslocadas para melhor visualização.

Conforme observamos, embora o aumento da concentração de POPC-OOH diminua a formação de multilamelas em tampão, no caso de vesículas dispersas em água, ocorre a formação de unilamelas para todas as membranas contendo o lipídeo oxidado (fig. 5.21 direita). Por outro lado, é evidente que o sal afeta de maneira mais significativa o empilhamento de membranas compostas por POPC do que POPC-OOH (fig. 5.7), refletido também no aumento de distância entres bicamadas contendo POPC-OOH (fig. 5.15)

Considerando o parâmetro de Caillé ( $\left.\eta_{\text {Caillé }}\right)$, relacionado às flutuações da bicamada, foi demonstrado que o valor de $\eta_{\text {Caillé praticamente não se altera (leve tendência de aumento) }}$ adicionando até $200 \mathrm{mM}$ de $\mathrm{NaCl}$ na solução a $27^{\circ} \mathrm{C}$ [154].

Em termos de $\eta_{\text {Caillé }}$ um aumento de temperatura pode influenciar o seu valor. Como exemplo, ao se analisar curvas de SAXS de DMPC em água de $50^{\circ} \mathrm{C}$ a $90^{\circ} \mathrm{C}$ observou-se que

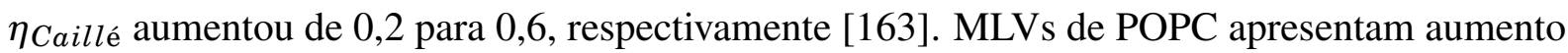

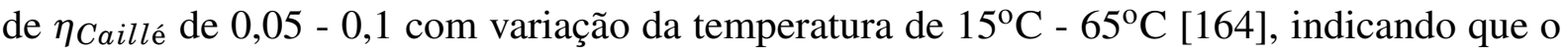
aumento de $T$ promove aumento da flutuação da bicamada lipídica.

Por outro lado, a partir do parâmetro de Caillé, pode-se calcular o valor do módulo de curvatura, $K_{c}$ (eq. 5.4), que é inversamente proporcional ao $\eta_{\text {Caillé }}$ Comparando dados da literatura pode-se perceber este efeito de maneira qualitativa. Experimentos com vesículas 
unilamelares gigantes (GUVs) de POPC a $20^{\circ} \mathrm{C}$ mostraram, através da análise de flutuações térmicas por microscopia ótica, que $K_{c}$ diminui em função do aumento da concentração de sal: $1,58 \times 10^{-19} \mathrm{~J}$ em água pura, para $1,27 \times 10^{-19} \mathrm{~J}$ em $100 \mathrm{mM}$ de $\mathrm{NaCl}$ e $1,01 \times 10^{-19} \mathrm{~J}$ em $100 \mathrm{mM}$ de $\mathrm{NaCl}$ e $10 \mathrm{mM}$ de Tris [165]. Além disso, com o aumento da temperatura de $15^{\circ} \mathrm{C}$ para $45^{\circ} \mathrm{C}$ há a diminuição de $K_{c}$ de $0,85 \times 10^{-19} \mathrm{~J}$ para $0,71 \times 10^{-19} \mathrm{~J}$ para MLVs compostas de DOPC como observado por difração de raio-X [166].

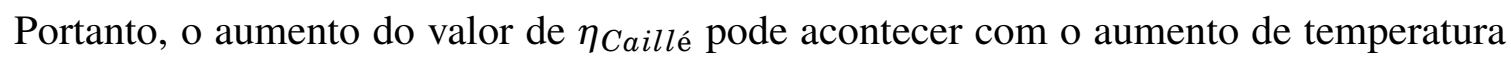
concomitantemente com a pequena diminuição do valor de $K_{c}$ (eq. 5.4), indicando que o aumento da flutuação da membrana lipídica está relacionado com a diminuição da energia necessária para causar a curvatura na mesma. Entretanto, ao se utilizar a equação de Caillé (eq. 5.4) para se obter informações sobre o $K_{c}$ pode-se cometer equívocos de interpretação dos resultados. Isto se explica porque o módulo de compressão do solvente $B$ (que multiplica $K_{c}$ na equação 5.4) pode sofrer alterações em função da distância entre as bicamadas, ou seja, em função da distância de repetição $D_{r e p}[155]$.

Vale a pena mencionar que, utilizando a técnica de SAXS, foi possível identificar picos de interferências oriundos de diferentes empilhamentos causados pela presença dos domínios lipídicos $\left(L_{o}\right)$ e $\left(L_{d}\right)$ em MLVs compostas por DOPC:DSPC:CHOL [159]. Importante notar que a transição de fases para o DSPC é de $55^{\circ} \mathrm{C}$ e que os experimentos foram realizados entre $15^{\circ} \mathrm{C}$ e $50^{\circ} \mathrm{C}$, não sendo mais perceptível a presença de domínios para temperaturas maiores do que $35^{\circ} \mathrm{C}$ [159]. Para as temperaturas nas quais a presença de domínio era perceptível, foram obtidas funções $P(q)$ e $S(q)$ distintas para cada fase [159]. Cabe destacar que o parâmetro de Caillé obtido para cada uma das fases foi de $\sim 0,03 \mathrm{e} \sim 0,08$ para $\left(L_{o}\right)$ e $\left(L_{d}\right)$, indicando que na fase $L_{o}$ há menor flutuação na bicamada lipídica (como era de se esperar) [159].

De maneira interessante, para MLVs de POPC preparadas em água e medidas por SAXS a $27^{\circ} \mathrm{C}$, a introdução de concentrações maiores do que $3 \mathrm{M}$ de $\mathrm{NaCl}$ induz a separação de fase na bicamada lípidica, como evidenciado pela presença de um novo pico de interferência entre o pico da primeira e segunda ordem de difração que já estavam presentes na curva [154]. Efeitos similares acontecem na presença de altas concentrações de $\mathrm{LiCl}$ e $\mathrm{KCl}$ e todos estes efeitos são interpretados como uma separação de fase induzida por uma distribuição não homogênea dos sais na membrana lipídica [154].

Tendo em vista estas informações sobre o impacto da adição de sal, da variação de temperatura nas curvas de SAXS de vesículas multilamelares bem como a correlação destes com os parâmetros do fator de estrutura $S(q)$, podemos discutir nossos resultados através das análises e ajustes das curvas experimentais de SAXS de membranas de POPC, com o aumento da concentração de POPC-OOH.

\section{Aumento do parâmetro de Caillé com aumento de concentração de POPC-OOH}


Com o aumento da concentração de POPC-OOH há o aumento do $\eta_{\text {Caillé }}$ (fig. 5.16) indicando que há maior flutuação da membrana ao introduzir o lipídeo oxidado. De fato, fotooxidação in situ de GUVs de POPC demonstram claramente que a formação de POPC-OOH promove o aumento da flutuação da membrana lipídica [40], em consonância com nossos dados.

Resultados de aspiração de membranas (GUVs) por micropipeta permitiram quantificar que a constante elástica da membrana de POPC-OOH é 4 vezes menor do que a da membrana composta apenas por POPC [46]. No entanto, os autores não conseguiram, por razões técnicas, quantificar a variação do módulo de curvatura $\left(K_{c}\right)$ naqueles experimentos [46]. Em nossos experimentos, é possível estimar o valor de $K_{c}$ a partir dos valores de $\eta_{\text {Caillé }}$ obtido no ajuste considerando, $B=15 \times 10^{13} \mathrm{ergcm}^{-4}$ [155], $\kappa_{B}=1.38 \times 10^{-16} \mathrm{ergK}^{-1}$ e $T=296 \mathrm{~K}$. Cabe acrescentar que o valor para $B$ obtido por Chu et al [155] é um valor médio, válido para valores de $D_{\text {rep }}$ entre $\sim 60 \AA$ e $65 \AA$. Para calcular $K_{c}$ para valores de $D_{\text {rep }}$ maiores do que $65 \AA$, extrapolamos os valores de $B$ obtidos por Chu et al [155] $\operatorname{com} B=10 \times 10^{13} \mathrm{ergcm}^{-4}$.

Com isso, calculamos $K_{c}$ (eq. 5.4) utilizando o valor médio entre os $D_{r e p}$ para cada ajuste e avaliamos a incerteza calculando também os valores do módulo de flutuação para o $D_{\text {rep }} p_{\text {máximo }}$

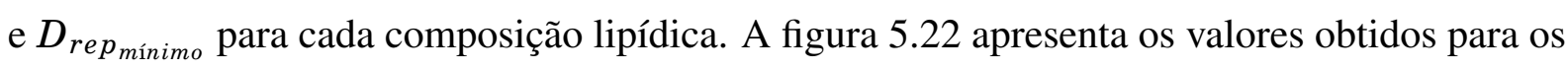
nossos dados. 


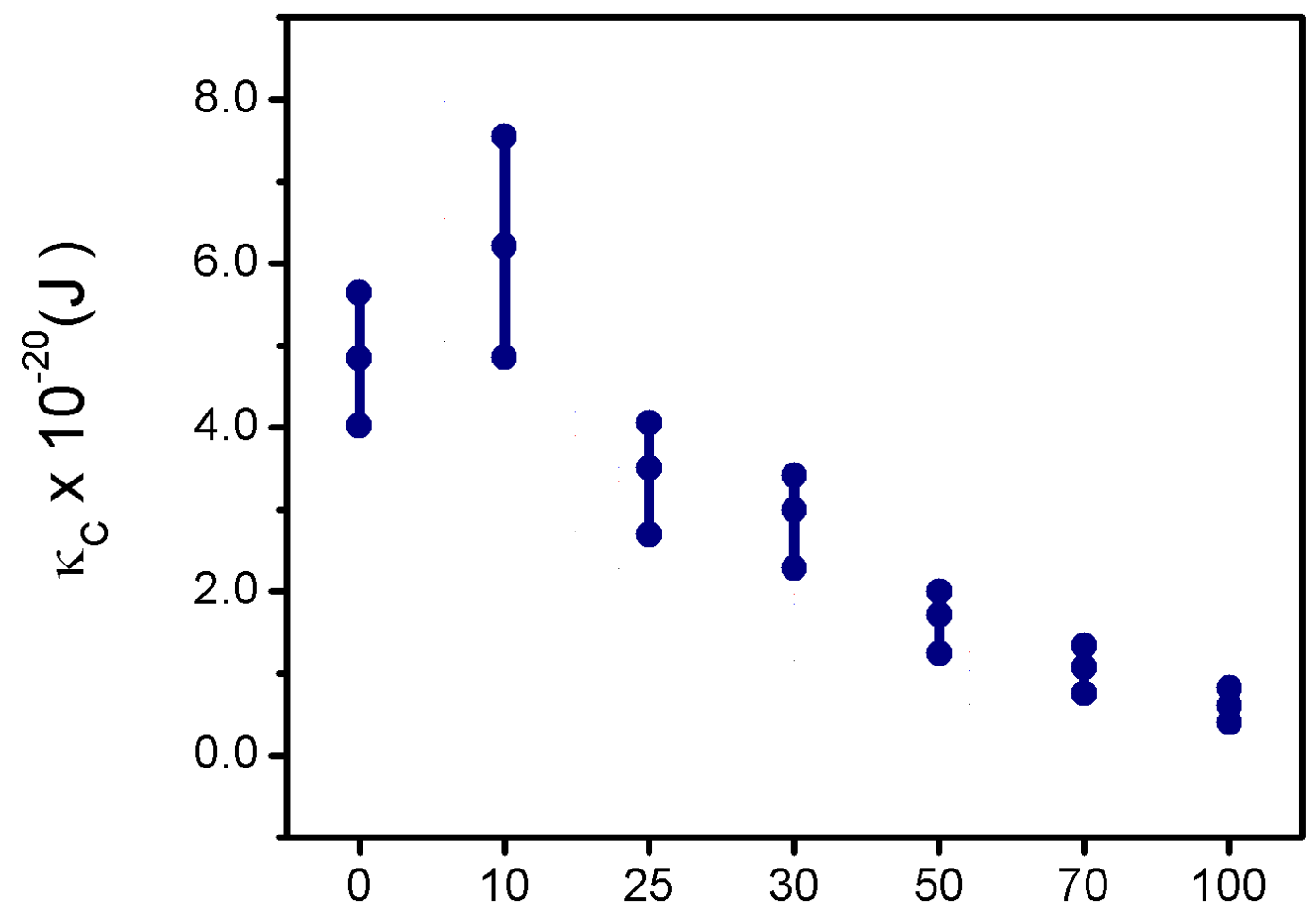

Figura 5.22: Valores calculados para o módulo de curvatura $K_{c}$ (em Joules) estimados a partir dos parâmetros de ajustes das curvas de SAXS para as amostras de POPC com o aumento da concentração de POPC-OOH não extrusadas. A linha é apenas guia para os olhos.

Primeiramente, para verificar a compatibilidade dos dados obtidos neste trabalho, comparamos o valor de $K_{c}=5(1) \times 10^{-20} \mathrm{~J}$ para membranas de POPC no tampão composto por $10 \mathrm{mM}$ HEPES, $150 \mathrm{mM} \mathrm{NaCl}, 0.2 \mathrm{mM}$ EDTA e pH 7.0 a $23^{\circ} \mathrm{C}$. Comparando os valores encontrados na literatura para o POPC em um tampão parecido com o que utilizamos, temos $12,7 \times 10^{-20}$ J em $100 \mathrm{mM}$ de $\mathrm{NaCl}$ e 10,1 x 10-20 J em $100 \mathrm{mM}$ de $\mathrm{NaCl}$ e $10 \mathrm{mM}$ de Tris [165]. Então, o valor que encontramos é ligeiramente menor do que aqueles. No entanto, utilizamos $10 \mathrm{mM}$ de HEPES ao invés de $10 \mathrm{mM}$ de Tris, mas a principal diferença é que nosso tampão possui $50 \mathrm{mM}$ a mais de $\mathrm{NaCl}$ do que estas duas comparações disponíveis na literatura e sabe-se que o valor de $K_{c}$ deveria diminuir com o aumento da concentração de sal [165]. Portanto, consideramos razoável o valor de $K_{c}=5(1)$ x $10^{-20} \mathrm{~J}$ determinado neste trabalho para membranas de POPC. Nossas análises estão, então, em bom acordo qualitativo com a previsão de diminuição do $K_{c}$ para as membranas de POPC com o aumento do POPC-OOH, pois esta tendência de diminuição é clara na figura 5.22.

O número médio de multilamelas, $N$, diminuiu de $10 \mathrm{em}$ amostras não extrusadas de $100 \%$ POPC para 4 para a amostra com 100\% POPC-OOH. Este efeito deve ter ocorrido pela 
perturbação que a presença deste lipídeo oxidado causa na membrana (diminuição de $K_{c}$ ).

Com o aumento da concentração de POPC-OOH em MLVs de POPC os picos de difração de Bragg, em média, se moveram para valores menores de $q$, indicando o aumento da distância de repetição, $D_{r e p}$, entre as bicamadas lipídicas (fig. 5.15) que deve ser resultado da dificuldade do empilhamento de diferentes lamelas, devido ao aumento de flutuação.

Em termos do efeito de temperatura, a diminuição do $2^{\circ}$ pico de difração (fig. 5.19) indica maior valor do parâmetro de Caillé, ou seja, maior flutuação da membrana. Logo, pode-se sugerir que o aumento da temperatura adiciona perturbação (maior flutuação)[164] à bicamada lipídica. Este efeito vai diminuindo a medida que mais lipídeo oxidado compõe a membrana. Para bicamadas lipídicas contendo 50\% de POPC-OOH (e maiores concentrações) a variação de temperatura de $23^{\circ} \mathrm{C}$ e $37^{\circ} \mathrm{C}$ já não afeta a função $S(q)$. Ou seja, este aumento de temperatura não altera significativamente os valores de $K_{c}$ de membranas de POPC contendo mais que $50 \%$ de POPC-OOH (fig. 5.19). 


\subsection{Resultados II - Impacto dos lipídeos oxidados PAZEPC e POVPC em membranas lipídicas}

Continuando o estudo do impacto da presença de lipídeos oxidados em membranas miméticas, realizamos os mesmos experimentos de SAXS utilizando os lipídeos PAZEPC e POVPC.

Primeiramente, para comparar o efeito da temperatura nas curvas de SAXS de amostras com diferentes composições lipídicas, a figura 5.23 apresenta os dados experimentais para as membranas de POPC compostas por $10 \%$ e $25 \%$ PAZEPC ou POVPC, não extrusadas e extrusadas a $23^{\circ} \mathrm{C}$ e $37^{\circ} \mathrm{C}$. Os dados estão deslocados para melhor visualização e para evidenciar o efeito da temperatura. As curvas de SAXS para a mesma composição lipídica possuem o mesmo deslocamento. 

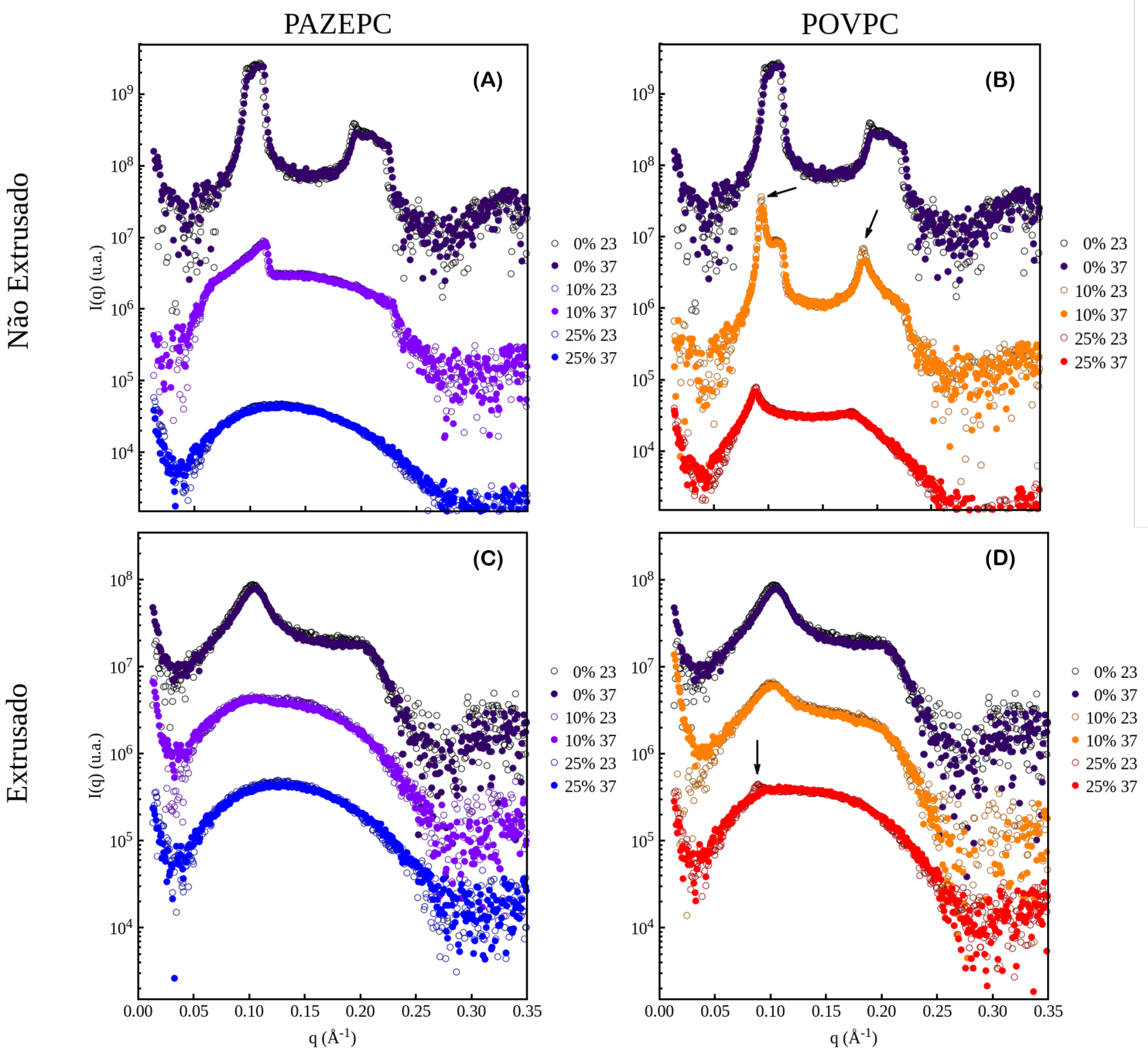

Figura 5.23: Curvas de SAXS para amostras de POPC (10 mM) com o aumento da concentração de PAZEPC (esquerda) e POVPC (direita) para suspensões não extrusadas (painel superior) e extrusadas (painel inferior) para $23^{\circ} \mathrm{C}$ (ponto vazios) e $37^{\circ} \mathrm{C}$ (pontos sólidos). As curvas estão deslocadas para melhor visualização, sendo que as mesmas composições lipídicas possuem o mesmo deslocamento.

Pode-se perceber que em ambas temperaturas e concentrações, os dois lipídeos oxidados alteram as curvas de SAXS em comparação com os dados experimentais das amostras controle compostas apenas por POPC. Esta constatação é válida tanto para as suspensões não extrusadas quanto para as extrusadas.

Além disso, a variação de temperatura em membranas contendo PAZEPC (fig 5.23 - 
esquerda) não causa alterações pronunciáveis nas curvas de SAXS para a mesma composição lipídica.

Por outro lado, para as curvas de SAXS na presença de POVPC (fig 5.23 - direita), o aumento da temperatura de $23^{\circ} \mathrm{C}$ para $37^{\circ} \mathrm{C}$ causa a diminuição da intensidade do pico de correlação $(S(q))$ para as amostras não extrusadas contendo 10\% (B) e extrusada contendo $25 \%$ (D) deste lipídeo oxidado, como indicado pelas setas na figura 5.23 (direita). Lembrando que esta diminuição da intensidade dos picos de $S(q)$ está relacionada com o aumento do parâmetro de Caillé, como visto anteriormente no caso da presença do POPC-OOH em bicamadas lipídicas, pode-se afirmar

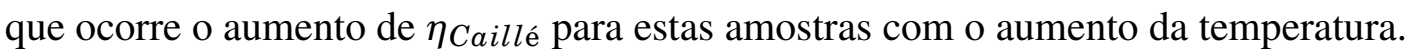

Como exposto acima, a variação de temperatura não causa um impacto significativo nas curvas de SAXS na presença de PAZEPC ou POVPC e para evitar repetições, apresentamos apenas os dados experimentais para a temperatura de $23^{\circ} \mathrm{C}$ (a menos que esteja indicado).

Para evidenciar a influência da variação da concentração do lipídeo oxidado nas curvas de SAXS de amostras de POPC, a figura 5.24 apresenta os dados experimentais, para as diferentes composições lipídicas, na mesma escala. 

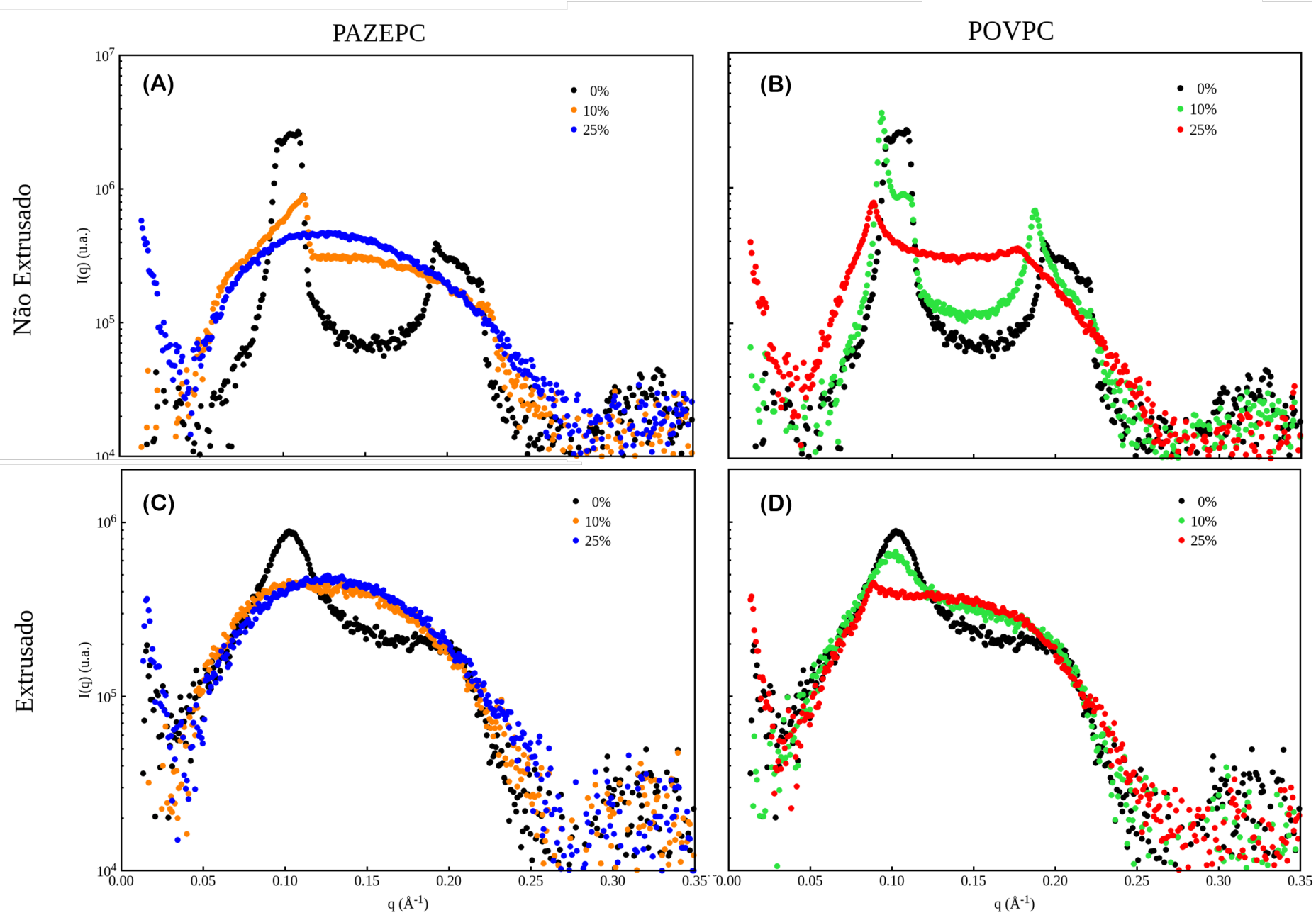

Figura 5.24: Curvas de SAXS para amostras de POPC (10 mM) com o aumento da concentração de PAZEPC (esquerda) e POVPC (direita) para soluções não extrusadas (painel superior) e extrusadas (painel inferior) a $23^{\circ} \mathrm{C}$.

Para as amostras não extrusadas (fig 5.24 (A) e (B)) a presença de PAZEPC ou 25\% POVPC causa a diminuição da intensidade do pico de interferência e aparente deslocamento da posição ao se comparar com a amostra de POPC 100\%, podendo chegar até o desaparecimento do mesmo para o caso de $25 \%$ de PAZEPC. Já para 10\% de POVPC há diminuição do pico de interferência para $q \sim 0,10$, e um pequeno aumento para $q \sim 0,08$.

Para as amostras extrusadas, a presença de POVPC diminui a intensidade do pico de interferência e para ambas as concentrações e para $25 \%$ há o deslocamento da posição do pico, enquanto não é possível observar a presença de nenhum pico de interferência ao se introduzir PAZEPC na amostra extrusada.

Como observado nos gráficos anteriores, a introdução de 25\% de PAZEPC nas amostras de POPC causou o desaparecimento dos picos de interferência tanto para as amostras não extrusadas quanto para as extrusadas (fig 5.24 (A) e (C)). Já o aumento da temperatura não causou alterações significativas nas curvas de SAXS destas amostras (fig 5.23 (A) e (C)). Sendo assim, as curvas de 
SAXS para as amostras contendo $25 \%$ de PAZEPC extrusadas ou não, para a mesma temperatura, devem ser similares. De fato, a figura 5.25 apresenta esta comparação deixando clara esta similaridade.

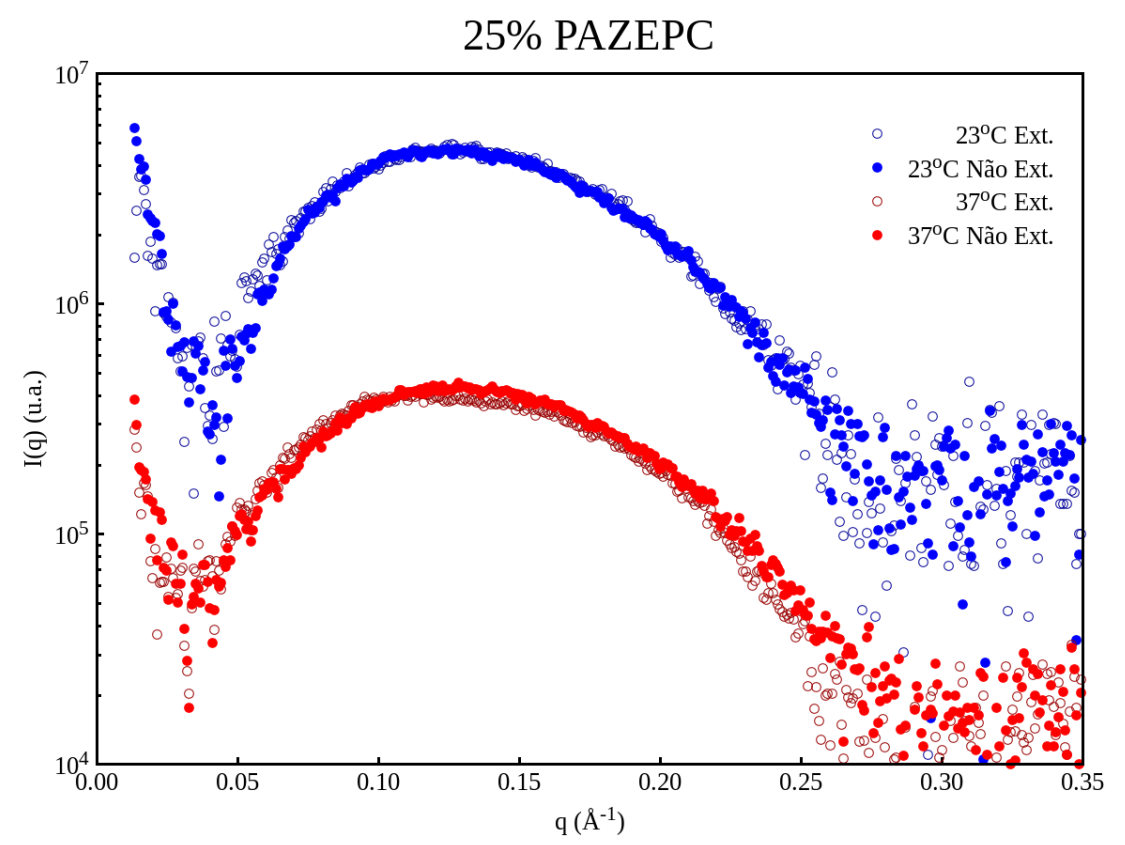

Figura 5.25: Curvas de SAXS para amostras de POPC (10 mM) na presença de 25\% PAZEPC para suspensões não extrusadas (pontos vazios) e extrusadas (pontos sólidos) para a temperatura de $23^{\circ} \mathrm{C}$ (azul) e $37^{\circ} \mathrm{C}$ (vermelho)

Até este ponto pôde-se apreciar a influência da temperatura nas curvas de SAXS para cada composição lipídica contendo PAZEPC ou POVPC (fig. 5.23) e a influência do aumento da concentração de cada um deste lipídeos oxidados em relação ao controle de POPC (fig. 5.24). Todas esta comparações também foram apresentadas para o caso das amostras não extrusadas e extrusadas (figs. 5.23 e 5.24).

Seguimos, então, para a comparação direta entre o impacto da presença dos diferentes lipídeos oxidados PAZEPC, POVPC, nas mesmas concentrações, nas curvas de SAXS para as amostras não extrusadas e extrusadas. Para comparação, incluimos os resultados dos experimentos na presença de POPC-OOH nas mesmas concentrações destes dois lipídeos oxidados (fig. 5.26). 

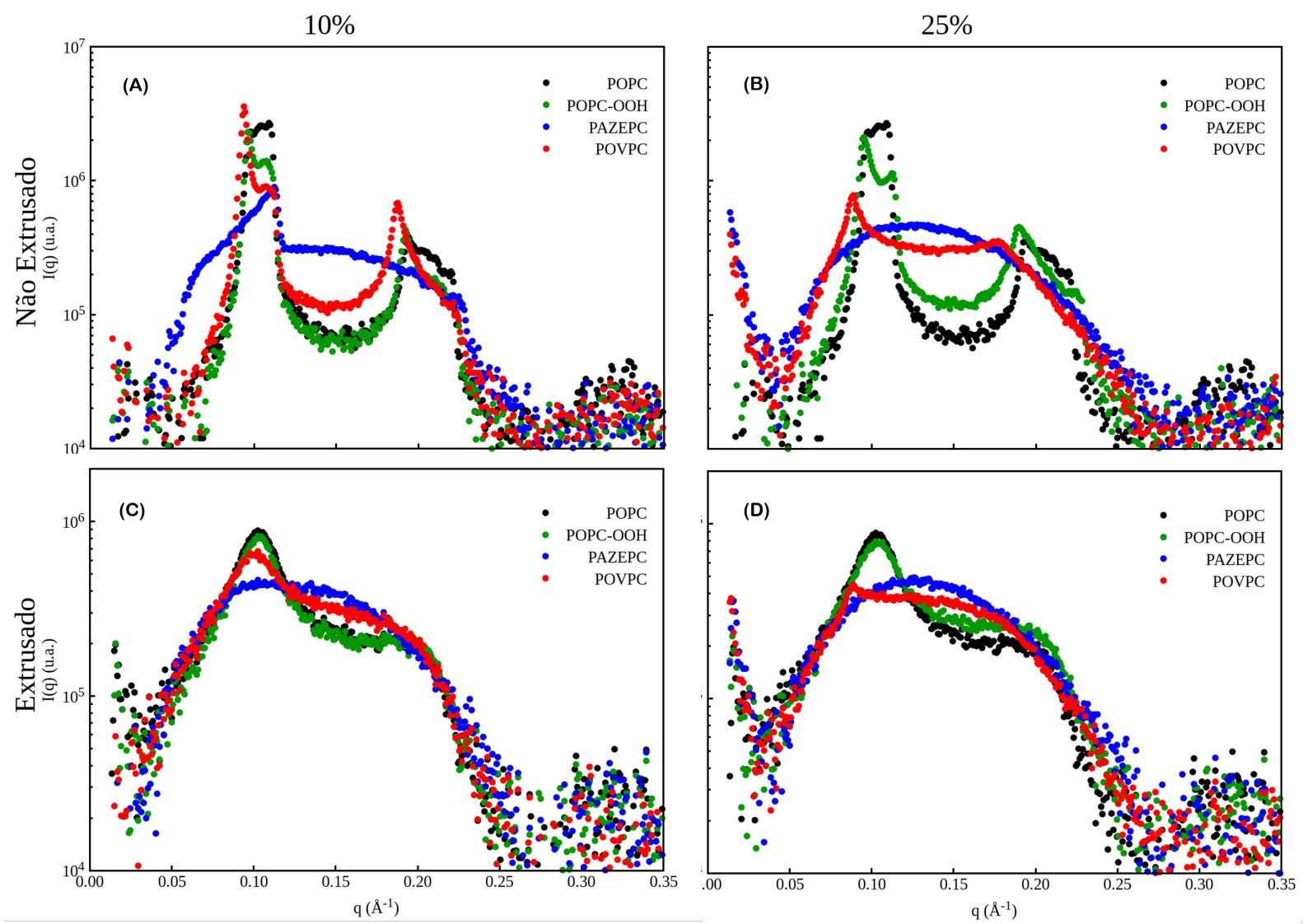

Figura 5.26: Curvas de SAXS para amostras de POPC (10 mM) com o aumento da concentração de lipídeo oxidado: POPC (preto), PAZEPC (azul), POVPC (vermelho) e POPC-OOH (verde) para soluções não extrusadas (painel superior) e extrusadas (painel inferior) para a temperatura de $23^{\circ} \mathrm{C}$.

Observando a figura 5.26 pode-se perceber que, em todos os casos, a diminuição da intensidade dos picos de interferência e o seu deslocamento de posição segue a ordem, do menos ao mais relevante, POPC-OOH, POVPC e PAZEPC, a menos pela intensidade para $q \sim 0,08$ $\AA^{-1}$ na presença de $10 \%$ dos lipídeos oxidados (fig. 5.26 (A)). Além disso, apenas na presença de PAZEPC é possível observar o desaparecimento do pico de interferência (fig. 5.26 (B)-(D)). Portanto, as diferentes características nas curvas de SAXS refletem a propriedade de formar agregados lipídicos multilamelares. Já com a presença de lipídeos oxidados, POVPC e PAZEPC, há a indução preferencial da formação de bicamadas lipídicas unilamelares.

Após estes resultados e comparações apresentados, realizou-se o ajuste das curvas experimentais das amostras de membranas de POPC na presença de $10 \%$ e $25 \%$ de PAZEPC ou POVPC a $23^{\circ} \mathrm{C}$ utilizando os modelos descritos anteriormente (Materiais e Métodos e soma de três diferentes $S(q)$ para as amostras não extrusadas - Resultados I). Cabe acrescentar que para a amostra contendo 25\% de PAZEPC não extrusada, utilizou-se apenas o fator de forma, ou seja, foi possível fazer o ajuste sem utilizar o fator de estrutura como sugerido pela ausência do pico de interferência. Os resultados estão presentes na figura 5.27. 
PAZEPC
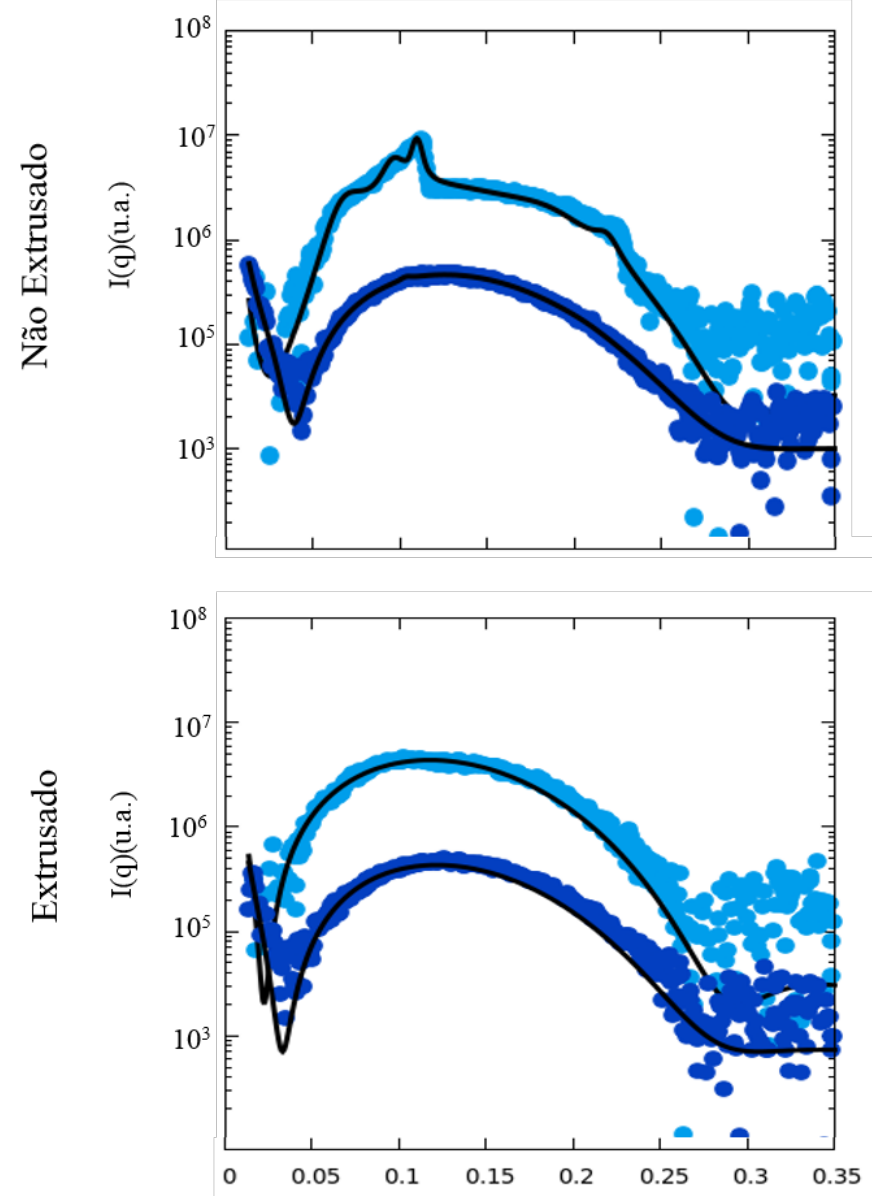

POVPC
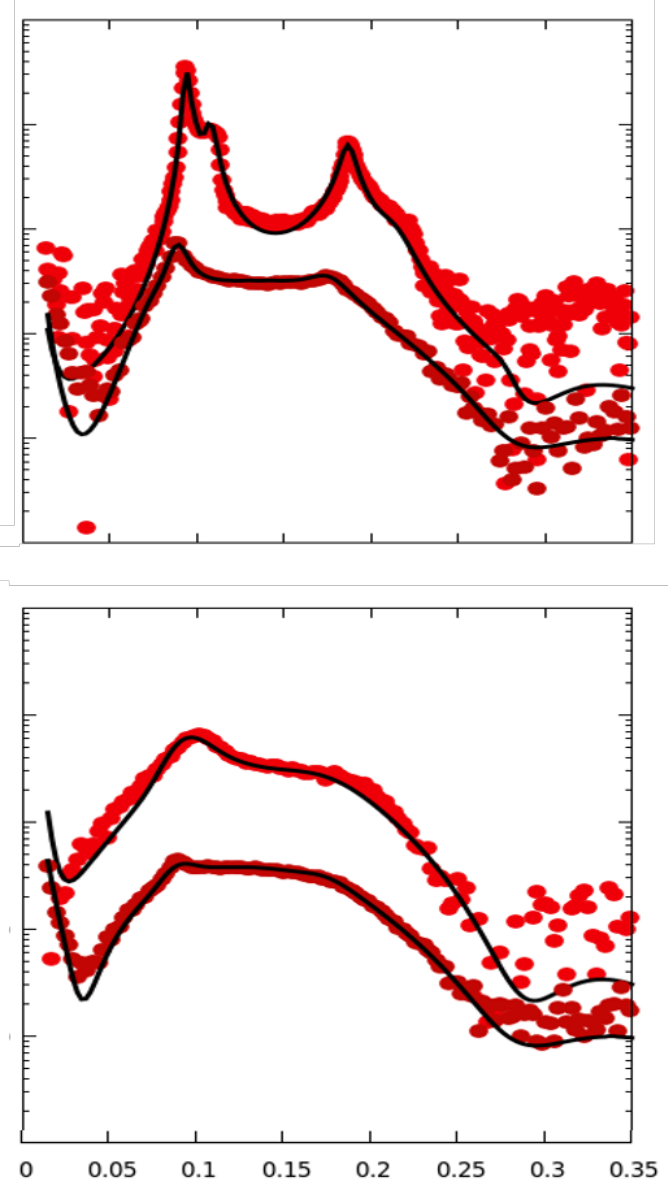

Figura 5.27: Curvas de SAXS para amostras de POPC (10 mM) contendo 10\% (tom claro) e $25 \%$ (tom escuro) de PAZEPC (esquerda - azul) ou de POVPC (direita - vermelho) a $23{ }^{\circ} \mathrm{C}$ acompanhadas dos ajustes (linha preta). As curvas estão deslocadas para melhor visualização.

Observando a figura 5.27 pode-se apreciar o bom acordo entre os modelos utilizados para os ajustes e as curvas experimentais para todas as amostras. Importante lembrar que o fator de forma, $P_{t}(q)$, é o mesmo para amostras não extrusadas e extrusadas compostas pela mesma razão molar POPC:lipídeos. Sendo assim, os parâmetros de ajustes envolvidos no cálculo do fator de forma $\left(R_{i}\right.$ e $\left.\rho_{i}\right)$ são comuns para os dois conjuntos de curvas e foram utilizados para o cálculo do perfil de densidade eletrônica $(\rho(r))$ (eq. 5.5).

Para comparação direta, as funções $\rho(r)$ na presença de $10 \%$ e $25 \%$ de POPC-OOH, apresentadas anteriormente, foram incluídas com as funções de densidade eletrônica na presença de PAZEPC e POVPC nas mesmas concentrações, como mostra a figura 5.28. 


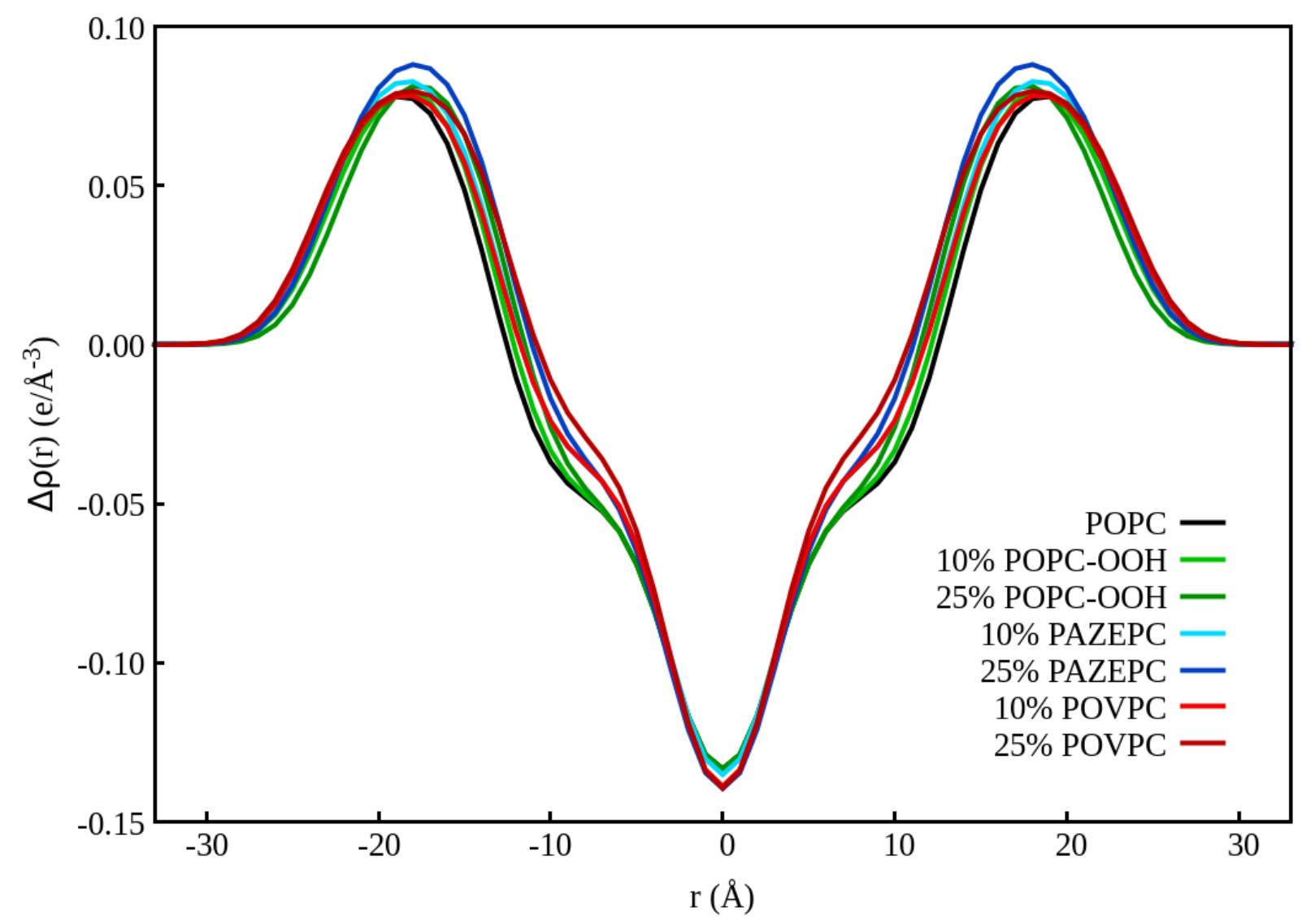

Figura 5.28: Perfil de densidade eletrônica $(\rho(r))$ calculado (eq. 5.5) utilizando os parâmetros de $P_{t}(q)$ obtidos através dos ajustes das curvas de SAXS de POPC:lipídeos: $10 \%$ (tom claro) e $25 \%$ (tom escuro) de PAZEPC (azul) ou de POVPC (vermelho) e 10\% (tracejada) e 25\% (sólida) POPC-OOH (verde).

Note-se que o perfil de densidade eletrônica na presença de um mesmo lipídeo oxidado a $10 \%$ ou $25 \%$ é muito similar. Além disso, as funções $\rho(r)$ na presença de POPC-OOH e POVPC são muito parecidas ao perfil de densidade eletrônica para a amostra controle de 100\% POPC, apresentando apenas um leve aumento da densidade eletrônica na região de $r \sim 10 \AA$.

Por outro lado, na presença de PAZEPC, a função $\rho(r)$ apresenta diferenças em relação ao controle de 100\% POPC: (i) aumento da densidade eletrônica na região de $r \sim 20 \AA$ e (ii) diminuição da mesma para $r \sim 5 \AA$.

Pode-se também comparar a espessura de metade da bicamada lipídica $\left(R_{\mathrm{CH}_{3}}+R_{\mathrm{CH}_{2}}+R_{p o l}\right)$

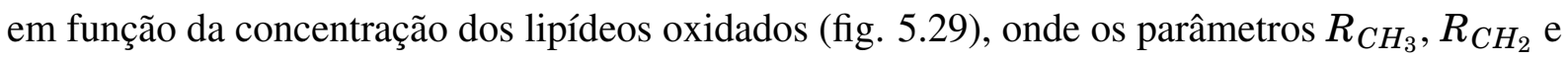
$R_{p o l}$ foram obtidos através dos ajustes mencionados anteriormente (fig. 5.27). 


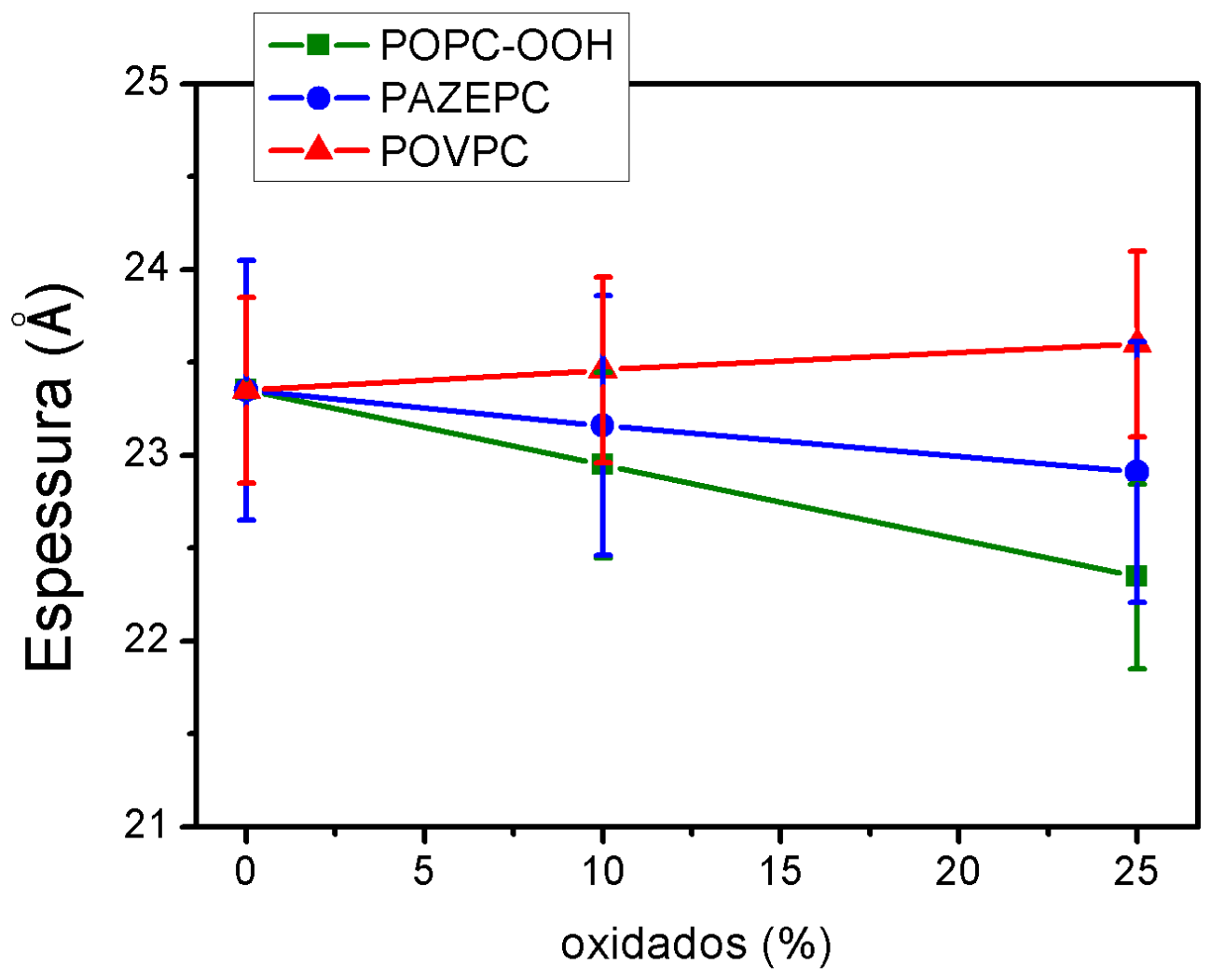

Figura 5.29: Espessura de uma camada lipídica obtida como $R_{\mathrm{CH}_{3}}+R_{\mathrm{CH}_{2}}+R_{\text {pol }}$ para as vesículas de POPC $(10 \mathrm{mM})$ em função do aumento de concentração dos lipídeos oxidados: PAZEPC (azul), POVPC (vermelho) e POPC-OOH (verde). As linhas são apenas guias para os olhos.

A espessura da camada lipídica apresenta apenas uma leve tendência de diminuição na presença de $10 \%$ e 25\% de POPC-OOH e POVPC em membranas de POPC e uma leve tendência de aumento na presença de $10 \%$ e $25 \%$ PAZEPC (fig. 5.29).

Os resultados obtidos para $\rho(r)$ e espessura da bicamada são válidos para as amostras não extrusadas e extrusadas, tendo em vista que estas informações são provenientes da $P_{t}(q)$ comum a estas amostras. Para obter informações do fator de estrutura $S(q)$, utilizamos as curvas experimentais não extrusadas, pois são as que apresentam as maiores intensidades para os picos de correlação.

Com os ajustes das curvas experimentais de SAXS das vesículas não extrusadas (fig. 5.27 - painel superior) obteve-se os valores das três distâncias de repetição, $D_{1}, D_{2}$ e $D_{3}$ para cada composição lipídica, como apresentado na figura 5.30. 


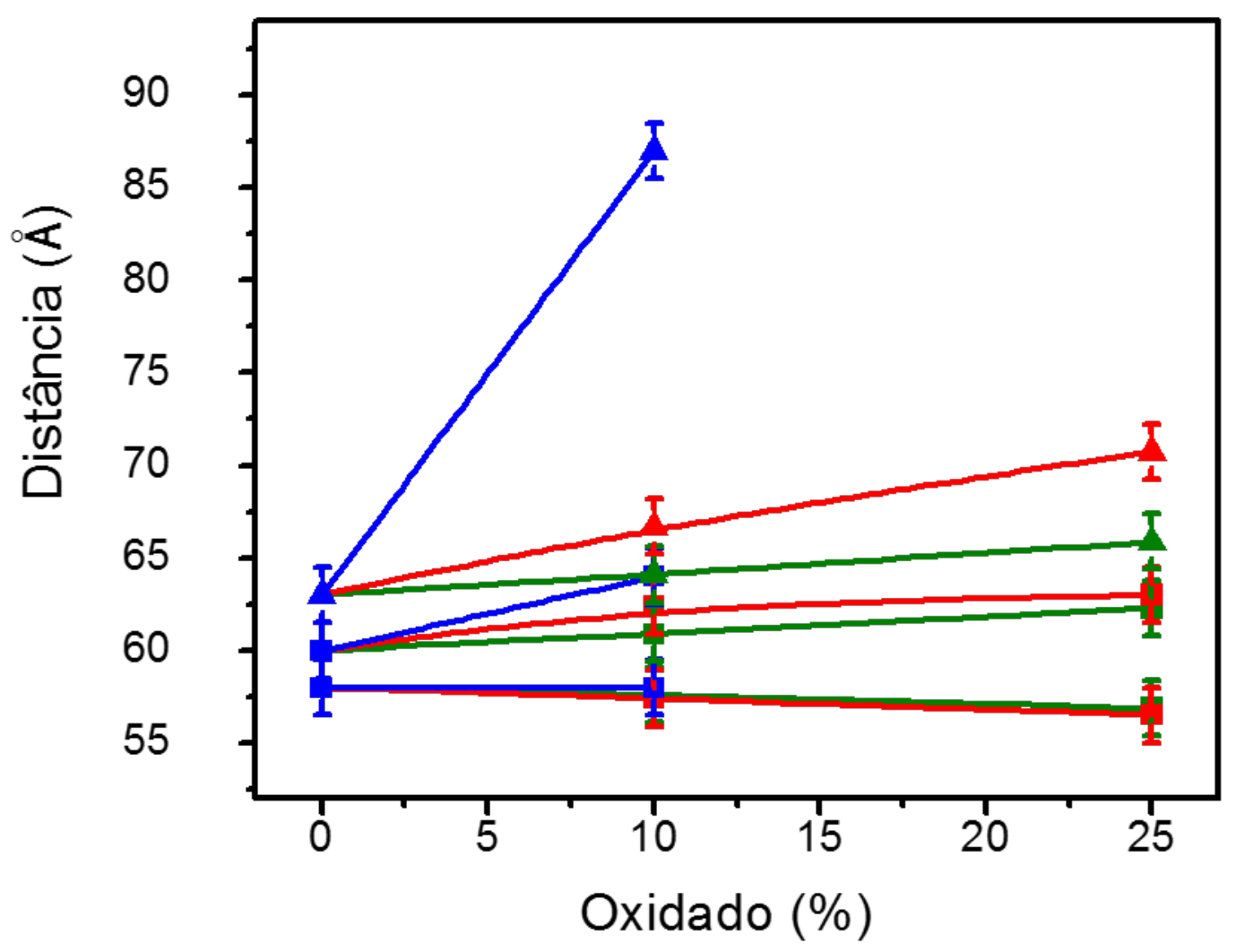

Figura 5.30: Três distâncias (círculo, quadrado e triângulo) de repetição obtidas para as vesículas de POPC (10 mM) em função do aumento da concentração dos lipídeos oxidados: PAZEPC (azul), POVPC (vermelho) e POPC-OOH (verde). As linhas são apenas guias para os olhos.

Para o caso de 10\% PAZEPC, pode-se observar que duas menores distâncias não apresentam significativa variação em relação ao controle, enquanto uma terceira apresenta um grande aumento para cerca de $D_{3}=87 \AA$ A. Esta distância é compatível com a posição de um pico em cerca de $q \sim 0,07 \AA^{-1}$, em bom acordo com o dado experimental e o ajuste (fig. 5.27 painel superior, azul claro).

Para o POVPC (10\% e 25\%), as duas menores distâncias estão praticamente inalteradas em relação à amostra de $100 \%$ POPC como também pode ser observado pela aparente manutenção da posição $q$ dos picos para estas duas amostras como apresentado na figura 5.26 (A). Já para a maior distância de repetição, há um leve aumento, sendo mais evidente no caso de $25 \%$ de POVPC com o $D_{r e p}$ de cerca de $70 \AA ̊$, o que equivaleria a um pico na posição $q \sim 0,089$. De maneira interessante, este pico pode ser observado na figura 5.27 parte de cima - vermelho escuro.

Além disso, o parâmetro de Caillé para as amostras contendo POVPC tiveram maior aumento do que na presença de POPC-OOH nas mesmas concentrações como apresentado na figura 5.31. Como a curva de SAXS de amostras não extrusadas contendo 25\% PAZEPC não 
apresentou $S(q)$ e na presença de $10 \%$ não foi possível realizar o ajuste utilizando apenas um valor de $\eta_{\text {Caille }}$, não apresentamos os valores obtidos para as amostras contendo PAZEPC.

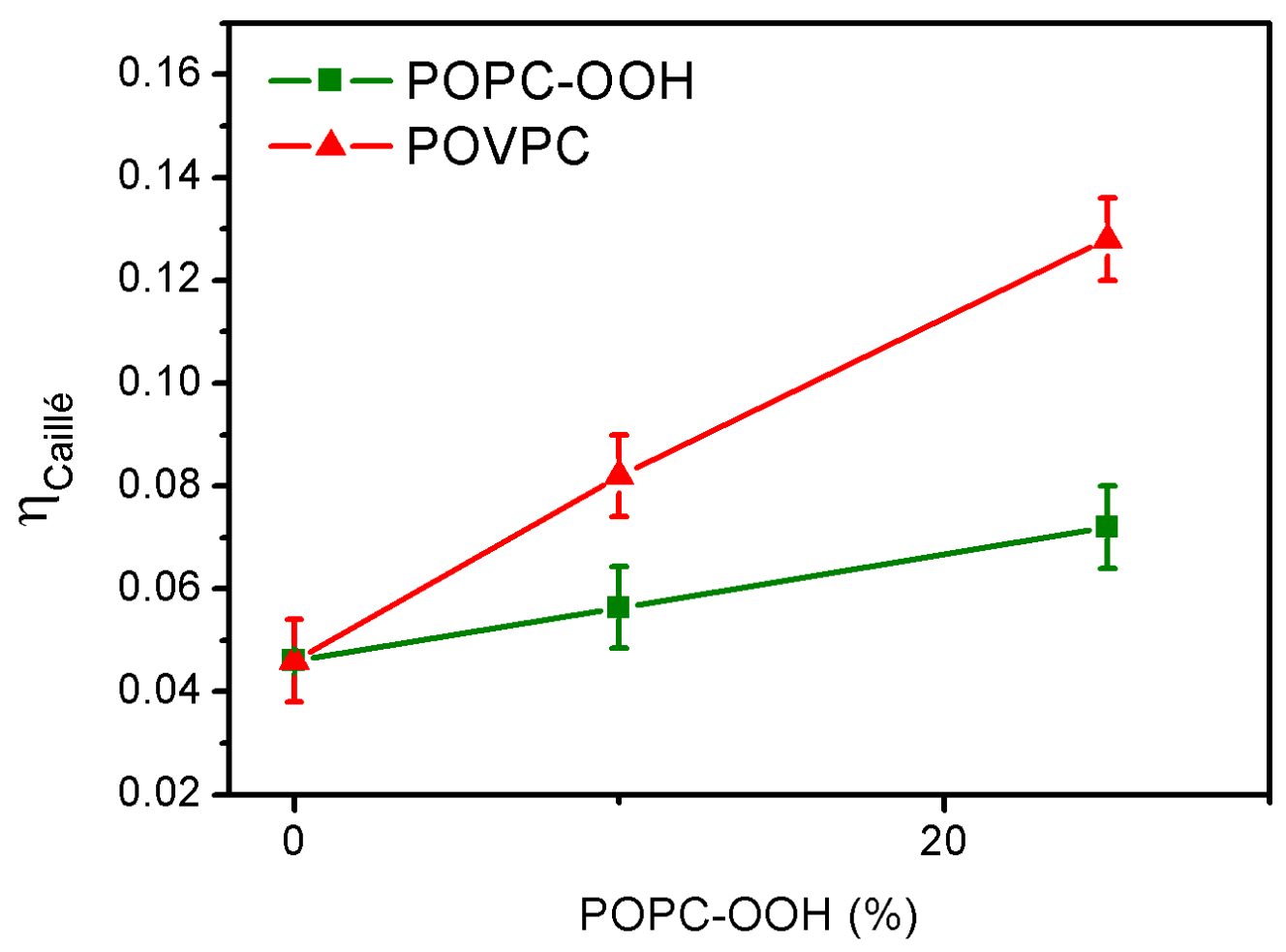

Figura 5.31: Valores médios de $\eta_{\text {Caille }}$ (eq. 5.4) para MLVs de POPC (10 mM) com aumento da concentração de POPC-OOH (verde) e de POVPC (vermelho). 


\subsection{Discussão II: Impacto dos lipídeos oxidados PAZEPC e POVPC em membranas lipídicas}

Tendo em vista os resultados da literatura sobre o impacto da presença de PAZEPC e POVPC em membranas lipídicas esquematizados na discussão do capítulo 4, bem como a literatura discutida na parte I da discussão deste capítulo (Discussão I) discustimos os resultados obtidos atráves das análises de SAXS.

Primeiramente, as funções de densidade eletrônica ( $\rho(r)$ - fig. 5.28) calculadas a partir dos parâmetros obtidos nos ajustes das curvas de SAXS das amostras extrusadas de POPC na presença de PAZEPC e POVPC indicam um padrão semelhante à $\rho(r)$ na presença de POPCOOH: aumento da densidade eletrônica na região das cadeias alifáticas $\mathrm{CH}_{2}(r \sim 10 \AA$ ), como no caso do POPC-OOH. Tal resultado deve indicar que os grupos carboxila e aldeído (PAZEPC e POVPC, respectivamente) estão localizados nesta região de interface. Desta maneira, nossos dados estão em bom acordo com as análises de SAXS utilizando o modelo SDP para amostras contendo PAZEPC [43] e resultados de dinâmica molecular que indicam a presença destes grupos carboxila e aldeído na região da interface polar/apolar da bicamada [48, 152].

Interessante notar que o aumento de $\rho(r)$ nesta região (grupos $\mathrm{CH}_{2}$ ) é mais pronúnciavel para a amostra composta por POPC:POVPC 75:25, seguido de 25\% PAZEPC e 25\% POPC-OOH o que está em bom acordo com o cálculo médio de densidade eletrônica por unidade de volume para as cadeias alifáticas oxidadas (a cadeia não oxidada é igual para os três casos) de cada um deste lipídeos: $25 \%$ POVPC $=0,291 \mathrm{e}^{-3}, 25 \%$ PAZEPC $=0,286 \mathrm{e}^{-3}$ e $25 \%$ POPC-OOH $=$ $0.279 \mathrm{e}^{-3}$.

Além disso, é possível observar um pequeno aumento da função $\rho(r)$ para a amostra contendo 25\% PAZEPC na região da cabeça polar $(r \sim 18 \AA)$ que pode estar relacionado à movimentação da cadeia alifática truncada para o meio aquoso e a localização do grupo carboxila no exterior da membrana, como sugerido por dinâmica molecular [167]. Também sugerimos a localização deste grupo carboxila com base nas análises da função $S(q)$. De qualquer maneira, nossa função $\rho(r)$ pode indicar a localização do grupo carboxila na região do $\mathrm{CH}_{2}$ e também no exterior da membrana. Por isso, o aumento da densidade eletrônica no interior da membrana é menos pronúnciavel do que na presença do POVPC, apesar da pequena diferença da densidade eletrônica média calculada acima. Sendo assim pode-se sugerir que o grupo carboxila se move para a parte hidrófobica e hidrofílica estando em bom acordo com as conclusões obtidas por Rosa el at [43].

Quanto a espessura da monocamada lipídica, nossas análises não apontaram diminuição da espessura na presença do PAZEPC ou do POVPC em relação ao controle de POPC, considerando as incertezas (fig. 5.29), como esperado na presença destes lipídeos [43, 48, 152].

Analisando agora os resultados obtidos a partir das funções $S(q)$ para as MLVs, nossos 
dados de SAXS para as amostras de POPC contendo PAZEPC ou POVPC mostraram uma expressiva diminuição das funções $S(q)$ indicando a diminuição da formação de multilamelas e de maior flutuação da membrana (aumento do parâmetro de Caillé). Estes resultados devem estar relacionados com a instabilidade no empacotamento da membrana causado pela introdução deste dois lipídeos oxidados [41, 167, 168].

Recentemente foi constatado que a presença de mais de $18 \%$ de PAZEPC em amostras lipídicas contendo DPPC:Chol impossibilita a formação de GUVs [41] e que LUVs compostas por DOPC na presença de 50\% ou mais deste lipídeo oxidado podem sofrer "decomposição" e podem ser formadas micelas ricas em PAZEPC [167]. Estes dois estudos indicaram que o PAZEPC possui uma estrutura cônica, que somada à instabilidade causada pela sua introdução na bicamada, impediria o empacotamento estável dos lipídeos da bicamada lipídica [41, 167]. Além disso, a presença do PAZEPC causa instabilidade nos domínios lipídicos presentes em GUVs compostas por DPPC:Chol e ainda aumenta a a permeabilidade da membrana [41].

Nesta mesma direção, o lipídeo oxidado POVPC forma apenas micelas quando disperso em solução aquosa, forma micelas e LUVs ao se preparar 25\% de lipídeo oxidados e $75 \%$ de DPPC e há a formação de LUVs nas mesmas concentrações, ao se trocar DPPC por DOPC [168].

Sendo assim, nossos dados de expressiva diminuição da $S(q)$, ou seja, formação preferencial de LUVs na presença do PAZEPC e POVPC podem estar relacionados a pertubação à membrana causado por eles.

Vale ressaltar que, apenas no caso das amostras extrusadas contendo PAZEPC, não observamos a presença de MLVs. Para as amostras não extrusadas contendo 15\% de PAZEPC, uma das distâncias de repetição aumentou cerca de $20 \AA$ em relação ao controle e demais lipídeos oxidados e com $25 \%$ de PAZEPC não foi observado $S(q)$, ou seja, observou-se apenas LUVs. Uma possível explicação para estes resultados pode ser obtida levando-se em conta o efeito da presença de carga elétrica na superfície da membrana.

É conhecido que blindagem de carga superficial de LUVs de DPPG pela adição de $\mathrm{NaCl}$ pode induzir a formação de MLVs e que a distância de repetição $\left(D_{r e p}\right)$ entres as MLVs diminui com o aumento do sal, podendo diminuir cerca de $30 \AA$ (100 mM para $700 \mathrm{mM}$ - aumento da blindagem de carga). [162]. Por outro lado, em MLVs neutras de POPC, há a indução de carga superficial ao se adicionar $\mathrm{CaCl}_{2}$ à solução, de maneira que a $D_{\text {rep }}$ aumenta com a concentração do sal.

Tendo isto em vista, lembrando que o grupo carboxila do PAZEPC é negativamente carregado[41] e pode estar na superfície da membrana [48] pode-se sugerir que estes efeitos expressivos na $D_{\text {rep }}$ e na formação preferencial de LUVs na presença do PAZEPC também pode estar relacionado à formação de carga superficial na bicamada lipídica: a cadeia truncada estaria exposta ao solvente [48] e o grupo carboxila com carga negativa [41] iria induzir a carga superficial. Seria um efeito semelhante ao reportado nas membranas de DPPG [162], mas de 
sentido contrário: naquele caso, havia LUVs de DPPG que se transformaram em MLVs pela blindagem de carga (efeito do sal), no nosso caso havia MLVs de POPC que se transformaram em LUVs pela indução de carga (efeito da presença da carboxila no meio aquoso).

Seguindo então para as análises dos valores obtidos para os parâmetros de Caillé ( $\left.\eta_{\text {Caille }}\right)$, pode-se observar que o POVPC causa maior flutuação na membrana (maior $\eta_{\text {Caille }}$ - fig. 5.31) nas mesmas concentrações do que o POPC-OOH, indicando que a cadeia truncada do POVPC deve induzir maior perturbação à bicamada lipídica.

Para quantificar este efeito, utilizamos a mesma análise descrita na Discussão I deste capítulo para calcular o módulo de curvatura $\left(K_{c}\right)$ para as amostras contendo POVPC a partir dos valores de $\eta_{\text {Caille }}$ e $D_{\text {rep }}$ obtidas nos ajustes. Os resultados estão na figura 5.32 e os valores de $K_{c}$ para o POPC-OOH foram reproduzidos para comparação.

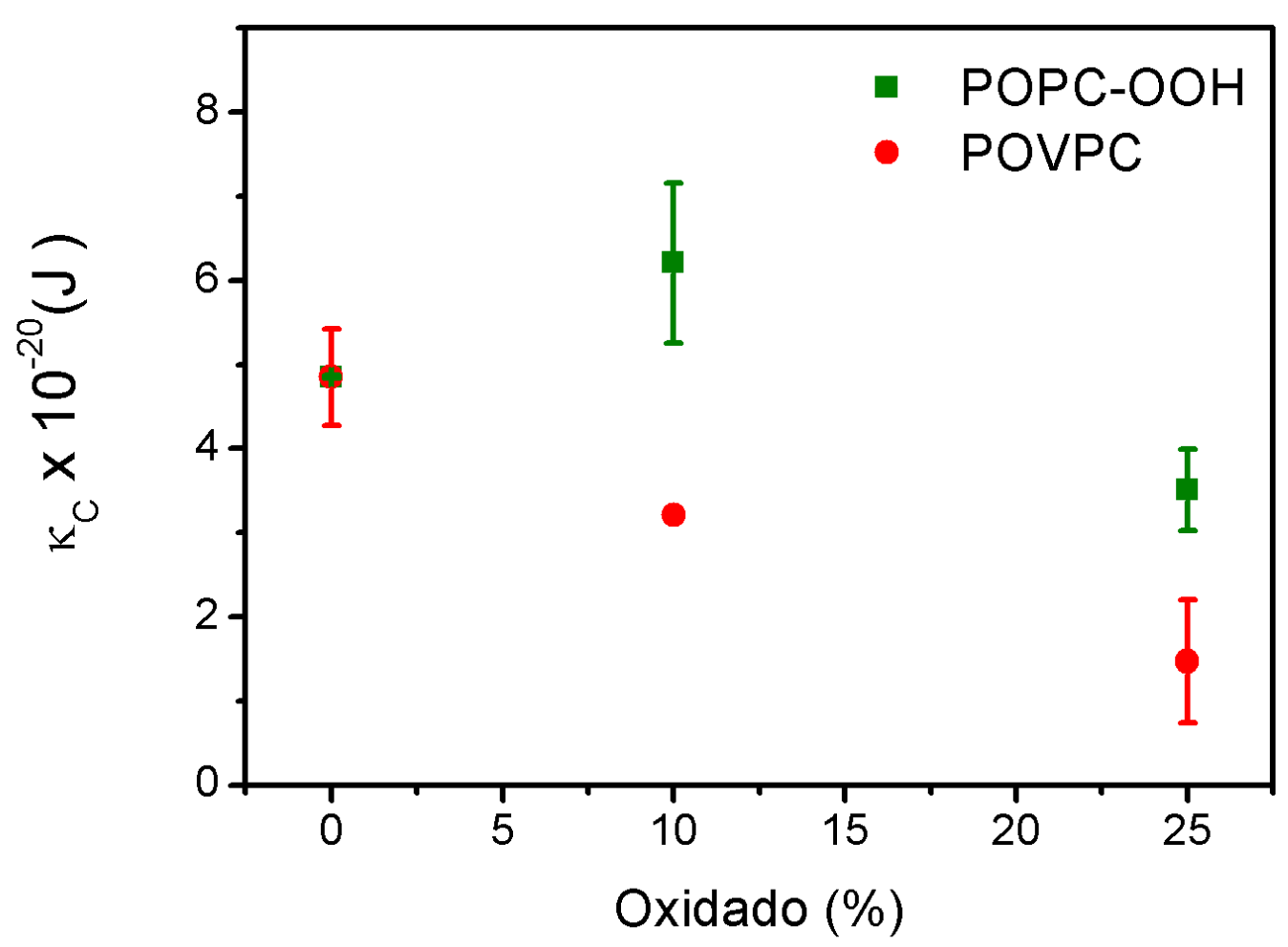

Figura 5.32: Valores calculados para o módulo de curvatura $K_{c}$ (em Joules) estimados a partir dos parâmetros de ajustes das curvas de SAXS para as amostras de POPC com o aumento da concentração de POPC-OOH e POVPC não extrusadas. As linhas são apenas guias para os olhos.

Pode-se observar a diminuição do $K_{c}$ com o aumento da concentração do POVPC (fig. 5.32). De maneira interessante, a diminuição de $K_{c}$ foi prevista por dinâmica molecular ao simular membranas de POPC:DPPC:SM (56:14:30) na ausência e presença de 10\% POVPC [169]. Os autores estimaram uma redução de $61 \%$, enquanto nós calculamos cerca de $66 \%$ de diminuição (fig. 5.32). 
Além disso, o impacto da presença do POVPC é maior no valor de $K_{c}$ de MLVs de POPC contendo $10 \%$ ou $25 \%$ deste lipídeo do que na presença de POPC-OOH. Mais que isso, com a introdução de $25 \%$ de POVPC o $K_{c}$ é de cerca de 1,47 x $10^{-20} \mathrm{~J}$ (fig. 5.32) que é compatível com o valor obtido na presença de 50\% - 70\% de POPC-OOH (fig. 5.22). Podemos sugerir então, que a presença de POVPC aumenta a flutuação da membrana de maneira mais expressiva do que a presença de POPC-OOH, provavelmente por sua cadeia ser truncada.

Por fim, em termos do efeito de temperatura, a introdução de PAZEPC promove relativa perturbação da bicamada lipídica sendo que o aumento da temperatura de $23^{\circ} \mathrm{C}$ para $37^{\circ} \mathrm{C}$ não causa um efeito expressivo na membrana (fig. 5.23). Já para o POVPC, o aumento da temperatura aumenta o parâmetro de Caillé (fig. 5.23) e diminui o valor de $K_{c}$ de membranas de POPC. 


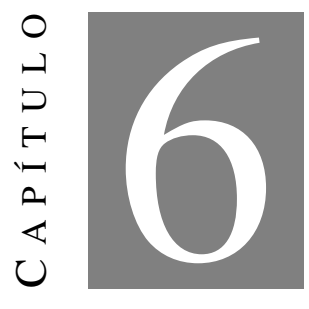

\section{INTERAÇÃO DO POLIPEPTÍdEO AMILÓIDE DAS}

\section{ILHOTAS HUMANO COM MEMBRANAS MODELO}

\section{CONTENDO LIPÍDEOS OXIDADOS}

\subsection{Introdução}

Para estudar a influência de lipídeos oxidados na indução de agregados proteicos tipo amilóides, escolhemos o polipeptídeo amilóide das ilhotas humano (IAPP) (também chamada de amilina) para interagir com as membranas modelos.

Este polipeptídeo possui 37-resíduos ( 3,9 kDa) e contém uma ligação de dissulfeto entre os resíduos de cisteína 2 e 7 (Figura 6.1) [170]. A estrutura cristalográfica do IAPP ainda não foi completamente resolvida. Em solução o IAPP possui uma estrutura predominantemente desordenada, com algumas estruturas em $\alpha$-hélice e folhas $\beta$; além disso, dependendo do $\mathrm{pH}$, este polipeptídeo pode conter 4 cargas positivas: N-terminal, K1, R11 e H18 [170, 171].

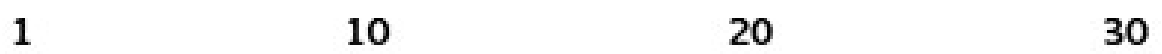

hIAPP

KCNTATCATQRLANFLVHSSNNFGA I LSSTNVGSNTY

Figura 6.1: Sequência de aminoácidos do polipeptídeo IAPP [170]

O IAPP é secretado, juntamente com a insulina (1:10 - IAPP:insulina), pelas células $\beta$ presentes nas ilhas de Langerhans, que são grupos de células circundadas por vasos sanguíneos localizadas no pâncreas [170, 171]. As funções da IAPP ainda não foram totalmente elucidadas, mas já é conhecido que ele participa do metabolismo de carboidrato, modulação da secreção de 
insulina e da secreção da bile, é inibidor de perda de minerais do osso e participa da regulação do apetite [170].

Apesar de possuir funções orgânicas, o IAPP pode ter um efeito tóxico quando forma as fibras amilóides e se deposita sobre as células $\beta$ pancreáticas [170]. Este acúmulo de fibras é considerado como o causador da doença diabetes mellitus tipo II (DM2), visto que tal polipeptídeo é o principal constituinte dos depósitos amilóides extracelulares observados em até $95 \%$ dos doentes com DM2 [171, 172]. Esta é caracterizada pela produção insuficiente de insulina ou pelo organismo se tornar resistente a mesma [26]. A insulina é responsável, entre outras coisas, pelo transporte de glicose para o meio intracelular. Portanto, as células dos portadores dessa doença não absorvem as quantidades necessárias de glicose, que é a principal fonte de energia para muitos tipos celulares [173]. A falta de glicose no meio intracelular, ou por outro lado, o excesso de glicose no sangue, pode ter consequências na saúde das pessoas que possuem DM2, como causar hipertensão, aumentar os riscos de ataques cardíacos e debilitar o indivíduo $[26,174]$.

Por outro lado, os depósitos amilóides de ex vivo com DM2 também apresentam lipídeos incorporados às fibras [171]. In vitro, este efeito foi identificado ao estudar a formação de fibras amiloides de IAPP em GUVs de DOPC e em células naturais (células pancreáticas de rato com insulinoma) por microscopia de fluorescência confocal [173]. No estudo com membranas modelo e naturais foi possível determinar que os lipídeos da membrana e o IAPP estavam co-localizados, sendo a fibra formada por ambos [173]. Outros estudos mostraram, através de transferência de energia por ressonância de Förster (FRET), que o IAPP ao formar fibras amiloides na presença de bicamadas lipídicas suportadas (SLB) se liga aos lipídeos da SLB [171]. Além disso, experimentos de crio-microscopia eletrônica de transmissão (Crio-TEM) [172] e de microscopia eletrônica de transmissão [175] mostraram que as fibras amilóides do IAPP estão entrelaçadas com LUVs de diferentes composições lipídicas (contendo os lipídeos DOPC, DOPS, DOPG, DOPE, DMPC, DPPC, POPC, colesterol e esfingomielina) podendo causar a ruptura das membranas $[172,175]$. Desta maneira, foi observado que a fibrilação do IAPP pode extrair os lipídeos da membrana, formando um único agregado [171-173, 175].

Uma consequência direta da extração de lipídeos da bicamada lipídica é a perda de integridade da membrana levando ao vazamento, seguido de destruição da mesma $[171,173]$. Este efeito também foi relatado para o peptídeo $\mathrm{A} \beta$ (responsável pela doença de Alzheimer quando forma amilóide) quando é adicionado à uma solução contendo GUVs, e para outras proteínas que formam fibras, sugerindo que este processo seja, talvez, genérico para as proteínas amiloidogênicas [176].

A perda de integridade da membrana lipídica causada pela presença do IAPP também foi observado por diversos estudos de vazamento da sonda fluorescente carboxifluoresceína previamente incubadas em LUVs de diferentes composições lipídicas contendo diferentes percentuais 
de lipídeos neutros (DOPC, POPC) e aniônicos (DOPG e POPS) e diferentes concentrações do polipeptídeo [177, 178]. Entretanto, ao substituir a carboxifluoresceína pela sonda fluorescente FITC-dextran com diferentes massas moleculares (4,1; 9,4; 65,6 e 154,9 kDa) foi observado que o vazamento causado pela presença do IAPP é inversamente proporcional à massa molecular da sonda [177]. Com isso, conclui-se que o IAPP não causa a completa destruição da membrana, mas a formação de poros na bicamada lipídica [177].

Nesta mesma direção, outros artigos mostraram que o IAPP não extrai os lipídeos da membrana, mas induz a formação de poros estáveis, levando apenas a um aumento de permeabilidade da mesma [170, 172, 179, 180]. Estudos utilizando LUVs (DOPC:DOPS - 7:3) mostraram que o IAPP, durante o processo fibrilar, forma oligômeros intermediários que interagem com a membrana formando canais iônicos estáveis e poros não específicos que podem chegar ao tamanho de uma calceina (600 Da) [172, 180]. Os canais iônicos formados não possuem seletividade, visto que íons de $\mathrm{Na}^{+}, \mathrm{K}^{+}, \mathrm{Ca}^{+}$e $\mathrm{Cl}^{-}$podem atravessá-los [170]. É interessante acrescentar que a formação de poros na membrana não está relacionada com a fibra madura ou com o monômero de IAPP, pois alguns artigos mostraram que as perturbações na membrana não acontecem na presença do monômero e diminuem à medida que surge a fibra madura [179]. Portanto, as espécies intermediárias na formação amilóide (protofibras) ou o próprio crescimento da fibra seriam os causadores de modificações na membrana [179]. Ao mesmo tempo, experimentos de Crio-TEM mostraram que LUVs (DOPC:DOPS - 7:3) em contato com a fibra madura de IAPP sofrem distorções em sua forma, tendo sido sugerido que a fibra madura tenha alguma importância na perda da homeostase celular in vivo [172].

Como exposto acima, ainda não há um consenso sobre o impacto da agregação do IAPP na estrutura de bicamadas lipídicas e tampouco quais oligômeros (intermediários ou fibra madura), são tóxicos à membrana. Os efeitos descritos aconteceram para diferentes tempos de incubação do polipeptídeo com as membranas, desde 5 minutos até 48 horas, e cada um destes tempos corresponde a um diferente estágio no processo de fibrilação do IAPP [20, 30, 170, 172, 178].

A cinética de agregação do IAPP é extremamente sensível às condições experimentais de pH, tampão, concentração de sal, concentração e composição lipídica dos lipossomos [181]. Por exemplo, a cinética de agregação de uma solução de $4 \mu \mathrm{M}$ de IAPP dissolvida em tampão de $50 \mu \mathrm{M}$ Tris- $\mathrm{HCl}, 150 \mu \mathrm{M}$ de $\mathrm{NaCl}$ a $\mathrm{pH} 7,6$ a $37^{\circ} \mathrm{C}$ indica que o tempo para atingir $50 \%$ da intensidade máxima de Th $\mathrm{T}\left(T_{50 \%}\right)$ é da ordem de 5 minutos [182], enquanto que $20 \mu \mathrm{M}$ do mesmo polipeptídeo demora aproximadamente 42 horas para atingir $T_{50 \%}$, quando disperso em tampão de $20 \mathrm{mM}$ Tris, $100 \mathrm{mM} \mathrm{NaCl}$ a pH 7,4 a $25^{\circ} \mathrm{C}$ [177].

No caso da influência de lipossomos na fibrilação do IAPP, há um consenso na literatura indicando que a presença de lipossomos induz a aceleração da formação de agregados do polipeptídeo [177, 178, 183]. Desta maneira, sugere-se que a membrana lipídica sirva de catalisadora do processo de nucleação do IAPP por oferecer uma superfície de ligação para os 
monômeros do polipeptídeo, onde o aumento da concentração local desencadearia a fibrilação $[180,181]$. De fato, simulações computacionais indicaram que o monômero do IAPP se liga à superfície de membranas de DPPG e DPPC:DPPG (7:3) penetrando até 1,62 nm [184].

Além disso, ao introduzir lipídeos aniônicos (POPS ou DOPG) em membranas compostas pelos lipídeos zwiteriônicos (POPC ou DOPC) o efeito de aceleração é ainda mais pronunciado e apresenta clara dependência em função da concentração dos lipídeos carregados [177, 178, 183, 185, 186]. Em soluções de $20 \mu \mathrm{M}$ de IAPP na presença de $400 \mu \mathrm{M}$ de lipossomos de DOPC a $25{ }^{\circ} \mathrm{C}$, o lag time é de cerca de 30 horas enquanto que para as mesmas condições experimentais e com a presença de 50\% DOPG (DOPC:DOPG - 50:50) o mesmo parâmetro diminui para aproximadamente 2 horas [177]. Isto é, o tempo para formar os primeiros núcleos de agregação é reduzido em 15 vezes na presença do lipídeo negativamente carregado [177]. Esta aceleração do processo de fibrilação é consequencia do aumento das interações eletrostáticas entre os monômeros de IAPP (positivo) com a membrana (negativa), resultando no aumento da concentração local de monômeros na superfície da membrana num menor tempo [177, 178, 180, 186].

Outros estudos interessantes mostraram que lipossomos formados por lipídeos extraídos de células $\beta$ de pâncreas de ratos são ainda mais eficientes em induzir a fibrilação do IAPP do que a adição de lipídeos aniônicos à membrana [185]. Estas células, in vivo, são danificadas pela formação das fibras amilóides do IAPP, sendo correlacionadas à diabetes tipo II [185]. Cabe acrescentar que estas células são compostas por diferentes tipos de lipídeos sendo 70\% PC, 20\% PE, 5\% de esfingomielina e o restante de PI, PS, PA e PG como determinado por espectroscopia de massa [185].

Por outro lado, a adição de insulina na solução de $10 \mu \mathrm{M}$ de IAPP $(100 \mathrm{mM} \mathrm{KCl}$ e 50 mM de fosfato a $\mathrm{pH} 7,4$ ) na presença de $1,3 \mathrm{mM}$ de lipossomos de DOPG desacelera a fibrilação do polipeptídeo para a razão molar 1:1 (insulina:IAPP) e quase impede a formação de agregados para a razão molar 10:1 [187]. Este resultado pode indicar a importância da manutenção da secreção normal de insulina-IAPP pelas células $\beta$ (10:1) para evitar a formação de fibras amilóides do IAPP e, possivelmente, evitar o surgimento da DM2 [187].

Em suma, como exposto acima, a membrana pode agir como um catalisadora da formação fibrilar do IAPP e simultaneamente ser alvo destes agregados. As membranas contendo lipídeo aniônico aceleram este processo de agregação. Neste trabalho, utilizamos inicialmente membranas compostas por POPS para investigar o impacto da presença de diferentes concentrações lipídicas na fibrilação do IAPP.

Mais que isso, é importante mimetizar sistemas biológicos relevantes para poder correlacionar os resultados de fibrilação do IAPP com efeitos in vivo [185, 187]. Para isso, realizamos experimentos de formação amiloide do IAPP na presença de lipossomos contendo lipídeos oxidados, que ocorrem naturalmente in vivo, atráves do estresse oxidativo. Ainda, o IAPP 
está relacionado à DM2, sendo o envelhecimento um fator de risco que pode estar também relacionado ao processo de oxidação lipídica. 


\subsection{Materiais e Métodos}

A preparação das vesículas grandes (LUVs) foi realizada de maneira semelhante à descrição do item 4.1.1 com pequenas modificações: a concentração lipídica utilizada variou entre 0,1 $\mathrm{mM}$ a $5 \mathrm{mM}$ para se obter diferentes razões molares de lipídeo:IAPP. O tampão utilizado foi HEPES-KOH $20 \mathrm{mM}$, EDTA $1 \mathrm{mM} \mathrm{pH} \mathrm{7,4} \mathrm{e} \mathrm{todas} \mathrm{as} \mathrm{amostras} \mathrm{foram} \mathrm{medidas} \mathrm{a} 25^{\circ} \mathrm{C}$. Em adição aos lipídeos oxidados utilizados nos capítulos anteriores, também se utilizou o lipídeo negativamente carregado POPS (1-palmitoil-2-oleoil-sn-glicerol-3-fosfoserina) adquirido comercialmente na empresa Avanti Lipids. O polipeptídeo das ilhotas humando (IAPP) utilizado foi sintetizado pela empresa Bachem. Para a solubilização do IAPP, utilizou-se o solvente HFIP (1,1,1,3,3,3-Hexafluoro-2-propanol-d2).

As vesículas lipídicas foram extrusadas por membrana com poro de $1 \mu \mathrm{m}$ (extrusor Avanti - mesmo utilizado nos caps. anteriores) para obtenção de LUVs. As composições lipídicas preparadas foram de $100 \%$ POPS com concentração entre $0,1 \mathrm{mM}$ e $5 \mathrm{mM}$; $100 \%$ POPC, 7:3 POPC:POPC-OOH e 100\% POPC-OOH com concentração de 0,1 mM e 0,5 mM.

Cabe acrescentar que também fizemos experimentos de interação do IAPP com membranas lipídicas contendo $10 \%$ e $25 \%$ de PAZEPC ou POVPC. Os resultados foram completamente não usuais. Portanto, não serão apresentados aqui, pois mais estudos devem ser realizados no futuro para melhor entendimento.

\subsubsection{Preparação do IAPP}

Soluções estoques de IAPP foram preparadas ao se dissolver $1 \mathrm{mg}$ do polipeptídeo sintético em $250 \mu \mathrm{L}$ de HFIP para se obter a concentração aproximada de 1,025 mM IAPP. Na sequência, $3 \mu \mathrm{L}$ desta solução foram adicionados em eppendorfs (Eppendorf® LoBind - para diminuir a ligação do IAPP com o recipiente) e se utilizou gás nitrogênio comprimido para purgar a solução até a obtenção de um filme na parede do eppendorf.

Em seguida, um volume apropriado de solução tampão foi adicionada ao filme de IAPP no eppendorf que foi sonicada por aproximadamente 1 minuto em banho ultrassônico para garantir a solubilização do polipeptídeo.

A concentração final de IAPP utilizada nas medidas de cinética de fluorescência de Tioflavina $\mathrm{T}$ (Th $\mathrm{T}$ ) foi de $10 \mu \mathrm{M}$ e de $\mathrm{Th} \mathrm{T}$ foi de $30 \mu \mathrm{M}$ (preparada no mesmo tampão).

\subsubsection{Medidas de cinética de fluorescência de $\mathbf{T h} \mathbf{T}$}

Para acompanhar a cinética de fibrilação do IAPP utilizou-se um leitor de micro-placa POLARstar OPTIMA (BMG Labtech) em placas de 96 poços Greiner F-Bottom. Isto possibilitou medir a cinética de fluorescência de Th $\mathrm{T}$ de múltiplas amostras simultaneamente. Foram 
realizadas medidas a cada 600 segundos, com leitura efetuadas pelo fundo da placa, 30 medidas por ciclo e média orbital com raio de $4 \mathrm{~mm}$. Antes de todo ciclo de medidas utilizou-se um agitador orbital com $100 \mathrm{rpm}$. O comprimento de onda de excitação foi de $\lambda=440(10) \mathrm{nm}$ e emissão com $\lambda=480(10) \mathrm{nm}$.

Todos os experimentos foram realizados em triplicatas e com amostras de controle: Th $\mathrm{T}$ livre em solução, IAPP na ausência de Th T e lipossomos na presença de Th $\mathrm{T}$ e ausência do IAPP.

\subsection{Resultados e Discussão}

Com intuito de acompanhar a cinética de fibrilação do IAPP em função do tempo e na ausência e na presença de lipossomos, mediu-se a evolução temporal da intensidade de fluorescência de Th T de $10 \mu \mathrm{M}$ de IAPP em solução e na presença de $0,1 \mu \mathrm{M}, 0,5 \mu \mathrm{M}, 1000 \mu \mathrm{M}, 2000$ $\mu \mathrm{M}$ e $5000 \mu \mathrm{M}$ de lipossomos extrusados de POPS. A figura 6.2 apresenta os resultados para as triplicatas destas 6 amostras, bem como as curvas experimentais obtidas para os diferentes controles. 

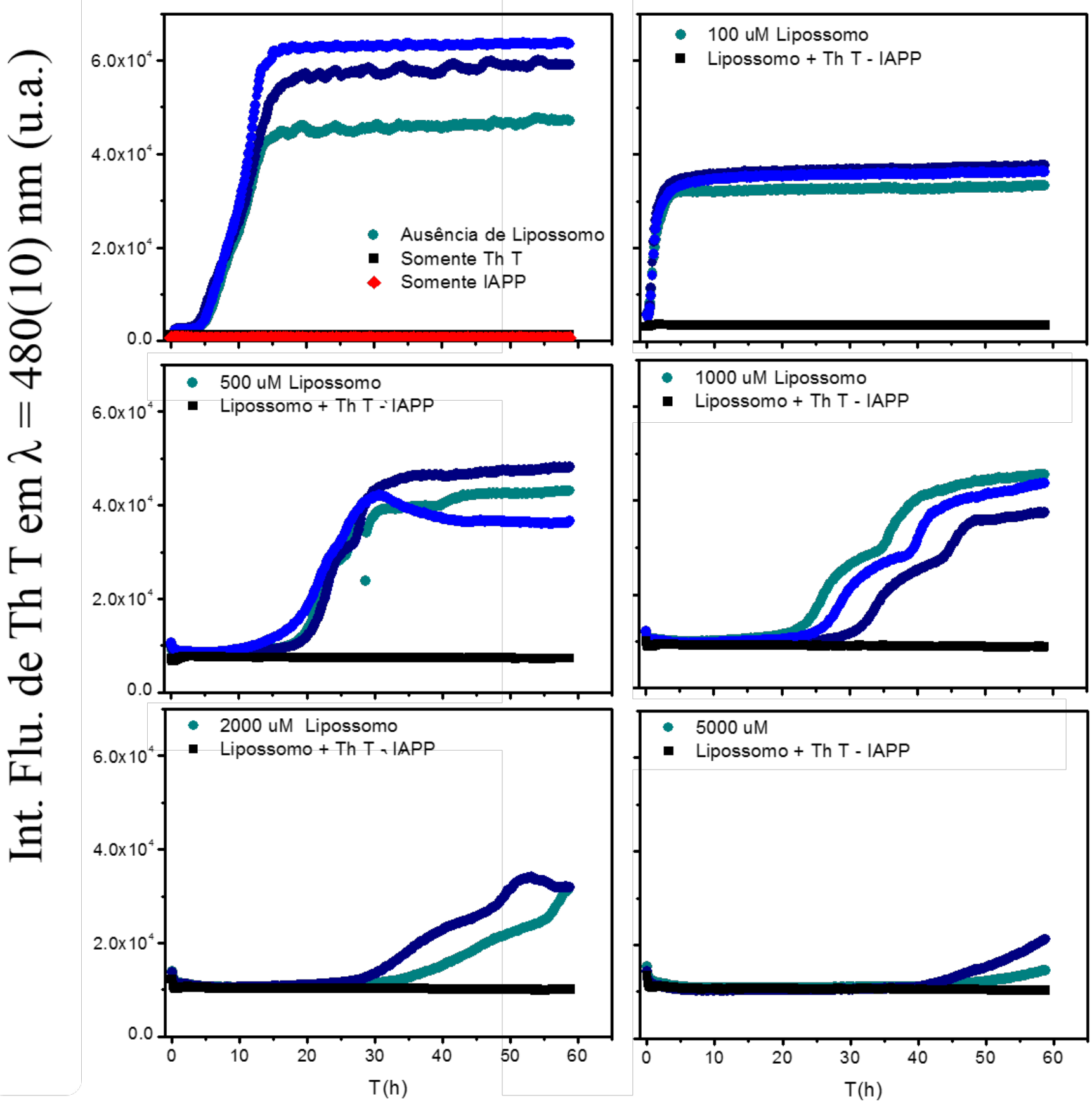

Figura 6.2: Curvas de intensidade de fluorescência de Th T $(30 \mu \mathrm{M})$ para amostras de $10 \mu \mathrm{M}$ de IAPP em $20 \mathrm{mM}$ HEPES-KOH, $1 \mathrm{mM}$ EDTA em pH 7,4 a $25^{\circ} \mathrm{C}$ na ausência de lipossomos (painel superior - esquerda) e presença de diferentes concentrações de lipossomos de POPS: dados experimentais para as triplicatas independentes (círculos em tons de azul), controles contendo apenas o lipossomo na presença de Th T (quadrados pretos, controle contendo apenas Th T disperso no tampão (quadrados pretos, painel superior - esquerda) e controle contendo apenas IAPP (losango vermelho, painel superior - esquerda).

Pode-se observar na figura 6.2 que há o aumento da intensidade de fluorescência de Th T em função do tempo em todos os casos, indicando a formação de estrutura secundária de folhas 
$\beta$ do IAPP que podem ser entendidas como formação de fibras amilóides $[177,178,186]$. Além disso, para as amostras contendo $2000 \mu \mathrm{M}$ e $5000 \mu \mathrm{M}$ de POPS (painel inferior) a cinética de agregação do IAPP é lenta e a fluorescência de Th T não atinge a saturação até 60 horas de observação.

Para comparar o impacto da presença dos lipossomos compostos por POPS, bem como a influência de sua concentração na fibrilação do IAPP, calculamos a média entres as triplicatas apresentadas na figura 6.2, normalizamos à unidade e avaliamos a incerteza experimental como sendo o valor máximo e mínimo de intensidade de Th T em cada tempo. Os resultados estão na figura 6.3. As curvas para $2000 \mu \mathrm{M}$ e $5000 \mu \mathrm{M}$ não foram incluídas nesta análise pois o IAPP não completou a fibrilação na escala de tempo de nossos experimentos.

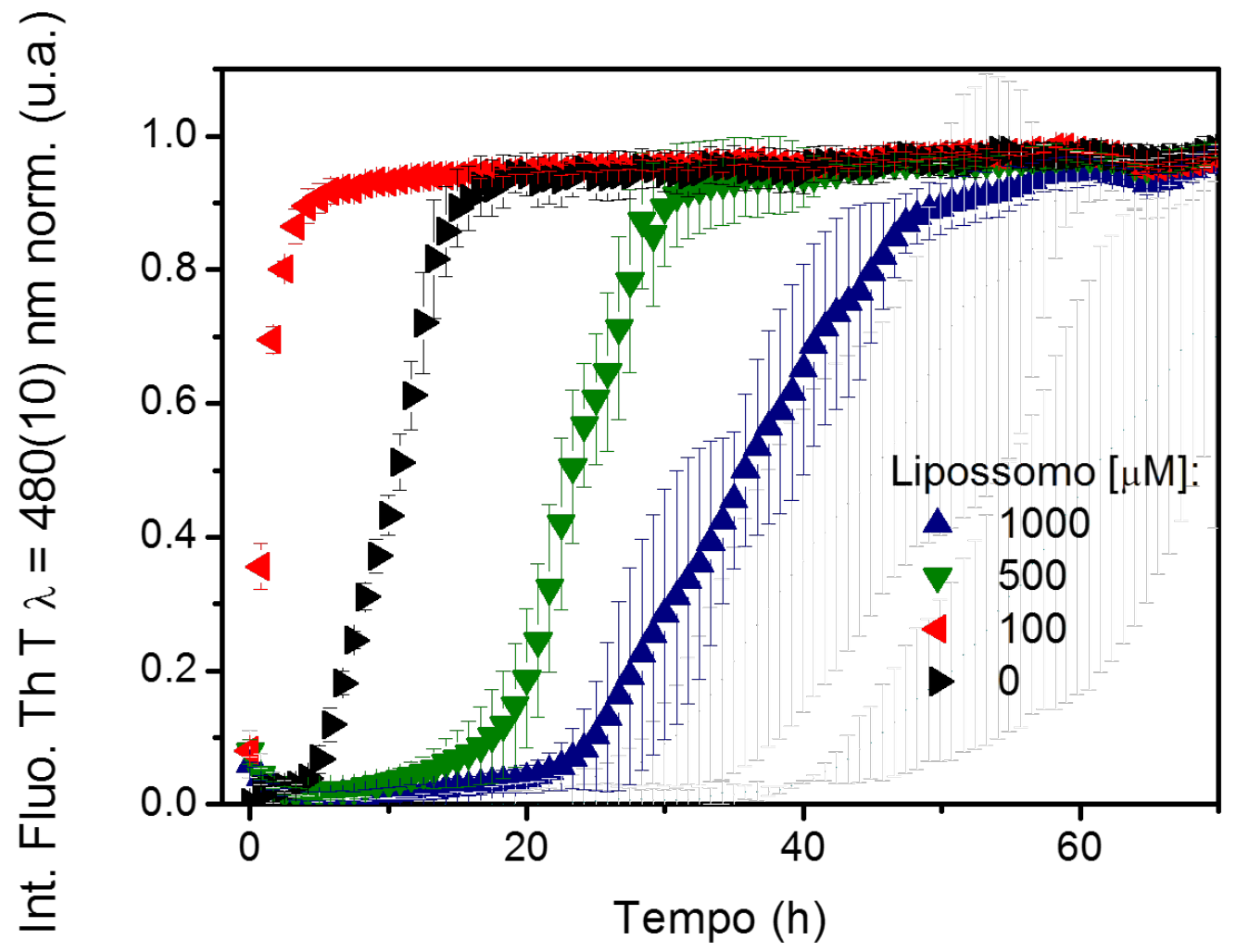

Figura 6.3: Curvas de intensidade de fluorescência de Th T $(30 \mu \mathrm{M})$ para amostras de $10 \mu \mathrm{M}$ de IAPP em $20 \mathrm{mM}$ HEPES-KOH, $1 \mathrm{mM}$ EDTA em pH 7,4 a $25^{\circ} \mathrm{C}$ na ausência de lipossomos (preto) e presença de diferentes concentrações de lipossomos de POPS: $100 \mu \mathrm{M}$ (vermelho), 500 $\mu \mathrm{M}$ (verde) e $1000 \mu \mathrm{M}$ (azul). As curvas representam as médias das triplicatas obtidas na figura 6.2 .

Ao apreciar a figura 6.3 nota-se que o aumento de fluorescência de Th T acontece mais rapidamente na presença de $100 \mu \mathrm{M}$ (vermelho) de lipossomos de POPS ao se comparar com o IAPP em solução (preto). Por outro lado, demora-se mais tempo para observar este aumento de intensidade de fluorescência com o aumento da concentração de lipossomos para $500 \mu \mathrm{M}$ (verde) 
e $1000 \mu \mathrm{M}$ (azul), respectivamente. Vale a pena ressaltar que nestes dois casos, o tempo para atingir a saturação de fluorescência é maior do que no caso do IAPP em solução.

Portanto, temos a clara indicação de que o processo de fibrilação do IAPP é acelerado na presença de $100 \mu \mathrm{M}$ de POPS e desacelerado na presença de $500 \mu \mathrm{M}$ e $1000 \mu \mathrm{M}$ em relação ao IAPP em solução (fig. 6.3).

Para quantificar este efeito, realizamos ajustes das curvas de cinética de agregação do Th $\mathrm{T}$ (fig 6.3) utilizando o modelo sigmoidal descrito anteriormente (eq. 1.1 - Introdução). Assim, calculamos o tempo necessário para atingir 50\% da intensidade de fluorescência máxima de Th $\mathrm{T}\left(T_{50 \%}\right)$, o valor do lag time e a constante de crescimento aparente da fibra $(\kappa)$ :

\begin{tabular}{cccc}
{$[\mu \mathrm{M}]$} & $T_{50 \%}(\mathrm{~h})$ & lag time $(\mathrm{h})$ & $\kappa\left(\mathrm{h}^{-1}\right)$ \\
\hline \multicolumn{1}{c}{0} & $10,3(3)$ & $5,7(7)$ & $0,45(3)$ \\
$\frac{100}{500}$ & $1,6(2)$ & - & $0,76(2)$ \\
\cline { 1 - 1 } & $23(2)$ & $18(2)$ & $0,39(4)$ \\
\hline
\end{tabular}

Tabela 6.1: Parâmetros cinéticos obtidos para a fibrilação do IAPP na ausência e na presença de diferentes concentrações de POPS a partir da análise das curvas de intensidade de Th T apresentadas na figura 6.3. Utilizou-se o modelo sigmoidal apresentado em 1 (fig. 1.3 e eq. 1.1).

O $T_{50 \%}$ aumentou seguindo a ordem 100, 0, 500 e $1000 \mu \mathrm{M}$ de lipossomos de POPS, como pode ser observado na figura 6.3, mas este parâmetro contém a contribuição do lag time e do $\kappa$. Analisando cada um destes parâmetros individualmente, nota-se que o IAPP em solução demora cerca de 6 horas para formar os primeiros núcleos de agregados para iniciar a fase de formação de fibra [20] e este tempo é cerca de 4 vezes maior na presença de $500 \mu \mathrm{M}$ e 5 vezes maior 1000 $\mu \mathrm{M}$ de lipossomo de POPS. Interessante notar que na presença de $100 \mu \mathrm{M}$ não se observou o lag time.

Além disso, a $\kappa$ de fibrilação do IAPP é de $0,76(2) \mathrm{h}^{-1}$ na presença de $100 \mu \mathrm{M}$ de lipossomo o que significa uma velocidade de formação de fibra $70 \%$ maior do que o IAPP em solução. Cabe acrescentar que apesar do maior tempo para o início da fibrilação do IAPP na presença de 500 $\mu \mathrm{M}$ de lipossomo, a $\kappa$ para esta amostra é similar à do IAPP em solução. Com esta observação, pode-se sugerir que a velocidade de formação da fibra, após a formação do núcleo de agregação, é similar entre o IAPP em solução e na presença de $500 \mu \mathrm{M}$ de lipossomo.

Em suma, nossos resultados podem ser indicam que (i) a presença de $100 \mu \mathrm{M}$ de lipossomos de $100 \%$ POPS acelera a fibrilação do IAPP, enquanto que (ii) o aumento da concentração de lipossomo desacelera.

A primeira indicação (i) está em bom acordo com resultados anteriores que mostraram que com lipossomos contendo lipídeo aniônico há aumento da velocidade da formação de fibras 
amilóides do IAPP $[177,178,183,186]$. Por exemplo, o $T_{50 \%}$ foi reduzido em cerca de 20 vezes na presença de lipossomos compostos por POPC:POPS (50:50) [177]. Vale a pena notar que este aumento da velocidade de formação da fibra é proporcional à quantidade lipídeo aniônico nos lipossomos [177, 178, 183, 186], evidenciando que este efeito acontece devido à interação eletrostática entre o IAPP (positivamente carregado) com o lipídeo negativo [177, 178, 183, 186].

Esta conclusão foi obtida em diversos trabalhos ao se comparar a velocidade de agregação do IAPP na presença de vesículas neutras (POPC ou DOPC) contendo diferentes concentrações de lipídeos aniônicos (POPS ou DOPG) [177, 178, 183, 186]. Outra observação experimental importante para esta conclusão foi obtida ao se comparar a interação do IAPP com membranas negativamente carregadas dispersas em tampão de $10 \mathrm{mM}$ de fosfato a $\mathrm{pH}$ 7,0 na presença e ausência de $100 \mathrm{mM}$ da $\mathrm{NaCl}[170,177]$. Com a adição de $\mathrm{NaCl}$, a velocidade de formação de agregados fibrilares de IAPP induzidos pela presença dos lipossomos se tornou mais lenta $[170,177]$. Portanto, conclui-se que o sal blinda as cargas dos lipídeos negativamente carregados, reduzindo assim a interação eletrostática com o IAPP, acarretando na diminuição da velocidade de fibrilação [170, 177].

A segunda indicação (ii) de nossos experimentos também está em acordo com resultados da literatura onde se evidenciou que a formação de agregados do IAPP, na presença de lipossomos, acontece na superfície da membrana lipídica $[175,180,181]$. Primeiramente, há a ligação do monômero do IAPP na superfície da membrana [184], seguido do enovelamento da proteína para uma conformação rica em $\alpha$ hélice [175, 180] (ou não [181]). Após, outros monômeros se agregam à estes primeiros e o oligômero formado passa por outra mundança de estrutura secundária rica em folhas $\beta$ acarretando na formação da fibra amiloide $[175,180,181]$. Assim, caso haja muita área superficial de membrana disponível para o IAPP se ligar, a probabilidade dos monômeros se ligarem à mesma região da membrana será menor acarretando na diminuição da velocidade da formação da fibra. De fato, este efeito foi determinado experimentalmente $[175,180,181]$ onde houve a diminuição da velocidade de fibrilação de $20 \mu \mathrm{M}$ de IAPP com o aumento da concentração de lipossomos de 100\% DOPG (até $8000 \mu \mathrm{M}$ ) [180]. Neste mesmo estudo, se quantificou a diminuição de monômeros de IAPP por lipídeo que estavam ligados aos lipossomos em função do aumento da concentração lipídica [180].

Portanto, nossos resultados estão de acordo com os dados da literatura. Sendo assim, preparamos vesículas nas concentrações de 100 e $500 \mu \mathrm{M}$ (melhores resultados obtidos para o POPS) de POPC contendo 10\% e 25\% dos lipídeos oxidados POPC-OOH, PAZEPC e POVPC e também vesículas de $100 \%$ POPC-OOH. No entanto, nossos resultados não foram reprodutíveis e apresentamos apenas alguns exemplos a seguir.

A figura 6.4 apresenta os resultados obtidos para o IAPP na ausência (preto) e na presença de lipossomos de POPC (vermelho), POPC:POPC-OOH (7:3 - azul) e POPC-OOH (verde) nas concentrações de $100 \mu \mathrm{M}$ (painel superior) e $500 \mu \mathrm{M}$ (painel inferior) para medidas realizadas 
em duas semanas distintas. Os resultados representam as médias de três triplicatas e estão normalizados (mesmo procedimento para obter a fig. 6.3)
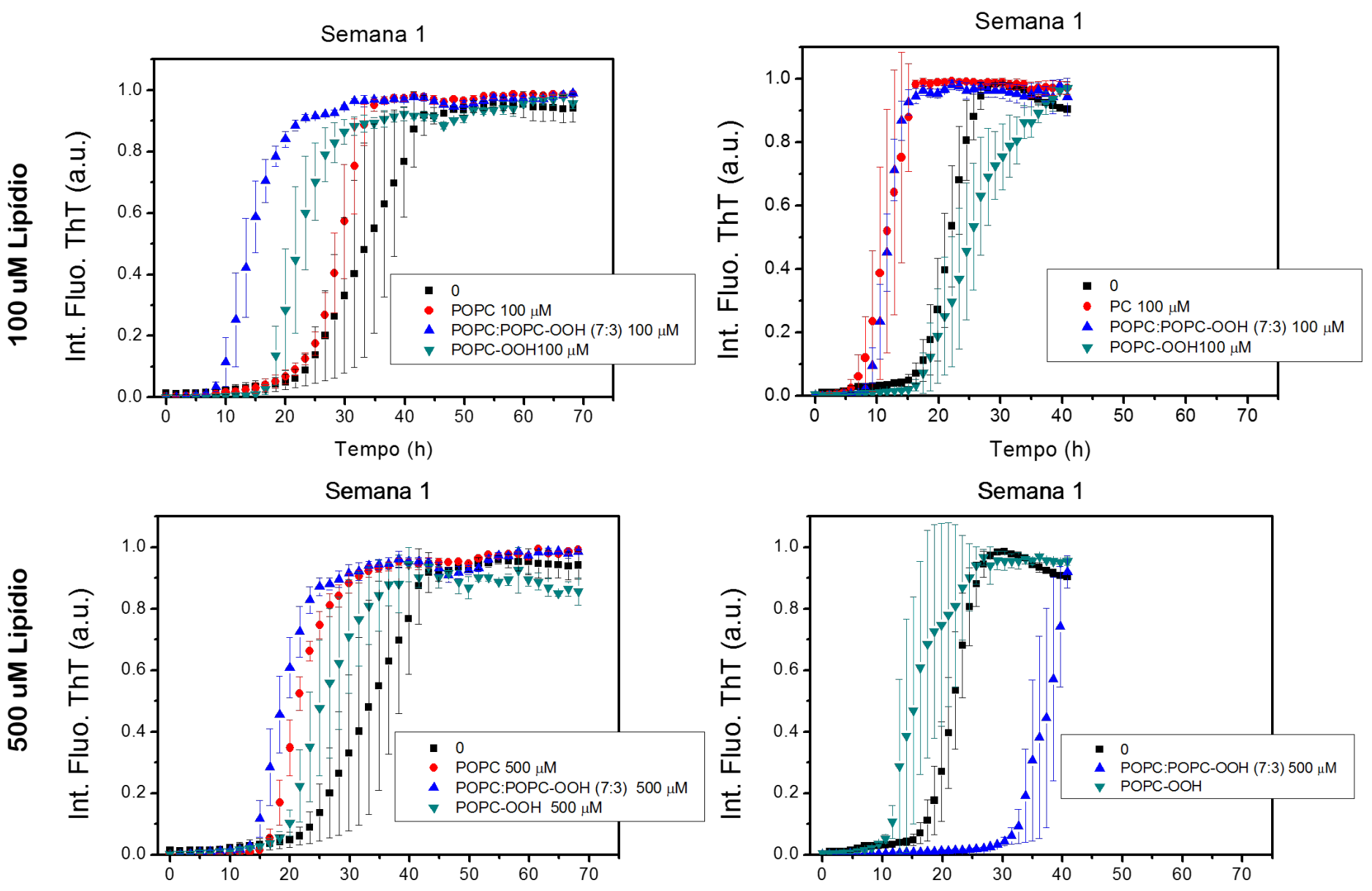

Figura 6.4: Curvas de intensidade de fluorescência de Th T $(30 \mu \mathrm{M})$ para amostras de $10 \mu \mathrm{M}$ de IAPP em $20 \mathrm{mM}$ HEPES-KOH, $1 \mathrm{mM}$ EDTA em pH 7,4 a $25^{\circ} \mathrm{C}$ na ausência de lipossomo (preto) e presença de $100 \mu \mathrm{M}$ (painel superior) e $500 \mu \mathrm{M}$ (painel inferior) de lipossomos de POPC (vermelho), POPC:POPC-OOH (7:3) (azul) e POPC-OOH (verde) em duas semanas distintas (esquerda e direita). As curvas representam as médias das triplicatas independentes.

Brevemente, nota-se que a cinética de fibrilação observada pela fluorescência de Th $\mathrm{T}$ para a amostra de POPC:POPC-OOH (7:3) na concentração de $100 \mu \mathrm{M}$ aparentemente foi reprodutível nestes dois experimentos (painel superior). No entanto, as curvas de intensidade de fluorescência de Th T para as outras três amostras na mesma concentração de lipídeo e na ausência de lipossomos não foram reprodutíveis. Este efeito é mais claro ainda nas curvas de

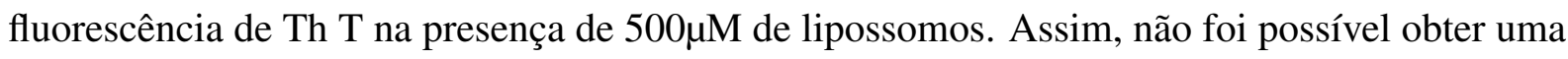
conclusão sobre o impacto da presença dos lipídeos oxidados na fibrilação do IAPP.

Para investigar mais profundamente esta falta de reprodutibilidade, elaboramos a figura 6.5 com as curvas de Th T para as amostras de IAPP em solução obtidas em diferentes dias. 


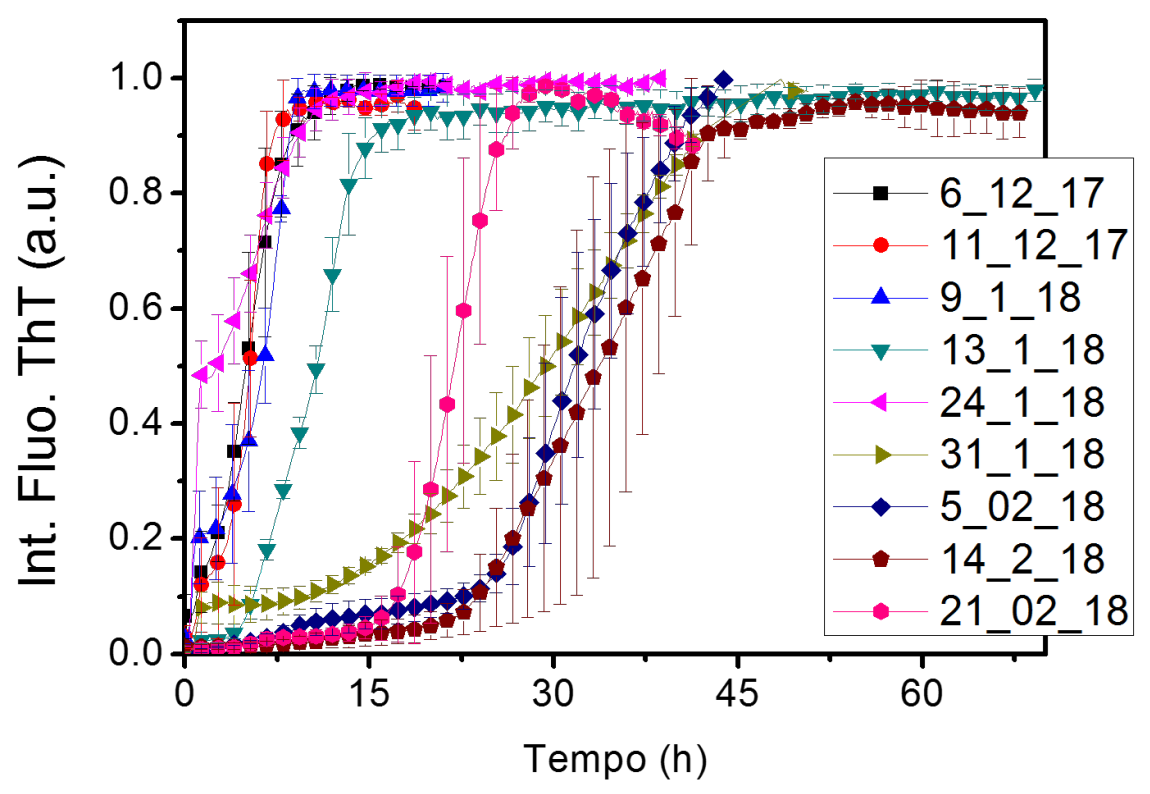

Figura 6.5: Curvas de intensidade de fluorescência de Th $\mathrm{T}(30 \mu \mathrm{M})$ para amostras de $10 \mu \mathrm{M}$ de IAPP em 20 mM HEPES-KOH, 1 mM EDTA em pH 7,4 a $25^{\circ} \mathrm{C}$ obtidas em dias diferentes como indicado na legenda.

A grande variabilidade das curvas de cinética obtidas por fluorescência de Th $\mathrm{T}$ para o IAPP em solução é evidente. Os motivos para tal variabilidade dos resultados ainda estão sendo estudados, mas já é conhecido que a cinética de fibrilação do IAPP é muito sensível a pequenas variações de condições experimentais [177, 181].

Como perspectiva, estudaremos a cinética de fibrilação de IAPP de rato com membranas oxidadas. Ressaltamos que experimentos preliminares mostraram que os resultados de fluorescência de Th T são mais reprodutíveis. 


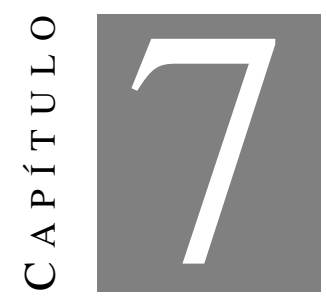

\section{CONCLUSÃo}

Seguem-se as principais conclusões desta tese de doutoramento:

\section{Captítulo 3:}

- A solução de proteína BSA a pH 3,7 apresenta coexistência entre uma isoforma parcialmente desenovelada (MD) e um dímero simétrico obtido pela associação daquele monômero, como analisado por SAXS.

- A adição de SDS e SPFO induz a formação de agregados de BSA em função da concentração do surfactante, como observado por SAXS, SEM e turbidez, que podem atingir dimensões micrométricas. Na presença de SDS, estes agregados são maiores.

- Os agregados de BSA induzidos por SPFO são mais ordenados, com indicação de maior quantidade de folhas $\beta$ do que os induzidos por SDS, como analisado por fluorescência de Th T e SRCD.

- Apesar da interação eletrostática e hidrofóbica terem um papel importante na formação de agregados proteícos de BSA, estas duas não são suficientes para determinar o tipo do agregado formado, visto que os dois surfactantes possuem a mesma carga e similar hidrofobicidade e os agregados induzidos por cada surfactantes são distintos.

- Propomos que, por ser mais volumoso e mais rígido, o SPFO induz a formação de agregados menores e mais ordenados de BSA a pH 3,7, enquanto o SDS, mais flexível, tende a induzir a formação de agregados maiores e menos ordenados. 


\section{Capítulos combinados 4 e 5:}

\section{Impacto da presença de POPC-OOH em membranas de POPC}

- Há indicação de que o grupo OOH do lipídeo hidroperoxidado POPC-OOH está localizado na região da interface da membrana, como analisado pelo aumento de cerca de $30 \%$ do valor de tempo médio de correlação rotacional e de microviscosidade obtido nas análises de anisotropia de fluorescência resolvida no tempo da sonda TMA-DPH, pela pertubação do processo de relaxação dipolar da sonda laurdan (TRES) e pelo aumento de densidade eletrônica na região dos grupos $\mathrm{CH}_{2}$ observado nos perfis de densidade eletrônica $(\rho(r))$ obtidos a partir das análises de SAXS.

- Aumenta a área por lipídeo em amostras com POPC-OOH, como sugerido pela diminuição da anisotropia residual da sonda TMA-DPH $(\sim 15 \%)$ e pela diminuição da espessura $(\sim 8$ Å) da bicamada lipídica para membranas de POPC-OOH, em comparação com membranas de POPC, indicando aumento de área por conservação de volume (obtido por análise de SAXS).

- Detecta-se maior hidratação da membrana na presença de POPC-OOH, indicado pela diminuição do tempo de vida da sonda TMA-DPH $(\sim 15 \%)$.

- Aumentou a flutuação da membrana com maior concentração de POPC-OOH, observado pela diminuição da intensidade de funções de correlação vertical (perpendicular à superfície da membrana) de vesículas multilamelares, nas curvas de SAXS de MLVs.

- Houve diminuição do módulo de curvatura $\left(K_{C}\right)$ de cerca de $5 \times 10^{-20} \mathrm{~J}$ em membranas compostas por POPC para 1 x $10^{-20} \mathrm{~J}$ em membranas contendo POPC-OOH.

- O aumento da temperatura aumentou a flutuação da membrana, ao se considerar a mesma composição lipídica. Este efeito diminuiu com o aumento da concentração do POPC$\mathrm{OOH}$, como observado pela diminuição da intensidade de funções de correlação vertical (perpendicular à superfície da membrana) nas curvas de SAXS de MLVs.

- O aumento de temperatura de membranas de POPC, e não a adição de POPC-OOH, foi responsável pela maior variação para todos os parâmetros obtidos por análises de fluorescência. Por outro lado, a adição de POPC-OOH, e não a variação de temperatura, apresentou o maior impacto nas curvas de SAXS. 


\section{Impacto da presença de PAZEPC e POVPC em membranas de POPC}

Detectamos:

- Maior hidratação da membrana na presença de POVPC, indicado pela diminuição do tempo de vida da sonda TMA-DPH $(\sim 15 \%)$, e na presença de PAZEPC $(\sim 10 \%)$, também sugerido pelas análises de TRES.

- Aumento da área por lipídeo para PAZEPC e POVPC, como sugerido pela diminuição da anisotropia residual da sonda TMA-DPH $(\sim 20 \%)$.

- Aumento expressivo da flutuação da membrana com o aumento da concentração de PAZEPC e POVPC, observado pela diminuição da intensidade de funções de correlação vertical (perpendicular à superfície da membrana) de vesículas multilamelares nas curvas de SAXS de MLVs.

- Que membranas contendo 25\% de PAZEPC são unilamelares.

- Diminuição do $K_{C}$ de cerca de $5 \times 10^{-20} \mathrm{~J}$ para membranas compostas por POPC para aproximadamente $1,5 \times 10^{-20} \mathrm{~J}$ em membranas de POPC:POVPC (75:25).

- O aumento de temperatura de membranas de POPC, e não a adição de PAZEPC e POVPC, causou a maior variação para todos os parâmetros obtidos por análises de fluorescência. Por outro lado, a adição dos lipídeos oxidados, e não a variação de temperatura, apresentou o maior impacto nas curvas de SAXS.

Por fim, a presença dos lipídeos de cadeia acil curta e oxidada, PAZEPC e POVPC, causou maior impacto nas membranas de POPC do que o POPC-OOH, considerando as mesmas concentrações (10\% e 25\%), como evidenciado pelas análises de fluorescência e SAXS. Em alguns casos, a presença de $25 \%$ de PAZEPC e $25 \%$ de POVPC em membranas de POPC causaram maior impacto do que a completa substituição de POPC por POPC-OOH. Por exemplo, a presença de $25 \%$ de PAZEPC em membranas de POPC impediram a formação de MLVs, enquanto que membranas de POPC-OOH ainda apresentaram empilhamento vertical; o $K_{C}$ de membranas de POPC contendo $25 \%$ de POVPC é compatível com o $K_{C}$ para MLVs de POPC-OOH. Tendo em vista estes resultados, pode-se concluir que o encurtamento da cadeia lipídica deve contribuir para maior desestabilização da bicamada lipídica.

\section{Captítulo 6:}

- Na presença de $100 \mu \mathrm{M}$ de lipossomos de POPS aumenta a velocidade de crescimento de fibra amiloide do IAPP $(10 \mu \mathrm{M})$ de $0,45(3) \mathrm{h}^{-1}$, na ausência de lipossomos, para 0,76(2) $\mathrm{h}^{-1}$. Além disso, o lag phase de fibrilação do IAPP não é observado na presença desta concentração de lipossomos. 
- Com o aumento da concentração de lipossomos, a fibrilação do IAPP leva mais tempo para acontecer devido a diminuição da concentração superficial de proteína por lipossomos.

Perspectiva: investir e ampliar os estudos de interação IAPP com membranas oxidadas. Além disso, iremos estudar a cinética de fibrilação de IAPP de rato com membranas oxidadas. 


\section{BIBLIOGRAFIA}

[1] J. D. Sipe and A. S. Cohen, "Review: History of the amyloid fibril," Journal of Structural Biology, vol. 130, no. 2, pp. 88 - 98, 2000.

[2] H. PUCHTLER, F. SWEAT, and M. LEVINE, "On the binding of congo red by amyloid," Journal of Histochemistry \& Cytochemistry, vol. 10, no. 3, pp. 355-364, 1962.

[3] A. Geddes, K. Parker, E. Atkins, and E. Beighton, ““cross- $\beta$ ” conformation in proteins,” Journal of Molecular Biology, vol. 32, no. 2, pp. 343 - 358, 1968.

[4] M. Biancalana and S. Koide, "Molecular mechanism of Thioflavin-T binding to amyloid fibrils," Biochim. Biophys. Acta, vol. 1804, no. 7, pp. 1405-1412, 2010.

[5] O. S. Makin, E. Atkins, P. Sikorski, J. Johansson, and L. C. Serpell, "Molecular basis for amyloid fibril formation and stability," Proc Natl Acad Sci U S A, vol. 102, no. 2, pp. 315-20, 2005.

[6] S. K. Maji, L. Wang, J. Greenwald, and R. Riek, "Structure-activity relationship of amyloid fibrils," FEBS Lett, vol. 583, no. 16, pp. 2610-7, 2009.

[7] M. G. Iadanza, M. P. Jackson, E. W. Hewitt, N. A. Ranson, and S. E. Radford, "A new era for understanding amyloid structures and disease," Nature Reviews Molecular Cell Biology, vol. 19, no. 12, pp. 755-773, 2018.

[8] J. S. Pedersen, C. B. Andersen, and D. E. Otzen, "Amyloid structure-one but not the same: the many levels of fibrillar polymorphism," FEBS J, vol. 277, no. 22, pp. 4591-601, 2010.

[9] V. N. Uversky and A. L. Fink, "Conformational constraints for amyloid fibrillation: the importance of being unfolded," Biochim Biophys Acta, vol. 1698, no. 2, pp. 131-53, 2004.

[10] V. N. Uversky, J. Li, and A. L. Fink, "Evidence for a partially folded intermediate in alpha-synuclein fibril formation," J Biol Chem, vol. 276, no. 14, pp. 10737-44, 2001. 
[11] D. Balchin, M. Hayer-Hartl, and F. U. Hartl, "In vivo aspects of protein folding and quality control," Science, vol. 353, no. 6294, p. aac4354, 2016.

[12] T. P. Knowles, M. Vendruscolo, and C. M. Dobson, "The amyloid state and its association with protein misfolding diseases," Nat. Rev. Mol. Cell Biol., vol. 15, no. 6, pp. 384-396, 2014.

[13] O. S. Makin, E. Atkins, P. Sikorski, J. Johansson, and L. C. Serpell, "Molecular basis for amyloid fibril formation and stability," Proc. Natl. Acad. Sci. U.S.A., vol. 102, no. 2 , pp. 315-320, 2005.

[14] J. M. Khan, A. Qadeer, S. K. Chaturvedi, E. Ahmad, S. A. Rehman, S. Gourinath, and R. H. Khan, "Sds can be utilized as an amyloid inducer: a case study on diverse proteins," PLoS One, vol. 7, no. 1, p. e29694, 2012.

[15] M. Bhattacharya, N. Jain, and S. Mukhopadhyay, "Insights into the mechanism of aggregation and fibril formation from bovine serum albumin," Journal of Physical Chemistry $B$, vol. 115, no. 14, pp. 4195-4205, 2011.

[16] N. K. Holm, S. K. Jespersen, L. V. Thomassen, T. Y. Wolff, P. Sehgal, L. A. Thomsen, G. Christiansen, C. B. Andersen, A. D. Knudsen, and D. E. Otzen, "Aggregation and fibrillation of bovine serum albumin," Biochimica et Biophysica Acta (BBA) - Proteins and Proteomics, vol. 1774, no. 9, pp. 1128-1138, 2007.

[17] C. Haass and D. J. Selkoe, "Soluble protein oligomers in neurodegeneration: lessons from the Alzheimer's amyloid beta-peptide," Nat. Rev. Mol. Cell Biol., vol. 8, no. 2, pp. 101-112, 2007.

[18] E. T. Jaikaran and A. Clark, "Islet amyloid and type 2 diabetes: from molecular misfolding to islet pathophysiology," Biochimica et Biophysica Acta (BBA) - Molecular Basis of Disease, vol. 1537, no. 3, pp. 179 - 203, 2001.

[19] J. Adamcik and R. Mezzenga, "Amyloid Polymorphism in the Protein Folding and Aggregation Energy Landscape," Angew. Chem. Int. Ed. Engl., vol. 57, no. 28, pp. 83708382, 2018.

[20] C.-C. Lee, A. Nayak, A. Sethuraman, G. Belfort, and G. J. McRae, "A three-stage kinetic model of amyloid fibrillation," Biophysical Journal, vol. 92, no. 10, pp. 3448-3458, 2007.

[21] F. Chiti and C. M. Dobson, "Protein misfolding, functional amyloid, and human disease," Annu. Rev. Biochem., vol. 75, pp. 333-366, 2006. 
[22] M. P. Jackson and E. W. Hewitt, "Why are Functional Amyloids Non-Toxic in Humans?," Biomolecules, vol. 7, no. 4, 2017.

[23] E. R. Dorsey, R. Constantinescu, J. P. Thompson, K. M. Biglan, R. G. Holloway, K. Kieburtz, F. J. Marshall, B. M. Ravina, G. Schifitto, A. Siderowf, and C. M. Tanner, "Projected number of people with Parkinson disease in the most populous nations, 2005 through 2030," Neurology, vol. 68, no. 5, pp. 384-386, 2007.

[24] E. R. Dorsey, A. Elbaz, E. Nichols, F. Abd-Allah, A. Abdelalim, J. C. Adsuar, M. G. Ansha, C. Brayne, J.-Y. J. Choi, D. Collado-Mateo, N. Dahodwala, H. P. Do, D. Edessa, M. Endres, S.-M. Fereshtehnejad, K. J. Foreman, F. G. Gankpe, R. Gupta, G. J. Hankey, S. I. Hay, M. I. Hegazy, D. T. Hibstu, A. Kasaeian, Y. Khader, I. Khalil, Y.-H. Khang, Y. J. Kim, Y. Kokubo, G. Logroscino, J. Massano, N. Mohamed Ibrahim, M. A. Mohammed, A. Mohammadi, M. Moradi-Lakeh, M. Naghavi, B. T. Nguyen, Y. L. Nirayo, F. A. Ogbo, M. O. Owolabi, D. M. Pereira, M. J. Postma, M. Qorbani, M. A. Rahman, K. T. Roba, H. Safari, S. Safiri, M. Satpathy, M. Sawhney, A. Shafieesabet, M. S. Shiferaw, M. Smith, C. E. I. Szoeke, R. Tabarés-Seisdedos, N. T. Truong, K. N. Ukwaja, N. Venketasubramanian, S. Villafaina, K. g. weldegwergs, R. Westerman, T. Wijeratne, A. S. Winkler, B. T. Xuan, N. Yonemoto, V. L. Feigin, T. Vos, and C. J. L. Murray, "Global, regional, and national burden of parkinson's disease, 1990\&\#x2013;2016: a systematic analysis for the global burden of disease study 2016," The Lancet Neurology, vol. 17, no. 11, pp. 939-953, 2018.

[25] O. B. Tysnes and A. Storstein, “Epidemiology of Parkinson's disease," J Neural Transm (Vienna), vol. 124, no. 8, pp. 901-905, 2017.

[26] T. I. D. F. (IDF), "Idf annual report 2017," The International Diabetes Federation (IDF), 2018.

[27] T. I. D. F. (IDF), “Atlas do diabetes 2014,” Sociedade Brasileira de Diabetes., 2014.

[28] H. Zhao, E. K. Tuominen, and P. K. Kinnunen, "Formation of amyloid fibers triggered by phosphatidylserine-containing membranes," Biochemistry, vol. 43, no. 32, pp. 10302 10307, 2004.

[29] A. K. Mahalka, C. P. Maury, and P. K. Kinnunen, “1-Palmitoyl-2-(9'-oxononanoyl)-snglycero-3-phosphocholine, an oxidized phospholipid, accelerates Finnish type familial gelsolin amyloidosis in vitro," Biochemistry, vol. 50, no. 22, pp. 4877-4889, 2011.

[30] P. K. Kinnunen, K. Kaarniranta, and A. K. Mahalka, "Protein-oxidized phospholipid interactions in cellular signaling for cell death: from biophysics to clinical correlations," Biochim Biophys Acta, vol. 1818, no. 10, pp. 2446-55, 2012. 
[31] V. A. Parsegian, "Long-range physical forces in the biological milieu," Annu. Rev. Biophys. Bioeng., vol. 2, pp. 221-255, 1973.

[32] G. P. Gorbenko and P. K. Kinnunen, "The role of lipid-protein interactions in amyloid-type protein fibril formation," Chem. Phys. Lipids, vol. 141, no. 1-2, pp. 72-82, 2006.

[33] V. Koppaka and P. H. Axelsen, "Accelerated accumulation of amyloid beta proteins on oxidatively damaged lipid membranes," Biochemistry, vol. 39, no. 32, pp. 1001110016, 2000.

[34] J. Bieschke, Q. Zhang, D. A. Bosco, R. A. Lerner, E. T. Powers, P. Wentworth, and J. W. Kelly, "Small molecule oxidation products trigger disease-associated protein misfolding," Accounts of Chemical Research, vol. 39, no. 9, pp. 611-619, 2006. PMID: 16981677.

[35] A. Catala, "Lipid peroxidation of membrane phospholipids generates hydroxy-alkenals and oxidized phospholipids active in physiological and/or pathological conditions," Chem. Phys. Lipids, vol. 157, no. 1, pp. 1-11, 2009.

[36] P. Siani, R. M. de Souza, L. G. Dias, R. Itri, and H. Khandelia, "An overview of molecular dynamics simulations of oxidized lipid systems, with a comparison of ELBA and MARTINI force fields for coarse grained lipid simulations," Biochim. Biophys. Acta, vol. 1858, no. 10, pp. 2498-2511, 2016.

[37] R. Itri, H. C. Junqueira, O. Mertins, and M. S. Baptista, "Membrane changes under oxidative stress: the impact of oxidized lipids," Biophys Rev, vol. 6, no. 1, pp. 47-61, 2014.

[38] I. O. L. Bacellar, M. C. Oliveira, L. S. Dantas, E. B. Costa, H. C. Junqueira, W. K. Martins, A. M. Durantini, G. Cosa, P. Di Mascio, M. Wainwright, R. Miotto, R. M. Cordeiro, S. Miyamoto, and M. S. Baptista, "Photosensitized membrane permeabilization requires contact-dependent reactions between photosensitizer and lipids," Journal of the American Chemical Society, vol. 140, no. 30, pp. 9606-9615, 2018.

[39] A. W. Girotti, "Lipid hydroperoxide generation, turnover, and effector action in biological systems," Journal of Lipid Research, vol. 39, no. 8, pp. 1529-1542, 1998.

[40] K. A. Riske, T. P. Sudbrack, N. L. Archilha, A. F. Uchoa, A. P. Schroder, C. M. Marques, M. S. Baptista, and R. Itri, "Giant vesicles under oxidative stress induced by a membrane-anchored photosensitizer," Biophys. J., vol. 97, no. 5, pp. 1362-1370, 2009. 
[41] T. M. Tsubone, H. C. Junqueira, M. S. Baptista, and R. Itri, "Contrasting roles of oxidized lipids in modulating membrane microdomains," Biochimica et Biophysica Acta (BBA) - Biomembranes, vol. 1861, no. 3, pp. 660 - 669, 2019.

[42] O. Mertins, I. O. L. Bacellar, F. Thalmann, C. M. Marques, M. S. Baptista, and R. Itri, "Physical damage on giant vesicles membrane as a result of methylene blue photoirradiation," Biophys J, vol. 106, no. 1, pp. 162-171, 2014.

24411248[pmid].

[43] R. Rosa, F. Spinozzi, and R. Itri, "Hydroperoxide and carboxyl groups preferential location in oxidized biomembranes experimentally determined by small angle $\mathrm{X}$-ray scattering: Implications in membrane structure," Biochim Biophys Acta Biomembr, vol. 1860, no. 11, pp. 2299-2307, 2018.

[44] W. Caetano, P. S. Haddad, R. Itri, D. Severino, V. C. Vieira, M. S. Baptista, A. P. Schröder, and C. M. Marques, "Photo-induced destruction of giant vesicles in methylene blue solutions," Langmuir, vol. 23, no. 3, pp. 1307-1314, 2007.

PMID: 17241051.

[45] C. K. Haluska, M. S. Baptista, A. U. Fernandes, A. P. Schroder, C. M. Marques, and R. Itri, "Photo-activated phase separation in giant vesicles made from different lipid mixtures," Biochimica et Biophysica Acta (BBA) - Biomembranes, vol. 1818, no. 3, pp. $666-672,2012$.

[46] G. Weber, T. Charitat, M. S. Baptista, A. F. Uchoa, C. Pavani, H. C. Junqueira, Y. Guo, V. A. Baulin, R. Itri, C. M. Marques, and A. P. Schroder, "Lipid oxidation induces structural changes in biomimetic membranes," Soft Matter, vol. 10, pp. 4241-4247, 2014.

[47] R. Volinsky, L. Cwiklik, P. Jurkiewicz, M. Hof, P. Jungwirth, and P. K. J. Kinnunen, "Oxidized phosphatidylcholines facilitate phospholipid flip-flop in liposomes," Biophys $J$, vol. 101, no. 6, pp. 1376-1384, 2011.

21943418[pmid].

[48] H. Khandelia and O. G. Mouritsen, "Lipid gymnastics: evidence of complete acyl chain reversal in oxidized phospholipids from molecular simulations," Biophys J, vol. 96, no. 7, pp. 2734-2743, 2009.

[49] T. Farooqui and A. A. Farooqui, "Lipid-mediated oxidative stress and inflammation in the pathogenesis of Parkinson's disease," Parkinsons Dis, vol. 2011, p. 247467, 2011. 
[50] K. Kaarniranta, A. Salminen, A. Haapasalo, H. Soininen, and M. Hiltunen, "Age-related macular degeneration (AMD): Alzheimer's disease in the eye?," J. Alzheimers Dis., vol. 24, no. 4, pp. 615-631, 2011.

[51] L. R. S. Barbosa, M. G. Ortore, F. Spinozzi, P. Mariani, S. Bernstorff, and R. Itri, "The importance of protein-protein interactions on the ph-induced conformational changes of bovine serum albumin: A small-angle x-ray scattering study," Biophysical Journal, vol. 98, no. 1, pp. 147-157, 2010.

[52] T. Peters, " 2 - the albumin molecule: Its structure and chemical properties," in All About Albumin (T. Peters, ed.), pp. 9 - II, San Diego: Academic Press, 1995.

[53] A. Valstar, M. Almgren, W. Brown, and M. Vasilescu, "The interaction of bovine serum albumin with surfactants studied by light scattering," Langmuir, vol. 16, no. 3, pp. 922 927, 2000.

[54] A. Bujacz, "Structures of bovine, equine and leporine serum albumin," Acta Crystallographica Section D-Biological Crystallography, vol. 68, pp. 1278-1289, 2012.

[55] P. V. Messina, G. Prieto, J. M. Ruso, and F. Sarmiento, "Conformational changes in human serum albumin induced by sodium perfluorooctanoate in aqueous solutions," The Journal of Physical Chemistry B, vol. 109, no. 32, pp. 15566-15573, 2005.

[56] S. F. Santos, D. Zanette, H. Fischer, and R. Itri, "A systematic study of bovine serum albumin (bsa) and sodium dodecyl sulfate (sds) interactions by surface tension and small angle x-ray scattering," Journal of Colloid and Interface Science, vol. 262, no. 2, pp. 400-408, 2003.

[57] J. L. López-Fontán, F. Sarmiento, and P. C. Schulz, "The aggregation of sodium perfluorooctanoate in water," Colloid and Polymer Science, vol. 283, no. 8, pp. 862-871, 2005.

[58] S. E. Friberg, "Interactions of surfactants with polymers and proteins. e.d.goddard and k.p. ananthapadmanabhan (eds.), crc press, boca raton, fl, 1993, pp. 1-427, \$169.95," Journal of Dispersion Science and Technology, vol. 15, no. 3, pp. 399-399, 1994.

[59] J. R. Baran, "Fluorinated surfactants and repellents: Second edition, revised and expanded surfactant science series. volume 97. by erik kissa (consultant, wilmington, de). marcel dekker: New york. 2001.," Journal of the American Chemical Society, vol. 123, no. 36, pp. 8882-8882, 2001.

[60] P. V. Messina, G. Prieto, F. Salgado, C. Varela, M. Nogueira, V. Dodero, J. M. Ruso, and F. Sarmiento, "The influence of sodium perfluorooctanoate on the conformational 
transitions of human immunoglobulin," Journal of Physical Chemistry B, vol. 111, no. 28, pp. 8045-8052, 2007.

[61] N. J. Turro, X. G. Lei, K. P. Ananthapadmanabhan, and M. Aronson, "Spectroscopic probe analysis of protein-surfactant interactions - the bsa/sds system," Langmuir, vol. 11, no. 7 , pp. 2525-2533, 1995.

[62] T. Takagi, K. Tsujii, and K. Shirahama, "Binding isotherms of sodium dodecyl sulfate to protein polypeptides with special reference to SDS-polyacylamide gel electrophoresis," J. Biochem., vol. 77, no. 5, pp. 939-947, 1975.

[63] R. E. Tanner, B. Herpigny, S. Chen, and C. K. Rha, "Conformational change of protein sodium dodecylsulfate complexes in solution: A study of dynamic light scattering," The Journal of Chemical Physics, vol. 76, no. 8, pp. 3866-3872, 1982.

[64] R. C. Lu, A. N. Cao, L. H. Lai, and J. X. Xiao, "Protein-surfactant interaction: differences between fluorinated and hydrogenated surfactants," Colloids Surf B Biointerfaces, vol. 64, no. 1, pp. 98-103, 2008.

[65] P. Messina, G. Prieto, V. Dodero, J. M. Ruso, P. Schulz, and F. Sarmiento, "Ultraviolet-circular dichroism spectroscopy and potentiometric study of the interaction between human serum albumin and sodium perfluorooctanoate," Biopolymers, vol. 79, no. 6, pp. 300-309, 2005.

[66] P. Messina, G. Prieto, V. Dodero, M. A. Cabrerizo-Vilchez, J. Maldonado-Valderrama, J. M. Ruso, and F. Sarmiento, "Surface characterization of human serum albumin and sodium perfluorooctanoate mixed solutions by pendant drop tensiometry and circular dichroism," Biopolymers, vol. 82, no. 3, pp. 261-271, 2006.

[67] N. Kovalchuk, A. Trybala, V. Starov, O. Matar, and N. Ivanova, "Fluoro- vs hydrocarbon surfactants: Why do they differ in wetting performance?," Advances in Colloid and Interface Science, vol. 210, pp. 65 - 71, 2014.

[68] A. González-Pérez, J. M. Ruso, G. Prieto, and F. Sarmiento, "The self-aggregation of sodium perfluorooctanoate in aqueous solution at different temperatures," Journal of Surfactants and Detergents, vol. 7, no. 4, pp. 387-395, 2004.

[69] E. Blanco, A. González-Pérez, J. M. Ruso, R. Pedrido, G. Prieto, and F. Sarmiento, "A comparative study of the physicochemical properties of perfluorinated and hydrogenated amphiphiles," Journal of Colloid and Interface Science, vol. 288, no. 1, pp. 247-260, 2005. 
[70] B. Hess, "Gromacs 4: Algorithms for highly efficient, load-balanced, and scalable molecular simulation," Abstracts of Papers of the American Chemical Society, vol. 237, 2009.

[71] W. Huang, Z. X. Lin, and W. F. van Gunsteren, "Validation of the gromos 54a7 force field with respect to beta-peptide folding," Journal of Chemical Theory and Computation, vol. 7, no. 5, pp. 1237-1243, 2011.

[72] T. J. Dolinsky, J. E. Nielsen, J. A. McCammon, and N. A. Baker, "Pdb2pqr: an automated pipeline for the setup of poisson-boltzmann electrostatics calculations," Nucleic Acids Research, vol. 32, pp. W665-W667, 2004.

[73] T. J. Dolinsky, P. Czodrowski, H. Li, J. E. Nielsen, J. H. Jensen, G. Klebe, and N. A. Baker, "Pdb2pqr: expanding and upgrading automated preparation of biomolecular structures for molecular simulations," Nucleic Acids Research, vol. 35, pp. W522-W525, 2007.

[74] H. J. C. Berendsen, J. R. Grigera, and T. P. Straatsma, "The missing term in effective pair potentials," Journal of Physical Chemistry, vol. 91, no. 24, pp. 6269-6271, 1987.

[75] K. Baler, O. A. Martin, M. A. Carignano, G. A. Ameer, J. A. Vila, and I. Szleifer, "Electrostatic unfolding and interactions of albumin driven by ph changes: a molecular dynamics study," Journal of Physical Chemistry B, vol. 118, no. 4, pp. 921-30, 2014.

[76] Y. R. Espinosa, J. R. Grigera, and E. R. Caffarena, "Essential dynamics of the cold denaturation: pressure and temperature effects in yeast frataxin," Proteins-Structure Function and Bioinformatics, vol. 85, no. 1, pp. 125-136, 2017.

[77] G. Bussi, D. Donadio, and M. Parrinello, "Canonical sampling through velocity rescaling," Journal of Chemical Physics, vol. 126, no. 1, 2007.

[78] H. J. C. Berendsen, J. P. M. Postma, W. F. Vangunsteren, A. Dinola, and J. R. Haak, "Molecular-dynamics with coupling to an external bath," Journal of Chemical Physics, vol. 81, no. 8, pp. 3684-3690, 1984.

[79] M. J. Abraham and J. E. Gready, "Optimization of parameters for molecular dynamics simulation using smooth particle-mesh ewald in gromacs 4.5," Journal of Computational Chemistry, vol. 32, no. 9, pp. 2031-2040, 2011.

[80] B. Hess, H. Bekker, H. J. C. Berendsen, and J. G. E. M. Fraaije, "Lincs: A linear constraint solver for molecular simulations," Journal of Computational Chemistry, vol. 18, no. 12, pp. 1463-1472, 1997. 
[81] L. R. S. Barbosa, F. Spinozzi, P. Mariani, and R. Itri, Small-Angle X-Ray Scattering Applied to Proteins in Solution, pp. 49-72.

John Wiley Sons, Inc., 2013.

[82] P. Heftberger, B. Kollmitzer, F. A. Heberle, J. Pan, M. Rappolt, H. Amenitsch, N. Kučerka, J. Katsaras, and G. Pabst, "Global small-angle X-ray scattering data analysis for multilamellar vesicles: the evolution of the scattering density profile model," Journal of Applied Crystallography, vol. 47, no. 1, pp. 173-180, 2014.

[83] Small angle x-ray scattering / edited by O. Glatter and O. Kratky.

London ; New York: Academic Press, 1982.

[84] C. L. Ávila, C. M. Torres-Bugeau, L. R. S. Barbosa, E. M. Sales, M. O. Ouidja, S. B. Socías, M. S. Celej, R. Raisman-Vozari, D. Papy-Garcia, R. Itri, and R. N. Chehín, "Structural characterization of heparin-induced glyceraldehyde-3-phosphate dehydrogenase protofibrils preventing a-synuclein oligomeric species toxicity," The Journal of biological chemistry, vol. 289, no. 20, pp. 13838-13850, 2014.

[85] A. Guinier and G. Fourmet, Small angle scattering of X-rays. New York: Wiley, 1955.

[86] A. G. Kikhney and D. I. Svergun, "A practical guide to small angle x-ray scattering (saxs) of flexible and intrinsically disordered proteins," FEBS Letters, vol. 589, no. 19, Part A, pp. $2570-2577,2015$.

[87] M. G. Ortore, F. Spinozzi, P. Mariani, A. Paciaroni, L. R. Barbosa, H. Amenitsch, M. Steinhart, J. Ollivier, and D. Russo, "Combining structure and dynamics: non-denaturing high-pressure effect on lysozyme in solution," $J R$ Soc Interface, vol. 6 Suppl 5, pp. S619-634, 2009.

[88] F. Spinozzi, C. Ferrero, M. G. Ortore, A. De Maria Antolinos, and P. Mariani, "GENFIT: software for the analysis of small-angle X-ray and neutron scattering data of macromolecules in solution," J Appl Crystallogr, vol. 47, no. Pt 3, pp. 1132-1139, 2014.

[89] J. Marignan, P. Bassereau, and P. Delord, "Effect of pentanol and concentration on the micelles in the system obs/water/n-pentanol," The Journal of Physical Chemistry, vol. 90, no. 4, pp. 645-652, 1986.

[90] D. Svergun, C. Barberato, and M. H. J. Koch, "Crysol - a program to evaluate X-ray solution scattering of biological macromolecules from atomic coordinates," Journal of Applied Crystallography, vol. 28, no. 6, pp. 768-773, 1995. 
[91] P. Mariani, F. Carsughi, F. Spinozzi, S. Romanzetti, G. Meier, R. Casadio, and C. M. Bergamini, "Ligand-induced conformational changes in tissue transglutaminase: Monte carlo analysis of small-angle scattering data," Biophysical Journal, vol. 78, no. 6, pp. $3240-3251,2000$.

[92] D. Franke, M. V. Petoukhov, P. V. Konarev, A. Panjkovich, A. Tuukkanen, H. D. T. Mertens, A. G. Kikhney, N. R. Hajizadeh, J. M. Franklin, C. M. Jeffries, and D. I. Svergun, "ATSAS 2.8: a comprehensive data analysis suite for small-angle scattering from macromolecular solutions," Journal of Applied Crystallography, vol. 50, no. 4, pp. 1212-1225, 2017.

[93] M. V. Petoukhov and D. I. Svergun, "Global rigid body modeling of macromolecular complexes against small-angle scattering data," Biophys. J., vol. 89, no. 2, pp. $1237-$ 1250, 2005.

[94] A. Bergmann, G. Fritz, and O. Glatter, "Solving the generalized indirect fourier transformation (gift) by boltzmann simplex simulated annealing (bssa)," Journal of Applied Crystallography, vol. 33, pp. 1212-1216, 2000.

[95] P. F. Bernath and A. Dalgarno, "Spectra of atoms and molecules," Physics Today, vol. 49, p. 94, 1996.

[96] G. R. Grimsley and C. N. Pace, "Spectrophotometric determination of protein concentration," Curr Protoc Protein Sci, vol. Chapter 3, p. Unit 3.1, 2004.

[97] C. N. Pace, F. Vajdos, L. Fee, G. Grimsley, and T. Gray, "How to measure and predict the molar absorption coefficient of a protein," Protein Science, vol. 4, no. 11, pp. 24112423, 1995.

[98] K. Michaelian and A. Simeonov, "Fundamental molecules of life are pigments which arose and co-evolved as a response to the thermodynamic imperative of dissipating the prevailing solar spectrum," Biogeosciences, vol. 12, pp. 4913-4937, 2015.

[99] R. Acharya, "Chapter 3 - interaction of waves with medium," in Satellite Signal Propagation, Impairments and Mitigation (R. Acharya, ed.), pp. 57 - 86, Academic Press, 2017.

[100] C. Bohren and D. R. Huffman, Absorption and Scattering of Light by Small Particles. Wiley Science Paperback Series, 1998.

[101] L. S. Wolfe, M. F. Calabrese, A. Nath, D. V. Blaho, A. D. Miranker, and Y. Xiong, "Protein-induced photophysical changes to the amyloid indicator dye thioflavin T," Proc. Natl. Acad. Sci. U.S.A., vol. 107, no. 39, pp. 16863-16868, 2010. 
[102] M. R. Krebs, E. H. Bromley, and A. M. Donald, "The binding of thioflavin-T to amyloid fibrils: localisation and implications," J. Struct. Biol., vol. 149, no. 1, pp. 30-37, 2005.

[103] M. Groenning, "Binding mode of Thioflavin T and other molecular probes in the context of amyloid fibrils-current status," J Chem Biol, vol. 3, no. 1, pp. 1-18, 2010.

[104] A. J. Miles and B. A. Wallace, "Circular dichroism spectroscopy of membrane proteins," Chem Soc Rev, vol. 45, no. 18, pp. 4859-4872, 2016.

[105] L. Whitmore and B. A. Wallace, "Protein secondary structure analyses from circular dichroism spectroscopy: methods and reference databases," Biopolymers, vol. 89, no. 5, pp. 392-400, 2008.

[106] N. Sreerama and R. W. Woody, "Estimation of protein secondary structure from circular dichroism spectra: Comparison of contin, selcon, and cdsstr methods with an expanded reference set," Analytical Biochemistry, vol. 287, no. 2, pp. 252 - 260, 2000.

[107] A. J. Miles and B. A. Wallace, "Cdtoolx, a downloadable software package for processing and analyses of circular dichroism spectroscopic data," Protein Science, vol. 27, no. 9, pp. 1717-1722.

[108] A. J. Miles and B. A. Wallace, "Synchrotron radiation circular dichroism spectroscopy of proteins and applications in structural and functional genomics," Chem Soc Rev, vol. 35 , no. 1 , pp. 39-51, 2006.

[109] D. W. Bolen and I. V. Baskakov, "The osmophobic effect: natural selection of a thermodynamic force in protein folding," Journal of Molecular Biology, vol. 310, no. 5, pp. 955-63, 2001.

[110] M. M. Santoro, Y. Liu, S. M. Khan, L. X. Hou, and D. W. Bolen, "Increased thermal stability of proteins in the presence of naturally occurring osmolytes," Biochemistry, vol. 31, no. 23, pp. 5278-83, 1992.

[111] L. Platts and R. J. Falconer, "Controlling protein stability: Mechanisms revealed using formulations of arginine, glycine and guanidinium hcl with three globular proteins," International Journal of Pharmaceutics, vol. 486, no. 1-2, pp. 131-135, 2015.

[112] Y. Q. Yeh, K. F. Liao, O. Shih, Y. J. Shiu, W. R. Wu, C. J. Su, P. C. Lin, and U. S. Jeng, "Probing the acid-induced packing structure changes of the molten globule domains of a protein near equilibrium unfolding," Journal of Physical Chemistry Letters, vol. 8, no. 2, pp. 470-477, 2017. 
[113] K. Aburai, T. Ogura, R. Hyodo, H. Sakai, M. Abe, and O. Glatter, "Location of cholesterol in liposomes by using small-angle x-ray scattering (saxs) data and the generalized indirect fourier transformation (gift) method," Journal of Oleo Science, vol. 62, no. 11, pp. 913-918, 2013.

[114] L. Boldon, F. Laliberte, and L. Liu, "Review of the fundamental theories behind small angle X-ray scattering, molecular dynamics simulations, and relevant integrated application," Nano Rev, vol. 6, p. 25661, 2015.

[115] G. Beaucage, "Small-Angle Scattering from Polymeric Mass Fractals of Arbitrary MassFractal Dimension,” Journal of Applied Crystallography, vol. 29, no. 2, pp. 134-146, 1996.

[116] R. Itri and L. Q. Amaral, "Micellar-shape anisometry near isotropic-liquid-crystal phase transitions," Phys. Rev. E, vol. 47, pp. 2551-2557, 1993.

[117] S. Kumar, A. K. Singh, G. Krishnamoorthy, and R. Swaminathan, "Thioflavin t displays enhanced fluorescence selectively inside anionic micelles and mammalian cells," $J$ Fluoresc, vol. 18, no. 6, pp. 1199-205, 2008.

[118] J. S. Pedersen, C. B. Andersen, and D. E. Otzen, "Amyloid structure-one but not the same: the many levels of fibrillar polymorphism," FEBS J, vol. 277, no. 22, pp. 4591-601, 2010.

[119] V. N. Uversky and A. L. Fink, "Conformational constraints for amyloid fibrillation: the importance of being unfolded," Biochim Biophys Acta, vol. 1698, no. 2, pp. 131-53, 2004.

[120] G. Bhak, Y. J. Choe, and S. R. Paik, "Mechanism of amyloidogenesis: nucleationdependent fibrillation versus double-concerted fibrillation," BMB Rep, vol. 42, no. 9, pp. 541-51, 2009.

[121] F. G. Prendergast, R. P. Haugland, and P. J. Callahan, “1-[4-(Trimethylamino)phenyl]-6phenylhexa-1,3,5-triene: synthesis, fluorescence properties, and use as a fluorescence probe of lipid bilayers," Biochemistry, vol. 20, no. 26, pp. 7333-7338, 1981.

[122] A. M. do Canto, J. R. Robalo, P. D. Santos, A. J. P. Carvalho, J. P. Ramalho, and L. M. Loura, "Diphenylhexatriene membrane probes dph and tma-dph: A comparative molecular dynamics simulation study," Biochimica et Biophysica Acta (BBA) Biomembranes, vol. 1858, no. 11, pp. 2647 - 2661, 2016.

[123] A. M. T. M. do Canto, J. R. Robalo, P. D. Santos, A. J. P. Carvalho, J. P. P. Ramalho, and L. M. S. Loura, "Diphenylhexatriene membrane probes DPH and TMA-DPH: A 
comparative molecular dynamics simulation study," Biochim. Biophys. Acta, vol. 1858, no. 11, pp. 2647-2661, 2016.

[124] R. Esquembre, M. L. Ferrer, M. C. Gutiérrez, R. Mallavia, and C. R. Mateo, "Fluorescence study of the fluidity and cooperativity of the phase transitions of zwitterionic and anionic liposomes confined in solgel glasses," The Journal of Physical Chemistry B, vol. 111, no. 14, pp. 3665-3673, 2007.

[125] G. Weber and F. J. Farris, "Synthesis and spectral properties of a hydrophobic fluorescent probe: 6-propionyl-2-(dimethylamino)naphthalene," Biochemistry, vol. 18, no. 14, pp. 3075-3078, 1979.

[126] T. Parasassi, E. K. Krasnowska, L. Bagatolli, and E. Gratton, "Laurdan and prodan as polarity-sensitive fluorescent membrane probes," Journal of Fluorescence, vol. 8, no. 4, pp. 365-373, 1998.

[127] T. Parasassi, G. De Stasio, A. d'Ubaldo, and E. Gratton, "Phase fluctuation in phospholipid membranes revealed by laurdan fluorescence," Biophys $J$, vol. 57 , no. 6, pp. 1179_ 1186, 1990.

[128] M. Amaro, F. Reina, M. Hof, C. Eggeling, and E. Sezgin, "Laurdan and Di-4-ANEPPDHQ probe different properties of the membrane," J Phys D Appl Phys, vol. 50, no. 13, p. 134004, 2017.

[129] G. Först, L. Cwiklik, P. Jurkiewicz, R. Schubert, and M. Hof, "Interactions of beta-blockers with model lipid membranes: Molecular view of the interaction of acebutolol, oxprenolol, and propranolol with phosphatidylcholine vesicles by time-dependent fluorescence shift and molecular dynamics simulations," European Journal of Pharmaceutics and Biopharmaceutics, vol. 87, no. 3, pp. 559 - 569, 2014.

[130] W. Kulig, A. Olzynska, P. Jurkiewicz, A. M. Kantola, S. Komulainen, M. Manna, M. Pourmousa, M. Vazdar, L. Cwiklik, T. Rog, G. Khelashvili, D. Harries, V. V. Telkki, M. Hof, I. Vattulainen, and P. Jungwirth, "Cholesterol under oxidative stress-How lipid membranes sense oxidation as cholesterol is being replaced by oxysterols," Free Radic. Biol. Med., vol. 84, pp. 30-41, 2015.

[131] M. P. M. B. M. A. Z. P. C. H. K. Elias Isler, Elias Hideo Teramoto, "Trapeamento de lnapl observado por meio da técnica de fluorescência induzida por laser (lif),” vol. 32, 2018.

[132] J. R. Lakowicz, Principles of fluorescence spectroscopy.

Second edition. New York : Kluwer Academic/Plenum, 1999. 
[133] A. V. Digris, E. G. Novikov, V. V. Skakun, and V. V. Apanasovich, "Global analysis of time-resolved fluorescence data," Methods Mol. Biol., vol. 1076, pp. 257-277, 2014.

[134] A. Marcel, v. Martin, A. A. Ulises, and V. Bernard, pac, vol. 85, ch. Fluorescence anisotropy measurements in solution: Methods and reference materials (IUPAC Technical Report), p. 589. 2013.

[135] B. R. Lentz, "Use of fluorescent probes to monitor molecular order and motions within liposome bilayers," Chemistry and Physics of Lipids, vol. 64, no. 1, pp. 99 - 116, 1993.

[136] M. Amaro, R. Sachl, P. Jurkiewicz, A. Coutinho, M. Prieto, and M. Hof, "Time-resolved fluorescence in lipid bilayers: selected applications and advantages over steady state," Biophys J, vol. 107, no. 12, pp. 2751-2760, 2014.

[137] M. L. Horng, J. A. Gardecki, A. Papazyan, and M. Maroncelli, "Subpicosecond measurements of polar solvation dynamics: Coumarin 153 revisited," The Journal of Physical Chemistry, vol. 99, no. 48, pp. 17311-17337, 1995.

[138] S. Pokorna, A. Olżyńska, P. Jurkiewicz, and M. Hof, Hydration and Mobility in Lipid Bilayers Probed by Time-Dependent Fluorescence Shift, pp. 141-159.

Berlin, Heidelberg: Springer Berlin Heidelberg, 2013.

[139] S. N. Pinto, L. C. Silva, R. F. de Almeida, and M. Prieto, "Membrane domain formation, interdigitation, and morphological alterations induced by the very long chain asymmetric C24:1 ceramide,” Biophys. J., vol. 95, no. 6, pp. 2867-2879, 2008.

[140] H. van Langen, G. van Ginkel, D. Shaw, and Y. K. Levine, “The fidelity of response by 1-[4(trimethylammonio)phenyl]-6-phenyl-1,3,5-hexatriene in time-resolved fluorescence anisotropy measurements on lipid vesicles," European Biophysics Journal, vol. 17, no. 1 , pp. 37-48, 1989.

[141] J. M. Muller, E. E. van Faassen, and G. van Ginkel, "Experimental support for a novel compount motion model for the time-resolved fluorescence anisotropy decay of tmapdh in lipid vesicle bilayers," Chemical Physics, vol. 185, no. 3, pp. 393 - 404, 1994.

[142] M. Straume and B. J. Litman, "Equilibrium and dynamic bilayer structural properties of unsaturated acyl chain phosphatidylcholine-cholesterol-rhodopsin recombinant vesicles and rod outer segment disk membranes as determined from higher order analysis of fluorescence anisotropy decay," Biochemistry, vol. 27, no. 20, pp. 7723 7733, 1988. 
[143] L. Best, E. John, and F. Jähnig, "Order and fluidity of lipid membranes as determined by fluorescence anisotropy decay," European Biophysics Journal, vol. 15, no. 2, pp. 87-102, 1987.

[144] P. Jurkiewicz, L. Cwiklik, A. Vojti?kova, P. Jungwirth, and M. Hof, "Structure, dynamics, and hydration of POPC/POPS bilayers suspended in $\mathrm{NaCl}, \mathrm{KCl}$, and $\mathrm{CsCl}$ solutions," Biochim. Biophys. Acta, vol. 1818, no. 3, pp. 609-616, 2012.

[145] J. Garrec, A. Monari, X. Assfeld, L. M. Mir, and M. Tarek, "Lipid peroxidation in membranes: The peroxyl radical does not "float"," The Journal of Physical Chemistry Letters, vol. 5, no. 10, pp. 1653-1658, 2014.

[146] P. Jurkiewicz, A. Olzynska, M. Langner, and M. Hof, "Headgroup hydration and mobility of dotap/dopc bilayers: A fluorescence solvent relaxation study," Langmuir, vol. 22, no. 21, pp. 8741-8749, 2006.

[147] D. Illinger, G. Duportail, Y. Mely, N. Poirel-Morales, D. Gerard, and J. G. Kuhry, “A comparison of the fluorescence properties of TMA-DPH as a probe for plasma membrane and for endocytic membrane," Biochim. Biophys. Acta, vol. 1239, no. 1, pp. 58-66, 1995.

[148] C. Bernsdorff, R. Winter, T. Hazlett, and E. Gratton, "Influence of cholesterol and $\beta-$ sitosterol on the dynamic behaviour of dppc as detected by tma-dph and pyrpc fluorescence: A fluorescence lifetime distribution and time-resolved anisotropy study," Berichte der Bunsengesellschaft für physikalische Chemie, vol. 99, no. 12, pp. 1479$1488,1995$.

[149] N. Kučerka, M.-P. Nieh, and J. Katsaras, "Fluid phase lipid areas and bilayer thicknesses of commonly used phosphatidylcholines as a function of temperature," Biochimica et Biophysica Acta (BBA) - Biomembranes, vol. 1808, no. 11, pp. 2761 - 2771, 2011.

[150] Q. Fei, D. Kent, W. M. Botello-Smith, F. Nur, S. Nur, A. Alsamarah, P. Chatterjee, M. Lambros, and Y. Luo, "Molecular mechanism of resveratrol's lipid membrane protection," Scientific Reports, vol. 8, no. 1, p. 1587, 2018.

[151] X. Zhuang, J. R. Makover, W. Im, and J. B. Klauda, "A systematic molecular dynamics simulation study of temperature dependent bilayer structural properties," Biochimica et Biophysica Acta (BBA) - Biomembranes, vol. 1838, no. 10, pp. 2520 - 2529, 2014.

[152] L. Beranova, L. Cwiklik, P. Jurkiewicz, M. Hof, and P. Jungwirth, "Oxidation changes physical properties of phospholipid bilayers: Fluorescence spectroscopy and molecular simulations," Langmuir, vol. 26, no. 9, pp. 6140-6144, 2010. 
[153] M. M. Domingues, M. L. Bianconi, L. R. Barbosa, P. S. Santiago, M. Tabak, M. A. Castanho, R. Itri, and N. C. Santos, "rBPI21 interacts with negative membranes endothermically promoting the formation of rigid multilamellar structures," Biochim. Biophys. Acta, vol. 1828, no. 11, pp. 2419-2427, 2013.

[154] G. Pabst, A. Hodzic, J. Štrancar, S. Danner, M. Rappolt, and P. Laggner, "Rigidification of neutral lipid bilayers in the presence of salts," Biophysical Journal, vol. 93, no. 8, pp. $2688-2696,2007$.

[155] N. Chu, N. Kucerka, Y. Liu, S. Tristram-Nagle, and J. F. Nagle, “Anomalous swelling of lipid bilayer stacks is caused by softening of the bending modulus," Phys Rev E Stat Nonlin Soft Matter Phys, vol. 71, no. 4 Pt 1, p. 041904, 2005.

[156] R. Dimova, "Recent developments in the field of bending rigidity measurements on membranes," Advances in Colloid and Interface Science, vol. 208, pp. 225 - 234, 2014.

Special issue in honour of Wolfgang Helfrich.

[157] C. Monzel and K. Sengupta, "Measuring shape fluctuations in biological membranes," Journal of Physics D: Applied Physics, vol. 49, no. 24, p. 243002, 2016.

[158] F. Spinozzi, L. Paccamiccio, P. Mariani, and L. Q. Amaral, "Melting regime of the anionic phospholipid DMPG: new lamellar phase and porous bilayer model," Langmuir, vol. 26, no. 9, pp. 6484-6493, 2010.

[159] P. Heftberger, B. Kollmitzer, A. A. Rieder, H. Amenitsch, and G. Pabst, "In situ determination of structure and fluctuations of coexisting fluid membrane domains," Biophys. J., vol. 108, no. 4, pp. 854-862, 2015.

[160] R. Zhang, S. Tristram-Nagle, W. Sun, R. L. Headrick, T. C. Irving, R. M. Suter, and J. F. Nagle, "Small-angle x-ray scattering from lipid bilayers is well described by modified Caillé theory but not by paracrystalline theory," Biophys. J., vol. 70, no. 1, pp. 349-357, 1996.

[161] A. Yaghmur, P. Laggner, B. Sartori, and M. Rappolt, "Calcium triggered L alpha-H2 phase transition monitored by combined rapid mixing and time-resolved synchrotron SAXS," PLoS ONE, vol. 3, no. 4, p. e2072, 2008.

[162] B.-S. Lu, S. P. Gupta, M. Belička, R. Podgornik, and G. Pabst, "Modulation of elasticity and interactions in charged lipid multibilayers: Monovalent salt solutions," Langmuir, vol. 32, no. 50, pp. 13546-13555, 2016.

PMID: 27993014. 
[163] V. I. Gordeliy, V. Cherezov, and J. Teixeira, "Strength of thermal undulations of phospholipid membranes," Phys Rev E Stat Nonlin Soft Matter Phys, vol. 72, no. 6 Pt 1, p. 061913, 2005.

[164] B. Drasler, D. Drobne, A. Sadeghpour, and M. Rappolt, "Fullerene up-take alters bilayer structure and elasticity: A small angle X-ray study," Chem. Phys. Lipids, vol. 188, pp. 46-53, 2015.

[165] H. Bouvrais, L. Duelund, and J. H. Ipsen, "Buffers affect the bending rigidity of model lipid membranes," Langmuir, vol. 30, no. 1, pp. 13-16, 2014. PMID: 24377876.

[166] J. Pan, S. Tristram-Nagle, N. Kucerka, and J. F. Nagle, “Temperature dependence of structure, bending rigidity, and bilayer interactions of dioleoylphosphatidylcholine bilayers," Biophys. J., vol. 94, no. 1, pp. 117-124, 2008.

[167] H. Khandelia, B. Loubet, A. Olzy?ska, P. Jurkiewicz, and M. Hof, "Pairing of cholesterol with oxidized phospholipid species in lipid bilayers," Soft Matter, vol. 10, no. 4, pp. 639-647, 2014.

[168] F. M. Megli, E. Conte, and L. Russo, "Comparative 5-doxylstearoyllecithin and 3doxylcholestane epr spin labeling study of phospholipid bilayer perturbation by different oxidized lecithin species," Biochimica et Biophysica Acta (BBA) - Biomembranes, vol. 1798, no. 10, pp. $1886-1898,2010$.

[169] M. A. A. Ayee, E. LeMaster, T. P. Shentu, D. K. Singh, N. Barbera, D. Soni, C. Tiruppathi, P. V. Subbaiah, E. Berdyshev, I. Bronova, M. Cho, B. S. Akpa, and I. Levitan, "Molecular-Scale Biophysical Modulation of an Endothelial Membrane by Oxidized Phospholipids," Biophys. J., vol. 112, no. 2, pp. 325-338, 2017.

[170] S. A. Jayasinghe and R. Langen, "Membrane interaction of islet amyloid polypeptide," Biochim Biophys Acta, vol. 1768, no. 8, pp. 2002-9, 2007.

[171] Y. A. Domanov and P. K. Kinnunen, "Islet amyloid polypeptide forms rigid lipid-protein amyloid fibrils on supported phospholipid bilayers," J. Mol. Biol., vol. 376, no. 1, pp. 42-54, 2008.

[172] M. F. Engel, L. Khemtemourian, C. C. Kleijer, H. J. Meeldijk, J. Jacobs, A. J. Verkleij, B. de Kruijff, J. A. Killian, and J. W. Hoppener, "Membrane damage by human islet amyloid polypeptide through fibril growth at the membrane," Proc. Natl. Acad. Sci. U.S.A., vol. 105, no. 16, pp. 6033-6038, 2008. 
[173] E. Sparr, M. F. Engel, D. V. Sakharov, M. Sprong, J. Jacobs, B. de Kruijff, J. W. Hoppener, and J. A. Killian, "Islet amyloid polypeptide-induced membrane leakage involves uptake of lipids by forming amyloid fibers," FEBS Lett., vol. 577, no. 1-2, pp. 117-120, 2004.

[174] G. G. Biondi-Zoccai, A. Abbate, G. Liuzzo, and L. M. Biasucci, "Atherothrombosis, inflammation, and diabetes," J. Am. Coll. Cardiol., vol. 41, no. 7, pp. 1071-1077, 2003.

[175] L. Caillon, O. Lequin, and L. Khemtemourian, "Evaluation of membrane models and their composition for islet amyloid polypeptide-membrane aggregation," Biochim. Biophys. Acta, vol. 1828, no. 9, pp. 2091-2098, 2013.

[176] M. Michikawa, J. S. Gong, Q. W. Fan, N. Sawamura, and K. Yanagisawa, "A novel action of alzheimer's amyloid beta-protein (Abeta): oligomeric Abeta promotes lipid release," J. Neurosci., vol. 21, no. 18, pp. 7226-7235, 2001.

[177] X. Zhang, J. R. St Clair, E. London, and D. P. Raleigh, "Islet Amyloid Polypeptide Membrane Interactions: Effects of Membrane Composition,” Biochemistry, vol. 56, no. 2, pp. 376-390, 2017.

[178] P. Cao, A. Abedini, H. Wang, L. H. Tu, X. Zhang, A. M. Schmidt, and D. P. Raleigh, "Islet amyloid polypeptide toxicity and membrane interactions," Proc. Natl. Acad. Sci. U.S.A., vol. 110, no. 48, pp. 19279-19284, 2013.

[179] M. Anguiano, R. J. Nowak, and P. T. Lansbury, "Protofibrillar islet amyloid polypeptide permeabilizes synthetic vesicles by a pore-like mechanism that may be relevant to type II diabetes," Biochemistry, vol. 41, no. 38, pp. 11338-11343, 2002.

[180] J. D. Knight, J. A. Hebda, and A. D. Miranker, "Conserved and cooperative assembly of membrane-bound alpha-helical states of islet amyloid polypeptide," Biochemistry, vol. 45, no. 31, pp. 9496-9508, 2006.

[181] J. Tan, J. Zhang, Y. Luo, and S. Ye, "Misfolding of a Human Islet Amyloid Polypeptide at the Lipid Membrane Populates through $\hat{~}^{2}$-Sheet Conformers without Involving Ît-Helical Intermediates,” J. Am. Chem. Soc., vol. 141, no. 5, pp. 1941-1948, 2019.

[182] D. Ribeiro, I. Horvath, N. Heath, R. Hicks, A. Forslow, and P. Wittung-Stafshede, "Extracellular vesicles from human pancreatic islets suppress human islet amyloid polypeptide amyloid formation," Proc. Natl. Acad. Sci. U.S.A., vol. 114, no. 42, pp. 1112711132, 2017. 
[183] S. A. Jayasinghe and R. Langen, "Lipid membranes modulate the structure of islet amyloid polypeptide," Biochemistry, vol. 44, no. 36, pp. 12113-12119, 2005.

PMID: 16142909.

[184] Z. Qian, Y. Zou, Q. Zhang, P. Chen, B. Ma, G. Wei, and R. Nussinov, “Atomistic-level study of the interactions between hIAPP protofibrils and membranes: Influence of $\mathrm{pH}$ and lipid composition," Biochim Biophys Acta Biomembr, 2018.

[185] J. Seeliger, K. Weise, N. Opitz, and R. Winter, “The effect of Ẫ $\hat{I}^{2}$ on IAPP aggregation in the presence of an isolated $\hat{\mathrm{I}}^{2}$-cell membrane," J. Mol. Biol., vol. 421, no. 2-3, pp. 348-363, 2012.

[186] N. C. Kegulian, S. Sankhagowit, M. Apostolidou, S. A. Jayasinghe, N. Malmstadt, P. C. Butler, and R. Langen, "Membrane Curvature-sensing and Curvature-inducing Activity of Islet Amyloid Polypeptide and Its Implications for Membrane Disruption,” J. Biol. Chem., vol. 290, no. 43, pp. 25782-25793, 2015.

[187] J. D. Knight, J. A. Williamson, and A. D. Miranker, "Interaction of membrane-bound islet amyloid polypeptide with soluble and crystalline insulin," Protein Sci., vol. 17, no. 10, pp. 1850-1856, 2008. 


\title{
APÊNDICE
}

Em paralelo aos trabalhos apresentados nesta tese de doutoramento, o aluno também está envolvido nos trabalhos a seguir:

\section{Artigos Científicos Publicados}

- Multimeric species in equilibrium in detergent-solubilized Na,K-ATPase Juliana Sakamoto Yoneda ${ }^{1}$, Gustavo Scanavachi ${ }^{1}$, Heitor Gobbi Sebinelli, Júlio Cesar Borges, Leandro R.S. Barbosa, Pietro Ciancaglini, Rosangela Itri. International Journal of Biological Macromolecules, Volume 89, Pages 238-245, 2016. ${ }^{1}$ Compartilha a primeira autoria.

\begin{abstract}
In this work, we find an equilibrium between different $\mathrm{Na}, \mathrm{K}$-ATPase (NKA) oligomeric species solubilized in a non-ionic detergent $\mathrm{C}_{12} \mathrm{E}_{8}$ by means of Dynamic Light Scattering (DLS), Analytical Ultracentrifugation (AUC), Small Angle X-ray Scattering (SAXS), Spectrophotometry (absorption at 280/350nm) and enzymatic activity assay. The NKA sample after chromatography purification presented seven different populations as identified by AUC, with monomers and tetramers amounting to $\sim 55 \%$ of the total protein mass in solution. These two species constituted less than $40 \%$ of the total protein mass after increasing the NKA concentration. Removal of higher-order oligomer/aggregate species from the NKA solution using 220nm-pore filter resulted in an increase of the specific enzymatic activity. Nevertheless, the enzyme forms new large aggregates over an elapsed time of $20 \mathrm{~h}$. The results thus point out that $\mathrm{C}_{12} \mathrm{E}_{8}$-solubilized NKA is in a dynamic equilibrium of monomers, tetramers and high-order oligomers/subunit aggregates. These latter have low or null activity. High amount of detergent leads to the dissociation of NKA into smaller aggregates with no enzymatic activity.
\end{abstract}

Keywords: Na-K,ATPase; Oligomerization; Equilibrium state

- Structural and energetic evolution of fibrinogen toward to the betablocker interactions Michael González-Durruthy, Gustavo Scanavachi, Ramón Rial, Zhen Liu, M. Natália D.S. Cordeiro, Rosangela Itri, Juan M. Ruso. International Journal of Biological Macromolecules, Volume 137, 2019, Pages 405-419. 


\begin{abstract}
We present a computational analysis coupled with experimental studies, focusing on the binding-interaction between beta-adrenoreceptor blocking agents (acebutolol and propranolol) with fibrinogen protein (E-region). Herein, computational modeling on structural validation and flexibility properties of fibrinogen E-region showed that the E-region interacting residues, which form the funnel-shaped hydrophobic cavity for ligand-binding, can be efficiently modeled. The obtained free energy of binding (FEB) values for the docking complexes, namely acebutolol/fibrinogen E-region and propranolol/fibrinogen E-region, were very close and amounted to - $6.9 \mathrm{kcal} / \mathrm{mol}$ and - 6.8 $\mathrm{kcal} / \mathrm{mol}$, respectively. They were supported by a high binding-accuracy (RMSD $<2 \AA$ ) for the best crystallographic binding-poses in both cases. In this regard, we identify a docking-mechanism of interaction for the propranolol and acebutolol mainly based on non-covalent hydrophobic contacts with the fibrinogen E-region binding-site. Besides, the beta-adrenoreceptor blocking agents are able to induce local perturbations affecting particularly the fibrinogen E-region allosteric residues linked to significant changes in the inter-residue communication and flexibility properties of residue network. In this sense, we show that the key biophysical parameters like frequency and collectivity degree may be compromised in different ways by the interaction with acebutolol and propranolol. Isothermal titration calorimetry, zeta potential and small angle X-ray scattering (SAXS) measurements were performed to complete and corroborate computational analysis. The combined experimental results point out that acebutolol acts to a lesser extent to fibrinogen structure than propranolol.
\end{abstract}

Keywords: Fibrinogen; Betablockers; Interactions; Docking; SAXS; ITC

\title{
Artigos Científicos em fase de redação
}

- Unveiling the role of surfactants on amyloid-like protein self-assembling

Gustavo Scanavachi, Yanis Espinosa, Juan Ruso, Rosangela Itri.

Este artigo científico contém os resultados e discussões apresentados no Cap. 3 desta tese de doutoramento.

- The impact of oxidized POPC derivatives on lipid bilayer: Insights from steady-state, time-resolved fluorescence methodologies and SAXS

Gustavo Scanavachi, Ana Melo, Ana Coutinho, Aleksander Fedorov, Manuel Prieto e Rosangela Itri.

Este artigo científico contém os resultados e discussões apresentados nos Cap. 4 e 5 desta tese de doutoramento. 
- Impacts of photoxidation in the Human Red Blood Cell: morphological and mechanical changes

Gustavo Scanavachi, Tayana Mazin Tsubone, Koji Kinoshita, Luis Bagatolli, Rosangela Itri.

Abstract: The red blood cell (RBC) can suffer a significant oxidative stress during its 120 days live span in the human body since its mainly function is to act as a oxygen/carbon dioxide exchanger. Sometimes, the RBC's anti-oxidant agents are not enough to avoid the attack by reagent oxygen species (ROS) which can led to RBC's alterations. To better understand the impact of this oxidative stress in the $\mathrm{RBC}$ and to correlated that to in vivo conditions, we used the porphyrin CisDimPyP to generate ROS in the RBC's membrane. The porphyrin is homogeneously distributed in the RBC's membrane as seen by confocal microscopy and there is hemolysis as a response to a higher oxidative stress. Laurdan generalized polarization (GP) analysis indicates a membrane's dehydration in function of oxidative damage degree. The millisecond image microscopy images showed that the morphology of the RBC transformed from a biconcave disk to a swelled-spherical shape prior the hemolysis. More importantly, laurdan GP analysis, pixel normalized intensity variation (NIV) and micropipette tecnique pointed out the increased rigidity and less deformability of the RBC during the oxidative stress. This effect was reported for various oxidative stress damage degrees and far before the hemolysis. Interestingly, the biophysical properties reported here, mainly the higher rigidity and morphological changes, are well correlated to RBC's conditions found in vivo, as in diabetes type 2 and chronic obstructive pulmonary disease (COPD) patients, smokers and aging.

- Structural Transition of the Intrinsically Disordered Protein SHERP: Disorder, Order and the Role of Charge

Elliot Drew, Gustavo Scanavachi, Francesco Spinozzi, Rosangela Itri, Bonnie Wallace

- The role of BMP on endosome/lysosome membrane and its dependence on pH Tayana Mazin Tsubone, Gustavo Scanavachi Campos, Ana Paula Ramos and Rosangela Itri

- Package for Image Processing and Analysis: PIPA software

Gustavo Scanavachi, Maressa Donato, Tayana Mazin Tsubone, Rosangela Itri

Este artigo científico refere-se ao program computacional desenvolvido para o tratamento de imagens de microscopia de contraste de fase e de fluorescência, mais especificamente para GUVs, mas pode ser utilizada para diferentes amostras. A rotina computacional foi elaborada em linguagem $\mathrm{C}++$ para realizar análises temporais de intensidade de pixel, 
simetria geométrica e colocalização contando com um "tracker"para rastrear o movimento da amostra (GUVs). 